\title{
DESARROLLO DE NUEVOS ANÁLOGOS NITROGENADOS DE COMBRETASTATINA A-4. DISEÑO, SÍNTESIS Y EVALUACIÓN
}

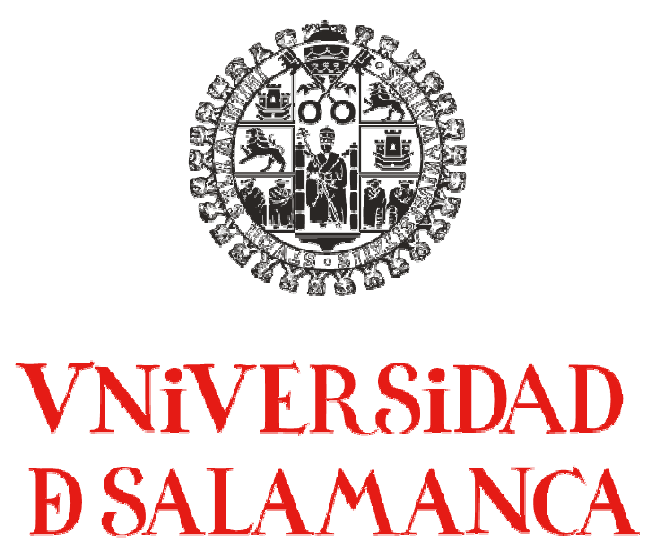

TESIS DOCTORAL

YOUNES ELLAHIOUI

FACULTAD DE FARMACIA

DEPARTAMENTO DE QUÍMICA FARMACÉUTICA

MARZO 2015 



\section{UNIVERSIDAD DE SALAMANCA \\ FACULTAD DE FARMACIA}

\section{DEPARTAMENTO DE QUÍMICA FARMACÉUTICA}

Trabajo Presentado Para Optar al Grado de Doctor en Farmacia por:

Younes Ellahioui

$\mathrm{V}^{\circ} \mathrm{B}^{\circ}$

Profesor Manuel Medarde Agustín

Director del Departamento de Química Farmacéutica 
DEPARTAMENTO DE QUIMICA FARMACÉUTICA

FACULTAD DE FARMACIA

Campus Miguel de Unamuno

37007 Salamanca

Tel.: + 34923294528

Fax:+34 923294515

Correo eletrónico: medarde@usal.es

DSALAMANCA

CAMPUS DE EXCELENCIA INTERNACIONAL.

http://www.usal.es

Negociado de Tercer Ciclo

Universidad de Salamanca

Patio de Escuelas.

SALAMANCA

ADENDA a la Tesis Doctoral de Younes ELLAHIOUI (fecha de defensa 23 de marzo de 2015) titulada "Desarrollo de nuevos análogos nitrogenados de combretastatina A-4. Diseño, síntesis y evaluación".

Este trabajo ha sido financiado por los proyectos de investigación:

$>$ Optimización de antitumorales inhibidores de tubulina por mejora de propiedades farmacocinéticas. Financiado por la Junta de Castilla y León (SA147U13).

esta ADENDA debe completar la información contenida en la página 7 del ejemplar de la tesis depositada en la Universidad de Salamanca, ya que el trabajo ha sido en parte realizado con los fondos procedentes de este proyecto de investigación.

Salamanca a veintitrés de marzo de dos mil quince

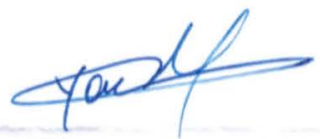

Firmado: Younes Ellahioui

$\mathrm{V}^{\circ} \mathrm{B}^{\circ}$ de los directores de la Tesis

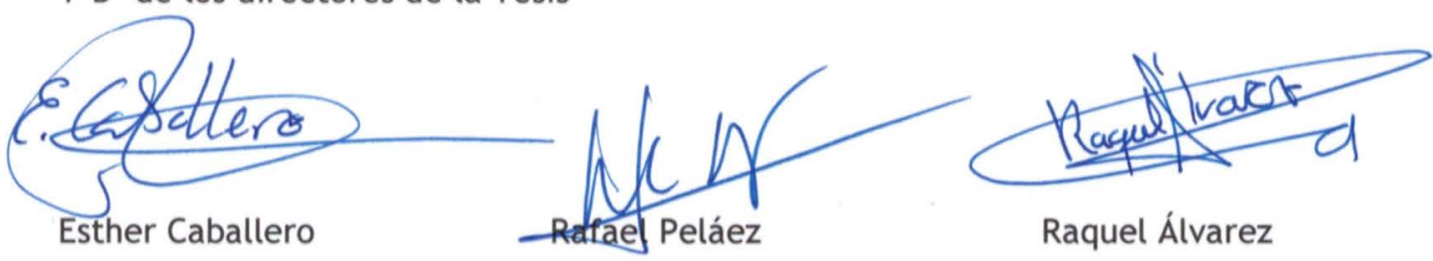


Esther Caballero Salvador, Profesora Titular de Química Orgánica, Rafael Peláez Lamamié de Clairac Arroyo, Profesor Titular de Química Orgánica y Raquel Álvarez Lozano, Profesora Ayudante Doctor, del Departamento de Química Farmacéutica, de la Facultad de Farmacia de la Universidad de Salamanca,

\section{CERTIFICAN:}

Que el licenciado en Química por la Universidad Abdelmalek Essaâdi de Tetuán, Marruecos, Younes Ellahioui, ha realizado en este Departamento, bajo su dirección, el trabajo titulado "Desarrollo de Nuevos Análogos Nitrogenados de Combretastatina A-4. Diseño, Síntesis y Evaluación”, para optar al Grado de Doctor en Farmacia por la Universidad de Salamanca. Considerándolo finalizado, autorizan su presentación para que sea juzgado por el tribunal correspondiente.

Salamanca, marzo de 2015

Fdo. Esther Caballero

Fdo. Rafael Peláez

Fdo. Raquel Álvarez 



\section{Este trabajo ha sido financiado por los proyectos de investigación:}

Síntesis y evaluación de nuevos agentes antitumorales basados en combretastatinas y fenstatinas: vectorización y modificación del mecanismo de acción. Financiado por el Ministerio de Ciencia e innovación (SAF 2008-04242).

Optimización de la aplicabilidad de fenstatinas mediante la combinación con complejos de platino: Diseño, síntesis de nuevos agentes citotóxicos de acción doble. Financiado por la Junta de Castilla y León (EDU/940/2009).

$>$ Aza-Indenofenonas, una nueva familia de agentes antimitóticos. Financiado por la AECID (PCI-Mediterráneo A1/037364/11).

$>$ Mejora de la solubilidad acuosa de agentes antimitóticos. Conversión de combretastatinas, fenstatinas y compuestos relacionados en fármacos útiles para el tratamiento del cáncer. Financiado por la Universidad de Salamanca (KAC8/2013)

Su realización ha sido posible gracias a:

La beca del proyecto AECID (PCI-Mediterráneo A1/037364/11) concedida para mi estancia en Salamanca (2011-2013).

Publicaciones:

Enviada al Journal of Medicinal Chemisty con el titulo "Exploring the size adaptability of the $\mathrm{B}$ ring binding zone of the colchicine site of tubulin with paraNitrogen substituted isocombretastatins. Importance for the SAR." Autores: Jiménez, Carmen; Ellahioui, Younes; Aramburu, Laura; Riesco, Alejandra; Dahdouh, Abdelaziz; IbnMansour, Ahmed; Jiménez, Carlos; Martín, Diego; Sarmiento, Rogelio; Medarde, Manuel; Álvarez, Raquel; Caballero, Esther; Pelaez, Rafael. 



\section{AGRADECIMIENTOS}

A mis directores de Tesis. A Esther Caballero por su plena disponibilidad y dedicación en mi aprendizaje, por tener la puerta de su despacho siempre abierta. A Rafa Peláez por todo lo que me ha enseñado, dispuesto a ayudarme en todo lo necesario y por su paciencia. A Raquel Álvarez por su accesibilidad, su ayuda y por su amistad, muchas gracias.

A Manolo por su ayuda, por facilitarme la estancia en el departamento para realizar la Tesis y por su apoyo. Gracias.

Quiero agradecer a mis profesores de la Facultad de Ciencias, Universidad Abdelmalek Essaâdi Tetuán, Marruecos. A. Ibnmansour y A. Dahdouh por darme la oportunidad de estar aquí y por animarme siempre.

A la AECID por la financiación concedida para mi estancia en Salamanca.

A mis compañeros del departamento, Laura, Elena, Ángela, Tiago, Myriam, Richi, Alba y los que pasaron por aquí, Carolina, Dina, Luis, Alejandra, Umer, por todos lo que hemos aprendido juntos. A los TFG y TFM por los buenos momentos compartidos en el departamento.

A todos los profesores y compañeros del departamento, por su ayuda, orientarme cuando lo he necesitado y por dejarme sentir como en mi casa.

A Rosa y Consta, por su ayuda y la sonrisa, porque sin ellos el departamento está oscuro.

A todos mis amigos, que estuvieron apoyándome siempre, con especial mención para Kaoutar, Paulo, Marta, Aziz, Mohamed, Nawal, Ali, Omar, Adnan, Bahija, Siham, Imad, Faouzi, Basil, Nourelimane. A mis amigos de Jbel Lahbib y Tetuán.

A mis amigos y compañeros del piso, Sobinson, Tiago y Milton por su paciencia, el cariño y por los buenos momentos que hemos compartido juntos. 
A mis tíos y primos de Madrid, de Bélgica y de Marruecos por su ayuda y por recibirme siempre en su casa con brazos abiertos.

También quiero agradecer de forma especial a mis padres, hermanos y hermanas, que han sufrido la distancia como yo y a los que quiero y admiro tanto, que no puedo explicarlo con palabras.

Muchas Gracias a todos. 
ÍNDICE Y ABREVIATURAS 



\section{ÍNDICE}

Lista de símbolos, abreviaturas y acrónimos 17

Resumen $\quad 21$

Abstract $\quad 23$

INTRODUCCIÓN 25

I. Compuestos que se unen al sitio de colchicina 31

II. Relación estructura-actividad de los derivados de 32 combretastatina

III. Métodos de síntesis de combretastatina -36

1. Por reacción de Wittig 36

2. Reacciones catalizadas por organometálicos 38

2.1 Acoplamiento de Suzuki 38

2.2 Acoplamiento de Kumada-Corriu $\quad 39$

3. Reacción de Ramberg-Backlund 39

4. Reacciones en Microondas 41

5. Condensación de Perkin 42

6. A partir de fenstatina: Reordenamiento de Colvin 43

7. A partir de alquinos 43

8. Isomerización del doble enlace 44

IV. Métodos de síntesis de fenstatinas

1. A partir de combretastatinas 44

2. Reacciones catalizadas por organometálicos $\quad 45$

2.1 Acoplamiento de Suzuki $\quad 45$

2.2 Catálisis con cobre $\quad 45$

2.3 Carbonilación acelerada por irradiación con microondas 46

3. Reacciones de Friedel-Crafts 46

4. A partir de productos naturales $\quad 47$

5. A partir de una adición nucleofilica 47

V. Métodos de síntesis de isocombretastatinas 48

1. A partir de fenstatinas $\quad 48$

2. Reacciones catalizadas por organometálicos $\quad 49$

$\begin{array}{ll}2.1 \text { Acoplamiento con paladio } & 49\end{array}$

2.2 Acoplamiento de Stille $\quad 50$

3. A partir de amida de Weinreb $\quad 50$

4. A partir de acetofenonas 51

PLANTEAMIENTO Y OBJETIVOS 53

I. Planteamiento $\quad 55$

$\begin{array}{ll}\text { II. Objetivos } & 57\end{array}$

1. Modificación del anillo B $\quad 57$

2. Modificación del anillo A 58

MÉTODOS Y RESULTADOS 61 
\begin{tabular}{lc}
\hline Estructuras de los compuestos sintetizados & 63
\end{tabular}

$\begin{array}{lll}\text { I. } \quad \text { Modificación en el anillo B } & 69\end{array}$

1. Síntesis de análogos de fenstatina $\quad 70$

$\begin{array}{ll}\text { 1.1 Síntesis de análogos de dimetilaminofenilo } & 70\end{array}$

$\begin{array}{ll}1.2 \text { Síntesis de análogos de piridina } & 74\end{array}$

1.3 Síntesis de análogos de dimetilaminofenilo sustituidos 77

$\begin{array}{ll}1.4 \text { Preparación de las sales de amonio de } p \text { - } & 79\end{array}$

dimetilaminofenilo

2. Síntesis de análogos de combretastatina $\quad 81$

2.1 Derivados del dimetilaminofenilo $\quad 82$

$\begin{array}{ll}2.2 \text { Derivados de piridina } & 85\end{array}$

2.3 Sales de amonio de combretastatinas $\quad 87$

3. Síntesis de fenstatina alifáticas 88

3.1 Derivados de 4-metoxiciclohexano 88

$\begin{array}{lr}3.2 \text { Derivados de piperidina } & 89\end{array}$

II. Modificación en el anillo A $\quad 92$

1. Síntesis de análogos de fenstatina 93

1.1 Síntesis de los derivados del $p$-metoxifenilo 93

1.2 Síntesis de los derivados $1 H$-indol 96

2. Síntesis de análogos de combretastatina 102

2.1 Síntesis de los derivados $p$-metoxifenilo 102

$\begin{array}{ll}2.2 \text { Síntesis de los derivados } p \text {-dimetilaminofenilo } & 107\end{array}$

$\begin{array}{ll}\text { III. Modificación en el puente } & 108\end{array}$

IV. Solubilidad 114

\begin{tabular}{ll}
\hline V. Actividad biológica & 117
\end{tabular}

1. Aislamiento de la proteína 117

2. Ensayos de inhibición de polimerización de tubulina 118

3. Determinación de la $\mathrm{IC}_{50}$ de inhibición de la 120 polimerización de la tubulina

4. Discusión de resultados 122

5. Ensayos de citotoxicidad 126

PARTE EXPERIMENTAL 129

$\begin{array}{ll}\text { I. Técnicas generales } & 131\end{array}$

1. Instrumentación 131

2. Técnicas cromatográficas 131

3. Tratamiento de disolventes y reactivos 132

II. Preparación de sales de amonio 133

$\begin{array}{ll}\text { III. Modificación del anillo B } & 137\end{array}$

III. 1. Derivados bencénicos 137

A. Análogos de isocombretastatinas 137

B. Análogos de combretastatinas 151

III. 2. Derivados piridínicos 160

A. Análogos de isocombretastatinas 160

B. Análogos de combretastatinas 174

C. Otros análogos de isocombretastatinas 181

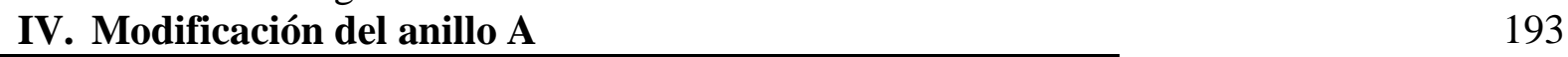

A. Análogos de isocombretastatinas 193 
B. Análogos de isocombretastatinas 202

C. Compuestos con indol como anillo B 221

V. Otras combretastatinas modificadas

A. Modificación en el puente etilénico 229

B. Derivados de isocombretastatina con anillos alifáticos $\quad 232$

VI. Determinación de la solubilidad acuosa $\quad 239$

VII. Actividad biológica $\quad 241$

1. Aislamiento de la proteína 241

2. Ensayos de actividad 242

3. Determinación de la $\mathrm{IC}_{50}$ de la inhibición de 243 polimerización de la tubulina 



\section{LISTA DE SIMBOLOS, ABREVIATURAS Y ACRÓNIMOS}

\begin{tabular}{|c|c|}
\hline $\mathrm{AB}$ & Tampón de ensamblaje \\
\hline Ac & Acetilo \\
\hline $\mathrm{Ar}$ & Arilo \\
\hline BSA & Seroalbúmina bovina \\
\hline$c$ & Cuartete \\
\hline CA-4 & Combretastatina A4 \\
\hline COSY & Espectroscopia de correlación \\
\hline $\mathrm{d}$ & Doblete \\
\hline dd & Doble doblete \\
\hline Diglime & Dietilenglicol dimetil éter \\
\hline $\mathrm{DM}$ & Dimetoxifenilo \\
\hline DME & Dimetoxietano \\
\hline DMF & $N, N$-Dimetilformamida \\
\hline DMSO & Dimetilsulfóxido \\
\hline EB & Tampón de extracción \\
\hline EM & Espectro de masas \\
\hline GDP & Difosfato de guanosina \\
\hline GTP & Trifosfato de guanosina \\
\hline Hex & Hexano \\
\hline HMBC & Correlación heteronuclear de múltiples enlaces \\
\hline HMQC & Correlación heteronuclear múltiple cuántica \\
\hline HRMS & Espectrometría de masas de alta resolución \\
\hline
\end{tabular}




\begin{tabular}{|c|c|}
\hline HPLC & Cromatografía líquida de alta eficacia \\
\hline$H z$ & Hercios \\
\hline $\mathrm{IC}_{50}$ & Concentración inhibitoria 50 \\
\hline IPT & Inhibición de la polimerización de tubulina \\
\hline IR & Infrarrojo \\
\hline$J$ & Constante de acoplamiento \\
\hline$\lambda$ & Longitud de onda (lambda) \\
\hline $\mathrm{L}$ & Litros \\
\hline $\mathrm{m}$ & Multiplete \\
\hline $\mathrm{M}^{+}$ & Ion molecular \\
\hline MAPs & Proteínas asociadas a microtúbulos \\
\hline $\mathrm{Me}$ & Metilo \\
\hline $\mathrm{MeI}$ & Yoduro de metilo \\
\hline MTP & Proteína microtubular \\
\hline $\mathrm{NEt}_{3}$ & Trietilamina \\
\hline $\mathrm{NMe}_{2}$ & Dimetilamino \\
\hline $\mathrm{P}$ & Grupo fosfato \\
\hline PDB & Banco de datos de proteínas \\
\hline PDC & Dicromato de piridinio \\
\hline Pf & Punto de fusión \\
\hline $\mathrm{Ph}$ & Fenilo \\
\hline PMSF & Fluoruro de fenilmetanosulfonilo \\
\hline ppm & Partes por millón \\
\hline pyr & Piridina \\
\hline
\end{tabular}




\begin{tabular}{|c|c|}
\hline p-TsOH & Ácido p-toluenosulfónico \\
\hline REA & Relación estructura actividad \\
\hline $\mathrm{RMN}{ }^{13} \mathrm{C}$ & Resonancia magnética nuclear de carbono 13 \\
\hline $\mathrm{RMN}{ }^{1} \mathrm{H}$ & Resonancia magnética nuclear de protón \\
\hline $\mathrm{rpm}$ & Revolución por minuto \\
\hline s & Singlete \\
\hline sa & Singlete ancho \\
\hline $\mathrm{t}$ & Triplete \\
\hline$t-\mathrm{BuOH}$ & terc-butanol \\
\hline $\mathrm{TB}$ & Tampón de transporte \\
\hline TBAF & Fluoruro de tetra-n-butilamonio \\
\hline TBDMSCl & Cloruro de terc-butildimetilsililo \\
\hline THF & Tetrahidrofurano \\
\hline $\mathrm{TM}$ & 3,4,5-Trimetoxifenilo \\
\hline TMG & 2,3,4-Trimetoxifenilo \\
\hline TMSCl & Cloruro de trimetilsililo \\
\hline$t_{R}$ & Tiempo de retención \\
\hline$\delta$ & Desplazamiento químico \\
\hline $\mathrm{TsNHNH}_{2}$ & Tosilhidrazida \\
\hline UV & Ultravioleta \\
\hline
\end{tabular}

XPhos 2-diciclohexilfosfino-2',4',6'-triisopropilbifenilo 



\section{RESUMEN}

El cáncer es una de las principales causas de mortalidad y el número de casos detectados va en aumento. Se considera uno de los temas más destacados en el mundo de la investigación científica y cada año se desarrollan miles de compuestos antitumorales para ver si pueden llegar a frenar esta enfermedad.

Una de las familias de agentes antimitóticos que tiene una potencia inhibidora importante frente a la polimerización de la tubulina en el sitio de la colchicina son las combretastatinas. La CA-4 presenta una actividad muy interesante por lo cual se puede considerar como molécula base para el desarrollo de análogos más potentes y que puedan mejorar la relación estructura actividad (REA) para este tipo de derivados.

Los principales problemas estructurales de CA-4 son la baja solubilidad acuosa y la rápida isomerización del doble enlace cis a trans. En nuestro grupo de trabajo, se han realizado numerosas modificaciones dirigidas a paliar esta problemática cambiando la naturaleza de los dos anillos aromáticos o los sustituyentes que contienen y el puente que los une.

En este trabajo se ha llevado a cabo la síntesis de nuevos análogos nitrogenados de combretastatina, fenstatina e isocombretastatina en los que se han introducido en los anillos aromáticos grupos nitrogenados con el fin de aumentar la potencia inhibitoria de polimerización de tubulina y la solubilidad acuosa de los mismos.

La estrategia seguida ha sido combinar en los dos anillos aromáticos A y B sustituyentes oxigenados con los nitrogenados, los cuales podrían unirse de forma similar a la tubulina y potenciar la solubilidad. Para ello se han sintetizado derivados de piridina o bencénicos sustituidos con grupos metil- o- dimetilamino, pirrolidino, conjuntamente y utilizando la reactividad de la molécula se han introducido funciones polares adicionales.

Se ha determinado la solubilidad acuosa de los compuestos sintetizados, comprobándose un incremento considerable respecto a las de CA-4. Además, de la mayor parte de los compuestos finales sintetizados se ha determinado la actividad inhibitoria de polimerización de tubulina, observándose que de las modificaciones realizadas en el anillo B solamente la isocombretastatina con anillo de $p$-dimetilaminofenilo posee una actividad similar a la de CA4. Sin embargo, la sustitución de uno de los metoxilos del anillo A por un grupo amino libre o metilado conduce a compuestos de igual o mayor potencia que la CA-4 y que poseen una 
mayor solubilidad acuosa, lo cual hace que estos compuestos sean candidatos para continuar la investigación.

Una serie de compuestos sintetizados en este trabajo han sido evaluados como citotóxicos frente a tres líneas celulares cancerosas (HeLa, HT29, HL60). 


\section{ABSTRACT}

Cancer is one of principal causes of mortality and the number of detected cases is increasing. It's considered one of the most prominent scientific research subjects and each year thousands of antitumor compounds are developed in an attempt to better treat this disease.

The combretastatins are a family of compounds binding at the colchicine site and having an important anti-mitotic inhibitory activity against tubulin polymerization. The CA-4 has a very interesting activity which sets it as a base molecule to develop more potent analogues and can improve the structure activity relationships (SAR) for such as derivatives.

The main problems of CA-4 are the low aqueous solubility and rapid cis isomerization of the double bond to trans. In our group, there have been numerous modifications aimed to solve these problems by changing the nature of the two aromatic rings or thier substituents and the bridge that connect them.

In this work we have synthesized new nitrogenated analogues of combretastatin, phenstatin and isocombretastatin with nitrogen groups on the aromatic rings, designed in order to increase the inhibitory potency on tubulin polymerization and the aqueous solubility.

The applied has been to combine in the two aromatic A and B rings oxygenated and nitrogen substituents. This has been accomplished with the synthesis of phenyl and pyridine derivatives with methyl- or -dimethylamino and pyrrolidino groups.

We have determined the aqueous solubility of the synthesized compounds and found a significant increase over the CA-4. Furthermore, we have determined the inhibitory activity of tubulin polymerization for most of the final compounds synthesized. For B ring modifications only isocombretastatins with unsubstituted $p$-dimethylaminophenyl rings have a similar potency to that of CA-4. However, replacement of one methoxyl groups of the A ring by a free amino or methylamino group leads to compounds with the same or greater potency than CA-4 and having an improved aqueous solubility, which makes these compounds are good candidates for continuing the investigation.

A series of compounds synthesized in this work have been evaluated by cytotoxicity assay against three cancer cell lines (HeLa, HT29, HL60). 


\section{ملخّص البحث}

يعتبر مرض السرطان من أكبر المعضلات التي نواجه العالم حيث يتسبب في وفاة أكثر من سبعة ملايين شخص سنويا، وعدد الحالات المكتشفة في ازدياد مستمر. لهذا يعتبر أحد أهم مواضيع البحث العلمي في هذا العصر حيث يتم إنتاج وتطوير سنويا آلاف المركبات القادرة على كبح تطور الأورام، في محاولة للحصول على علاج فعال لوقف هذا المرض

تعتبر فصيلة الكومبريتاستاستين (combretastatins) من أهم المركبات المضادة للتفتل و التي لديها قوة كبيرة ضد بلمرة التوبولين (tubulin) في موقع الكولثيسين. الكومبريتاستاتين لديها فعالية جد مهمة، لذلك تعتبر العنصر الأساس والقاعدة لتطوير نظائر أكثر فعالية وقادرة على تحسين العلاقة بين الهيكل و الفعالية لهذه المشتقات.

من بين أهم المشاكل التي نواجه هذا الصنف من المركبات هي الذوبان المنخفض في الماء والمماكبة السريعة للرابطة المزدوجة من سيز (cis) إلى تر انس (trans). للتخفيف من حدة هذه المشكلة قام فريق العمل لدينا بإدخال العديد من التعديلات عن طريق تغيير طبيعة الحلقات العطرية أو البدائل الملتصقة بها أو في الجسر الذي يربط بينها.

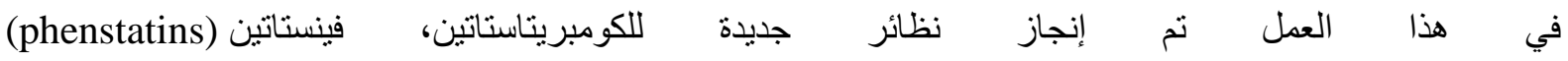
وإيزوكومبريتاستاتين (isocombretastatins) بإخخال عنصر النيتروجين في الحلقات العطرية على أساس الرفع من القوة الكابحة لبلمرة التوبولين و تحسين ذوبانيتها في الماء.

الطريقة المتبعة في هذا البحث هو العمل على إدخال بدائل أوكسيجينية أو نبتروجينية في الحلقتين (أ) أو (ب) و التي يمكن أن تتصل بشكل مماثل مع التوبولين وتعمل على الرفع من قوتها الذوبانية. من أجل هذا تم إنجاز نظائر البيريدين أو مركبات عطرية تحتوي على عنصر ميثيل أمين، ثنائي ميثيل أمين أو البيروليدين أو هما معا وبالإعنماد على تفاعلية الجزيئة نم إدخال وظائف قطبية إضافية.

تم إيجاد على أن ذوبانية المركَبات المنجزة في الماء أكبر بكثير بالمقارنة مع الكومبريتاستاتين A-4. بالإضافة إلى ذلك، تم إنجاز إختبار الفعالية الكابحة لبلمرة النوبولين لمعضم المركبات النهائية المنجزة، حيث تبين على أنه من بين كل المركبات التي تم إدخال تغيير في الحلقة (ب) فقط الإزوكومبريتاستاتين ذات الحلقة 4-ثنائي ميثيل أمين فيلين هي التي لها قوة كابحة مماثلة للكومبريتاستاتين A-4. عكس ذلك، إستبدال عنصر الميثوكسي في الحلقة (أ) بعنصر الأمين أو الميثيل أمين يقود إلى مركبات ذات فعالية مماثلة أو أكبر من الكومبريتاستاتين A-4 ضد بلمرة التوبولين وذوبانية جد مهمة في الماء، الأمر الذي يجعل هذه المركبات هي المرشحة لمواصلة الأبحاث مستقبلا.

في هذا العمل تم إنجاز إختبار السُمِيّة الخلوية لسلسلة من المركبات على ثلاثة خطوط لخلايا سرطانية (HeLa, HT29, HL60). 


\section{INTRODUCCIÓN}



El cáncer es actualmente una de las enfermedades humana con mayor índice de mortalidad. Es la segunda causa de muerte en los países occidentales, precedido por las enfermedades cardiovasculares y la primera causa de pérdida de años potenciales de vida. Según la OMS, en 2012 se le atribuyeron 8,2 millones de muertos en todo el mundo como consecuencia de tumores malignos y se piensa que esta cifra podría aumentar hasta casi 12 millones en el año 2030.

En España, en 2012 se han muerto 102.762, con una predicción para 2015 de 108.390 muertos, según las estadísticas de Sociedad Española de Oncología Médica ${ }^{1}$.

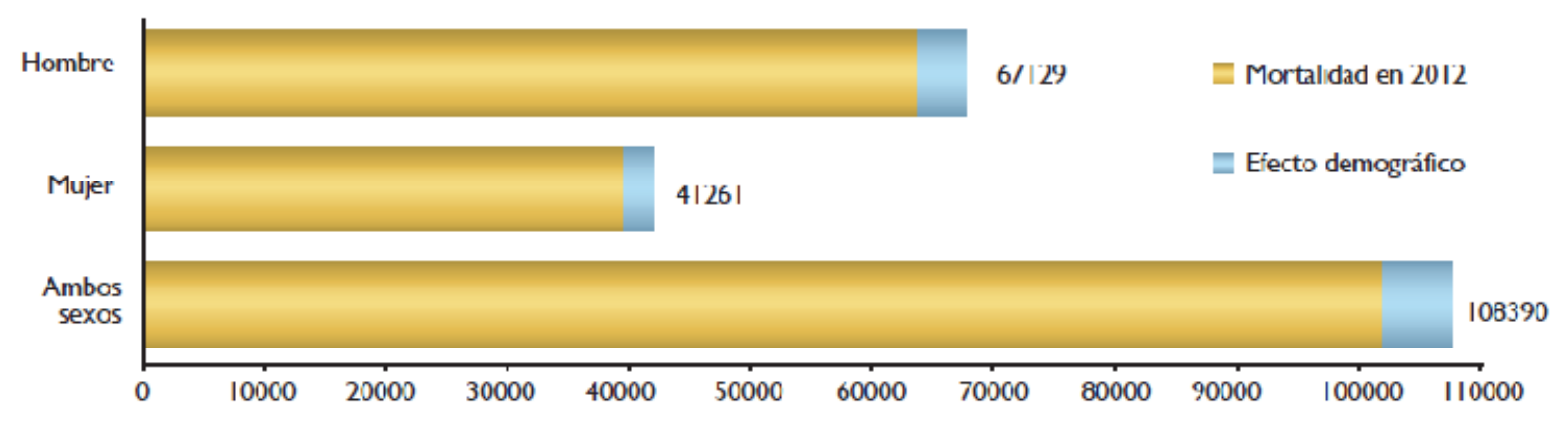

Figura 1: mortalidad de cáncer en España en ambos sexos en 2012 y predicción para $\mathbf{2 0 1 5}^{2}$

Según los últimos datos publicados por el Instituto Nacional de Estadística el 31 de enero de 2014, los tumores fueron la segunda causa de muerte en ambos sexos y responsables de 27,5 de cada 100 defunciones. La primera causa de muerte son las enfermedades del sistema circulatorio. A nivel mundial, el cáncer con mayor mortalidad es el de pulmón (19,4 \%).

Bajo la denominación de cáncer se engloba a un grupo numeroso y heterogéneo de enfermedades malignas, caracterizadas por una proliferación celular anormal, anaplásica, autónoma, progresiva y destructiva ${ }^{3}$. Comienza por una falta de control en el proceso de división celular en un tejido en el que las células se reproducen de forma autónoma, anárquica e irreversible, sin regulación ni finalidad. El comportamiento de las células cancerosas se caracteriza por carecer del control reproductivo que requiere su función original, perdiendo

\footnotetext{
${ }^{1}$ Las cifras del cáncer en España 2014. Sociedad Española de Oncología Médica. www.SEOM.com.

${ }^{2}$ Ferlay, J.; Soerjomataram, I.; Ervik, M.; Dikshit, R.; Eser, S.; Mathers, C.; Rebelo, M.; Parkin, DM.; Forman, D.; Bray, F. Cancer Incidence and Mortality Worldwide: IARC. GLOBOCAN. 2012, 1.0.

${ }^{3}$ Cotran, S. R.; Robbins, S. L.; Kuma, V. Patología estructural y funcional. Editorial McGraw-Hill. 1999. Madrid.
} 
sus características primitivas y adquiriendo otras que no les corresponden. La pérdida de la capacidad celular de realizar apoptosis se traduce en la aparición del fenómeno de metástasis, que es el rasgo biológico más característico de esta enfermedad. El nuevo tejido patológico, así formado, tiene tendencia a expandirse a través de las vías linfáticas o hemáticas, formando nuevos focos tumorales o metástasis en órganos distantes, donde continúa la expansión ${ }^{3}$.

Afortunadamente, en los últimos años se ha elevado el número de personas con cáncer en remisión. Este avance se debe, en gran parte, al resultado de un mayor conocimiento y compresión de los aspectos biológicos de esta enfermedad. El enorme interés desde enfoques muy diferentes, se ha traducido en un extenso y exhaustivo estudio biológico y farmacológico destinado a desarrollar nuevos fármacos que, de forma selectiva, eliminen las células enfermas. Los posibles tratamientos contra el cáncer son hasta el momento, la cirugía, la radioterapia, la quimioterapia y el trasplante de médula.

Actualmente, uno de los tratamientos antitumorales más exitosos, y por tanto más extendidos, se basa en la administración de diversos compuestos químicos con fines terapéuticos. La vía común por la que los agentes quimioterapéuticos ejercen su efecto citotóxico en la célula es la inducción de apoptosis como respuesta a la aparición de daños irreparables en las células.

La tubulina es el componente principal de los microtúbulos. La molécula de tubulina está compuesta por dos monómeros: alfa y beta. Cada monómero contiene alrededor de 450 aminoácidos y un nucleótido de guanina. Los monómeros alfa y beta comparten aproximadamente el $40 \%$ de identidad de secuencia y sus estructuras tridimensionales son muy similares ${ }^{4}$. El descubrimiento de la tubulina está relacionado con la identificación del sitio de enlace de la colchicina.

\footnotetext{
${ }^{4}$ Nogales, E.; Wolf, S. G.; Downing, K. H. Structure of the alpha beta tubulin dimer by electron crystallography. Nature. 1998, 391, 199.
} 


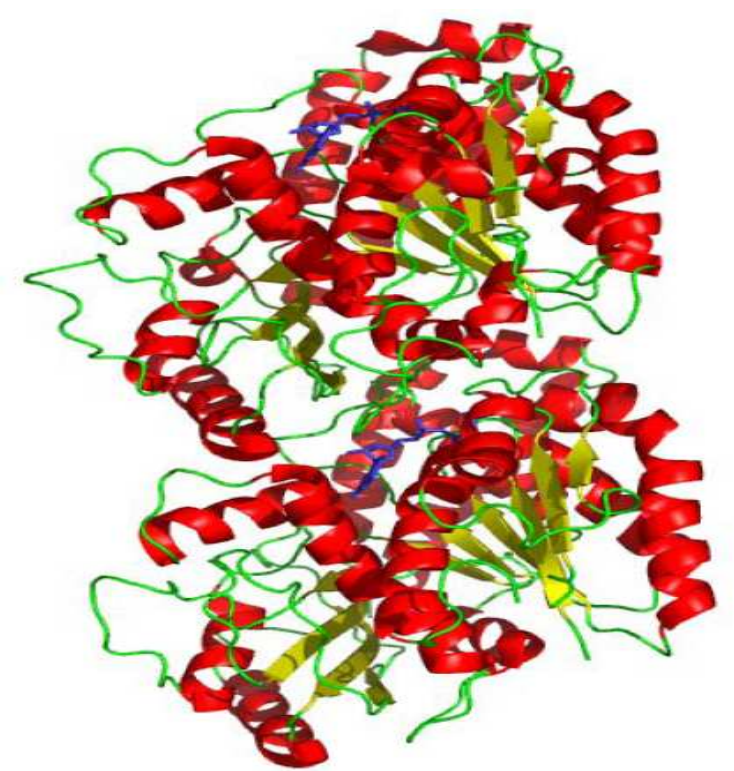

Figura 2. Estructura tridimensional del dímero de tubulina (código PDB 1JFF). Se muestra la subunidad alfa (abajo) unida a GTP y la subunidad beta (arriba) unida a GDP. Las cadenas beta están coloreadas en amarillo y las hélices alfa en rojo. El GTP y el GDP se están coloreados en azul.

La tubulina con su diversidad funcional forma los microtúbulos para server a un papel tanto esencial en la morfogénesis celular como en la polaridad de la célula, migración y la división. Los microtúbulos ocupan también el espacio citoplásmico e interaccionan con las señales de las proteínas y órganos, además tienen un papel importante en la circulación celular, como el transporte de vesículas y mitocondrias ${ }^{5}$. Además los microtúbulos juegan un papel esencial en la división celular durante la mitosis, mantener la estructura de la célula y transportar las proteínas.

La velocidad del crecimiento de microtúbulos, el encogimiento y la frecuencia de transición son las variables que describen la dinámica de los microtúbulos ${ }^{6}$.

Los microtúbulos son polímeros proteicos cilíndricos de longitud variable cuya polimerización y despolimerización depende del nucleótido GTP o GDP unido a la tubulina. Los dímeros de tubulina interaccionan para formar protofilamentos rectos que se asocian de forma paralela, para formar la pared cilíndrica del microtúbulo. El número de profilamentos que constituyen el microtúbulo no es fijo, varía en función de las condiciones de disolución y de las proteínas o ligandos asociados. Las proteínas asociadas a microtúbulos (MAPs) actúan

\footnotetext{
${ }^{5}$ Stanton, R. A.; Gernert, K. M.; Nettles, J. H.; Aneja, R. Drugs That Target Dynamic Microtubules: A New Molecular Perspective. Med. Res. Rev. 2011, 31, 443.

${ }^{6}$ Hyman, A. A.; Karsenti, E. Morphogenetic properties of microtubules and mitotic spindle assembly. Cell. 1996, 84, 401.
} 
estabilizando los microtúbulos contra el desensamblaje y regulan la dinámica de los microtúbulos a lo largo de las diversas etapas del ciclo celular. ${ }^{7}$

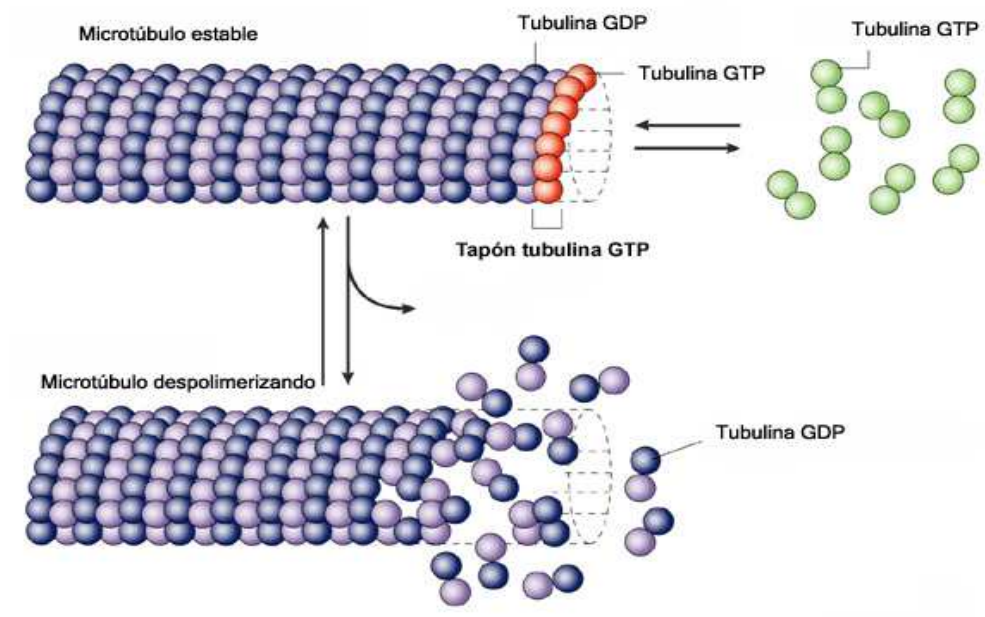

Figura 3. Dinámica de la polimerización de tubulina y modelo del tapón de tubulina-GTP.

Los fármacos que actúan sobre la tubulina (figura 2) se unen al menos en cuatro sitios diferentes, además de los dos sitios donde se unen GTP y GDP: El sitio de la vinblastina y la vincristina, el sitio de la colchicina, el recientemente descrito sitio de laulimalida y pelorusida $\mathrm{A}^{8}$, cuyos ligandos inhiben el ensamblaje de los microtúbulos (provocando una despolimerización de la tubulina) y el sitio del taxol ${ }^{\circledR}$ que se genera en la cara interior de los microtúbulos al formarse y cuyos ligandos favorecen la polimerización y estabilizan los microtúbulos. El sitio del taxol ${ }^{\circledR}$ se encuentra en la $\beta$-tubulina en el lumen microtubular, mientras que la vinca tiene un unión específica a la $\beta$-tubulina, en una región llamada el dominio vinca y la colchicina se une en la interfaz entre los dímeros de $\alpha$ y $\beta$ - tubulina.

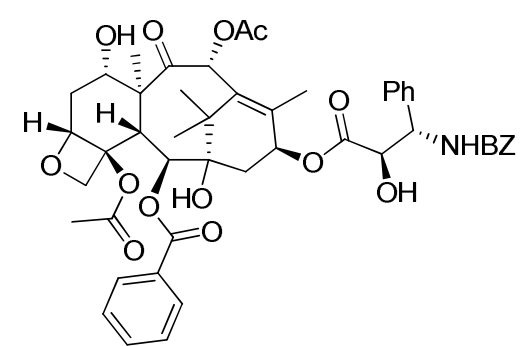

Paclitaxel

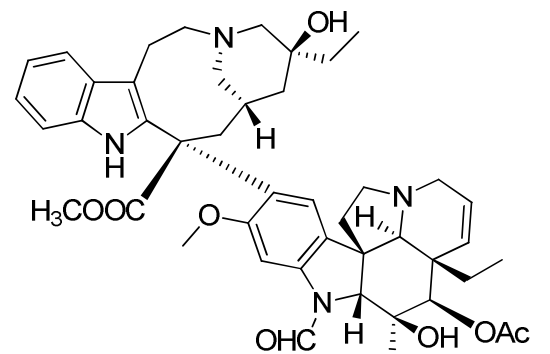

Vincristina $\mathrm{H}_{3} \mathrm{COOC \overline { \textrm {C } }}$<smiles>CCNCCN[C@@H]1CCc2cc(OC)c(OC)c(OC)c2-c2ccc(OC)c(=O)cc21</smiles>

Colchicina

Figura 4. Estructuras de colchicina, vincristina y paclitaxel (taxol®)

\footnotetext{
${ }^{7}$ Heald, R.; Nogales, E. Microtubule dynamics. J Cell. Sci. 2002, 115, 3.

${ }^{8}$ Prota, A. E.; Bargsten, K.; Northcote, P. T.; Marsh, M.; Altmann, K. H.; Miller, J. H.; et al. Structural basis of microtubule stabilization by laulimalide and peloruside A. Angew. Chem. 2014, 53, 1621.
} 


\section{COMPUESTOS QUE SE UNEN AL SITIO DE COLCHICINA}

La colchicina se ha aislado de Colchicum autumnale L. y es el primer agente desestabilizador de la tubulina. La colchicina se ha utilizado durante muchos años como un fármaco para tratar la gota y la fiebre mediterránea antes de descubrir que se podía tratar varios tipos de cáncer actuando sobre la mitosis. Aunque en el desarrollo clínico falló por su elevada toxicidad, la colchicina ha jugado un papel importante en la determinación de las propiedades de los microtúbulos y las subunidades de tubulina debido a su fuerte unión a la tubulina. Esta unión es seguida por un cambio conformacional que implica una flexión intradímero, en la que los monómeros de tubulina sufren una torsión alrededor de la interfase. Este cambio en la conformación permite la inclusión de complejo colchicina-tubulina en el interior del filamento.

Numerosos ligandos de origenen natural o sintéticos se unen a la tubulina en el sitio de unión de la colchicina, algunos de los cuales son las combretastatinas y las fenstatinas, que presentan una actividad muy interesante. La combretastatina A-4 (CA-4) es un producto natural, aislado de un arbusto sudafricano (Combretum caffrum $)^{9}$. Las combretastatinas ejercen una actividad citotóxica muy importante frente a muchas líneas celulares de cáncer humano e inhiben la angiogénesis, por lo que se han utilizado para atacar selectivamente la vasculatura del tumor como una alternativa a la quimioterapia convencional. ${ }^{10}$ Estos agentes pueden bloquear y eliminar el núcleo del tumor, pero son incapaces de eliminar el borde externo del tumor, a menos que se utilicen en combinación con otros fármacos como paclitaxel. ${ }^{11} \mathrm{CA}-4 \mathrm{P}$ se considera el profármaco más potente en la polimerización de tubulina y se encuentra en ensayos clínicos para el tratamiento de tumores sólidos.

\footnotetext{
${ }^{9}$ Pettit, G. R.; Singh, S. B.; Niven, M. L.; Hamel, E.; Schmidt, J. M. J. Nat. Prod. 1987, 50, 119.

${ }^{10}$ Ahmed, B.; Van Eijk, L. I.; Steege, B.-T. J. C. A.; Van Der Schaft, D. W. J.; DW, Van Esch, A. M.; JoostenAchjanie, S. R, Lambin, P.; Landuyt, W.; Griffioen, A. W. Vascular targeting effect of combretastatinA-4 phosphate dominates the inherent angiogenesis inhibitory activity. Int. J. Cancer. 2003, 105, 20.

${ }^{11}$ Risinger, A. L.; Giles FJ, Mooberry SL. Microtubule dynamics as a target in oncology. Cancer Treat. Rev. 2009, 35, 255.
} 
<smiles>COc1cc([C@H]2c3cc4c(cc3[C@@H](O)[C@@H]3COC(=O)[C@H]23)OCO4)cc(OC)c1OC</smiles><smiles>COc1ccc(/C=C\c2cc(OC)c(OC)c(OC)c2)cc1O</smiles><smiles>COc1ccc(C(=O)c2cc(OC)c(OC)c(OC)c2)cc1O</smiles><smiles>C=C(c1ccc(OC)c(O)c1)c1cc(OC)c(OC)c(OCC2CC2)c1</smiles>
(IsoCA-4)

Podofilotoxina<smiles>COc1ccc(-c2ccc(OC)c(=O)cc2)c(OC)c1OC</smiles>

(bifenilo)<smiles>COc1ccc(S(=O)(=O)Nc2cccnc2Nc2ccc(O)cc2)cc1</smiles>

ABT-751<smiles>COc1ccc(OC)c(C(=O)/C(C)=C/c2ccc(N(C)C)cc2)c1</smiles>

Figura 5. Estructuras de los compuestos que de unen en el sitio de la colchicina.

\section{RELACIÓN ESTRUCTURA-ACTIVIDAD DE LOS DERIVADOS DE COMBRETASTATINA}

La combretastatina A-4 tiene dos anillos aromáticos (A y B) y un puente de dos carbonos con un doble enlace de configuración cis. Su estructura puede emplearse para resumir de los requerimientos estructurales de los compuestos que se unen al sitio de la colchicina, ya que tiene una eficacia inhibidora de la polimerización de la tubulina muy elevada. Por isomerización del doble enlace "in vitro" e "in vivo" de la combretastatina de cis a trans, isómero más estable termodinámicamente, la combretastatina pierde su eficacia ${ }^{12}$. El anillo A de trimetoxifenilo se considera importante para la actividad inhibidora de la polimerización de la tubulina, su sustitución generalmente conduce a una disminución significativa en la citotoxicidad $^{13}$.

\footnotetext{
${ }^{12}$ Chaudhary, A.; Pandeya, S. N.; Kumar, P.; Sharma, P. P.; Gupta, S.; Soni, N.; Verma, K. K.; Bhardwaj, G. Mini-Rev. Med. Chem. 2007, 7, 1186.

${ }^{13}$ Gaukroger, K.; Hadfield, J. A.; Lawrence, N. J.; Nolan, S.; McGown, A. T. Structural requirements for the interaction of combretastatins with tubulin: how important is the trimethoxy unit? Org. Biomol. Chem. 2003, 1, 3033.
} 
<smiles>COc1cc(/C=C\c2ccc(OC)c(OC)c2O)cc(OC)c1OC</smiles>

CA-1P

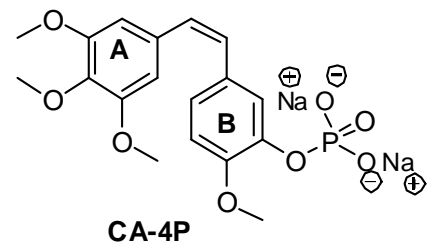

Figura 6: Estructuras de combretastatinas probadas en los ensayos clínicos

Uno de los problemas que presenta la combretastatina A-4 es la baja solubilidad acuosa, por lo cual se han trabajado sobre la manera de mejorar esta solubilidad del compuesto a partir de las modificaciones tanto en los anillos aromáticos como en el puente. CA-4P es una de las combretastatinas modificadas que ha llegado hasta la fase II en los ensayos clínicos en el tratamiento de diferentes tipos de cáncer, cáncer de pulmón, tiroides, anaplástico y ovario ${ }^{14}$.

Combretastatina A-1 difosfato también se han utilizado por el tratamiento de tumores sólidos en fase I.

AVE8062 (Ombrabulina) es un análogo de CA-4, que ejerce su actividad contra el cáncer a través de la interrupción de la formación de los vasos sanguíneos en los tumores. En comparación con CA-4, es más soluble en agua y disponible por vía oral. También es eficaz contra un número de células cancerosas que son resistentes a taxanos ${ }^{15}$. La combinación de AVE8062 con docetaxel fue bien tolerada y está en la fase I de los ensayos clínicos y un estudio actualmente está en la fase III para el tratamiento de cáncer avanzado ${ }^{16}$.

El compuesto CA-4P presenta una alta afinidad por la tubulina en sitio de la unión con la colchicina, ha llegado hasta la fase II en los ensayos clínicos para tratar el cáncer de tiroides anaplásico, usado como agente único o en combinación con otros fármacos como cisplatino o doxorrubicina y radiación.
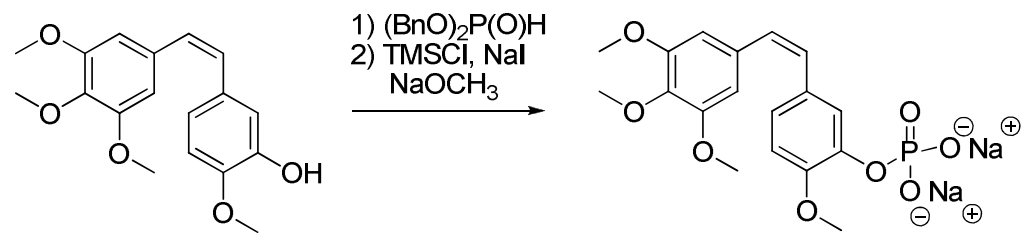

\footnotetext{
${ }^{14}$ Rustin, GJ.; Shreeves, G.; Nathan, PD.; Gaya, A.; Ganesan, TS.; Wang, D.; Boxall, J.; Poupard, L.; Chaplin, DJ.; Stratford, MRL.; Balkissoon, J.; Zweifel, M. A Phase Ib trial of CA4P (combretastatin A-4 phosphate), carboplatin, and paclitaxel in patients with advanced cancer. Br. J. Cancer. 2010, 102, 1355.

${ }^{15}$ Lu, Y.; Chen, J.; Xiao, M.; Li, W.; Miller, D. D. An Overview of Tubulin Inhibitors That Interact with the Colchicine Binding Site. Pharm Res. 2012, 29, 2943.

${ }^{16} \mathrm{http}: / / \mathrm{clinicaltrials.gov/ct} 2 /$ results?term=AVE8062.
} 


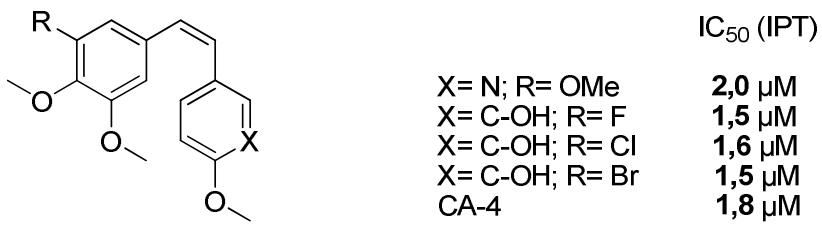

El derivado piridínico de combretastatina A-4 presenta una actividad antitubulina $(2 \mu \mathrm{M})$ y citotóxica $\left(\mathrm{IC}_{50}=29,2 \mathrm{nM}\right)$ muy interesante, además presenta una solubilidad en plasma muy alta $(3400 \mu \mathrm{g} / \mathrm{ml})^{17}$. La sustitución del grupo metoxilo en posición meta del anillo A de CA-4 por grupos halogenados $(\mathrm{F}, \mathrm{Cl}, \mathrm{Br})$ mejora la actividad antitubulina del compuesto $\left(\mathrm{IC}_{50}=\right.$ 1,5-1,6 $\mu \mathrm{M})$ y presentan una potencia inhibidora similar a la de CA-4 $\left(\mathrm{IC}_{50}=1,8 \mu \mathrm{M}\right)$. Además, al tratar células endoteliales de vena umbilical humanas (HUVECs) con halocombretastatinas se observó la pérdida de los microtubulos celulares y la interrupción de la división celular despues de $30 \mathrm{~min}$ del tratamiento con una concentración de $1 \mu \mathrm{M}{ }^{18}$

Al cambiar el anillo B por derivados del indol ${ }^{19}$ o anillo con piridina ${ }^{20}$ conlleva a una importante mejora de la actividad.<smiles>[X]C(c1cc(OC)c(OC)c(OC)c1)c1ccc2c(ccn2C)c1</smiles>

$\mathrm{X}=\mathrm{O} \quad 7,5 \mu \mathrm{M}$

$\mathrm{X}=\mathrm{CH}_{2} \quad 0,7 \mu \mathrm{M}$

$\mathrm{X}=\mathrm{CH}_{3} \quad 1,0 \mu \mathrm{M}$

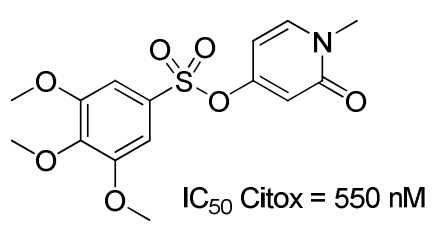<smiles>[X]C(c1ccc2c(ccn2C)c1)c1ccc(OC)c(OC)c1OC</smiles>

$\mathrm{IC}_{50} \mathrm{IPT}$

$\mathrm{X}=\mathrm{O} \quad 0,4 \mu \mathrm{M}$

$\mathrm{X}=\mathrm{CH} 2 \quad 4,7 \mu \mathrm{M}$

Figura 7: Estructura y actividad de compuestos con piridina ó indol en anillo B

\footnotetext{
${ }^{17}$ Hatanaka, T.; Fujita, K.; Ohsumi, K.; Nakagawa, R.; Fukuda, Y.; Nihei, Y.; Suga, Y.; Akiyama, Y.; Tsuji, T. Novel b-ring modified combretastatin analogues : Syntheses and antineoplastic activity. Bioorg. Med. Chem. Lett. 1998, 8, 3371.

${ }^{18}$ Pettit, G. R.; Minardi, M. D.; Rosenberg, H. J.; Hamel, E.; Bibby, M. C.; Martin, S. W.; Jung, M. K.; Pettit, R. K..; Cuthbertson, T. J.; Chapuis, J.-C. Antineoplastic agents. 509. Synthesis of fluorcombretastatin phosphate and related 3-halostilbenes. J. Nat. Prod. 2005, 68, 1450.

${ }^{19}$ Álvarez, C.; Álvarez, R.; Corchete, P.; Pérez-Melero, C.; Pelàez, R.; Medarde, M. Exploring the effect of 2,3,4-trimethoxy-phenyl moiety as a component of indolephenstatins. Eur. J. Med. Chem. 2010, 45, 588.

${ }^{20}$ Gwaltney, S. L.; Imade, H. M.; Barr, K. J.; Li, Q.; Gehrke, L.; Credo, R. B.; Warner, R. B.; Lee, J. Y.; Kovar, P.; Wang, J.; Nukkala, M. A.; Zielinski, N. A.; Frost, D.; Ng, S. -C.; Sham, H. L. Novel Sulfonate Analogues of Combretastatin A-4: Potent Antimitotic Agents. Bioorg. Med. Chem. Lett. .2001, 11, 871.
} 
Recientemente se han sintetizado compuestos sustituyendo el anillo A de 3,4,5trimetoxifenilo por piridina sustituida con grupos metoxilos y metilsulfanilos que mantienen actividad inhibidora de la polimerización de tublina y mejoran la solubilidad acuosa la de los compuestos $^{21}$.

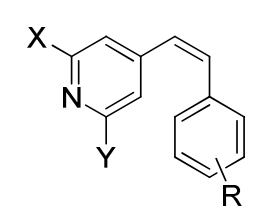<smiles></smiles>

Las fenstatinas ${ }^{22}$ son nuevos derivados modificados en el puente con estructura de benzofenona, que mantienen una potencia elevada y mejoran la solubilidad acuosa. En las fenstatinas, la estructura de benzofenona hace que los anillos se dispongan de forma no coplanar, igual que en las combretastatinas. Sin embargo, el carbonilo de las fenstatinas no es esencial para el comportamiento antimitótico, puesto que los análogos 1,1-diarileténicos, llamados isocombretastatinas, muestran una potente inhibición de la tubulina y citotoxicidad frente a líneas celulares de cáncer, similares a las de las combretastatinas correspondientes. ${ }^{23}$

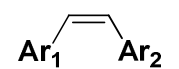

Combretastatinas<smiles></smiles>

Fenstatinas<smiles>C=C([15CH2])[18F]</smiles>

Isocombretastatinas

Figura 8: Estructuras modelos de combretastatina, fenstatina e isocombretastatina

A continuación se realiza una exposición de distintas metodologías utilizadas en la preparación de combretastatinas, fenstatinas e isocombretastatinas.

\footnotetext{
${ }^{21}$ Aramburu, L. Tesis doctoral. Universidad de Salamanca. 2014.

${ }^{22}$ Pettit, G. R.; Toki, B.; Herald, D. L.; Verdier-Pinard, P.; Boyd, M. R.; Hamel, E.; Pettit, R. K. Antineoplastic Agents. 379. Synthesis of Phenstatin Phosphate. J. Med. Chem. 1998, 41, 1688.

${ }_{23}$ Álvarez, R.; Álvarez, C.; Mollinedo, F.; Sierra, B. G.; Medarde, M.; Pelàez, R. Isocombretastatins A: 1,1diarylethenes as potent inhibitors of tubulin polymerization and cytotoxic compounds. Bioorg. Med. Chem. 2009, 17, 6422 .
} 


\section{MÉTODOS DE SÍNTESIS DE COMBRETASTATINAS}

Existen varios métodos de síntesis de combretastatinas, que se describen a continuación aplicados a la síntesis de combretastatina A-4.

\section{Por reacción de Wittig:}

Esta es la vía más utilizada en bibliografía. La reacción de Wittig se puede efectuar por condensación de un bromuro de trifenilfosfonio con un aldehído, obteniéndose una mezcla de isómeros $Z / E$ en proporción variable.

La sal de fosfonio 5 se prepara a partir de protección del grupo hidroxi del aldehído $\mathbf{1}$ con TBSCl para evitar las reacciones indeseadas, luego se reduce el grupo aldehído al alcohol $\mathbf{3}$ con $\mathrm{NaBH}_{4}$, después de la formación de derivado halogenado 4, éste se trata con trifenilfosfina para obtener la sal correspondiente.

La aplicación de la síntesis de Wittig a CA-4 podría realizarse por dos vías dependiendo de la elección del aldehído y de la sal de fosfonio utilizados como material de partida. La diferencia principal es la proporcion de isómeros $Z / E$ obtenidos: 1:1,5 para la sal de fosfonio 5 y el aldehído 6 y 1:4 para el aldehído 1.

Las principales desventajas de este método son su pobre selectividad, su bajo rendimiento y que la separación del isómero por cromatografía a veces resulta difícil. ${ }^{24}$ Sin embargo, la fácil preparación de los materiales de partida hace que sea una de las rutas sintéticas más utilizadas.

\footnotetext{
${ }^{24}$ Pettit, G. R.; Singh, S. B.; Boyd, M. R.; Hamel, E.; Pettit, R. K.; Schmidt, J. M.; Hogan, F. Antineoplastic agents. 291. Isolation and synthesis of combretastatins A-4, A-5 and A-6. J. Med. Chem. 1995, 38, 1666.
} 


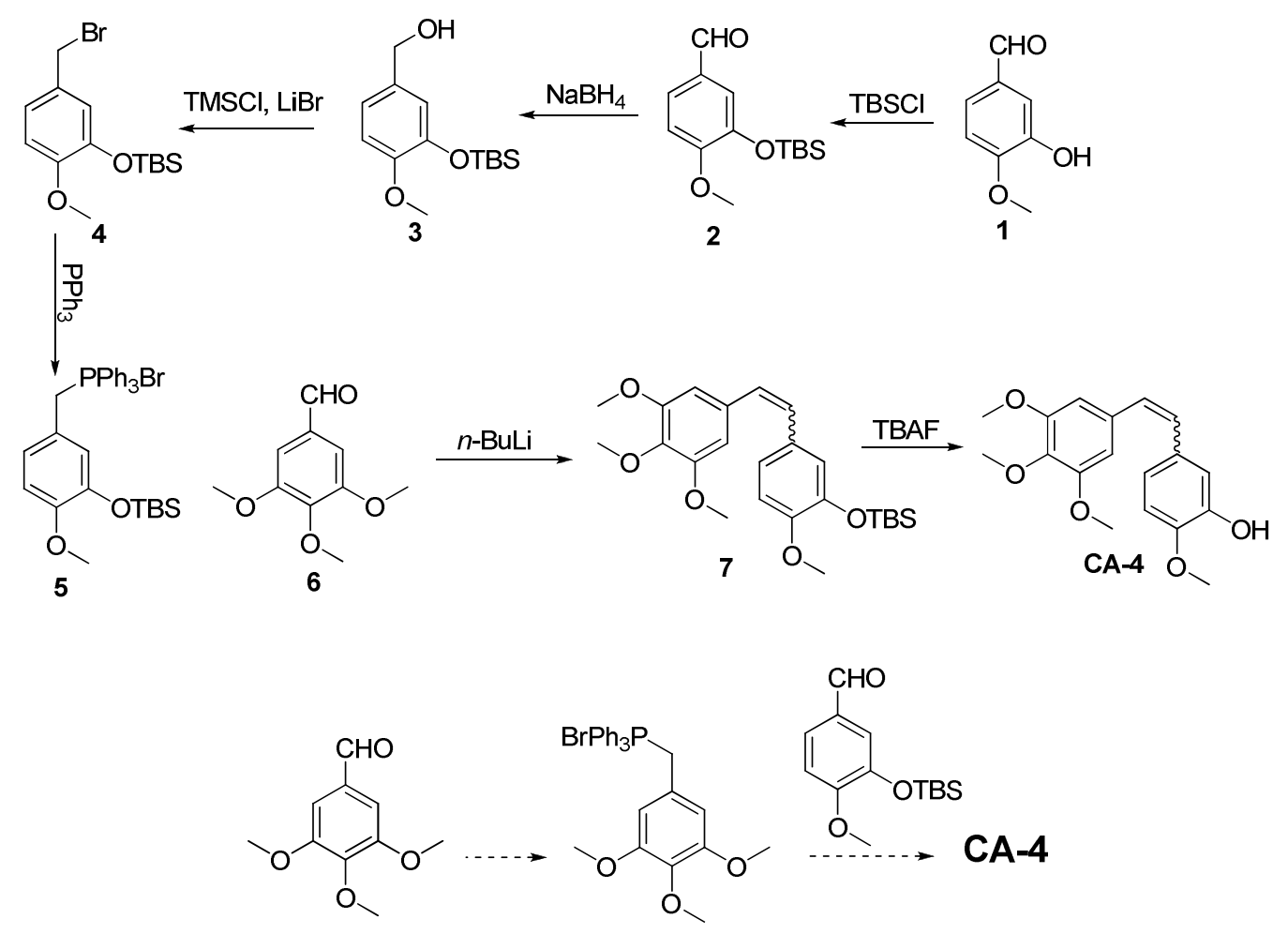

Figura 9: Síntesis de Wittig de la CA-4.

Los estilbenos se pueden formar mediante la reacciones tipo Wittig de un alcohol bencílico con una sal de fosfonio utilizando nano-partículas de Níquel (NiNPs) como catalizador, asi se obtienen las olefinas con buenos rendimientos y con poco tiempo de reacción ${ }^{25}$. Las NiNPs se preparan por tratamiento de $\mathrm{NiCl}_{2}$ con litio en presencia de DTBB (4,4'-di-terc-butilbifenil) como catalizador en THF. El Ni(0) en forma de nanoparticulas (NiNPs) se considera como el primer metal usado en la síntesis Wittig a partir de los alcoholes (en lugar de aldehídos) en la que no hay etapa redox estándar.

En primer lugar se probó la reacción de alcoholes bencílicos con el derivado fosforano sin catalizador de NiNPs pero no se observó la evolución de la reacción, lo mismo que cuando se puso la NiNP pocos equivalentes del catalizador. La reacción obtuvo un buen rendimiento cuando se puso en proporción 1:1. Se obtienen mezclas $Z / E$ en los cuales predomina el isómero $E$.

\footnotetext{
${ }^{25}$ Alonso, F.; Riente, P.; Yus, M. Wittig-Type Olefination of Alcohols Promoted by Nickel Nanoparticles: Synthesis of Polymethoxylated and Polyhydroxylated Stilbenes. Eur. J. Org. Chem. 2009, 6034.
} 

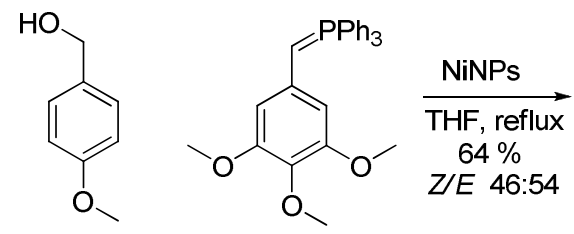<smiles>COc1ccc(C=Cc2cc(OC)c(OC)c(OC)c2)cc1</smiles>

Figura 10: Preparación de estilbenos con NiNPs

\section{Reacciones catalizadas por organometálicos}

\subsection{Acoplamiento de Suzuki:}

La combretastatina A-4 se prepara a partir de acoplamiento cruzado de Suzuki de derivados de bromoetenilo y ácidos borónicos, utilizando tetrakis(trifenilfosfina) $\mathrm{Pd}(0)$ como catalizador, solución acuosa de $\mathrm{Na}_{2} \mathrm{CO}_{3}$ como base y 1,2-dimetoxietano como disolvente. Esta reacción es estereoselectiva y se obtiene el isómero $Z$ al $70 \%{ }^{26}$<smiles>COc1cc(O)cc(OC)c1OC</smiles><smiles>COc1ccc(/C=C\Br)cc1O</smiles><smiles>COc1ccc(/C=C\c2cc(OC)c(OC)c(OC)c2)cc1OC</smiles>

Figura 11: Síntesis de CA-4 por acoplamiento de Suzuki

El bromuro de vinilo se prepara mediante la reacción de Corey-Fuchs ${ }^{27}$ seguida de una reducción catalizada con paladio. La utilización del hidroxi-aldehído da bajos rendimientos mientras que si se utiliza protegido en forma de OTMS, éste aumenta considerablemente.

\footnotetext{
${ }^{26}$ Gaukroger. K.; Hadfield. J, A.; Hepworth. L, A.; Lawrence. N, J.; McGown. A, T. Novel Syntheses of Cis and Trans Isomers of Combretastatin A-4. J. Org. Chem. 2001, 66, 8135.

${ }^{27}$ Gibtner, T.; Hampel, F.; Gisselbrecht, J.-P.; Hirsch, A. End-Cap Stabilized Oligoynes: Model Compounds for the Linear sp Carbon Allotrope Carbyne. Chem. Eur. J. 2002, 8, 408.
} 

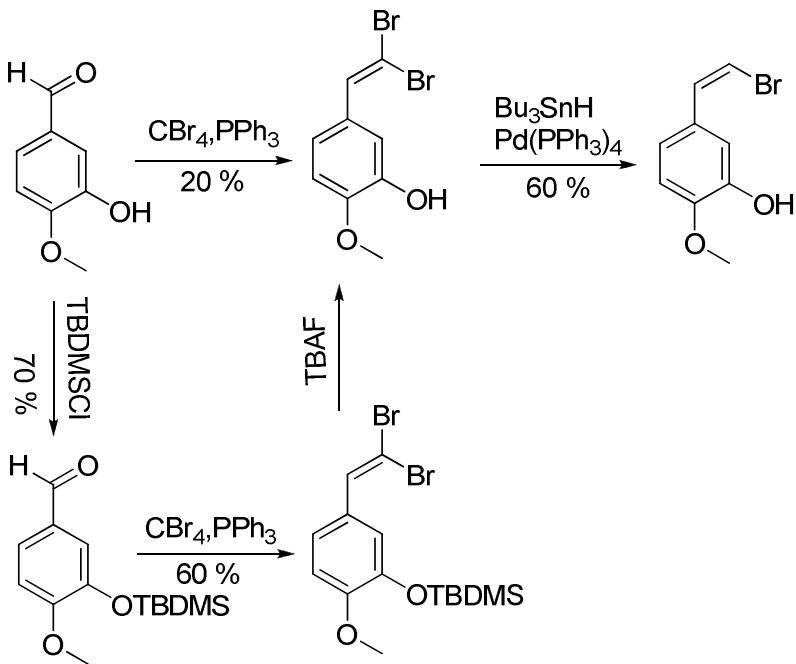

Figura 12: Síntesis del derivado bromuro de vinilo

\subsection{Acoplamiento de Kumada-Corriu:}

Camacho-Davila $^{28}$ ha sintetizado la combretastatina CA-4 a partir del acoplamiento de Kumada-Corriu de un magnesiano y el derivado halogenado obtenido en las condiciones de reacción de reducción de Corey-Fuchs, utilizando acetilacetonato férrico $\left(\mathrm{Fe}(\mathrm{acac})_{3}\right)$ como catalizador. Se obtiene el producto con $40 \%$ de rendimiento.<smiles>COc1cc(/C=C\Br)cc(OC)c1OC</smiles><smiles>COc1ccc([N+]Br)cc1OC</smiles>

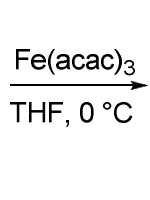<smiles>COc1ccc(/C=C\c2ccc(OC)c(OC)c2)cc1OC</smiles><smiles>COc1ccc(/C=C\c2ccc(OC)c(OC)c2)cc1OC</smiles>

Figura 13: Síntesis de CA-4 con la reacción de acoplamiento de Kumada-Corriu

\section{Reacción de Ramberg-Backlund}

En el esquema siguiente se explica los pasos de la síntesis de combretastatina A-4 utilizando la reacción de Ramberg-Backlund. ${ }^{29}$

\footnotetext{
${ }^{28}$ Camacho-Davila, A. A. Kumada-Corriu Cross Coupling Route to the Anti-Cancer Agent Combretastatin A-4. Synth. Commun. 2008, 2823.

${ }^{29}$ Robinson, J. E.; Taylor, R. J. K.. A Ramberg-Bäcklund route to the stilbenoid anti-cancer agents combretastatin A-4 and DMU-212. Chem. Commun. 2007, 1617.
} 


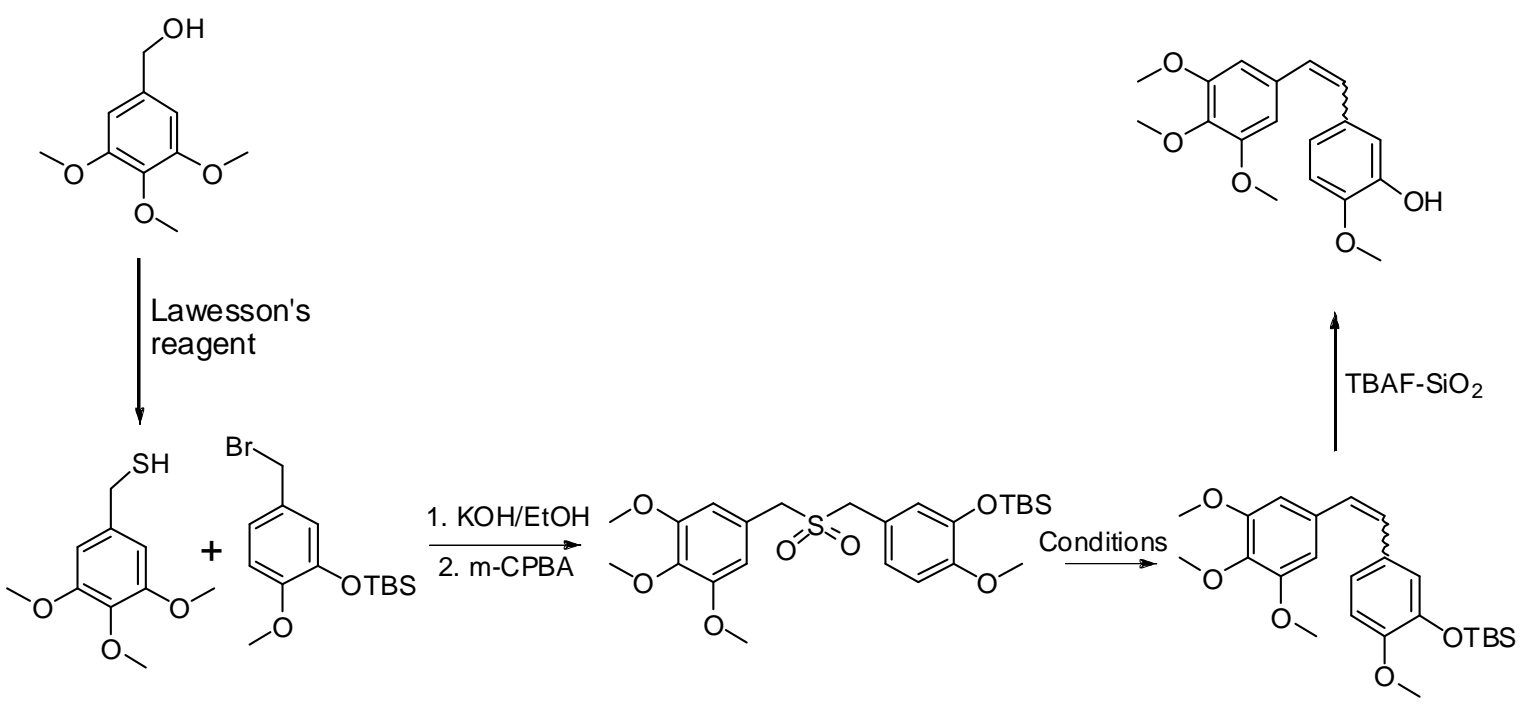

Figura 14: Síntesis de análogos de CA-4 mediante las condiciones de Ramberg-Backlund

La síntesis de CA-4 comienza por acoplamiento de derivado halogenado y el tiol obtenido por el tratamiento de alcohol 3,4,5-trimetoxibencílico con reactivo de Lawesson's, utilizando como base hidróxido potásico y se obtiene el sulfuro que se oxida con el ácido metacloroperbenzoico para dar la sulfona correspondiente. El derivado sulfonado se ha transformado en el estilbeno en distintas condiciones variando las proporciones de los estéreoisómeros formados. Bajo las condiciones de Chan et $\mathrm{al}^{30}\left(\mathrm{CF}_{2} \mathrm{Br}_{2}, \mathrm{KOH}-\mathrm{Al}_{2} \mathrm{O}_{3}\right.$, t$\left.\mathrm{BuOH}, 0^{\circ} \mathrm{C}, 12 \mathrm{~h}\right)$ se obtiene combretastatina A-4 con un rendimiento de $81 \%(Z / E=1: 9)$, en las condiciones de Franck ${ }^{31}\left(\mathrm{C}_{2} \mathrm{~F}_{4} \mathrm{Br}_{2}, \mathrm{t}-\mathrm{BuOH}, \mathrm{KOH}-\mathrm{Al}_{2} \mathrm{O}_{3}, \Delta, 12\right.$ h) se obtiene en $72 \%(\mathrm{Z} / \mathrm{E}$ 15:85), mientras el rendimiento se disminuye al $69 \%$ (Z/E 53:47) en las condiciones de Meyers et $\mathrm{al}^{32}\left(\mathrm{CCl}_{4}\right.$, t-BuOH, $\left.\mathrm{KOH}, \mathrm{H}_{2} \mathrm{O}\right)$.

De los tres casos anteriores; se observo que al tratar el compuesto bajo las condiciones de Franck se mejoro el rendimiento, pero en las condiciones de Meyers se obtuvo la mejor estéreo-selectividad con el isómero cis mayoritario.

\footnotetext{
${ }^{30}$ Chan, T. -L.; Fong, S.; Li, Y.; Man, T. -O.; Poon, C. -D. A New One-flask Ramberg-Backlund Reaction. $J$. Chem. Soc., Chem. Commun. 1994, 1771.

${ }^{31}$ Yang, G.; Franck, R. W.; Byun, H. -S.; Bittman, R.; Samadder, P.; Arthur, G. Convergent C-Glycolipid Synthesis via the Ramberg-Ba1cklund Reaction: Active Antiproliferative Glycolipids. Org. Lett. 1999, 1, 2149.

${ }^{32}$ Meyers, C. Y.; Malte, A. M. ; Matthews, W. S. Ionic Reactions of Carbon Tetrachloride. Survey of Reactions with Ketones, Alcohols, and Sulfones. J. Am. Chem. Soc. 1969, 91, 7510.
} 


\section{Reacciones en microondas:}

Se prepara los derivados de combretastatina A-4 mediante las irradiaciones en microondas del bromuro de trietilbenzilfosfonio y aldehído y en presencia de carbonato potásico. Se obtienen con excelente rendimiento pero con el isómero trans mayoritario ${ }^{33}$. Esta reacción se desarrolla en dos partes; se prepara el bromuro de trietilbencilfosfonio a partir de la reacción del alcohobencílico con la sal de bromuro de trietilfosfonio a $100{ }^{\circ} \mathrm{C}$ sin disolvente, luego se enfría a temperatura ambiente y se le añade el carbonato potásico a un matraz sellado y el aldehído bencílico correspondiente, después se pone a microondas a $75{ }^{\circ} \mathrm{C}$ durante $30 \mathrm{~min}$.

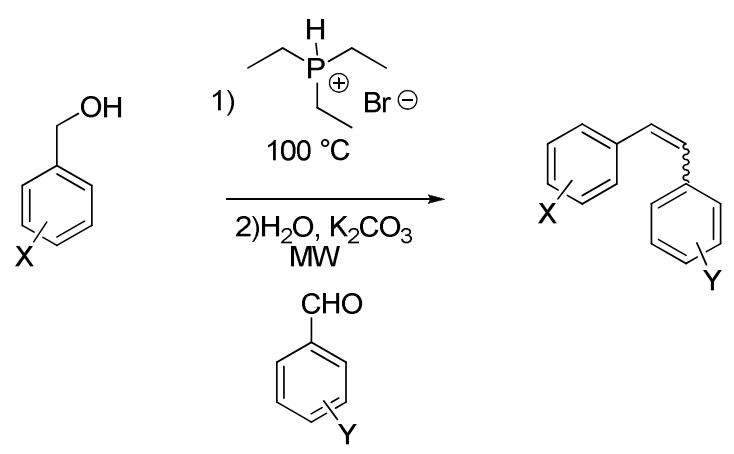

Figura 15: Preparación de estilbenos con radiaciones en microondas

Se preparan los estilbenos también a partir de la escisión oxidativa y la reacción de HornerEmmons, ambas reacciones se realizan en microondas, utilizando $\mathrm{Al}_{2} \mathrm{O}_{3}$ como soporte.
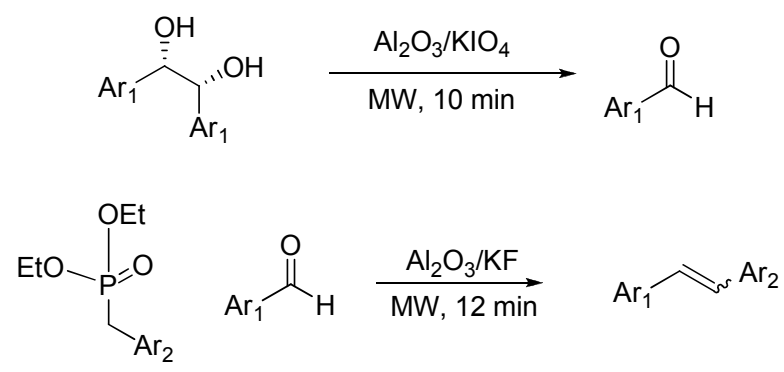

Figura 16: Formación de estilbenos por microondas

\footnotetext{
${ }^{33}$ McNulty, J.; Das, P.; McLeod, D. Microwave-Assisted, aqueous Wittig reactions: organic-solvent- and Protecting-group-free chemoselective synthesis of functionalized alkenes. Chem. Eur. J. 2010, 16, 6756.
} 
En primer lugar se prepara el aldehído a partir de la ruptura oxidativa de 1,2-dioles simétricos, la reacción se efectúa en columna y el aldehído se hace pasar a otra columna en la que reacciona con el derivado fosfato mediante las irradiaciones en microondas y se obtienen trans estilbenos con buen rendimiento. En esta reacción que se utilizan dioles simétricos para evitar la formación de productos indeseados, necesita corto tiempo y transcurre con un rendimiento de $60-75 \% .^{34}$

\section{Condensación de Perkin}

Las combretastatinas se sintetizan también por condensación de Perkin entre un aldehído aromático y un ácido carboxílico en presencia de anhídrido acético y trietilamina, obteniendose el derivado del acido acrílico en buen rendimiento y con excelente estéreoselectividad (Z/E 19:1). La reacción genera una función ácido carboxílico en el puente que se puede eliminar por descarboxilación con quinolina y cobre a $220{ }^{\circ} \mathrm{C} .{ }^{35}$

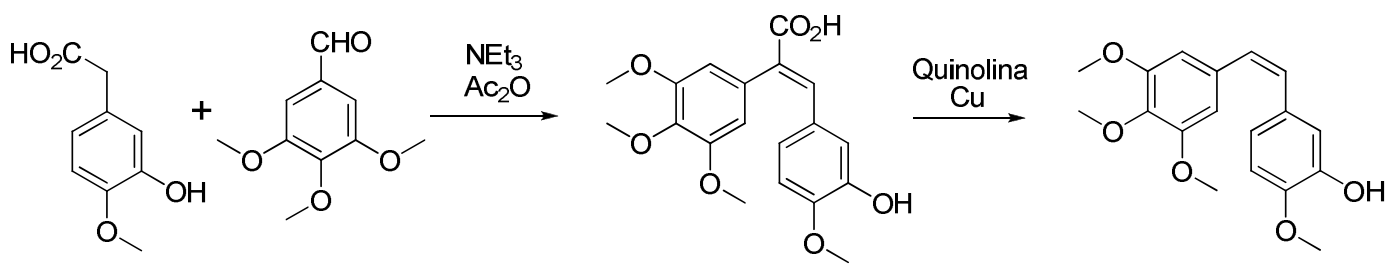

Figura 17: Síntesis de Perkin de CA-4.

A partir de esta reacción de condensación de Perkin se han preparado combretastatinas con función nitrilo en el puente, haciendo reaccionar el aldehído aromático con 3,4,5trimetoxifenilacetonitrilo, se obtiene con buen rendimiento, además la presencia del grupo nitrilo en la olefina del puente mejora la unión con la tubulina ${ }^{36}$.

\footnotetext{
${ }^{34}$ Dakdouki, S. C.; Villemin, D.; Bar, N. An Original On-Column Oxidative Cleavage of Vicinal Diols Using Alumina/Potassium Periodate: Application to Sequential Oxidation/Horner-Emmons Reactions. Eur. J. Org. Chem. 2011, 4448.

${ }^{35}$ Zou, Y.; Xiao, C. -F.; Zhong, R. -Q.; Wei, W.; Huang, W. -M.; He, S. -J. Synthesis of combretastatin A-4 and erianin. J. Chem. Res. 2008, 354.

${ }^{36}$ Jalily, P. H.; Hadfield, J, A.; Hirst, N.; Rossington, S. B. Novel cyanocombretastatins as potent tubulin polymerisation inhibitors. Bioorg. Med. Chem. Lett. 2012, 22, 6731.
} 


\section{A partir de la fenstatina: Reordenamiento de Colvin}

Una síntesis alternativa de combretastatina es a partir de fenstatina, a través de un intermedio de diarilalquilo. ${ }^{37}$

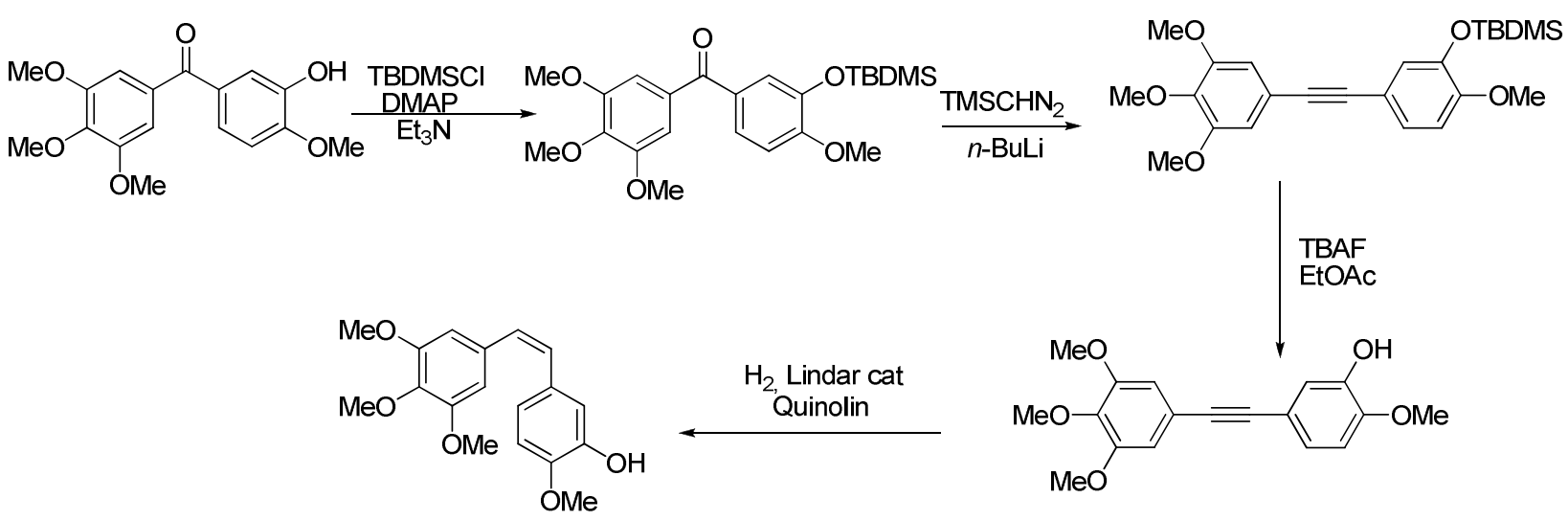

Figura 18: Síntesis de CA-4 a partir de fenstatina

\section{A partir de alquinos}

Alami et $\mathrm{al}^{38}$ han publicado un nuevo procedimiento para la obtención de los análogos de CA4 por hidrosilación-protodesilación.

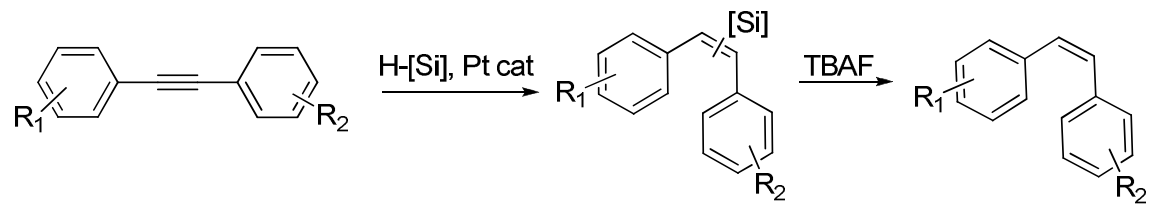

Figura 19: Síntesis de análogos de CA-4 mediante el proceso hidrosililación-protodesililación

\footnotetext{
${ }^{37}$ Pitrov, O. I.; Gerova, M. S.; Chaniv, C. D.; Petrova, K. V. New Efficient Synyhesis of Combretastatin A-4 via Colvin Rearrangement. Synthesis. 2011, 3711.

${ }^{38}$ Giraud, A.; Provot, O.; Hamzé, A.; Brion, J. -D.; Alami, M. One-pot hydrosilylation-protodesilylation of functionalized diarylalkynes: a highly selective access to Z-stilbenes. Application to the synthesis of combretastatin A-4. Tetrahedron. Lett. 2008, 491107.
} 
Este método permite la obtención de (Z)-combretastatina mediante una reacción estéreoselectiva a partir de la hidrosililación de diarilalquino utilizando óxido de platino como catalizador, seguido de la desililación con fluoruro de tetrabutilamonio. Se obtienen $(Z)$ estilbenos con un buen rendimiento.

\section{Isomerización del doble enlace:}

Si se desea, se pueden preparar los isómeros $E$ a partir de los derivados de bromoetinilo $E$ o por tratamiento de cis-combretastatinas con yodo.<smiles>COc1ccc(/C=C/c2cc(OC)c(OC)c(OCC(C)(C)C)c2)cc1/C=C/c1ccc(OC)c(OC)c1</smiles>

Figura 20: Isomerización CA-4 de cis a trans

\section{MÉTODOS DE SÍNTESIS DE FENSTATINAS}

\section{A partir de combretastatinas:}

La fenstatina se preparó por primera vez por Pettit et al ${ }^{19}$, durante una investigación dirigida al estudio de la REA de combretastatinas, como un producto inesperado de la oxidación de un silil derivado de combretastatina A-4 con el complejo de Jacobsen.

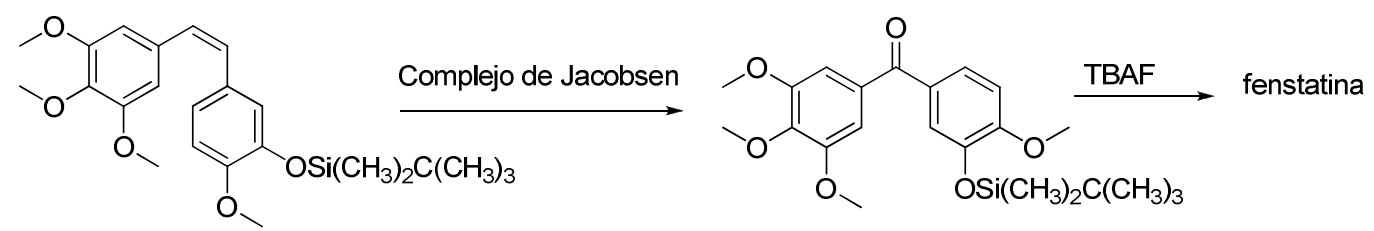

Figura 20: Síntesis de fenstatina a partir de CA-4 protegida 


\section{Reacciones catalizadas por organometálicos:}

\subsection{Acoplamiento de Suzuki:}

Se pueden preparar derivados de fenstatinas vía carbonilación de Suzuki. Recientemente se ha descrito la preparación de diarilcetonas utilizando nanoparticulas de paladio con ácido arilborónico, CO (1 atm), PEG-400 (polietilénglicol con un peso molecular de 400 Da), una base y a temperatura ambiente, con rendimientos de hasta el $96 \% .^{39,40}$

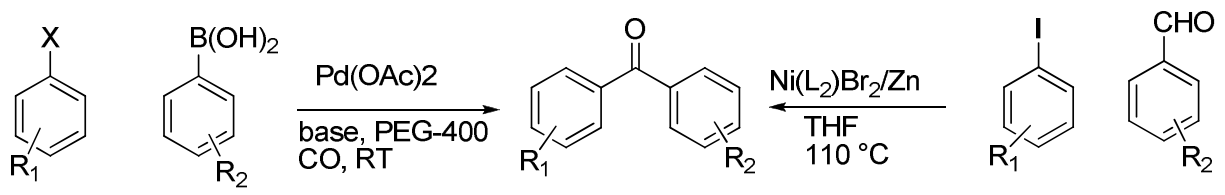

Figura 21: Síntesis de fenstatina a partir de acoplamiento de Suzuki

Otra reacción de acoplamiento entre un aldehído aromático y yoduros de arilo que permite la formación de diarilcetonas es la catalización con $\mathrm{Ni}(\mathrm{dppe}) \mathrm{Br}_{2}$ en presencia de $\mathrm{Zn}$ como ácido de Lewis y se obtienen buenos rendimientos ${ }^{41}$. En esta reacción la elección del disolvente es importante, porque con disolventes menos polares no se observa evolución de esta reacción.

\subsection{Catálisis con cobre:}

Recientemente se han descrito otra síntesis de diarilcetonas a partir de epóxidos utilizando metales de transición como catalizadores, en concreto $\mathrm{Cu}(\mathrm{OAc})_{2}$, anilina, atmosfera de $\mathrm{O}_{2} \mathrm{y}$ DMSO como disolvente.

\footnotetext{
${ }^{39}$ Wu, X-F.; Neumann, H.; Matthias Beller. Synthesis of Heterocycles via Palladium-Catalyzed Carbonylations. Chem. Rev. 2013, 113, 1.

${ }^{40}$ Qing, Z.; Shaohua, W.; Wei, H.; In Situ Generation of Palladium Nanoparticles: Ligand-Free Palladium Catalyzed Pivalic Acid Assisted Carbonylative Suzuki Reactions at Ambient Conditions. J. Org. Chem. 2014, 79, 1454.

${ }^{41}$ Huang ,Y. -C.; Majumdar, K. K.; Cheng, C. -H. Nickel-Catalyzed Coupling of Aryl Iodides with Aromatic Aldehydes: Chemoselective Synthesis of Ketones. J. Org. Chem. 2002, 67, 1682.
} 


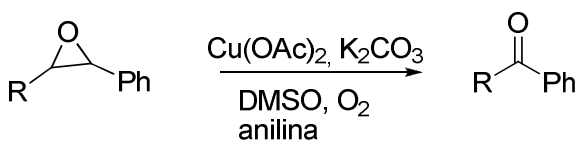

Figura 22: Síntesis de fenstatina a partir de catálisis con cobre

\subsection{Carbonilación acelerada por irradiación con microondas:}

Para mejorar la reacción de carbonilación, reducir el tiempo de reacción y evitar las problemas de los disolventes, se preparan benzofenonas usando las irradiaciones en el aparato de microondas con complejo de carbonilcobalto. En esta reacción el yoduro de arilo, $\mathrm{Co}(\mathrm{CO})_{8}$ y acetonitrilo en microondas forma la benzofenona correspondiente ${ }^{42}$.<smiles>[X]c1ccccc1</smiles>

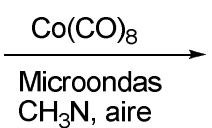<smiles>[R]c1ccc(C(=O)c2ccccc2)cc1</smiles>

Figura 23: Irradiación en microondas

\section{Reacciones de Friedel-Crafts:}

Las benzofenonas se pueden preparar mediante la reacción de Friedel-Crafts vía acilación o alquilación y posterior oxidación.

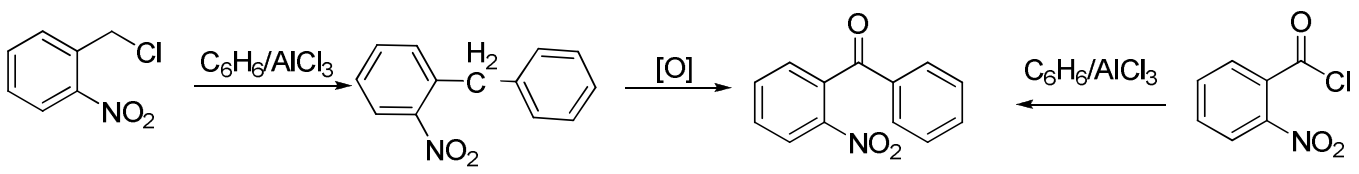

Figura 24: Síntesis de fenstatina a partir de acilación o alquilación de Friedel-Crafts

\footnotetext{
${ }^{42}$ Enquist, P-A.; Nilsson, P.; Larhed, M. Ultrafast Chemistry: Cobalt Carbonyl-Mediated Synthesis of Diaryl Ketones under Microwave Irradiation. Org. Lett. 2003, 25, 4875.
} 


\section{A partir de productos naturales:}

La síntesis de los derivados de la fenstatina se ha realizado a partir de alilpolialcoxibencenos aislados de las plantas, Petroselinum sativum Hoffm. cultivada en Rusia y Anethum graveolens $L$. de India. Este compuesto fue utilizado en la síntesis de los análogos de la combretastatina con una actividad muy significativa frente a la polimerización de la tubulina $^{43}$.

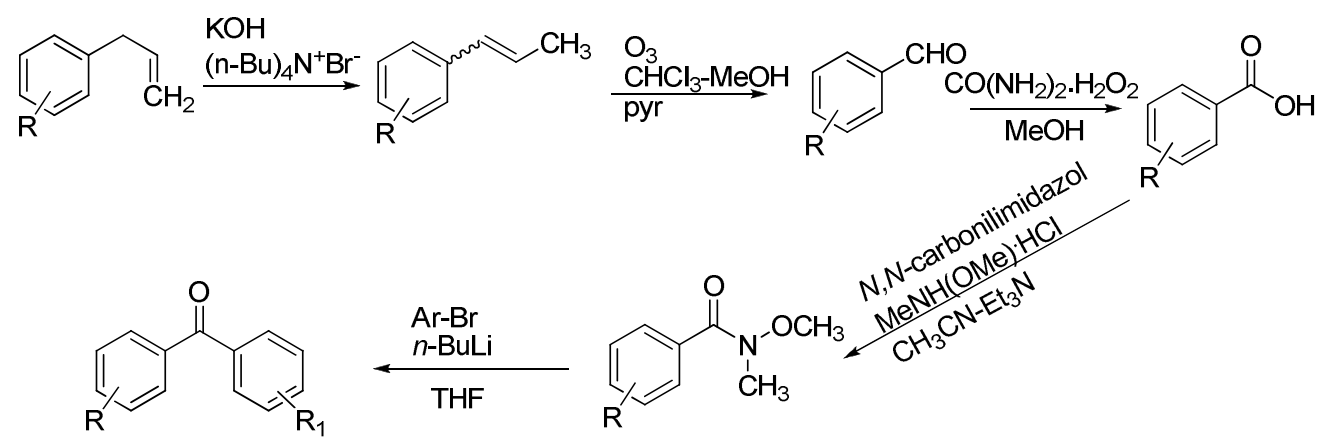

Figura 25: Preparación de la fenstatina a partir de allilpolialkoxibenceno

El aldehído se obtiene por ozonólisis del estireno obtenido de la reacción de isomerización en condiciones de transferencia de fase del alilpolialcoxibenceno. El tratamiento de aldehído con un complejo de urea produce el ácido que reacciona con agente activante para formar la amida de Weinreb, que se condensa con el derivado de litio para formar la fenstatina.

\section{A partir de una adición nucleofilica:}

Las fenstatinas se sintetizan también a partir de una condensación entre el derivado organometálico y un aldehído o ácido aromático ${ }^{44}$. Este método es el más utilizado por nuestro grupo de trabajo.

\footnotetext{
${ }^{43}$ Titov, I. Y.; Sagamanova, I. K.; Gritsenko, R. T.; Karmanova, I. B.; Atamanenko, O. P.; Semenova, M, N.; Semenov, V. V. Application of plant allylpolyalkoxybenzenes in synthesis of antimitotic phenstatin analogues. Bioorg. Med. Chem. Lett. 2011, 21, 1578.

${ }^{44}$ a) Liou, J. -P.; Chang, J. -Y.; Chang, C. -W.; Chang, C. -Y.; Mahindroo, N.; Kuo, F. -M.; Hsieh, H. -P. Synthesis and Structure-Activity Relationships of 3-Aminobenzophenones as Antimitotic Agents. J. Med. Chem. 2004, 47, 2897. b) Álvarez, C.; Álvarez, R.; Corchete P.; Pérez-Melero C.; Peláez, R.; Medarde, M. Synthesis
} 


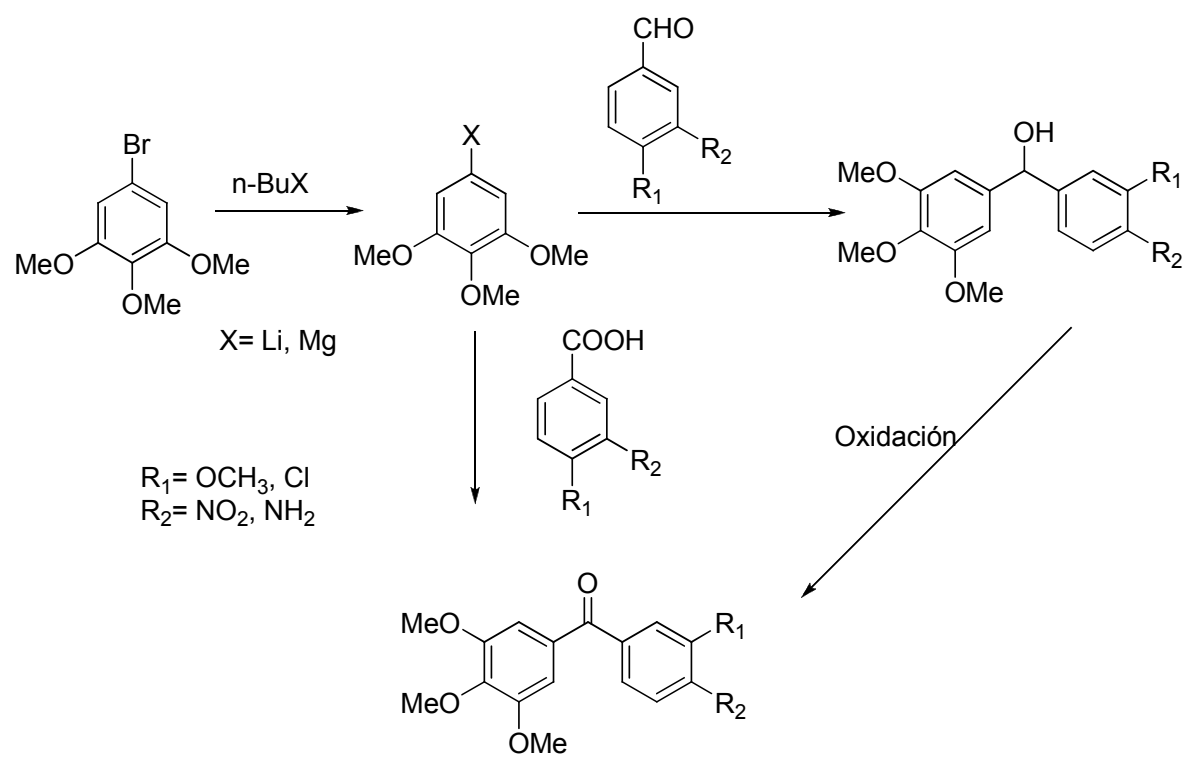

Figura 26: Ruta sintética de fenstatina

\section{MÉTODOS DE SÍNTESIS DE ISOCOMBRETASTATINAS}

Las isocombretastatinas son los 1,1-diariletenos isómeros de las combretastatinas (1,2diariletenos), que tienen un efecto citotóxico más potente que las fenstatinas. Se pueden sintetizar por varias rutas sintéticas.

\section{A partir de la fenstatinas}

Las isocombretastatinas se preparan a partir de fenstatinas por reacción de Wittig ${ }^{23}$. Este procedimiento es el que se usa en el desarrollo de las isocombretastatinas sintetizadas en esta memoria.

and biological activity of naphthalene analogues of phenstatins: Naphthylphenstatins. Bioorg. Med. Chem. Lett. 2007, 17, 3417. c) Álvarez, R.; Álvarez, C.; Mollinedo, F.; Sierra, G. Beatriz.; Medarde, M.; Peláez, R. Isocombretastatins A: 1,1-Diarylethenes as potent inhibitors of tubulin polymerization and cytotoxic compounds. Bioorg. Med. Chem. 2009, 17, 6422. 


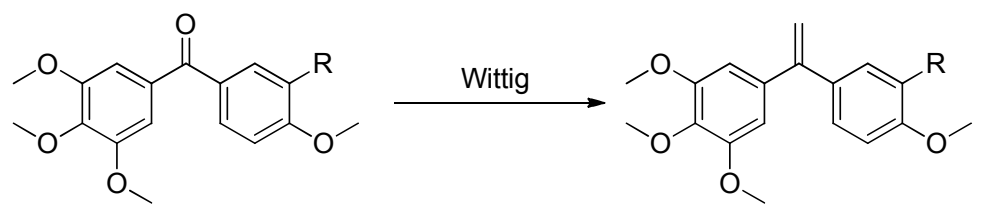

$\mathrm{R}=\mathrm{H}, \mathrm{I}, \mathrm{NO}_{2}$, OTBDPS

Figura 27: Síntesis de isoCA-4 por reacción de Wittig

\section{Reacciones catalizadas por organometálicos:}

\subsection{Acoplamiento con paladio}

Las isocombretastatinas se preparan por la reacción de acoplamiento de $N$-tosilhidrazonas y yoduros de arilo catalizadas por Pd. ${ }^{45}$ Después de la desprotección del grupo hidroxi, se obtiene isoCA4 en buen rendimiento.<smiles>COc1cc(C(C)=NNC(C)COc2c(OC)cc(C(C)=O)cc2OC)cc(OC)c1OC</smiles><smiles>C=C(c1ccc(OC)c(O)c1)c1cc(OC)c(OC)c(OC)c1</smiles>

Figura 28: Síntesis de isoCA-4 por acoplamiento con Pd

Se preparó también la isocombretastatina por reacción de acoplamiento de $N$-tosilhidrazonas con derivados ariltriflato, utilizando $\mathrm{Pd}(\mathrm{OAc})_{2}$ y $\mathrm{PdCl}_{2}(\mathrm{MeCN})_{2}$ como catalizadores, cuya catalítica es similar a $\mathrm{Pd}_{2}(\mathrm{dba})_{3}$ y conducen a excelentes rendimientos ${ }^{46}$.

\footnotetext{
45 a) Messaoudi, S.; Treguier, B.; Hamze, A.; Provot, O.; Peyrat, J. F.; De Losada, J. R.; Liu, J. M.; Bignon, J.; Bakala, J. W.; Thoret, S.; Dubois, J.; Brion, J. Daniel.; Alami, M. Isocombretastatins A versus Combretastatins A: The Forgotten isoCA-4 Isomer as a Highly Promising Cytotoxic and Antitubulin Agent. J. Med. Chem. 2009, 52, 4538. b) Brachet, E.; Hamze, A.; Peyrat, J. -F.; Brion, J. -D.; Alami, M. Pd-Catalyzed Reaction of Sterically Hindered Hydrazones with Aryl Halides: Synthesis of Tetra-Substituted Olefins Related to iso Combretastatin A4. Org. Lett. 2010, 12, 4042.

${ }^{46}$ Tréguier, B.; Hamze, A.; Provot, O.; Brion, J. -D.; Alami, M. Expeditious synthesis of 1,1-diarylethylenes related to isocombretastatina A-4 (isoCA-4) via palladium-catalyzed arylation of N-tosylhydrazones with aryl triflates. Tetrahedron. Lett. 2009, 50, 6549.
} 


\subsection{Acoplamiento de Stille}

Para el acoplamiento de Stille se prepara el derivado de estaño a partir del alquino correspondiente y posteriormente, en presencia del catalizador de paladio, se hace reaccionar con los haluros de arilo ${ }^{47}$.

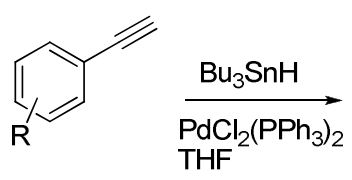

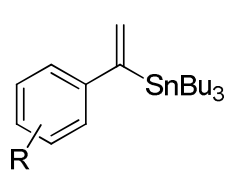

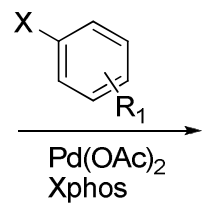<smiles>[R][R]1cccc(C(=C)c2ccc([R])cc2)c1</smiles>

Figura 29: Síntesis de isocombretastatina por acoplamiento de Stille

\section{A partir de amida de Weinreb:}

En esta síntesis se utiliza como producto de partida el ácido glioxálico susceptible de transformarse en dos etapas en la amida de Weinreb a gran escala ${ }^{48}$.

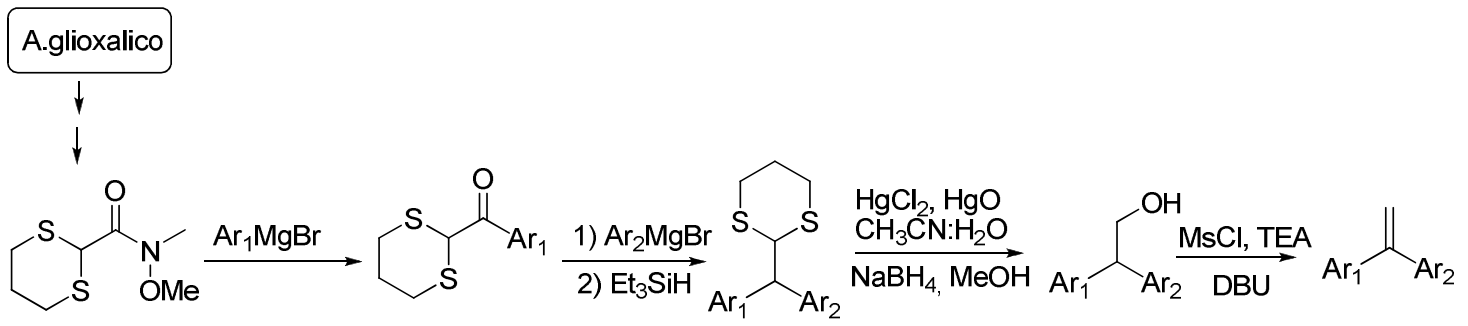

Figura 30: Preparación de isoCA-4 a partir de amida de Weinreb

Los dos anillos aromáticos del compuesto se obtienen después de la adición consecutiva de los dos derivados arilmagnesianos. La desprotección del puente produce un alcohol primario

\footnotetext{
${ }^{47}$ Hamze, A.; Veau, D.; Provot, O.; Brion, J. -D.; Alami, M. Palladium-Catalyzed Markovnikov Terminal Arylalkynes Hydrostannation: Application to the Synthesis of 1,1-Diarylethylenes. J. Org. Chem. 2009, 74, 1337.

${ }^{48}$ Balasubramaniam, S.; Kommidi, H.; Aidhen, I. S. Weinreb amide based building blocks for convenient access to 1,1-diarylethenes and isocombretastatin analogues. Tetrahedron. Lett. 2011, 52, 2683.
} 
que se elimina como mesilato por tratamiento con DBU, obteniéndose el derivado de la isocombretastatina.

\section{A partir de acetofenonas:}

Como alternativa de la reacción de acoplamiento con paladio, se ha encontrado otro método de sintetizar derivados de isocombretastatina a partir de la reacción de acetofenona con el derivado magnesiano para formar alcoholes terciarios. La deshidratación de los alcoholes en presencia del acido $p$-toluensulfónico como catalizador produce la isocombretastatina ${ }^{49}$. Los rendimientos varían dependiendo del grupo $\mathrm{R}$.<smiles>COc1cc(C(C)=O)cc(OC)c1OC</smiles>

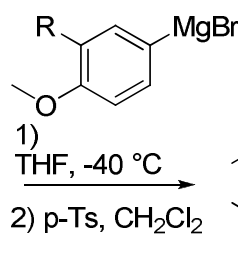<smiles>[R]c1cc(C(=C)c2ccc(OC)c(OC)c2)ccc1OC</smiles><smiles>COc1cc(N(C)c2ccc(F)cc2)cc(OC)c1OC</smiles><smiles>[R]c1cc(C(C)=O)ccc1OC</smiles>

$\mathrm{R}=\mathrm{H}, \mathrm{F}, \mathrm{Br}, \mathrm{NH}_{2}, \mathrm{NO}_{2}$, OTBDMS, Alquilo

Figura 31: Preparación de isoCA-4 a partir de acetofenonas

\footnotetext{
${ }^{49}$ Hamze, A.;Giraud, A.; Messaoudi, S.; Provot O.; Peyrat, J. -F.; Bignon, J.; Liu, J. -M.; Wdzieczak-Bakala, J.; Thoret, S.; Dubois, J.; Brion, J. -D.; Alami, M. Synthesis, Biological Evaluation of 1,1-Diarylethylenes as a Novel Class of Antimitotic Agents. ChemMedChem. 2009, 4, 1912.
} 



\section{PLANTEAMIENTO Y OBJETIVOS}





\section{PLANTEAMIENTO}

El objetivo general de este trabajo es la síntesis y evaluación de nuevos agentes antimitóticos pertenecientes a las familias de combretastatinas, fenstatinas e isocombretastatinas y que contengan agrupaciones nitrogenadas como sustituto de alguno de los grupos hidroxilo ó metoxilo de combretastatina A-4.

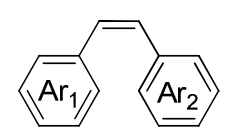

combretastatinas

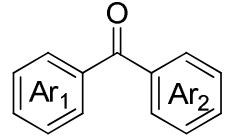

Fenstatinas

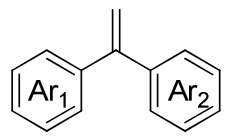

Isocombretastatinas

Figura 32. Estructura básica de los compuestos sintetizados

Los estudios de relación estructura-actividad (REA) han mostrado que el anillo de 3,4,5trimetoxifenilo (anillo A) es importante para la actividad citotóxica, tanto en combretastatinas $^{50}$ como fenstatinas $^{40} \mathrm{y}$, en general, cualquier otra sustitución en el anillo A disminuye la actividad antimitótica del compuesto ${ }^{13}$. En nuestro grupo el anillo B ha sido sustituido con éxito por sistemas heterocíclicos como carbazol o indol, pero las propiedades farmacocinéticas no son muy adecuadas. Con el fin de mejorarlas en la agrupación indólica se han introducido distintos grupos como aldehídos, ácidos o amidas obteniendo resultados prometedores.

Un primer apartado de esta memoria de Tesis doctoral está dirigido a realizar variaciones del anillo B. Estas variaciones incluyen la presencia de un grupo amino situado en posición paradel anillo aromático (fenilo o piridilo) que equivale a la posición del átomo de nitrógeno en el indol. Como agrupaciones nitrogenadas se introducirán los grupos dimetilamino y pirrolidina. Teniendo en cuenta la disponibilidad de los materiales de partida y para realizar estudios de REA en ocasiones se preparan compuestos con las agrupaciones nitrogenadas en otras posiciones del anillo.

\footnotetext{
${ }^{50}$ Akselsen, Ø. W.; Odlo, K.; Cheng, J. -J.; Maccari, G.; Botta, M.; Hansen, T. V. Synthesis, biological evaluation and molecular modeling of 1,2,3-triazole analogs of combretastatin A-1. Bioorg. Med. Chem. 2012, $20,234$.
} 
Con el fin de mejorar sustancialmente la solubilidad de estos compuestos a $\mathrm{pH}$ fisiológico se llevará a cabo la preparación de sales de amonio cuaternarias ya que los grupos dimetilamino y pirrolidina se presentan como agrupaciones óptimas a este fin.

Al revisar la bibliografía se ha observado, que a pesar de ser cuantiosos los grupos descritos como sustitutos de los restos metoxilos del anillo A, la presencia de grupos amino en este anillo no está muy explorada. Esto nos sirve para proponer un segundo apartado del trabajo en el cual se sustituye uno de los grupos $\mathrm{OMe}$ por $\mathrm{NH}_{2}, \mathrm{NHMe}, \mathrm{NHAc}, \mathrm{NMe}_{2}$.

Estos dos apartados u objetivos generales del trabajo se completan con variaciones en el puente que une los dos anillos aromáticos, con la introducción de otras funciones que faciliten la unión a los distintos aminoácidos de la tubulina, con variaciones en los sustituyentes de los anillos A y B ó con la sustitución del anillo B por anillos no aromáticos con el fin de completar en la medida de lo posible estudios de REA.

La ruta de síntesis seleccionada para obtener las fenstatinas (diarilmetanonas), comienza con la adición del compuesto organometálico a un aldehído o un ácido carboxílico. Por su parte, para la síntesis de las combretastatinas se ha optado por la reacción de Wittig entre trifenilbenzilfosforanos y aldehídos adecuadamente sustituidos que aunque origina mezclas de isómeros $Z / E$ se pueden separar por métodos cromatográficos. Sobre estos materiales de partida se efectuará la introducción de otras agrupaciones en función de su reactividad química.

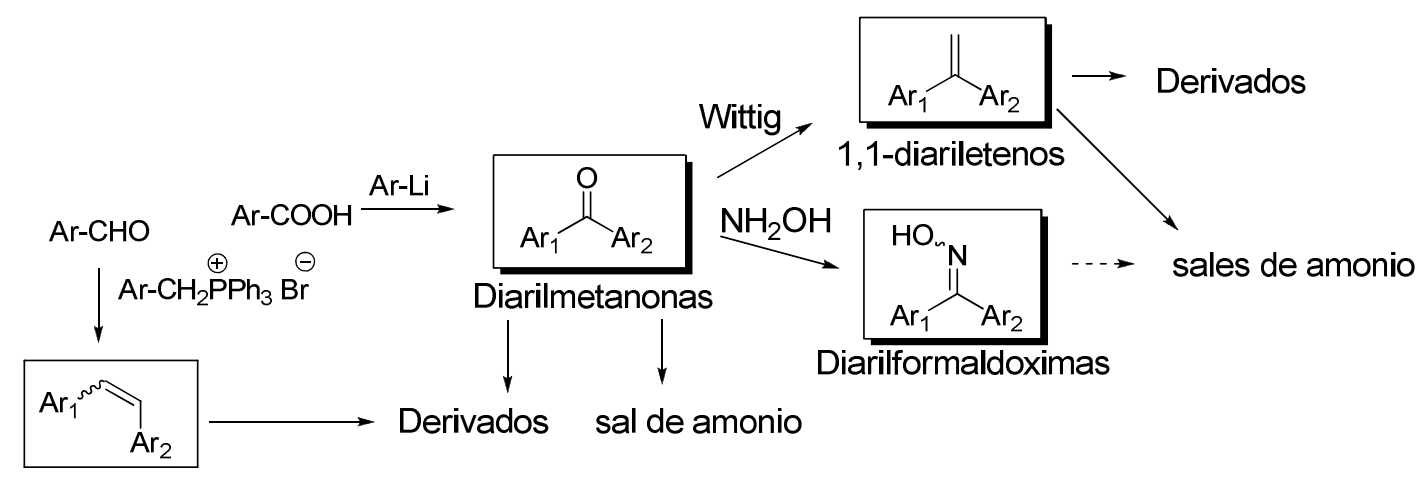

Figura 33: Esquema general de síntesis de los compuestos objetivos 


\section{OBJETIVOS:}

De acuerdo con el planteamiento y siguiendo los antecedentes del grupo de trabajo, los objetivos concretos de esta memoria son los siguientes:

\section{Modificaciones del anillo B}

El primer objetivo sintético del trabajo se resume en la figura siguiente donde se incluyen las variaciones a introducir en el anillo B.

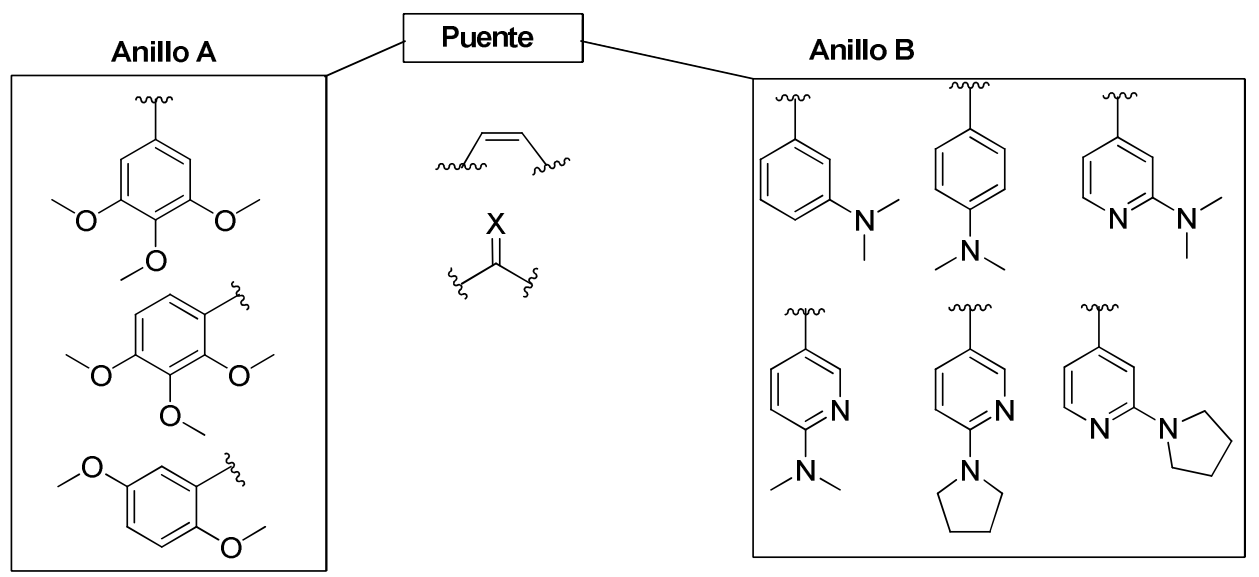

Figura 34: Variaciones en el anillo B

Se combinan los anillos aromáticos A de trimetoxi o dimetoxifenil con anillos bencénicos y piridínicos que se unen con un puente de uno ó dos átomos de carbono. Además se sustituye el anillo aromático B por otros no aromáticos.<smiles>[X]C(c1cc(OC)c(OC)c(OC)c1)C1CCC(OC)CC1</smiles><smiles>[R]C1CCN(C(C)c2cc(OC)c(OC)c(OC)c2)CC1</smiles>

El segundo objetivo es la introducción de grupos polares en el anillo aromático B, que favorezcan la solubilidad acuosa de los compuestos y que puedan aumentar la interacción con la tubulina por posible formación de un enlace de hidrógeno adicional. 


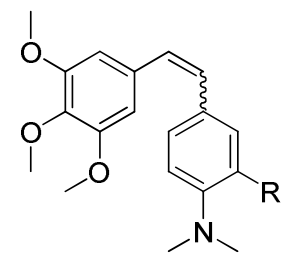<smiles></smiles>

$\mathrm{R}=\mathrm{CHO}, \mathrm{CHNOH}, \mathrm{CN}, \ldots$

Figura 35: Sutitucion en el anillo B

\section{Modificaciones del anillo A}

Utilizando las agrupaciones del anillo B marcadas en la figura, se modificará el anillo A en la familia de isocombretastatinas y combretastatinas. Se realizarán las siguientes modificaciones:

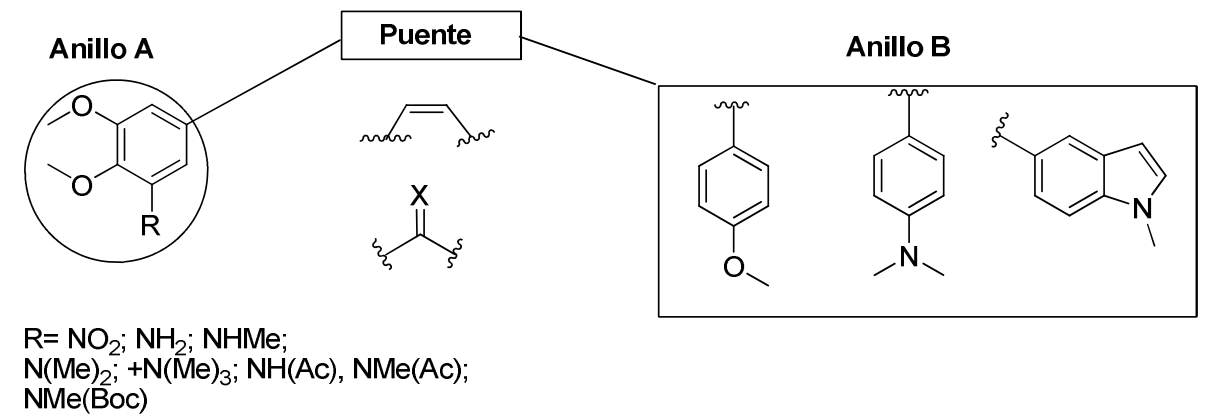

Figura 36: Variaciones introducidas en el anillo A en combinación con las tres agrupaciones elegidas en el anillo B.

El tercer objetivo es sustituir el grupo metoxilo de la posición 3 del anillo A con varios grupos polares, y se combina con tres agrupaciones en el anillo aromático B (4-metoxifenilo, 4-dimetilaminofenilo y 1-metilindol), para ver la influencia de cada uno sobre la potencia inhibidora frente a la polimerización de la tubulina.

Para aumentar la solubilidad acuosa, se preparan las sales de amonio de los compuestos. La realización de estas sales completaría el cuarto objetivo.

El quinto objetivo es la determinación de la solubilidad acuosa de los compuestos finales seleccionados. 
La realización de los ensayos de inhibición de la polimerización de tubulina y de citotoxicidad de los compuestos seleccionados constituye el sexto objetivo, que se completará con los estudios de Relación Estructura-Actividad. 



\section{MÉTODOS Y RESULT ADOS}





\section{Estructuras de los compuestos sintetizados}<smiles>COc1cc(CBr)cc(OC)c1OC</smiles>

2<smiles>COc1cc(C[Pb]Br)cc(OC)c1OC</smiles>

3<smiles>COc1ccc(Br)cc1</smiles>

4<smiles>COc1ccc(CP)cc1</smiles>

5

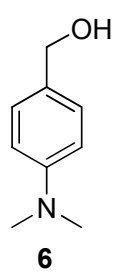<smiles>CN(C)c1ccc(CCl)cc1</smiles>

7<smiles>[Z2]COc1cc(C(=O)c2ccc(N(C)C)cc2)cc(OC)c1OC</smiles><smiles>C=C(c1ccc(N(C)C)c(C(=C)c2ccc(N(C)C)c(OC)c2)c1)c1ccc(N(C)C)c(C(=O)c2ccc(N(C)C)c(C(=O)c3cc(OC)c(OC)c(C(=C)c4cc(OC)c(OC)c(OC)c4)c3)c2)c1</smiles><smiles>C=C(c1ccc(N(C)C)c(/C=N/O)c1)c1ccc(N(C)C)c(C(=C)c2ccc(N(C)C)c(C(=C)c3ccc(C(=O)c4cc(OC)c(OC)c(OC)c4)c(OC)c3)c2)c1</smiles>

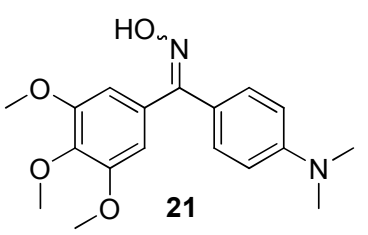<smiles>COc1cc(/C(=N\O)c2ccc(N(C)C)cc2)cc(OC)c1OC</smiles><smiles>COc1cc(/C=C\c2ccc(N(C)C)cc2)cc(OC)c1OC</smiles><smiles>COc1cc(/C=C/c2ccc(N(C)C)cc2)cc(OC)c1OC</smiles><smiles>COc1cc(/C(C=O)=C\c2ccc(N(C)C)cc2)cc(OC)c1OC</smiles><smiles>COc1cc(/C(C=O)=C\c2ccc(N(C)C)c(C=O)c2)cc(OC)c1OC</smiles><smiles>COc1cc(/C=C/c2ccc(N(C)C)c(C)c2)c(C=O)c(OC)c1OC</smiles><smiles>CCCN(C)c1ccc(/C=C(\C=N\O)c2cc(OC)c(OC)c(OC)c2)cc1</smiles> 
<smiles>COc1cc(/C(C=NO)=C/c2ccc(N(C)C)c(/C=N\O)c2)cc(OC)c1OC</smiles><smiles>COc1cc(/C(C#N)=C\c2ccc(N(C)C)cc2)cc(OC)c1OC</smiles><smiles>COc1cc(/C(C#N)=C\c2ccc(N(C)C)c(C#N)c2)cc(OC)c1OC</smiles><smiles>COc1cc(/C=C\c2ccc(N(C)[14CH3])cc2)cc(OC)c1OC</smiles><smiles>COc1cc(C(=O)c2ccnc(N(C)C)c2)cc(OC)c1OC</smiles><smiles>COc1cc(/C(=N/O)c2ccnc(N(C)C)c2)cc(OC)c1OC</smiles><smiles>C=C(c1ccnc(N(C)C)c1)c1cc(OC)c(OC)c(OC)c1</smiles><smiles>COc1cc(C(=O)c2ccc(N(C)C)nc2)cc(OC)c1OC</smiles><smiles>C=C(c1ccc(N(C)C)nc1)c1cc(OC)c(OC)c(OC)c1</smiles><smiles>COc1cc(C(O)c2ccnc(N3CCCC3)c2)cc(OC)c1OC</smiles><smiles>COc1cc(C(=O)c2ccnc(N3CCCC3)c2)cc(OC)c1OC</smiles><smiles>C=C(c1ccnc(N2CCCC2)c1)c1cc(OC)c(OC)c(OC)c1</smiles><smiles>COc1cc(/C(=N/O)c2ccnc(N3CCCC3)c2)cc(OC)c1OC</smiles><smiles>COc1cc(C(O)c2ccc(N3CCCC3)nc2)cc(OC)c1OC</smiles><smiles>COc1cc(C(=O)c2ccc(N3CCCC3)nc2)cc(OC)c1OC</smiles><smiles>C=C(c1ccc(N2CCCC2)nc1)c1cc(OC)c(OC)c(OC)c1</smiles><smiles>COc1cc(/C(=N\O)c2ccc(N3CCCC3)nc2)cc(OC)c1OC</smiles><smiles>CN(C)c1ccc(Br)cn1</smiles><smiles>CN(C)c1ccc(C=O)cn1</smiles><smiles>CN(C)c1ccc(C(=O)O)cn1</smiles><smiles>CN(C)c1ccc(CO)cn1</smiles><smiles>COc1cc(/C=C\c2ccc(N(C)C)nc2)cc(OC)c1OC</smiles><smiles>COc1cc(C=Cc2ccc(N(C)[14CH2][13CH2])nc2)cc(OC)c1OC</smiles><smiles>[R6][Z16]#[Z6]</smiles><smiles>COc1cc(/C=C\c2ccc(N3CCCC3)nc2)cc(OC)c1OC</smiles><smiles>C=C(c1cccc(N(C)C)c1)c1cc(OC)c(OC)c(OC)c1</smiles> 
<smiles>C=C(c1ccc(N(C)C)cc1)c1ccc(OC)c(OC)c1OC</smiles><smiles>C=C(c1ccc(N(C)C)cc1)c1ccc(OC)c(C(=C)c2ccc(OC)c(OC)c2OC)c1</smiles><smiles></smiles><smiles>COc1cc(C=O)cc([N+](=O)[O-])c1O</smiles><smiles>COc1cc(C=O)cc([N+](=O)[O-])c1OC</smiles><smiles>COc1ccc(C(O)c2cc(OC)c(OC)c([N+](=O)[O-])c2)cc1</smiles><smiles>COc1ccc(C(=O)c2cc(OC)c(OC)c([N+](=O)[O-])c2)cc1</smiles><smiles>COc1ccc(C(=O)c2cc(N)c(OC)c(OC)c2)cc1</smiles><smiles>[Z10]Oc1cc(C(=C)c2ccc(OC)cc2)cc(N)c1OC</smiles><smiles>[Z4]N(C)c1cc(C(=C)c2ccc(OC)cc2)cc(OC)c1OC</smiles><smiles>C=C(c1ccc(OC)cc1)c1cc(OC)c(OC)c([N+](C)(C)C)c1</smiles><smiles>COc1ccc(Nc2cc(C(O)c3ccc(OC)cc3)cc(OC)c2OC)cc1</smiles><smiles>COc1ccc(Nc2cc(C(=O)c3ccc(OC)cc3)cc(OC)c2OC)cc1</smiles><smiles>COc1cc(/C=C\c2ccc(OC[14CH3])cc2)cc([N+](=O)[O-])c1OC</smiles><smiles>COc1ccc(C=Cc2cc(N)c(OC)c(OC)c2)cc1</smiles><smiles>COc1ccc(C=Cc2cc(OC)c(OC)c(N(C)C)c2)cc1</smiles><smiles>[Z16]=CN(C)c1ccc(/C=C\c2cc(OC)c(OC)c([N+](=O)[O-])c2)cc1</smiles><smiles>COc1cc(/C=C\c2ccc(N(C)C(=O)OC(C)(C)C)cc2)cc(N)c1OC</smiles><smiles>COc1cc(C2OCCO2)cc([N+](=O)[O-])c1OC</smiles><smiles>COc1cc(C2OCCO2)cc(N)c1OC</smiles><smiles>COc1cc(C2OCCO2)cc(N(C)C)c1OC</smiles><smiles>COc1cc(C=O)cc(N(C)C)c1OC</smiles><smiles>COc1ccc(/C=C\c2cc(OC)c(OC)c([N+](C)(C)C)c2)cc1</smiles><smiles>COc1cc(C=O)cc(N)c1OC</smiles>

88<smiles>COc1cc(C=O)cc(NC(C)=O)c1OC</smiles><smiles>COc1ccc(C=Cc2cc(NC(=O)OCc3ccccc3)c(OC)c(OC)c2)cc1</smiles><smiles>[CH2+]C(=O)N(C)c1cc(C=Cc2ccc(OC)cc2)cc(OC)c1OC</smiles> 

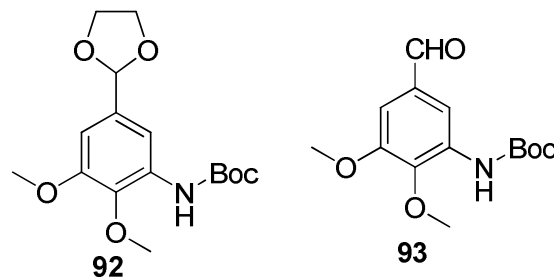<smiles>COc1cc(C2OCCO2)cc(N(C)C(=O)OC(C)(C)C)c1OC</smiles><smiles>COc1cc(C=O)cc(N(C)C(=O)OC(C)(C)C)c1OC</smiles><smiles>COc1ccc(C=Cc2cc(OC)c(OC)c(N(C)C(=O)OC(C)(C)C)c2)cc1</smiles><smiles>CNc1cc(/C=C/c2ccc(OC)cc2)cc(OC)c1OC</smiles><smiles>CNc1cc(/C=C\c2ccc(OC)cc2)cc(OC)c1OC</smiles>

$\mathrm{Br}$<smiles>Cc1ccc2c(ccn2C)c1</smiles>

98<smiles>COc1cc(C(O)c2ccc3c(ccn3C)c2)cc([N+](=O)[O-])c1OC</smiles><smiles>C=C(c1cc(OC)c(OC)c([N+](=O)[O-])c1)c1ccc2c(ccn2C)c1</smiles><smiles>C=C(c1cc(OC)c(OC)c(N(C(=O)OC(C)(C)C)C(C)(C)C)c1)c1ccc2c(ccn2C)c1</smiles><smiles>COc1ccc(C2OC2c2cc(OC)c(OC)c([N+](=O)[O-])c2)cc1</smiles><smiles>COc1ccc(C(=O)Cc2cc(OC)c(OC)c([N+](=O)[O-])c2)cc1</smiles><smiles>COc1ccc(C=Cc2cc(N(C)C)c(OC)c(OC)c2Br)cc1</smiles><smiles>COc1cc(C(=O)C2CCC(OC)CC2)cc(OC)c1OC</smiles><smiles>C=C(c1cc(OC)c(OC)c(OC)c1)C1CCC(OC)CC1</smiles><smiles>COc1cc(/C(=N/O)C2CCC(OC)CC2)cc(OC)c1OC</smiles><smiles>COc1cc(C(C)O)cc(OC)c1OC</smiles><smiles>COc1cc(C(C)Br)cc(OC)c1OC(F)(F)F</smiles><smiles>C=Cc1cc(OC)c(OC)c(OC)c1</smiles> 


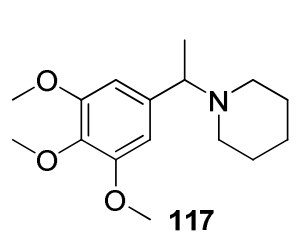<smiles>COc1cc(C(C)N2CCC(O)CC2)cc(OC)c1OC</smiles><smiles>CNc1cc(C(=O)c2ccc3c(c2)c(CCCCO)cn3C)cc(OC)c1OC</smiles><smiles>C=Cc1cc(OC)c(OC)c(N(C)C(=O)OC(C)(C)C)c1</smiles><smiles>C=Cc1cc(NC)c(OC)c(OC)c1</smiles><smiles>CNc1cc(Br)ccn1</smiles>

PS-3

A 



\section{Modificaciones en el anillo B}

El objetivo de esta parte del trabajo es introducir en el anillo B agrupaciones derivadas de anilina o piridina, cuyas funciones nitrogenadas pueden aumentar la solubilidad acuosa directamente o por la formación de sales de amonio.
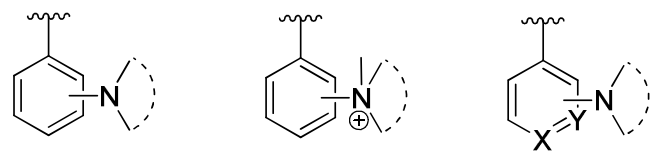

$\mathrm{R}=\mathrm{H}, \mathrm{Me}$

$\mathrm{X}, \mathrm{Y}=\mathrm{C}, \mathrm{N}$

Como anillo A se han seleccionado los anillos aromáticos de 3,4,5-trimetoxifenilo (TM), 2,3,4-trimetoxifenilo (TMG) o 2,5-dimetoxifenilo (DM), porque han demostrado previamente que conducen a una potente actividad inhibidora de la polimerización de la tubulina ${ }^{50}$.

Los dos anillos aromáticos se unirán por puentes de 1 ó 2 átomos de carbono. Cuando hay dos átomos de carbono la configuración del doble enlace podría ser $Z$ o $E$, aunque como ya se ha dicho anteriormente, lo más interesante será obtener productos con configuración $\mathrm{Z}$ del doble enlace entre los dos anillos aromáticos.

En esta secuencia se sintetizarán compuestos de las familias de fenstatinas (diarilmetanonas), isocombretastatinas (1,1-diariletilenos) y combretastatinas que de forma general se recogen en la figura 37.

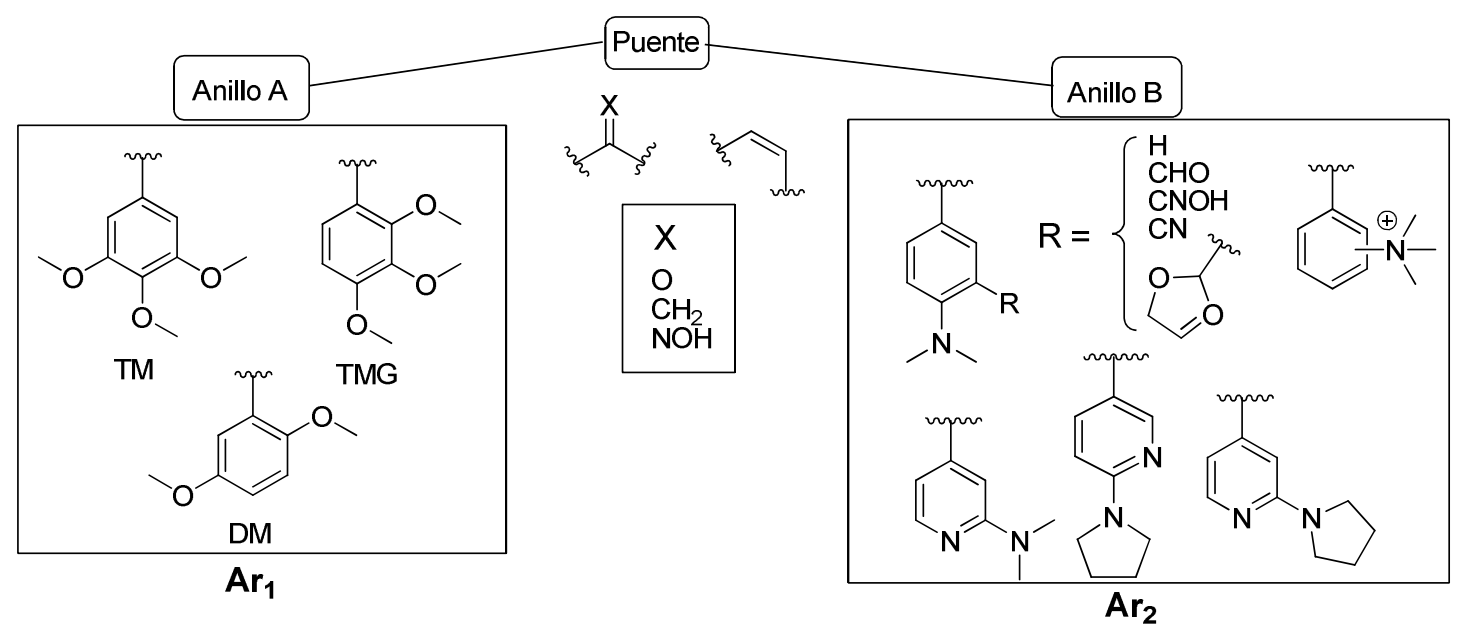

Figura 37: Esquema general de los compuestos sintetizados

\footnotetext{
${ }^{50}$ (a) Álvarez, C.; Álvarez, R.; Corchete, P.; López, J. L.; Pérez-Melero, C.; Peláez, R.; Medarde, M. Diarylmethyloxime and hydrazone derivatives with 5-indolyl moieties as potent inhibitors of tubulin polymerization. Bioorg. Med. Chem. 2008, 16, 5952. (b) Álvarez, R. Tesis Doctoral. Universidad de Salamanca. 2009. (c) Álvarez, C. Tesis Doctoral. Universidad de Salamanca. 2006.
} 


\section{Síntesis de análogos de fenstatina}

La síntesis del esqueleto básico de las fenstatinas se realiza por tratamiento del organometálico aromático que contiene los grupos amino con el aldehído ó el ácido carboxílico correspondiente. Cuando se utiliza el ácido carboxílico se obtiene directamente la cetona, pero con aldehído pasa por un intermedio alcohólico (diarilmetanol), que es necesario oxidar para llegar a la fenstatina.

A partir de la fenstatina, que se considera la molécula base en el esquema de síntesis, se sintetizan derivados como las isocombretastatinas, las oximas, las sales de amonio y sus derivados.

En el esquema siguiente se incluyen los pasos seguidos en todas las rutas sintéticas empleadas en esta parte del trabajo:

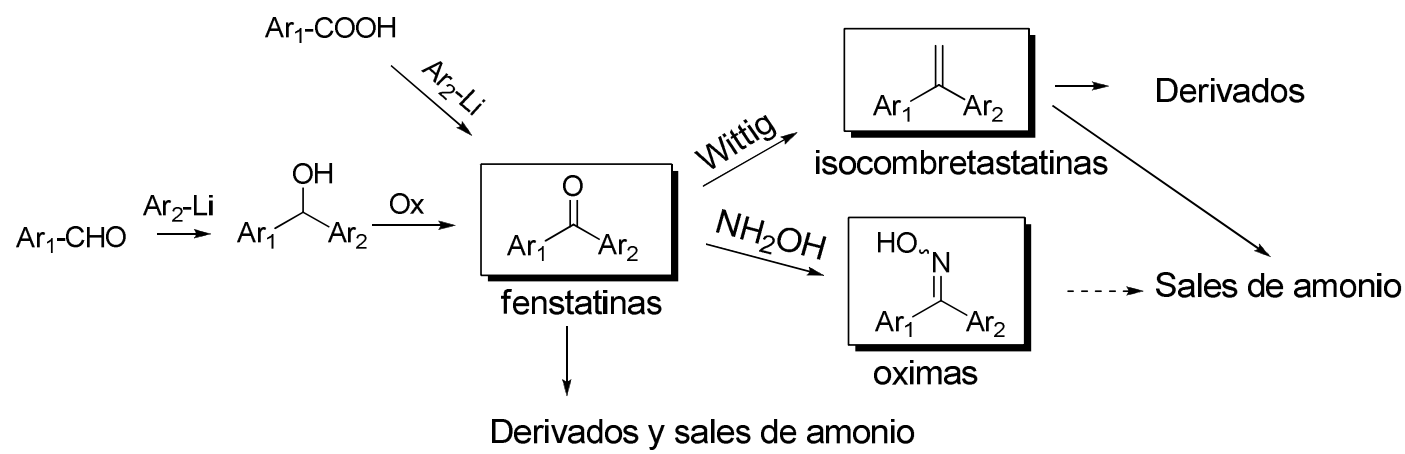

Figura 38: Esquema general de la síntesis de fenstatinas, isocombretastatinas y oximas

\subsection{Síntesis de análogos de dimetilaminofenilo}

\section{Anillo A: 3,4,5-trimetoxifenilo:}

En primer lugar se describe la síntesis de los compuestos en los que el anillo A corresponde a 3,4,5-timetoxifenilo (TM) y el anillo B a meta y para-dimetilaminofenilo.

En el esquema siguiente se explica la síntesis de la fenstatina según una adición nucleofilica del derivado litiado obtenido a partir de la reacción de transmetalación del bromoderivado a la sal del ácido formada por el tratamiento del ácido carboxílico con hidruro de sodio. 


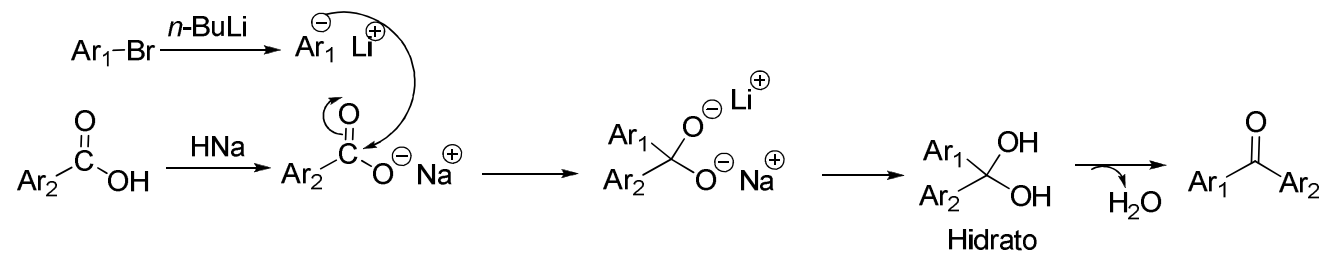

Figura 39: Mecanismo de formación de la fenstatina

La fenstatina 12 se sintetiza a partir de 4-bromodimetilanilina y la sal del ácido en exceso, con un rendimiento del $46 \%$. El compuesto 54 se prepara en las mismas condiciones utilizando 3bromodimetilanilina con un rendimiento del $75 \%$.
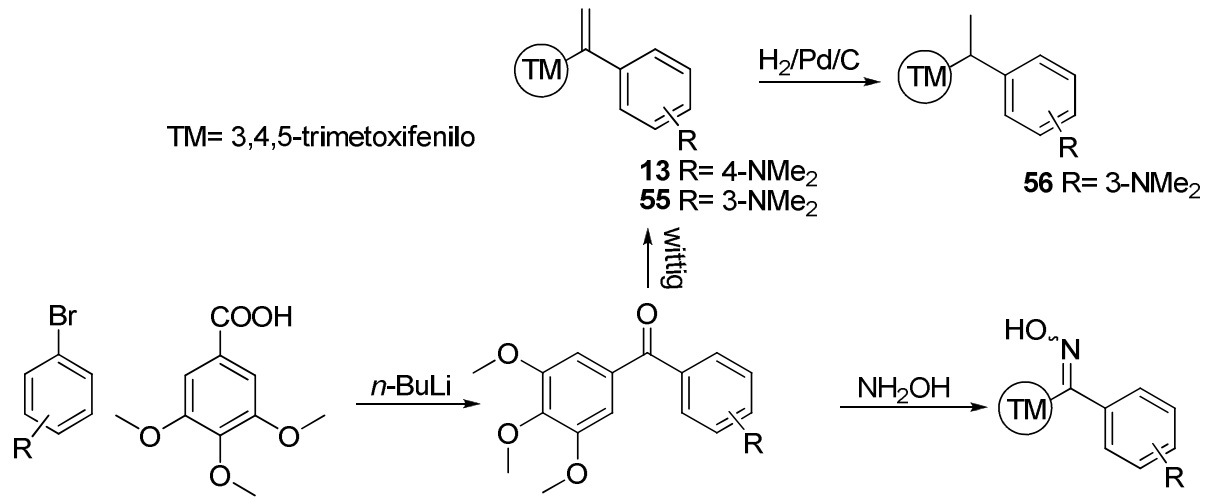

$$
12 \mathrm{R}=4-\mathrm{NMe}_{2}
$$
$54 \mathrm{R}=3-\mathrm{NMe}_{2}$

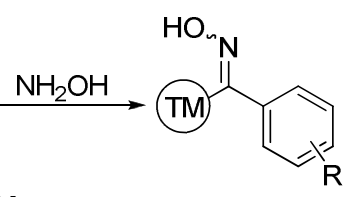

$21 \mathrm{R}=4-\mathrm{NMe}_{2}$ $57 \mathrm{R}=3-\mathrm{NMe}_{2}$

Figura 40: Ruta sintética empleada para la síntesis de los compuestos con la agrupación dimetilaminofenilo.

El compuesto 12 se caracteriza en $\mathrm{RMN}-{ }^{1} \mathrm{H}$ por señales de $\operatorname{los}{ }^{1} \mathrm{H}$ aromáticos que resuenan como dobletes a 6,66 y 7,80 ppm y la señal del grupo carbonilo a 194,4 ppm en $\mathrm{RMN}^{13} \mathrm{C}$. En el IR las cetonas de $\mathbf{1 2}$ y $\mathbf{5 4}$ presentan la vibración de tensión del grupo carbonilo a 1681 y $1650 \mathrm{~cm}^{-1}$, respectivamente.

La isocombretastatina 13 se sintetiza con un rendimiento del 75\% por reacción de Wittig ${ }^{51}$ de la fenstatina 12 con el yoduro de metiltrifenilfosfonio $\left(\mathrm{PPh}_{3} \mathrm{CH}_{3} \mathrm{I}\right)$ y BuLi para formar el iluro de fósforo, y se caracteriza por dos señales dobletes a 5,24 y 5,36 ppm en RMN ${ }^{1} \mathrm{H}$ que

\footnotetext{
${ }^{51}$ (a) Wittig, G.; Schöllkopf, U. Über triphenyl-phosphin-methylene als olefinbildende reagenzien (I. Mitteil). Ber. 1954, 87, 1318. (b) Wittig, G.; Haag, W. Über triphenyl-phosphin-methylene als olefinbildende reagenzien (II. Mitteil). Ber. 1955, 88, 1654.
} 
corresponden a los protones del grupo metileno del puente. $\mathbf{5 5}$ se obtiene con un rendimiento del $94 \%$ y se caracteriza por las señales de la olefina a 5,38 y a 5,41 ppm en $\mathrm{RMN}{ }^{1} \mathrm{H}$.

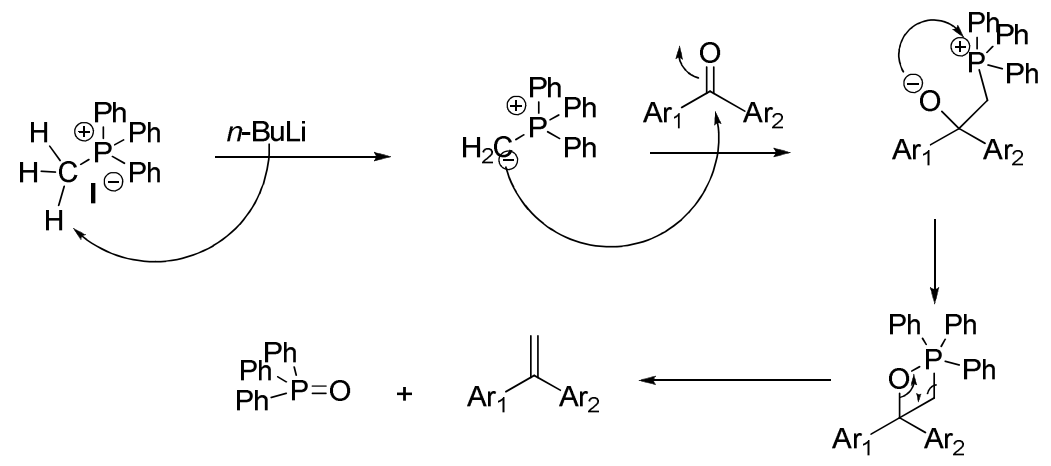

Figura 41: Mecanismo de la reacción de Wittig

El objetivo de la síntesis de las oximas es mejorar la solubilidad del compuesto por la introducción de agrupaciones polares, pudiendo además formar enlaces de hidrógeno con la proteína $^{52}$.

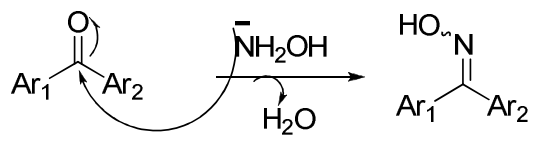

Figura 42: Formación de la oxima

Las oximas 21 y 57 se preparan a reflujo mediante tratamiento de las fenstatinas con clorhidrato de hidroxilamina, piridina y metanol como disolvente. En esta reacción se obtienen dos isómeros $Z / E$ en proporción aproximada 1:1.

La asignación estereoquímica de las oximas se ha realizado teniendo en cuenta que cuando el grupo $\mathrm{OH}$ de la oxima se dirige hacia un determinado anillo aromático se observa un apantallamiento de los protones de ese anillo, de acuerdo con lo observado para otras oximas parecidas $^{50 c}$ cuya estructura ha sido establecida por difracción de rayos X (figura 43). Las oximas se obtienen con buen rendimiento, $57 \%$ para 21 y $91 \%$ para 57.

\footnotetext{
52 Álvarez, C.; Álvarez, R.; Corchete, P.; Pérez-Melero, C.; Peláez, R.; Medarde, M. Naphthylphenstatins as tubulin ligands: synthesis and biological evaluation. Bioorg. Med. Chem. 2008, 16, 8999.
} 
Las oximas se caracterizan en $\mathrm{RMN}{ }^{1} \mathrm{H}$ por un apantallamiento de las señales de los protones aromáticos con respecto a los de la cetona (ver figura 43) y por la aparición de la banda del grupo funcional $\mathrm{OH}$ en el IR a $3410 \mathrm{~cm}^{-1}$.

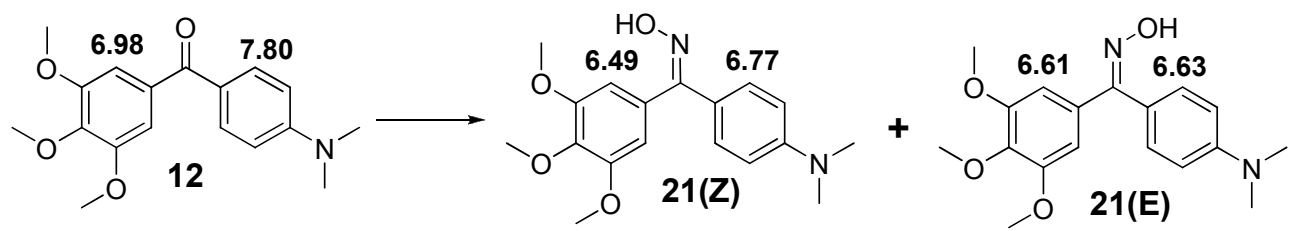

Figura 43: Desplazamientos químicos característicos de $\mathbf{1 2}$ y los isómeros $Z / E$ de $\mathbf{2 1}$

El compuesto 56 se prepara por hidrogenación catalítica con paladio sobre C de la isocombretastatina $\mathbf{5 5}$, con un rendimiento del $94 \%$, se caracteriza por la aparición de la señal del metilo a 1,63 ppm que resuena como doblete y la del metino a 4,10 ppm que resuena como cuartete en $\mathrm{RMN}{ }^{1} \mathrm{H}$.

\section{Anillo A: 2,3,4-trimetoxifenilo y 2,5-dimetoxifenilo:}

La síntesis de los derivados de $p$-dimetilanilina de las fenstatinas con el anillo A de 2,3,4trimetoxifenilo (TMG) y 2,5-dimetoxifenilo (DM) se ha realizado siguiendo el esquema de la figura 44 .

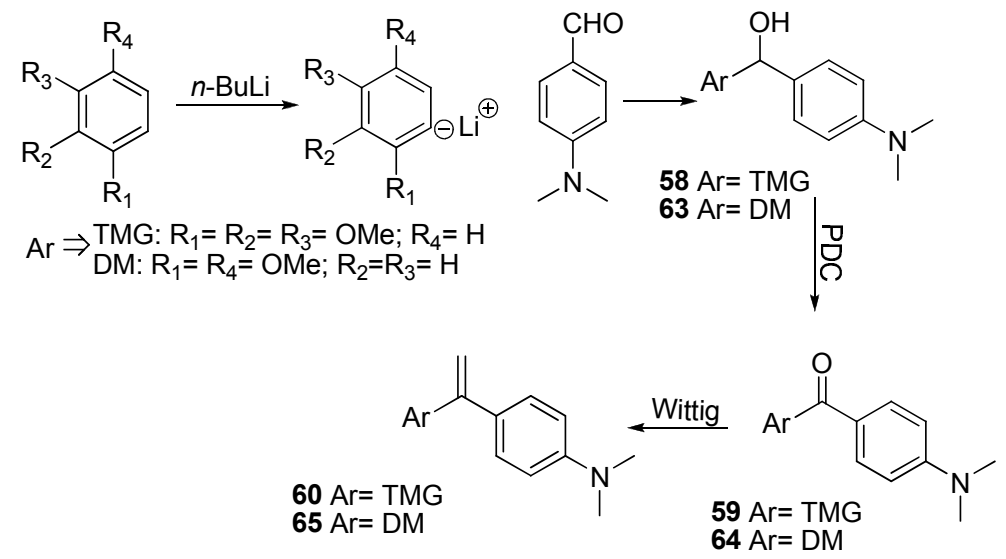

Figura 44: Esquema sintético de las isocombretastatinas 60 y 65

La síntesis de las fenstatinas 59 y $\mathbf{6 4}$ pasa por la formación del intermedio alcohólico, que se prepara a partir de la adición nucleofilica de un derivado de litio a $p$ dimetilaminobenzaldehído. El derivado de litio se genera en la posición más reactiva de la 
molécula, posición 4 para 1,2,3-trimetoxibenceno y posición 2 en el caso de 1,4dimetoxibenceno. Los alcoholes 58 y 63 se oxidan con dicromato de piridinio (PDC) ${ }^{53}$ para obtener las cetonas correspondientes como indican las señales a 193,6 y 194,0 ppm en RMN ${ }^{13} \mathrm{C}$, para las fenstatinas 59 y 64 , respectivamente.

La etapa de oxidación reduce notablemente el rendimiento global y sólo se obtienen las cetonas con el 20 y el $32 \%$ respectivamente. Por lo tanto es preferible la síntesis de las fenstatinas a partir de los ácidos carboxílicos.

Las isocombretastatinas 60 y 65 se obtienen a partir de las cetonas 59 y 64 por reacción de Wittig, con rendimientos del 70 y $53 \%$. Se identifican por las señales en la RMN ${ }^{1} \mathrm{H}$ de los protones olefínicos a 5,15 y 5,60 ppm para 60 y 5,18 y 5,70 ppm para $\mathbf{6 5}$.

\subsection{Síntesis de análogos de piridina:}

Se han sintetizado cuatro familias derivadas de piridina, sustituidas con agrupaciones dimetilamino o pirrolidina, y en las que se varía la posición de unión del resto piridina al carbono del puente (figura 45).

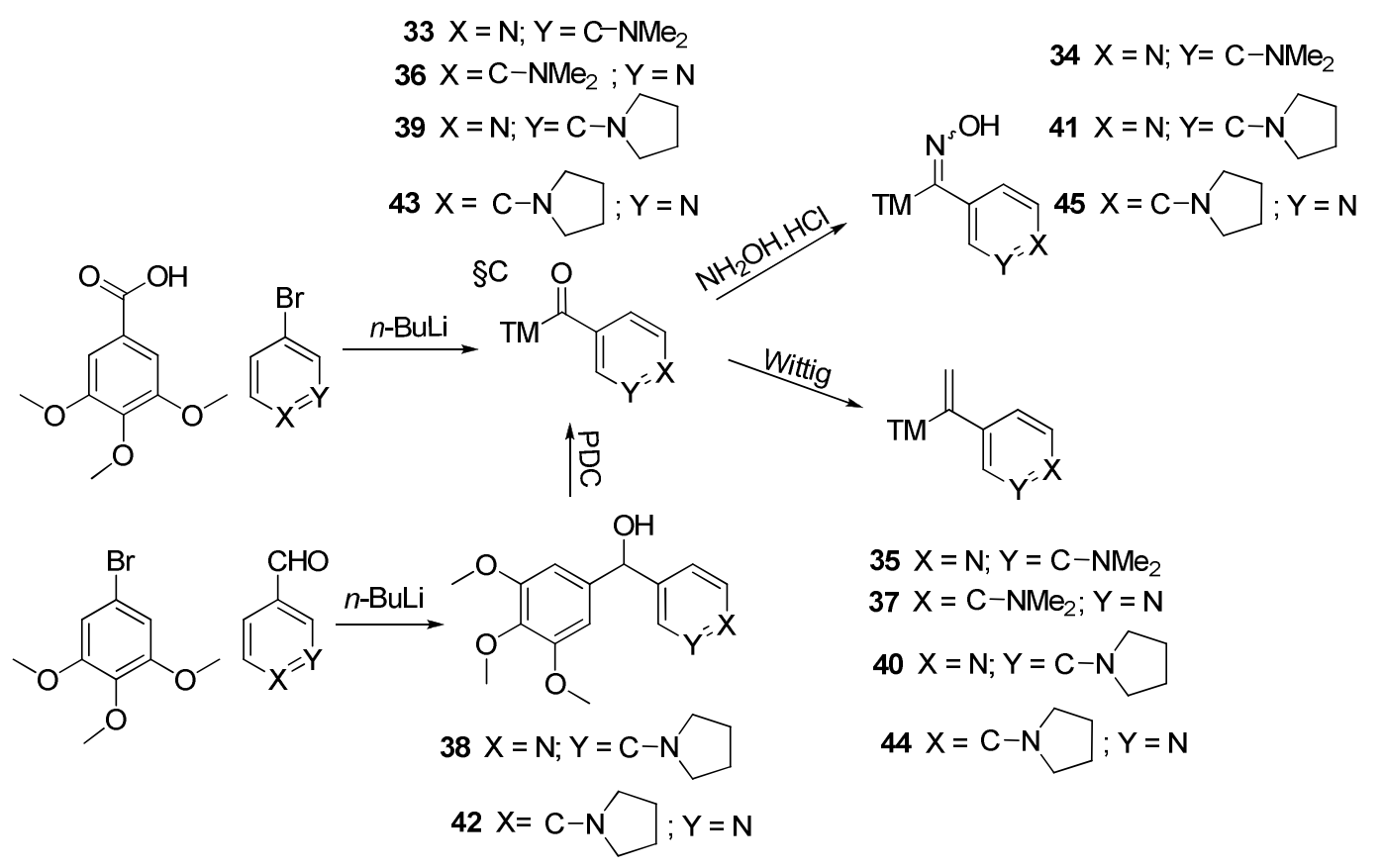

Figura 45: Esquema sintético de los compuestos basados en el anillo de piridina

\footnotetext{
${ }^{53}$ Lee, J.; Kim, S. J.; Choi, H.; Kim, Y. H.; Lim, I. T.; Yang, H-m.; Lee, C. S.; Kang, H. R.; Ahn, S. K.; Moon, S. K.; Kim, D. -H.; Lee, S.; Choi, N. S.; Lee, K. J. Identification of CKD-516: A Potent Tubulin Polymerization Inhibitor with Marked Antitumor Activity against Murine and Human Solid Tumors. J. Med. Chem. 2010, 53, 6337.
} 
El compuesto de partida 32 se prepara por aminación reductiva de 2-amino-4-bromopiridina con paraformaldehído y cianoborohidruro sódico. A temperatura ambiente se observó la formación de una mezcla con distinto grado de metilación en proporción 2:1 y a reflujo se transformó todo al compuesto dimetilado 32, con un rendimiento de $54 \%$.
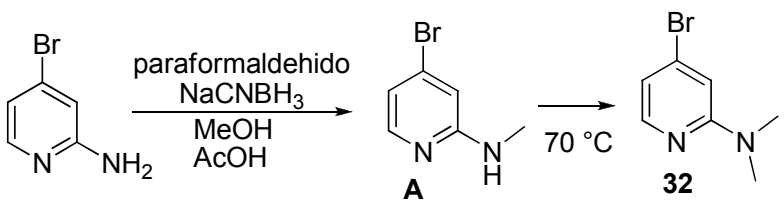

Figura 46: Síntesis del compuesto 32

En la bibliografía se ha descrito la aminacion reductora utilizando Si-CBH (cianoborhidruro modificado por sílice); este reductor mejora el rendimiento en un $25 \%$ en comparación con el cianoborohidruro sódico, pero no se usa en este trabajo por el coste de reactivo. ${ }^{54}$

La síntesis de las fenstatinas 33 y $\mathbf{3 6}$ se realiza a partir de la adición del derivado litiado de 3ó 4-bromodimetilaminopiridina con el ácido 3,4,5-trimetoxibenzoico con un rendimiento de 26 y $84 \%$, respectivamente. En RMN ${ }^{13} \mathrm{C}$ aparecen las señales a 194,9 y a 187,6 ppm indicando la formación de la cetona.

La ruta de síntesis de las cetonas 39 y $\mathbf{4 3}$ pasa por la formación de los alcoholes intermedios 38 y 42, que después se oxidan con dicromato de piridinio para obtener las fenstatinas con rendimientos de 83 y $75 \%$ respectivamente. Las fenstatinas 39 y 43 se caracterizan por desapantallamiento de los protones en $\mathrm{RMN}{ }^{1} \mathrm{H}$ y por a parición de los señales de grupo carbonilo a 195,1 y 193,1 ppm en $\mathrm{RMN}^{13} \mathrm{C}$.

Las isocombretastatinas $35,37,40$ y 44 se preparan siguiendo el procedimiento habitual de la reacción de Wittig a partir de las fenstatinas correspondientes con rendimientos aceptables. En la tabla siguiente se muestran los datos de las señales de $\mathrm{RMN}{ }^{1} \mathrm{H}$ del grupo metileno, que salen como singletes más o menos distanciados.

\footnotetext{
${ }^{54}$ Grenga, P, N.; Sumbler, B, L.; Beland, F.; Priefer, R. Reductive amination agents: comparison of $\mathrm{Na}(\mathrm{CN}) \mathrm{BH} 3$ and Si-CBH. Tetrahedron Lett. 2009, 50, 6658.
} 


\begin{tabular}{|c|c|c|}
\hline Isocombretastatinas & Rendimiento & Señales de ${ }^{1} \mathrm{H}$ olefínicos \\
\hline $\mathbf{3 5}$ & $73 \%$ & $5,50(2 \mathrm{H}, \mathrm{s})$ \\
\hline $\mathbf{3 7}$ & $41 \%$ & $5,25(1 \mathrm{H}, \mathrm{s}) ; 5,33(1 \mathrm{H}, \mathrm{s})$ \\
\hline $\mathbf{4 0}$ & $83 \%$ & $5,48(1 \mathrm{H}, \mathrm{s}) ; 5,50(1 \mathrm{H}, \mathrm{s})$ \\
\hline $\mathbf{4 4}$ & $46 \%$ & $5,23(1 \mathrm{H}, \mathrm{s}) ; 5,31(1 \mathrm{H}, \mathrm{s})$ \\
\hline
\end{tabular}

Tabla 1: Rendimiento y desplazamiento químico de las isocombretastatinas

Las oximas se preparan a partir de las fenstatinas utilizando clorhidrato de hidroxilamina y unas gotas de piridina. Las oximas se pueden obtener como mezcla de isómeros $Z / E$, sin embargo, en el caso del compuesto 45 únicamente se ha aislado uno de los isómeros.
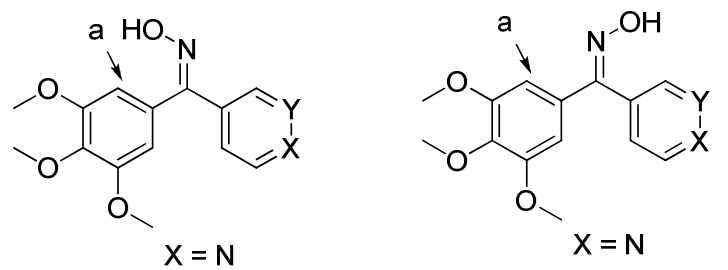

Figura 47: Estereisómeros de las oximas sintetizadas

\begin{tabular}{|c|c|c|c|c|}
\hline \multirow{2}{*}{ Oximas } & \multirow{2}{*}{ Rendimiento } & \multicolumn{2}{|c|}{$\delta(\mathrm{ppm})$ del proton (a) } & \multirow{2}{*}{$Z / E$} \\
\cline { 3 - 4 } & & $Z$ & $E$ & \\
\hline $\mathbf{3 4}$ & $23 \%$ & 6,61 & 6,74 & $40: 60$ \\
\hline $\mathbf{4 1}$ & $42 \%$ & 6,61 & 6,76 & $40: 60$ \\
\hline $\mathbf{4 5}$ & $25 \%$ & \multicolumn{2}{|c|}{6,99} & $Z$ Z $E$ \\
\hline
\end{tabular}

Tabla 2: Rendimiento y desplazamiento químico de las oximas

Como en los casos anteriores, los desplazamientos químicos de cada isómero dependen de la estereoquímica de la oxima. En la oxima 45 no se dispone de ambos estereoisómeros, por lo cual no se puede realizar la asignación estereoquímica. 


\subsection{Síntesis de análogos de dimetilaminofenilo sustituidos:}

Se pretende funcionalizar el anillo B que contiene el grupo dimetilamino en posición 4 con otros grupos que puedan interaccionar con la diana. Entre ellos se han elegido, aldehídos, oximas y nitrilos. La posición elegida es en orto del grupo amino debido a la mayor facilidad sintética. Para ello la primera vía elegida (figura 49) fue preparar el compuesto 10 que contiene el aldehído susceptible de transformación en los grupos mencionados y además está protegido para evitar interferencias con el $n$-BuLi que se debe utilizar a continuación.

En primer lugar se sintetiza el compuesto 9 a partir de 4-bromodimetilanilina por reacción de formilación de Vilsmeier-Haack. El grupo $\mathrm{CHO}$ entra en orto ya que la posición para se encuentra sustituida. La reacción se lleva a cabo con $N, N$-dimetilformamida, que en presencia de oxicloruro de fosforo $\left(\mathrm{POCl}_{3}\right)$ produce un catión iminio. Este catión es el encargado de realizar la sustitución electrofilica aromática, generando un intermedio que se hidroliza para dar el aldehído 55 .

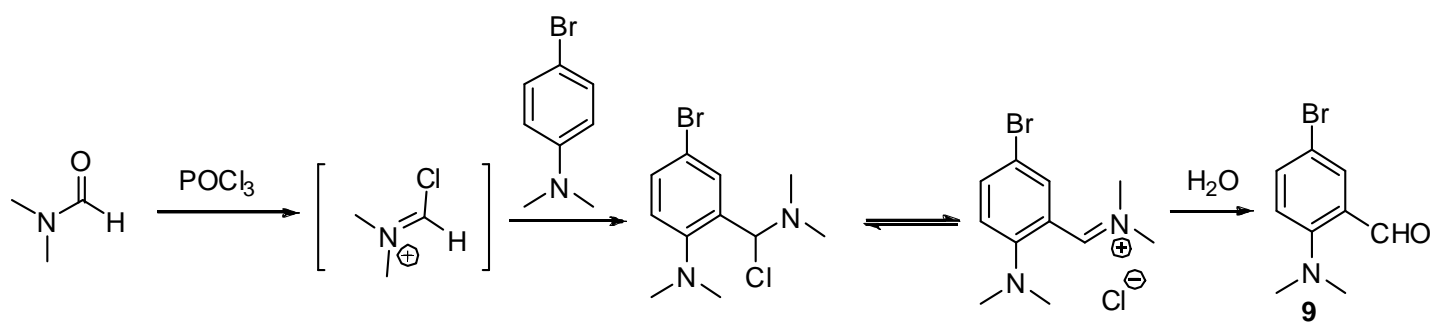

Figura 48: Mecanismo de la reacción de Vilsmeier-Haack

El aldehído 9 se protegió en forma de dioxolano, grupo protector que aguanta las condiciones básicas que se utilizan para la condensación posterior ${ }^{56}$ (figura 49). El compuesto protegido 10 se utiliza para la síntesis de la fenstatina 11. La reacción se efectúa vía acoplamiento con el ácido trimetoxibenzoico en condiciones análogas a las de otras reacciones similares que se describen en este trabajo; sin embargo, en este caso, la reacción no se produjo.

Por ello se intenta otra ruta sintética a partir de la fenstatina 12 (figura 49). Se realiza la formilación en orto de 12 obteniéndose el aldehído 14, que se caracteriza por la aparición de un sínglete a 10,03 ppm en $\mathrm{RMN}{ }^{1} \mathrm{H}$.

\footnotetext{
${ }^{55}$ Campaigne, E.; Archer, W. L. Formylation of dimethylaniline. Org. Syn. Coll. 1963, 4, 331.

${ }^{56}$ Wuts, P. G. M.; Greene, T. W. Protective Groups in Organic Synthesis. $4^{\text {th }}$ edition. Wiley-Interscience. 2007. New Jersey.
} 
Como los aldehídos son más reactivos que las cetonas en la reacción de Wittig, porque tienen mayor carácter electrofílico, se necesita proteger el aldehído para que dicha reacción tenga lugar con la cetona y no con el aldehído. En la figura 49 se indican los pasos seguidos.

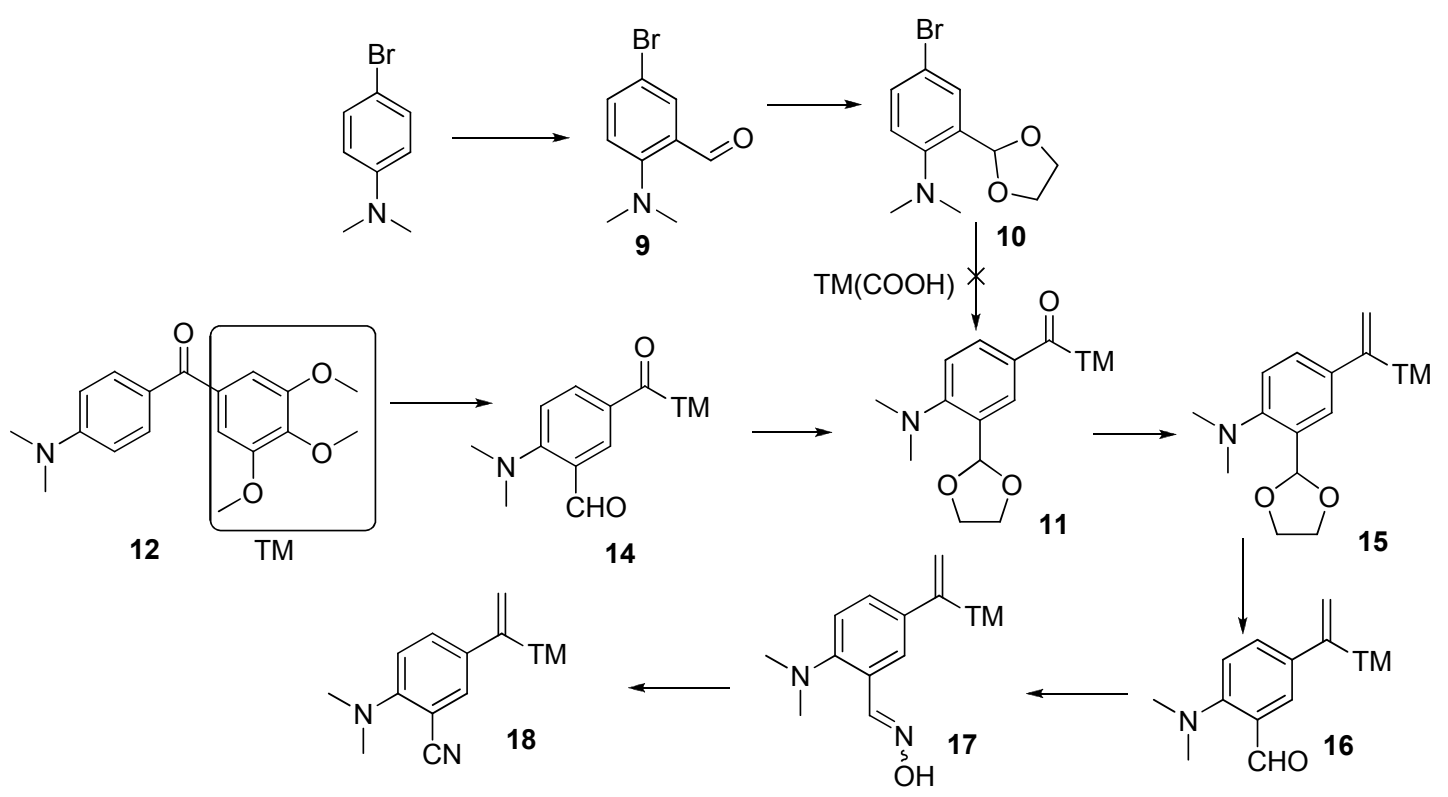

Figura 49: Preparación de los derivados de isocombretastatina sustituidos

El dioxolano 11 se obtiene a partir de la protección del grupo formilo de la fenstatina $\mathbf{1 4}$ con etilénglicol en presencia de cloruro de trimetilsililo. En $\mathrm{RMN}{ }^{1} \mathrm{H}$ se observa la desaparición del singlete del aldehído, apareciendo un multiplete a 4,10 ppm de cuatro protones y un singlete a 6,10 ppm correspondiente a un protón.

La reacción de la fenstatina $\mathbf{1 1}$ con el iluro de fósforo da la isocombretastatina $\mathbf{1 5}$ que se identifica a partir de la aparición de dos singletes anchos a 5,33 y 5,40 ppm de los protones olefínicos. El aldehído se obtiene por desprotección del grupo dioxolano mediante hidrólisis en medio ácido durante $4 \mathrm{~h}$. De la reacción se aísla la isocombretastatina 16, que se caracteriza por la presencia de los protones olefínicos a 5,34 y 5,41 ppm y la aparición de la señal del aldehído a 10,18 ppm.

La oxima se prepara a partir del aldehído con clorhidrato de hidroxilamina y unas gotas de piridina. Se aísla el compuesto 17 con un rendimiento de $55 \%$. En la figura 50 se presenta la asignación de los desplazamientos químicos de protones en $\mathrm{RMN}{ }^{1} \mathrm{H}$. 


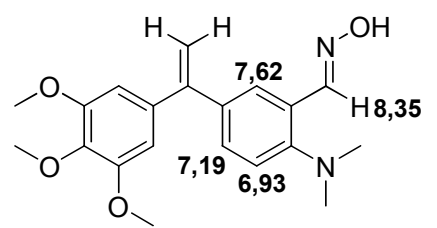

Figura 50: Desplazamientos químicos de $\mathrm{RMN}{ }^{1} \mathrm{H}$ del compuesto 17

La ruta sintética de esta secuencia se cierra con la síntesis de nitrilo $\mathbf{1 8}$, compuesto que se sintetiza a partir del tratamiento de la mezcla de oximas con anhídrido acético y piridina. Al poner la reacción a temperatura ambiente se observa la formación de dos productos, nitrilo como mayoritario y el derivado acetilado como minoritario. En tolueno a reflujo se transforma todo el derivado acetilado en el nitrilo 18. Se identifica por la aparición de la señal del grupo nitrilo a 119,8 ppm en $\mathrm{RMN}{ }^{13} \mathrm{C}$ y en IR presenta la vibración de tensión del grupo nitrilo a $2214 \mathrm{~cm}^{-1}$.

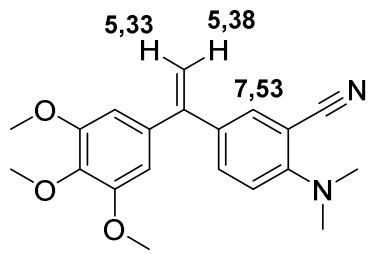

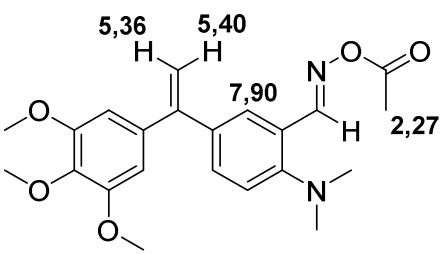

Figura 51: Desplazamientos químicos de $\mathrm{RMN}{ }^{1} \mathrm{H}$ del compuesto 18 y del derivado acetilado.

\subsection{Preparación de las sales de amonio de $p$-dimetilaminofenilo:}

Habiendo preparado un amplio grupo de compuestos en los cuales el anillo B contiene la agrupación dimetilamino, se tiene una buena oportunidad para aumentar la solubilidad acuosa de los mismos por formación de sus sales y constatar si se modifica la actividad biológica en estos derivados.

Esta reacción se realiza por disolución de cada uno de los derivados de dimetilaminofenilo en acetona y adición de yodometano ${ }^{57}$ calentando en un tubo sellado para evitar la evaporación del MeI. Después de unas horas de agitación aparece un precipitado en el tubo, que se filtra para obtener la sal correspondiente de cada compuesto. La formación de las sales se

\footnotetext{
${ }^{57}$ Yuan, H.; Zhou, Z.; Xiao, J.; Liang, L.; Dai, L. Preparation of quaternary ammonium salt-tagged ferrocenylphosphine-imine ligands and their application to palladium-catalyzed asymmetric allylic Substitution. Tetrahedron: Asymmetry. 2010, 21, 1874.
} 
comprueba por espectrometría de masas y por $\mathrm{RMN}{ }^{1} \mathrm{H}$, ya que las señales de los metilos de trimetilamonio de la sal de amonio se encuentran más desapantalladas que los del dimetilamino.
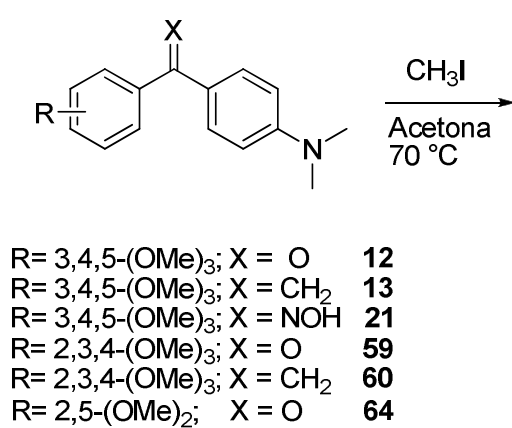<smiles>[R][R]1ccc(C([X])c2ccc(N(C)C)cc2)cc1</smiles>

$\mathrm{R}=3,4,5-(\mathrm{OMe})_{3} ; \mathrm{X}=\mathrm{O} \quad 19$

$\mathrm{R}=3,4,5-(\mathrm{OMe})_{3} ; \mathrm{X}=\mathrm{CH}_{2} \quad 20$

$\mathrm{R}=3,4,5-(\mathrm{OMe})_{3} ; \mathrm{X}=\mathrm{NOH} 22$

$\mathrm{R}=2,3,4-(\mathrm{OMe}) ; \mathrm{X}=\mathrm{O} \quad 61$

$\mathrm{R}=2,3,4-(\mathrm{OMe}) 3 ; \mathrm{X}=\mathrm{CH}_{2} \quad 62$

$\mathrm{R}=2,5-(\mathrm{OMe})_{2} ; \quad \mathrm{X}=\mathrm{O} \quad 66$

Figura 52: Preparación de sales de amonio de las fenstatinas

El tratamiento de la fenstatina 12 con yodometano genera la sal de amonio 19 con buen rendimiento. Se caracteriza por el desplazamiento químico de los protones de metilos nitrogenados, que pasan de 3,06 ppm de dimetilamino a 3,68 ppm de trimetilamonio. De igual forma ocurre con la sal de amonio 20 a partir de la isocombretastatina 13. Las variaciones en el desplazamiento químico de los protones se recogen en la figura siguiente.<smiles>[Y6]N(C)c1ccc(C(=C)c2cc(OC)c(OC)c(OC)c2)cc1</smiles><smiles>C=C(c1ccc(N(C)C)c(OC)c1)c1cc(OC)c(OC)c(OCC(C)(C)C)c1</smiles>

Figura 53: Desplazamiento químico de los protones de 20

El intento de formación de la sal de amonio de las oximas 21 siguiendo el procedimiento anterior no conduce a la oxima esperada, se hidroliza la oxima del puente a la cetona aunque sí se produce la metilación del grupo amino.
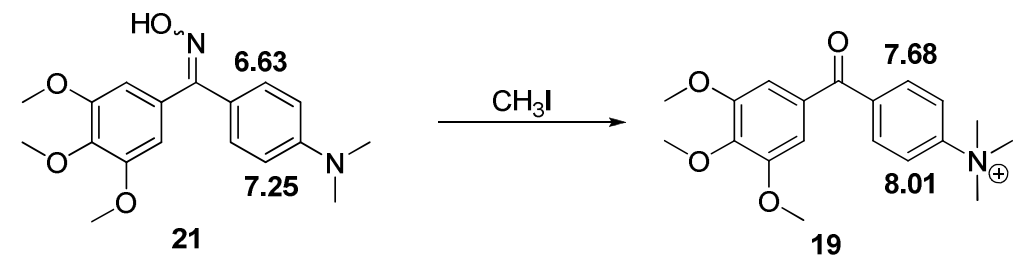

Figura 54: Formación del compuesto 19 
Después de intentar varias veces formar la sal de amonio de la oxima 21 por metilación del grupo amino, siempre conduce a 19. El compuesto 22 se prepara entonces por tratamiento de la sal de amonio 19 con clorhidrato de hidroxilamina, y se aísla como en los casos anteriores una mezcla de oximas aunque con bajo rendimiento.
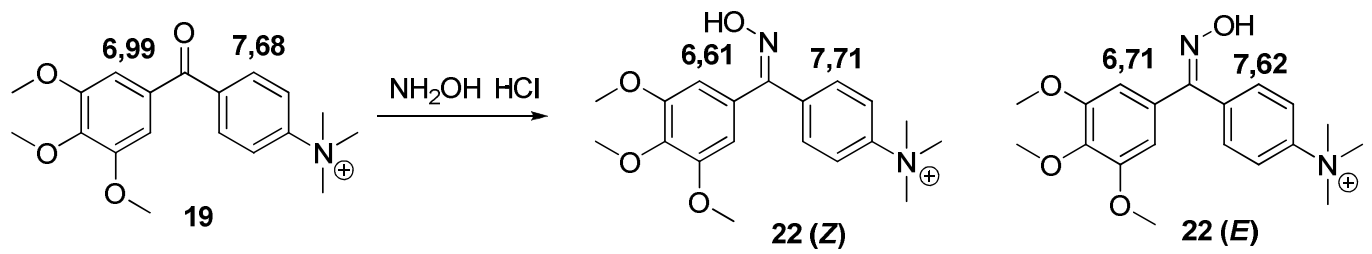

Figura 55: Formación de 22 a partir de $\mathbf{1 9}$

Las sales de amonio 61, 62 y 66 se preparan con MeI en acetona, añadiendo nitrato de plata para facilitar la eliminación de yoduro como un precipitado de AgI y aumentar el rendimiento de la reacción.

\begin{tabular}{|c|c|}
\hline Compuesto & Rendimiento (\%) \\
\hline $\mathbf{1 9}$ & 62 \\
\hline $\mathbf{2 0}$ & 95 \\
\hline $\mathbf{2 2}$ & 15 \\
\hline $\mathbf{6 1}$ & 69 \\
\hline $\mathbf{6 2}$ & 91 \\
\hline $\mathbf{6 6}$ & 52 \\
\hline
\end{tabular}

Tabla 3: Rendimiento de las sales de amonio preparadas.

\section{Síntesis de análogos de combretastatina:}

Las familias de combretastatinas preparadas son similares a las de isocombretastatina, con el fin de estudiar la influencia de esta modificación en la actividad. 
Se ha partido inicialmente del anillo trimetoxifenilo (anillo A) y se ha modificado el anillo B con grupos aminofenilo o aminopiridilo. Posteriormente se han realizado modificaciones en los anillos aromáticos o en el puente etilénico.

\subsection{Derivados del dimetilaminofenilo:}

El compuesto de partida es la combretastatina 23 que ya ha sido descrito en bibliografía ${ }^{58}$ y presenta una actividad citotóxica $\left(\mathrm{ED}_{50}<10^{-1} \mu \mathrm{M}\right)$ y una $\mathrm{IC}_{50}$ de $3,4 \pm 0,1 \mu \mathrm{M}$ en el ensayo de inhibición de polimerización de tubulina. Sin embargo, no se han descrito las modificaciones realizadas en este trabajo.

La secuencia de reacciones seguida en este apartado de la memoria se representa en la figura 56 y comienza con la preparación de 23.

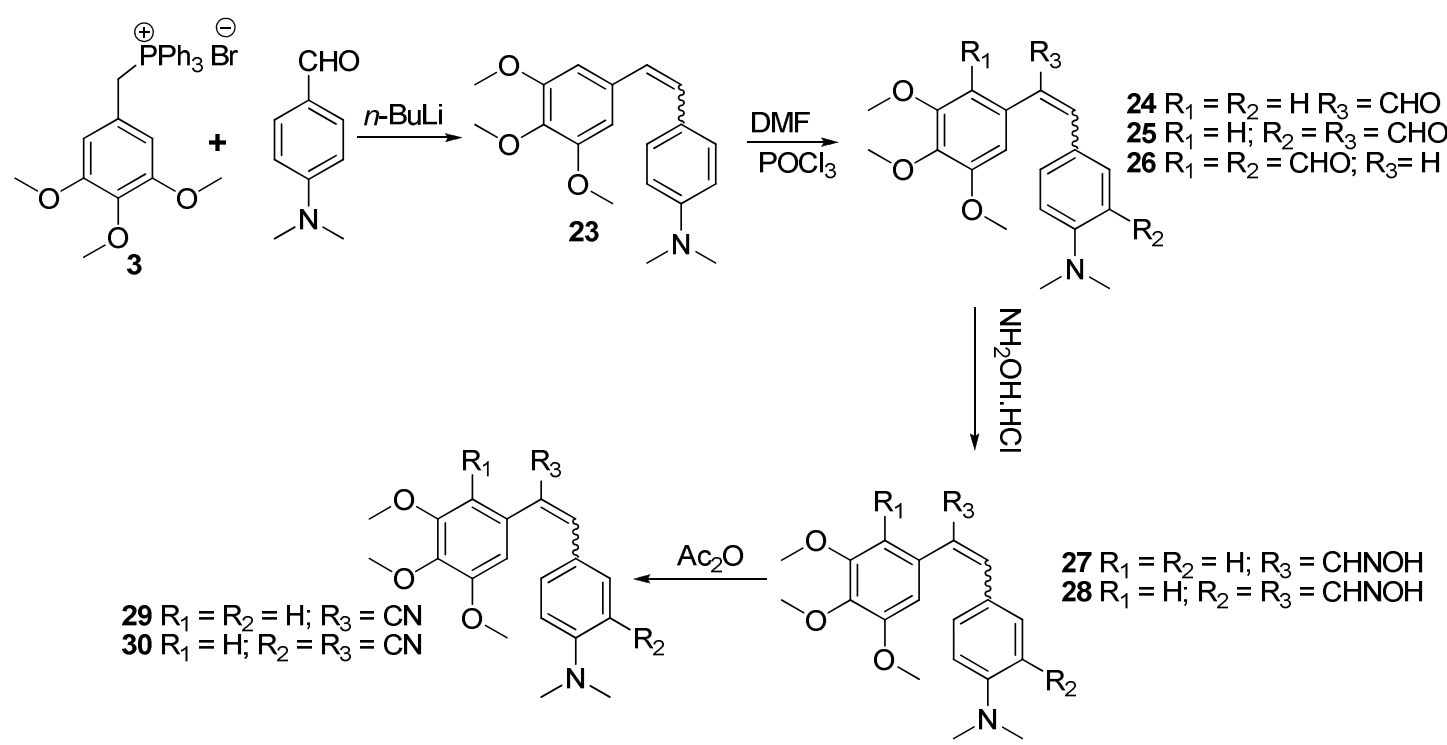

Figura 56: Síntesis de los derivados de combretastatina

Los dos isómeros Z/E se obtienen en proporción 6:4 en la reacción de Wittig. Se identifican a partir de las señales de los protones del puente que resuenan como dobletes de $J_{c i s}=12,2 \mathrm{~Hz}$ a 6,32 y 6,46 ppm para el $Z$ y $J_{\text {trans }}=15,4 \mathrm{~Hz}$ a 6,82 y $6,92 \mathrm{ppm}$ para el $E$.

\footnotetext{
${ }^{58}$ Cushman, M.; Nagarathnam, D.; Gopal, D.; Chakraborti, A. K.; Lin, C. M.; Hamel, E. Synthesis and evaluation of stilbene and dihydrostilbene derivatives as potential anticancer agents that inhibit tubulin polymerization. J. Med. Chem. 1991, 34, 2579.
} 
El siguiente paso de esta secuencia es la formilación de 23 con $\mathrm{POCl}_{3}$ y DMF, esta reacción se realiza como se ha descrito anteriormente y se obtienen el compuesto monoformilado $\mathbf{2 4}$, y el diformilado 25.

El compuesto 24 presenta señales de un único protón olefínico en RMN que resuena como sínglete a 7,30 ppm y se mantienen las de los protones de los anillos aromáticos. Aparece una señal adicional de un protón de aldehído que por tanto debe situarse en el puente etilénico. La formilación en la posición 9 del puente se puede interpretar de acuerdo con el mecanismo de la reacción de Vilsmeier-Haak, y es debido a la conjugación del sistema aromático con el doble enlace.

Siguiendo el mecanismo de la reacción de formilacion se propone la estructura de $\mathbf{2 5}$, formilado en el puente y en la posición orto del dimetilamino (la más reactiva en el anillo aromático). Además de la interpretación de las señales de RMN, se ha identificado 25 por las correlaciones H/C observadas en los experimentos HMBC y HMQC de RMN. Se han detallado los resultados en la tabla 4.

\begin{tabular}{|c|c|c|c|c|}
\hline $\begin{array}{l}\delta(\mathrm{C}) \\
(\mathrm{ppm})\end{array}$ & $\mathrm{C}$ & $\begin{array}{c}\delta(\mathrm{H})(\mathrm{ppm}) \\
\text { HMQC }\end{array}$ & $\begin{array}{c}\text { Correlaciones } \\
\text { HMBC }\end{array}$ & Estructura \\
\hline 189,2 & 1 & 9,92 & $2,3,7$ & \\
\hline 124,1 & 2 & - & - & \\
\hline 154,9 & 3 & - & - & \\
\hline 116,3 & 4 & 6,72 & 2 & \\
\hline 135,5 & 5 & 7,11 & $3,7,8$ & 10 \\
\hline 122,2 & 6 & - & - & \\
\hline 137,5 & 7 & 7,70 & $1,3,8$ & \\
\hline 149,6 & 8 & 7,30 & $7,9,10,11$ & 4 \\
\hline 139,5 & 9 & - & - & 194 \\
\hline 193,4 & 10 & 9,69 & $8,9,11$ & 20 \\
\hline 129,2 & 11 & - & - & \\
\hline 106,1 & 12,16 & 6,40 & $11,13(15), 14$ & \\
\hline 153,9 & 13,15 & - & - & \\
\hline 138,0 & 14 & - & - & \\
\hline
\end{tabular}




\begin{tabular}{|c|c|c|c|c|}
\hline 56,1 & 17,19 & 3,79 & $13(15)$ & \\
\hline 60,9 & 18 & 3,90 & 14 & \\
\hline 44,4 & 20,21 & 3,00 & 3 & \\
\hline
\end{tabular}

Tabla 4: Asignación de datos espectroscópicos obtenidos de las correlaciones H/C del compuesto 25

Esta misma reacción de formilación se realizó utilizando diferentes proporciones de moles de DMF y $\mathrm{POCl}_{3}$ respecto al caso anterior, aislándose los dialdehídos $\mathbf{2 5}$ y 26 en proporcion 8:2. El aldehído 26 se caracteriza en $\mathrm{RMN}{ }^{1} \mathrm{H}$ por la existencia de dos dobletes de $\mathrm{J}_{\text {trans }}$ a 6,89 y 8,07 ppm señalando a la presencia del puente olefinico con configuración trans del doble enlace, señales de dos protones de grupos $\mathrm{CHO}$ y la desaparición de simetría en las señales de los protones aromáticos del material de partida. Teniendo en cuenta el mecanismo de la reacción de Vilsmeier-Haak, deberían situarse uno de ellos en la posición orto del grupo amino y el otro en el otro anillo aromático. Esto se confirma por los datos de los protones aromáticos en $\mathrm{RMN}{ }^{1} \mathrm{H}$.
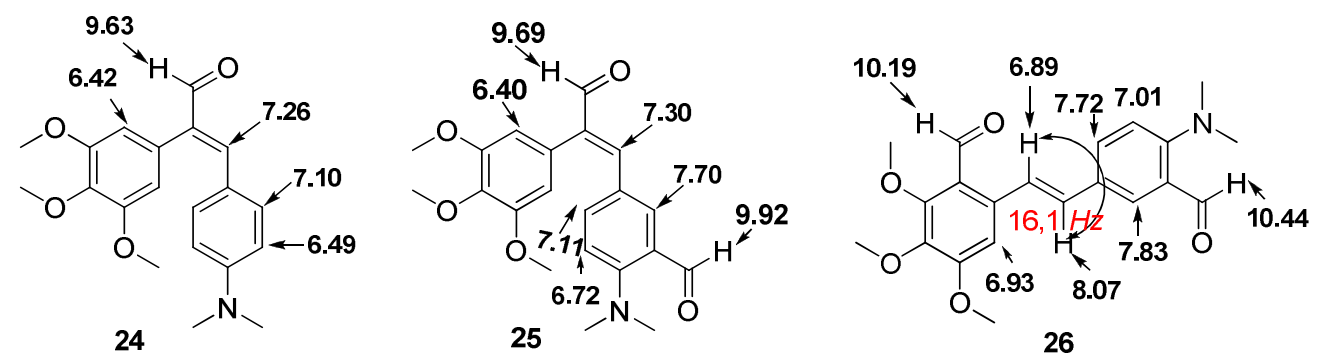

Figura 57: Estructura y datos de $\mathrm{RMN}{ }^{1} \mathrm{H}$ de los aldehídos 24, 25 y 26

Las oximas 27 y 28 se preparan a partir del monoaldehído 24 y dialdehído 25 . La oxima 27 se cristaliza en AcOEt/MeOH y se aísla un $32 \%$ de cristales amarillos, mientras la oxima 28 se aísla por cristalización en éter/ $\mathrm{CH}_{2} \mathrm{Cl}_{2}$ en forma de cristales amarillos, solubles en agua. En la figura siguiente se indican los desplazamientos químicos de los protones en $\mathrm{RMN}{ }^{1} \mathrm{H}$ de las oximas 27 y 28. 

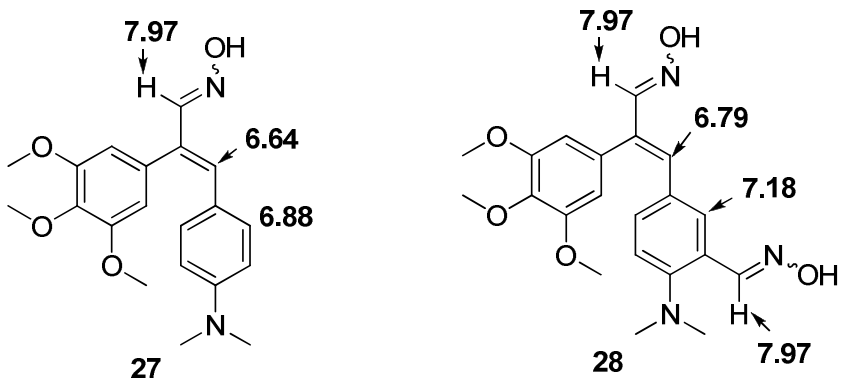

Figura 58: Oximas 27 y 28

Los derivados del nitrilo 29 y 30 se preparan mediante tratamiento de las oximas 27 y 28 con anhídrido acético a $90{ }^{\circ} \mathrm{C}^{59}$ durante $24 \mathrm{~h}$ y se obtienen con un rendimiento del 30 y $28 \%$ respectivamente. En el espectro de IR absorben a 2211 y a $2207 \mathrm{~cm}^{-1}$ correspondientes a la función nitrilo (figura 59).
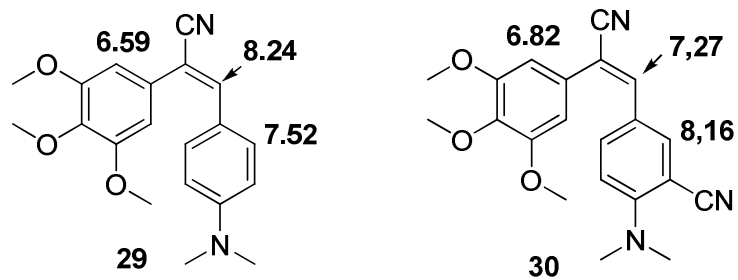

Figura 59: Estructura de 29 y 30 y algunos datos de $\mathrm{RMN}{ }^{1} \mathrm{H}$

\subsection{Derivados de piridina:}

Como hemos visto en el caso de las fenstatinas, los compuestos basados en piridina se preparan para mejorar la solubilidad acuosa ya que la existencia del anillo de piridina aumenta la basicidad del compuesto y su polaridad.

Se han utilizado para su preparación derivados nitrogenados de los aldehídos nicotínicos e isonicotinicos.

\footnotetext{
${ }^{59}$ Trofimov, A. B.; Vasil'tsov, M. A.; Mikhaleva, I. A.; Ivanov, V. A.; Skital'tseva, V. E.; Schmidt, Y. E.; Senotrusova, Y. E.; Ushakov, A. I.; Petrushenko, B. K. Synthesis of 1-vinylpyrrole-2-carbonitriles. Tetrahedron Lett. 2009, 50, 97.
} 


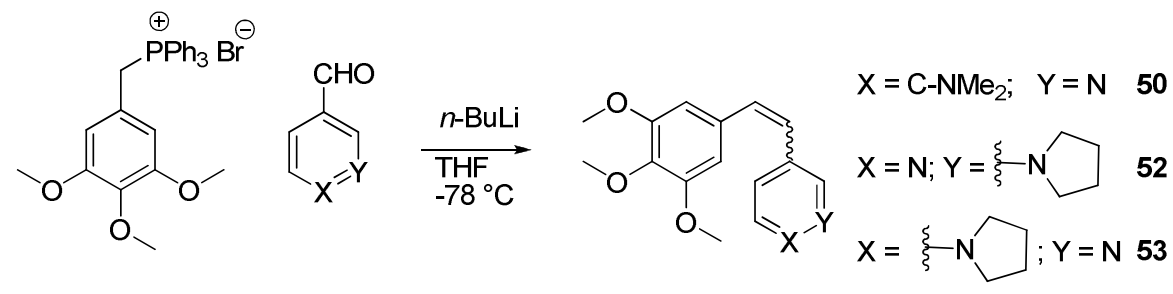

Figura 60: Síntesis de los derivados piridínicos de combretastatina

La combretastatina 50 se prepara mediante la reacción de Wittig entre el 6(dimetilamino)nicotinaldehído y el iluro de la sal de fosfonio 3 obteniéndose la mezcla de isómeros con un rendimiento global del $58 \%$. Los protones del puente del isómero $Z$ se observan a 6,38 ppm como singlete, mientras los del isómero $E$ lo hacen como dobletes de $J_{\text {trans }}=16,4 \mathrm{~Hz}$ a 6,80 y $6,89 \mathrm{ppm}$.

Las combretastatinas $\mathbf{5 2}$ y $\mathbf{5 3}$ se preparan de la misma manera que las anteriores, en el caso de la combretastatina 52 se utiliza el 6-(pirrolidin-1-il)nicotinaldehído y se obtiene con un $33 \%$; la combretastatina 53 se obtiene a partir de (2-pirrolidin-1-il)isonicotinaldehído y se obtiene como una mezcla de isómeros Z/E en proporción 1:1 con un rendimiento global de $38 \%$. Las señales de los protones de los isómeros de la combretastatina $\mathbf{5 2}$ se observan como dos dobletes de $J_{c i s}=12,2 \mathrm{~Hz}$ a 6,40 y $6,54 \mathrm{ppm}$ que corresponden al isómero $Z$ y dobletes de $J_{\text {trans }}=16,1 \mathrm{~Hz}$ a 6,88 y 7,08 ppm en $\mathrm{RMN}{ }^{1} \mathrm{H}$ para el $E$. En el caso de $\mathbf{5 3}$ no se ha logrado separar los dos isómeros y se han caracterizado a partir de la mezcla.

A partir de los antecedentes del grupo del trabajo y la bibliografía, el isómero que presenta un actividad más interesante frente a la polimerización de la tubulina es el isómero $Z$, por lo cual siempre se intenta aislarlo puro, mientras el isómero $E$ en muchos casos se caracteriza a partir de la mezcla de isómeros.

Los rendimientos del producto puro no son muy buenos porque la reacción no transcurre completamente y se obtienen material de partida y productos secundarios. Además existe una gran dificultad para su separación cromatográfica pues los $\mathrm{R}_{\mathrm{f}}$ son muy próximos. 


\subsection{Sales de amonio de combretastatinas:}

Las sales de amonio de las combretastatinas se preparan de la misma manera que los de la familia de fenstatina: la combretastatina deseada se disuelve en acetona con yodometano y se calienta a $70{ }^{\circ} \mathrm{C}$, en un tubo sellado. La formación de la sal de amonio se identifica por los datos de $\mathrm{RMN}{ }^{1} \mathrm{H}$ y ${ }^{13} \mathrm{C}$ y espectrometría de masas.
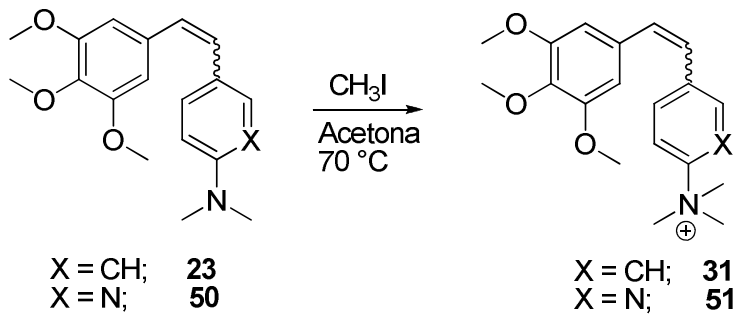

Figura 61: Preparación de sales de amonio de las combretastatinas

Las sales de amonio 31 y $\mathbf{5 1}$ se aíslan como mezcla de isómeros $Z / E$ y con un rendimiento bajo, por lo que las combretastatinas piridínicas deben ser menos reactivas.

Se intentó preparar el compuesto 31 utilizando la sal de amonio del aldehído y haciéndolo reaccionar con el iluro de fosforo, pero no se detecta la formación de la combretastatina 31 esperada.

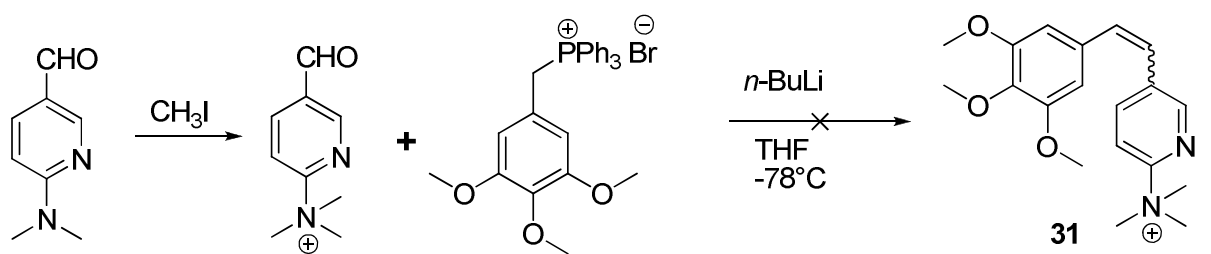

Figura 62: Intento de preparar la sal de amonio $\mathbf{3 1}$

Las sales de amonio de 25 y 26 no han podido obtenerse aunque se aumentó el tiempo de reacción y se variaron los disolventes empleados, pero la reacción no evoluciona y se obtiene material de partida sin reaccionar. Por lo cual el aldehído en orto del dimetilamino debe influir desactivando el par de electrones libre del átomo de nitrógeno y disminuyendo su capacidad para alquilarse. 


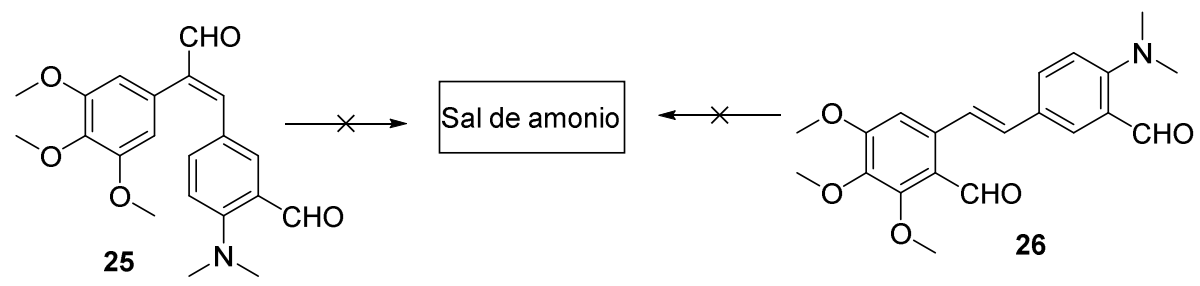

Figura 63: Intento de preparar las sales de amonio 25 y 26

\section{Síntesis de fenstatina alifáticas}

\subsection{Derivados de 4-metoxiciclohexano:}

Siguiendo con los objetivos propuestos se han sintetizado fenstatinas con el anillo de 3,4,5trimetoxifenilo y en las que se ha sustituido el grupo aromático del anillo B por uno alifático. En la siguiente figura se indican los pasos de la síntesis de los análogos de fenstatina basados en 4-metoxiciclohexano.

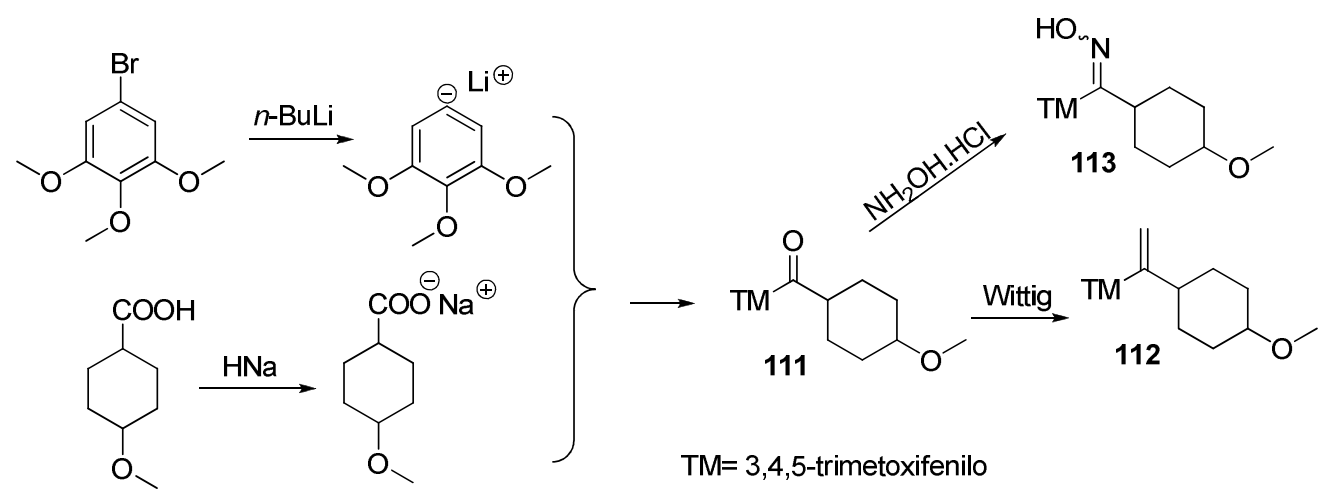

Figura 64: Síntesis de los derivados de fenstatina con ciclohexano

El compuesto 111 se prepara siguiendo el método habitual, a partir del derivado litiado y la mezcla de isómeros cis y trans del ácido 4-metoxiciclohexanocarboxilico en proporción 2:1, se aísla la cetona como mezcla cis/trans en proporcion 6:4. El isómero más estable debe ser el trans cuando se sitúan los dos sustituyentes en la posición diecuatorial, pero en los datos de RMN ${ }^{1} \mathrm{H}$ se observa que el isómero mayoritario corresponde al cis (protón más apantallado en la posición 4 del ciclohexano). 

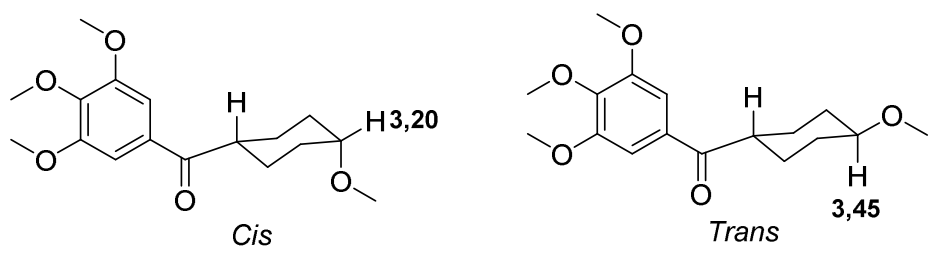

Figura 65: Isómeros geométricos del compuesto 111

En la reacción de Wittig, la isocombretastatina 112 se aísla como una mezcla de isómeros cis/trans en proporción 6:4. Eso significa que ha conservado la estereoquímica del material de partida durante las condiciones básicas de la reacción de Wittig. La formación del metileno olefínico se caracteriza por la aparición de dos señales (5,02 y 5,10 ppm) en RMN ${ }^{1} \mathrm{H}$.

El tratamiento de la fenstatina 111 con el cloruro de hidroxilamina da la oxima 113 como mezcla cis/trans en proporción 8:4. En estas condiciones de reacción se favorece la isomerización parcial del trans al cis.

De todo lo detallado anteriormente se puede concluir, que la estructura más estable para este tipo de compuestos es la siguiente:

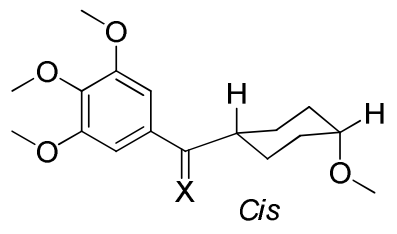

\subsection{Derivados de piperidina:}

Siguiendo con la síntesis de los compuestos con el anillo B alifático, se prepara el compuesto 117 tras una sustitución nucleofilica del bromo por piperidina con un rendimiento de $62 \%$. Se caracteriza por la aparición de la señal del protón del puente como cuartete a 3,23 ppm en $\mathrm{RMN}{ }^{1} \mathrm{H}$. 


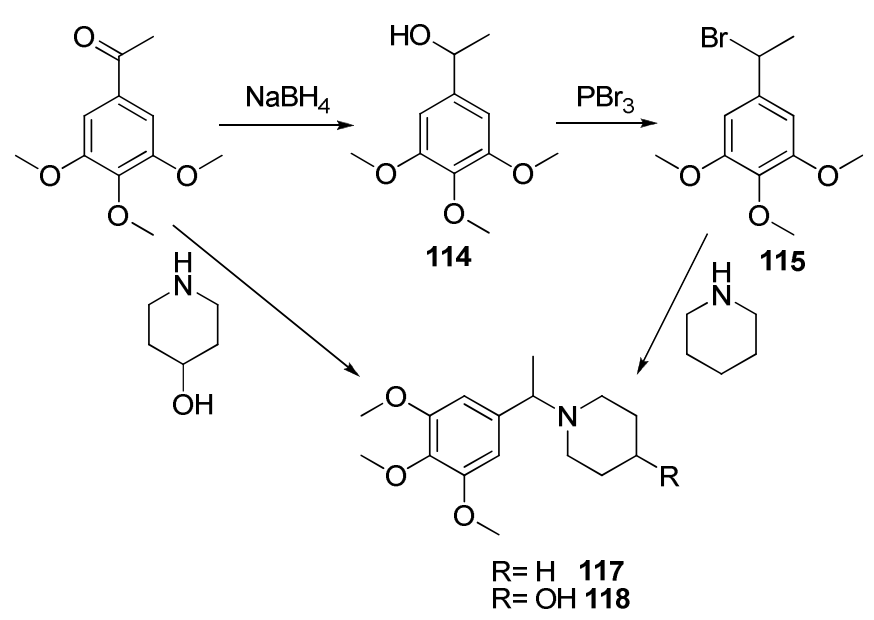

Figura 66: Síntesis del compuesto 117 y 118

El derivado halogenado 115 se prepara por reducción de 3,4,5-trimetoxiacetofenona al alcohol, seguida de halogenación con tribromuro de fósforo para formar un buen grupo saliente y favorecer la sustitución nucleofilica por la piperidina. Cuando se trata el alcohol 114 con tribromuro de fosforo, se forma el producto de la sustitución como mayoritario y el de eliminación 116 como minoritario.

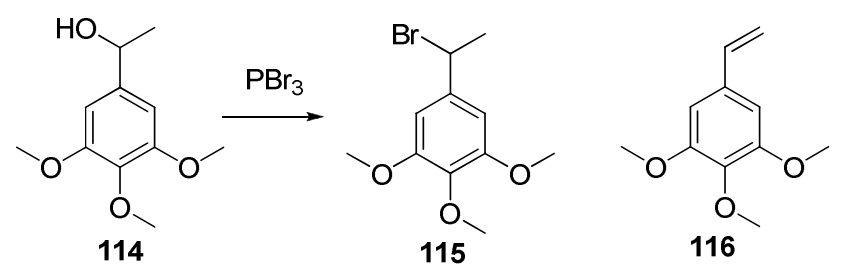

Figura 67: Formación de $\mathbf{1 1 5}$ y 116

Se intentó preparar el compuesto 118 mediante la aminación reductora con cianoborohidruro sódico de piperidinol y 3,4,5-trimetoxiacetofenona a temperatura ambiente y a reflujo pero no se observó ninguna evolución por problemas de disolución del piperidinol en los disolventes orgánicos ensayados $\left(\mathrm{CH}_{2} \mathrm{Cl}_{2}, \mathrm{MeOH}\right.$ y $\left.\mathrm{CH}_{3} \mathrm{CN}\right)$.

Aunque en la bibliografía ${ }^{60}$ se han preparado aminas terciarias semejantes mediante Nalquilación de las aminas secundarias utilizando $\left[\mathrm{Ru}_{3}(\mathrm{CO})_{12}\right]$ como catalizador, $N$-fenil2(diciclohexilfosfonil)pirrol como ligando y terc-amil alcohol como disolvente con altos rendimientos, se prefirió ensayar la reacción anterior asistida por microondas. Utilizando un

\footnotetext{
${ }^{60}$ Tillack, A.; Hollmann, D.; Mevius, K.; Michalik, D.; Bähn, S.; Beller, M. Salt-Free Synthesis of Tertiary Amines by Ruthenium-Catalyzed Amination of Alcohols. Eur. J. Org. Chem. 2008, 4745.
} 
aparato casero en fase sólida utilizando sílice como soporte y tres minutos de tiempo de reacción, después de extracción y purificación se aisló 118 con un de 41 \% de rendimiento. 


\section{Modificaciones en el anillo A}

Siguiendo los objetivos generales del trabajo en este capítulo se aborda la síntesis de compuestos por modificaciones en el anillo aromático A. Para ello se sustituye uno de los grupos metoxilos por derivados nitrogenados que pueden mejorar la solubilidad del compuesto y además formar sales de amonio que la aumentarían notablemente. El anillo B se mantiene sin modificación y en el puente se desarrollan las sustituciones que pueden dar los compuestos habituales de las familias de combretastatina, fenstatina e isocombretastatina. En el esquema general se muestran las modificaciones introducidas en los compuestos sintetizados.

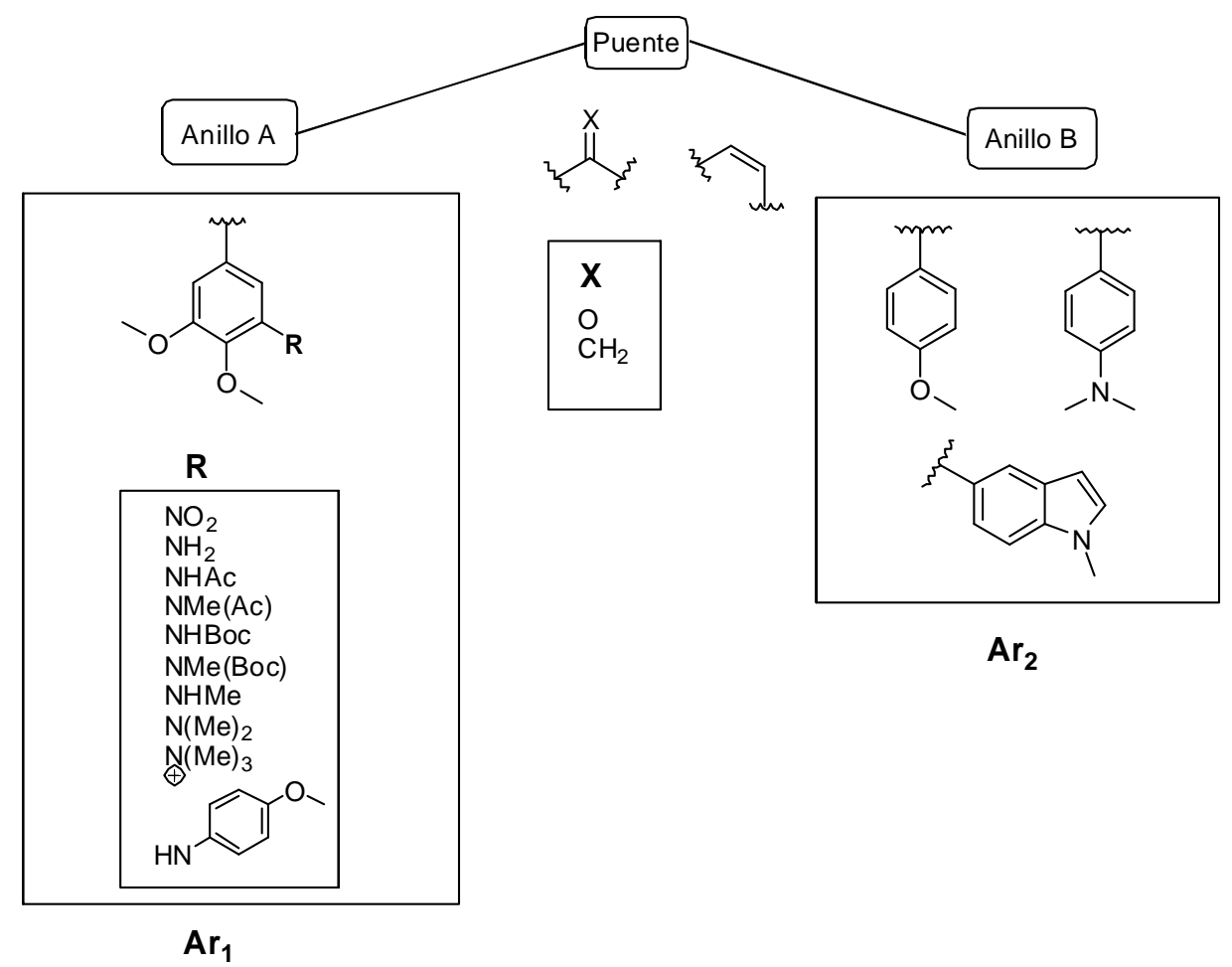

Figura 68: Esquema general de los compuestos sintetizados 


\section{Síntesis de análogos de fenstatina:}

Se sintetizan los compuestos de la familia de fenstatina que mantienen el anillo B como $p$ metoxifenilo o 1-metil-1H-indol mientras en anillo A se sustituye un grupo metoxilo de la agrupación 3,4,5-trimetoxifenilo por diferentes sustituyentes nitrogenados para ver la influencia de cada uno sobre la actividad de la molécula.

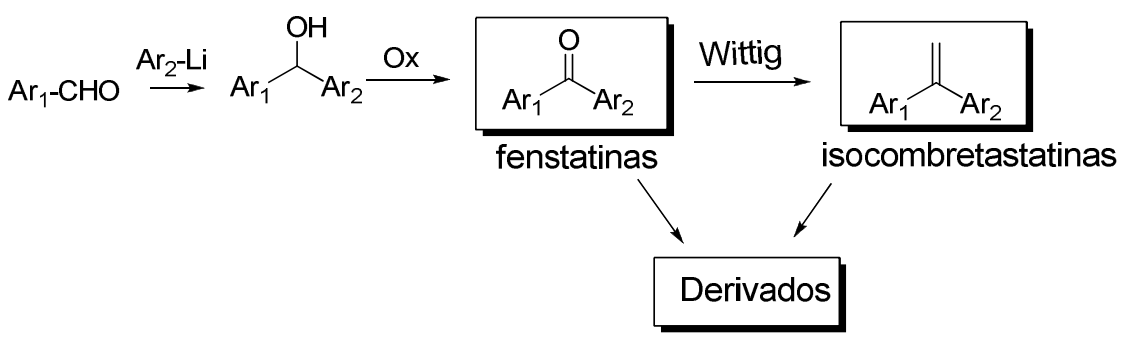

Figura 69: Esquema general de la síntesis de fenstatina

\subsection{Síntesis de los derivados del $p$-metoxifenilo:}

La síntesis de la fenstatina se realiza siguiendo el procedimiento habitual de la reacción del aldehído con el derivado litiado.

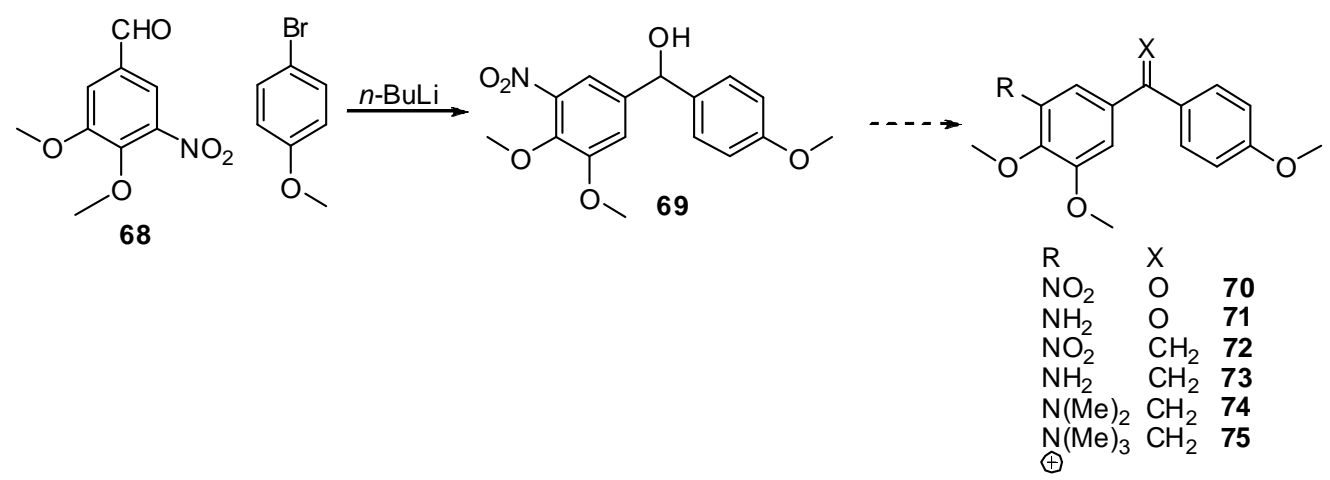

Figura 70: Síntesis de las fenstatinas e isocombretastatinas

Se sintetiza el alcohol 69 mediante la reacción del aldehído 68 con el derivado litiado de 4bromoanisol, siguiendo el método habitual de este tipo de reacciones, y se utiliza en la reacción de oxidación sin purificar para evitar la pérdida de rendimiento. 
El aldehído 68, que también es utilizado posteriormente en la preparación de otros materiales de partida como 86 y 95 , se sintetiza a partir de vainillina por nitración ${ }^{61}$ y metilación.

La metilación se ha realizado de dos formas diferentes, usando sulfato de dimetilo en presencia de una base y acetona o en condiciones de transferencia de fase ${ }^{62}$. El segundo método transcurre a temperatura ambiente y da ligeramente mejor rendimiento (88\%) frente al anterior $(81 \%)$, por lo cual se utiliza en los casos que hemos tenido que repetir la reacción.

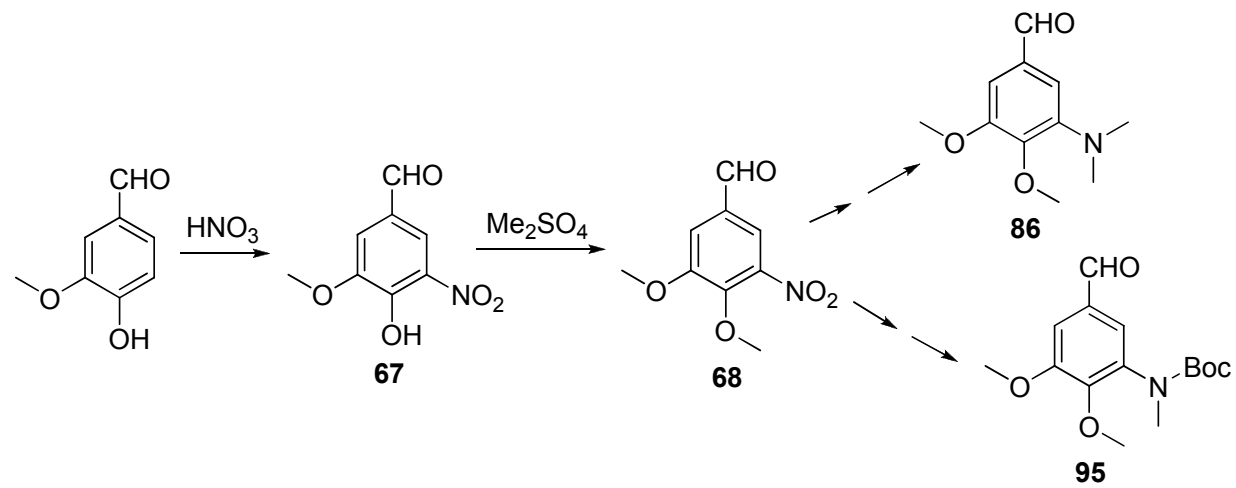

Figura 71: Síntesis del aldehído 68

En la bibliografía la reducción de $\mathrm{NO}_{2}$ a $\mathrm{NH}_{2}$ se ha realizado utilizando hierro ${ }^{41 \mathrm{~b}}$ ó zinc como reductores. Los mejores rendimientos se obtienen con el zinc en acido acético, por lo cual es el método elegido en nuestro caso para la preparación de 71 y 73.

El alcohol 69 se oxida con dicromato de piridinio en $\mathrm{CH}_{2} \mathrm{Cl}_{2}$ para formar la fenstatina 70, que se identifica por la aparición de la señal en $\mathrm{RMN}{ }^{13} \mathrm{C}$ del grupo carbonilo a 192,3 ppm. La aminofenstatina 71 se prepara a partir de la reducción de $\mathbf{7 0}$ con zinc y ácido acético. ${ }^{48 b}$ También para reducir los pasos de reacciones y aumentar el rendimiento de la reacción, se intentó preparar 71 utilizando el amino-aldehído 88 (figura 72). La reacción de condensación transcurre con muy bajo rendimiento y aunque en el crudo de reacción se detecta una señal en RMN ${ }^{1} \mathrm{H}$ del protón geminal al grupo hidroxilo no se continúa la secuencia de reacción. Por ello la secuencia final de reacciones se prosigue a partir de la fenstatina $\mathbf{7 0 .}$

\footnotetext{
${ }^{61}$ Kiss, L. E.; Ferreira, H. S.; Torrao, L.; Bonifacio, M. J.; Palma, P. N.; Da Silva, P. S.; Learmonth, D. A. Discovery of a Long-Acting, Peripherally Selective Inhibitor of Catechol-O-methyltransferase. J. Med. Chem. 2010, 53, 3396.

${ }^{62}$ Bailey, K.; Tan, E. T. Synthesis and evaluation of bifunctional nitrocatechol inhibitors of pig liver catechol-Omethyltransferase. Bioorg. Med. Chem. 2005, 13, 5740.
} 
<smiles>COc1ccc(C(=O)c2cc(N)c(OC)c(OC)c2)cc1</smiles>

Figura 72: Intento de preparación de 71

La isocombretastatina $\mathbf{7 2}$ obtenida mediante la reacción de Wittig de 70, se identifica por las señales de los protones olefínicos a 5,36 y 5,45 ppm. La reducción del compuesto 72 al amino 73 implica un apantallamiento de los protones aromáticos del anillo A. La reacción de alquilación de la amina nos permitió formar el derivado dimetilado $\mathbf{7 4}$ por tratamiento con yodometano a $70{ }^{\circ} \mathrm{C}$. A partir de él con más equivalentes de yodometano y $\mathrm{AgNO}_{3}$ en acetona en un tubo sellado, se obtiene la sal de amonio 75. Los datos de espectroscopía de masas permiten confirmar la formación de la sal de amonio $\mathbf{7 5}$.

En la tabla siguiente se muestran el rendimiento obtenido de cada compuesto y las variaciones del desplazamiento químico de los protones aromáticos del anillo A en función de la sustitución del mismo.

\begin{tabular}{|c|c|c|c|c|}
\hline & Compuesto & Rendimiento & $\begin{array}{c}\text { Desplazamiento químico } \\
\text { de los protones } \\
\text { aromáticos } 2 \text { y } 6\end{array}$ & Estructura \\
\hline 70 & $\mathrm{X}=\mathrm{O} ; \mathrm{R}=\mathrm{NO}_{2}$ & $37 \%$ & 7,59 y $7,66 \mathrm{ppm}$ & \\
\hline 71 & $\mathrm{X}=\mathrm{O} ; \mathrm{R}=\mathrm{NH}_{2}$ & $95 \%$ & 6,76 у $6,77 \mathrm{ppm}$ & \\
\hline 72 & $\mathrm{X}=\mathrm{CH}_{2} ; \mathrm{R}=\mathrm{NO}_{2}$ & $72 \%$ & 7,06 y $7,30 \mathrm{ppm}$ & \\
\hline 73 & $\mathrm{X}=\mathrm{CH}_{2} ; \mathrm{R}=\mathrm{NH}_{2}$ & $80 \%$ & 6,34 y $6,40 \mathrm{ppm}$ & \\
\hline 74 & $\mathrm{X}=\mathrm{CH}_{2} ; \mathrm{R}=\mathrm{NMe}_{2}$ & $97 \%$ & 6,89 y $7,15 \mathrm{ppm}$ & \\
\hline 75 & $\mathrm{X}=\mathrm{CH}_{2} ; \mathrm{R}=\stackrel{\oplus}{\mathrm{NM}} \mathrm{e}_{3}$ & $84 \%$ & 7,07 y 7,12 ppm & \\
\hline
\end{tabular}

Tabla 5: Rendimiento y desplazamiento químico de los protones aromáticos del anillo A de 70-75

En la purificación del compuesto $\mathbf{7 0}$ después de las etapas de condensación y oxidación se aisló un subproducto identificado como 77. Este compuesto resulta de la reacción de condensación de una fracción del aldehído $\mathbf{6 8}$ contaminada con el aldehído 88 (ver la página 
74) con 4-metoxibromobenceno, seguido de la oxidación de la mezcla con PDC. La cetona 77 se ha identificado por $\mathrm{RMN}{ }^{1} \mathrm{H},{ }^{13} \mathrm{C}$ y espectrometría de masas $394,1647\left(\mathrm{M}+\mathrm{H}^{+}\right)$.<smiles>COc1ccc(Nc2cc(C(O)c3ccc(OC)cc3)cc(OC)c2Nc2ccc(OC)cc2C(=O)c2cc(Nc3ccc(OC)cc3)c(OC)c(OC)c2)cc1</smiles>

Figura 73: Obtencion del compuesto secundario 77

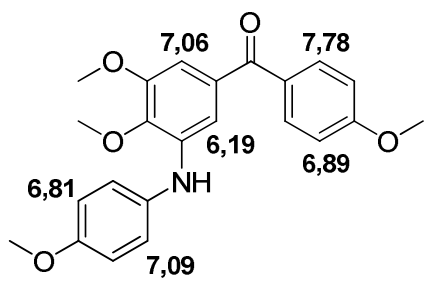

Figura 74: Desplazamiento químico de los protones aromáticos de 77

\subsection{Síntesis de los derivados de $1 H$-indol:}

A partir de los antecedentes del grupo del trabajo conocemos que los compuestos que contienen el indol como sustituyente del anillo B mejoran la potencia inhibidora de la polimerización de la tubulina del compuesto ${ }^{19}$. Por ello, se decidió incorporar este anillo en la nueva familia de compuestos a preparar. El anillo A será análogo a los del apartado anterior.

La protección del $\mathrm{NH}$ del indol es necesaria para evitar las reacciones secundarias que se pueden producir debido al carácter ácido del protón del NH del 5-bromo-1H-indol. Hemos comprobado también que la introducción del grupo metilo, $N$-Me, no solo mantiene la actividad biológica y además contribuye a mejorar la actividad y la purificación de los derivados. 
El compuesto de partida para la condensación es el 5-bromo-1-metil-1H-indol 98. La alquilación del indol se realiza mediante la reacción con yodometano después de formar el anión por tratamiento con bases, en presencia de un catalizador de transferencia de fase, que facilita la formación de $\mathrm{N}$-alquilo ${ }^{63}$ con buenos rendimientos.

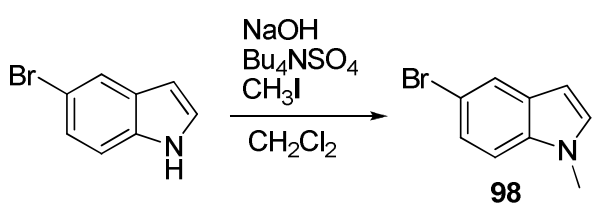

Figura 75: Obtención del compuesto 98

La secuencia utilizada en primer lugar es la preparacion del alcohol 99, oxidación a la fenstatina 100 y posterior reacción de Wittig a 101.<smiles>[X]C(c1cc(OCC)c(OCC)c([N+](=O)[O-])c1)c1cc(OCC)c(OCC)c([N+](=O)[O-])c1</smiles>

Figura 76: Síntesis de la isocombretastatina 101

Estos compuestos se han purificado y caracterizado pero los bajos rendimientos de las tres etapas obligan a buscar otra ruta alternativa para preparar los compuestos finales. Se intentó preparar la cetona utilizando como aldehído de partida el dimetilamino derivado 86, pero no se observó la formación de la cetona correspondiente.

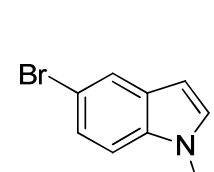

98<smiles>COc1cc(C=O)cc(N(C)C)c1OC</smiles>

86

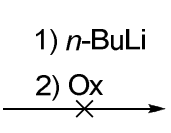<smiles>COc1cc(C(=O)c2ccc3c(ccn3C)c2)cc(N(C)C)c1OC</smiles>

Otra aproximación posible para efectuar la síntesis de la familia de compuestos $N$-Metil sustituidos sería partir con el grupo metilamino en el aldehído de partida. La preparación del

\footnotetext{
${ }^{63}$ Liou, J-P.; Wu, J-Y.; Hsieh, H-P.; Chang, C-Y.; Chen, C-M.; Kuo, C-C.; Chang, J-Y. 4- and 5-Aroylindoles as Novel Classes of Potent Antitubulin Agents. J. Med. Chem. 2007, 50, 4548.
} 
mismo se utiliza a partir del aldehído $\mathbf{6 8}$ obtenido anteriormente. La protección en forma de acetal y reducción origina $\mathbf{8 4}$ que se protege en forma de $N$-Boc para evitar la polimetilación del grupo amino.

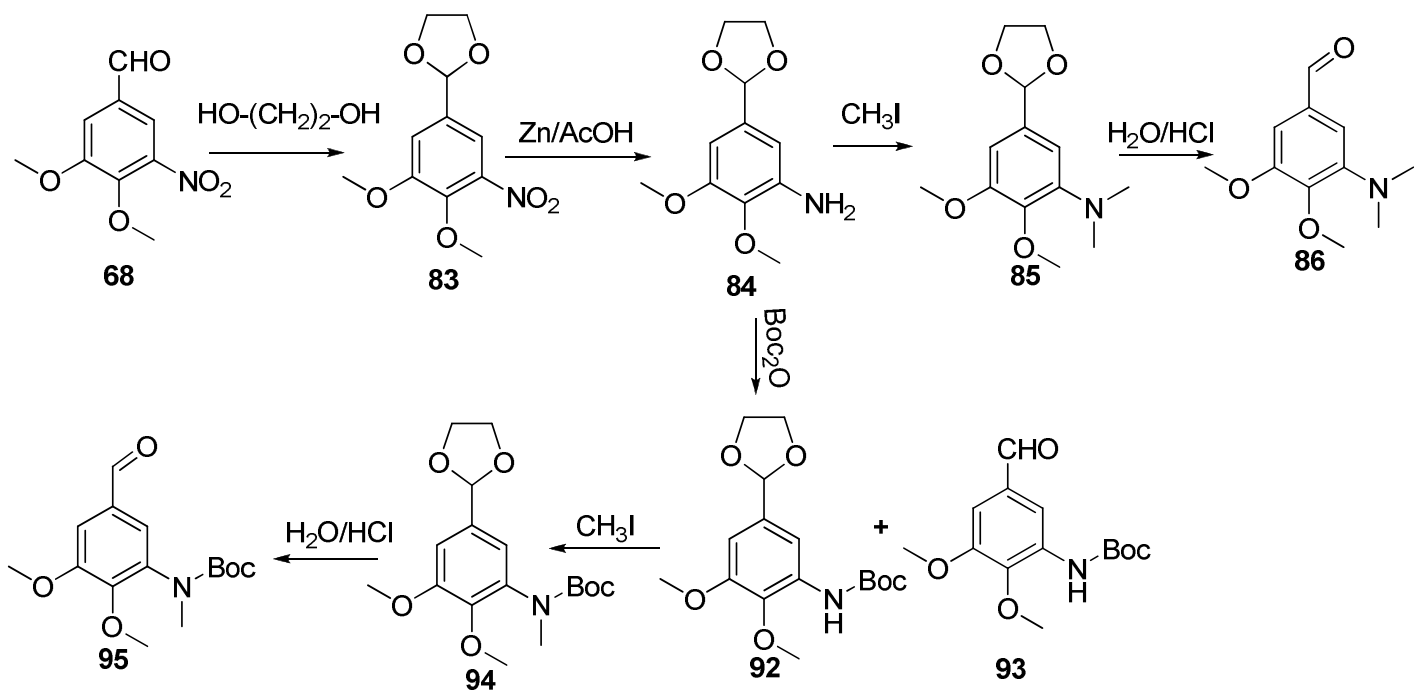

Figura 77: Síntesis del aldehído 95

La protección del aldehído $\mathbf{6 8}$ se realiza de dos maneras diferentes, con etilénglicol y cloruro de trimetilsililo, ${ }^{54}$ obteniéndose el compuesto 83 con un rendimiento de $52 \%$; se prepara también con etilenglicol y acido p-toluensulfónico, usando un Dean-Stark para eliminar el agua del medio ${ }^{64}$, incrementando el rendimiento hasta el $96 \%$. Por lo cual es el método que se usa a posteriori. La protección del aldehído se caracteriza por la desaparición de la señal del protón del aldehído y la aparición de las señales de los protones de grupo dioxolano a 4,04 y 5,75 ppm en $\mathrm{RMN}{ }^{1} \mathrm{H}$.

El aldehído 86 se prepara después de reducción con zinc del grupo nitro al amino 84. Esta reacción de reducción también se intentó con otros reductores como $\mathrm{NaBH}_{4}, \mathrm{LiAlH}_{4}$ y reducción catalítica con $\mathrm{H}_{2} / \mathrm{Pd}-\mathrm{C}$ en etanol o en AcOEt, pero no se observó evolución en ninguna de estas condiciones.

El compuesto 84 se trata con yodometano y trietilamina para obtener el derivado metilado $\mathbf{8 5}$, observándose la parcial desprotección del aldehído ya que se aísla la mezcla de $\mathbf{8 5 / 8 6}$ en proporción 3:1, esta mezcla se pone a desproteger con $\mathrm{H}_{2} \mathrm{O} / \mathrm{HCl}$ para transformarlo todo al

\footnotetext{
${ }^{64}$ Borchardt, R. T.; Huber, J. A.; Houston, M. Catechol $O$-Methyltransferase. 10. 5-Substituted 3-Hydroxy-4methoxybenzoic Acids (Isovanillic Acids) and 5-Substituted 3-Hydroxy-4-methoxybenzaldehydes (Isovanillins) as Potential Inhibitors. J. Med. Chem. 1982, 25, 258.
} 
aldehído 86. La metilación de 84 se intentó realizar con $\mathrm{CH}_{3} \mathrm{I}$ utilizando $\mathrm{K}_{2} \mathrm{CO}_{3}$ como base pero en estas condiciones no se produce la reacción de metilación.

También se intentó preparar el compuesto 86 efectuando en primer lugar la desprotección del aldehído 84 y luego la metilación pero no se detecta evolución de la reacción de metilación.

Para la preparación de derivados monometilados en el grupo amino se procedió a la protección previa del mismo. Se utiliza como protector terc-butil dicarbonato ${ }^{65}$, porque es fácil de eliminar en comparación con otros grupos protectores. A la hora de la protección del grupo amino se desprotege una parte del aldehído, por lo cual se obtiene una mezcla de dos compuestos con $N$-Boc, 92 con el aldehído protegido y 93 desprotegido en proporción 3:1. Los derivados protegidos se identifican por la aparición de la señal del grupo Boc a 1,52 ppm en $\mathrm{RMN}{ }^{1} \mathrm{H}$.

La metilación del grupo -NH-Boc de la mezcla obtenida anteriormente $(\mathbf{9 2 + 9 3})$ se realiza con yodometano, hidruro sódico como base y THF como disolvente. ${ }^{66}$ La reacción de metilación se produce con desprotección parcial del aldehído que se completa por hidrólisis ácida. El aldehído 95 se caracteriza por las señales del metilamino a 3,16 y del aldehído a 9,85 ppm en $\mathrm{RMN}{ }^{1} \mathrm{H}$.

Al cambiar el THF por DMF en la reacción de metilación se obtiene el compuesto protegido $94^{67}$ al $90 \%$, y cuando se prepara mediante la transferencia de fase no se observa ninguna evolución.

De todas formas, como es necesario desproteger el aldehído para continuar la secuencia, se utiliza el primer método donde se obtiene con una mayor parte desprotegida para reducir las etapas de reacción. El aldehído 95 se considera como la molécula base de esta secuencia, por lo cual se prepara en mayor cantidad.

\footnotetext{
65 a) Chelucci, G.; Manca, I.; Pinna, A. G. Synthesis of regiospecifically substituted quinolines from anilines. Tetrehedron Lett. 2005, 46, 767. b) Muchowski, J. A.; Venuti, M. C. Ortho Functionalization of N-(tertButoxycarbonyl)aniline. J. Org. Chem. 1980, 45, 4798.

66 Wang, X-F.; Wang, S-B.; Ohkoshi, E.; Wang, L-T.; Hamel, E.; Qian, K.; Susan L. M-N.; Lee, K-H.; Xie, L. N-Aryl-6-methoxy-1,2,3,4-tetrahydroquinolines: A novel class of antitumor agents targeting the colchicine site on tubulin. Eur. J. Med. Chem. 2013, 67, 196.

67 Pinto, A.; Neuville, L.; Retailleau, P.; Zhu, J. Synthesis of 3-(Diarylmethylenyl)oxindole by a Palladium-Catalyzed Domino Carbopalladation/C-H Activation/C-C BondForming Process. Org. Lett. 2006, 21, 4927.
} 


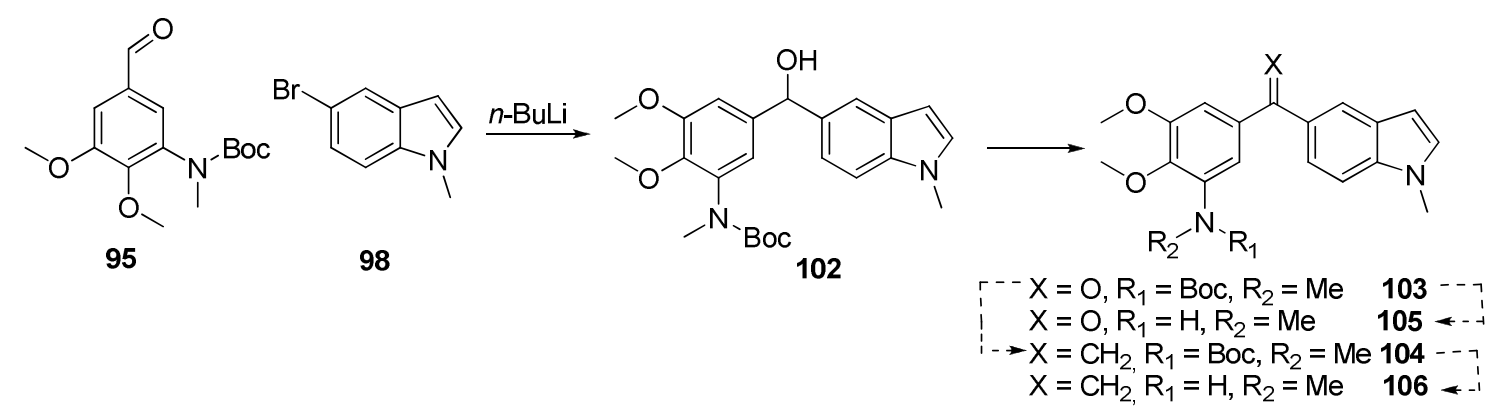

Figura 78: Esquema de síntesis de la fenstatina 105 y de la isocombretastatina 106

El alcohol 102 (figura 78) se sintetiza a partir de la condensación del derivado litiado del bromo metil indol 98 con el aldehído 95. La oxidación del alcohol 102 con PDC da la fenstatina 103 con un $83 \%$. Al contrario que en la secuencia anterior de la síntesis de las fenstatinas a partir del derivado nitrado $\mathbf{6 8}$ se obtiene un rendimiento muy aceptable, que indica que los productos con grupo nitro en la reacción de adición nucleofilica en presencia de $n$-BuLi se degradan con mayor facilidad. Por lo cual es conveniente sustituir el grupo nitro por otros grupos que favorecen la reacción en estas condiciones. Siguiendo el proceso habitual del trabajo, se prepara la isocombretastatina 104 a partir de $\mathbf{1 0 3 .}$

Para buscar las condiciones óptimas de desprotección del grupo Boc se realizó una prueba de desprotección del aldehído de partida 95. Con $p$ - Ts $\mathrm{OH}$ en $\mathrm{CH}_{2} \mathrm{Cl}_{2}$ se observó la desprotección del grupo amino. Sin embargo, al realizar la desprotección de $\mathbf{1 0 3}$ en estas condiciones no se produce la desprotección.

La desprotección del grupo $N$-Boc de la fenstatina 103 se consigue mediante su tratamiento con cloruro de trimetilsililo en $\mathrm{MeOH}^{68}$ y se obtiene la fenstatina 105. Cuando se utiliza ácido $p$-toluensulfónico en THF a reflujo se obtiene el compuesto desprotegido PS-1, producido porque la posición 3 del indol reacciona con apertura del THF en las condiciones ácidas de la reacción.

\footnotetext{
${ }^{68}$ Chen, B-C.; Skoumbourdis, A. P.; Guo, P.; Bednarz, M. S.; Kocy, O. R.; Sundeen, J. E.; Vite, G. D. A Facile Method for the Transformation of N-(tert-Butoxycarbonyl) $\alpha$-Amino Acids to N-Unprotected $\alpha$-Amino Methyl Esters. J. Org. Chem. 1999, 64, 9294.
} 


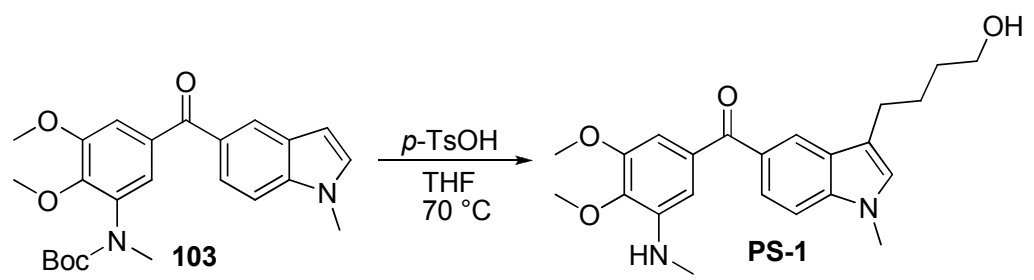

Figura 79: Formación del compuesto secundario PS-1

La isocombretastatina 104 se intentó desproteger con $\mathrm{TMSCl} / \mathrm{MeOH}$ como en el caso de la fenstatina $\mathbf{1 0 3}$ pero la molécula se rompe y se aísla el producto de degradación y desprotección PS-3. Luego se probó también $p$-TsOH/THF a temperatura ambiente y a reflujo, TFA/ $\mathrm{CH}_{2} \mathrm{Cl}_{2}{ }^{69}$ y $\mathrm{HCl}(3 \mathrm{M}) / \mathrm{AcOEt}$, en estos casos se identifica el mismo producto de degradación pero con el grupo amino todavía protegido en forma de Boc. Por lo cual es necesario buscar otra alternativa para preparar la isocombretastatina monometilada $\mathbf{1 0 6}$.

El compuesto secundario PS-2 se identifica por $\mathrm{RMN}{ }^{1} \mathrm{H}$, donde se muestra que la molécula sigue manteniendo el grupo Boc y se ha roto en el puente, apareciendo las señales características del grupo vinilo. En el compuesto PS-3 no se aparece la señal de grupo Boc.

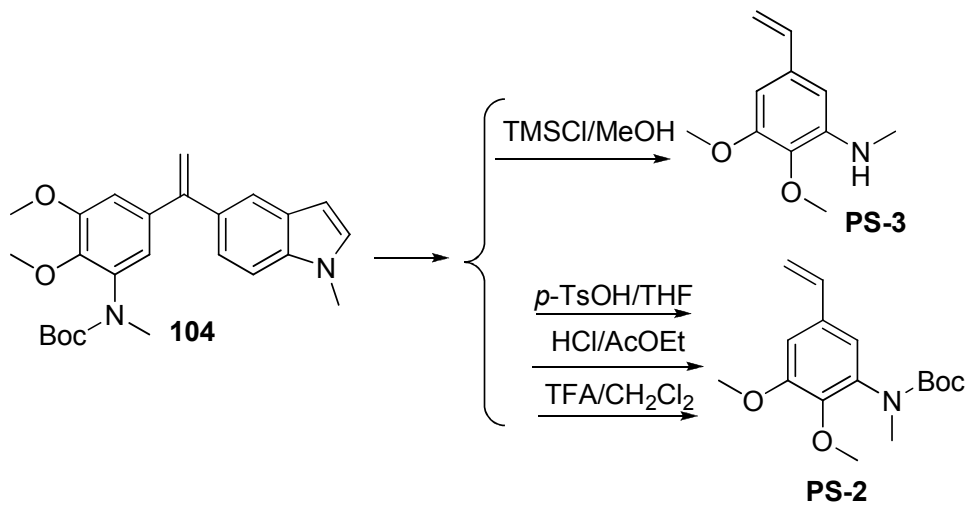

Figura 80: Formación del compuesto secundario PS-2

Ante la imposibilidad de conseguir la desprotección de 104, la isocombretastatina 106 se prepara a partir de la fenstatina desprotegida 105. Esta reacción se produce con un rendimiento bajo que se puede atribuir a la reacción del protón ácido del grupo amino con el n-BuLi empleado como base.

\footnotetext{
${ }^{69}$ Mitsunaga, S.; Ohbayashi, T.; Sugiyama, Shimpei.; Saitou, T.; Tadokoro M.; Satoh, T. Asymmetric synthesis of cyclic $\alpha$-amino acid derivatives by the intramolecular reaction of magnesium carbenoid with an $\mathrm{N}$ magnesioarylamine. Tetrahedron. Asym. 2009, 20, 1697.
} 


\begin{tabular}{|c|c|c|c|}
\hline Compuestos & Rendimiento & Desplazamiento químico & Estructuras \\
\hline 103 & $83 \%$ & 4,6: 7,23 у 7,28 ppm; 4': 8,11 ppm & \\
\hline 104 & $56 \%$ & 4,6: 6,76 у 6,81 ppm; 4’: 8,17 ppm & \\
\hline 105 & $47 \%$ & $\begin{array}{c}\text { Puente: singletes a 5,36 y 5,42 ppm; 6,4: } \\
\text { 6,78 y 7,27 ppm; 4': 7,60 ppm }\end{array}$ & \\
\hline 106 & $27 \%$ & $\begin{array}{l}\text { Puente: singletes a 5,17 y 5,21 ppm; 6,4: } \\
\text { 6,19 y 6,23 ppm; 4': 7,63 ppm }\end{array}$ & $\mathrm{R}=\mathrm{H}$ \\
\hline
\end{tabular}

Tabla 6: Rendimiento y desplazamiento químico de los protones aromáticos de 103-106

En esta serie de compuestos, las fenstatina se obtienen con buen rendimiento, en comparación con los índoles partidos del derivado nitro, que se obtienen con un rendimiento muy pobre, mientras en el caso de las isocombretastatinas, el rendimiento se disminuye porque se obtienen productos secundarios, como consecuencia de la degradación de la molécula.

\section{Síntesis de análogos de combretastatina:}

El objetivo del trabajo se completa con la serie de combretastatinas con los mismos sustituyentes del anillo A introducidos en fenstatinas.

\subsection{Síntesis de los derivados $p$-metoxifenilo:}

Se inicia la síntesis por reacción del aldehído $\mathbf{6 8}$ con el iluro de fósforo preparado a partir de la sal de fosfonio 5. Mediante la reacción de Wittig se forma la combretastatina $\mathbf{7 8}$ como mezcla de isómeros Z/E en proporción 1:2 con un rendimiento global de $94 \%$. Se identifican por la aparición de las señales de los protones del puente en $\mathrm{RMN}{ }^{1} \mathrm{H}$ de ambos isómeros, el isómero $Z$ a 6,35 y 6,61 ppm y el isómero $E$ a 6,82 y 6,99 ppm. 


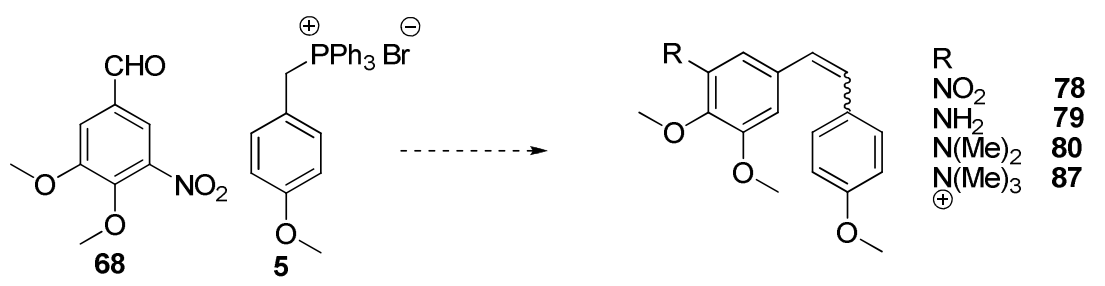

Figura 81: Síntesis de las combretastatinas

La reducción del grupo nitro a amino en la mezcla $Z / E$ 1:2 de 78 se efectúa con zinc y ácido acético dando 79 una mezcla de isómeros $Z / E$ 1:3 con un rendimiento del $98 \% .79$ se caracteriza por el apantallamiento en $\mathrm{RMN}{ }^{1} \mathrm{H}$ de los protones aromáticos del anillo A por el grupo amino (6,32 y 6,38 ppm del isómero $Z$ ) en relación al anillo A sustituido por un grupo nitro.

La metilación del grupo amino de la combretastatina 79 con yodometano en acetona produce la dimetilamino-combretastatina $\mathbf{8 0}$ como una mezcla de isómeros $Z / E$ en proporción 1:3 y con un rendimiento de $88 \%$. Se identifica por la aparición de los protones del dimetilamino a 2,86 ppm en $\mathrm{RMN}{ }^{1} \mathrm{H}$.

Con el fin de mejorar la proporción del isómero con configuración $\mathrm{Z}$ se probó la reacción de Wittig con el aldehído 86 que contiene el grupo dimetilamino y en este caso la proporción Z/E obtenida es 1:1 y con un rendimiento similar a la preparación de 78. La igualdad en la proporción de los isómeros permite el aislamiento de cada uno de ellos.

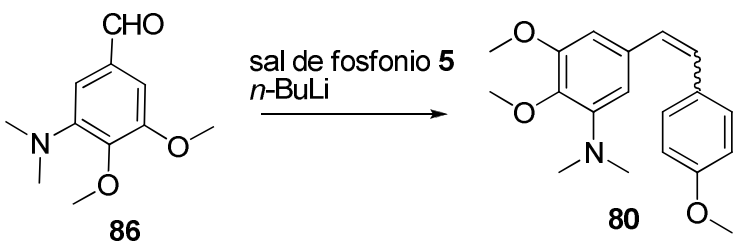

Figura 82: Preparación de la combretastatina 80

A partir del isómero $Z$ de combretastatina $\mathbf{8 0}$ se prepara la sal de amonio $\mathbf{8 7}$, que se obtiene como isómero $Z$ puro. La reacción de metilación conserva la configuración del doble enlace. 


\begin{tabular}{|c|c|c|c|}
\hline Compuestos & Rendimiento & Proporción & Desplazamiento químico $(Z$ y $E)$ \\
\hline 78 & $94 \%$ & $Z / E 1: 2$ & $\begin{array}{l}\text { (Z): } 6,24 \text { у } 6,55 \mathrm{ppm} ; J=12,0 \mathrm{~Hz} \\
\text { (E): } 6,78 \text { у } 6,96 \mathrm{ppm} ; J=16,4 \mathrm{~Hz}\end{array}$ \\
\hline 79 & $98 \%$ & $Z / E 1: 3$ & $\begin{array}{l}\text { (Z): 6,27 y } 6,39 \mathrm{ppm} ; J=12,0 \mathrm{~Hz} \\
\text { (E): } 6,76 \text { у } 6,89 \mathrm{ppm} ; J=16,0 \mathrm{~Hz}\end{array}$ \\
\hline 80 & $88 \%$ & Z/E 1:1 & $\begin{array}{l}\text { (Z): } 6,40 \text { y } 6,48 \mathrm{ppm} ; J=12,0 \mathrm{~Hz} \\
\text { (E): } 6,48 \text { y } 6,85 \mathrm{ppm} ; J=16,4 \mathrm{~Hz}\end{array}$ \\
\hline 87 & $49 \%$ & $Z$ solo & $\begin{array}{c}2 \text { dobletes a } 6,50 \text { y } 6,70 \mathrm{ppm} ; \\
\quad J=12,0 \mathrm{~Hz}\end{array}$ \\
\hline
\end{tabular}

Tabla 7: Rendimiento y desplazamiento químico de los protones olefínicos de 78-80 y 87

Además de esta secuencia que permitió obtener las agrupaciones $\left(\mathrm{NMe}_{2}\right)$ y $\left({ }^{+} \mathrm{NMe}_{3}\right)$ en el anillo A de la combretastatinas se decidió introducir las agrupaciones (NHAc) y (NMeAc).

Por ello se empieza la síntesis por la desprotección del aldehído 84 por hidrólisis para obtener $\mathbf{8 8}$, luego el grupo amino para formar la amida 89 con un rendimiento del $72 \%$. Se identifican por la aparición de la señal del metilo del grupo acetato a 2,21 ppm en $\mathrm{RMN}{ }^{1} \mathrm{H}$.

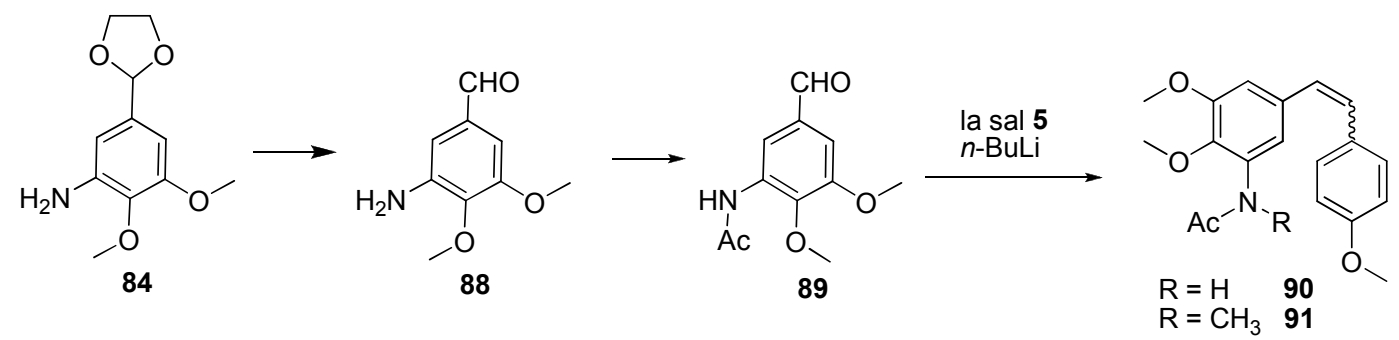

Figura 83: Preparación de la combretastatina 91

La combretastatina 90 se obtiene a partir de la reacción de Wittig de $\mathbf{8 9}$ con la sal de fosfonio 5. En esta reacción se obtiene mezcla de isómeros $Z / E$ en proporción 1:3. El producto $Z$ se purifica por cromatografía de columna y una de las fracciones de la mezcla de isómeros $Z / E$ (1:1) se trata con yodometano en presencia de la base de hidruro sódico formándose el producto metilado 91 como isómeros $Z / E$ 2:1. Eso significa que la metilación en estas condiciones favorece la isomerización de $E$ a $Z$. La formación del compuesto 91 se identifica por la aparición de la señal de los protones de $N$-Me a 3,13 ppm en $\mathrm{RMN}{ }^{1} \mathrm{H}$. En la tabla siguiente se muestran los desplazamientos químicos de los protones olefínicos Z/E de 90 y 91. 


\begin{tabular}{|c|c|c|c|}
\hline \multirow{2}{*}{ compuesto } & Rendimiento & $\begin{array}{c}\text { Desplazamiento químico de los protones del } \\
\text { puente de los isómeros }\end{array}$ & $J$ en $H z$ \\
\hline \multirow{2}{*}{90} & $55 \%$ & $(Z): 6,45 ; 6,49 \mathrm{ppm}$ & 12,0 \\
\cline { 3 - 4 } & \multirow{2}{*}{91} & $(E): 6,89 ; 6,97 \mathrm{ppm}$ & 16,4 \\
\cline { 3 - 4 } & $72 \%$ & $(Z): 6,38 ; 6,54 \mathrm{ppm}$ & 12,0 \\
\hline
\end{tabular}

Tabla 8: Rendimiento y desplazamiento químico de los protones olefínicos de 90-91

El objetivo siguiente era obtener el grupo metilamino de la combretastatina de esta familia para comparar su actividad biológica con otros derivados. Como no ha sido posible obtenerlo a partir de una monometilación se protege el grupo amino y metila para obtener el aldehído 95 descrito anteriormente.

La combretastatina 96 se prepara a partir de la reacción de Wittig del aldehído 95 y el iluro de la sal de fosfonio 5. Esta reacción se obtiene como mezcla de isómeros Z/E en proporción 1:2. En este caso la proporción del isómero cis es relativamente mayor que las veces anteriores (1:3), por lo cual, el grupo Boc afecta a la proporción de los estereoisomeros.
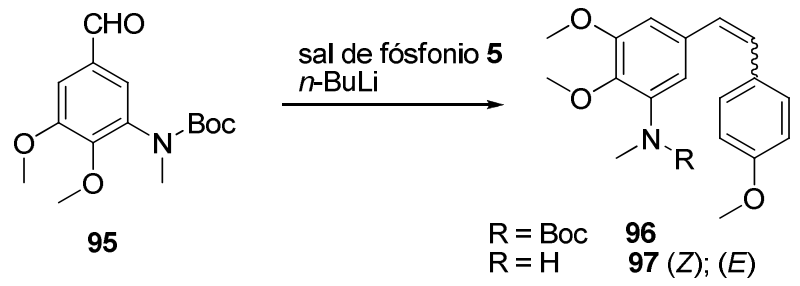

Figura 84: Síntesis de las combretastatinas 97

La desprotección del grupo terc-butil carbamato hay que realizarla en condiciones que no se produzca isomerización $Z / E$, por lo que se hicieron varios intentos con diferentes reactivos. Al principio se desprotegió el isómero $E$ con $p$-TsOH en THF a reflujo, y se obtuvo el compuesto 97 manteniendo la configuración $E$. La desprotección del isómero $Z$ con el mismo procedimiento transforma todo al isómero $E$. Se realizó a temperatura ambiente, pero no se observó ninguna evolución, por lo cual fue necesario buscar otras condiciones. 
En la tabla siguiente se muestran las condiciones ensayadas para la desprotección de los isómeros $Z$ y $E$ de la combretastatina 96, que se realizaron en tubo de RMN para poder hacer el seguimiento de la reacción.

\begin{tabular}{|c|c|c|}
\hline Condiciones de reacción & Compuesto & Resultados obtenidos \\
\hline $\mathrm{p}-\mathrm{TsOH} / \mathrm{THF} / \Delta$ & Isómero $E$ & $\mathrm{El}$ isómero $E$ desprotegido \\
\hline $\mathrm{p}$-TsOH/THF/ $\Delta$ & Isómero $Z$ & $\mathrm{El}$ isómero $E$ desprotegido \\
\hline $\mathrm{TFA} / \mathrm{CH}_{2} \mathrm{Cl}_{2}$ & Isómero $Z$ & No reacciona \\
\hline $\mathrm{TFA} / \mathrm{Acetona}$ & Isómero $Z$ & No reacciona \\
\hline $\mathrm{HCl}(3 \mathrm{M}) / \mathrm{AcOEt}$ & Isómero $Z$ & Isómero $Z$ mayoritario \\
\hline $\mathrm{TMSCl} / \mathrm{MeOH}$ y $\mathrm{MeOD}$ & Isómero $Z$ & Isómero $Z$ mayoritario \\
\hline
\end{tabular}

Tabla 9: Condiciones probadas para desprotección de los isómeros de 96

Por ello, la desprotección del isómero $Z$ se realizó con (TMSCl/MeOH), obteniéndose el isómero $Z$ como mayoritario ( $Z / E$ en proporción 6:4), purificándose por cromatografía de columna.

Las combretastatinas obtenidas se caracterizan por la desaparición de las señales de los protones del grupo Boc en RMN ${ }^{1} \mathrm{H}$. En la tabla siguiente se muestra los rendimientos y los desplazamientos químicos de las señales de 96 y 97.

\begin{tabular}{|c|c|c|c|}
\hline compuesto & Rendimiento & $\begin{array}{c}\text { Desplazamiento químico de los protones } \\
\text { del puente de los isómeros }\end{array}$ & $J$ en $\mathrm{Hz}$ \\
\hline $\mathbf{9 6}$ & $96 \%$ & $(Z): 6,36 ; 6,46 \mathrm{ppm}$ & 12,0 \\
\cline { 3 - 4 } & & $(E): 6,85 ; 6,93 \mathrm{ppm}$ & 16,4 \\
\hline $\mathbf{9 7}(Z)$ & $49 \%$ & $(Z): 6,33 ; 6,37 \mathrm{ppm}$ & 12,0 \\
\hline $\mathbf{9 7}(E)$ & $57 \%$ & $(E): 6,92 ; 6,95 \mathrm{ppm}$ & 16,0 \\
\hline
\end{tabular}

Tabla 10: Rendimiento y desplazamiento químico de los protones olefínicos de 96 y 97 


\subsection{Síntesis de los derivados $p$-dimetilaminofenilo:}

En esta parte se sintetiza los derivados de combretastatina con dimetilaminofenilo en anillo B y en el anillo A, 3-amino-4,5-dimetoxifenilo.
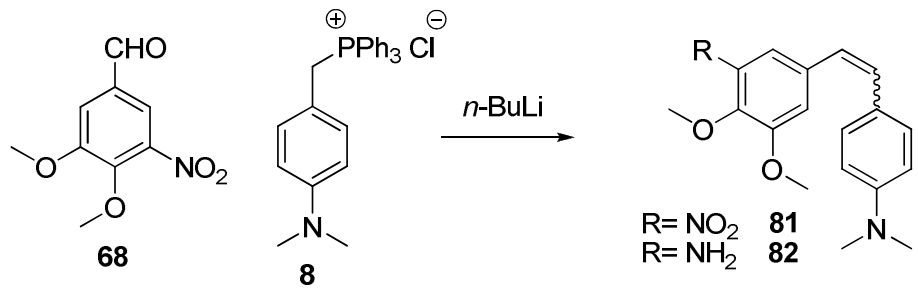

Figura 85: Preparación de la combretastatina 82

La reacción de Wittig entre el aldehído 68 y el iluro de la sal de fosfonio 8 produce la combretastatina 81 como mezcla $Z / E$ en proporción 1:3, que se separan por cromatografía de columna.

La reducción del isómero $Z$ de $\mathbf{8 1}$ con zinc y ácido acético produce $\mathbf{8 2}$ como una mezcla de isómeros $Z / E$ en proporción 3:1, que se separan por cromatografía de columna.

\begin{tabular}{|c|c|c|}
\hline compuesto & Rendimiento & $\begin{array}{l}\text { Desplazamiento químico de los } \\
\text { protones aromáticos del anillo A }\end{array}$ \\
\hline \multirow{2}{*}{81} & \multirow{2}{*}{$47 \%$} & $(Z)$ : dobletes : 7,09; 7,26 ppm \\
\hline & & $(E)$ : singletes: 7,16; 7,40 ppm \\
\hline \multirow{2}{*}{82} & \multirow{2}{*}{$69 \%$} & (Z): dobletes: 6,34; 6,38 ppm \\
\hline & & (E): dobletes: 6,$48 ; 6,53 \mathrm{ppm}$ \\
\hline
\end{tabular}

Tabla 11: Rendimiento y desplazamiento químico de los protones olefínicos de $\mathbf{8 1}$ y $\mathbf{8 2}$ 


\section{Modificación en el puente}

El objetivo de esta parte del trabajo es intentar mejorar la actividad y la solubilidad de las combretastatinas sintetizadas, a partir de la formación de heterociclos pentagonales como oxazoles, tiazoles, imidazoles, ...

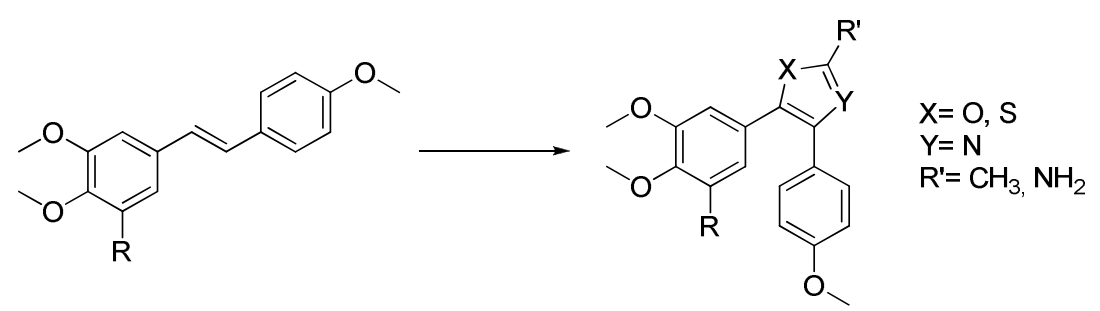

Nuestro grupo de trabajo ha preparado anteriormente, a partir de diversos análogos de combretastatinas, derivados heterocíclicos aromáticos pentagonales (pirazoles, oxazoles y isoxazoles) y hexagonales (pirimidinas, pirazinas) ${ }^{70}$.

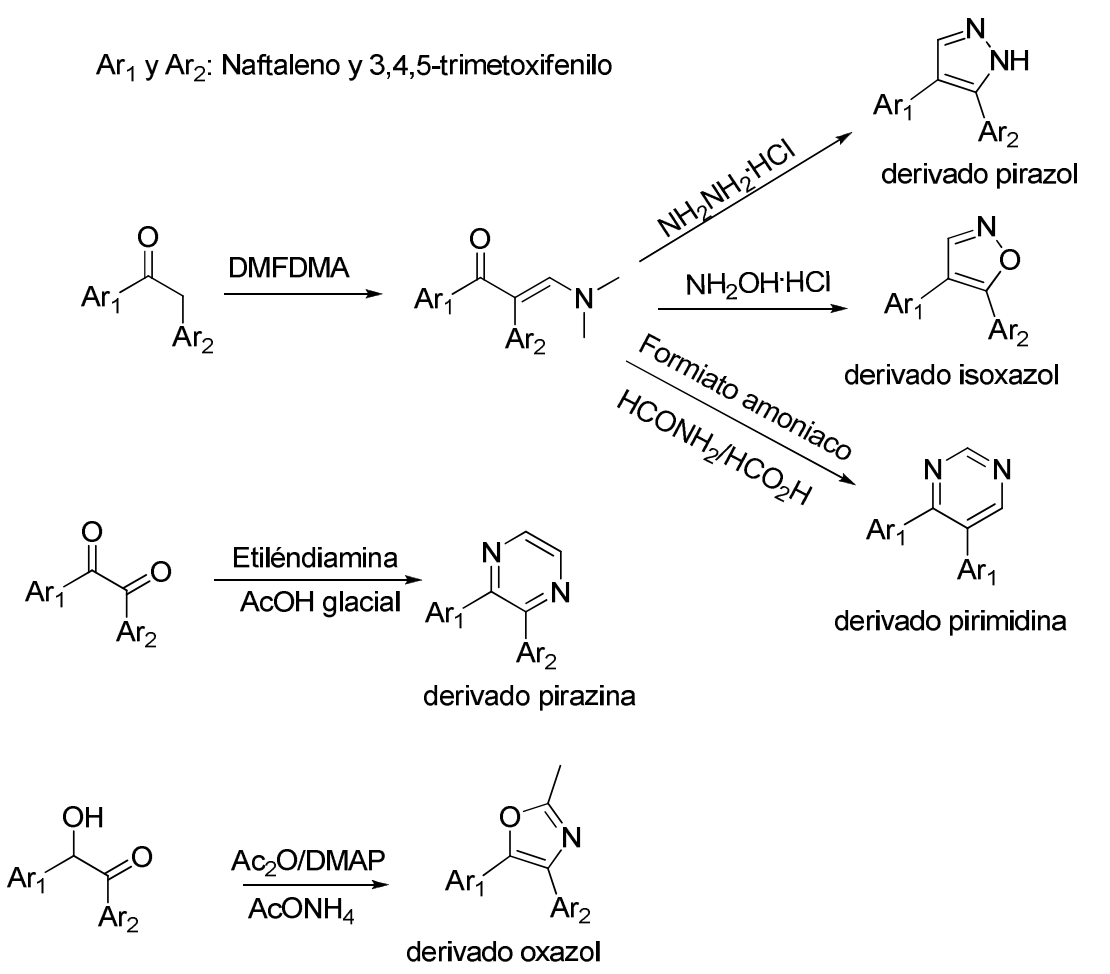

Figura 86: Síntesis de puentes heterocíclicos pentagonales y hexagonales

\footnotetext{
70 Maya, A. B. S.; Pérez, C. M.; Salvador, N.; Peláez, R.; Caballero, E.; Medarde, M. New
} naphthylcombretastatins. Modifications on the ethylene bridge. Bioorg. Med. Chem. 2005, 13, 2097. 
Las enaminonas se preparan por la reacción de diariletanona con DMFDMA (dimetilacetal de la $N, N$-dimetilformamida) en tolueno seco.

Los anillos de pirazol se han obtenido por el tratamiento de enaminonas con clorohidrato de hidracina en EtOH seco. Los isoxazoles se obtienen tras su tratamiento con clorohidrato de hidroxilamina en $\mathrm{MeOH}$. Los oxazoles se preparan por reacción de hidroxi-etanonas con anhídrido acético, DMAP y $\mathrm{AcONH}_{4}$.

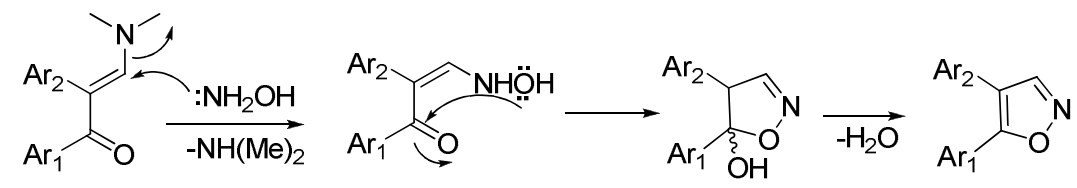

Figura 87: Mecanismo de formación de diarilisoxazoles

Se observó que en este caso la reacción es regioselectiva, se obtiene solo el producto del ataque nucleofilico del nitrógeno de hidroxilamina a la posición $\beta$ de la enaminona y no al grupo carbonilo, de acuerdo con lo que está descrito en la bibliografía para esta reacción ${ }^{71}$.

A partir de las aminación reductiva de Leuckart con formiato amónico de las enaminonas se puede obtener los heterocíclicos hexagonales de una forma regioselectiva según el mecanismo $^{72}$ descrito en el esquema siguiente:

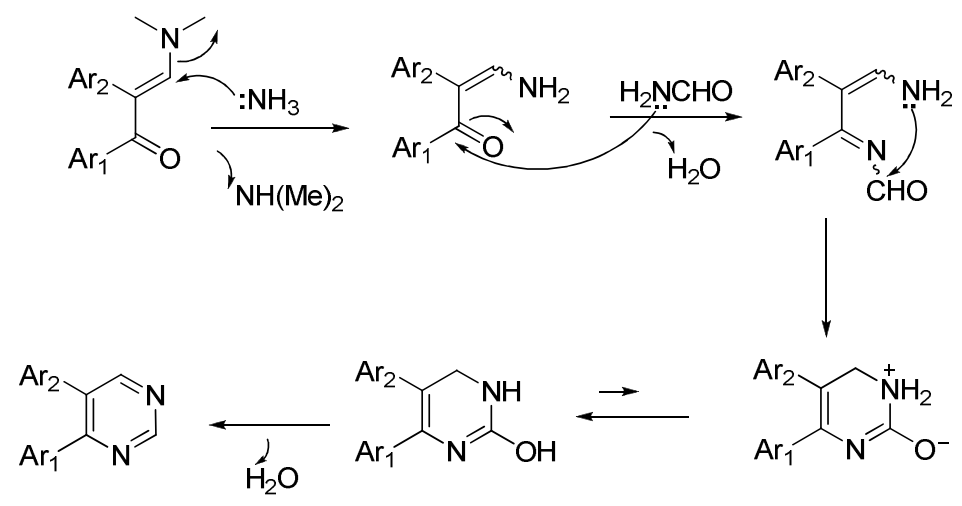

Figura 88: Mecanismo de formación de diarilpirimidinas

\footnotetext{
${ }^{71}$ Dominguez, E.; Ibeas, E.; de Marigorta, E. M.; Palacios, J. Kepa.; SanMartin, R. A convenient one-pot preparative method for 4,5-diarylisoxazoles involving amine exchange reactions. J. Org. Chem. 1996, 61, 5436.

72 a) Dominguez, E.; de Marigorta, E. M.; Olivera, R.; SanMartin, R. A short and efficient synthesis of 4,5diarylpyrimidines. Synlett. 1995, 9, 955. b) Olivera, R.; SanMartin, R.; Tellitu, I.; Dominguez, E. The amine exchange/biaryl coupling sequence: a direct entry to the phenanthro[9,10- $d]$ heterocyclic framework. Tetrahedron. 2002, 58, 3021.
} 
Se han observado que al formar puentes heterocíclicos pentagonales se mejora notablemente la actividad citotóxica de los compuestos en comparación con el puente etileno, mientras los puentes más voluminosos como hexagonales ó bicíclicos no son adecuados para generar compuestos activos de esta familia.

La síntesis más frecuente de tiazoles es a partir de la halocetona ${ }^{16,73}$. Para obtenerla se trata el compuesto con NBS y DMSO- $\mathrm{H}_{2} \mathrm{O}$ para formar la halohidrina luego se oxida con anhídrido trifluoroacético (TFAA) en DMSO para formar bromocetona, ó a partir de oxidación de la olefina con acido peryódico y alumina para formar el derivado bencilfenilcetona ${ }^{74}$, que se trata con el bromo en cloroformo para formar bromocetona. Este último se condensa con tiourea ó sus derivados (tioacetamida, tiosemicarbazida) y $\mathrm{Na}_{2} \mathrm{CO}_{3}$ en DMF para obtener los derivados tiazoles correspondiente ${ }^{75}$.

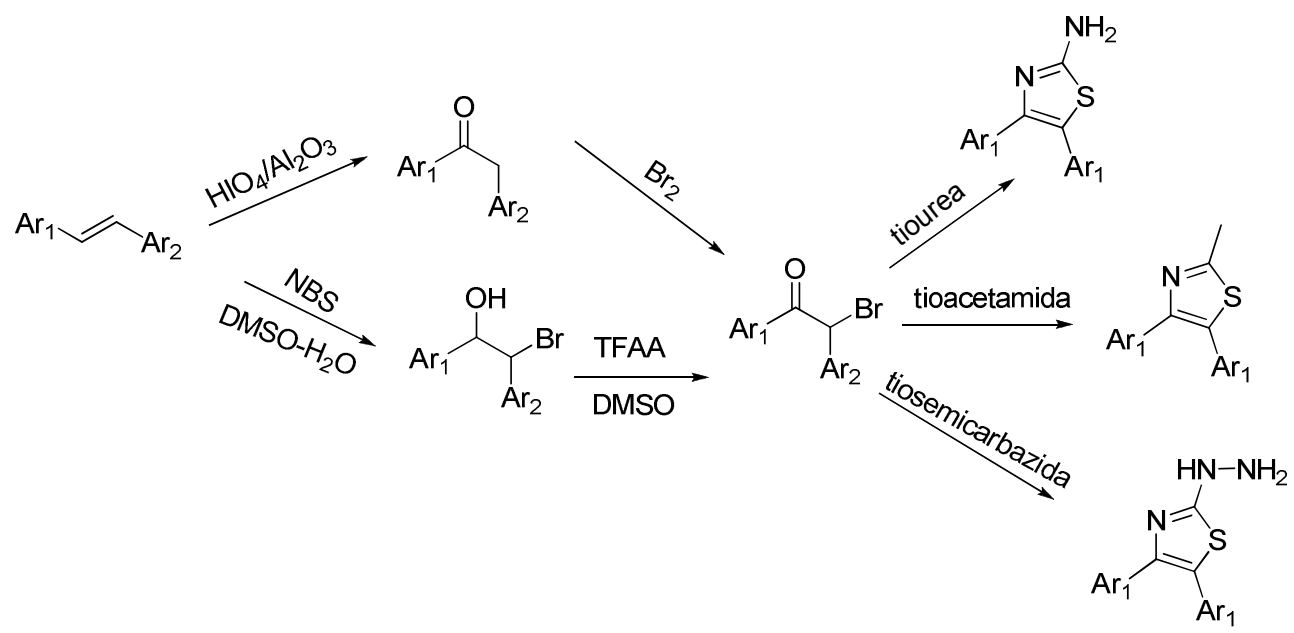

Figura 89: Síntesis de derivados tiazoles

\footnotetext{
${ }^{73}$ Aberle, N.; Catimel, J.; Nice, E. C.; Watson , K. G. Synthesis and biological evaluation of analogues of the anti-tumor alkaloid naamidine A. Bioorg. Med. Chem. Lett. 2007, $20,5879$.

${ }^{74}$ Khalilzadeh,M. A.;Hosseini, A.;Shokrollahzadeh,M.; Halvagar,M. R.; Ahmadi,D.;Mohannazadeh, F.; Tajbakhsh,M. HIO4/Al2O3 as a new system for iodination of activated aromatics and 1,3-dicarbonyl compounds. Tetrahedron. Lett. 2006, 47, 3525.

${ }^{75}$ Walter, M.; von Coburg, Y.; Isensee, K.; Sander, K..; Ligneau, X.; Camelin, J. -C.; Schwartz, J. -C.; Stark, H. Azole derivatives as histamine H3 receptor antagonists, Part I: Thiazol-2-yl ethers. Bioorg. Med. Chem. Lett. 2010, 20, 5879 .
} 


\section{$>$ Funcionalización del puente oléfinico en las combretastatinas 80 y 78 :}

Siguiendo el objetivo del trabajo y tomando como base los trabajos bibliográficos detallados anteriormente para formar heterociclos en el puente, en esta memoria se intentó la preparación de análogos pentagonales.

En primer lugar se intentó preparar el anillo de dihidro-oxazol mediante la formación de un bromo-amida en el puente y posterior ciclación y oxidación. ${ }^{76}$ Para ello se siguieron las condiciones descritas en bibliografía aplicable a doble enlaces conjugados con anillos aromáticos o aislados y que consisten en el tratamiento con $\mathrm{NBS}, \mathrm{NaHCO}_{3}, \mathrm{H}_{2} \mathrm{O}, \mathrm{CH}_{3} \mathrm{CN}$ y un ácido de Lewis $\mathrm{Zn}(\mathrm{OTf})_{2}$ o $\mathrm{Cu}(\mathrm{OTf})_{2}$. Se utiliza una pequeña cantidad de agua para evitar la posible formación de una halohidrina.

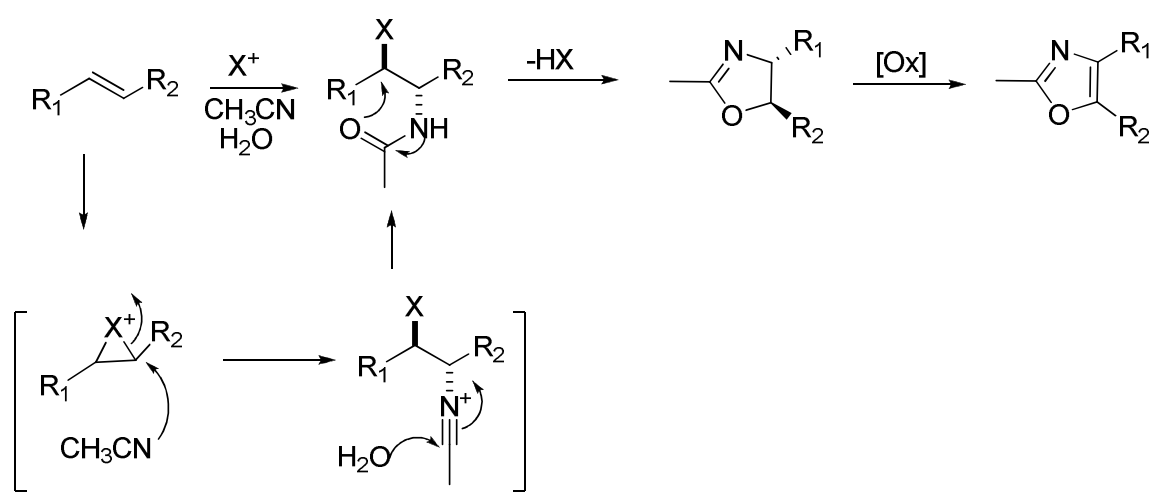

Figura 90: Mecanismo para la formación del dihidro-oxazol precursor del oxazol

Siguiendo el procedimiento detallado por Saumen et al, se utilizala mezcla de isómeros Z/E de combretastatina 80 controlando la reacción por cromatografía de capa fina durante 72 h. No se forma el compuesto esperado y en su lugar se identifica el compuesto de bromación en el anillo más activado, 110, como mezcla $Z / E$ 1:1. Se caracteriza por la aparición de una sola señal de protón del anillo A a 6,58 ppm como sínglete en $\mathrm{RMN}{ }^{1} \mathrm{H}$, y por espectrometría de masas que indica la presencia del átomo de bromo.

\footnotetext{
${ }^{76}$ Saumen, H.; Sukanta, B.; Derarshi, S.; Biswajit, M. Stereoselective One-Pot Synthesis of Oxazolines. J. Org. Chem. 2008, 73, 4320 .
} 
<smiles>COc1cccc(/C=C\c2ccc(OC)c(N(C)C)c2)c1</smiles><smiles>COc1ccc(/C=C\c2cc(N(C)C)c(OC)c(Br)c2OC)cc1</smiles>

Figura 91: formación de $\mathbf{1 1 0}$

En el caso de $\mathbf{7 8}$ cuando se trata en las mismas condiciones que 80, se observa la evolución de la reacción con el tiempo, controlándose por $\mathrm{RMN}{ }^{1} \mathrm{H}$. Después de $48 \mathrm{~h}$ de reacción se observó la formación de la halohidrina 107, y al cabo de dos días se transforma en el epóxido 108. Durante el proceso de extracción de la reacción el epóxido se transforma en la cetona 109 que se caracteriza por los datos de RMN, IR y masas.<smiles>CCOc1c(OC)cc(C(=O)Cc2ccc(OC)cc2)cc1[N+](=O)[O-]</smiles>

Figura 92: Modificación en el puente de la combretastatina $\mathbf{7 8}$

La formación de estos intermedios de reacción se identifica por el desplazamiento químico de los protones del puente. En la tabla siguiente se muestra las variaciones de los valores del desplazamiento químico de los protones observados durante la evolución de esta reacción.

\begin{tabular}{|c|c|c|c|}
\cline { 2 - 4 } \multicolumn{1}{c|}{} & \multicolumn{3}{c|}{ Desplazamiento químico en ppm } \\
\hline compuesto & Anillo A & Anillo B & Puente \\
\hline $\mathbf{1 0 7}$ & 7,08 y 7,32 & 6,83 y 7,16 & 5,02 y 5,15 \\
\hline $\mathbf{1 0 8}$ & 7,03 y 7,30 & 6,88 y 7,22 & 4,20 \\
\hline $\mathbf{1 0 9}$ & 7,72 y 7,98 & 6,86 y 7,15 & 4,18 \\
\hline
\end{tabular}

Tabla12: Desplazamiento químico de los compuestos 107, 108 y 109 
Los desplazamientos químicos de los protones del anillo aromático A son los más afectados y su desapantallamiento permite identificar la posición de la cetona en los dos carbonos del puente.

Se observa que en el caso de $\mathbf{8 0}$ el grupo dimetilamino favorece la sustitución en el anillo A, mientras en el caso de $\mathbf{7 8}$ el grupo nitro desactiva la posible reacción en el anillo A y se dirige la reacción al etileno del puente.

Utilizando también los compuestos 78 y $\mathbf{8 0}$, se intentó la preparación de oxazoles y tiazoles en el puente utilizando tiourea y urea con $\mathrm{Zn}(\mathrm{OTf})_{2}, \mathrm{NBS}, \mathrm{NaHCO}_{3}, \mathrm{H}_{2} \mathrm{O}$ en $\mathrm{CH}_{2} \mathrm{Cl}_{2}$ y en $\mathrm{CH}_{3} \mathrm{CN}$ a temperatura ambiente y a reflujo. En el caso de $\mathbf{8 0}$ se forma nuevamente el compuesto bromado 110 y en el caso de $\mathbf{7 8}$ se recupera el material de partida. En la tabla siguiente semuestra el resumen de las reacciones de tiourea y la urea realizadas.

\begin{tabular}{|c|c|c|}
\hline Compuestos & Reactivos & Resultados \\
\hline \multirow{3}{*}{80} & $\begin{array}{c}\mathrm{Zn}(\mathrm{OTf})_{2}, \mathrm{NBS}, \mathrm{p}-\mathrm{TsOH}, \\
\text { tiourea, } \mathrm{CH}_{2} \mathrm{Cl}_{2}\end{array}$ & 110 \\
\hline & $\begin{array}{c}\mathrm{Zn}(\mathrm{OTf})_{2}, \mathrm{NBS}, \mathrm{NaHCO}_{3}, \\
\mathrm{H}_{2} \mathrm{O} \text {, tiourea, } \mathrm{CH}_{2} \mathrm{Cl}_{2}\end{array}$ & 110 \\
\hline & $\begin{array}{c}\mathrm{Zn}(\mathrm{OTf})_{2}, \mathrm{I}_{2}, \mathrm{NaHCO}_{3}, \mathrm{H}_{2} \mathrm{O}, \\
\text { tiourea, } \mathrm{CH}_{2} \mathrm{Cl}_{2}\end{array}$ & 80 \\
\hline \multirow{2}{*}{78} & $\begin{array}{c}\mathrm{Zn}(\mathrm{OTf})_{2}, \mathrm{NBS}, \mathrm{NaHCO}_{3}, \\
\mathrm{H}_{2} \mathrm{O}, \text { tiourea, } \mathrm{CH}_{2} \mathrm{Cl}_{2}\end{array}$ & 78 \\
\hline & $\begin{array}{c}\mathrm{Zn}(\mathrm{OTf})_{2}, \mathrm{NBS}, \mathrm{NaHCO}_{3}, \\
\text { urea, } \mathrm{CH}_{3} \mathrm{CN}\end{array}$ & 78 \\
\hline
\end{tabular}

Tabla13: condiciones de reacción de $\mathbf{8 0}$ y $\mathbf{7 8}$

En el caso de sustituir NBS por $\mathrm{I}_{2}$, no se observa la evolución de reacción y se obtiene el material de partida $\mathbf{8 0}$ sin reaccionar.

En este trabajo no se logró formar puentes pentagonales a partir de puentes etilénicos (combretastatinas) empleando las metodologías ensayadas. La formación de este tipo de derivados pentagonales con agrupaciones 2,3-dimetoxi-4-aminofenilo como anillo A son de gran interés y serán objetivo de trabajos futuros. 


\section{SOLUBILIDAD}

La baja solubilidad acuosa es uno de los problemas que presentan los análogos de combretastatina A-4, por lo cual uno de los objetivos de este trabajo es determinar la solubilidad de los compuestos sintetizados para comprobar si las modificaciones introducidas en el esqueleto de la molécula conducen a compuestos más solubles en agua.

La determinación de la solubilidad acuosa se ha llevado a cabo en un espectrofotómetro, midiendo la absorbancia de la muestra problema a una longitud de onda y comprobando con una recta de calibrado realizada previamente.

En la determinación de la solubilidad de los compuestos se ha seguido la metodología siguiente:

- Determinación de las longitudes de onda de absorción máxima en el espectrofotómetro para cada compuesto.

- Realización de la recta de calibrado a partir de disoluciones de concentración conocida $(0,1 \mathrm{mg} / \mathrm{ml})$. Las medidas se realizan en una mezcla DMSO/tampón fosfato a pH 7 en relación $9 / 1$.

- Preparación de las muestras problema. Se pesa entre 1 y $2 \mathrm{mg}$ de compuesto y se añaden $300 \mu \mathrm{L}$ de tampón fosfato $10 \mathrm{mM}$ a pH=7, que se mantienen un mínimo de 48 horas agitando para después filtrar el contenido a través de un filtro de $22 \mu \mathrm{m}$, de manera que se retira todo el compuesto que no se haya solubilizado en el tampón. Se preparan tres cubetas con $30 \mu \mathrm{L}$ de filtrado y $270 \mu \mathrm{L}$ de DMSO y se mide la absorbancia a la longitud de onda escogida, obteniendo de esta manera tres valores de solubilidad, con los que hace la media aritmética. 
En la tabla siguiente se muestran los resultados obtenidos:

\begin{tabular}{|c|c|c|c|c|c|}
\hline $\mathbf{N}^{\circ}$ & $\begin{array}{c}\boldsymbol{\lambda} \\
\text { seleccionada } \\
(\mathbf{n m})\end{array}$ & $\begin{array}{c}\text { Solubilidad } \\
(\boldsymbol{\mu g} / \mathbf{m l})\end{array}$ & $\mathbf{N}^{\circ}$ & $\begin{array}{c}\boldsymbol{\lambda} \text { seleccionada } \\
(\mathbf{n m})\end{array}$ & $\begin{array}{c}\text { Solubilidad } \\
(\boldsymbol{\mu g} / \mathbf{m l})\end{array}$ \\
\hline $\mathbf{1 2}$ & 360 & 48 & $\mathbf{5 1}$ & 330 & 679 \\
\hline $\mathbf{1 3}$ & 360 & 30 & $\mathbf{5 2}$ & 290 & 65 \\
\hline $\mathbf{1 4}$ & 340 & 9 & $\mathbf{5 4}$ & 290 & 11 \\
\hline $\mathbf{1 5}$ & 280 & 11 & $\mathbf{5 5}$ & 275 & 21 \\
\hline $\mathbf{1 6}$ & 305 & 107 & $\mathbf{5 7}$ & 275 & 153 \\
\hline $\mathbf{1 7}$ & 280 & 123 & $\mathbf{6 1}$ & 280 & $4,4 \mathrm{mg} / \mathrm{ml}$ \\
\hline $\mathbf{1 8}$ & 300 & 84 & $\mathbf{6 2}$ & 285 & $1,0 \mathrm{mg} / \mathrm{ml}$ \\
\hline $\mathbf{2 0}$ & 285 & $\approx 2,5 \mathrm{mg} / \mathrm{ml}$ & $\mathbf{6 6}$ & 350 & $>5 \mathrm{mg} / \mathrm{ml}$ \\
\hline $\mathbf{2 1}$ & 308 & 74 & $\mathbf{7 1}$ & 290 & 110 \\
\hline $\mathbf{2 2}$ & 295 & $\approx 1,5 \mathrm{mg} / \mathrm{ml}$ & $\mathbf{7 3}$ & 275 & 102 \\
\hline $\mathbf{3 3}$ & 305 & 33,8 & $\mathbf{8 0}$ & 295 & 71 \\
\hline $\mathbf{3 4}$ & 275 & 583 & $\mathbf{8 2}$ & 330 & 6,7 \\
\hline $\mathbf{3 5}$ & 285 & 136 & $\mathbf{8 7}$ & 310 & $1,0 \mathrm{mg} / \mathrm{ml}$ \\
\hline $\mathbf{3 6}$ & 340 & 10,5 & $\mathbf{9 0}$ & 295 & 48 \\
\hline $\mathbf{3 7}$ & 290 & 13,5 & $\mathbf{9 1}$ & 290 & 44 \\
\hline $\mathbf{4 0}$ & 275 & 62 & $\mathbf{9 7}$ & 285 & 52 \\
\hline $\mathbf{5 0}$ & 320 & 44 & $\mathbf{1 0 4}$ & 280 & 6,3 \\
\hline $\mathbf{C A - 4}$ & - & 1,0 & $\mathbf{1 0 5}$ & 290 & 10 \\
\hline
\end{tabular}

Tabla 14: Valores de solubilidad de los compuestos sintetizados. Se han sombreado los valores de las sales de amonio

En la gráfica siguiente se muestra la esperada diferencia de solubilidad entre los derivados de la combretastatina sintetizados y sus sales de amonio correspondiente.

\footnotetext{
${ }^{77}$ Chen, J.; Wang, Z.; Li, C. M.; Lu, Y.; Vaddady, Pavan. K.; Meibohm, B.; Dalton, J. T.; Miller, D. D.; Li, W. Discovery of Novel 2-Aryl-4-benzoyl-imidazoles Targeting the Colchicines Binding Site in Tubulin As Potential Anticancer Agents. J. Med. Chem. 2010, 53, 7414.
} 


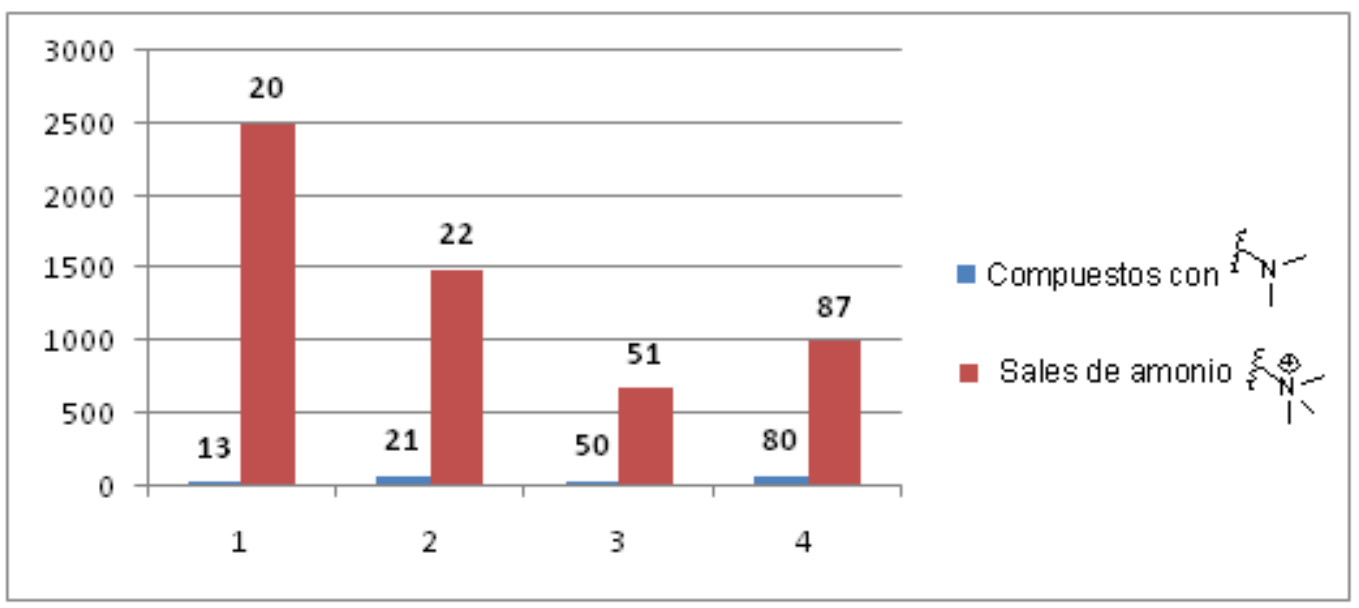

Figura 93: La diferencia de solubilidad en $(\mu \mathrm{g} / \mathrm{ml})$ de los derivados nitrogenados y sus sales de amonio

De la tabla anterior se observa que la mayoría de los compuestos no cargados ensayados presentan un valor muy superior a la de la combretastatina A-4, y en muchos casos $(\mathbf{1 6}, \mathbf{1 7}$, $35,57,71,73$ ) más de cien veces mayor o incluso quinientas veces más mayor como en el caso del compuesto 34. Aparte de las sales de amonio, los compuestos con oximas en el puente y que en el anillo B tienen un grupo nitrogenado presentan las solubilidades más elevadas, además la sustitución del grupo metoxilo por grupo amino aumenta notablemente la solubilidad del compuesto.

Como cabía esperar y se observa en el histograma las sales de amonio aumentan considerablemente la solubilidad acuosa de sus homólogos neutros. En comparación con la combretastatina A-4 los compuestos sustituidos con grupos nitrogenados mejoran apreciablemente la solubilidad acuosa del compuesto, cumpliéndose uno de los objetivos de este trabajo.

En el siguiente apartado se muestran los resultados de actividad biológica de estos compuestos, de manera que será posible determinar si los compuestos propuestos y sintetizados cumplen con los dos objetivos planteados: aumentar la solubilidad acuosa y la potencia antimitótica. 


\section{ACTIVIDAD BIOLÓGICA}

Otro de los objetivos de este trabajo es la realización de los ensayos in vitro de inhibición de la polimerización de tubulina para evaluar si los compuestos sintetizados poseen la actividad biológica que se pretende. Para ello, se utiliza proteína microtubular aislada y purificada a partir de cerebros de ternero.

\section{Aislamiento de la proteína}

El método seguido en nuestro laboratorio para el aislamiento y la purificación de la proteína microtubular es el método de Shelanski ${ }^{78}$, con algunas modificaciones.

La proteína se aísla de cerebro de ternero recién sacrificado mediante dos ciclos de polimerización/despolimerización, dependiente de la temperatura. A $37{ }^{\circ} \mathrm{C}$ se forman los microtúbulos (polimerización) y por el contrario se despolimeriza a $4{ }^{\circ} \mathrm{C}$. Mediante centrifugaciones después de cada polimerización/despolimerización y seleccionando precipitado (a $37^{\circ} \mathrm{C}$ ) o sobrenadante $\left(\mathrm{a} 4{ }^{\circ} \mathrm{C}\right)$ se va purificando la proteína.

El esquema siguiente representa el proceso del aislamiento desde los cerebros hasta la separación de la proteína que se utiliza en los ensayos de inhibición de polimerización de tubulina (IPT).

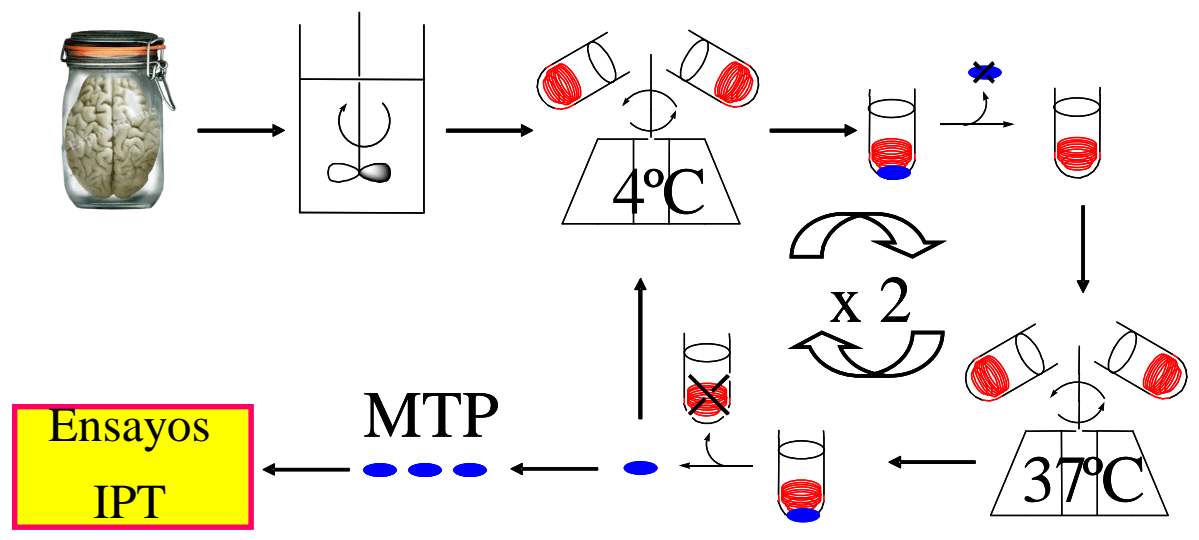

Figura 94. Proceso de aislamiento de tubulina

\footnotetext{
${ }^{78}$ Shelanski, M. L.; Gaskin, F.; Cantor, C. R. Microtubule assembly in the absence of added nucleotides. Proc. Nat. Acad. Sci. 1973, 70, 765.
} 
La proteína microtubular (MTP) aislada mediante este proceso está formada por subunidades $\alpha$ y $\beta$ tubulina en un $70 \%$ y por proteínas asociadas a los microtúbulos (MAPs) en un $30 \%$.

\section{Ensayos de inhibición de polimerización de tubulina}

Los ensayos se realizan en cubetas de cuarzo que contienen $1,0 \mathrm{mg} / \mathrm{mL}$ de proteína microtubular (MTP) en un tampón a pH 6,7 que contiene el GTP y $\mathrm{Mg}^{2+}$ necesario para la polimerización de la tubulina, y los ligandos a una concentración de 5, 10 ó $20 \mu \mathrm{M}$. Los ensayos se realizan en un espectrofotómetro y se mide la turbidez generada por la formación de microtúbulos a $450 \mathrm{~nm}$, longitud de onda a la que los ligandos sintetizados no absorben. En cada ensayo se utiliza como referencia una cubeta control sin ligando.

Para evitar problemas de solubilidad, todos los compuestos utilizados se disuelven en DMSO, siendo la concentración máxima de DMSO en la cubeta de un $4 \%$, concentración que no afecta a los ensayos de polimerización de la tubulina ${ }^{79}$.

El ensayo se inicia a $4{ }^{\circ} \mathrm{C}$. A esta temperatura la proteína se encuentra despolimerizada por lo que se registra una absorbancia mínima. Posteriormente se aumenta la temperatura a $37{ }^{\circ} \mathrm{C}$, la proteína polimeriza y se observa un incremento en la absorbancia debido a la turbidez que generan los microtúbulos. El incremento de absorbancia registrado para la cubeta control, sin ligando, se considera el $100 \%$ de polimerización y se calcula el porcentaje de inhibición de los ligandos ensayados comparando su incremento en la absorbancia con el de la cubeta control.

Los ensayos se realizan inicialmente a una concentración de 5, 10 ó $20 \mu \mathrm{M}$. Los compuestos que a estas concentraciones presentan un elevado porcentaje de inhibición se seleccionan para calcular su $\mathrm{IC}_{50}$ (concentración a la que el ligando inhibe la polimerización en un 50 \%).

La elección de estas concentraciones viene determinada por la $\mathrm{IC}_{50}$ de la CA-4, compuesto de referencia de este trabajo. Para que los compuestos sintetizados presenten una potencia similar o mejor que la CA-4 ${ }^{20,80}$ deben inhibir la polimerización de la tubulina en más de $50 \%$ a una concentración de $5 \mu \mathrm{M}$.

\footnotetext{
${ }^{79}$ Durmotier, C.; Gorbunoff, M.; Andreu, J. M.; Engelborghs, Y. Different kinetic pathway of the binding of two biphenyl analogues colchicines to tubulin. Biochemistry. 1996, 35, 4387.

${ }^{80}$ Tron, G. C.; Pirali, T.; Sorba, G.; Pagliai, F.; Busacca, S.; Genazzani, A. A.; Medicinal chemistry of combretastatin A4: present and future directions. J. Med. Chem. 2006, 49, 3033.
} 


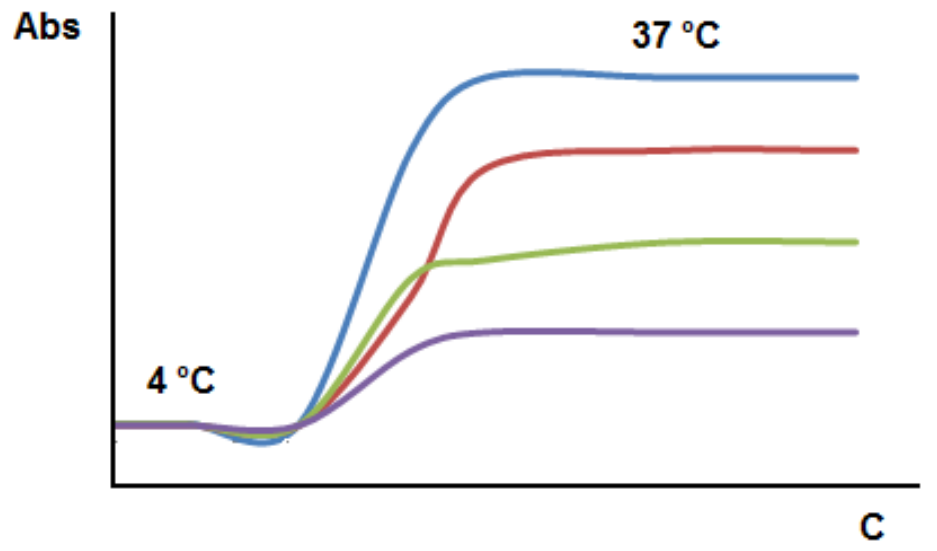

Figura 95. Ejemplo de grafica de un ensayo de inhibición de polimerización de tubulina. La diferencia entre la línea roja que representa el $100 \%$ de polimerización y cada una de las muestras (resto de líneas de colores) se corresponde con la inhibición que ejerce ese compuesto (\%) a la concentración ensayada.

En la tabla siguiente se muestran los resultados de los compuestos ensayados en las concentraciones de 5, 10 y/o $20 \mu \mathrm{M}$.

\begin{tabular}{|c|c|c|c|c|c|c|c|c|c|c|c|}
\hline COMP & $\begin{array}{l}\text { CONC } \\
(\mu \mathrm{M})\end{array}$ & $\begin{array}{c}\text { INHIB } \\
\%\end{array}$ & COMP & $\begin{array}{l}\text { CONC } \\
(\mu \mathrm{M})\end{array}$ & $\begin{array}{c}\text { INHIB } \\
\%\end{array}$ & COMP & $\begin{array}{l}\text { CONC } \\
(\mu \mathrm{M})\end{array}$ & $\begin{array}{c}\% \\
\text { INHIB }\end{array}$ & COMP & $\begin{array}{l}\text { CONC } \\
(\mu \mathrm{M})\end{array}$ & $\begin{array}{c}\text { INHIB } \\
\%\end{array}$ \\
\hline 12 & 5 & 25 & 33 & 5 & 0 & 54 & 10 & 16 & 79 & 5 & 74 \\
\hline 13 & $\begin{array}{c}5 \\
20\end{array}$ & $\begin{array}{c}90 \\
100\end{array}$ & 34 & 5 & 26 & 55 & 5 & 5 & 80 & 5 & 92 \\
\hline 14 & $\begin{array}{c}5 \\
20\end{array}$ & $\begin{array}{c}4 \\
20\end{array}$ & 35 & 5 & 0 & 56 & 5 & 12 & 82 & 5 & 25 \\
\hline 15 & 5 & 43 & 36 & 10 & 0 & 57 & 5 & 0 & 87 & $\begin{array}{c}5 \\
20\end{array}$ & $\begin{array}{l}16 \\
32\end{array}$ \\
\hline 16 & $\begin{array}{c}5 \\
10\end{array}$ & $\begin{array}{l}14 \\
19\end{array}$ & 37 & 10 & 11 & 59 & $\begin{array}{c}5 \\
20\end{array}$ & $\begin{array}{c}0 \\
30\end{array}$ & 90 & 5 & 3 \\
\hline 17 & 5 & 15 & 39 & $\begin{array}{c}5 \\
20\end{array}$ & $\begin{array}{l}35 \\
57\end{array}$ & 60 & 5 & 0 & 91 & 5 & 23 \\
\hline 18 & 5 & 35 & 40 & 5 & 16 & 61 & 5 & 12 & 96 & $\begin{array}{c}5 \\
10\end{array}$ & $\begin{array}{l}14 \\
43\end{array}$ \\
\hline 19 & 5 & 2 & 43 & 5 & 23 & 62 & 5 & 11 & $97 Z$ & 5 & 85 \\
\hline
\end{tabular}




\begin{tabular}{|c|c|c|c|c|c|c|c|c|c|c|c|}
\hline 20 & 5 & 22 & 44 & $\begin{array}{c}5 \\
10\end{array}$ & $\begin{array}{l}25 \\
32\end{array}$ & 64 & $\begin{array}{c}5 \\
20\end{array}$ & $\begin{array}{l}0 \\
5\end{array}$ & 104 & 5 & 3 \\
\hline 21 & $\begin{array}{c}5 \\
10\end{array}$ & $\begin{array}{c}7 \\
23\end{array}$ & 45 & 5 & 12 & 65 & $\begin{array}{c}5 \\
20\end{array}$ & $\begin{array}{c}0 \\
50\end{array}$ & 105 & 5 & 97 \\
\hline 22 & 5 & 22 & 50 & $\begin{array}{c}5 \\
10\end{array}$ & $\begin{array}{l}55 \\
65\end{array}$ & 66 & 5 & 12 & 111 & 5 & 0 \\
\hline 25 & 5 & 31 & 51 & 5 & 0 & 71 & 5 & 28 & $112 a$ & 5 & 25 \\
\hline 26 & 5 & 35 & 52 & 5 & 7 & 73 & 5 & 63 & $112 b$ & 5 & 0 \\
\hline 28 & 5 & 73 & 53 & 5 & 23 & 74 & $\begin{array}{c}5 \\
10\end{array}$ & $\begin{array}{l}47 \\
64\end{array}$ & 113 & 5 & 0 \\
\hline
\end{tabular}

Tabla 15: Resultados de los ensayos de inhibición de la polimerización de tubulina. Se han sombreado los compuestos seleccionados para calcular su $\mathrm{IC}_{50}$.

\section{Determinación de la $\mathrm{IC}_{50}$ de inhibición de la polimerización de la tubulina:}

En este trabajo se ha realizado los ensayos de inhibición de polimerización de tubulina de 56 compuestos, a una concentración de 5, 10 ó $20 \mu \mathrm{M}$. Los resultados que se muestran en la tabla 15 constituyen una media de los valores obtenidos en los ensayos, los cuales se han hecho por duplicado o triplicado. Teniendo en cuenta estos resultados iníciales, los compuestos 13, 73, 74, 79, 80, 97Z y 105 se seleccionan para calcular su $\mathrm{IC}_{50}$ ya que presentan una inhibición de la polimerización de la tubulina superior al $50 \%$ cuando se emplean a una concentración de 5 $\mu \mathrm{M}$.

Para calcular la $\mathrm{IC}_{50}$ de los diferentes ligandos inhibidores de polimerización de tubulina se ensaya cada compuesto a diferentes concentraciones (generalmente 0,5, 1, 2, 4, 5, 10 y 20 $\mu \mathrm{M})$ y se representa el porcentaje de polimerización frente a cada concentración ensayada. Los datos así representados se ajustan a una ecuación monoexponencial decreciente, de manera que es posible calcular la concentración a la que el compuesto inhibe la 
polimerización de la proteína en un $50 \%$. El ajuste de los datos y el cálculo de la $\mathrm{IC}_{50}$ se ha llevado a cabo con el programa OriginPro $8^{81}$.

En la tabla siguiente se muestran los resultados de los compuestos que han sido seleccionados para calcular la $\mathrm{IC}_{50}$.

\begin{tabular}{|c|c|c|c|c|c|}
\hline COMP & Estructura & $\begin{array}{l}\mathrm{IC}_{50} \\
(\boldsymbol{\mu M})\end{array}$ & COMP & Estructura & $\begin{array}{l}\mathrm{IC}_{50} \\
(\boldsymbol{\mu M})\end{array}$ \\
\hline 13 & & 1,9 & 80 & & 1,1 \\
\hline 73 & & 2,5 & $97(Z)$ & & 0,8 \\
\hline 74 & & 6,0 & 105 & & 1,2 \\
\hline 79 & & 6,2 & CA-4 & & 2,0 \\
\hline
\end{tabular}

Tabla 16: Valores de $\mathrm{IC}_{50}$ calculados.

\footnotetext{
${ }^{81}$ Origin ${ }^{\circledR}$ Pro 8.0:http://originlab.com/
} 


\section{Discusión de resultados:}

A continuación se van a analizar los resultados en función de las modificaciones en el anillo

B. En la tabla siguiente se presentan los valores de IPT de los compuestos modificados en el anillo B.

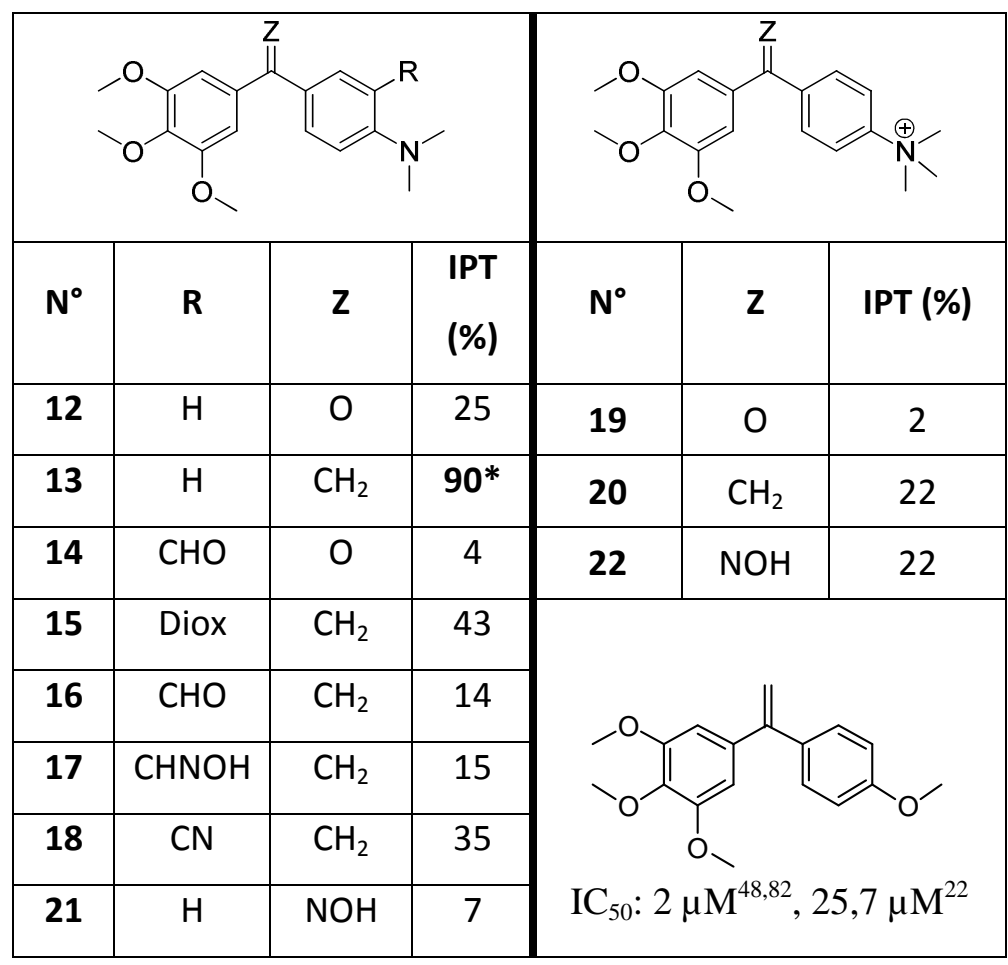

(*): $\mathrm{IC}_{50}$ de $\mathbf{1 3}=1,9 \mu \mathrm{M}$

Tabla 17: valores de IPT (\%) de los derivados de fenstatina a $5 \mu \mathrm{M}$

Cuando se sustituye el anillo 3-hidroxi-4-metoxifenilo de la CA-4 por un anillo pdimetilaminofenilo, solamente se mantiene la potencia inhibidora de la polimerización de tubulina cuando el puente es 1,1-diarileteno (la isocombretastatina 13). Sin embargo, cuando el puente está formado por un grupo carbonilo o por una oxima la inhibición disminuye considerablemente. A pesar de que el puente de fenstatinas y oximas, de acuerdo con el farmacóforo propuesto por Nguyen e $\mathrm{al}^{83}$, deberían conferir mayor potencia ya que pueden formar enlaces de $\mathrm{H}$ con la proteína, el hecho de que sean menor potentes que la isocombretastatina, conduce a pensar que tiene mayor importancia en la unión ligando-

\footnotetext{
${ }^{82}$ Hamze, A.; Brion, J. D.; Alami, M. Synthesis of 1,1-Diarylethylenes via Efficient Iron/Copper Co Catalyzed Coupling of 1-Arylvinyl Halides with Grignard Reagents. Org. Lett. 2012, 14, 2782.

${ }^{83}$ Nguyen, T. L.; McGrath, C.; Hermone, A. R.; Burnett, J. C.; Zaharevitz, D. W.; Day, B. W.; Wip, Peter.; Hamel, E.; Gussio, R. A Common Pharmacophore for a Diverse Set of Colchicine Site Inhibitors Using a Structure-Based Approach. J. Med. Chem. 2005, 48, 6107.
} 
proteina, la disposición de los anillos en un ángulo aproximado de $45^{\circ}$, posible en el compuesto 13 ya que la conjugación de los anillos aromáticos con el puente es menor que en los compuestos $\mathbf{1 2}$ y $\mathbf{2 1}$.

Del mismo modo cuando se introduce un sustituyente en posición orto del DMA se produce una pérdida de la capacidad inhibidora, no presentando ninguno de estos compuestos una $\mathrm{IC}_{50}$ inferior a $5 \mu \mathrm{M}$. Esta pérdida de actividad es independiente de que los sustituyentes aporten dadores o aceptores de enlaces de $\mathrm{H}$ y puede deberse a que la presencia de los sustituyentes obliga al grupo dimetilamino a colocarse fuera del plano del anillo aromático modificando la interacción con el sitio de unión en la proteína.

La formación de la sal de amonio de estos derivados, aunque como hemos visto en el anterior apartado presenten la ventaja del elevado incremento en la solubilidad acuosa, conduce a inhibidores poco potentes.

A pesar de que los valores de inhibición de polimerización son muy modestos, el mero hecho de que inhiban resulta interesante, pues estos compuestos deben presentar una solubilidad acuosa mejorada y es posible que combinadas con otras modificaciones conduzcan a compuestos potentes y solubles en agua.

En la siguiente tabla se muestran los compuestos con anillo A modificado que presentan mejor perfil como inhibidores de la polimerización de tubulina. 


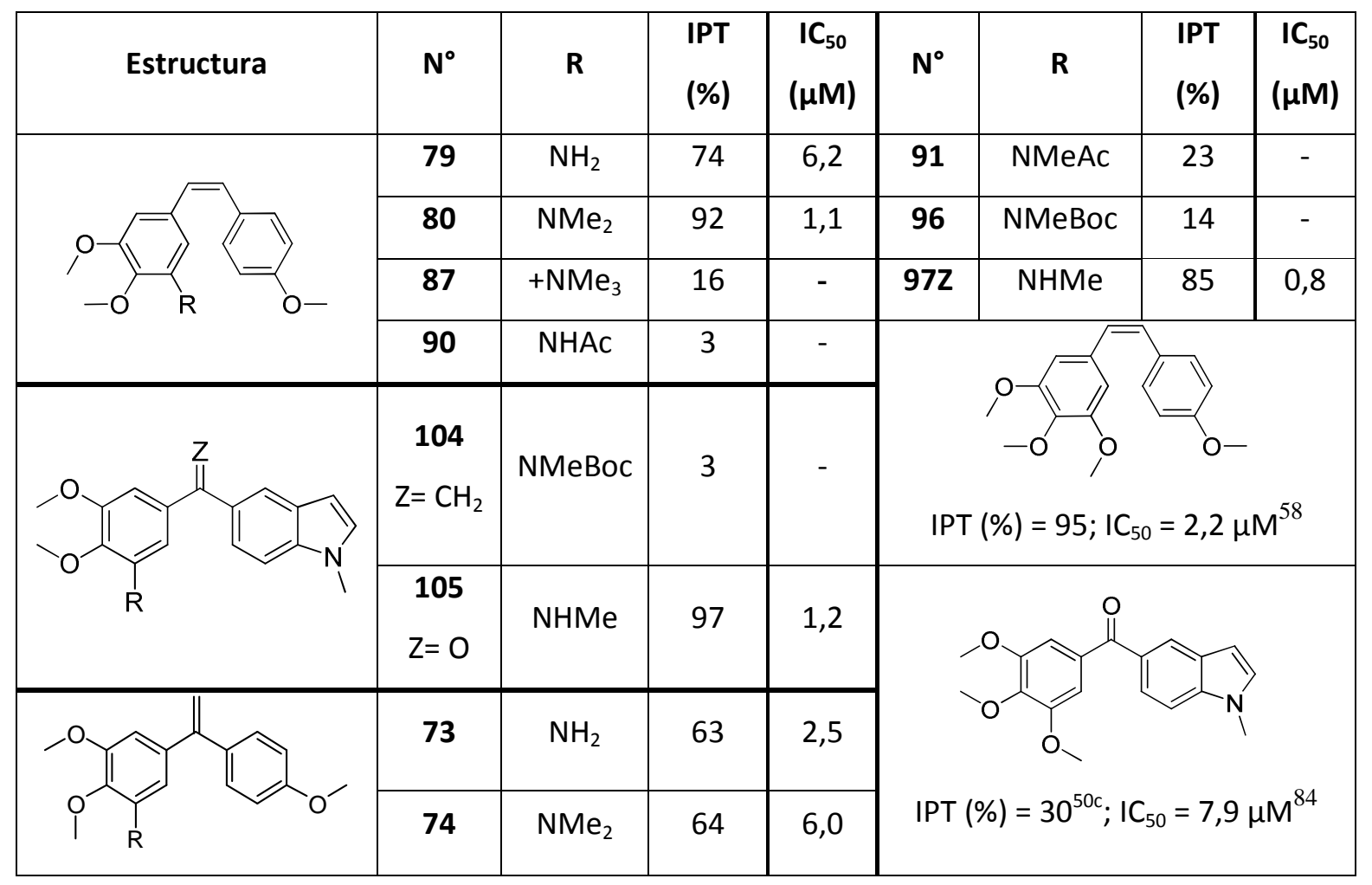

Tabla 18: valores de IPT (\%) de los derivados de combretastatina y fenstatina de metilindol a $5 \mu \mathrm{M}$ e $\mathrm{IC}_{50}$

Si observamos los resultados obtenidos para las combretastatinas en las que se ha sustituido un grupo metoxilo del anillo de TM por un grupo amino libre o metilado, vemos como se mantiene e incluso se mejora la capacidad de inhibir la formación de microtúbulos en comparación con la CA-4 y desoxicombretastatina, siendo el grupo metilamino (97Z) el mejor remplazo seguido del grupo dimetilamino (80) y por último el amino libre (79).

Del mismo modo en la familia de isocombretastatinas con anillo $\mathrm{B}$ de p-metoxifenilo y fenstatinas con anillo B indólico, también se ha podido obtener compuestos que mantienen o mejoran la actividad antimitótica.

A diferencia de las combretastatinas, en las isocombretastatinas ha resultado ser más potente el compuesto con el grupo amino libre que con el dimetilamino, lo cual puede implicar que debido a la diferencia en la longitud del puente los anillos A se disponen ligeramente diferentes en el sitio de unión.

\footnotetext{
${ }^{84}$ Álvarez, R.; Puebla, P.; Díaz, J. F.; Bento, A. C.; García-Navas, R.; de la Iglesia-Vicente, J.; Mollinedo, F.; Andreu, J. M.; Medarde, M.; Peláez, R. Endowing Indole-Based Tubulin Inhibitors with an Anchor for Derivatization: Highly Potent 3-Substituted Indolephenstatins and Indoleisocombretastatins. J. Med. Chem. 2013, 56, 2813.
} 
En el caso del derivado indolico, solo se ha podido obtener el analogo de fenstatina y cabe destacar que presente una $\mathrm{IC}_{50}$ de 1,2 $\mu \mathrm{M}$, similar a las de isocombretastatinas mas potentes, lo cual hace pensar que a pesar de las dificultades sinteticas se debe intentar conseguir suficiente cantidad de las correspondientes isocombretastatinas ya que si sigue el mismo patrón observado en las otras familias deberían tener una actividad antimitótica submicromolar.

En la tabla siguiente se muestra los valores de $\mathrm{IC}_{50} \mathrm{y}$ de solubilidad acuosa de los compuestos los más potentes.

\begin{tabular}{|c|c|c|c|c|c|}
\hline Comp & $\begin{array}{c}I_{50} \\
(\mu \mathrm{M})\end{array}$ & $\begin{array}{c}\text { Solub } \\
(\mu \mathrm{g} / \mathrm{mL})\end{array}$ & Comp & $\begin{array}{c}\mathrm{IC}_{\mathbf{5 0}} \\
(\mu \mathrm{M})\end{array}$ & $\begin{array}{c}\text { Solub } \\
(\mu \mathrm{g} / \mathrm{mL})\end{array}$ \\
\hline $\mathbf{1 3}$ & 1,9 & 30 & $\mathbf{5 0}$ & 5,1 & 48 \\
\hline $\mathbf{7 3}$ & 2,5 & 102 & $\mathbf{7 4}$ & 6,0 & - \\
\hline $\mathbf{7 9}$ & 6,2 & - & $\mathbf{8 0}$ & 1,1 & 71 \\
\hline $\mathbf{9 7 Z}$ & 0,8 & 52 & $\mathbf{1 0 5}$ & 1,2 & 10 \\
\hline CA-4 & 2,0 & 1,0 & \multicolumn{3}{|l}{} \\
\hline
\end{tabular}

Tabla 19: valores de $\mathrm{IC}_{50}$ solubilidad acuosa de los compuestos seleccionados.

De la tabla anterior se observa que los compuestos que tienen una potencia antimitótica elevada también presentan un valor de solubilidad acuosa muy importante. En comparación con la molécula base (CA-4), se observa que los compuestos 73, 80 y $97 \mathbf{Z}$ presentan un valor de $\mathrm{IC}_{50}$ mejor o similar que CA-4 y una solubilidad hasta cien veces mayor como en el caso del compuesto 73, resultando los más prometedores para investigaciones posteriores. Estos tres compuestos tienen en común la sustitución del grupo 3-metoxi del anillo A por grupo nitrogenado que varía de amino en $\mathbf{7 3}$, metilamnio en $\mathbf{9 7 Z}$ a dimetilamino en $\mathbf{8 0 .}$ 


\section{Ensayos de citotoxicidad:}

Los ensayos de citotoxicidad frente las líneas de células cancerígenas representativa de los compuestos sintetizados en este trabajo han sido realizados en el Departamento de Química Farmacéutica por la Dra. Raquel Álvarez y Dra. Laura Aramburu. Los ensayos han sido frente distintas líneas celulares para determinar la citotoxicidad ${ }^{85}$. Con este fin se han utilizado los siguientes tipos de células:

- HL-60: Leucemia mieloide humana.

- HeLa: Carcinoma cervical humano.

- HT-29: Carcinoma de colon humano.

Los resultados obtenidos se recogen en la tabla siguiente y expresan la concentración que produce un $50 \%$ de inhibición de proliferación celular $\left(\mathrm{IC}_{50}\right)$.<smiles></smiles>

\begin{tabular}{|c|c|c|c|c|c|c|}
\hline $\mathbf{X}$ & $\mathbf{R}$ & Compuesto & $\begin{array}{c}\text { IPT IC } \\
(\boldsymbol{\mu M})\end{array}$ & $\begin{array}{c}\text { HeLa } \\
(\boldsymbol{\mu M})\end{array}$ & $\begin{array}{c}\text { HT-29 } \\
(\boldsymbol{\mu M})\end{array}$ & $\begin{array}{c}\text { HL-60 } \\
(\boldsymbol{\mu M})\end{array}$ \\
\hline $\mathrm{O}$ & $\mathrm{H}$ & $\mathbf{1 2}$ & $>20$ & 0,09 & 0,4 & 0,2 \\
\hline $\mathrm{CH}_{2}$ & $\mathrm{H}$ & $\mathbf{1 3}$ & 1,9 & 0,04 & 0,07 & 0,01 \\
\hline $\mathrm{NOH}$ & $\mathrm{H}$ & $\mathbf{2 1}$ & $>10$ & 0,8 & 10 & 0,6 \\
\hline $\mathrm{O}$ & $\mathrm{CHO}$ & $\mathbf{1 4}$ & $>20$ & $>1$ & $>1$ & $>1$ \\
\hline $\mathrm{CH}_{2}$ & $\begin{array}{c}\text { 5 } \\
\mathrm{O}\end{array}$ & $\mathbf{1 5}$ & $>5$ & 0,6 & $>1$ & 0,8 \\
\hline
\end{tabular}

\footnotetext{
${ }^{85}$ Skehan, P.; Storeng, R.; Scudiero, D.; Monks, A.; McMahon, J.; Vistica, D.; Warren, J. T.; Bokesh, H.; Kenney, S.; Boyd, M. R. New colorimetric cytotoxicity assay for anticancer-drug screening. J. Natl. Cancer Inst. 1990, 82, 1107.
} 


\begin{tabular}{|c|c|c|c|c|c|c|}
\hline $\mathrm{CH}_{2}$ & $\mathrm{CHO}$ & $\mathbf{1 6}$ & $>10$ & 0,8 & $>1$ & 0,9 \\
\hline $\mathrm{CH}_{2}$ & $\mathrm{NOH}$ & $\mathbf{1 7}$ & $>5$ & 0,9 & $>1$ & 1 \\
\hline $\mathrm{CH}_{2}$ & $\mathrm{CN}$ & $\mathbf{1 8}$ & $>5$ & 0,4 & 0,96 & 0,8 \\
\hline
\end{tabular}

Tabla 20: Resultados de actividad en citotoxicidad y en IPT de los compuestos ensayados.

De los resultados obtenidos en la tabla arriba se observa que la potencia citotóxica frente a las diferentes líneas celulares es variable, HeLa y HL-60 son más sensible que HT-29 que se muestra una resistencia. El compuesto $\mathbf{1 3}$ presenta tanto la potencia inhibitoria de la polimerización de la tubulina como una actividad citotóxica elevada frente las 3 líneas celulares ensayadas, mientras los otros compuestos probados no son activos frente esta línea celular. 

PARTE EXPERIMENTAL 



\section{TÉCNICAS GENERALES:}

\section{INSTRUMENTACIÓN}

La instrumentación utilizada en este trabajo se indica a continuación:

- Puntos de fusión: Se determinaron de forma automática en los aparatos MPMHV2 y GALLENCAMP, no fueron corregidos.

- Espectros IR: Espectrofotómetro FT-IR, en pastillas de $\mathrm{KBr}$ al $1 \%$ ó en película. Los valores de la frecuencia de absorción se expresan en $\mathrm{cm}^{-1}$.

- Lampara UV: Se determina la evolución de las reacciones en cromatografía en capa fina en una longitud de onda 254-366 nm.

- Espectros de $\mathbf{R M N}{ }^{\mathbf{1}} \mathbf{H}$ y de $\mathbf{R M N}{ }^{\mathbf{1 3}} \mathbf{C}$ : Espectrómetros BRUKER AC 200 (200 MHz), Varian Mercury (200 MHz), Varian Mercury (400 MHz) y BRUKER DRX 400 (400 MHz), utilizando $\mathrm{CDCl}_{3}$ como disolvente, salvo indicación contraria y TMS como referencia interna. Los valores de desplazamiento químico $(\delta)$ se expresan en ppm y los de las constantes de acoplamiento $(J)$ en $\mathrm{Hz}$.

- Espectros masas (IE): Se determinaron en un Espectrómetro QSTAR XL, acoplada a un HPLC, determinándose la masa exacta.

\section{TÉCNICAS CROMATOGRÁFICAS}

- Cromatografía flash. Se utilizó gel de sílice MERCK 60 (0,040-0,063 mm) en proporción 30-40 g de sílice por gramo de sustancia.

- Cromatografía de capa fina (CCF). Se utilizaron láminas de poliéster prefabricadas POLYCHROM de 0,25 mm de espesor, con recubrimiento de gel de sílice con indicador fluorescente UV-254. Para el revelado se pulveriza con una disolución de ácido sulfúrico al 10\% en etanol, o ácido fosfomolíbdico al 10\% en etanol, calentando a continuación a $110^{\circ} \mathrm{C}$ durante unos minutos. 
- Cromatografía de capa fina preparativa (CCP). Se utilizaron placas PLC Silica gel $60 \mathrm{~F}_{254} \mathrm{MERCK}{ }^{\circledR}$ con $1 \mathrm{~mm}$ de espesor.

- HPLC. Se utilizó equipo de Agilent HP Series 1100, equipado con columnas Waters X-Terra ${ }^{\circledR} M S C_{8}(5 \mu \mathrm{M}, 4,6 \times 150 \mathrm{~mm})$, Waters Waters X-Terra ${ }^{\circ} \mathrm{MS} \mathrm{C}_{18}(5$ $\mu \mathrm{M}, 4,6 \times 150 \mathrm{~mm})$

\section{TRATAMIENTO DE DISOLVENTES Y REACTIVOS}

- Tolueno. El tolueno comercial se seca sobre láminas de Na.

- Cloruro de metileno. $\mathrm{El} \mathrm{CH}_{2} \mathrm{Cl}_{2}$ comercial se seca sobre tamiz molecular.

- Hexano. El hexano comercial se destila en columna de rectificación y se recoge sobre $\mathrm{CaCl}_{2}$.

- DMF seca. La DMF comercial se seca sobre Tamiz molecular.

- Tetrahidrofurano. El THF comercial se destila, inmediatamente antes de su uso, sobre láminas de sodio, bajo atmósfera de argón, usando benzofenona como indicador. 


\section{Preparación de sales de fosfonio}

\section{Preparación de la sal de fosfonio 1}

$$
\mathrm{CH}_{3} \mathrm{I} \quad \stackrel{\mathrm{PPh}_{3}}{\text { tolueno }} \underset{\mathbf{1}}{\stackrel{\oplus}{\mathrm{P} h_{3} \mathrm{CH}_{3} \mathrm{I}^{-}}} \underset{\mathbf{1}}{\ominus}
$$

Sobre una disolución de 37,00 g (141,07 mmol) de trifenilfosfina en $250 \mathrm{ml}$ de tolueno seco se añade $8,8 \mathrm{ml}(141,25 \mathrm{mmol})$ de yodometano, la mezcla se agita $24 \mathrm{~h}$ a temperatura ambiente en atmósfera de nitrógeno, se forma un precipitado blanco que se filtra, obteniéndose 52,20 g (129,14 mmol, $91 \%)$ de la sal de fosfonio $\mathbf{1}$.

\section{Preparación de la sal de fosfonio 3}<smiles>COc1cc(CO)cc(OC)c1OC</smiles><smiles>CCOCCOCC</smiles><smiles>COc1cc(CBr)cc(OC)c1OC</smiles>

2

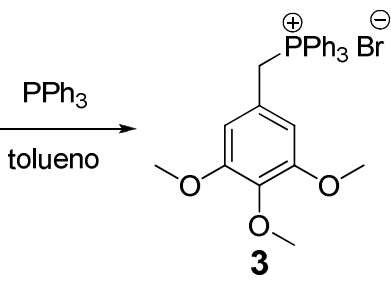

3

\section{a) Bromuro de bencilo 2}

Se disuelven 8,20 g (41,4 mmol) de alcohol 3,4,5-trimetoxibencílico en $60 \mathrm{ml} \mathrm{de} \mathrm{Et}_{2} \mathrm{O}$ seco a $-40^{\circ} \mathrm{C}$ y se le añaden $2,0 \mathrm{ml}(21,3 \mathrm{mmol})$ de $\mathrm{PBr}_{3}$, la reacción se agita durante $2 \mathrm{~h}$ en atmósfera de nitrógeno. Posteriormente se neutraliza el exceso de ácido con $\mathrm{NaHCO}_{3}$ y se extrae con $\mathrm{Et}_{2} \mathrm{O}$, luego se lava con una disolución saturada de $\mathrm{NaCl}$ hasta $\mathrm{pH}$ neutro, se seca con $\mathrm{Na}_{2} \mathrm{SO}_{4}$ anhidro y se evapora el disolvente. El sólido obtenido se purifica por cristalización en hexano caliente obteniéndose 10,2 g (39,2 mmol, $95 \%)$ de cristales blancos del compuesto 2 .

\section{5-bromometil-1,2,3-trimetoxibenceno (2):}


$\mathbf{R M N}^{1} \mathbf{H}: 3,86(3 \mathrm{H}, \mathrm{s}) ; 3,89(6 \mathrm{H}, \mathrm{s}) ; 4,48(2 \mathrm{H}, \mathrm{s}) ; 6,64(2 \mathrm{H}, \mathrm{s})$.

RMN ${ }^{13} \mathrm{C}: 33,9\left(\mathrm{CH}_{2}\right) ; 55,7$ (2) $\left(\mathrm{CH}_{3}\right) ; 60,4\left(\mathrm{CH}_{3}\right) ; 105,8$ (2) (CH); 132,9 (C); 137,8 (C); $152,9(2)(\mathrm{C})$.

Pf (Hex): $68^{\circ} \mathrm{C}$

\section{b) Sal de fosfonio 3}

Sobre una disolución de 4,72 g (18,1 mmol) del compuesto 2 en $12 \mathrm{ml}$ de tolueno seco y en agitación se le añaden 7,11 g $(27,1 \mathrm{mmol})$ de trifenilfosfina disueltos en $20 \mathrm{ml}$ de tolueno seco, se continúa la agitación durante $24 \mathrm{~h}$ a temperatura ambiente, observándose la formación de un sólido blanco, se filtra y se obtienen 8,86 g (16,9 mmol, $94 \%)$ de la sal 3.

\section{Bromuro de 3,4,5-trimetoxibenciltrifenilfosfonio (3):}

$\mathbf{R M N}^{1} \mathbf{H}: 3,50(6 \mathrm{H}, \mathrm{s}) ; 3,76(3 \mathrm{H}, \mathrm{s}) ; 5,39(2 \mathrm{H}, \mathrm{d}, 14,2) ; 6,50(2 \mathrm{H}, \mathrm{s}) ; 7,10-7,90$ (15H, m).

RMN ${ }^{13} \mathbf{C}: 30,5\left(\mathrm{CH}_{2}, \mathrm{~d}, 45\right) ; 55,9(2)\left(\mathrm{CH}_{3}\right) ; 60,5\left(\mathrm{CH}_{3}\right) ; 108,5$ (2) (CH); 117,4 (3) (C, d, 85); 122,1 (C, d, 9); 129,6 (6) (CH, d, 11); 134,4 (6) (CH, d, 11); 134,3 (C); 137,3 (C); 152,6 (2) (C).

Pf (benceno): $214^{\circ} \mathrm{C}$

\section{Preparación de la sal de fosfonio 5}

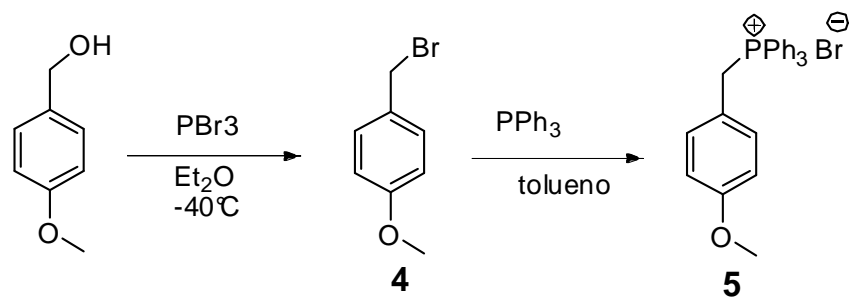

\section{a) Bromuro de bencilo 4}

Sobre una disolución de 4,9 $\mathrm{ml}$ (39 mmol) de (4-metoxifenil)metanol en $30 \mathrm{ml} \mathrm{de} \mathrm{Et}_{2} \mathrm{O}$ seco a $-40{ }^{\circ} \mathrm{C}$ se añaden $3,7 \mathrm{ml}(39 \mathrm{mmol})$ de $\mathrm{PBr}_{3}$, en atmosfera de nitrógeno y agitación constante. 
Después de $4 \mathrm{~h}$ de agitación a temperatura ambiente, se neutraliza con $\mathrm{NaHCO}_{3}$, se extrae con $\mathrm{CH}_{2} \mathrm{Cl}_{2}$, se seca con $\mathrm{Na}_{2} \mathrm{SO}_{4}$ y se evapora el disolvente y se obtiene 7,79 $\mathrm{g}(38,7 \mathrm{mmol}$, $98 \%$ ) del compuesto 4.

\section{1-bromometil-4-metoxibenceno (4):}

$\mathbf{R M N}^{1} \mathbf{H}: 3,81(3 \mathrm{H}, \mathrm{s}) ; 4,51(2 \mathrm{H}, \mathrm{s}) ; 6,86(2 \mathrm{H}, \mathrm{d}, 8,8) ; 7,32(2 \mathrm{H}, \mathrm{d}, 8,8)$.

\section{b) Sal de fosfonio 5}

Sobre una disolución de 7,79 g (38,7 mmol) del compuesto 4 en $30 \mathrm{ml}$ de tolueno seco y en agitación se le añaden 10,2 g (38,7 mmol) de trifenilfosfina disuelta en $20 \mathrm{ml}$ de tolueno seco, se continúa la agitación durante 15 h a temperatura ambiente, observándose la formación de un sólido blanco que se filtra obteniéndose 13,3 g (28,7 mmol, 75 \%) de la sal 5.

\section{Bromuro de 4-metoxibenciltrifenilfosfonio (5):}

RMN ${ }^{1} \mathbf{H}: 3,73(3 \mathrm{H}, \mathrm{s}) ; 5,33(2 \mathrm{H}, \mathrm{d}, 13,9) ; 6,65(2 \mathrm{H}, \mathrm{d}, 8,8) ; 7,02(2 \mathrm{H}, \mathrm{d}, 8,8) ; 7,50-7,80$ $(15 \mathrm{H}, \mathrm{m})$.

RMN ${ }^{13} \mathbf{C}: 29,9\left(\mathrm{CH}_{2}, \mathrm{~d}, 45\right) ; 54,9\left(\mathrm{CH}_{3}\right) ; 114,0$ (2) $(\mathrm{CH}) ; 117,5$ (3) (C, d, 85); 118,2 (C, d, 9); 129,9 (6) (CH, d, 11); 132,3 (2) (CH).

Pf (benceno): $240{ }^{\circ} \mathrm{C}$

\section{Preparación de la sal de fosfonio 8}

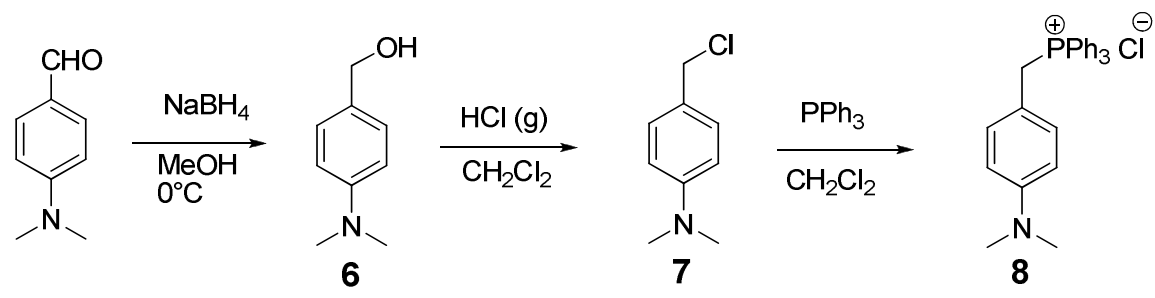




\section{a) Alcohol 6}

Se disuelven 3,00 g (20,1 mmol) de 4-dimetilaminobenzaldehído en $20 \mathrm{ml}$ de $\mathrm{MeOH}$ y se le añaden $761 \mathrm{mg}(20,1 \mathrm{mmol})$ de $\mathrm{NaBH}_{4}$ a $0^{\circ} \mathrm{C}$. La reacción se agita durante $2 \mathrm{~h}$ en atmósfera de nitrógeno. Posteriormente se evapora el $\mathrm{MeOH}$ y se extrae con agua/AcOEt, se seca con $\mathrm{Na}_{2} \mathrm{SO}_{4}$ anhidro y se evapora el disolvente, obteniéndose 2,90 g (19,2 mmol, $\left.95 \%\right)$ del compuesto 6, en forma de un aceite transparente.

\section{(4-dimetilaminofenil)metanol (6):}

$\mathbf{R M N}^{1} \mathbf{H}: 2,95$ (6H, s); 4,53 (2H, s); 6,77 (2H, d, 8,8); 7,26 (2H, d, 8,8).

RMN ${ }^{13} \mathbf{C}: 41,3(2)\left(\mathrm{CH}_{3}\right) ; 65,0\left(\mathrm{CH}_{2}\right) ; 113,4(2)(\mathrm{CH}) ; 129,1(2)(\mathrm{CH}) ; 130,0(\mathrm{C}) ; 150,6(\mathrm{C})$.

IR (película): 3385; 2870; 1521; $1225 \mathrm{~cm}^{-1}$.

\section{b) Sal de fósfonio 8}

Se disuelven 1,60 g (10,6 mmol) de (4-dimetilaminofenil)metanol en $20 \mathrm{ml} \mathrm{de} \mathrm{CH}_{2} \mathrm{Cl}_{2}$ y se borbotea una corriente de $\mathrm{HCl}(\mathrm{g})$, generada a partir del tratamiento de $\mathrm{NaCl}$ con $\mathrm{H}_{2} \mathrm{SO}_{4}$, aparece color amarillo indicando la formación del compuesto 7. Posteriormente se le añade 3,40 g (12,7 mmol) de trifenilfosfina disuelta en $15 \mathrm{ml} \mathrm{de} \mathrm{CH}_{2} \mathrm{Cl}_{2}$, la mezcla se agita durante 24h a temperatura ambiente en atmósfera de nitrógeno, después se evapora el $\mathrm{CH}_{2} \mathrm{Cl}_{2}$ y se cristaliza en tolueno, se obtiene 2,72 g (6,30 mmol, $60 \%)$ de cristales blancos de la sal 8.

\section{Cloruro de (4-dimetilaminobencil)trifenilfosfonio (8):}

RMN ${ }^{1} \mathbf{H}: 3,14(6 \mathrm{H}, \mathrm{s}) ; 5,57$ (1H, s); 5,65 (1H, s); 7,33-7,78 (19H, m). 


\section{Modificaciones del anillo B}

\section{1. Derivados bencénicos}

\section{A. Análogos de isocombretastatinas}

\section{Preparación del aldehído protegido 10}

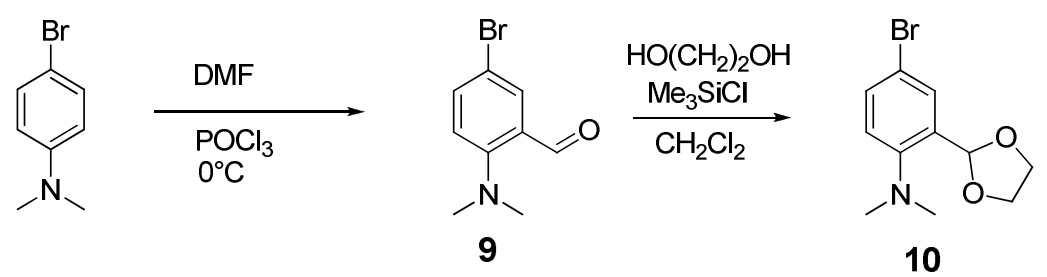

a) Formilación de 4-bromo- $N, N$-dimetilanilina

Se ponen en un matraz 11,5 $\mathrm{ml}(150 \mathrm{mmol})$ de DMF y 4,1 $\mathrm{ml}(45 \mathrm{mmol})$ de oxicloruro de fósforo a $0^{\circ} \mathrm{C}$. Después de una hora se añaden $3,00 \mathrm{~g}(15,0 \mathrm{mmol})$ de 4-bromo- $N, N$ dimetilanilina disuelta en $20 \mathrm{ml}$ de $\mathrm{CH}_{2} \mathrm{Cl}_{2}$, apareciendo un color amarillo. La mezcla se agita durante 24 horas a $70^{\circ} \mathrm{C}$, posteriormente se trata con AcOEt y se lava con agua. La fase orgánica se seca y se evapora el disolvente, obteniéndose 3,19 g de un aceite amarillo.

El crudo se cromatografía flash con Hex/AcOEt 8:2 obteniéndose 2,20 g (4,45 mmol; 64 \%) de aldehído 9, que se cristaliza en $\mathrm{Hex} / \mathrm{CH}_{2} \mathrm{Cl}_{2}$, obteniéndose $652 \mathrm{mg}$ de cristales amarillos.

\section{5-bromo-2-dimetilaminobenzaldehído (9):}

RMN ${ }^{1} \mathbf{H}: 2,93(6 \mathrm{H}, \mathrm{s}) ; 6,98(1 \mathrm{H}, \mathrm{d}, 9.0) ; 7,53(1 \mathrm{H}, \mathrm{dd}, 9,0 ; 2,6) ; 7,86(1 \mathrm{H}, \mathrm{d}, 2,6) ; 10,14$ $(1 \mathrm{H}, \mathrm{s})$.

RMN ${ }^{13} \mathbf{C}: 45,5(2)\left(\mathrm{CH}_{3}\right) ; 113,0(\mathrm{C}) ; 119,6(\mathrm{CH}) ; 128,0(\mathrm{C}) ; 132,8(\mathrm{CH}) ; 137,0(\mathrm{CH}) ; 154,5$ (C); 189,5 (CH).

IR (película): 2949; 1667; 1589; 1495, $804 \mathrm{~cm}^{-1}$.

Pf $\left(\mathrm{Hexano} / \mathrm{CH}_{2} \mathrm{Cl}_{2}\right): 45-47{ }^{\circ} \mathrm{C}$ 


\section{b) Protección del aldehído 9}

Una disolución de 1,50 g (6,58 mmol) de 5-bromo-2-dimetilaminobenzaldehído, 1,0 ml (18 mmol) de etilenglicol y $0,84 \mathrm{ml}(6,58 \mathrm{mmol})$ de cloruro de trimetilsililo en $\mathrm{CH}_{2} \mathrm{Cl}_{2}$ se deja en agitación durante $24 \mathrm{~h}$ a temperatura ambiente. Se extrae con agua saturada con $\mathrm{NaCl}$ y se seca con $\mathrm{Na}_{2} \mathrm{SO}_{4}$, se filtra y se evapora el disolvente, obteniéndose 1,05 g (3,86 mmol, $\left.59 \%\right)$ de 10. Mediante cristalización en $\mathrm{Hex} / \mathrm{CH}_{2} \mathrm{Cl}_{2}$ se aíslan $436 \mathrm{mg}$ de cristales amarillos.

\section{$\underline{N, N \text {-dimetil-4-bromo-2-(1,3-dioxolan-2-il)anilina (10): }}$}

$\mathbf{R M N}^{1} \mathbf{H}: 2,68(6 \mathrm{H}, \mathrm{s}) ; 3,75(4 \mathrm{H}, \mathrm{m}) ; 5,86(1 \mathrm{H}, \mathrm{s}) ; 7,05(1 \mathrm{H}, \mathrm{d}, 8,7) ; 7,42(1 \mathrm{H}, \mathrm{dd}, 8,7 ; 2,5)$; $7,68(1 \mathrm{H}, \mathrm{d}, 2,5)$.

RMN ${ }^{13} \mathbf{C}: 45,6(2)\left(\mathrm{CH}_{3}\right) ; 62,0(2)\left(\mathrm{CH}_{2}\right) ; 99,4(\mathrm{CH}) ; 117,1(\mathrm{C}) ; 121,9(\mathrm{CH}) ; 130,3(\mathrm{C})$; 132,5 (CH); 134,9 (CH); 151,5 (C).

IR (película): 1595; 1488; 1386; 1065; $817 \mathrm{~cm}^{-1}$.

Pf $\left(\mathrm{Hexano} / \mathrm{CH}_{2} \mathrm{Cl}_{2}\right): 87-88^{\circ} \mathrm{C}$

\section{Intento de preparación de la fenstatina 11 por reacción entre los derivados litiado y carboxílico}

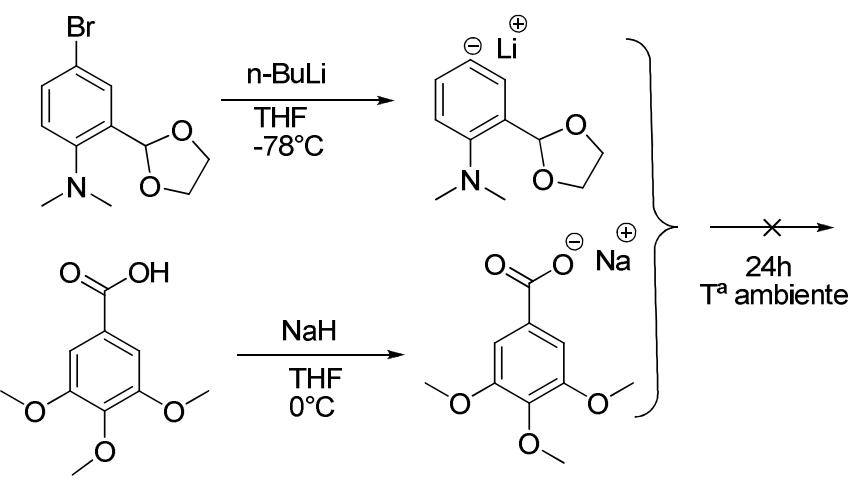<smiles>COc1cc(C(=O)c2ccc(N(C)C)c(C3OCCO3)c2)cc(OC)c1O</smiles>

Se disuelven $540 \mathrm{mg}$ (1,98 mmol) del compuesto 10 en $30 \mathrm{ml}$ de THF seco y se le añaden 1,5 $\mathrm{ml}(2,4 \mathrm{mmol})$ de $n$-BuLi $1,6 \mathrm{M}$ en hexano a $-78^{\circ} \mathrm{C}$ con agitación y atmósfera de nitrógeno. La mezcla se pone de coloración amarilla. 
En otro matraz se ponen a reaccionar $840 \mathrm{mg}$ (3,96 mmol) de ácido 3,4,5-trimetoxibenzoico disuelto también en THF seco y a $0{ }^{\circ} \mathrm{C}$, con $180 \mathrm{mg}(7,50 \mathrm{mmol})$ de hidruro sodio al $60 \%$. La mezcla se pone de coloración blanca.

Al cabo de una hora de agitación de las dos reacciones se añade el contenido de la primera reacción sobre la segunda y se deja a temperatura ambiente durante $24 \mathrm{~h}$. Posteriormente se añade sobre una disolución de $\mathrm{NH}_{4} \mathrm{Cl}$, se evapora el THF y extrae con AcOEt, obteniéndose $555 \mathrm{mg}$ de crudo de reacción de coloración amarilla. Después de varias pruebas se ve que esta reacción no ha ido, por eso se busca otra vía de preparación del compuesto 11.

\section{Preparación de la fenstatina 12}

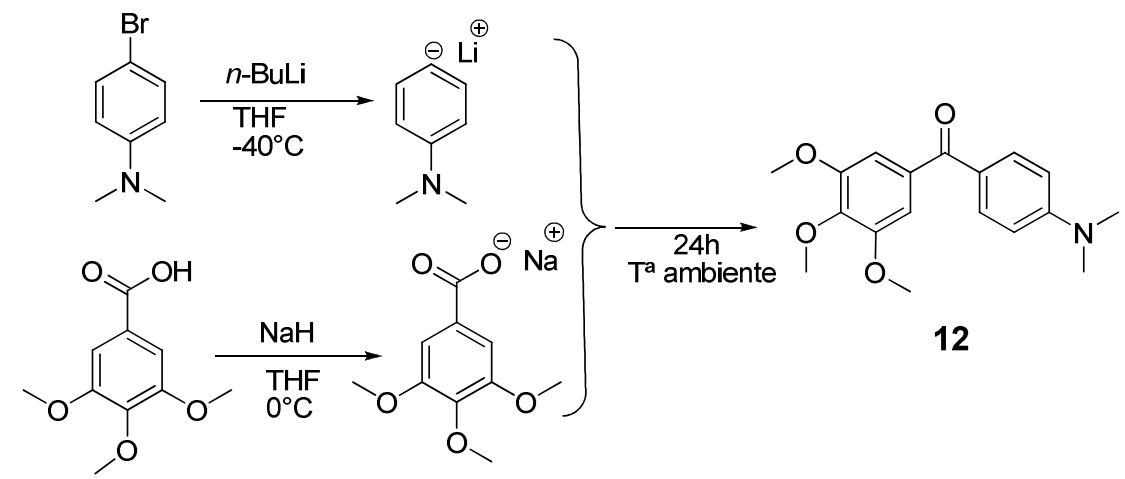

Se disuelven 3,50 g (17,5 mmol) de 4-bromodimetilanilina en $60 \mathrm{ml}$ de THF, después se le añaden $16,4 \mathrm{ml}(26,2 \mathrm{mmol})$ de $n$-BuLi 1,6 $\mathrm{M}$ en hexano a $-78^{\circ} \mathrm{C}$ con agitación y atmósfera de nitrógeno. La mezcla se pone de coloración amarilla.

En otro matraz se prepara una disolución de 7,42 g $(35,0 \mathrm{mmol})$ de ácido 3,4,5trimetoxibenzoico en THF y a $0{ }^{\circ} \mathrm{C}$, se le añaden lentamente $1,25 \mathrm{~g}(52,50 \mathrm{mmol})$ de hidruro sodio al 60 \% con agitación. La mezcla se vuelve de coloración blanca.

Al cabo de una hora de reacción se añade el contenido de la primera reacción sobre la segunda y se deja a temperatura ambiente durante 24h. Posteriormente se añade sobre una disolución de $\mathrm{NH}_{4} \mathrm{Cl}$, se evapora el THF y extrae con AcOEt, obteniéndose 4,22 g de crudo.

La reacción se purifica por cromatografía flash Hex/AcOEt 1:1, aislándose 2,50 g (7,93 mmol, $46 \%$ ) del compuesto 12 . 


\section{(4-dimetilaminofenil)(3,4,5-trimetoxifenil)metanona (12):}

$\mathbf{R M N}^{1} \mathbf{H}: 3,06(6 \mathrm{H}, \mathrm{s}) ; 3,85(6 \mathrm{H}, \mathrm{s}) ; 3,90(3 \mathrm{H}, \mathrm{s}) ; 6,66(2 \mathrm{H}, \mathrm{d}, 8,6) ; 6,98(2 \mathrm{H}, \mathrm{s}) ; 7,80(2 \mathrm{H}, \mathrm{d}$, $8,6)$.

RMN ${ }^{13} \mathbf{C}: 40,1(2)\left(\mathrm{CH}_{3}\right) ; 56,3(2)\left(\mathrm{CH}_{3}\right) ; 61,0\left(\mathrm{CH}_{3}\right) ; 107,1(2)(\mathrm{CH}) ; 110,6(2)(\mathrm{CH}) ; 124,8$ (C); 132,7 (2) (CH); 134,5 (C); 140,8 (C); 152,8 (2) (C); 153,3 (C); 194,4 (C).

IR (película): $1681 ; 1583 ; 1411 ; 1328 ; 1121 \mathrm{~cm}^{-1}$.

Pf (Diisopropileter): $107-109^{\circ} \mathrm{C}$

HMRS (m/z): Obtenido 338,1368 $\left(\mathrm{M}+\mathrm{Na}^{+}\right)$; esperado 338,1363 $\left(\mathrm{C}_{18} \mathrm{H}_{21} \mathrm{NO}_{4} \mathrm{Na}^{+}\right)$.

HPLC: Columna $\mathrm{C}_{18} \quad \mathrm{t}_{\mathrm{R}}: 15,1 \mathrm{~min}$.

\section{Síntesis de la isocombretastatina 13}
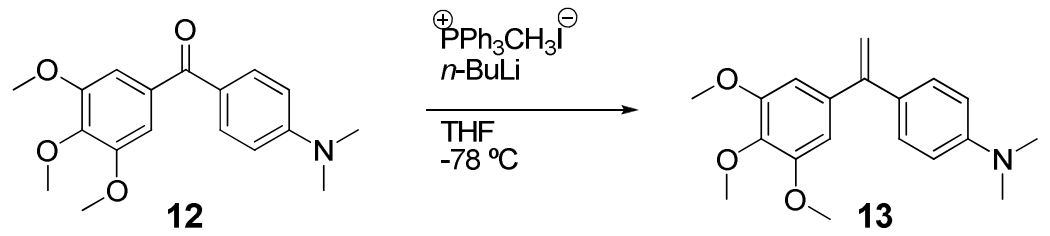

Se suspenden 5,40 g (13,3 mmol) de la sal de fosfonio 1 en $50 \mathrm{ml}$ de THF y se añaden 6,90 ml (11,0 mmol) de $n$-BuLi 1,6 M en hexano a $-78^{\circ} \mathrm{C}$, apareciendo una coloración amarilla. La mezcla se agita durante $1 \mathrm{~h}$ en atmósfera de nitrógeno y se añaden 1,40 g (4,44 mmol) de la cetona 12 disuelta en THF. Se observa que el color cambia de amarillo a naranja. La reacción se agita durante $24 \mathrm{~h}$ a temperatura ambiente, luego se añade sobre una disolución de $\mathrm{NH}_{4} \mathrm{Cl}$ al $5 \%$ y se extrae con AcOEt, se seca la fase orgánica y se evapora el disolvente obteniéndose 3,78 g. El crudo se purifica por una cromatografía flash (Hex/AcOEt 6:4) y se aíslan 1,05 g (3,35 mmol, $75 \%)$ del metilén derivado 13.

\section{$\underline{N, N \text {-dimetil-4-(1-(3,4,5-trimetoxifenil)etenil)anilina (13): }}$}

RMN ${ }^{1} \mathbf{H}: 2,93(6 \mathrm{H}, \mathrm{s}) ; 3,80(6 \mathrm{H}, \mathrm{s}) ; 3,90(3 \mathrm{H}, \mathrm{s}) ; 5,24(1 \mathrm{H}, \mathrm{d}, 1,4) ; 5,36(1 \mathrm{H}, \mathrm{d}, 1,4) ; 6,62$ $(2 \mathrm{H}, \mathrm{s}) ; 6,65(2 \mathrm{H}, \mathrm{d}, 8,6) ; 7,23(2 \mathrm{H}, \mathrm{d}, 8,6)$. 
$\mathbf{R M N}{ }^{13} \mathbf{C}: 40,4(2)\left(\mathrm{CH}_{3}\right) ; 56,1(2)\left(\mathrm{CH}_{3}\right) ; 60,9\left(\mathrm{CH}_{3}\right) ; 105,8(2)(\mathrm{CH}) ; 110,9\left(\mathrm{CH}_{2}\right) ; 111,9$ (2) (CH); 129,1 (2) (CH); 137,6 (C); 138,1 (2) (C); 149,9 (C); 150,3(C); 152,9 (2) (C).

IR (película): $1605 ; 1579 ; 1516 ; 1350 ; 1126 ; 1008 \mathrm{~cm}^{-1}$.

HMRS (m/z): Obtenido 314,1755 $\left(\mathrm{M}+\mathrm{H}^{+}\right)$; esperado 314,1751 $\left(\mathrm{C}_{19} \mathrm{H}_{24} \mathrm{NO}_{3}{ }^{+}\right)$.

HPLC: Columna $\mathrm{C}_{18} \quad \mathrm{t}_{\mathrm{R}}: 20,8 \mathrm{~min}$.

\section{Formilación del compuesto 12}<smiles>COc1cc(C(=O)c2ccc(N(C)C)cc2)cc(OC)c1OC</smiles><smiles>COc1cc(C(=O)c2ccc(N(C)C)c(C=O)c2)cc(OC)c1OC</smiles>

A una mezcla de 4,0 $\mathrm{ml}$ (42 $\mathrm{mmol})$ de DMF y 1,2 $\mathrm{ml}$ (12,6 mmol) de oxicloruro de fósforo a $0^{\circ} \mathrm{C}$, después de una hora de reacción se le añaden $1,32 \mathrm{~g}(4,20 \mathrm{mmol})$ de 12 disueltos en 20 $\mathrm{ml} \mathrm{CH} \mathrm{Cl}_{2}$. La mezcla se agita durante $4 \mathrm{~h}$ a $0^{\circ} \mathrm{C}$, luego se aumenta la temperatura a $70^{\circ} \mathrm{C} \mathrm{y}$ se deja $20 \mathrm{~h}$. El color pasa de naranja a amarillo, se disuelve en $\mathrm{CH}_{2} \mathrm{Cl}_{2}$ y se lava con agua, la fase orgánica se seca con $\mathrm{Na}_{2} \mathrm{SO}_{4}$, se filtra y se evapora. Se aíslan $940 \mathrm{mg}$ (2,74 mmol, 65\%) del compuesto formilado 14.

\section{2-dimetilamino-5-(3,4,5-trimetoxibenzoil)benzaldehído (14):}

RMN ${ }^{1} \mathbf{H}: 3,11(6 \mathrm{H}, \mathrm{s}) ; 3,88(6 \mathrm{H}, \mathrm{s}) ; 3,94(3 \mathrm{H}, \mathrm{s}) ; 6,99(1 \mathrm{H}, \mathrm{d}, 9,0) ; 7,00(2 \mathrm{H}, \mathrm{s}) ; 7,94(1 \mathrm{H}$, dd, 9,0, 2,2); 8,21 (1H, d, 2,2); 10,03 (1H, s).

RMN ${ }^{13} \mathbf{C}: 44,4(2)\left(\mathrm{CH}_{3}\right) ; 56,2(2)\left(\mathrm{CH}_{3}\right) ; 60,8\left(\mathrm{CH}_{3}\right) ; 107,1(2)(\mathrm{CH}) ; 115,8(\mathrm{CH}) ; 123,2$ (C); 127,0 (C); 133,1 (C); 135,6 (CH); 136,8 (CH); 141,5 (C); 152,8 (2) (C); 156,3 (C); 189,3 $(\mathrm{CH}) ; 193,4(\mathrm{C})$.

IR (película): 2833; 1674; 1652;1589; 1409; 1336; $1129 \mathrm{~cm}^{-1}$.

Pf $\left(\mathrm{Hex} / \mathrm{CH}_{2} \mathrm{Cl}_{2}\right): 113-115^{\circ} \mathrm{C}$

HMRS (m/z): Obtenido 344,1505 $\left(\mathrm{M}+\mathrm{H}^{+}\right)$; esperado 344,1492 $\left(\mathrm{C}_{19} \mathrm{H}_{22} \mathrm{NO}_{5}{ }^{+}\right)$. 
HPLC: Columna $\mathrm{C}_{18} \quad \mathrm{t}_{\mathrm{R}}: 8,9 \mathrm{~min}$.

\section{Protección del aldehído 14}
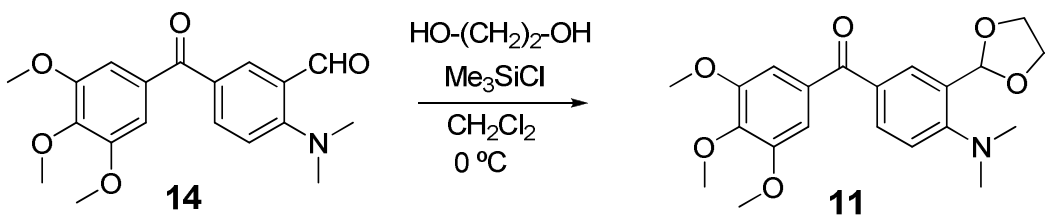

Se disuelven $250 \mathrm{mg}(0,73 \mathrm{mmol})$ del aldehído 14 en $20 \mathrm{ml}$ de $\mathrm{CH}_{2} \mathrm{Cl}_{2}$, se añaden $81 \mu \mathrm{l}(1,5$ mmol) de etano-1,2-diol al 30\% en metanol y $93 \mu \mathrm{l}(0,73 \mathrm{mmol})$ de cloruro de trimetilsililo a $0{ }^{\circ} \mathrm{C}$ con agitación. El color pasa de rosa a violeta. La reacción se agita durante $24 \mathrm{~h}$ a temperatura ambiente, luego se disuelve en $\mathrm{CH}_{2} \mathrm{Cl}_{2}$ y se extrae con agua saturada con $\mathrm{NaCl}$, la fase orgánica se seca con $\mathrm{Na}_{2} \mathrm{SO}_{4}$, se filtra y se evapora, recuperándose $265 \mathrm{mg}$. Se purifica el producto por cromatografía flash (Hex/AcOEt 1:1), aislándose $235 \mathrm{mg}$ (0,61mmol, 84 \%) del compuesto 11.

\section{(4-dimetilamino-3-(1,3-dioxolan-2-il)fenil)(3,4,5-trimetoxifenil)metanona (11):}

RMN ${ }^{1} \mathbf{H}: 2,90(6 \mathrm{H}, \mathrm{s}) ; 3,93(6 \mathrm{H}, \mathrm{s}) ; 3,97$ (3H, s); 4,10 (4H, m); 6,10 (1H, s); 7,04 (2H, s); 7,06 (1H, d, 8,2); 7,78 (1H, dd, 8,2, 2,1); 8,07 (1H, d, 2,1).

RMN ${ }^{13} \mathbf{C}: 44,8(2)\left(\mathrm{CH}_{3}\right) ; 56,1(2)\left(\mathrm{CH}_{3}\right) ; 60,8\left(\mathrm{CH}_{3}\right) ; 65,4$ (2) $\left(\mathrm{CH}_{2}\right) ; 99,7(\mathrm{CH}) ; 107,4$ (2) $(\mathrm{CH}) ; 117,5(\mathrm{CH}) ; 128,8(\mathrm{C}) ; 130,4(\mathrm{CH}) ; 130,9(\mathrm{CH}) ; 131,2(\mathrm{C}) ; 141,3(\mathrm{C}) ; 152,7(\mathrm{C}) ; 152,8$ (2) (C); 156,8 (C); 194,2 (C).

IR (película): 1647; 1592; 1503; 1411;1332; 1234; $1126 \mathrm{~cm}^{-1}$. 


\section{Reacción de Wittig de la fenstatina 11}<smiles>COc1cc(C(=O)c2ccc(N(C)C)c(C3OCCO3)c2)cc(OC)c1OC</smiles>

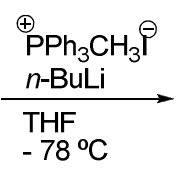<smiles>C=C(c1cc(OC)c(OC)c(OC)c1)c1ccc(N(C)C)c(C2OCCO2)c1</smiles>

Se disuelven $563 \mathrm{mg}(1,39 \mathrm{mmol})$ de sal de fosfonio 1 en $30 \mathrm{ml}$ de THF y a $-78^{\circ} \mathrm{C}$ se le añaden $726 \mu \mathrm{l}(1,16 \mathrm{mmol})$ de $n$-BuLi 1,6 M en hexano en atmósfera de nitrógeno, tomando coloración amarilla. La mezcla se agita durante $1 \mathrm{~h}$, luego se añaden $180 \mathrm{mg}(0,46 \mathrm{mmol}) \mathrm{de}$ la cetona $\mathbf{1 1}$ disuelta en THF, el color pasa de amarillo a naranja.

La reacción se agita durante $24 \mathrm{~h}$ a temperatura ambiente, luego se extrae siguiendo la metodología descrita en casos similares y se obtienen 359 mg de crudo.

El crudo se purifica por cromatografía flash eluyéndose con Hex/AcOEt 7:3, $125 \mathrm{mg}$ (0,32 mmol, $70 \%$ ) del compuesto 15.

\section{$\underline{N, N \text {-dimetil-2-(1,3-dioxolan-2-il)-4-(1-(3,4,5-trimetoxifenil)etenil)anilina (15): }}$}

RMN ${ }^{1} \mathbf{H}: 2,77$ (6H, s); 3,80 (6H, s); 3,89 (3H, s); 4,00-4,20 (4H, m); 5,34 (1H, sa); 5,42 (1H, sa); 6,18 (1H, s); 6,56 (2H, s); 7,00 (1H, d, 8,6); 7,22 (1H, dd, 8,6, 2,1); 7,64 (1H, d, 2,1).

RMN ${ }^{13} \mathbf{C}: 45,6(2)\left(\mathrm{CH}_{3}\right) ; 56,1(2)\left(\mathrm{CH}_{3}\right) ; 60,9\left(\mathrm{CH}_{3}\right) ; 65,3$ (2) $\left(\mathrm{CH}_{2}\right) ; 99,8(\mathrm{CH}) ; 105,7$ (2) $(\mathrm{CH}) ; 113,1\left(\mathrm{CH}_{2}\right) ; 118,5(\mathrm{CH}) ; 127,4(\mathrm{CH}) ; 129,9(\mathrm{CH}) ; 130,6(\mathrm{C}) ; 135,6(\mathrm{C}) ; 137,3(\mathrm{C})$; 137,6 (C); 149,5 (C); 152,8 (2) (C); 153,3 (C).

IR (película): $1578 ; 1502 ; 1345 ; 1235 ; 1126 ; 1064 \mathrm{~cm}^{-1}$.

HMRS (m/z): Obtenido 386,1958 $\left(\mathrm{M}+\mathrm{H}^{+}\right)$; esperado 386, $1962\left(\mathrm{C}_{22} \mathrm{H}_{28} \mathrm{NO}_{5}{ }^{+}\right)$.

HPLC: Columna $\mathrm{C}_{18} \quad \mathrm{t}_{\mathrm{R}}: 19,5 \mathrm{~min}$. 


\section{Obtención de la isocombretastatina 16}<smiles>C=C(c1cc(OC)c(OC)c(OC)c1)c1ccc(N(C)C)c(C2OCCO2)c1</smiles>

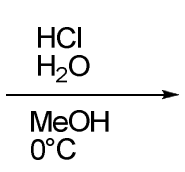<smiles>C=C(c1ccc(N(C)C)c(C=O)c1)c1cc(OC)c(OC)c(OC)c1</smiles>

Se disuelven $328 \mathrm{mg}$ (0,85 mmol) del dioxolano 15 en $6 \mathrm{ml}$ de metanol, después se añade un poco de agua y dos gotas de $\mathrm{HCl}$ concentrado a $0^{\circ} \mathrm{C}$, aparece coloración amarilla. La mezcla se agita durante 4 h, luego se extrae con AcOEt, se obtiene $250 \mathrm{mg}(0,73 \mathrm{mmol} ; 86 \%)$ de un aceite naranja del compuesto desprotegido $\mathbf{1 6 .}$

\section{2-dimetilamino-5-(1-(3,4,5 trimetoxifenil)etenil)benzaldehído (16):}

RMN ${ }^{1} \mathbf{H}: 2,96(6 \mathrm{H}, \mathrm{s}) ; 3,81(6 \mathrm{H}, \mathrm{s}) ; 3,87(3 \mathrm{H}, \mathrm{s}) ; 5,34(1 \mathrm{H}, \mathrm{s}) ; 5,41(1 \mathrm{H}, \mathrm{s}) ; 6,52(2 \mathrm{H}, \mathrm{s})$; $6,96(1 \mathrm{H}, \mathrm{d}, 8.2) ; 7,41(1 \mathrm{H}, \mathrm{dd}, 8.2,2.2) ; 7,77(1 \mathrm{H}, \mathrm{d}, 2.2) ; 10,18(1 \mathrm{H}, \mathrm{s})$.

RMN ${ }^{13} \mathbf{C}: 45,4$ (2) $\left(\mathrm{CH}_{3}\right) ; 56,2$ (2) $\left(\mathrm{CH}_{3}\right) ; 60,9\left(\mathrm{CH}_{3}\right) ; 105,6(2)(\mathrm{CH}) ; 113,2\left(\mathrm{CH}_{2}\right) ; 117,1$ (CH); 126,1 (C); 131,0 (CH); 133,1 (C); 134,3 (CH); 137,1 (C); 137,9 (C); 148,8 (C); 153,0 (2) $(\mathrm{C}) ; 155,1(\mathrm{C}) ; 191,0(\mathrm{CH})$.

IR (película): 2837; 1679; 1602; 1579; 1504; 1235; $1126 \mathrm{~cm}^{-1}$.

HMRS (m/z): Obtenido 364,1521 $\left(\mathrm{M}+\mathrm{Na}^{+}\right)$; esperado 364,1520 $\left(\mathrm{C}_{20} \mathrm{H}_{23} \mathrm{NO}_{4} \mathrm{Na}^{+}\right)$.

HPLC: Columna $\mathrm{C}_{18} \quad \mathrm{t}_{\mathrm{R}}: 19,2 \mathrm{~min}$.

\section{Preparación de la oxima 17}
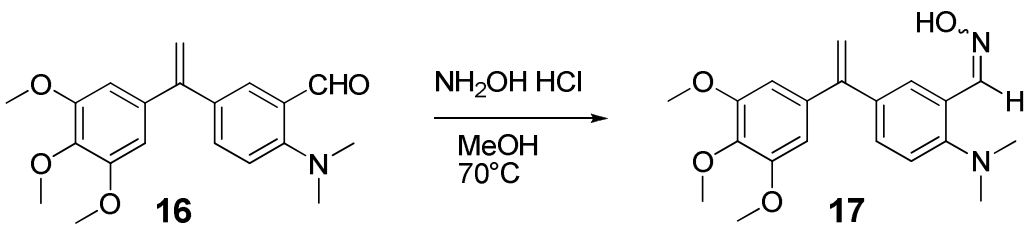
Se disuelven $100 \mathrm{mg}(0,29 \mathrm{mmol})$ del compuesto 16 en $10 \mathrm{ml}$ de metanol, después se añaden $205 \mathrm{mg}$ (2,93 mmol) de clorhidrato de hidroxilamina y tres gotas de piridina apareciendo coloración naranja. La reacción se deja a $70^{\circ} \mathrm{C} 24$ h, luego se evapora el metanol, se extrae con agua/ $\mathrm{CH}_{2} \mathrm{Cl}_{2}$ y se aíslan $56 \mathrm{mg}(0,16 \mathrm{mmol}, 55 \%)$ de un aceite amarillo corresponde al compuesto 17.

\section{Oxima de 2-dimetilamino-5-(1-(3,4,5-trimetoxifenil)etenil)benzaldehído (17):}

RMN ${ }^{1} \mathbf{H}: 2,75(6 \mathrm{H}, \mathrm{s}) ; 3,73(6 \mathrm{H}, \mathrm{s}) ; 3,80(3 \mathrm{H}, \mathrm{s}) ; 5,27(1 \mathrm{H}, \mathrm{s}) ; 5,34(1 \mathrm{H}, \mathrm{s}) ; 6,46(2 \mathrm{H}, \mathrm{s})$; 6,93 (1H, d, 8,4); 7,19 (1H, dd, 8,4, 2,0); 7,62 (1H, d, 2,4); 8,35 (1H, s).

RMN ${ }^{13} \mathbf{C}: 45,0$ (2) $\left(\mathrm{CH}_{3}\right) ; 56,1$ (2) $\left(\mathrm{CH}_{3}\right) ; 60,8\left(\mathrm{CH}_{3}\right) ; 105,5$ (2) $(\mathrm{CH}) ; 113,3\left(\mathrm{CH}_{2}\right) ; 118,0$ $(\mathrm{CH}) ; 124,7(\mathrm{C}) ; 127,3(\mathrm{CH}) ; 130,3(\mathrm{CH}) ; 131,9$ (C); 135,2 (C); 137,1 (C); 137,6 (C); 148,8 $(\mathrm{CH}) ; 149,1(\mathrm{C}) ; 152,8(2)(\mathrm{C})$.

IR (película): 3439; 1580; 1503; 1410; 1236; $1126 \mathrm{~cm}^{-1}$.

HMRS (m/z): Obtenido 357,1816 $\left(\mathrm{M}+\mathrm{H}^{+}\right)$; esperado $357,1814\left(\mathrm{C}_{20} \mathrm{H}_{25} \mathrm{~N}_{2} \mathrm{O}_{4}{ }^{+}\right)$.

HPLC: Columna $\mathrm{C}_{18} \quad \mathrm{t}_{\mathrm{R}}: 17,9 \mathrm{~min} ; \mathrm{t}_{\mathrm{R}}: 18,5 \mathrm{~min}$.

\section{Preparación de la isocombretastatina 18}

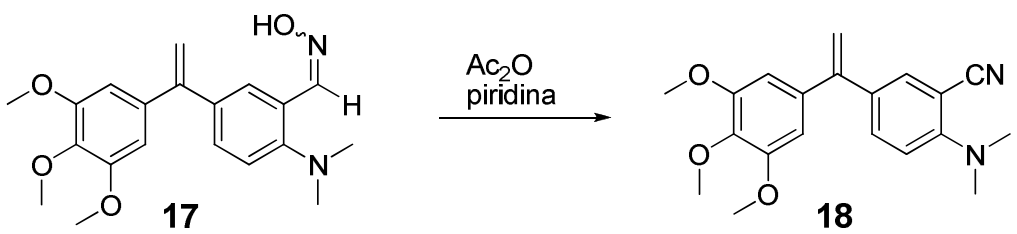

Se disuelven $66 \mathrm{mg}(0,18 \mathrm{mmol})$ de la oxima 17 en $300 \mu \mathrm{L}$ de piridina y $300 \mu \mathrm{L}$ de anhídrido acético. La reacción se agita durante $4 \mathrm{~h}$ a temperatura ambiente, apareciendo un color marrón. Al crudo de reacción se le añade hielo y extrae con AcOEt, obteniéndose 45 mg de un producto cuyo espectro de $\mathrm{RMN}{ }^{1} \mathrm{H}$ indica la presencia de una mezcla en la que coexisten el nitrilo y el derivado acetilado.

Esta mezcla se vuelve a poner otra vez en tolueno, tamiz molecular y unas gotas de $\mathrm{HCl}(\mathrm{c})$ a reflujo durante $2 \mathrm{~h}$. Evaporando el tolueno, se extrae con $\mathrm{CH}_{2} \mathrm{Cl}_{2}$, lleva a $\mathrm{pH}$ neutro, se seca con $\mathrm{Na}_{2} \mathrm{SO}_{4}$, se filtra y se evapora, se aíslan $35 \mathrm{mg}(0,10 \mathrm{mmol}, 56 \%)$ del nitrilo 18 . 


\section{2-dimetilamino-5-(1-(3,4,5-trimetoxifenil)etenil)benzonitrilo (18):}

RMN ${ }^{1} \mathbf{H}: 3,11(6 \mathrm{H}, \mathrm{s}) ; 3,82(6 \mathrm{H}, \mathrm{s}) ; 3,89(3 \mathrm{H}, \mathrm{s}) ; 5,33(1 \mathrm{H}, \mathrm{sa}) ; 5,38(1 \mathrm{H}, \mathrm{sa}) ; 6,51(2 \mathrm{H}, \mathrm{s})$; $6,81(1 \mathrm{H}, \mathrm{d}, 8,9) ; 7,42(1 \mathrm{H}, \mathrm{dd}, 8,9 ; 2,2) ; 7,53(1 \mathrm{H}, \mathrm{d}, 2,2)$.

RMN ${ }^{13} \mathbf{C}: 42,9$ (2) $\left(\mathrm{CH}_{3}\right) ; 56,2$ (2) $\left(\mathrm{CH}_{3}\right) ; 60,9\left(\mathrm{CH}_{3}\right) ; 105,8(2)(\mathrm{CH}) ; 113,2\left(\mathrm{CH}_{2}\right) ; 116,2$ (CH); 119,8 (C); 131,8 (C); 133,2 (CH); 134,6 (CH); 136,7 (C); 137,6 (C); 138,0 (C); 148,0 (C); 153,0 (2) (C); 154,4 (C).

IR (película): 2214; 1581; 1505; 1410; 1235; $1112 \mathrm{~cm}^{-1}$.

HMRS (m/z): Obtenido 339,1724 $\left(\mathrm{M}+\mathrm{H}^{+}\right)$; esperado 339,1704 $\left(\mathrm{C}_{20} \mathrm{H}_{23} \mathrm{~N}_{2} \mathrm{O}_{3}{ }^{+}\right)$.

HPLC: Columna $\mathrm{C}_{18} \quad \mathrm{t}_{\mathrm{R}}: 19,5 \mathrm{~min}$.

\section{Preparación de la sal de amonio de la fenstatina 12}<smiles>COc1cc(C(=O)c2ccc([N+](=O)[O-])cc2)cc(OC)c1OC</smiles>

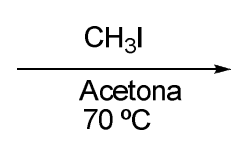<smiles></smiles>

Se disuelven $200 \mathrm{mg}(0,63 \mathrm{mmol})$ de la cetona 12 en $20 \mathrm{ml}$ de acetona, después se añaden 237 $\mu \mathrm{L}(3,81 \mathrm{mmol})$ de yodometano y aparece color amarillo. La mezcla se agita durante $24 \mathrm{~h}$ a $70^{\circ} \mathrm{C}$ en tubo sellado, se forma un precipitado que se aísla por filtración. Se aíslan $130 \mathrm{mg}$ (0,39 mmol, $62 \%)$ de compuesto 19 sólido.

\section{Yoduro de $N, N, N$-trimetil-4-(3,4,5-trimetoxibenzoil)bencenamonio (19):}

RMN ${ }^{1} \mathbf{H}\left(\mathbf{C D}_{\mathbf{3}} \mathbf{O D}\right): 3,68(9 \mathrm{H}, \mathrm{s}) ; 3,75$ (6H, s); 3,77 (3H, s); 6,99 (2H, s); 7,88 (2H, d, 6,8); $8,01(2 \mathrm{H}, \mathrm{d}, 6,8)$.

RMN ${ }^{13} \mathbf{C}$ (CD) $\left.\mathbf{C D}\right): 56,9$ (3) $\left(\mathrm{CH}_{3}\right) ; 57,3$ (2) $\left(\mathrm{CH}_{3}\right) ; 64,5\left(\mathrm{CH}_{3}\right) ; 109,1$ (2) $(\mathrm{CH}) ; 121,5$ (2) $(\mathrm{CH}) ; 132,7$ (2) (CH); 141,0 (C); 147,8 (C); 150,8 (C); 153,8 (C); 154,5 (2) (C); 190,0 (C).

IR (KBr): 3002; 1661; 1582; 1332; $1125 \mathrm{~cm}^{-1}$.

HMRS (m/z): Obtenido 330,1690 $\left(\mathrm{M}^{+}\right)$; esperado 330,1700 $\left(\mathrm{C}_{19} \mathrm{H}_{24} \mathrm{NO}_{4}{ }^{+}\right)$. 


\section{Preparación de la sal de amonio de la isocombretastatina 13}
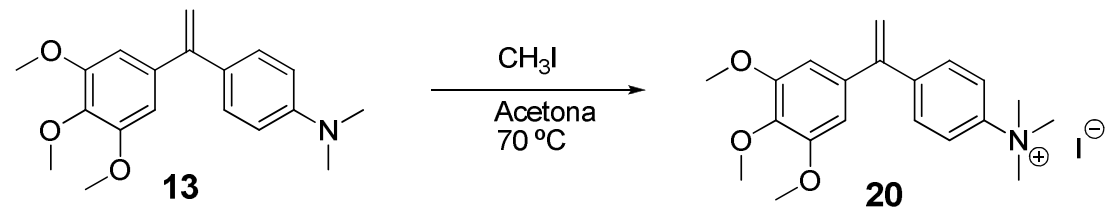

Se disuelven $250 \mathrm{mg}(0,83 \mathrm{mmol})$ de la olefina 13 en $25 \mathrm{ml}$ de acetona, y se le añaden $2 \mathrm{ml}$ (25 mmol) de yodometano, aparece color amarillo. La mezcla se agita durante $4 \mathrm{~h}$ a $70^{\circ} \mathrm{C}$ en tubo sellado apareciendo un precipitado que se filtra y se obtienen $260 \mathrm{mg}(0,79 \mathrm{mmol}, 95 \%)$ del compuesto 20.

\section{Yoduro de $N, N, N$-trimetil-4-(1-(3,4,5-trimetoxifenil)vinil)bencenamonio (20):}

RMN ${ }^{1} \mathbf{H}\left(\mathbf{C D}_{\mathbf{3}} \mathbf{O D}\right): 3,62(9 \mathrm{H}, \mathrm{s}) ; 3,68$ (6H, s); 3,73 (3H, s); 5,59 (1H, s); 5,63 (1H, s); 6,53 $(2 \mathrm{H}, \mathrm{s}) ; 7,53(2 \mathrm{H}, \mathrm{d}, 8,3) ; 7,93(2 \mathrm{H}, \mathrm{d}, 8,3)$.

RMN ${ }^{13} \mathbf{C}$ (CD $\left.\mathbf{C} \mathrm{OD}\right): 56,7$ (3) $\left(\mathrm{CH}_{3}\right) ; 57,8$ (2) $\left(\mathrm{CH}_{3}\right) ; 61,1\left(\mathrm{CH}_{3}\right) ; 106,8$ (2) (CH); 116,9 $\left(\mathrm{CH}_{2}\right) ; 121,2(2)(\mathrm{CH}) ; 131,0$ (2) $(\mathrm{CH}) ; 137,7$ (C); 144,8 (C); 145,9 (C); 147,7 (C); 149,5 (C); $154,4(2)(C)$.

IR (KBr): 3000; 1580; 1505; 1351; $1130 \mathrm{~cm}^{-1}$.

Pf (Acetona): $176-177^{\circ} \mathrm{C}$

HMRS (m/z): Obtenido 328,1899 $\left(\mathrm{M}^{+}\right)$; esperado 328, $1913\left(\mathrm{C}_{20} \mathrm{H}_{26} \mathrm{NO}_{3}{ }^{+}\right)$.

\section{Preparación de la oxima 21}
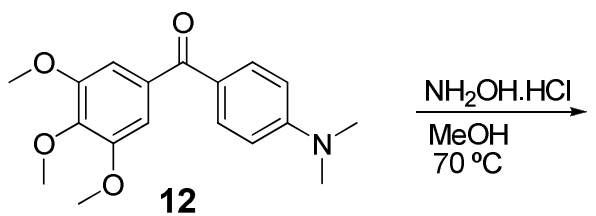<smiles>COc1cc(/C(=N\O)c2ccc(N(C)C)cc2)cc(OC)c1OC</smiles> 
Se disuelven $500 \mathrm{mg}(1,59 \mathrm{mmol})$ de la cetona 12 en $10 \mathrm{ml}$ de metanol, después se añaden $560 \mathrm{mg}(7,93 \mathrm{mmol})$ de clorhidrato de hidroxilamina y tres gotas de piridina apareciendo color amarillo. La mezcla se agita a $70^{\circ} \mathrm{C}$ durante $20 \mathrm{~h}$, luego se evapora el metanol y se obtiene 620 mg del crudo de reacción.

El crudo se purifica por cristalización en MeOH/AcOEt aislándose 300 mg (0,91 mmol, 57 $\%$ ) de la mezcla $Z / E$ en proporción 45:55. Se observa la formación de dos tipos de cristales que se logran separar manualmente, cristales amarillos que contienen el isómero $E$ y verdes que corresponden a la mezcla $\mathrm{Z} / \mathrm{E}$.

\section{$\underline{(E) \text { oxima de (4-dimetilaminofenil)(3,4,5-trimetoxifenil)metanona (21): }}$}

RMN ${ }^{1} \mathbf{H}\left(\mathbf{C D}_{3} \mathbf{O D}\right): 2,89(6 \mathrm{H}, \mathrm{s}) ; 3,65(6 \mathrm{H}, \mathrm{s}) ; 3,67$ (3H, s); 6,61 (2H, s); 6,63 (2H, d, 8,9); $7,25(2 \mathrm{H}, \mathrm{d}, 8,9)$.

RMN ${ }^{13} \mathbf{C}$ (CD $\left.\mathbf{C} \mathbf{O D}\right): 40,5$ (2) $\left(\mathrm{CH}_{3}\right) ; 56,4$ (2) $\left(\mathrm{CH}_{3}\right) ; 61,1\left(\mathrm{CH}_{3}\right) ; 107,0$ (2) $(\mathrm{CH}) ; 111,7$ (2) (CH); 121,6 (C); 132,4 (2) (CH); 135,0 (C); 139,8 (C); 152,1 (C); 154,1 (2) (C); 158,1 (C).

Pf $(\mathrm{MeOH} / \mathrm{AcOEt}): 148-149^{\circ} \mathrm{C}$

\section{$\underline{(Z) \text { oxima de (4-dimetilaminofenil)(3,4,5-trimetoxifenil)metanona (21): }}$}

\section{Datos espectroscópicos obtenidos de la mezcla $Z / E$}

RMN ${ }^{1} \mathbf{H}$ (CD) $\left.\mathbf{O D}\right):$ 2,90 (6H, s); 3,68 (6H, s); 3,71 (3H, s); 6,49 (2H, s); 6,77 (2H, d, 8,9); $7,24(2 \mathrm{H}, \mathrm{d}, 8,9)$.

RMN ${ }^{13} \mathbf{C}$ (CD $\mathbf{C}$ OD): 40,5 (2) $\left(\mathrm{CH}_{3}\right) ; 56,4$ (2) $\left(\mathrm{CH}_{3}\right) ; 61,1\left(\mathrm{CH}_{3}\right) ; 107,8$ (2) (CH); 112,3 (2) (CH); 121,6 (C); 129,7 (2) (CH); 135,0 (C); 139,8 (C); 152,1 (C); 154,1 (2) (C); 158,1 (C).

IR (KBr): $3410 ; 1604 ; 1527 ; 1126 \mathrm{~cm}^{-1}$.

Pf $(\mathrm{MeOH} / \mathrm{AcOEt}): 163-164{ }^{\circ} \mathrm{C}$

HMRS (m/z): Obtenido 353,1470 $\left(\mathrm{M}+\mathrm{Na}^{+}\right)$; esperado 353,1472 $\left(\mathrm{C}_{18} \mathrm{H}_{22} \mathrm{~N}_{2} \mathrm{O}_{4} \mathrm{Na}^{+}\right)$.

HPLC: Columna $\mathrm{C}_{18} \quad \mathrm{t}_{\mathrm{R}}: 9,8 \mathrm{~min} ; \mathrm{t}_{\mathrm{R}}: 10,4 \mathrm{~min}$ 


\section{Metilación de la oxima 21}

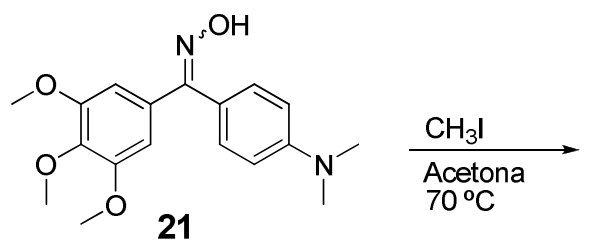<smiles></smiles>

Se disuelven $100 \mathrm{mg}(0,30 \mathrm{mmol})$ de $\mathbf{2 1}$ en $20 \mathrm{ml}$ de acetona, después se añaden $600 \mu \mathrm{L}$ (9,08 mmol) de yodometano, volviéndose la disolución de color amarillo. La mezcla se agita durante $24 \mathrm{~h}$ a $70^{\circ} \mathrm{C}$, luego se evapora la acetona y se purifica por cristalización en MeOH/éter/acetona. Se obtienen 96 mg (0,29 mmol, $97 \%)$ de la sal de amonio 19.

\section{Formación de la oxima 22}
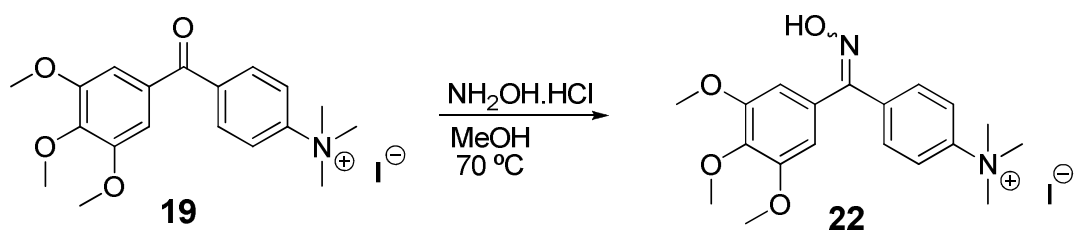

Se disuelve $200 \mathrm{mg}(0,60 \mathrm{mmol})$ de la sal de amonio 19 en $10 \mathrm{ml}$ de metanol, después se le añaden $250 \mathrm{mg}(3,60 \mathrm{mmol})$ de clorhidrato de hidroxilamina y tres gotas de piridina apareciendo coloración naranja. La mezcla se agita durante $20 \mathrm{~h} \mathrm{a} 70^{\circ} \mathrm{C}$, luego se evapora el metanol y se obtienen $419 \mathrm{mg}$ de crudo.

El producto se purifica por cristalización en $\mathrm{MeOH} / \mathrm{AcOEt}$, obteniéndose $31 \mathrm{mg}$ (0,09 mmol, $15 \%)$ de cristales amarillos de la mezcla de isómeros $(Z / E)$ del compuesto 22 en proporción $8: 2$.

\section{4-((hidroxiimino)(3,4,5-trimetoxifenil)metil)- $N, N, N$-trimetilbencenamonio (22):}

\section{Isómero (Z):}

RMN ${ }^{1} \mathbf{H}\left(\mathbf{C D}_{\mathbf{3}} \mathbf{O D}\right): 3,28(9 \mathrm{H}, \mathrm{s}) ; 3,73(6 \mathrm{H}, \mathrm{s}) ; 3,78(3 \mathrm{H}, \mathrm{s}) ; 6,71(2 \mathrm{H}, \mathrm{s}) ; 7,62(2 \mathrm{H}, \mathrm{d}, 8,8)$; $8,01(2 \mathrm{H}, \mathrm{d}, 8,8)$. 


\section{Isómero $(E)$ :}

RMN ${ }^{1} \mathbf{H}$ (CD) $\left.\mathbf{O D}\right): 3,30(9 \mathrm{H}, \mathrm{s}) ; 3,68(6 \mathrm{H}, \mathrm{s}) ; 3,78(3 \mathrm{H}, \mathrm{s}) ; 6,60(2 \mathrm{H}, \mathrm{s}) ; 7,71(2 \mathrm{H}, \mathrm{d}, 8,8)$; $7,88(2 \mathrm{H}, \mathrm{d}, 8,8)$.

IR (KBr): 3470; 1582; 1505; 1344; $1130 \mathrm{~cm}^{-1}$.

Pf $(\mathrm{AcOEt} / \mathrm{MeOH}): 179-180{ }^{\circ} \mathrm{C}$

HMRS (m/z): Obtenido 345,1806 $\left(\mathrm{M}^{+}\right)$; esperado 345,1814 $\left(\mathrm{C}_{19} \mathrm{H}_{25} \mathrm{~N}_{2} \mathrm{O}_{4}{ }^{+}\right)$.

HPLC: Columna $\mathrm{C}_{18} \quad \mathrm{t}_{\mathrm{R}}: 9,8 \mathrm{~min} ; \mathrm{t}_{\mathrm{R}}: 10,5 \mathrm{~min}$. 


\section{B. Análogos de combretastatinas}

\section{Obtención de la combretastatina 23}

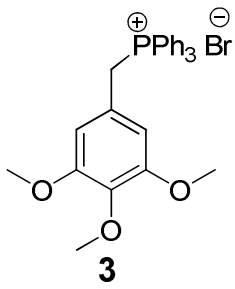<smiles>CN(C)c1ccc(C=O)cc1</smiles><smiles>COc1cc(/C=C\c2ccc(N(C)C)cc2)cc(OC)c1OCC(C)C</smiles>

Sobre una suspensión de 4,20 g (8,04 mmol) de la sal de fosfonio 3 en THF seco, a una temperatura de $-78^{\circ} \mathrm{C}$, en agitación y atmósfera de nitrógeno, se añade 6,1 $\mathrm{ml}(9,65 \mathrm{mmol}) \mathrm{de}$ $n$-BuLi 1,6 M en hexano. A la suspensión naranja obtenida se añaden, transcurrida 1 hora, 1,00 g (6,70 mmol) de 4-dimetilaminobenzaldehído disuelto en THF seco y se lleva progresivamente hasta temperatura ambiente. Se forma una disolución naranja en la que aparece un precipitado blanco. Tras 24 horas, se detiene la reacción con una disolución de cloruro de amonio y extrae con acetato de etilo, y se recupera la fase orgánica lavando con agua hasta neutralidad. Finalmente se seca la disolución con $\mathrm{Na}_{2} \mathrm{SO}_{4}$ anhidro y se filtra y evapora el disolvente, hasta obtener el crudo de reacción, cuyo peso es de 4,00 g de la mezcla Z/E en proporción 6:4.

El producto obtenido se purifica mediante cromatografía flash (Hex/AcOEt 7:3). Tras la cromatografía en columna, y tras realizar sucesivas cristalizaciones y una cromatografía en capa fina preparativa, se obtienen $290 \mathrm{mg}(0.92 \mathrm{mmol}, 14 \%)$ del isómero $Z$ como un aceite incoloro, $113 \mathrm{mg}(0,36 \mathrm{mmol}, 5 \%)$ del isómero $E$ y 1,20 g de mezcla de ambos isómeros.

\section{$\underline{(Z)-N, N \text {-dimetil-4-(2-(3,4,5-trimetoxifenil)vinil)anilina (23a): }}$}

RMN ${ }^{1} \mathbf{H}: 2,93(6 \mathrm{H}, \mathrm{s}) ; 3,71(6 \mathrm{H}, \mathrm{s}) ; 3,85(3 \mathrm{H}, \mathrm{s}) ; 6,32(1 \mathrm{H}, \mathrm{d}, 12,2) ; 6,46(1 \mathrm{H}, \mathrm{d}, 12,2) ; 6,57$ $(2 \mathrm{H}, \mathrm{s}) ; 6,60(2 \mathrm{H}, \mathrm{d} ; 8,6) ; 7,20(2 \mathrm{H}, \mathrm{d}, 8,6)$.

RMN ${ }^{13} \mathbf{C}: 40,5(2)\left(\mathrm{CH}_{3}\right) ; 55,9$ (2) $\left(\mathrm{CH}_{3}\right) ; 60,9\left(\mathrm{CH}_{3}\right) ; 105,8$ (2) $(\mathrm{CH}) ; 112,0$ (2) $(\mathrm{CH}) ; 125,1$

(C); 126,8 (CH); 130,1 (3) (CH); 133,6 (C); 136,7 (C); 149,7 (C); 152,9 (2) (C).

IR (película): 1606, 1585, 1516, 1236, 1126, $767 \mathrm{~cm}^{-1}$. 
HPLC: Columna $\mathrm{C}_{18} \quad \mathrm{t}_{\mathrm{R}}: 22,3$ min.

\section{$\underline{(E)-N, N \text {-dimetil-4-(2-(3,4,5-trimetoxifenil)vinil)anilina (23b): }}$}

RMN ${ }^{1} \mathbf{H}: 2,99(6 \mathrm{H}, \mathrm{s}) ; 3,87(3 \mathrm{H}, \mathrm{s}) ; 3,92(6 \mathrm{H}, \mathrm{s}) ; 6,74(2 \mathrm{H}, \mathrm{s}) ; 6,76(2 \mathrm{H}, \mathrm{d}, 8,8) ; 6,82(1 \mathrm{H}, \mathrm{d}$, $15,4) ; 6,96(1 \mathrm{H}, \mathrm{d}, 15,4) ; 7,40(2 \mathrm{H}, \mathrm{d}, 8,8)$.

RMN ${ }^{13} \mathbf{C}: 40,6(2)\left(\mathrm{CH}_{3}\right) ; 56,1(2)\left(\mathrm{CH}_{3}\right) ; 61,0\left(\mathrm{CH}_{3}\right) ; 103,0(2)(\mathrm{CH}) ; 112,6(2)(\mathrm{CH}) ; 124,4$ $(\mathrm{CH}) ; 125,8(\mathrm{C}) ; 127,6(2)(\mathrm{CH}) ; 128,4(\mathrm{CH}) ; 134,0(\mathrm{C}) ; 137,2$ (C); 150,0 (C); 153,4 (2) (C).

IR (película): 1583, 1520, 1234, 1126, $816 \mathrm{~cm}^{-1}$.

Pf (éter): $94-95^{\circ} \mathrm{C}$

HPLC: Columna $\mathrm{C}_{18} \quad \mathrm{t}_{\mathrm{R}}: 5,3 \mathrm{~min}$.

\section{Reacción de formilación de $23 a$}
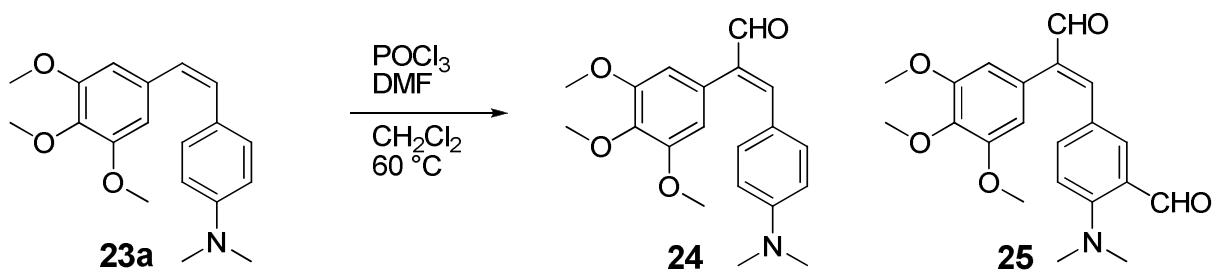

Se ponen en un matraz 1,93 $\mathrm{ml}(25,1 \mathrm{mmol})$ de DMF con 1,35 $\mathrm{ml}(14,7 \mathrm{mmol})$ de oxicloruro de fósforo a $0^{\circ} \mathrm{C}$, después de una hora de agitación se añaden $920 \mathrm{mg}(2,93 \mathrm{mmol})$ de $\mathbf{2 3 a}$ disuelto en $\mathrm{CH}_{2} \mathrm{Cl}_{2}$. La mezcla mantiene en agitación durante $4 \mathrm{~h}$ a $0{ }^{\circ} \mathrm{C}$, luego $20 \mathrm{~h} \mathrm{a} 60{ }^{\circ} \mathrm{C}$ en presencia de atmósfera de nitrógeno, el color pasa de naranja a amarillo. A continuación se disuelve en $\mathrm{CH}_{2} \mathrm{Cl}_{2}$ y se extrae con agua, se seca con sulfato sódico anhidro, se aíslan 1,42 $\mathrm{g}$ de crudo, que contiene una mezcla de $\mathbf{2 4}$ y 25 en proporción de 1:3.

El crudo se purifica por una cromatografía flash (Hex/AcOEt 6:4), obteniéndose $200 \mathrm{mg}$ (0,59 mmol, 20 \%) del aldehído 24 y 420 mg (1,37 mmol, 47 \%) del aldehído 25.

\section{3-(4-dimetilaminofenil)-2-(3,4,5-trimetoxifenil)acrilaldehído (24):}


RMN ${ }^{1} \mathbf{H}: 3,00(6 \mathrm{H}, \mathrm{s}) ; 3,80(6 \mathrm{H}, \mathrm{s}) ; 3,90(3 \mathrm{H}, \mathrm{s}) ; 6,42(2 \mathrm{H}, \mathrm{s}) ; 6,49(2 \mathrm{H}, \mathrm{d}, 9,4) ; 7,10(2 \mathrm{H}, \mathrm{d}$, 9,4); 7,26 (1H, s); 9,63 (1H, s).

RMN ${ }^{13} \mathbf{C}: 40,1(2)\left(\mathrm{CH}_{3}\right) ; 56,1\left(\mathrm{CH}_{3}\right) ; 61,0(2)\left(\mathrm{CH}_{3}\right) ; 106,2$ (2) $(\mathrm{CH}) ; 110,0(\mathrm{C}) ; 111,4$ (2) $(\mathrm{CH}) ; 121,5$ (C); 130,4 (C); 133,2 (2) (CH); 137,3 (C); 151,8 (C); 152,0 (CH); 153,9 (2) (C); 193,9 (CH).

IR (película): 2715; 1666; 1587; 1525; $1366 ; 1125 \mathrm{~cm}^{-1}$.

Pf (éter/ $\left.\mathrm{CH}_{2} \mathrm{Cl}_{2}\right): 155^{\circ} \mathrm{C}$

HMRS (m/z): Obtenido 364,1528 $\left(\mathrm{M}+\mathrm{Na}^{+}\right)$; esperado 364,1525 $\left(\mathrm{C}_{20} \mathrm{H}_{23} \mathrm{NNaO}_{4}{ }^{+}\right)$.

HPLC: Columna $\mathrm{C}_{18} \quad \mathrm{t}_{\mathrm{R}}: 14,6 \mathrm{~min}$.

\section{Reacción de formilación de 23}<smiles>COc1cc(/C=C\c2ccc(N(C)C)cc2)cc(OC)c1OC</smiles>
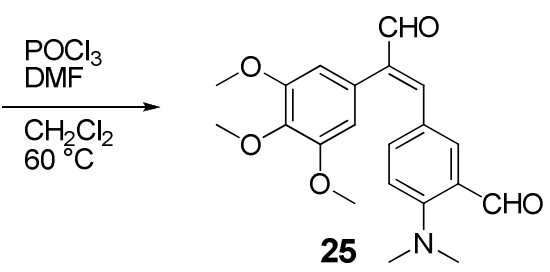<smiles>COc1cc(/C=C/c2ccc(N(C)C)c(C=O)c2)c(CO)c(OC)c1OC</smiles>

Se ponen en un matraz $1,5 \mathrm{ml}(18,5 \mathrm{mmol})$ de DMF con $0,52 \mathrm{ml}(5,55 \mathrm{mmol})$ de oxicloruro de fósforo a $0^{\circ} \mathrm{C}$, después de una hora de agitación se añaden $580 \mathrm{mg}(1,85 \mathrm{mmol})$ de 23 como mezcla $\mathrm{Z} / \mathrm{E}$ en proporción 7:3 disueltos en $\mathrm{CH}_{2} \mathrm{Cl}_{2}$. La mezcla se agita durante $4 \mathrm{~h}$ a $0^{\circ} \mathrm{C}$, luego $20 \mathrm{~h}$ a $60{ }^{\circ} \mathrm{C}$, el color cambia de naranja a amarillo. A continuación se disuelve en $\mathrm{CH}_{2} \mathrm{Cl}_{2}$ y se extrae con agua saturada con $\mathrm{NaCl}$, se seca con sulfato sódico anhidro, se aíslan $500 \mathrm{mg}$ de crudo, que contiene una mezcla de $\mathbf{2 5}$ y $\mathbf{2 6}$ en proporción de 8:2.

El crudo se purifica por cromatografía flash (Hex/AcOEt 6:4) obteniéndose $231 \mathrm{mg}(0,58$ mmol, $31 \%)$ del aldehído 25, $74 \mathrm{mg}(0,30 \mathrm{mmol}, 11 \%)$ del aldehído 26 y $150 \mathrm{mg}$ de la mezcla de ambos.

\section{$\underline{(E)-2-d i m e t i l a m i n o-5-(2-(2-f o r m i l-3,4,5-t r i m e t o x i f e n i l) e t e n i l) b e n z a l d e h i ́ d o ~(25): ~}$}


RMN ${ }^{1} \mathbf{H}: 3,00(6 \mathrm{H}, \mathrm{s}) ; 3,79(6 \mathrm{H}, \mathrm{s}) ; 3,90(3 \mathrm{H}, \mathrm{s}) ; 6,40(2 \mathrm{H}, \mathrm{s}) ; 6,72(1 \mathrm{H}, \mathrm{d}, 8,6) ; 7,11(1 \mathrm{H}$, dd, 2,1; 8,6); 7,30 (1H, s); 7,70 (1H, d, 2,1); 9,69 (1H, s); 9,92 (1H, s).

RMN ${ }^{13} \mathbf{C}: 44,5(2)\left(\mathrm{CH}_{3}\right) ; 56,2$ (2) $\left(\mathrm{CH}_{3}\right) ; 61,0\left(\mathrm{CH}_{3}\right) ; 106,1$ (2) $(\mathrm{CH}) ; 116,4(\mathrm{CH}) ; 124,1$ (2) (C); 129,3 (C); 135,6 (CH); 137,8 (CH); 138,0 (C); 139,5 (C); 149,6 (CH); 154,0 (2) (C); 155,0 (C); 189,4 (CH); 193,6 (CH).

HPLC: Columna $\mathrm{C}_{18} \quad \mathrm{t}_{\mathrm{R}}: 7,7 \mathrm{~min}$.

\section{$\underline{(E)-2-d i m e t i l a m i n o-5-(2-f o r m i l-3,4,5-(t r i m e t o x i f e n i l) e t e n i l) b e n z a l d e h i ́ d o ~(26): ~}$}

RMN ${ }^{1} \mathbf{H}: 2,97$ (6H, s); 3,90 (3H, s); 3,99 (6H, s); 6,89 (1H, d, 16,1); 6,93 (1H, s); 7,01 (1H, d, 8,6); 7,72 (1H, dd, 8,6; 2,1); 7,83 (1H, d, 2,1); 8,07 (1H, d, 16,1); 10,19 (1H, s); 10,44 (1H, s).

RMN ${ }^{13} \mathbf{C}: 45,3(2)\left(\mathrm{CH}_{3}\right) ; 56,2\left(\mathrm{CH}_{3}\right) ; 61,1\left(\mathrm{CH}_{3}\right) ; 62,5\left(\mathrm{CH}_{3}\right) ; 105,1(\mathrm{CH}) ; 117,8(\mathrm{CH})$; $120,3(\mathrm{C}) ; 125,7(\mathrm{CH}) ; 126,1(\mathrm{C}) ; 129,3(\mathrm{C}) ; 130,8(2)(\mathrm{CH}) ; 132,1(\mathrm{CH}) ; 136,7(\mathrm{C}) ; 141,0$ (C); 155,1 (C); 158,0 (2) (C); 190,8 (CH); 191,2 (CH).

IR (película): 2940; 2846; 1677; 1550; $1127 \mathrm{~cm}^{-1}$.

HMRS (m/z): Obtenido 370,1657 $\left(\mathrm{M}+\mathrm{H}^{+}\right)$; esperado 370,1654 $\left(\mathrm{C}_{21} \mathrm{H}_{23} \mathrm{NO}_{5}{ }^{+}\right)$.

HPLC: Columna $\mathrm{C}_{18} \quad \mathrm{t}_{\mathrm{R}}: 16,6 \mathrm{~min} ; \mathrm{t}_{\mathrm{R}}: 18,9 \mathrm{~min}$.

\section{Preparación la oxima del aldehído 24}
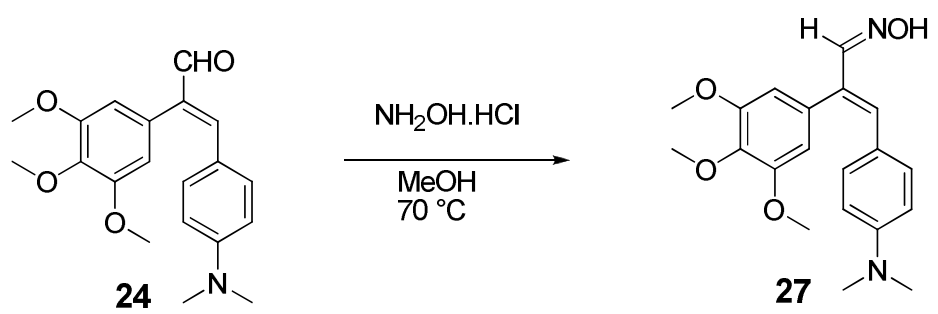

Se disuelven $250 \mathrm{mg}(0,73 \mathrm{mmol})$ del aldehído 24 en $20 \mathrm{ml}$ de metanol, después se añaden $205 \mathrm{mg}$ (2,93 mmol) de clorhidrato de hidroxilamina, apareciendo color naranja. La mezcla se agita durante $24 \mathrm{~h} \mathrm{a} 70^{\circ} \mathrm{C}$, luego se evapora el metanol y se extrae con agua/AcOEt y se 
obtienen $500 \mathrm{mg}$. El crudo se cristaliza en AcOEt/MeOH, aislándose $80 \mathrm{mg}$ (0,23 mmol, 32

$\%)$ de cristales de la oxima 27.

\section{Oxima de 3-(4-(dimetilamino)fenil)-2-(3,4,5-trimetoxifenil)acrilaldehído (27):}

$\mathbf{R M N}^{1} \mathbf{H}: 2,93$ (6H, s); 3,79 (6H, s); 3,91 (3H, s); 6,44 (2H, s); 6,47 (2H, d, 9,0); 6,64 (1H, s); $6,88(2 \mathrm{H}, \mathrm{d}, 9,0) ; 7,97(1 \mathrm{H}, \mathrm{s})$.

IR (KBr): 3480; 1598; 1521; 1363; 1235; $1126 \mathrm{~cm}^{-1}$.

Pf $\left(\mathbf{C H}_{2} \mathbf{C l}_{2}\right): 144-145^{\circ} \mathrm{C}$

\section{Preparación de la oxima 28}
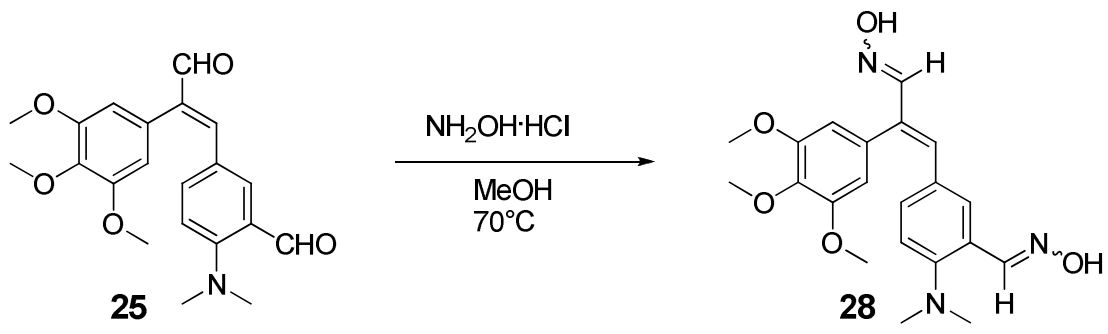

Se disuelven $338 \mathrm{mg}$ (0,91 mmol) del dialdehído 25 en $10 \mathrm{ml}$ de metanol, después se añaden $318 \mathrm{mg}(4,57 \mathrm{mmol})$ de clorhidrato de hidroxilamina y tres gotas de piridina apareciendo coloración naranja. La mezcla se agita durante $24 \mathrm{~h}$ a $70^{\circ} \mathrm{C}$, luego se evapora el metanol. El crudo se cristaliza en éter/ $\mathrm{CH}_{2} \mathrm{Cl}_{2}$ y se aíslan $173 \mathrm{mg}(0,43 \mathrm{mmol}, 48 \%)$ de cristales amarillos de 28.

Dioxima de 2-dimetilamino-5-[-2-formil-2-(3,4,5-trimetoxifenil)etenil]benzaldehído (28):

RMN ${ }^{1} \mathbf{H}$ (CD $\left.\mathbf{C D}_{3} \mathbf{O D}\right): 3,18(6 \mathrm{H}, \mathrm{s}) ; 3,62$ (3H, s); 3,70 (6H, s); 6,40 (2H, s); 6,79 (1H, s); 7,06 $(1 \mathrm{H}, \mathrm{d}, 8,6) ; 7,18(1 \mathrm{H}, \mathrm{s}) ; 7,59(1 \mathrm{H}, \mathrm{d}, 8,6) ; 7,97(2 \mathrm{H}, \mathrm{s})$.

RMN ${ }^{13} \mathbf{C}$ (DMSO-D $)$ : 44,6 (2) $\left(\mathrm{CH}_{3}\right) ; 56,0(2)\left(\mathrm{CH}_{3}\right) ; 61,2\left(\mathrm{CH}_{3}\right) ; 106,4(2)(\mathrm{CH}) ; 109,1$ (C); 119,8 (CH); 125,0 (C); 129,8 (CH); 130,0 (CH); 131,9 (CH); 132,6 (C); 137,1 (2) (C); $145,9(\mathrm{CH}) ; 148,0(\mathrm{C}) ; 153,0(\mathrm{CH}) ; 153,2$ (2) (C).

IR (KBr): 3206; 1581; 1460; $1124 \mathrm{~cm}^{-1}$. 
Pf $\left(\mathrm{Eter} / \mathrm{CH}_{2} \mathrm{Cl}_{2}\right): 131-132{ }^{\circ} \mathrm{C}$

HMRS (m/z): Obtenido 400,1865 $\left(\mathrm{M}+\mathrm{H}^{+}\right)$; esperado 400,1867 $\left(\mathrm{C}_{21} \mathrm{H}_{26} \mathrm{~N}_{3} \mathrm{O}_{5}{ }^{+}\right)$.

HPLC: Columna $\mathrm{C}_{18} \quad \mathrm{t}_{\mathrm{R}}: 10,0 \mathrm{~min} ; \mathrm{t}_{\mathrm{R}}: 15,8 \mathrm{~min}$.

\section{Preparación del nitrilo 29}

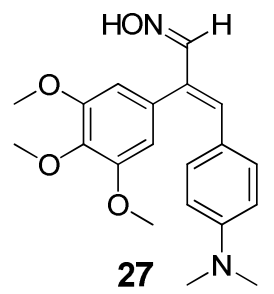

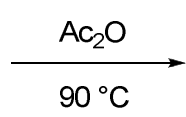

27<smiles>COc1cc(/C(C#N)=C\c2ccc(N(C)C)cc2)cc(OC)c1OC</smiles>

29

Se disuelven $400 \mathrm{mg}(1,22 \mathrm{mmol})$ de las aguas madres de la oxima 27 en $10 \mathrm{ml}(80 \mathrm{mmol}) \mathrm{de}$ anhídrido acético, la mezcla pone color marrón. La reacción se agita durante $24 \mathrm{~h}$ a $90{ }^{\circ} \mathrm{C}$. Posteriormente se quita la reacción diluyéndose en $\mathrm{CH}_{2} \mathrm{Cl}_{2}$, se lava con $\mathrm{NaHCO}_{3}$ al $5 \%$, se extrae con agua y $\mathrm{CH}_{2} \mathrm{Cl}_{2}$, se evapora el disolvente y se obtienen $305 \mathrm{mg}$.

El crudo se purifica por cromatografía flash (Hex/AcOEt 7:3) y se aíslan $125 \mathrm{mg}(0,37 \mathrm{mmol}$, $30 \%$ ) del compuesto 29.

\section{$\underline{\text { 3-(4-dimetilaminofenil)-2-(3,4,5-trimetoxifenil) acrilonitrilo (29): }}$}

RMN ${ }^{1} \mathbf{H}$ (CD) $\left.\mathbf{O D}\right): 2,97$ (6H, s); 3,76 (6H, s); 3,85 (3H, s); 6,59 (2H, s); 6,61 (2H, d, 9,2); 7,52 (2H, d, 9,2); 8,24 (1H, s).

RMN ${ }^{13} \mathbf{C}\left(\mathbf{C D}_{3} \mathbf{O D}\right): 40,3$ (2) $\left(\mathrm{CH}_{3}\right) ; 56,4(2)\left(\mathrm{CH}_{3}\right) ; 61,2\left(\mathrm{CH}_{3}\right) ; 95,1(\mathrm{C}) ; 106,1$ (2) (CH); $111,8(2)(\mathrm{CH}) ; 114,0(\mathrm{C}) ; 115,2$ (C); 126,7 (C); 128,5 (2) (CH); 137,8 (C); 151,4 (CH); 152,0 (2) (C); 153,7 (C).

IR (película): 2211; 1728; 1609; 1232; $1126 \mathrm{~cm}^{-1}$.

HMRS (m/z): Obtenido 339,1708 $\left(\mathrm{M}+\mathrm{H}^{+}\right)$; esperado 339,1709 $\left(\mathrm{C}_{20} \mathrm{H}_{23} \mathrm{~N}_{2} \mathrm{O}_{3}{ }^{+}\right)$. 


\section{Preparación del dinitrilo 30}
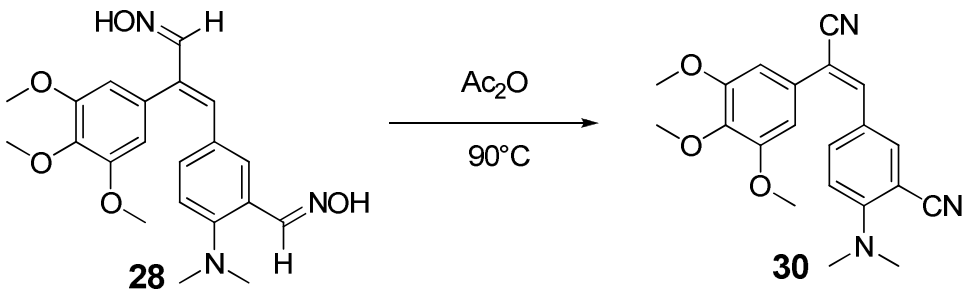

Se disuelven $400 \mathrm{mg}$ (1,00 mmol) de la dioxima 28 en 5,0 $\mathrm{ml}(53 \mathrm{mmol})$ de anhídrido acético, la mezcla se pone de color marrón. La reacción se agita durante 24 h a $90{ }^{\circ} \mathrm{C}$. Posteriormente se extrae con $\mathrm{CH}_{2} \mathrm{Cl}_{2}$ y se lava con $\mathrm{NaHCO}_{3}$ y se evapora el disolvente, se obtiene $307 \mathrm{mg}$ de crudo de reacción.

El crudo se purifica por cromatografía flash (Hex/AcOEt 8:2), aislándose $100 \mathrm{mg}(0,27$ mmol, $28 \%$ ) del compuesto 30, que se cristaliza en (hexano/ $\mathrm{CH}_{2} \mathrm{Cl}_{2}$ ) y se obtiene unos cristales amarillos.

\section{5-(2-ciano-2-(3,4,5-trimetoxifenil)etenil)-2-(dimetilamino)benzonitrilo (30):}

$\mathbf{R M N}^{1} \mathbf{H}: 3,24(6 \mathrm{H}, \mathrm{s}) ; 3,88(3 \mathrm{H}, \mathrm{s}) ; 3,93(6 \mathrm{H}, \mathrm{s}) ; 6,82(2 \mathrm{H}, \mathrm{s}) ; 6,88(1 \mathrm{H}, \mathrm{d}, 8,8) ; 7,27$ (1H, s); $7,81(1 \mathrm{H}, \mathrm{d}, 2,4) ; 8,16(1 \mathrm{H}, \mathrm{dd}, 8,8,2,4)$.

RMN ${ }^{13} \mathbf{C}: 42,4(2)\left(\mathrm{CH}_{3}\right) ; 56,3(2)\left(\mathrm{CH}_{3}\right) ; 61,0\left(\mathrm{CH}_{3}\right) ; 97,8(\mathrm{C}) ; 103,0(2)(\mathrm{CH}) ; 108,6(\mathrm{C})$; 115,9 (CH); 118,3 (C); 119,4 (C); 123,3 (C); 130,1 (CH); 132,8 (CH); 134,1 (C); 138,2 (C); $139,2(\mathrm{CH}) ; 153,6(2)(\mathrm{C}) ; 154,4(\mathrm{C})$.

IR (KBr): 2207; 1603; 1505; 1454; 1413;1411; 1239; $1127 \mathrm{~cm}^{-1}$.

Pf $\left(\mathrm{Hexano} / \mathrm{CH}_{2} \mathrm{Cl}_{2}\right): 190-191{ }^{\circ} \mathrm{C}$

HMRS (m/z): Obtenido 364,1658 $\left(\mathrm{M}+\mathrm{H}^{+}\right)$; esperado 364,1661 $\left(\mathrm{C}_{21} \mathrm{H}_{24} \mathrm{~N}_{3} \mathrm{O}_{3}{ }^{+}\right)$. 


\section{Metilación de las combretastatinas (Z/E) 23}
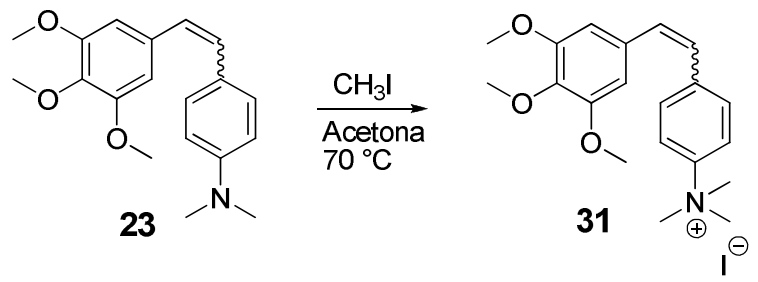

Se disuelven $290 \mathrm{mg}(0,92 \mathrm{mmol})$ de la mezcla $Z / E$ en proporción 1:1 de combretastatina 23 en $10 \mathrm{ml}$ de acetona, después se añaden $1,7 \mathrm{ml}(27,5 \mathrm{mmol})$ de yodometano y aparece un color amarillo. La mezcla se agita durante $48 \mathrm{~h}$ a $70^{\circ} \mathrm{C}$ en un tubo sellado, luego se evapora la acetona y se obtienen $260 \mathrm{mg}$ de crudo de reacción como mezcla de isómeros en proporción $7: 3$, se purifica mediante sucesivas cristalizaciones en acetona/AcOEt. Finalmente, por cristalización en acetona/AcOEt, se obtienen $61 \mathrm{mg}(0,19 \mathrm{mmol}, 21 \%)$ de una mezcla enriquecida en el isómero $Z$ (9:1) de $\mathbf{3 1}$.

\section{Yoduro de (Z)- $N, N, N$-trimetil-4-(2-(3,4,5-trimetoxifenil)etenil)bencenamonio (31):}

RMN ${ }^{1} \mathbf{H}: 3,65(6 \mathrm{H}, \mathrm{s}) ; 3,79(3 \mathrm{H}, \mathrm{s}) ; 3,95(9 \mathrm{H}, \mathrm{s}) ; 6,37(2 \mathrm{H}, \mathrm{s}) ; 6,48(1 \mathrm{H}, \mathrm{d} ; 12,2) ; 6,64(1 \mathrm{H}$, $\mathrm{d} ; 12,2) ; 7,45(2 \mathrm{H}, \mathrm{d} ; 8,6) ; 7,84(2 \mathrm{H}, \mathrm{d} ; 8,6)$.

RMN ${ }^{13} \mathbf{C}: 56,2(2)\left(\mathrm{CH}_{3}\right) ; 57,9(3)\left(\mathrm{CH}_{3}\right) ; 60,9\left(\mathrm{CH}_{3}\right) ; 105,8(2)(\mathrm{CH}) ; 120,0(2)(\mathrm{CH}) ; 127,2$ $(\mathrm{CH}) ; 131,0$ (2) (CH), 132,9 (CH); 138,4 (C); 139,6 (C); 139,8 (C); 145,4 (C); 153,4 (2) (C).

Yoduro de (E)- $N, N, N$-trimetil-4-(2-(3,4,5-trimetoxifenil)etenil)bencenamonio (31):

\section{Datos sacados de la mezcla $\mathrm{Z} / \mathrm{E}$}

RMN ${ }^{1} \mathbf{H}: 3,80(3 \mathrm{H}, \mathrm{s}) ; 3,90(6 \mathrm{H}, \mathrm{s}) ; 3,97(9 \mathrm{H}, \mathrm{s}) ; 6,75(2 \mathrm{H}, \mathrm{s}) ; 7,00(1 \mathrm{H}, \mathrm{d} ; 16,2) ; 7,15(1 \mathrm{H}$, d; 16,2); 7,67 (2H, d; 8,8); 7,96 (2H, d; 8,8).

RMN ${ }^{13} \mathbf{C}$ (señales diferenciales): 60,3 $\left(\mathrm{CH}_{3}\right) ; 104,0(\mathrm{CH}) ; 120,6(\mathrm{CH}) ; 125,2(\mathrm{CH}) ; 128,0$ $(\mathrm{CH}), 131,7(\mathrm{CH}) ; 137,5(\mathrm{C})$.

IR (KBr): 1581, 1240, 1125, $844 \mathrm{~cm}^{-1}$. Pf (Acetona/AcOEt): $75^{\circ} \mathrm{C}$

HRMS (m/z): Obtenido 328,1916 $\left(\mathrm{M}^{+}\right)$; esperado 328, $1913\left(\mathrm{C}_{20} \mathrm{H}_{26} \mathrm{NO}_{3}{ }^{+}\right)$. 


\section{Intento de preparación de la sal de amonio 31}

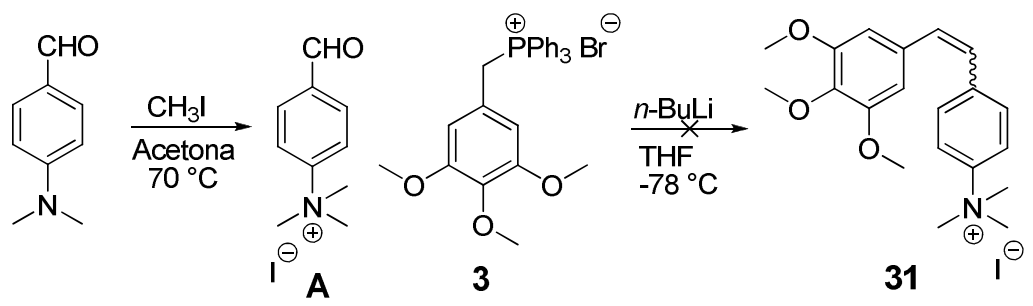

Se disuelven 1,50 g (10,1 mmol) de 4-dimetilaminobenzaldehído en $10 \mathrm{ml}$ de acetona, después se le añaden 1,9 $\mathrm{ml}(30 \mathrm{mmol})$ de yodometano, aparece un color amarillo. La reacción se agita durante $12 \mathrm{~h}$ a $70{ }^{\circ} \mathrm{C}$, posteriormente se le añade el éter y se forma un sólido amarillo que se filtra para obtener 1,60 g (9,74 mmol, $97 \%)$ de A.

Siguiendo el procedimiento habitual de la preparacion de las combretastatinas se disuelven $3,35 \mathrm{~g}(6,39 \mathrm{mmol})$ de la sal de fosfonio 3 en $30 \mathrm{ml}$ de THF y se le añaden 4,0 $\mathrm{ml}(6,4 \mathrm{mmol})$ de $n$-BuLi 1,6 M en hexano a $-78{ }^{\circ} \mathrm{C}$ en presencia de atmósfera de nitrógeno, aparece un color naranja, despues de $1 \mathrm{~h}$ de agitación, se le añaden $750 \mathrm{mg}(4,75 \mathrm{mmol})$ del compuesto $\mathbf{A}$ disuelto en THF, el color pasa de naranja a amarillo. La mezcla se agita durante $24 \mathrm{~h}$ a temperatura ambiente, luego se trata con $\mathrm{NH}_{4} \mathrm{Cl}$, se evapora el THF y se extrae con AcOEt, obteniéndose 2,01 g del crudo de reacción, del que no se aísla el compuesto 31 ni se identifican otros productos de reacción.

\section{Datos del compuesto A}

Yoduro de 4-formil- $N, N, N$-trimetilbencenamonio (A):

$\mathbf{R M N}^{1} \mathbf{H}: 3,72(9 \mathrm{H}, \mathrm{s}) ; 7,39(2 \mathrm{H}, \mathrm{d}, 8,6) ; 7,85(2 \mathrm{H}, \mathrm{d}, 8,6) ; 9,91(1 \mathrm{H}, \mathrm{s})$.

$\mathbf{R M N}^{13} \mathbf{C}: 57,2(3)\left(\mathrm{CH}_{3}\right) ; 122,0(2)(\mathrm{CH}) ; 128,8(2)(\mathrm{CH}) ; 131,5(\mathrm{C}) ; 146,5(\mathrm{C}) ; 190,7(\mathrm{CH})$. 


\section{2. Derivados piridínicos}

\section{A. Análogos de isocombretastatinas}

\section{Preparación del dimetilaminoderivado 32}

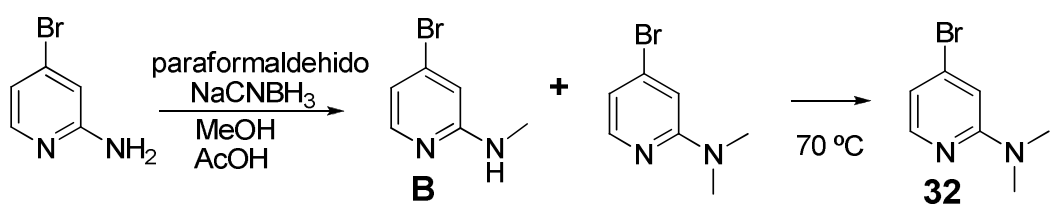

Sobre una disolución de 1,50 g (8,67 mmol) de 2-amino-4-bromopiridina en $10 \mathrm{ml}$ de $\mathrm{MeOH}$ y en agitación, se añaden 2,80 g (44,5 mmol) de cianoborohidruro sódico y 1,07 g (35,6 mmol) de paraformaldehído. Se continúa en agitación durante 24 h a temperatura ambiente observándose una coloración amarilla. Después de la evaporación del disolvente, se extrae con agua/AcOEt, se seca con $\mathrm{Na}_{2} \mathrm{SO}_{4}$ y se obtienen $1,43 \mathrm{~g}(7,11 \mathrm{mmol})$ de aceite amarillo, en el que se ve que han formado dos productos $\mathbf{B}$ y 32. La reacción se vuelve a poner a reflujo y se transforma todo a $\mathbf{3 2}$.

El crudo se purifica por cromatografía flash (Hex/AcOEt; 6:4), obteniéndose 946 mg (4,70 mmol; $54 \%$ ) del compuesto 32.

\section{4-bromo- $N$-metilamino piridina (B): (datos sacados de la mezcla)}

$\mathbf{R M N}^{1} \mathbf{H}: 2,89(3 \mathrm{H}, \mathrm{s}) ; 6,31(1 \mathrm{H}, \mathrm{d}, 8,8) ; 7,53(1 \mathrm{H}, \mathrm{dd}, 8,8,2,4) ; 8,06(1 \mathrm{H}, \mathrm{d}, 2,4)$.

\section{4-bromo- $N, N$-dimetilamino piridina (32):}

$\mathbf{R M N}^{1} \mathbf{H}:$ 2,97 (6H, s); 6,30 (1H, d, 8,8); 6,70 (1H, dd, 8,8, 2,4); 7,95 (1H, d, 2,4).

RMN ${ }^{13} \mathbf{C}: 38,2(2)\left(\mathrm{CH}_{3}\right) ; 105,9(\mathrm{CH}) ; 107,2(\mathrm{C}) ; 139,3(\mathrm{CH}) ; 148,3(\mathrm{CH}) ; 157,8(\mathrm{C})$.

IR (película): 1588; 1545; 1508; 1319; 1213; $807 \mathrm{~cm}^{-1}$. 


\section{Síntesis de la fenstatina 33}

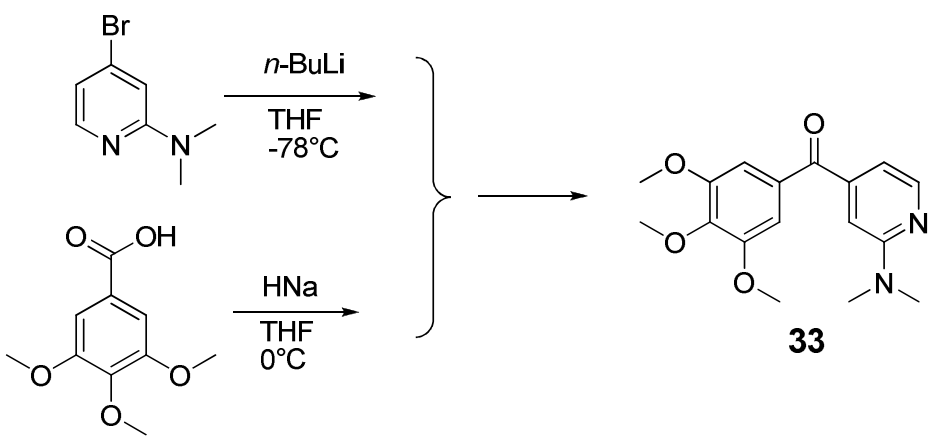

Se disuelven $713 \mathrm{mg}$ (3,54 mmol) de 32 en $30 \mathrm{ml}$ de THF y se le añaden 2,9 ml (4,6 mmol) de $n$-BuLi a $-78{ }^{\circ} \mathrm{C}$ en atmósfera de nitrógeno, la coloración pasa de amarillo a marrón. En paralelo se prepara una disolución de 1,50 g (7,07 mmol) del ácido 3,4,5-trimetoxibenzoico en $60 \mathrm{ml}$ de THF y se trata con $425 \mathrm{mg}(17,7 \mathrm{mmol})$ de $\mathrm{HNa}$ a $0{ }^{\circ} \mathrm{C}$ en presencia de $\mathrm{N}_{2}$, apareciendo un color amarillo. Después de una hora en agitación, se adiciona la primera reacción sobre la segunda permaneciendo el color amarillo. La reacción se deja 24 h a temperatura ambiente. Posteriormente se evapora el THF y se trata con $\mathrm{NH}_{4} \mathrm{Cl}$, se extrae con AcOEt, se seca con $\mathrm{Na}_{2} \mathrm{SO}_{4}$ y evapora el disolvente, obteniéndose $874 \mathrm{mg}$ de crudo de reacción.

El crudo se purifica con cromatografía flash (Hex/AcOEt, 7:3), aislándose $282 \mathrm{mg}(0,90$ mmol, $26 \%$ ) del compuesto 33. Esta fracción se cristaliza en Hex/AcOEt aislándose 81 mg de cristales amarillos.

\section{(2-dimetilaminopiridin-4-il)(3,4,5-trimetoxifenil)metanona (33):}

RMN ${ }^{1} \mathbf{H}: 3,13(6 \mathrm{H}, \mathrm{s}) ; 3,86(6 \mathrm{H}, \mathrm{s}) ; 3,93(3 \mathrm{H}, \mathrm{s}) ; 6,72(1 \mathrm{H}, \mathrm{d}, 9,4) ; 6,75(1 \mathrm{H}, \mathrm{d}, 2,2) ; 7,10$ $(2 \mathrm{H}, \mathrm{s}) ; 8,27(1 \mathrm{H}, \mathrm{dd}, 9,4,2,2)$.

RMN ${ }^{13} \mathrm{C}: 37,9$ (2) $\left(\mathrm{CH}_{3}\right) ; 56,1(2)\left(\mathrm{CH}_{3}\right) ; 60,7\left(\mathrm{CH}_{3}\right) ; 105,0(\mathrm{CH}) ; 107,6(2)(\mathrm{CH}) ; 110,4$ $(\mathrm{CH}) ; 131,2$ (C); 142,5 (C); 146,1 (C); 148,1 (CH); 152,8 (2) (C); 159,3 (C); 194,9 (C).

IR (película): 1659; 1595, 1411; 1328; $1125 \mathrm{~cm}^{-1}$.

Pf (Hexano/AcOEt): $101-102{ }^{\circ} \mathrm{C}$

HMRS (m/z): Obtenido 317,1498 $\left(\mathrm{M}+\mathrm{H}^{+}\right)$; esperado 317,1501 $\left(\mathrm{C}_{17} \mathrm{H}_{20} \mathrm{~N}_{2} \mathrm{O}_{4}{ }^{+}\right)$. 
HPLC: Columna $\mathrm{C}_{18} \quad \mathrm{t}_{\mathrm{R}}: 11,7 \mathrm{~min}$.

\section{Preparación de la oxima 34}<smiles>COc1cc(C(=O)c2ccnc(N(C)C)c2)cc(OC)c1OC</smiles>

33

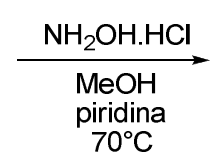

$70^{\circ} \mathrm{C}$

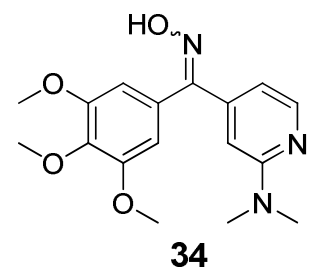

34

Se disuelve $55 \mathrm{mg}(0,17 \mathrm{mmol})$ del compuesto 33 en $5 \mathrm{ml}$ de metanol, después se le añaden $40 \mathrm{mg}(0,54 \mathrm{mmol})$ de clorhidrato de hidroxilamina y tres gotas de piridina. La reacción se agita durante $22 \mathrm{~h}$ a $70^{\circ} \mathrm{C}$. Posteriormente se evapora el metanol y se extrae con agua y AcOEt, obteniéndose $48 \mathrm{mg}$ de un aceite amarillo.

El crudo se purifica por cromatografía flash (Hex/AcOEt 1:1) y se aíslan $12 \mathrm{mg}(0,04 \mathrm{mmol}$, $23 \%$ ) de la mezcla $Z / E$ del compuesto 34 en proporción 4:6.

\section{Oximas de (2-dimetilaminopirid-4-il)(3,4,5-trimetoxifenil)metanona (34):}

\section{Datos de la mezcla}

Isómero (Z):

RMN 1H: 3,11 (6H, s); 3,86 (6H, s); 3,91 (3H, s); 6,61 (2H, s); 6,66 (1H, s); 8,13 (1H, d, 5,4); $8,25(1 \mathrm{H}, \mathrm{d}, 5,4)$.

Isómero (E):

RMN 1H: 3,16 (6H, s); 3,79 (6H, s); 3,83 (3H, s); 6,47 (1H, s); 6,50 (1H, d, 5,4); 6,74 (2H, s); $8,22(1 \mathrm{H}, \mathrm{d}, 5,4)$.

RMN ${ }^{13} \mathbf{C}: 38,6(2)\left(\mathrm{CH}_{3}\right) ; 56,2(2)\left(\mathrm{CH}_{3}\right) ; 60,9\left(\mathrm{CH}_{3}\right) ; 104,1(\mathrm{CH}) ; 104,8(2)(\mathrm{CH}) ; 110,0$ (CH); 126,7 (C); 130,4 (C); 146,1 (C); 142,3 (CH); 153,1 (2) (C); 156,3 (C); 158,9 (C).

IR (película): 3205; 1650; 1586; 1458; 1236; $1125 \mathrm{~cm}^{-1}$.

HMRS (m/z): Obtenido 332,1609 $\left(\mathrm{M}+\mathrm{H}^{+}\right)$; esperado 332,1610 $\left(\mathrm{C}_{17} \mathrm{H}_{22} \mathrm{~N}_{3} \mathrm{O}_{4}{ }^{+}\right)$. 
HPLC: Columna $\mathrm{C}_{18} \quad \mathrm{t}_{\mathrm{R}}: 20,3 \mathrm{~min} ; \mathrm{t}_{\mathrm{R}}: 21,4 \mathrm{~min}$.

\section{Obtención de la isocombretastatina 35}<smiles>COc1cc(C(=O)c2ccnc(N(C)C)c2)cc(OC)c1OC</smiles><smiles>C=C(c1ccnc(N(C)C)c1)c1cc(OC)c(OC)c(OC)c1</smiles>

$510 \mathrm{mg}(1,26 \mathrm{mmol})$ de la sal de fosfonio 1 se disuelven en $50 \mathrm{ml}$ de THF y después se le añaden 1,0 $\mathrm{ml}(1,5 \mathrm{mmol})$ de $n$-BuLi 1,6 $\mathrm{M}$ en hexano. La reacción se agita durante $1 \mathrm{~h}$ a -78 ${ }^{\circ} \mathrm{C}$ en presencia de atmósfera de nitrógeno, posteriormente se añade $141 \mathrm{mg}(0,44 \mathrm{mmol}) \mathrm{del}$ compuesto 33 disuelto también en THF, se pone de color amarillo. La reacción se agita durante $24 \mathrm{~h}$ a temperatura ambiente y luego se extrae con agua y AcOEt, obteniéndose 147 mg de crudo de reacción.

El crudo se purifica por cromatografía flash $\left(\mathrm{CH}_{2} \mathrm{Cl}_{2} / \mathrm{AcOEt}\right.$ 9:1), se aíslan $102 \mathrm{mg}(0,32$ mmol; $73 \%$ ) del compuesto 35 .

\section{2-dimetilamino-4-(1-(3,4,5-trimetoxifenil)vinil)piridina (35):}

$\mathbf{R M N}^{1} \mathbf{H}: 3,10(6 \mathrm{H}, \mathrm{s}) ; 3,82(6 \mathrm{H}, \mathrm{s}) ; 3,88(3 \mathrm{H}, \mathrm{s}) ; 5,51(1 \mathrm{H}, \mathrm{s}) ; 5,53(1 \mathrm{H}, \mathrm{s}) ; 6,49(1 \mathrm{H}, \mathrm{d}, 8,2)$; $6,52(1 \mathrm{H}, \mathrm{s}) ; 6,53(2 \mathrm{H}, \mathrm{s}) ; 8,12(1 \mathrm{H}, \mathrm{d}, 8,2)$;

RMN ${ }^{13} \mathbf{C}$ (CD $\mathbf{C D}$ ): 37,1 (2) $\left(\mathrm{CH}_{3}\right) ; 55,0$ (2) $\left(\mathrm{CH}_{3}\right) ; 59,5\left(\mathrm{CH}_{3}\right) ; 105,1$ (2) (CH); 110,9 $(\mathrm{CH}) ; 111,9(\mathrm{CH}) ; 114,9\left(\mathrm{CH}_{2}\right) ; 135,8(\mathrm{C}) ; 137,6(\mathrm{C}) ; 146,5(\mathrm{CH}) ; 148,6(\mathrm{C}) ; 150,3(\mathrm{C})$; 152,6 (2) (C); 159,3 (C).

IR (película): 1594; 1541; 1502; 1409; 1234; $1127 \mathrm{~cm}^{-1}$.

HMRS (m/z): Obtenido 315,1718 $\left(\mathrm{M}+\mathrm{H}^{+}\right)$; esperado 315,1704 $\left(\mathrm{C}_{18} \mathrm{H}_{23} \mathrm{~N}_{2} \mathrm{O}_{3}{ }^{+}\right)$.

HPLC: Columna $\mathrm{C}_{18} \quad \mathrm{t}_{\mathrm{R}}: 16,1 \mathrm{~min}$. 


\section{Síntesis de la fenstatina 36}

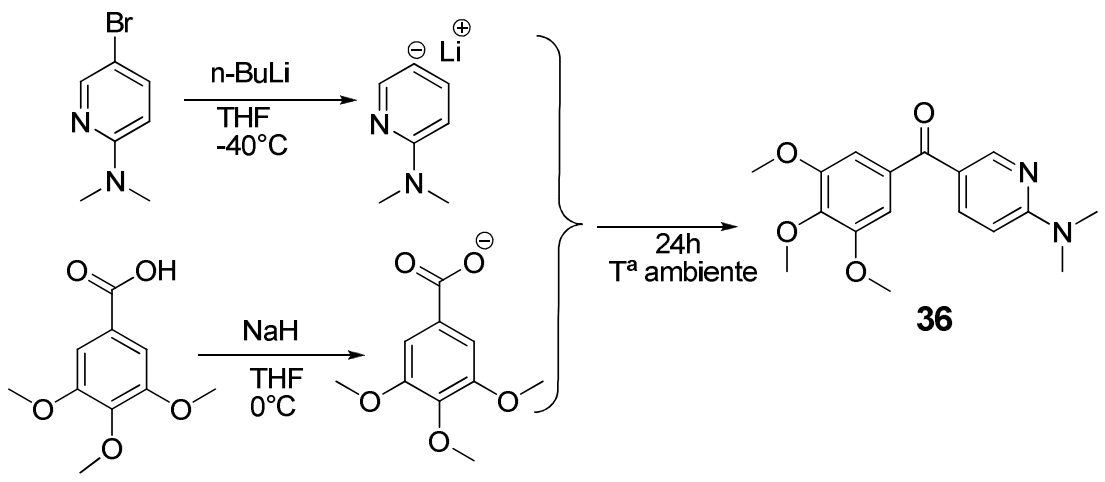

Se disuelven $627 \mathrm{mg}$ (3,12 mmol) de 5-bromo- $N$, $N$-dimetilpiridin-2-amina en $30 \mathrm{ml}$ de THF y se le añaden $1,9 \mathrm{ml}(3,1 \mathrm{mmol})$ de $n$-BuLi $1,6 \mathrm{M}$ en hexano a $-78{ }^{\circ} \mathrm{C}$ en atmósfera de nitrógeno, la coloración pasa de amarillo a naranja. En paralelo se prepara una disolución de 1,32 g (6,22 mmol) del ácido 3,4,5-trimetoxibenzoico en $60 \mathrm{ml}$ de THF y se trata con $370 \mathrm{mg}$ $(15,41 \mathrm{mmol})$ de $\mathrm{HNa}$ al $60 \%$ a $0{ }^{\circ} \mathrm{C}$, apareciendo un color amarillo. Después de una hora en agitación, se adiciona la primera reacción sobre la segunda permaneciendo el color amarillo. La reacción se deja 24 h a temperatura ambiente. Posteriormente se evapora el THF y se trata con $\mathrm{NH}_{4} \mathrm{Cl}$, se extrae con AcOEt, se seca con $\mathrm{Na}_{2} \mathrm{SO}_{4}$ y evapora el disolvente, obteniéndose $1,25 \mathrm{~g}$ de crudo de reacción.

El crudo se purifica con cromatografía flash (Hex/AcOEt, 9:1), aislándose $833 \mathrm{mg}$ (2,63 mmol, $84 \%$ ) del compuesto 36. Esta fracción se cristaliza en diisopropileter aislándose 254 mg de cristales amarillos.

\section{(2-dimetilaminopirid-4-il)(3,4,5-trimetoxifenil)metanona (36):}

RMN ${ }^{1} \mathbf{H}: 3,20(6 \mathrm{H}, \mathrm{s}) ; 3,88(6 \mathrm{H}, \mathrm{s}) ; 3,91(3 \mathrm{H}, \mathrm{s}) ; 6,56(1 \mathrm{H}, \mathrm{d}, 9,2) ; 6,99(2 \mathrm{H}, \mathrm{s}) ; 8,01$ (1H, dd, $9,2,2,4) ; 8,63(1 \mathrm{H}, \mathrm{d}, 2,4)$.

RMN ${ }^{13} \mathrm{C}: 38,2(2)\left(\mathrm{CH}_{3}\right) ; 56,3(2)\left(\mathrm{CH}_{3}\right) ; 60,9\left(\mathrm{CH}_{3}\right) ; 105,1(\mathrm{CH}) ; 107,0(2)(\mathrm{CH}) ; 121,2$ (C); 133,7 (C); 138,8 (CH); 143,4 (C); 152,4 (CH); 152,8 (2) (C); 160,4 (C); 187,6 (C).

IR (KBr): 1686; 1608; 1584; 1508; 1403; 1337; $1132 \mathrm{~cm}^{-1}$.

Pf (diisopropiléter): $119-120^{\circ} \mathrm{C}$

HMRS (m/z): Obtenido 317,1507 $\left(\mathrm{M}+\mathrm{H}^{+}\right)$; esperado 317,1501 $\left(\mathrm{C}_{17} \mathrm{H}_{21} \mathrm{~N}_{2} \mathrm{O}_{4}{ }^{+}\right)$. 
HPLC: Columna $\mathrm{C}_{18} \quad \mathrm{t}_{\mathrm{R}}: 7,4 \mathrm{~min}$.

\section{Síntesis de la isocombretastatina 37}
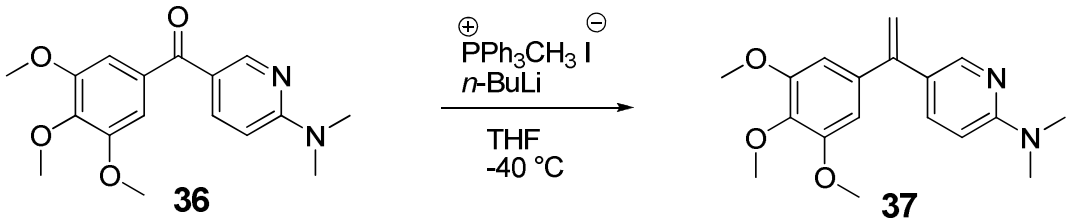

Se disuelven $485 \mathrm{mg}(1,20 \mathrm{mmol})$ de yoduro de metiltrifenilfosfonio en $40 \mathrm{ml}$ de THF, después se le añaden $226 \mu \mathrm{l}(1,0 \mathrm{mmol})$ de $n$-BuLi a $-40{ }^{\circ} \mathrm{C}$, aparece color amarillo. La mezcla se agita durante $1 \mathrm{~h} \mathrm{a}-40{ }^{\circ} \mathrm{C}$ en presencia de atmósfera de nitrógeno, luego se añaden $127 \mathrm{mg}(0,40 \mathrm{mmol})$ de la cetona 36 disuelta en $10 \mathrm{ml}$ de THF, el color pasa de amarillo a naranja. La reacción se agita durante $24 \mathrm{~h}$ a temperatura ambiente, luego se trata con $\mathrm{NH}_{4} \mathrm{Cl}$ y se extrae con AcOEt, obteniéndose 168 mg de crudo de reacción.

El crudo se purifica por cromatografía flash con Hex/AcOEt, 7:3 y se aíslan $51 \mathrm{mg}(0,2$ mmol; $41 \%$ ) del compuesto 37 que se cristaliza en Hex/AcOEt para obtener unos cristales amarillos.

\section{$\underline{N, N \text {-dimetil-5-(1-(3,4,5-trimetoxifenil)etenil)piridin-2-amina (37): }}$}

$\mathbf{R M N}^{1} \mathbf{H}: 3,12(6 \mathrm{H}, \mathrm{s}) ; 3,82(6 \mathrm{H}, \mathrm{s}) ; 3,86(3 \mathrm{H}, \mathrm{s}) ; 5,25(1 \mathrm{H}, \mathrm{s}) ; 5,33(1 \mathrm{H}, \mathrm{s}) ; 6,47$ (1H, d, 8,8); $6,55(2 \mathrm{H}, \mathrm{s}) ; 7,40(1 \mathrm{H}, \mathrm{dd}, 8,8,2,4) ; 8,20(1 \mathrm{H}, \mathrm{d}, 2,4)$.

RMN ${ }^{13} \mathrm{C}: 38,3(2)\left(\mathrm{CH}_{3}\right) ; 56,2(2)\left(\mathrm{CH}_{3}\right) ; 61,0\left(\mathrm{CH}_{3}\right) ; 105,2(\mathrm{CH}) ; 105,4(2)(\mathrm{CH}) ; 111,6$ $(\mathrm{C}) ; 111,8\left(\mathrm{CH}_{2}\right) ; 124,7(\mathrm{C}) ; 137,2(\mathrm{C}) ; 137,6(\mathrm{CH}) ; 146,5(\mathrm{C}) ; 147,0(\mathrm{CH}) ; 153,0$ (2) (C); $158,3(\mathrm{C})$.

IR (KBr): $1603 ; 1577 ; 1510 ; 1454 ; 1388 ; 1125 \mathrm{~cm}^{-1}$.

Pf (Hex/AcOEt): $92-93{ }^{\circ} \mathrm{C}$.

HMRS (m/z): Obtenido 315,1524 $\left(\mathrm{M}+\mathrm{Na}^{+}\right)$; esperado 315,1528 $\left(\mathrm{C}_{18} \mathrm{H}_{22} \mathrm{~N}_{2} \mathrm{O}_{3} \mathrm{Na}^{+}\right)$.

HPLC: Columna $\mathrm{C}_{18} \quad \mathrm{t}_{\mathrm{R}}: 16,4 \mathrm{~min}$. 


\section{Preparación del alcohol 38}
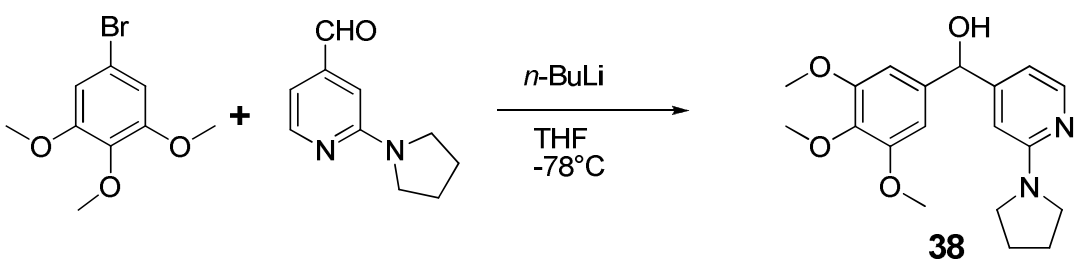

Se disuelven 2,15 g (8,51 mmol) de 5-bromo-1,2,3-trimetoxibenceno en $50 \mathrm{ml}$ de THF, después se le añaden $6,4 \mathrm{ml}(10,2 \mathrm{mmol})$ de $n$-BuLi a $-78{ }^{\circ} \mathrm{C}$ y aparece un color amarillo. La mezcla se agita durante $1 \mathrm{~h}$, después se añade 1,00 g (5,67 mmol) de 2-(pirrolid-1-il) isonicotinaldehído disuelto en THF y la coloración pasa de rosa al amarillo.

La reacción se agita durante $24 \mathrm{~h}$ a temperatura ambiente, luego se extrae con AcOEt, obteniéndose otros 2,56 g de sólido amarillo.

El crudo se cristaliza en éter/ $\mathrm{CH}_{2} \mathrm{Cl}_{2}$ se aíslan $510 \mathrm{mg}(1,48 \mathrm{mmol}, 17 \%)$ de cristales blancos de 38. Las aguas madres se cromatografían en gel de sílice flash con Hex/AcOEt, aislándose $553 \mathrm{mg}(1,61 \mathrm{mmol}, 19 \%)$ de 38.

\section{(2-(pirrolid-1-il)piridin-4-il)(3,4,5-trimetoxifenil)metanol (38):}

RMN ${ }^{1} \mathbf{H}: 1,96(4 \mathrm{H}, \mathrm{m}) ; 3,30(4 \mathrm{H}, \mathrm{m}) ; 3,72(6 \mathrm{H}, \mathrm{s}) ; 3,76(3 \mathrm{H}, \mathrm{s}) ; 5,48(1 \mathrm{H}, \mathrm{s}) ; 6,41(1 \mathrm{H}, \mathrm{d}$, $5,8) ; 6,42(1 \mathrm{H}, \mathrm{s}) ; 6,58(2 \mathrm{H}, \mathrm{s}) ; 7,83(1 \mathrm{H}, \mathrm{d}, 5,8)$.

RMN ${ }^{13} \mathbf{C}: 25,5(2)\left(\mathrm{CH}_{2}\right) ; 46,9(2)\left(\mathrm{CH}_{2}\right) ; 56,2(2)\left(\mathrm{CH}_{3}\right) ; 60,9\left(\mathrm{CH}_{3}\right) ; 75,6(\mathrm{CH}) ; 103,7(2)$ $(\mathrm{CH}) ; 109,2$ (2) (CH); 137,5 (C); 138,7 (2) (C); 147,8 (CH); 153,3 (2) (C); 157,36 (C).

IR (película): 3158; 1607; 1460; 1232; $1124 \mathrm{~cm}^{-1}$.

Pf (Hex/AcOEt): $140-141{ }^{\circ} \mathrm{C}$

HMRS (m/z): Obtenido 345,1819 $\left(\mathrm{M}+\mathrm{H}^{+}\right)$; esperado 345,1814 $\left(\mathrm{C}_{19} \mathrm{H}_{25} \mathrm{~N}_{2} \mathrm{O}_{4}{ }^{+}\right)$. 


\section{Obtención de la fenstatina 39}

\section{a) Oxidación con CCP}<smiles>COc1cc(C(O)c2ccnc(N3CCCC3)c2)cc(OC)c1OC</smiles><smiles>COc1cc(C(=O)c2ccnc(N3CCCC3)c2)cc(OC)c1OC</smiles>

Se disuelve $895 \mathrm{mg}(2,60 \mathrm{mmol})$ de alcohol 38 en $20 \mathrm{ml}$ de $\mathrm{CH}_{2} \mathrm{Cl}_{2}$ a $0{ }^{\circ} \mathrm{C}$, después se le añaden $782 \mathrm{mg}$ (14,2 mmol) de clorocromato de piridinio, el color pasa de naranja a marrón. La reacción se agita durante $4 \mathrm{~h}$ a temperatura ambiente, luego se extrae con $\mathrm{CH}_{2} \mathrm{Cl}_{2}$, obteniéndose 1,40 g de crudo de reacción.

El crudo se purifica por cromatografía flash $\left(\mathrm{CH}_{2} \mathrm{Cl}_{2} / \mathrm{MeOH} 98: 2\right)$ y se aíslan $735 \mathrm{mg}(2,15$ mmol; $83 \%$ ) de la cetona 39.

\section{(2-(pirrolidin-1-il)pirid-4-il)(3,4,5-trimetoxifenil)metanona (39):}

RMN ${ }^{1} \mathbf{H}: 1,98(4 \mathrm{H}, \mathrm{m}) ; 3,43(4 \mathrm{H}, \mathrm{m}) ; 3,82(6 \mathrm{H}, \mathrm{s}) ; 3,89(3 \mathrm{H}, \mathrm{s}) ; 6,55(1 \mathrm{H}, \mathrm{s}) ; 6,60(1 \mathrm{H}, \mathrm{d}$, $5,6) ; 7,07(2 \mathrm{H}, \mathrm{s}) ; 8,20(1 \mathrm{H}, \mathrm{d}, 5,6)$.

RMN ${ }^{13} \mathbf{C}: 25,4(2)\left(\mathrm{CH}_{2}\right) ; 46,8(2)\left(\mathrm{CH}_{2}\right) ; 56,2(2)\left(\mathrm{CH}_{3}\right) ; 60,9\left(\mathrm{CH}_{3}\right) ; 106,0(\mathrm{CH}) ; 107,7$ (2) $(\mathrm{CH}) ; 110,1(\mathrm{CH}) ; 131,2(\mathrm{C}) ; 146,1(\mathrm{C}) ; 148,1(\mathrm{CH}) ; 152,9$ (2) (C); 155,0 (C); 157,1 (C); 195,1 (C).

IR (película): 1650; 1598; 1538; 1456; $1328 ; 1127 \mathrm{~cm}^{-1}$.

HMRS (m/z): Obtenido 343,1162 $\left(\mathrm{M}+\mathrm{H}^{+}\right)$; esperado 343,1658 $\left(\mathrm{C}_{19} \mathrm{H}_{23} \mathrm{~N}_{2} \mathrm{O}_{4}{ }^{+}\right)$.

\section{b) Oxidación con PDC}<smiles>COc1cc(C(O)c2ccnc(N3CCCC3)c2)cc(OC)c1OC</smiles>

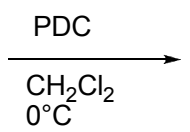<smiles>COc1cc(C(=O)c2ccnc(N3CCCC3)c2)cc(OC)c1OC</smiles> 
Se disuelven en un matraz $680 \mathrm{mg}(1,97 \mathrm{mmol})$ de alcohol 38 en $20 \mathrm{ml}$ de $\mathrm{CH}_{2} \mathrm{Cl}_{2}$ a $0{ }^{\circ} \mathrm{C}$, después se le añaden 1,06 g (2,83 mmol) de dicromato de piridinio, el color pasa de naranja a marrón. La reaccion se agita durante $4 \mathrm{~h}$ a temperatura ambiente, luego se extrae con agua y $\mathrm{CH}_{2} \mathrm{Cl}_{2}$, obteniéndose $1,44 \mathrm{~g}$.

El crudo se purifica por cromatografía flash $\left(\mathrm{CH}_{2} \mathrm{Cl}_{2} / \mathrm{MeOH}, 98: 2\right)$ y se aíslan $278 \mathrm{mg}(0,82$ mmol; $42 \%$ ) de la cetona 39.

\section{Síntesis de la isocombretastatina 40}
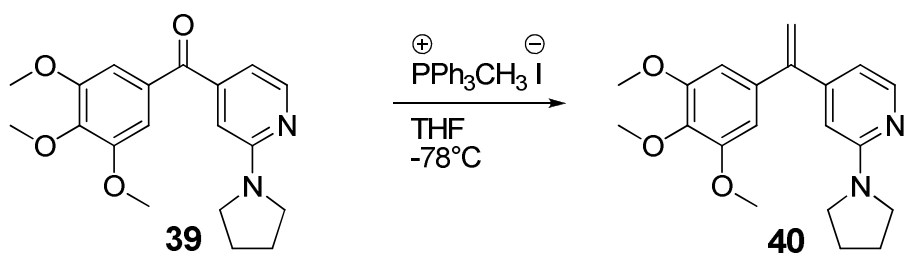

Se disuelven 1,27 g (3,15 mmol) de la sal de fosfonio 1 en $40 \mathrm{ml}$ de THF, después se le añaden 1,6 $\mathrm{ml}(2,6 \mathrm{mmol})$ de $n$-BuLi $1,6 \mathrm{M}$ en hexano a $-78^{\circ} \mathrm{C}$, aparece color naranja. La mezcla se agita durante $1 \mathrm{~h}$, luego se añade $360 \mathrm{mg}(1,05 \mathrm{mmol})$ de la cetona 39, el color pasa de naranja a amarillo. La reacción se agita durante $24 \mathrm{~h}$ a temperatura ambiente, luego se trata con $\mathrm{NH}_{4} \mathrm{Cl}$ y se extrae con AcOEt y se obtienen $624 \mathrm{mg}$ siguiendo el procedimiento habitual.

El crudo se purifica por cromatografía flash (Hex/AcOEt, 8:2) y se aíslan $295 \mathrm{mg}(0,87$ mmol; $83 \%$ ) del compuesto 40.

\section{$\underline{\text { 2-(pirrolidin-1-il)-4-(1-(3,4,5-trimetoxifenil)etenil)piridina (40): }}$}

RMN ${ }^{1} \mathbf{H}: 1,98(4 \mathrm{H}, \mathrm{m}) ; 3,43(4 \mathrm{H}, \mathrm{m}) ; 3,80(6 \mathrm{H}, \mathrm{s}) ; 3,86(3 \mathrm{H}, \mathrm{s}) ; 5,47(1 \mathrm{H}, \mathrm{s}) ; 5,50(1 \mathrm{H}, \mathrm{s})$; $6,31(2 \mathrm{H}, \mathrm{s}) ; 6,46(1 \mathrm{H}, \mathrm{d}, 5,0) ; 6,53(1 \mathrm{H}, \mathrm{s}) ; 8,10(1 \mathrm{H}, \mathrm{d}, 5,0)$.

RMN ${ }^{13} \mathbf{C}: 25,5(2)\left(\mathrm{CH}_{2}\right) ; 46,8(2)\left(\mathrm{CH}_{2}\right) ; 56,1(2)\left(\mathrm{CH}_{3}\right) ; 60,9\left(\mathrm{CH}_{3}\right) ; 105,5$ (2) (CH); 105,8 $(\mathrm{CH}) ; 111,1(\mathrm{CH}) ; 115,3\left(\mathrm{CH}_{2}\right) ; 135,9(\mathrm{C}) ; 137,9(\mathrm{C}) ; 147,9(\mathrm{C}) ; 149(\mathrm{CH}) ; 149,7(\mathrm{C}) ; 152,9$ (2) $(\mathrm{C}) ; 157,6(\mathrm{C})$.

IR (película): 1593; 1535; 1492; 1454; 1236; $1126 \mathrm{~cm}^{-1}$.

HMRS (m/z): Obtenido 341,1862 $\left(\mathrm{M}+\mathrm{H}^{+}\right)$; esperado 341,1860 $\left(\mathrm{C}_{20} \mathrm{H}_{25} \mathrm{~N}_{2} \mathrm{O}_{3}{ }^{+}\right)$. 
HPLC: Columna $\mathrm{C}_{18} \quad \mathrm{t}_{\mathrm{R}}: 17,1 \mathrm{~min}$.

\section{Preparación de la oxima 41}
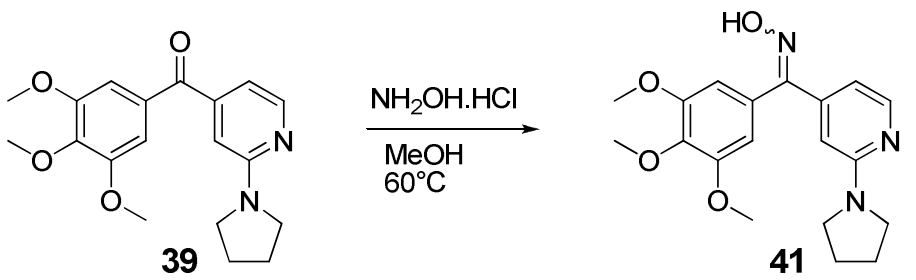

Se disuelven $275 \mathrm{mg}(0,80 \mathrm{mmol})$ de la cetona 39 en $10 \mathrm{ml}$ de metanol y se le añade $167 \mathrm{mg}$ (2,41 mmol) de clorhidrato de hidroxilamina, la reacción se agita durante $22 \mathrm{~h} \mathrm{a} 60{ }^{\circ} \mathrm{C}$, después se extrae con agua y $\mathrm{CH}_{2} \mathrm{Cl}_{2}$, se seca con $\mathrm{Na}_{2} \mathrm{SO}_{4}$ y se obtienen $390 \mathrm{mg}$ de crudo de reacción.

El crudo se purifica por cromatografía flash (Hex/AcOEt, 6:4), aislándose $120 \mathrm{mg}(0,34$ mmol, 42 \%) de una mezcla de isómeros Z/E en proporción 40:60 del compuesto 41.

\section{Oxima de (2-(pirrolidin-1-il)piridin-4-il)(3,4,5-trimetoxifenil)metanona (41):}

\section{Datos sacados de la mezcla}

\section{Isómero minoritario $(Z)$ :}

RMN ${ }^{1} \mathbf{H}: 1,60(4 \mathrm{H}, \mathrm{m}) ; 3,43(4 \mathrm{H}, \mathrm{m}) ; 3,83(6 \mathrm{H}, \mathrm{s}) ; 3,91(3 \mathrm{H}, \mathrm{s}) ; 6,46(1 \mathrm{H}, \mathrm{d}, 4,6) ; 6,60(1 \mathrm{H}$, s); 6,61 (2H, s); 8,14 (1H, d, 4,6).

\section{Isómero mayoritario $(E)$ :}

RMN ${ }^{1} \mathbf{H}: 2,02(4 \mathrm{H}, \mathrm{m}) ; 3,47(4 \mathrm{H}, \mathrm{m}) ; 3,80(6 \mathrm{H}, \mathrm{s}) ; 3,87(3 \mathrm{H}, \mathrm{s}) ; 6,30(1 \mathrm{H}, \mathrm{s}) ; 6,42(1 \mathrm{H}, \mathrm{d}$, 4,6); 6,76 (2H, s); 8,26 (1H, d, 4,6).

RMN ${ }^{13} \mathbf{C}: 25,5(2)\left(\mathrm{CH}_{2}\right) ; 46,9(2)\left(\mathrm{CH}_{2}\right) ; 56,2(2)\left(\mathrm{CH}_{3}\right) ; 60,9\left(\mathrm{CH}_{3}\right) ; 104,9$ (2) (CH); 114,6 $(\mathrm{CH}) ; 119,5(\mathrm{CH}) ; 130,2(\mathrm{C}) ; 139,6(\mathrm{C}) ; 142,7(\mathrm{C}) ; 147,7(\mathrm{CH}) ; 153,0(2)(\mathrm{C}) ; 155,4(\mathrm{C})$; $155,4(\mathrm{C})$.

IR (KBr): 3433; 1605; 1542; 1238; $1127 \mathrm{~cm}^{-1}$. 


\section{Preparación del alcohol 42}

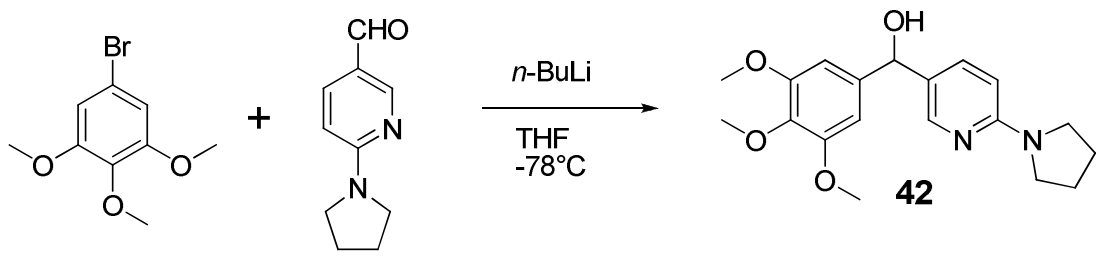

Una suspensión de $840 \mathrm{mg}$ (3,40 mmol) de bromuro de 3,4,5-trimetoxifenilo en $40 \mathrm{ml}$ de THF seco de color amarillo claro, se pone en agitación y atmósfera de nitrógeno a $-78^{\circ} \mathrm{C}$. Se añaden 2,6 $\mathrm{ml}(4,2 \mathrm{mmol})$ de $n$-BuLi 1,6 $\mathrm{M}$ en hexano sin observarse cambio de coloración y tras 1 hora se adiciona una disolución de $500 \mathrm{mg}$ (2,84 mmol) del aldehído 6-pirrolidinil-nicotínico en $10 \mathrm{ml}$ de THF, gota a gota. Se observa que la disolución cambia a un color marrón anaranjado. Se deja alcanzar la temperatura ambiente espontáneamente y después de 20 horas de reacción, se añade agua y extrae con AcOEt. Se obtienen 870 mg del compuesto 42 como un sólido amarillo que se utiliza sin purificar en la siguiente reacción.

\section{$\underline{\text { (6-(pirrolidin-1-il)piridin-3-il)(3,4,5-trimetoxifenil)metanol (42): }}$}

RMN ${ }^{1} \mathbf{H}: 1,87(4 \mathrm{H}, \mathrm{m}) ; 3,35(4 \mathrm{H}, \mathrm{m}), 3,71(3 \mathrm{H}, \mathrm{s}), 3,72(6 \mathrm{H}, \mathrm{s}) ; 5,50(1 \mathrm{H}, \mathrm{s}), 6,18(1 \mathrm{H}, \mathrm{d}$, 8,4), 6,52 (2H, s), 7,28 (1H, dd, 8,4, 2,6), 7,87 (1H, d, 2,6).

IR (película): 3386, 1604, 1502, 1460, 1418, $1126 \mathrm{~cm}^{-1}$.

\section{Obtención de la fenstatina 43}<smiles>COc1cc(C(O)c2ccc(N3CCCC3)nc2)cc(OC)c1OC</smiles><smiles>CC(C)(C)C1(C(C)(C)C)CCCCC1</smiles><smiles>COc1cc(C(=O)c2ccc(N3CCCC3)nc2)cc(OC)c1OC</smiles>

A una disolución de $600 \mathrm{mg}(1,74 \mathrm{mmol})$ del alcohol 42 en $5 \mathrm{ml} \mathrm{de} \mathrm{CH}_{2} \mathrm{Cl}_{2}$, se le añaden 393 mg (1,76 mmol) de CCP a temperatura ambiente. Al añadirlo la solución pasa a un color marrón oscuro. La reacción se controla por cromatografía de capa fina comprobándose la total desaparición del producto de partida al cabo de diez minutos. La reacción se pasa por una 
columna de gel de sílice eluyéndose con $\mathrm{CH}_{2} \mathrm{Cl}_{2}$ y AcOEt, obteniéndose $450 \mathrm{mg}$ (1,31 mmol, $75 \%$ ) de cetona 43 en forma de un sólido blanco.

\section{$\underline{\text { (6-(pirrolidin-1-il)piridin-3-il)(3,4,5-trimetoxifenil)metanona (43): }}$}

RMN ${ }^{1} \mathbf{H}: 2,03$ (4H, m); 3,54 (4H, m); 3,86 (6H, s); 3,89 (3H, s); 6,40 (1H, d, 8,8); 6,98 (2H, s); 7,98 (1H, d, 8,8); 8,62 (1H, s).

RMN ${ }^{13} \mathbf{C}: 25,4$ (2) $\left(\mathrm{CH}_{2}\right) ; 47,0$ (2) $\left(\mathrm{CH}_{2}\right) ; 56,2$ (2) $\left(\mathrm{OCH}_{3}\right) ; 60,9\left(\mathrm{OCH}_{3}\right) ; 106,0(\mathrm{CH}) ; 107,0$

(2) $(\mathrm{CH}) ; 121,1(\mathrm{C}) ; 133,7(\mathrm{C}) ; 138,5(\mathrm{CH}) ; 141,0(\mathrm{C}) ; 152,8$ (2) (C); 152,9 (CH); 158,3 (C); 193,1 (C).

IR (KBr): 1640; 1548; 1330; $1127 \mathrm{~cm}^{-1}$.

Pf (éter): $140-141^{\circ} \mathrm{C}$

HRMS (m/z): Obtenido 343,1651 $\left(\mathrm{M}+\mathrm{H}^{+}\right)$; esperado 343,1652 $\left(\mathrm{C}_{19} \mathrm{H}_{23} \mathrm{~N}_{2} \mathrm{O}_{4}{ }^{+}\right)$.

HPLC: Columna $\mathrm{C}_{18} \quad \mathrm{t}_{\mathrm{R}}: 11,6 \mathrm{~min}$.

\section{Obtención de la isocombretastatina 44}

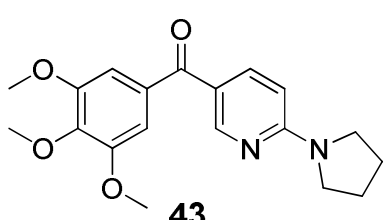

43

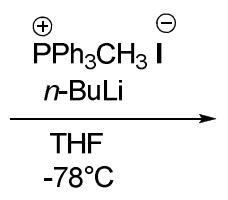

$-78^{\circ} \mathrm{C}$<smiles>C=C(c1ccc(N2CCCC2)nc1)c1cc(OC)c(OC)c(OC)c1</smiles>

Una suspensión de color blanco de $623 \mathrm{mg}(1,54 \mathrm{mmol})$ de sal de fosfonio 1 en $30 \mathrm{ml}$ de THF seco, se pone en agitación y atmósfera de nitrógeno a $-78^{\circ} \mathrm{C}$. Se añade $1,0 \mathrm{ml}(1,6 \mathrm{mmol}) \mathrm{de}$ n-BuLi 1,6 M en hexano, se forma una disolución amarilla en la que aparece algo de precipitado. Tras 1 hora se adicionan lentamente $176 \mathrm{mg}(0,51 \mathrm{mmol})$ de una solución amarilla de la cetona 43 en $10 \mathrm{ml}$ de THF seco. Al realizar la adición la disolución no cambia de color y se forma un pequeño precipitado. La mezcla se deja agitando $24 \mathrm{~h}$ a temperatura ambiente. Siguiendo el procedimiento descrito anteriormente se aíslan $230 \mathrm{mg}$ de crudo de reacción. 
El producto obtenido se purifica por cromatografía flash con Hex/AcOEt 1:1, aislándose 80 mg (0,23 mmol, $46 \%)$ del compuesto 44 en forma de un sólido amarillo pálido.

\section{2-(pirrolidin-1-il)-5-(1-(3,4,5-trimetoxifenil)etenil)piridina (44):}

RMN ${ }^{1} \mathrm{H}: 2,00$ (4H, m); 3,47 (4H, m); 3,79 (6H, s); 3,85 (3H, s); 5,23 (1H, s); 5,31 (1H, s); $6,33(1 \mathrm{H}, \mathrm{d}, 8,8) ; 6,54(2 \mathrm{H}, \mathrm{s}) ; 7,41(1 \mathrm{H}, \mathrm{dd}, 8,8,2,2) ; 8,18(1 \mathrm{H}, \mathrm{d}, 2,2)$.

RMN ${ }^{13} \mathbf{C}: 25,5$ (2) $\left(\mathrm{CH}_{2}\right) ; 46,9$ (2) $\left(\mathrm{CH}_{2}\right) ; 56,1$ (2) $\left(\mathrm{OCH}_{3}\right) ; 60,8\left(\mathrm{OCH}_{3}\right) ; 105,5$ (2) (CH); 106,0 (CH); 111,2 ( $\left.\mathrm{CH}_{2}\right) ; 124,3(\mathrm{C}) ; 137,1(\mathrm{CH}) ; 134,5(\mathrm{C}) ; 137,8(\mathrm{C}) ; 147,0(\mathrm{CH}) ; 147,2$ (C); 152,8 (2) (C); 156,3 (C).

IR (KBr): 1600; 1506; 1235; 1126; $1006 \mathrm{~cm}^{-1}$.

HRMS (m/z): Obtenido 341,1870 $\left(\mathrm{M}+\mathrm{H}^{+}\right)$; esperado 341,1859 $\left(\mathrm{C}_{20} \mathrm{H}_{25} \mathrm{~N}_{2} \mathrm{O}_{3}{ }^{+}\right)$.

HPLC: Columna $\mathrm{C}_{18} \quad \mathrm{t}_{\mathrm{R}}: 18,2 \mathrm{~min}$.

\section{Preparación de la oxima 45}
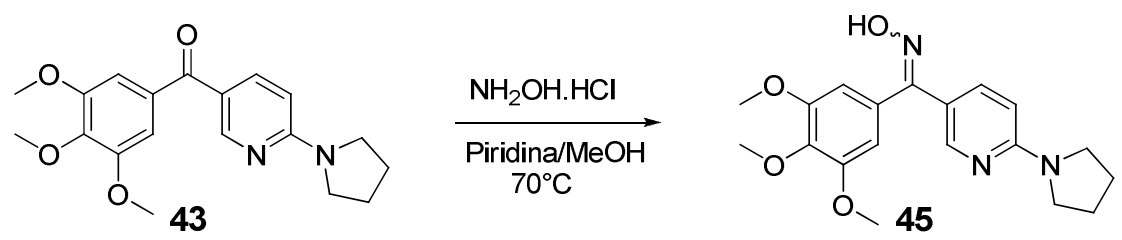

A una disolución de $56 \mathrm{mg}(0,16 \mathrm{mmol})$ de la cetona 43 en $\mathrm{MeOH}(10 \mathrm{~mL})$, se añaden $170 \mathrm{mg}$ (2,46 $\mathrm{mmol})$ de clorhidrato de hidroxilamina y 4 gotas de piridina. La reacción se mantiene en agitación durante $24 \mathrm{~h} \mathrm{a} 70^{\circ} \mathrm{C}$. Tras este tiempo se evapora el metanol, se añade agua y extrae con AcOEt, siguiendo el procedimiento habitual las fases orgánicas se secan y evaporan, obteniéndose $68 \mathrm{mg}$ de crudo de reacción.

El crudo se purifica por cristalización en $\mathrm{MeOH}$ aislándose $15 \mathrm{mg}(0,04 \mathrm{mmol}, 25 \%)$ de la oxima 45.

Oxima de (6-(pirrolidin-1-il)piridin-3-il)(3,4,5-trimetoxifenil)metanona (45): 
RMN ${ }^{1} \mathbf{H}: 2,13$ (4H, m); 3,80 (4H, m); 3,88 (6H, s); 3,92 (3H, s); 6,68 (1H, d, 8,8); 6,99 (2H, s); $8,22(1 \mathrm{H}, \mathrm{dd}, 8,8,2,0) ; 8,65(1 \mathrm{H}, \mathrm{d}, 2,0)$.

IR (KBr): $3490 ; 1610 ; 1590 ; 1430 ; 1380 ; 1210 \mathrm{~cm}^{-1}$.

HPLC: Columna $\mathrm{C}_{18} \quad \mathrm{t}_{\mathrm{R}}: 11,6 \mathrm{~min} ; \mathrm{t}_{\mathrm{R}}: 27,8 \mathrm{~min}$. 


\section{B. Análogos de combretastatinas}

\section{Obtención del aldehído 47:}

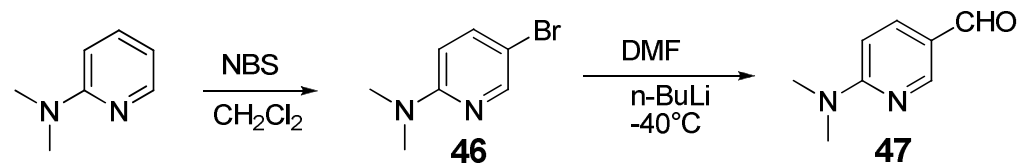

\section{a) Preparación del compuesto 46:}

Se disuelven $209 \mathrm{mg}(1,71 \mathrm{mmol})$ de $N, N$-dimetilpiridin-2-amina en $20 \mathrm{ml} \mathrm{de} \mathrm{CH}_{2} \mathrm{Cl}_{2}$ y se añaden $365 \mathrm{mg}(2,05 \mathrm{mmol})$ de NBS, apareciendo un color amarillo oscuro. La mezcla se agita durante $24 \mathrm{~h}$ a temperatura ambiente, después se extrae con $\mathrm{CH}_{2} \mathrm{Cl}_{2}$ y se lava con agua saturada con $\mathrm{NaCl}$, se obtienen 380 mg del crudo de reacción.

El crudo se purifica por cromatografía flash $\left(\mathrm{Hex} / \mathrm{CH}_{2} \mathrm{Cl}_{2}\right.$ 4:6), aislándose $218 \mathrm{mg}(1,08$ mmol, $63 \%$ ) del compuesto 46.

\section{4-bromo- $N, N$-dimetilpiridin-2-amina (46):}

RMN ${ }^{1} \mathbf{H}: 3,06(6 \mathrm{H}, \mathrm{s}) ; 6,38(1 \mathrm{H}, \mathrm{d}, 9,2) ; 7,45(1 \mathrm{H}, \mathrm{dd}, 9,2,2,4) ; 8,16(1 \mathrm{H}, \mathrm{d}, 2,4)$.

IR (KBr): 1594; 1338; 1211; $805 \mathrm{~cm}^{-1}$.

\section{b) Preparación del compuesto 47:}

Se disuelven $720 \mathrm{mg}(3,85 \mathrm{mmol})$ de 46 en $20 \mathrm{ml}$ de THF, después se añaden $2,5 \mathrm{ml}(4,00$ mmol) de $n$-BuLi a $-40^{\circ} \mathrm{C}$. La mezcla se agita durante $1 \mathrm{~h}$ luego se añade $2,8 \mathrm{ml}(36 \mathrm{mmol})$ DMF, la reacción se deja agitando durante $24 \mathrm{~h}$ a temperatura ambiente, posteriormente se extrae con AcOEt y agua, se seca con $\mathrm{Na}_{2} \mathrm{SO}_{4}$, se filtra y se evapora el disolvente, se obtienen $393 \mathrm{mg}$.

El crudo se purifica por cromatografía de columna con Hex/AcOEt (8:2), obteniéndose 116 mg $(0,77 \mathrm{mmol}, 20 \%)$ de 47. 


\section{6-dimetilaminonicotinaldehído (47):}

$\mathbf{R M N}^{1} \mathbf{H}: 3,21(6 \mathrm{H}, \mathrm{s}) ; 6,53(1 \mathrm{H}, \mathrm{d}, 8,8) ; 7,89$ (1H, dd, 8,8, 2,2); 8,55 (1H, d, 2,2); 9,77 (1H, s).

RMN ${ }^{13} \mathbf{C}: 38,2(2)\left(\mathrm{CH}_{3}\right) ; 105,7(\mathrm{CH}) ; 121,5(\mathrm{C}) ; 136,0(\mathrm{CH}) ; 154,5(\mathrm{CH}) ; 161,2(\mathrm{C}) ; 189,1$ $(\mathrm{CH})$.

IR (película): 1681;1600;1531; 1498; 1395; $1131 \mathrm{~cm}^{-1}$.

\section{Otro metodo de obtención de 47}

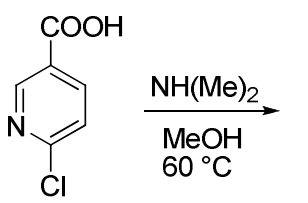<smiles>CN(C)c1ccc(C(=O)O)cn1</smiles>

48

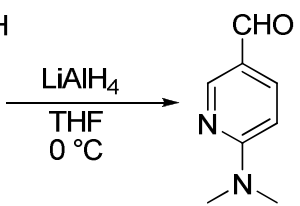

47

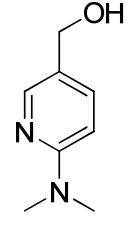

49

\section{a) Preparación de 48:}

Se disuelven $200 \mathrm{mg}(1,27 \mathrm{mmol})$ de ácido 6-cloronicotínico en $10 \mathrm{ml}$ de $\mathrm{MeOH}$ y se le añaden $5 \mathrm{ml}$ de $N, N$-dimetilamina disuelto en metanol al 30\%, la reacción se agita durante $24 \mathrm{~h}$ a $60{ }^{\circ} \mathrm{C}$, mantenido color marrón. Luego se evapora el metanol y se obtienen 220 del crudo de reacción.

A continuación se cristaliza en $\left(\mathrm{CH}_{2} \mathrm{Cl}_{2} / \mathrm{MeOH}\right)$ y se aíslan $157 \mathrm{mg}(0,94 \mathrm{mmol}, 78 \%)$ del compuesto 48 .

Ácido 6-dimetilaminonicotínico (48):

RMN ${ }^{1} \mathbf{H}$ (CD) $\left.\mathbf{C D}\right): 3,06$ (6H, s); 6,55 (1H, d, 9,4); 7,90 (1H, dd, 9,4, 2,2); 8,57 (1H, d, 2,2).

RMN ${ }^{13} \mathbf{C}\left(\mathbf{C D}_{\mathbf{3}} \mathbf{O D}\right): 38,4$ (2) $\left(\mathrm{CH}_{3}\right) ; 106,3(\mathrm{CH}) ; 114,9(\mathrm{C}) ; 139,5(\mathrm{CH}) ; 151,6(\mathrm{CH}) ; 162,04$ (C); 169,3 (C).

IR (película): $3500,1675,1284 \mathrm{~cm}^{-1}$. 


\section{b) Preparación de 47:}

Se disuelven 2,00 g (12,1 mmol) del compuesto 48 en $30 \mathrm{ml}$ de THF y se le añade $500 \mathrm{mg}$ $(13,3 \mathrm{mmol})$ de $\mathrm{LiAlH}_{4}$ a $0^{\circ} \mathrm{C}$, aparece color marrón. La mezcla se agita durante $20 \mathrm{~h}$ a temperatura ambiente controlándose por cromatografía de capa fina, después se evapora el THF y se extrae con AcOEt, se obtiene 1,65 g de una mezcla de 47 y 49 en proporción 1:2.

El crudo se purifica por cromatografía de columna, se aíslan $262 \mathrm{mg}(1,75 \mathrm{mmol}, 15 \%)$ del aldehído 47 y $525 \mathrm{mg}$ (3,45 mmol, $29 \%)$ de 49.

\section{(6-dimetilaminopiridin-3-il)metanol (49):}

$\mathbf{R M N}^{1} \mathbf{H}: 3,10(6 \mathrm{H}, \mathrm{s}) ; 4,53(2 \mathrm{H}, \mathrm{s}) ; 6,46(1 \mathrm{H}, \mathrm{d}, 8,6) ; 7,45(1 \mathrm{H}, \mathrm{dd}, 8,6,2,2) ; 8,02(1 \mathrm{H}, \mathrm{d}$, 2,2).

\section{Obtención de la combretastatina 50}
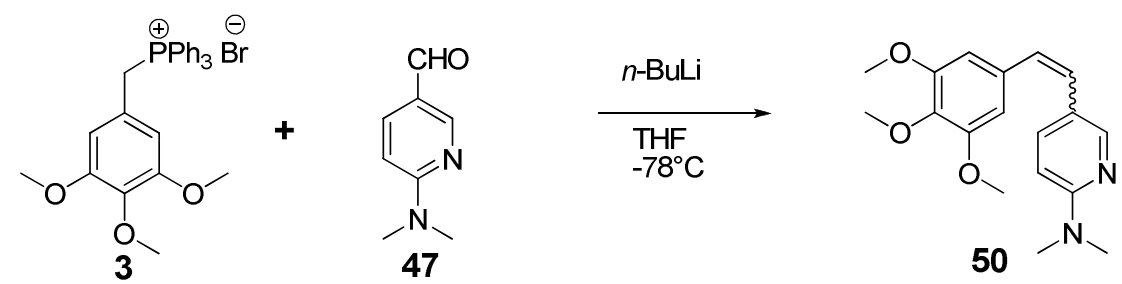

A una suspensión de 1,30 g (2,14 mmol) de la sal de fosfonio 3 en $40 \mathrm{ml}$ de THF seco, se le añaden $1,5 \mathrm{ml}(2,1 \mathrm{mmol})$ de $n$-BuLi a $-78^{\circ} \mathrm{C}$, apareciendo color naranja. La mezcla se agita durante $1 \mathrm{~h}$, después se añaden $230 \mathrm{mg}(1,53 \mathrm{mmol})$ de aldehído 47 disuelto en THF. La reacción se deja agitar durante $24 \mathrm{~h}$ a temperatura ambiente, luego se trata con $\mathrm{NH}_{4} \mathrm{Cl}$ y se extrae con AcOEt, obteniéndose $848 \mathrm{mg}$ del compuesto $\mathbf{5 0}$ como una mezcla Z/E en proporción 1:2.

El crudo se purifica por cromatografía flash (Hex/AcOEt 1:1), obteniéndose $65 \mathrm{mg}(0,21$ mmol, $14 \%)$ del isómero $Z$ y $213 \mathrm{mg}(0,68 \mathrm{mmol}, 44 \%)$ de la mezcla $Z / E$.

\section{$\underline{(Z)-2-d i m e t i l a m i n o-5-(2-(3,4,5-t r i m e t o x i f e n i l) e t e n i l) p i r i d i n a ~(50): ~}$}


$\mathbf{R M N}^{1} \mathbf{H}: 3,05(6 \mathrm{H}, \mathrm{s}) ; 3,72(6 \mathrm{H}, \mathrm{s}) ; 3,83(3 \mathrm{H}, \mathrm{s}) ; 6,32(1 \mathrm{H}, \mathrm{d}, 8,8) ; 6,38(2 \mathrm{H}, \mathrm{s}) ; 6,51$ (2H, s); 7,38 (1H, dd, 8,8, 2,2); 8,09 (1H, d, 2,2).

RMN ${ }^{13} \mathbf{C}: 38,1(2)\left(\mathrm{CH}_{3}\right) ; 56,0(2)\left(\mathrm{CH}_{3}\right) ; 60,8\left(\mathrm{CH}_{3}\right) ; 104,7(\mathrm{CH}) ; 105,7(2)(\mathrm{CH}) ; 109,5$ (C); 120,4 (C); 126,9 (CH); 127,8 (CH); 133,2 (C); 133,6 (C); 137,2 (CH); 148,9 (CH); 153,3 (2) $(\mathrm{C}) ; 158,5(\mathrm{C})$.

HPLC: Columna $\mathrm{C}_{18} \quad \mathrm{t}_{\mathrm{R}}: 16,4 \mathrm{~min}$.

\section{Datos obtenidos del espectro de la mezcla $Z / E$}

\section{$\underline{(E)-2-d i m e t i l a m i n o-5-(2-(3,4,5-t r i m e t o x i f e n i l) e t e n i l) p i r i d i n a ~(50): ~}$}

RMN ${ }^{1} \mathbf{H}: 3,11(6 \mathrm{H}, \mathrm{s}) ; 3,86(3 \mathrm{H}, \mathrm{s}) ; 3,92(6 \mathrm{H}, \mathrm{s}) ; 6,52(1 \mathrm{H}, \mathrm{d}, 8,8) ; 6,69(2 \mathrm{H}, \mathrm{s}) ; 6,80(1 \mathrm{H}, \mathrm{d}$, 16,4); 6,89 (1H, d, 16,4); 7,67 (1H, dd, 8,8, 2,2); 8,22 (1H, d, 2,2).

RMN ${ }^{13} \mathbf{C}: 38,5(2)\left(\mathrm{CH}_{3}\right) ; 56,4(2)\left(\mathrm{CH}_{3}\right) ; 61,2\left(\mathrm{CH}_{3}\right) ; 103,2(2)(\mathrm{CH}) ; 106,2(\mathrm{CH}) ; 121,3$ (C); 125,5 (CH); 128,1 (CH); 133,8 (C); 134,1 (CH); 137,6 (CH); 147,5 (C); 153,6 (2) (C); $158,8(\mathrm{C})$.

IR (película): $1600 ; 1508 ; 1457 ; 1389 ; 1236 ; 1126 \mathrm{~cm}^{-1}$.

HRMS (m/z): Obtenido 315,1708 $\left(\mathrm{M}+\mathrm{H}^{+}\right)$; esperado 315,1707 $\left(\mathrm{C}_{20} \mathrm{H}_{25} \mathrm{~N}_{2} \mathrm{O}_{3}{ }^{+}\right)$.

\section{Metilación de la combretastatina 51}
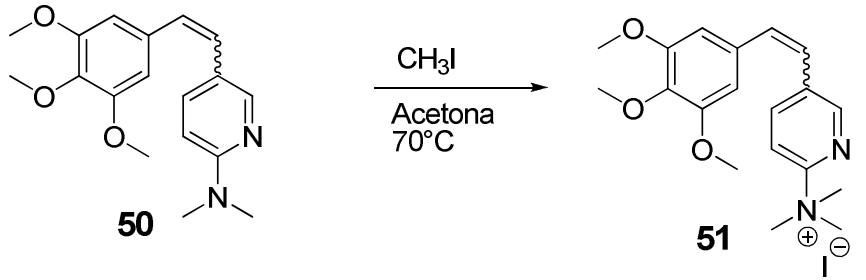

Se disuelven $160 \mathrm{mg}(0,51 \mathrm{mmol})$ de la mezcla $Z / E$ de la aminocombretastatina $\mathbf{5 0}$ en $15 \mathrm{ml}$ de acetona, después se añaden $320 \mu \mathrm{L}(5,09 \mathrm{mmol})$ de yodometano y aparece un color amarillo. La mezcla se agita durante $24 \mathrm{~h}$ a $70^{\circ} \mathrm{C}$ en un tubo sellado, luego se evapora la acetona y se obtienen 213 mg de crudo de reacción. 
El crudo se purifíca por cristalización en AcOEt/MeOH, se aíslan 35 mg (0,11 mmol, 22 \%) del isómero $E$ del compuesto $\mathbf{5 1 .}$

Yoduro de $(E)-N, N, N$-trimetil-5-(2-(3,4,5-trimetoxifenil)etenil)piridinio (51):

RMN ${ }^{1} \mathbf{H}$ (CD) $\left.\mathbf{O D}\right): 3,56$ (9H, s); 3,75 (3H, s); 3,79 (6H, s); 6,84 (2H, s); 7,18 (1H, d, 16,0); 7,34 (1H, d, 16,0); 7,79 (1H, d, 8,6); 8, 17 (1H, dd, 8,6, 2,2); 8,64 (1H, d, 2,2).

IR (película): $1579 ; 1462 ; 1244 ; 1122 \mathrm{~cm}^{-1}$.

HMRS (m/z): Obtenido 329,1850 $\left(\mathrm{M}^{+}\right)$; esperado 329, $1860\left(\mathrm{C}_{19} \mathrm{H}_{25} \mathrm{~N}_{2} \mathrm{O}_{3}{ }^{+}\right)$.

HPLC: Columna $\mathrm{C}_{18} \quad \mathrm{t}_{\mathrm{R}}: 5,2 \mathrm{~min}$.

\section{Preparación de la combretastatina 52}
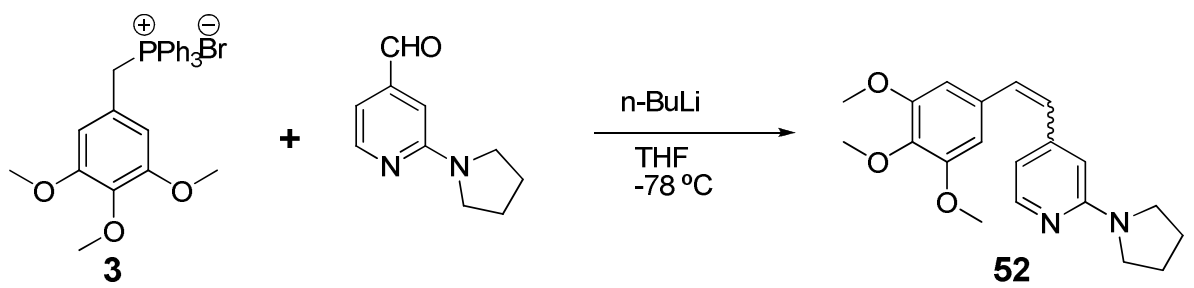

Se disuelven en un matraz 1,66 g $(3,18 \mathrm{mmol})$ de la sal de fosfonio 3 en $40 \mathrm{ml}$ de THF, después se le añaden $2,0 \mathrm{ml}(3,18 \mathrm{mmol})$ de $n$-BuLi a $-78{ }^{\circ} \mathrm{C}$, apareciendo un color amarillo. La mezcla se agita durante $1 \mathrm{~h}$, luego se añaden $400 \mathrm{mg}(2,27 \mathrm{mmol})$ del aldehído, el color pasa de amarillo a naranja. La reacción se agita durante $24 \mathrm{~h}$ a temperatura ambiente, posteriormente se trata con $\mathrm{NH}_{4} \mathrm{Cl}$ y se extrae con AcOEt, obteniéndose 1,09 g del compuesto 52 como una mezcla que tiene los isómeros $Z / E$ en proporción 1:3.

El crudo se purifica por cromatografía flash (Hex/AcOEt 6:4), obteniéndose $123 \mathrm{mg}(0,23$ mmol; $16 \%)$ del isómero $Z$ y $181 \mathrm{mg}(0,53 \mathrm{mmol} ; 17 \%)$ de la mezcla $Z / E$.

\section{$\underline{\text { (Z)-2-(pirrolidin-1-il)-4-(2-(3,4,5-trimetoxifenil)etenil)piridina (52): }}$}

RMN ${ }^{1} \mathbf{H}: 1,95$ (4H, m); 3,35 (4H, m); 3,68 (6H, s); 3,82 (3H, s); 6,24 (1H, d, 1,4); 6,40 (1H, d, 12,2); 6,41 (1H, dd, 5,2, 1,4); 6,50 (2H, s); 6,54 (1H, d, 12,2); 8,02 (1H, d, 5,2). 
RMN ${ }^{13} \mathbf{C}: 25,5(2)\left(\mathrm{CH}_{2}\right) ; 46,6(2)\left(\mathrm{CH}_{2}\right) ; 56,0(2)\left(\mathrm{CH}_{3}\right) ; 60,9\left(\mathrm{CH}_{3}\right) ; 106,1$ (2) (CH); 106,1 $(\mathrm{CH}) ; 111,3(\mathrm{CH}) ; 128,5(\mathrm{CH}) ; 132,2(\mathrm{C}) ; 132,3(\mathrm{CH}) ; 137,5$ (C) 145,9 (C); 147,9 (2) (C); $152,9(\mathrm{CH}) ; 157,6(\mathrm{C})$.

\section{Datos del isómero $E$ sacados de la mezcla $Z / E$ :}

RMN ${ }^{1} \mathbf{H}: 1,98(4 \mathrm{H}, \mathrm{m}) ; 3,45(4 \mathrm{H}, \mathrm{m}) ; 3,80(6 \mathrm{H}, \mathrm{s}) ; 3,84(3 \mathrm{H}, \mathrm{s}) ; 6,48(1 \mathrm{H}, \mathrm{s}) ; 6,66(1 \mathrm{H}, \mathrm{d}$, 5,4); 6,88 (1H, d, 16,1); 6,72 (2H, s); 7,08 (1H, d, 16,1); 8,07 (1H, d, 5,4).

RMN ${ }^{13} \mathbf{C}: 25,6(2)\left(\mathrm{CH}_{2}\right) ; 46,8$ (2) $\left(\mathrm{CH}_{2}\right) ; 56,1(2)\left(\mathrm{CH}_{3}\right) ; 60,9\left(\mathrm{CH}_{3}\right) ; 104,0$ (2) (CH); 104,5 $(\mathrm{CH}) ; 106,2(\mathrm{CH}) ; 126,6(\mathrm{C}) ; 126,7(\mathrm{CH}) ; 131,8(\mathrm{C}) ; 132,0(\mathrm{CH}) ; 137,5(\mathrm{CH})$ 145,6 (C); $152,8(2)(\mathrm{C}) ; 155,2(\mathrm{C})$.

IR (película): 1650; 1598; 1538; 1329; 1229; $1127 \mathrm{~cm}^{-1}$.

HMRS (m/z): Obtenido 341,1886 $\left(\mathrm{M}+\mathrm{H}^{+}\right)$; esperado 341,1860 $\left(\mathrm{C}_{20} \mathrm{H}_{25} \mathrm{~N}_{2} \mathrm{O}_{3}{ }^{+}\right)$. HPLC: Columna $\mathrm{C}_{18} \quad \mathrm{t}_{\mathrm{R}}: 15,6 \mathrm{~min} ; \mathrm{t}_{\mathrm{R}}: 20,1 \mathrm{~min}$.

\section{Preparación de la combretastatina 53}

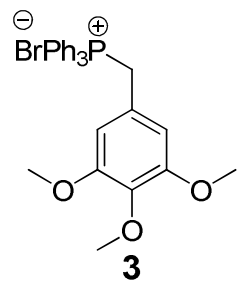<smiles>O=Cc1ccnc(N2CCCC2)c1</smiles>
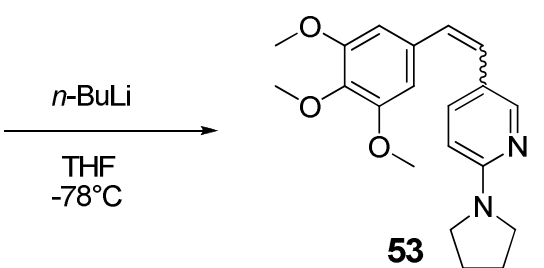

A $156 \mathrm{mg}(0,27 \mathrm{mmol})$ de la sal de fosfonio 3 en THF seco $(10 \mathrm{ml})$ y en atmósfera de nitrógeno, se añaden $0,2 \mathrm{ml}(0,12 \mathrm{mmol})$ de $n$-BuLi y se mantiene 1 h en agitación a $-78^{\circ} \mathrm{C}$. A continuación se añaden lentamente una disolución de 57 mg $(0,32 \mathrm{mmol})$ del aldehído de 6pirrolidinilnicotinico en $10 \mathrm{ml}$ de THF, formándose una solución naranja oscura y se deja que alcance progresivamente la temperatura ambiente. Transcurridas $24 \mathrm{~h}$, se añade agua y se realiza la extracción con AcOEt.

Las fases orgánicas se reúnen y se secan con $\mathrm{Na}_{2} \mathrm{SO}_{4}$, se filtran y se evaporan, obteniéndose un aceite amarillo, se purifica por cromatografía flash (Hex/AcOEt 1:1), obteniéndose $40 \mathrm{mg}$ $(0,12 \mathrm{mmol}, 38 \%)$ de una mezcla que contiene los isómeros $Z / E$ en proporción 1:1. 


\section{$\underline{(Z / E)-2-(p i r r o l i d i n-1-i l)-5-(2-(3,4,5-t r i m e t o x i f e n i l) e t e n i l) p i r i d i n a ~(53): ~}$}

\section{Datos sacados de la mezcla}

\section{Isómero Z:}

RMN ${ }^{1} \mathrm{H}: 2,04(4 \mathrm{H}, \mathrm{m}) ; 3,50(4 \mathrm{H}, \mathrm{m}) ; 3,78(6 \mathrm{H}, \mathrm{s}) ; 3,92(3 \mathrm{H}, \mathrm{s}) ; 6,23(1 \mathrm{H}, \mathrm{d}, 8,8) ; 6,33(1 \mathrm{H}$, $\mathrm{d}, 12,0) ; 6,43(1 \mathrm{H}, \mathrm{d}, 12,0) ; 6,49(2 \mathrm{H}, \mathrm{s}) ; 7,40(1 \mathrm{H}, \mathrm{dd}, 8,8,2,2) ; 8,11(1 \mathrm{H}, \mathrm{d}, 2,2)$.

\section{Isómero $E$ :}

RMN ${ }^{1} \mathrm{H}:$ 2,02 (4H, m); 3,50 (4H, m); 3,85 (6H, s); 3,93 (3H, s); 6,36 (1H, s); 6,70 (2H, s); $6,71(1 \mathrm{H}, \mathrm{d}, 4,4) ; 6,84(1 \mathrm{H}, \mathrm{d}, 2,2) ; 6,94(1 \mathrm{H}, \mathrm{s}) ; 8,22(1 \mathrm{H}, \mathrm{d}, 2,2)$.

HPLC: Columna $\mathrm{C}_{18} \quad \mathrm{t}_{\mathrm{R}}: 17,8 \mathrm{~min} ; \mathrm{t}_{\mathrm{R}}: 18,6 \mathrm{~min}$. 


\section{Otros análogos de isocombretastatinas}

\section{Obtención de la fenstatina 54}

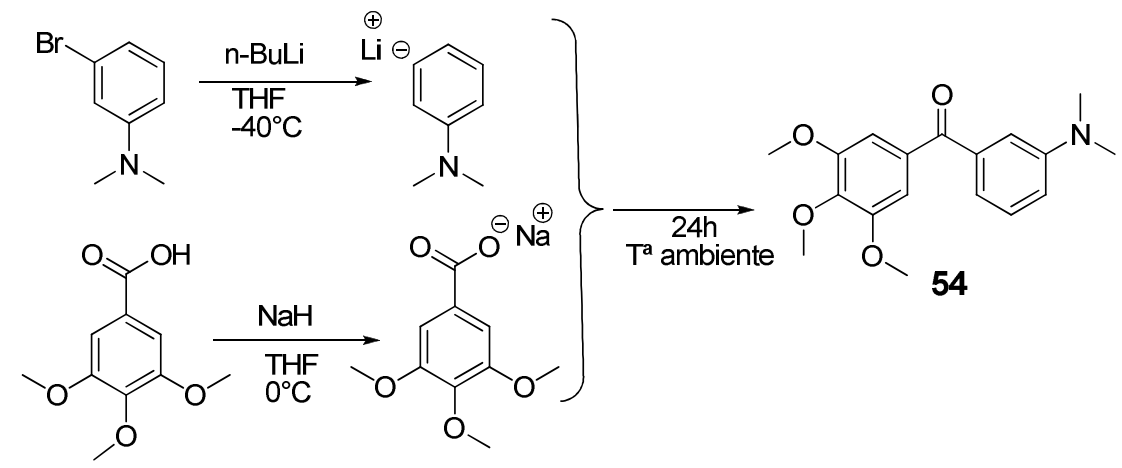

Se disuelven 2,78 g (13,9 mmol) de 3-bromodimetilanilina en $70 \mathrm{ml}$ de THF seco, después se le añaden 9,5 $\mathrm{ml}(15 \mathrm{mmol})$ de $n$-BuLi $1,6 \mathrm{M}$ en hexano a $-40^{\circ} \mathrm{C}$ con agitación y atmósfera de nitrógeno. La mezcla se pone de coloración amarilla.

En otro matraz se disuelven 4,42 g (20,8 mmol) del ácido 3,4,5-trimetoxibenzoico en $150 \mathrm{ml}$ de THF seco y se le añaden lentamente $1,11 \mathrm{~g}(27,8 \mathrm{mmol})$ de hidruro sodio al $60 \%$ a $0{ }^{\circ} \mathrm{C}$. La mezcla se pone de coloración blanca. Al cabo de una hora de reacción se añade el contenido de la primera reacción sobre la segunda y se deja agitando a temperatura ambiente durante 24 h. Posteriormente se añade sobre una disolución de $\mathrm{NH}_{4} \mathrm{Cl}$, se evapora el THF y extrae con AcOEt, obteniéndose 3,27 g de crudo.

La reacción se purifica por cromatografía flash (Hex/AcEt 7:3), aislándose 3,27 g (10,4 mmol, $75 \%$ ) del compuesto 54, que se cristaliza en $\mathrm{MeOH}$ aislándose en forma de cristales amarillos.

\section{(3-(dimetilamino)fenil)(3,4,5-trimetoxifenil)metanona (54):}

RMN ${ }^{1} \mathbf{H}: 2,89(6 \mathrm{H}, \mathrm{s}) ; 3,76(6 \mathrm{H}, \mathrm{s}) ; 3,83(3 \mathrm{H}, \mathrm{s}) ; 6,82(1 \mathrm{H}, \mathrm{dd}, 8,0,2,8) ; 6,95(1 \mathrm{H}, \mathrm{da}, 8,0)$; $6,99(2 \mathrm{H}, \mathrm{s}) ; 7,04(1 \mathrm{H}, \mathrm{sa}) ; 7,29(1 \mathrm{H} ; \mathrm{t}, 8,0)$.

RMN ${ }^{13} \mathbf{C}: 40,5$ (2) $\left(\mathrm{CH}_{3}\right) ; 56,3(2)\left(\mathrm{CH}_{3}\right) ; 61,0\left(\mathrm{CH}_{3}\right) ; 107,8(2)(\mathrm{CH}) ; 113,2(\mathrm{CH}) ; 116,2$ $(\mathrm{CH}) ; 118,3(\mathrm{CH}) ; 128,8(\mathrm{CH}) ; 133,0(\mathrm{C}) ; 138,5(\mathrm{C}) ; 141,8(\mathrm{C}) ; 150,4(\mathrm{C}) ; 152,8$ (2) (C); $196,4(C)$. 
IR (KBr): $1650 ; 1589 ; 1412 ; 1334 ; 1230 ; 1124 \mathrm{~cm}^{-1}$.

Pf $(\mathrm{MeOH}): 77-78^{\circ} \mathrm{C}$

HMRS (m/z): Obtenido 338,1361 $\left(\mathrm{M}+\mathrm{Na}^{+}\right)$; esperado 338, $1368\left(\mathrm{C}_{18} \mathrm{H}_{21} \mathrm{NO}_{4} \mathrm{Na}+\right)$.

HPLC: Columna $\mathrm{C}_{18} \quad \mathrm{t}_{\mathrm{R}}: 15,8 \mathrm{~min}$.

\section{Obtención de la isocombretastatina 55}
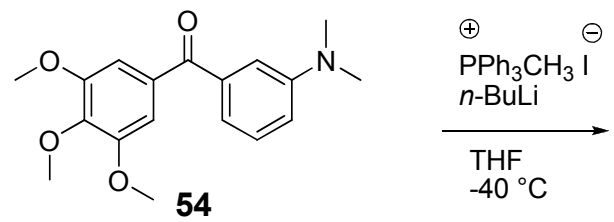<smiles>C=C(c1cccc(N(C)C)c1)c1cc(OC)c(OC)c(OC)c1</smiles>

Se disuelven 1,15 g (2,85 mmol) de la sal de fosfonio 1 en $50 \mathrm{ml}$ de THF, después se le añaden $1,2 \mathrm{ml}(2,0 \mathrm{mmol})$ de $n$-BuLi a $-40{ }^{\circ} \mathrm{C}$, apareciendo color amarillo. La mezcla se agita durante $1 \mathrm{~h} \mathrm{a}-40^{\circ}$ en atmósfera de nitrógeno, luego se añade $300 \mathrm{mg}(0,95 \mathrm{mmol})$ de la cetona 54 disuelta en $10 \mathrm{ml}$ de THF, el color pasa de amarillo a naranja. La reacción se agita durante $24 \mathrm{~h}$ a temperatura ambiente, luego se trata con $\mathrm{NH}_{4} \mathrm{Cl}$ y se extrae con AcOEt, obteniéndose 800 mg de crudo de reacción.

El crudo se purifica por cromatografía flash (Hex/AcOEt, 7:3), aislándose $280 \mathrm{mg}(0,89$ mmol; $94 \%$ ) del compuesto 55.

\section{$\underline{N, N \text {-dimetil-3-(1-(3,4,5-trimetoxifenil)etenil)anilina (55): }}$}

RMN ${ }^{1} \mathbf{H}\left(\mathbf{C D}_{3} \mathbf{O D}\right): 2,90(6 \mathrm{H}, \mathrm{s}) ; 3,75(6 \mathrm{H}, \mathrm{s}) ; 3,78(3 \mathrm{H}, \mathrm{s}) ; 5,38(1 \mathrm{H}, \mathrm{d}, 1,2) ; 5,41(1 \mathrm{H}, \mathrm{d}$, $1,2) ; 6,61(2 \mathrm{H}, \mathrm{s}) ; 6,65(1 \mathrm{H}, \mathrm{d}, 8,0) ; 6,73(1 \mathrm{H}, \mathrm{s}) ; 6,75(1 \mathrm{H}, \mathrm{dd}, 8,0) ; 7,16(1 \mathrm{H}, \mathrm{t}, 8,0)$

RMN ${ }^{13} \mathbf{C}: 40,8(2)\left(\mathrm{CH}_{3}\right) ; 56,2(2)\left(\mathrm{CH}_{3}\right) ; 60,9\left(\mathrm{CH}_{3}\right) ; 105,7$ (2) $(\mathrm{CH}) ; 112,3(\mathrm{CH}) ; 112,8$ $(\mathrm{CH}) ; 113,6\left(\mathrm{CH}_{2}\right) ; 117,3(\mathrm{CH}) ; 128,8(\mathrm{CH}) ; 137,5(\mathrm{C}) ; 137,7(\mathrm{C}) ; 142,1(\mathrm{C}) ; 150,5(\mathrm{C})$; $150,8(\mathrm{C}) ; 152,8(2)(\mathrm{C})$.

IR (película): 1596; 1578; 1503; 1411; 1353; 1235; 1127; $898 \mathrm{~cm}^{-1}$.

HMRS (m/z): Obtenido 314,1750 $\left(\mathrm{M}+\mathrm{H}^{+}\right)$; esperado 314,1756 $\left(\mathrm{C}_{19} \mathrm{H}_{24} \mathrm{NO}_{3}{ }^{+}\right)$. 
HPLC: Columna $\mathrm{C}_{18} \quad \mathrm{t}_{\mathrm{R}}: 19,4 \mathrm{~min}$.

\section{Reducción de la isocombretastatina 55}
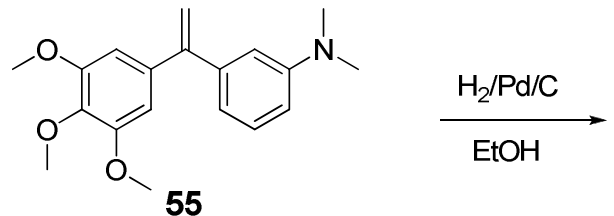<smiles>COc1cc(C(C)c2cccc(N(C)C)c2)cc(OC)c1OC</smiles>

Se disuelven $50 \mathrm{mg}(0,16 \mathrm{mmol})$ de $\mathbf{5 5}$ en $10 \mathrm{ml}$ de EtOH y se le añaden $10 \mathrm{mg}$ del catalizador de paladio. La reacción se agita fuertemente durante $4 \mathrm{~h}$ a temperatura ambiente en atmósfera de hidrogenó, después se filtra sobre celita, se evapora el disolvente y se obtienen $47 \mathrm{mg}(0,15 \mathrm{mmol} ; 94 \%)$ de producto reducido.

\section{$\underline{N, N \text {-dimetil-3-(1-(3,4,5-trimetoxifenil)etil)anilina (56): }}$}

RMN ${ }^{1} \mathbf{H}: 1,63(3 \mathrm{H}, \mathrm{d}, 7,5) ; 2,93(6 \mathrm{H}, \mathrm{s}) ; 3,99(9 \mathrm{H}, \mathrm{s}) ; 4,10(1 \mathrm{H}, \mathrm{c}, 7,5) ; 6,48(2 \mathrm{H}, \mathrm{s}) ; 6,60$ $(1 \mathrm{H}, \mathrm{d}, 6,5) ; 6,62(1 \mathrm{H}, \mathrm{d}, 6,5) ; 6,66(1 \mathrm{H}, \mathrm{sa}) ; 7,22(1 \mathrm{H}, \mathrm{t}, 6,5)$.

RMN ${ }^{13} \mathbf{C}: 22,2\left(\mathrm{CH}_{3}\right) ; 41,1(2)\left(\mathrm{CH}_{3}\right) ; 45,5(\mathrm{CH}) ; 56,1$ (2) $\left(\mathrm{CH}_{3}\right) ; 60,9\left(\mathrm{CH}_{3}\right) ; 104,7$ (2) $(\mathrm{CH}) ; 111,1(\mathrm{CH}) ; 112,7(\mathrm{CH}) ; 129,2$ (2) $(\mathrm{CH}) ; 136,2$ (C); 142,2 (C); 147,2 (C); 150,2 (C); $153,0(2)(\mathrm{C})$.

IR (película): 1589; 1499; 1458; 1327; $1233 ; 1126 \mathrm{~cm}^{-1}$.

HMRS (m/z): Obtenido 316,1909 $\left(\mathrm{M}+\mathrm{H}^{+}\right)$; esperado 316,1913 $\left(\mathrm{C}_{19} \mathrm{H}_{26} \mathrm{NO}_{3}{ }^{+}\right)$.

HPLC: Columna $\mathrm{C}_{18} \quad \mathrm{t}_{\mathrm{R}}: 18,6 \mathrm{~min}$. 


\section{Preparación de la oxima 57}<smiles>COc1cc(C(=O)c2cccc(N(C)C)c2)cc(OC)c1OC</smiles>

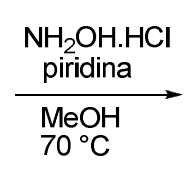<smiles>COc1cc(C(=NO)c2cccc(N(C)C)c2)cc(OC)c1OC</smiles>

Se disuelven $100 \mathrm{mg}(0,32 \mathrm{mmol})$ de $\mathbf{5 4}$ en $15 \mathrm{ml}$ de $\mathrm{MeOH}$, después se le añaden $220 \mathrm{mg}$ (3,17 $\mathrm{mmol})$ de clorhidrato de hidroxilamina y 4 gotas de piridina. La mezcla se agita durante $24 \mathrm{~h} \mathrm{a} 70{ }^{\circ} \mathrm{C}$, posteriormente se evapora el $\mathrm{MeOH}$ y se extrae con agua/AcOEt, obteniéndose $96 \mathrm{mg}(0,29 \mathrm{mmol}, 91 \%)$ de una mezcla de isómeros en proporción 1:1.

\section{$\underline{\text { Oxima de (3-(dimetilamino)fenil)(3,4,5-trimetoxifenil)metanona (57): }}$}

\section{Datos sacados del espectro de la mezcla}

\section{Isómero Z:}

RMN ${ }^{1} \mathbf{H}: 2,87(6 \mathrm{H}, \mathrm{s}) ; 3,72(6 \mathrm{H}, \mathrm{s}) ; 3,80(3 \mathrm{H}, \mathrm{s}) ; 6,55(2 \mathrm{H}, \mathrm{s}) ; 6,61(1 \mathrm{H}, \mathrm{d}, 8,0) ; 6,65(1 \mathrm{H}, \mathrm{d}$, $8,0) ; 6,72(1 \mathrm{H}, \mathrm{s}) ; 7,26(1 \mathrm{H} ; \mathrm{t}, 8,0)$.

RMN ${ }^{13} \mathbf{C}: 40,6(2)\left(\mathrm{CH}_{3}\right) ; 56,2(2)\left(\mathrm{CH}_{3}\right) ; 60,9\left(\mathrm{CH}_{3}\right) ; 106,7(2)(\mathrm{CH}) ; 113,1(\mathrm{CH}) ; 114,0$ $(\mathrm{CH}) ; 117,3(\mathrm{CH}) ; 128,3(\mathrm{C}) ; 128,9(\mathrm{CH}) ; 133,3(\mathrm{C}) ; 136,9(\mathrm{C}) ; 150,3(\mathrm{C}) ; 152,9$ (2) (C); $158,5(\mathrm{C})$.

\section{Isómero $E$ :}

$\mathbf{R M N}^{1} \mathbf{H}: 2,90(6 \mathrm{H}, \mathrm{s}) ; 3,76(6 \mathrm{H}, \mathrm{s}) ; 3,84(3 \mathrm{H}, \mathrm{s}) ; 6,62(1 \mathrm{H}, \mathrm{s}) ; 6,71(2 \mathrm{H}, \mathrm{s}) ; 6,74(1 \mathrm{H}, \mathrm{d}, 8,0)$; $6,90(1 \mathrm{H}, \mathrm{d}, 8,0) ; 7,13(1 \mathrm{H} ; \mathrm{t}, 8,0)$.

RMN ${ }^{13} \mathbf{C}: 40,6(2)\left(\mathrm{CH}_{3}\right) ; 56,2(2)\left(\mathrm{CH}_{3}\right) ; 60,9\left(\mathrm{CH}_{3}\right) ; 105,3(2)(\mathrm{CH}) ; 111,8(\mathrm{CH}) ; 113,4$ $(\mathrm{CH}) ; 117,1(\mathrm{CH}) ; 128,3(\mathrm{C}) ; 128,9(\mathrm{CH}) ; 133,3(\mathrm{C}) ; 136,9(\mathrm{C}) ; 150,3(\mathrm{C}) ; 152,9$ (2) (C); $158,1(\mathrm{C})$.

IR (película): 3428; 1582; 1503; 1411; 1344; 1236; $1127 \mathrm{~cm}^{-1}$.

HMRS (m/z): Obtenido 331,1658 $\left(\mathrm{M}+\mathrm{H}^{+}\right)$; esperado 331,1658 $\left(\mathrm{C}_{18} \mathrm{H}_{23} \mathrm{~N}_{2} \mathrm{O}_{4}{ }^{+}\right)$.

HPLC: Columna $\mathrm{C}_{18} \quad \mathrm{t}_{\mathrm{R}}: 9,0 \mathrm{~min}$. 


\section{Preparación del alcohol 58}
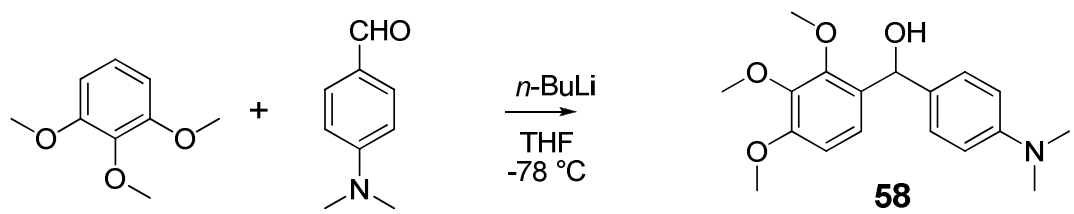

A 5,00 g (29,7 mmol) de 2,3,4-trimetoxibenceno disueltos en $30 \mathrm{ml}$ de THF seco a $-78^{\circ} \mathrm{C}$, en atmósfera de nitrógeno y con agitación magnética, se le adicionan lentamente 18,6 ml (29,73 mmol) de $n$-BuLi 1,6 M en hexano. Tras $1 \mathrm{~h}$ se añade gota a gota a esa temperatura 4,43 $\mathrm{g}$ (29,7 mmol) de 4-(dimetilamino)benzaldehído disueltos en $30 \mathrm{ml}$ de THF. La mezcla se mantiene en agitación y atmósfera de nitrógeno durante $24 \mathrm{~h}$ a temperatura ambiente. La reacción se vierte sobre una disolución de $\mathrm{NH}_{4} \mathrm{Cl}$ al $4 \%$ y AcOEt, se evapora el THF y se extrae con AcOEt. Se lava hasta $\mathrm{pH}$ neutro con una disolución saturada de $\mathrm{NaCl}$, se seca con $\mathrm{Na}_{2} \mathrm{SO}_{4}$ anhidro, se filtra y se evapora, obteniéndose 9,44 g, que se utilizarán sin purificar en la siguiente reacción.

\section{(4-dimetilaminofenil)(2,3,4-trimetoxifenil)metanol (58):}

RMN ${ }^{1} \mathbf{H}: 2,93(6 \mathrm{H}, \mathrm{s}) ; 3,67(3 \mathrm{H}, \mathrm{s}) ; 3,89(6 \mathrm{H}, \mathrm{s}) ; 5,87(\mathrm{CH}) ; 6,56(2 \mathrm{H}, \mathrm{d}, 8,6) ; 6,63(1 \mathrm{H}, \mathrm{s})$; $6,67(1 \mathrm{H}, \mathrm{d}, 6,4) ; 6,71(1 \mathrm{H}, \mathrm{d}, 6,4) ; 7,00(2 \mathrm{H}, \mathrm{d}, 8,6)$.

\section{Obtención de la fenstatina 59}<smiles>COc1ccc(C(O)c2ccc(N(C)C)cc2)c(OC)c1OC</smiles><smiles>CC(C)OC1CCCCC1</smiles><smiles>COc1ccc(C(=O)c2ccc(N(C)C)cc2)c(OC)c1OC</smiles>

A los 9,44 g (29,7 mmol) del crudo de 58 disueltos en $15 \mathrm{ml}$ de $\mathrm{CH}_{2} \mathrm{Cl}_{2}$ seco a $0{ }^{\circ} \mathrm{C}$ se le añaden 16,8 g (44,7 mmol) de dicromato de piridinio, en atmósfera de nitrógeno y con agitación. La reacción se mantiene 24 h permitiendo que alcance la temperatura ambiente. Se filtra con celita y se extrae, obteniéndose $8,09 \mathrm{~g}$ de crudo de reacción. 
El crudo se purifica por cromatografía de columna flash (Hex/AcOEt 8:2), obteniéndose 1,86 g (5,90 mmol, $20 \%)$ de $\mathbf{5 9}$.

\section{(4-dimetilaminofenil)(2,3,4-trimetoxifenil)metanona (59):}

RMN ${ }^{1} \mathbf{H}: 3,02(6 \mathrm{H}, \mathrm{s}) ; 3,76(3 \mathrm{H}, \mathrm{s}) ; 3,87(6 \mathrm{H}, \mathrm{s}) ; 6,60(2 \mathrm{H}, \mathrm{d}, 9,0) ; 6,67(1 \mathrm{H}, \mathrm{d}, 8,6) ; 7,01$ $(1 \mathrm{H}, \mathrm{d}, 8,6) ; 7,72(2 \mathrm{H}, \mathrm{d}, 9,0)$.

RMN ${ }^{13} \mathbf{C}: 40,1(2)\left(\mathrm{CH}_{3}\right) ; 56,1\left(\mathrm{CH}_{3}\right) ; 61,1\left(\mathrm{CH}_{3}\right) ; 61,9\left(\mathrm{CH}_{3}\right) ; 106,8(\mathrm{CH}) ; 110,5(2)(\mathrm{CH})$; 124,2 (CH); 125,5 (C); 127,7 (C); 132,4 (2) (CH); 142,0 (C); 152,0 (C); 153,5 (C); 155,0 (C); $193,6(C)$.

IR (KBr): $1636 ; 1588 \mathrm{~cm}^{-1}$.

Pf $\left(\mathrm{Hexano} / \mathrm{CH}_{2} \mathrm{Cl}_{2}\right): 205-207^{\circ} \mathrm{C}$

HMRS (m/z): Obtenido 316,1560 $\left(\mathrm{M}+\mathrm{Na}^{+}\right)$; esperado 316,1549 $\left(\mathrm{C}_{18} \mathrm{H}_{22} \mathrm{NO}_{4}{ }^{+}\right)$.

HPLC: Columna $\mathrm{C}_{18} \quad \mathrm{t}_{\mathrm{R}}: 12,9 \mathrm{~min}$.

\section{Obtención de la isocombretastatina 60}
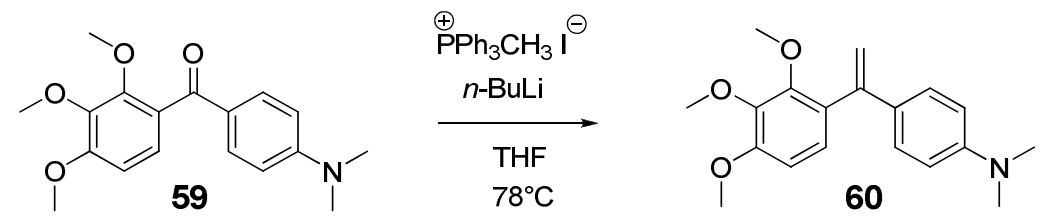

A $1,93 \mathrm{mg}(4,80 \mathrm{mmol})$ de la sal de fosfonio 1 suspendidos en $30 \mathrm{~mL}$ de $\mathrm{THF}$ seco a $-78{ }^{\circ} \mathrm{C}$ en atmósfera de nitrógeno se le añaden 2,5 $\mathrm{ml}$ (4,0 mmol) de $n$-BuLi 1,6 M en hexano y se mantiene $1 \mathrm{~h}$ en agitación, después se añaden $500 \mathrm{mg}(1,58 \mathrm{mmol})$ de la cetona $\mathbf{5 9}$ disueltos en $15 \mathrm{ml}$ de THF seco. La mezcla se agita durante $24 \mathrm{~h}$ a temperatura ambiente y con agitación. Posteriormente según el procedimiento habitual, se obtienen $408 \mathrm{mg}$ de crudo de reacción.

El crudo se purifica mediante cromatografía flash (Hex/AcOEt 9:1), se obtienen $349 \mathrm{mg}$ $(1,11 \mathrm{mmol}, 70 \%)$ de $\mathbf{6 0}$, que se cristaliza en $t$-butilmetiléter para obtener $293 \mathrm{mg}$ de cristales amarillos. 


\section{$\underline{N, N \text {-dimetil-4-(1-(2,3,4-trimetoxifenil)etenil)anilina (60): }}$}

$\mathbf{R M N}^{1} \mathbf{H}: 2,95(6 \mathrm{H}, \mathrm{s}) ; 3,59(3 \mathrm{H}, \mathrm{s}) ; 3,87(3 \mathrm{H}, \mathrm{s}) ; 3,89(3 \mathrm{H}, \mathrm{s}) ; 5,09(1 \mathrm{H}, \mathrm{d}, 1,6) ; 5,54(1 \mathrm{H}, \mathrm{d}$, 1,6); 6,64 (2H, d, 8,8); 6,67 (1H, d, 8,4); 6,92 (1H, d, 8,4); 7,19 (2H, d, 8,8).

RMN ${ }^{13} \mathbf{C}: 40,5(2)\left(\mathrm{CH}_{3}\right) ; 56,0\left(\mathrm{CH}_{3}\right) ; 60,8\left(\mathrm{CH}_{3}\right) ; 60,9\left(\mathrm{CH}_{3}\right) ; 106,9(\mathrm{CH}) ; 111,8\left(\mathrm{CH}_{2}\right)$; 112,1 (2) (CH); 125,4 (CH); 127,6 (2) (CH); 129,8 (C); 129,9 (C); 142,4 (C); 146,5 (C); 150,1 (C); 151,8 (C); 153,3 (C).

IR (KBr): $1602 ; 1521 \mathrm{~cm}^{-1}$.

Pf ( $t$-butilmetiléter): $63-65^{\circ} \mathrm{C}$

HMRS (m/z): Obtenido 314,1738 $\left(\mathrm{M}+\mathrm{H}^{+}\right)$; esperado 314,1756 $\left(\mathrm{C}_{19} \mathrm{H}_{24} \mathrm{NO}_{3}{ }^{+}\right)$.

HPLC: Columna $\mathrm{C}_{18} \quad \mathrm{t}_{\mathrm{R}}: 19,7 \mathrm{~min}$.

\section{Metilación de la fenstatina 59}
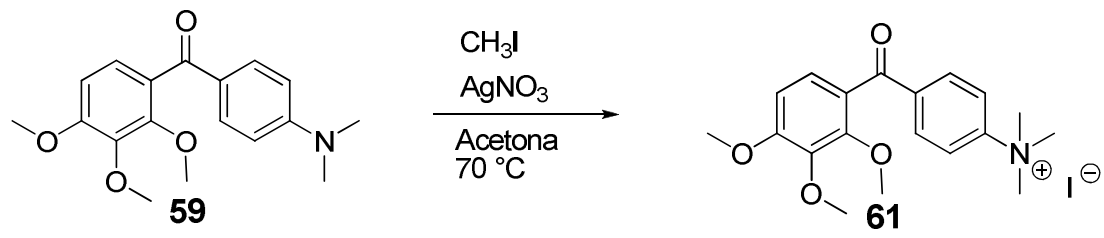

En un tubo sellado se disuelven $250 \mathrm{mg}(0,79 \mathrm{mmol})$ de la cetona 59 en $15 \mathrm{ml}$ de acetona, después se añaden $494 \mu \mathrm{l}(7,9 \mathrm{mmol})$ de yodometano y $269 \mathrm{mg}(1,58 \mathrm{mmol})$ de nitrato de plata, apareciendo un precipitado blanco. La mezcla se agita durante $24 \mathrm{~h}$ a $70{ }^{\circ} \mathrm{C}$, luego se filtra y se aísla $330 \mathrm{mg}$ de crudo de reacción.

El crudo se cristaliza en metanol aislándose $180 \mathrm{mg}(0,54 \mathrm{mmol}, 69 \%)$ de $\mathbf{6 1}$ en forma de cristales blancos y $140 \mathrm{mg}$ de aguas madres.

Yoduro de $N, N, N$-trimetil-4-(2,3,4-trimetoxibenzoil)bencenamonio (61):

RMN ${ }^{1} \mathbf{H}$ (piridina): 3,35 (3H, s); 3,40 (3H, s); 3,45 (3H, s); 3,74 (9H, s); 6,47 (1H, d, 8,8); 7,02 (1H, d, 8,8); 7,70 (2H, d, 8,4); 7,72 (2H, d, 8,4). 
RMN ${ }^{13} \mathbf{C}$ (piridina): 54,8 $\left(\mathrm{CH}_{3}\right) ; 56,8(3)\left(\mathrm{CH}_{3}\right) ; 59,4\left(\mathrm{CH}_{3}\right) ; 60,6\left(\mathrm{CH}_{3}\right) ; 106,6(\mathrm{CH}) ; 119,6$ (2) $(\mathrm{CH}) ; 124,1(\mathrm{CH}) ; 124,6(\mathrm{C}) ; 130,2$ (2) (CH); 139,4 (C); 141,0 (C); 148,7 (C); 151,9 (C); 156,2 (C); 192,2 (C).

IR (KBr): 1648; 1592; 1461; 1412; 1296; $1094 \mathrm{~cm}^{-1}$.

Pf (Acetona/MeOH): $172-173{ }^{\circ} \mathrm{C}$

HMRS (m/z): Obtenido 330,1698 $\left(\mathrm{M}^{+}\right)$; esperado 330, $1705\left(\mathrm{C}_{19} \mathrm{H}_{24} \mathrm{NO}_{4}{ }^{+}\right)$.

HPLC: Columna $\mathrm{C}_{18} \quad \mathrm{t}_{\mathrm{R}}: 6,8 \mathrm{~min}$.

\section{Metilación de la isocombretastatina 60}
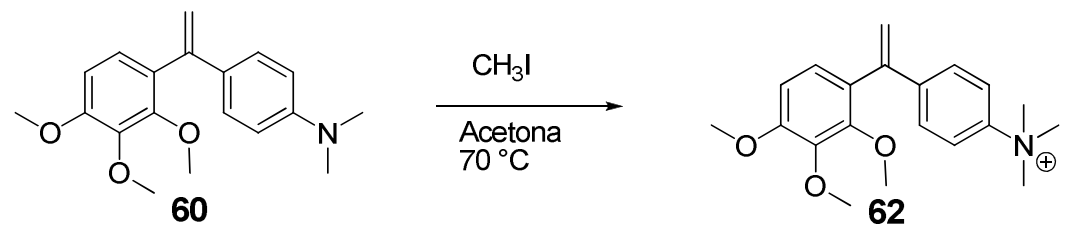

Se disuelve en un matraz $170 \mathrm{mg}(0,54 \mathrm{mmol})$ de la olefina 60 en $10 \mathrm{ml}$ de acetona, después se añaden $170 \mu \mathrm{L}$ de $\mathrm{CH}_{3} \mathrm{I}$ a $60^{\circ} \mathrm{C}$, apareciendo coloración naranja. La mezcla se agita durante $24 \mathrm{~h}$, apareciendo un precipitado de color amarillo que se filtra y lava con éter aislándose 220 mg de crudo de reacción.

El crudo se cristaliza en metanol obteniéndose 160 mg (0,49 mmol, $91 \%)$ de 62 como un sólido amarillo.

Yoduro de $N, N, N$-trimetil-4-(1-(2,3,4-trimetoxifenil)vinil)bencenamonio (62):

RMN ${ }^{1} \mathbf{H}$ (DMSO): 3,35 (3H, s); 3,51 (9H, s); 3,66 (3H, s); 3,76 (3H, s); 5,32 (1H, s); 5,70 $(1 \mathrm{H}, \mathrm{s}) ; 6,79(1 \mathrm{H}, \mathrm{d}, 8,2) ; 6,89(1 \mathrm{H}, \mathrm{d}, 8,2) ; 7,37(2 \mathrm{H}, \mathrm{d}, 8,6) ; 7,76(2 \mathrm{H}, \mathrm{d}, 8,6)$.

RMN ${ }^{13}$ C (DMSO): 55,9 $\left(\mathrm{CH}_{3}\right) ; 56,4$ (3) $\left(\mathrm{CH}_{3}\right) ; 60,4$ (2) $\left(\mathrm{CH}_{3}\right) ; 107,9(\mathrm{CH}) ; 117,7\left(\mathrm{CH}_{2}\right)$; 120,3 (2) (CH); 124,8 (CH); 127,2 (C); 127,4 (2) (CH); 141,8 (C); 142,6 (C); 144,6 (C); 146,1 (C); 150,9 (C); 153,6 (C).

IR (KBr): 1594; 1496; 1459; 1406; 1295; $1090 \mathrm{~cm}^{-1}$. 
Pf $(\mathrm{MeOH}): 168-169^{\circ} \mathrm{C}$

HMRS (m/z): Obtenido 328,1907 $\left(\mathrm{M}^{+}\right)$; esperado 328, $1913\left(\mathrm{C}_{20} \mathrm{H}_{26} \mathrm{NO}_{3}{ }^{+}\right)$.

\section{Preparación del alcohol 63}<smiles>COc1ccc(OC)c(C(O)c2ccc(OC)c(OC)c2)c1</smiles>

A 5,02 g (36,2 mmol) de 1,4-dimetoxibenceno disueltos en $30 \mathrm{ml}$ de THF seco a $-78{ }^{\circ} \mathrm{C}$, en atmósfera de nitrógeno y con agitación magnética se le adicionan lentamente 22,6 ml (36,2 mmol) de $n$-BuLi 1,6 M en hexano. Tras $1 \mathrm{~h}$ de reacción se añaden gota a gota a esa temperatura 5,40 g (36,2 mmol) de 4-(dimetilamino)benzaldehído disueltos en $20 \mathrm{ml}$ de THF seco. La reacción se mantiene en agitación y atmósfera de nitrógeno durante $24 \mathrm{~h}$ a temperatura ambiente. La reacción se vierte sobre una disolución de $\mathrm{NH}_{4} \mathrm{Cl}$ al $4 \%$ y AcOEt, se evapora el THF y se extrae con AcOEt. La fase orgánica se lava hasta $\mathrm{pH}$ neutro con una disolución saturada de $\mathrm{NaCl}$, se seca con $\mathrm{Na}_{2} \mathrm{SO}_{4}$ anhidro, se filtra y se evapora, obteniéndose 11,20 g, que se utilizarán sin purificar en la siguiente reacción.

\section{(4-dimetilaminofenil)(2,5-dimetoxifenil)metanol (63):}

RMN ${ }^{1} \mathbf{H}: 2,93(6 \mathrm{H}, \mathrm{s}) ; 3,75(3 \mathrm{H}, \mathrm{s}) ; 3,76(3 \mathrm{H}, \mathrm{s}) ; 5,96(1 \mathrm{H}, \mathrm{s}) ; 6,68(2 \mathrm{H}, \mathrm{d}, 8,6) ; 6,77(1 \mathrm{H}$, s); 6,79 (1H, d, 2,6); 6,94 (1H, d, 2,6); 7,23 (2H, d, 8,8).

RMN ${ }^{13} \mathbf{C}: 40,5(2)\left(\mathrm{CH}_{3}\right) ; 55,4\left(\mathrm{CH}_{3}\right) ; 55,8\left(\mathrm{CH}_{3}\right) ; 70,9(\mathrm{CH}) ; 111,6(\mathrm{CH}) ; 112,3(3)(\mathrm{CH})$; 113,3 (CH); 127,5 (2) (CH); 131,7 (C); 134,1 (C); 149,8 (C); 150,6 (C); 153,7 (C). 


\section{Preparación de la fenstatina 64}<smiles>COc1ccc(OC)c(C(O)c2ccc(N(C)C)cc2)c1</smiles>

A los 11,20 g (39,0 mmol) del crudo de 63 disueltos en $15 \mathrm{ml} \mathrm{de} \mathrm{CH}_{2} \mathrm{Cl}_{2}$ seco a $0{ }^{\circ} \mathrm{C}$, se le añaden 22,05 g de PDC (58,6 mmol), en atmósfera de nitrógeno y con agitación. La reacción se mantiene $24 \mathrm{~h}$ a temperatura ambiente. Se filtra a través de celita y se extrae con $\mathrm{CH}_{2} \mathrm{Cl}_{2}$, lavando la fase orgánica primero con $\mathrm{HCl}$ y después con $\mathrm{NaHCO}_{3}$ al $5 \%$, se seca con $\mathrm{Na}_{2} \mathrm{SO}_{4}$ anhidro, se filtra y se evapora, obteniéndose 8,52 g (29,9 mmol) de crudo de reacción. Se purifica mediante cromatografía flash (Hex/AcOEt 8:2), se aíslan 3,52 g (12,4 mmol, 32 \%). Se cristaliza con $t$-butilmetiléter y se obtienen $1,14 \mathrm{~g}$ de cristales de 64.

\section{(4-dimetilaminofenil)(2,5-dimetoxifenil)metanona (64):}

RMN ${ }^{1} \mathbf{H}: 3,03(6 \mathrm{H}, \mathrm{s}) ; 3,68(3 \mathrm{H}, \mathrm{s}) ; 3,75(3 \mathrm{H}, \mathrm{s}) ; 6,61(2 \mathrm{H}, \mathrm{d}, 8,8) ; 6,85(1 \mathrm{H}, \mathrm{d}, 2,5) ; 6,90$ $(1 \mathrm{H}, \mathrm{dd}, 8,8,2,5) ; 6,92(1 \mathrm{H}, \mathrm{d}, 8,8) ; 7,74(2 \mathrm{H}, \mathrm{d}, 8,8)$.

RMN ${ }^{13} \mathbf{C}: 40,0(2)\left(\mathrm{CH}_{3}\right) ; 55,8\left(\mathrm{CH}_{3}\right) ; 56,5\left(\mathrm{CH}_{3}\right) ; 110,4(2)(\mathrm{CH}) ; 113,0(\mathrm{CH}) ; 114,1(\mathrm{CH})$; 115,9 (CH); 125,1 (C); 130,9 (C); 132,3 (2) (CH); 150,9 (C); 153,3 (C); 153,5 (C); 194,0 (C).

IR (KBr): $1637 ; 1588 ; 1544 \mathrm{~cm}^{-1}$.

Pf $\left(\mathrm{Hexano} / \mathrm{CH}_{2} \mathrm{Cl}_{2}\right): 78-80{ }^{\circ} \mathrm{C}$

HMRS (m/z): Obtenido 286,1420 $\left(\mathrm{M}+\mathrm{H}^{+}\right)$; esperado 286,1443 $\left(\mathrm{C}_{17} \mathrm{H}_{20} \mathrm{NO}_{3}{ }^{+}\right)$.

HPLC: Columna $\mathrm{C}_{18} \quad \mathrm{t}_{\mathrm{R}}: 13,1 \mathrm{~min}$. 


\section{Obtención de la isocombretastatina 65}

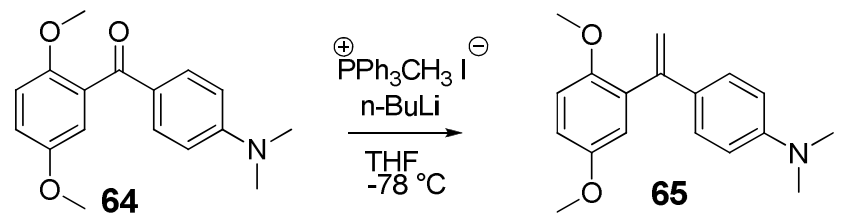

A 2,12 g (5,24 mmol) de la sal de fosfonio 1 suspendidos en $30 \mathrm{~mL}$ de THF seco a $-78{ }^{\circ} \mathrm{C}$ en atmósfera de nitrógeno, se le añaden $2,7 \mathrm{ml}(4,38 \mathrm{mmol})$ de $n$-BuLi 1,6 $\mathrm{M}$ en hexano y se mantiene $1 \mathrm{~h}$ en agitación. En estas condiciones se añaden, desde un embudo de adición, gota a gota, $500 \mathrm{mg}(1,75 \mathrm{mmol})$ de $\mathbf{6 4}$ disueltos en $20 \mathrm{ml}$ de THF seco, permitiendo que alcance espontáneamente la temperatura ambiente y con agitación. Tras 24 horas se vierte la reacción sobre una mezcla de $\mathrm{NH}_{4} \mathrm{Cl}$ al $4 \%$ y AcOEt, despues se evapora el THF y se extrae con AcOEt. La reunión de las fases orgánicas se lava hasta $\mathrm{pH}$ neutro con una disolución saturada de $\mathrm{NaCl}$, se seca con $\mathrm{Na}_{2} \mathrm{SO}_{4}$ anhidro, se filtra y se evapora, obteniéndose $411 \mathrm{mg}(1,45$ mmol) de crudo de reacción.

El crudo se purifica mediante cromatografía flash (Hex/AcOEt 6:4), obteniéndose $245 \mathrm{mg}$ $(0,87 \mathrm{mmol}, 50 \%)$ del compuesto $\mathbf{6 5}$ en forma de aceite amarillo, que se cristaliza utilizando como disolvente $t$-butilmetiléter para obtener $151 \mathrm{mg}$ de cristales de color amarillo.

\section{4-(1-(2,5-dimetoxifenil)vinil)- $N, N$-dimetilbencenamina (65):}

$\mathbf{R M N}^{1} \mathbf{H}: 2,99(6 \mathrm{H}, \mathrm{s}) ; 3,68(3 \mathrm{H}, \mathrm{s}) ; 3,82(3 \mathrm{H}, \mathrm{s}) ; 5,18(1 \mathrm{H}, \mathrm{s}) ; 5,70(1 \mathrm{H}, \mathrm{s}) ; 6,70(2 \mathrm{H}, \mathrm{d}, 9,0)$; $6,90(3 \mathrm{H}, \mathrm{s}) ; 7,28(2 \mathrm{H}, \mathrm{d}, 9,0)$.

RMN ${ }^{13} \mathbf{C}: 40,6(2)\left(\mathrm{CH}_{3}\right) ; 55,8\left(\mathrm{CH}_{3}\right) ; 56,7\left(\mathrm{CH}_{3}\right) ; 111,7\left(\mathrm{CH}_{2}\right) ; 112,1(2)(\mathrm{CH}) ; 112,8(\mathrm{CH})$; 113,2 (CH); 117,1 (CH); 127,3 (2) (CH); 128,8 (C); 133,0 (C); 146,4 (C); 150,1 (C); 151,6 (C); 153,7 (C).

IR (KBr): $1525,1605 \mathrm{~cm}^{-1}$.

Pf ( $t$-butilmetiléter): $68-70^{\circ} \mathrm{C}$

HMRS (m/z): Obtenido 284,1635 $\left(\mathrm{M}+\mathrm{H}^{+}\right)$; esperado 284,1651 $\left(\mathrm{C}_{18} \mathrm{H}_{22} \mathrm{NO}_{2}{ }^{+}\right)$.

HPLC: Columna $\mathrm{C}_{18} \quad \mathrm{t}_{\mathrm{R}}: 19,5 \mathrm{~min}$. 


\section{Metilación de la fenstatina 64}<smiles>COc1ccc(OC)c(C(=O)c2ccc(N(C)C)cc2)c1</smiles>
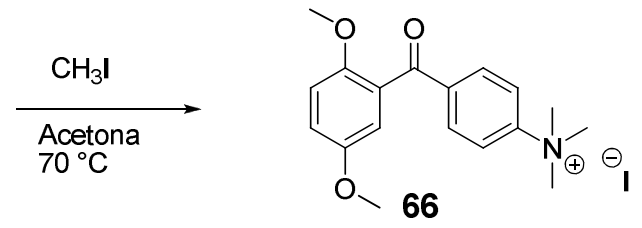

En un tubo sellado se disuelven $260 \mathrm{mg}(0,91 \mathrm{mmol})$ de la cetona $64 \mathrm{en} 10 \mathrm{ml}$ de acetona y se le añaden $170 \mu \mathrm{l}$ de yodometano y se calienta a $70^{\circ} \mathrm{C}$, apareciendo un color naranja. La mezcla se agita durante $24 \mathrm{~h}$, luego se trata con éter y se filtra, aislándose $135 \mathrm{mg}(0,47$ mmol, $52 \%$ ) de sólido amarillo del compuesto 66.

\section{Yoduro de $N, N, N$-trimetil-4-(2,5-dimetoxibenzoil)bencenamonio (66):}

RMN ${ }^{1} \mathbf{H}$ (DMSO): 3,60 (3H, s); 3,63 (9H, s); 3,73 (3H, s); 6,93 (1H, t, 1,8); 7,15 (2H, d, $1,8) ; 7,84(2 \mathrm{H}, \mathrm{d}, 9,0) ; 8,08(2 \mathrm{H}, \mathrm{d}, 9,0)$.

RMN ${ }^{13} \mathbf{C}$ (DMSO): 40,4 (3) $\left(\mathrm{CH}_{3}\right) ; 56,3\left(\mathrm{CH}_{3}\right) ; 56,4\left(\mathrm{CH}_{3}\right) ; 113,6(\mathrm{CH}) ; 114,0(\mathrm{CH}) ; 117,8$ $(\mathrm{CH}) ; 121,3$ (2) (CH); 127,9 (C); 130,6 (2) (CH); 138,0 (C); 150,2 (C); 150,8 (C); 153,1 (C); 194,1 (C).

IR (KBr): 1662; 1600; 1496; 1413; 1226; $1035 \mathrm{~cm}^{-1}$.

Pf (éter): $162^{\circ} \mathrm{C}$

HMRS (m/z): Obtenido 300,1593 $\left(\mathrm{M}^{+}\right)$; esperado 300,1600 $\left(\mathrm{C}_{18} \mathrm{H}_{22} \mathrm{NO}_{3}{ }^{+}\right)$.

HPLC: Columna $\mathrm{C}_{18} \quad \mathrm{t}_{\mathrm{R}}: 4,2 \mathrm{~min}$. 


\section{Modificaciones en el anillo A}

\section{A. Análogos de isocombretastatinas}

\section{Nitración de vainillina}<smiles>COc1cc(C=O)ccc1O</smiles><smiles>CC(C)COc1cc(C=O)cc([N+](=O)[O-])c1O</smiles>

67

Se disuelven 11,50 g (75,66 mmol) de vainillina en $150 \mathrm{ml}$ de ácido acético y se le añaden 4,7 ml (98 mmol) de ácido nítrico, el color pasa de blanco a amarillo. La reacción se deja agitando durante $2 \mathrm{~h}$ a temperatura ambiente, luego se trata con agua apareciendo un precipitado que se filtra, obteniéndose 11,90 g (60,40 mmol, $80 \%)$ de 5-nitrovainillina.

\section{4-hidroxi-3-metoxi-5-nitrobenzaldehído (67):}

$\mathbf{R M N}^{1} \mathbf{H}:$ 4,02 (3H, s); 7,64 (1H, d, 2,0); 8,22 (1H, d, 2,0); 9,89 (1H, s).

IR (KBr): 3206; 1681; 1548; 1336; 1232; $1104 \mathrm{~cm}^{-1}$.

Pf $\left(\mathrm{AcOH} / \mathrm{H}_{2} \mathrm{O}\right): 176-177^{\circ} \mathrm{C}$

\section{Metilación del compuesto 67}
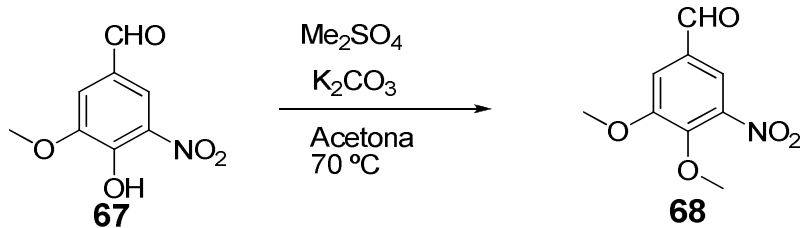

Se disuelven 5,00 g (25,36 mmol) de 67 en $40 \mathrm{ml}$ de acetona, después se le añaden 12,30 g (89,0 $\mathrm{mmol})$ de carbonato potásico y $12 \mathrm{ml}(127 \mathrm{mmol})$ de sulfato de dimetilo. La reacción se 
agita durante $48 \mathrm{~h}$ a temperatura ambiente y $8 \mathrm{~h} \mathrm{a} 70^{\circ} \mathrm{C}$, posteriormente se filtra sobre Celita y se evapora el disolvente, obteniéndose 5,8 g del crudo de reacción.

El crudo se purifica por cromatografía flash con $\mathrm{CH}_{2} \mathrm{Cl}_{2} / \mathrm{Hex}$ 8:2 para quitar el sulfato de dimetilo y se aíslan 4,36 g (20,65 mmol, $81 \%)$ de compuesto $\mathbf{6 8}$, que se cristaliza en 2propanol.

\section{3,4-dimetoxi-5-nitrobenzaldehído (68):}

$\mathbf{R M N}^{1} \mathbf{H}:$ 4,00 (3H, s); 4,08 (3H, s); 7,62 (1H, d, 2,0); 7,84 (1H, d, 2,0); 9,92 (1H, s).

RMN ${ }^{13} \mathrm{C}:$ 56,6 $\left(\mathrm{CH}_{3}\right) ; 62,2\left(\mathrm{CH}_{3}\right) ; 113,5(\mathrm{CH}) ; 119,3(\mathrm{CH}) ; 131,3(\mathrm{C}) ; 147,6(\mathrm{C}) ; 154,6(\mathrm{C})$; $155,2(\mathrm{C}) ; 189,0(\mathrm{CH})$.

IR (KBr): 2955; 1699; 1539; 1363; 1287; 1139; $980 \mathrm{~cm}^{-1}$.

Pf (2-propanol): $91-92{ }^{\circ} \mathrm{C}$

\section{Metilación del compuesto 63 en condiciones de transferencia de fase}

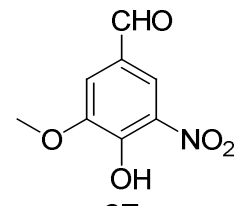

67

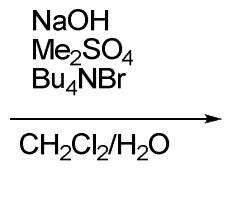

Se disuelven $6,60 \mathrm{~g}(33,47 \mathrm{mmol})$ de 67 en $75 \mathrm{ml}$ de $\mathrm{CH}_{2} \mathrm{Cl}_{2}$ y $75 \mathrm{ml}$ de $\mathrm{H}_{2} \mathrm{O}$, después se le añaden 2,70 g (67,5 mmol) de hidróxido sódico en polvo, 1,00 g (3,55 mmol) de bromuro de tetrabutil amonio y $16 \mathrm{ml}(167 \mathrm{mmol})$ de sulfato de dimetilo, la reacción se pone naranja. La mezcla se agita fuertamente durante $24 \mathrm{~h}$ a temperatura ambiente, luego se extrae con $\mathrm{CH}_{2} \mathrm{Cl}_{2}$, se obtiene un aceite amarillo que se disuelve en éter y se extrae con $\mathrm{H}_{2} \mathrm{O}, \mathrm{NH}_{3}(2 \mathrm{M})$ y $\mathrm{NaOH}(2 \mathrm{M})$, después se evapora el disolvente, obteniéndose 13,30 g de un aceite naranja que solidifica al frío. Este sólido se recristaliza en acetona/ $\mathrm{H}_{2} \mathrm{O}$ para obtener 6,20 g (29,36 mmol, $88 \%$ ) del compuesto $\mathbf{6 8}$ como un aceite amarillo. 


\section{Preparación del alcohol 69}

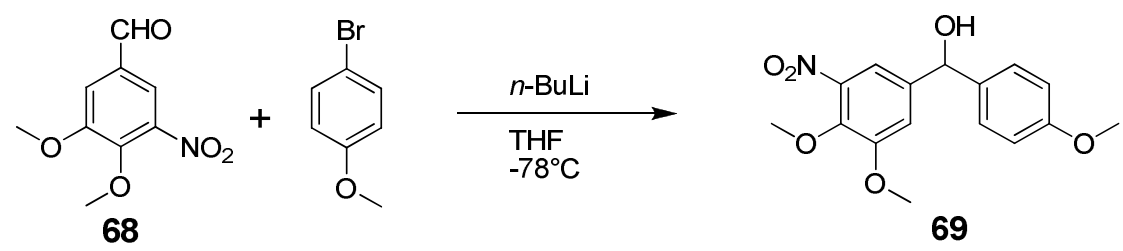

Se disuelven 4,25 g (22,73 mmol) de 4-bromoanisol en $30 \mathrm{ml}$ de THF seco, después se le añaden $9,5 \mathrm{ml}(15,2 \mathrm{mmol})$ de $n$-BuLi $1,6 \mathrm{M}$ en hexano a $-78{ }^{\circ} \mathrm{C}$ apareciendo un color amarillo. La mezcla se agita durante $1 \mathrm{~h}$ a $-78^{\circ} \mathrm{C}$ en atmósfera de nitrógeno, luego se añaden 1,60 g (7,58 mmol) del aldehído $\mathbf{6 8}$, el color cambia de amarillo a marrón. La reacción se agita durante $24 \mathrm{~h}$ a temperatura ambiente, posteriormente se trata con $\mathrm{NH}_{4} \mathrm{Cl}$ y AcOEt, se evapora el THF y se extrae con AcOEt obteniéndose 3,50 g del compuesto 69 que se utiliza sin purificar para la siguiente reacción.

\section{(3,4-dimetoxi-5-nitrofenil)(4-metoxifenil)metanol (69):}

$\mathbf{R M N}^{1} \mathbf{H}: 3,70(6 \mathrm{H}, \mathrm{s}) ; 3,76(3 \mathrm{H}, \mathrm{s}) ; 5,74(1 \mathrm{H}, \mathrm{s}) ; 6,90(2 \mathrm{H}, \mathrm{d}, 9,0) ; 7,15(1 \mathrm{H}, \mathrm{s}) ; 7,30(2 \mathrm{H}, \mathrm{d}$, $9,0) ; 7,77(1 \mathrm{H}, \mathrm{s})$.

IR (pelicula): 3407; 1595; 1512; 1455; 1352; 1244; $1173 ; 832 ; \mathrm{cm}^{-1}$.

\section{Obtención de la fenstatina 70}<smiles>COc1cc(C(O)c2ccc(OCC(C)C)cc2)cc([N+](=O)[O-])c1O</smiles><smiles>COc1ccc(C(=O)c2cc(OC)c(OC)c([N+](=O)[O-])c2)cc1</smiles>

Se disuelven 3,50 g (10,96 mmol) de 69 en $30 \mathrm{ml}$ de $\mathrm{CH}_{2} \mathrm{Cl}_{2}$ y se le añaden $6,20 \mathrm{~g}(16,44$ mmol) de dicromato de piridinio a $0^{\circ} \mathrm{C}$ apareciendo un color marrón. La reacción se agita durante $4 \mathrm{~h}$ a temperatura ambiente, posteriormente se filtra sobre Celita, se eluye con $\mathrm{CH}_{2} \mathrm{Cl}_{2}$ y se evapora el disolvente obteniéndose $2,40 \mathrm{~g}$ de crudo de reacción. 
El crudo se purifica por cromatografía flash (Hex/AcOEt 7:3) y se obtienen $895 \mathrm{mg}(1,73$ mmol, $37 \%$ ) del compuesto $\mathbf{7 0}$ en forma de sólido blanco.

\section{(3,4-dimetoxi-5-nitrofenil)(4-metoxifenil)metanona (70):}

RMN ${ }^{1} \mathbf{H}: 3,90(3 \mathrm{H}, \mathrm{s}) ; 3,98(3 \mathrm{H}, \mathrm{s}) ; 4,07$ (3H, s); 6,97 (2H, d, 9,0); 7,59 (1H, d, 2,0); 7,66 $(1 \mathrm{H}, \mathrm{d}, 2,0) ; 7,78(2 \mathrm{H}, \mathrm{d}, 9,0)$.

RMN ${ }^{13} \mathbf{C}: 55,5\left(\mathrm{CH}_{3}\right) ; 56,6\left(\mathrm{CH}_{3}\right) ; 62,1\left(\mathrm{CH}_{3}\right) ; 113,9(2)(\mathrm{CH}) ; 116,3(\mathrm{CH}) ; 118,1(\mathrm{CH})$; 129,0 (C); 132,3 (2) (CH); 133,3 (C); 143,9 (C); 145,7 (C); 154,1 (C); 163,6 (C); 192,3 (C).

IR (KBr): $1653 ; 1605 ; 1533 ; 1362 ; 1298 ; 1172 ; 844 \mathrm{~cm}^{-1}$.

Pf $\left(\mathrm{Hexano} / \mathrm{CH}_{2} \mathrm{Cl}_{2}\right): 117-118^{\circ} \mathrm{C}$.

HMRS (m/z): Obtenido 318,0974 $\left(\mathrm{M}+\mathrm{H}^{+}\right)$; esperado 318,0978 $\left(\mathrm{C}_{16} \mathrm{H}_{16} \mathrm{NO}_{6}{ }^{+}\right)$.

\section{Obtención de la fenstatina 71}
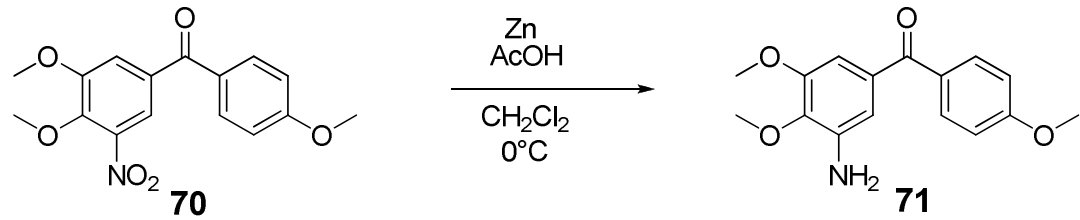

Se disuelven $55 \mathrm{mg}(0,17 \mathrm{mmol})$ de 70 en $5 \mathrm{ml}$ de $\mathrm{CH}_{2} \mathrm{Cl}_{2}$ y se le añaden $70 \mathrm{mg}(1,05 \mathrm{mmol})$ de zinc en polvo y 2 gotas de ácido acético a $0^{\circ} \mathrm{C}$, aparece un color verde que luego pasa a amarillo. La mezcla se deja agitando $24 \mathrm{~h}$ a temperatura ambiente, posteriormente se filtra sobre celita y se extrae con agua/ $\mathrm{CH}_{2} \mathrm{Cl}_{2}$ obteniéndose $47 \mathrm{mg}(0,16 \mathrm{mmol}, 95 \%)$ de crudo de reacción.

\section{(3-amino-4,5-dimetoxifenil)(4-metoxifenil)metanona (71):}

$\mathbf{R M N}^{1} \mathbf{H}: 3,85(3 \mathrm{H}, \mathrm{s}) ; 3,87(3 \mathrm{H}, \mathrm{s}) ; 3,88(3 \mathrm{H}, \mathrm{s}) ; 6,76(1 \mathrm{H}, \mathrm{s}) ; 6,77(1 \mathrm{H}, \mathrm{s}) ; 7,93(2 \mathrm{H}, \mathrm{d}, 8,8)$; $7,81(2 \mathrm{H}, \mathrm{d}, 8,8)$.

RMN ${ }^{13} \mathbf{C}: 56,3\left(\mathrm{CH}_{3}\right) ; 56,7\left(\mathrm{CH}_{3}\right) ; 60,8\left(\mathrm{CH}_{3}\right) ; 104,8(\mathrm{CH}) ; 111,9(\mathrm{CH}) ; 114,2(2)(\mathrm{CH})$; 131,3 (C); 133,2 (2) (CH); 134,8 (C); 139,7 (C); 140,8 (C); 153,4 (C); 163,8 (C); 195,9 (C). 
IR (KBr): 3364; 1640; 1594; 1353; 1250; 1172; 1126; $847 \mathrm{~cm}^{-1}$.

HMRS (m/z): Obtenido 288,1234 $\left(\mathrm{M}+\mathrm{H}^{+}\right)$; esperado 288,1238 $\left(\mathrm{C}_{16} \mathrm{H}_{18} \mathrm{NO}_{4}{ }^{+}\right)$.

HPLC: Columna $\mathrm{C}_{18} \quad \mathrm{t}_{\mathrm{R}}: 6,3 \mathrm{~min}$.

\section{Obtención de la isocombretastatina 72}
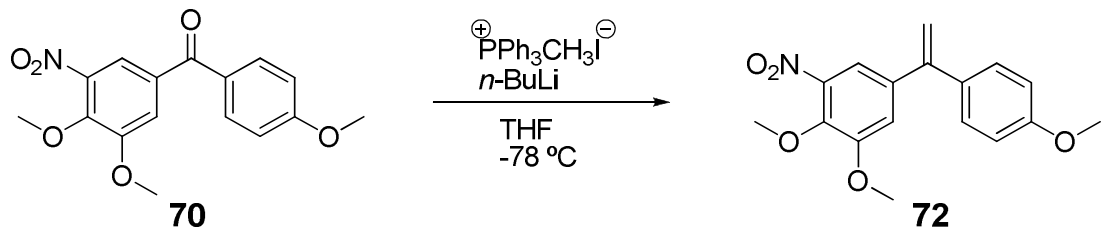

Se disuelven 1,80 g (4,35 mmol) de la sal 1 en $30 \mathrm{ml}$ de THF seco y se le añaden 2,3 $\mathrm{ml}(3,62$ mmol) de $n$-BuLi $1,6 \mathrm{M}$ en hexano a $-78^{\circ} \mathrm{C}$ apareciendo un color amarillo. La mezcla se mantiene agitando durante $1 \mathrm{~h}$ a $-78^{\circ} \mathrm{C}$ en atmósfera de nitrógeno, después se añaden $460 \mathrm{mg}$ (1,45 mmol) de la cetona $\mathbf{7 0}$ disuelta en THF. La reacción se agita durante 24 h a temperatura ambiente, posteriormente se trata con $\mathrm{NH}_{4} \mathrm{Cl}$ y AcOEt, se evapora el THF y después de extracción líquido-líquido, se obtienen 1,25 g de crudo de reacción.

El crudo se purifica por cromatografía flash (Hex/AcOEt 8:2), se aíslan $327 \mathrm{mg}$ (1,04 mmol, $72 \%$ ) del compuesto $\mathbf{7 2}$ en forma de un aceite amarillo.

\section{1,2-dimetoxi-5-(1-(4-metoxifenil)vinil)-3-nitrobenceno (72):}

RMN ${ }^{1} \mathrm{H}: 3,82(3 \mathrm{H}, \mathrm{s}) ; 3,85(3 \mathrm{H}, \mathrm{s}) ; 3,99(3 \mathrm{H}, \mathrm{s}) ; 5,36(1 \mathrm{H}, \mathrm{s}) ; 5,44(1 \mathrm{H}, \mathrm{s}) ; 6,87$ (2H, d, 8,4); 7,04 (1H, d, 2,4); 7,24 (2H, d, 8,4); 7,30 (1H, d, 2,4).

RMN ${ }^{13} \mathbf{C}: 55,3\left(\mathrm{CH}_{3}\right) ; 56,4\left(\mathrm{CH}_{3}\right) ; 62,0\left(\mathrm{CH}_{3}\right) ; 113,8(2)(\mathrm{CH}) ; 114,3\left(\mathrm{CH}_{2}\right) ; 115,7(\mathrm{CH})$; 115,8 (CH); 128,4 (C); 129,3 (2) (CH); 132,1 (C); 138,0 (C); 142,2 (C); 147,6 (C); 153,6 (C); $159,7(\mathrm{C})$.

IR (película): 1606; 1531; 1458; 1361; 1253;1179; $838 \mathrm{~cm}^{-1}$.

HMRS (m/z): Obtenido 338,0999 $\left(\mathrm{M}+\mathrm{Na}^{+}\right)$; esperado 338,1004 $\left(\mathrm{C}_{17} \mathrm{H}_{17} \mathrm{NNaO}_{5}{ }^{+}\right)$. 


\section{Obtención de la isocombretastatina 73}
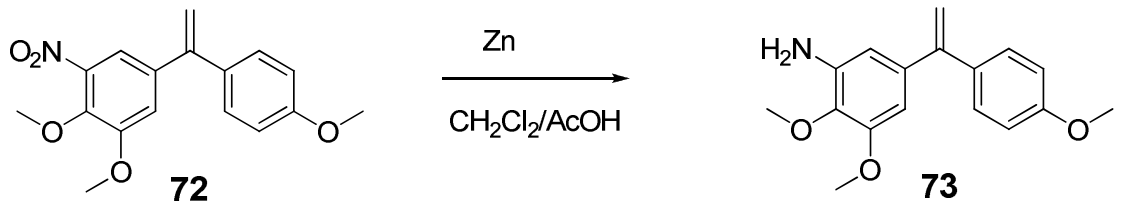

A $300 \mathrm{mg}(0,95 \mathrm{mmol})$ del compuesto 72 en $30 \mathrm{ml}$ de $\mathrm{CH}_{2} \mathrm{Cl}_{2}$ se le añaden $600 \mu \mathrm{l}(10,47$ mmol) de $\mathrm{AcOH}$ y $375 \mathrm{mg}(5,71 \mathrm{mmol})$ de zinc en polvo lentamente, apareciendo un color verde. La reacción se agita durante 16 h a temperatura ambiente y en atmósfera de nitrógeno, posteriormente se filtra sobre Celita, se evapora el disolvente y se obtienen $360 \mathrm{mg}$ de crudo de reacción.

El crudo se purifica por cromatografía flash (Hex/AcOEt 7:3), se aíslan $210 \mathrm{mg}(0,74 \mathrm{mmol}$; $80 \%$ ) del compuesto $\mathbf{7 3}$ en forma de un aceite naranja.

\section{2,3-dimetoxi-5-(1-(4-metoxifenil)vinil)anilina (73):}

RMN ${ }^{1} \mathbf{H}:$ 4,10 (3H, s); 4,13 (3H, s); 4,18 (3H, s); 5,62 (1H, d, 1,2); 5,64 (1H, d, 1,2); 6,66 $(1 \mathrm{H}, \mathrm{d}, 2,0) ; 6,72(1 \mathrm{H}, \mathrm{d}, 2,0) ; 7,18(2 \mathrm{H}, \mathrm{d}, 6,4) ; 7,61(2 \mathrm{H}, \mathrm{d}, 6,4)$.

RMN ${ }^{13} \mathbf{C}: 55,3\left(\mathrm{CH}_{3}\right) ; 55,7\left(\mathrm{CH}_{3}\right) ; 59,9\left(\mathrm{CH}_{3}\right) ; 103,1(\mathrm{CH}) ; 109,3\left(\mathrm{CH}_{2}\right) ; 112,2(\mathrm{CH}) ; 113,4$ (2) $(\mathrm{CH}) ; 129,5$ (2) $(\mathrm{CH}) ; 133,9(\mathrm{C}) ; 135,8(\mathrm{C}) ; 137,9$ (C); 139,5 (C); 149,5 (C); 152,4 (C); $159,3(\mathrm{C})$.

IR (pelicula): 3370; 1607; 1508; 1243; 1126; $839 \mathrm{~cm}^{-1}$.

HMRS (m/z): Obtenido 286,1440 $\left(\mathrm{M}+\mathrm{H}^{+}\right)$; esperado 286,1443 $\left(\mathrm{C}_{17} \mathrm{H}_{20} \mathrm{NO}_{3}{ }^{+}\right)$.

HPLC: Columna $\mathrm{C}_{18} \quad \mathrm{t}_{\mathrm{R}}: 14,6$ min.

\section{Obtención de la isocombretastatina 74}<smiles>C=C(c1ccc(OC)cc1)c1cc(N)c(OC)c(OC)c1</smiles>

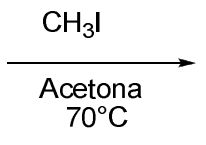<smiles>[Z4]N(C)c1cc(C(=C)c2ccc(OC)cc2)cc(OC)c1OC</smiles> 
Se disuelven $90 \mathrm{mg}(0,32 \mathrm{mmol})$ de $74 \mathrm{en} 5 \mathrm{~mL}$ de acetona y se le añade $200 \mu \mathrm{L}(3,15 \mathrm{mmol})$ de yodometano. La reacción se agita durante $24 \mathrm{~h}$ a $70{ }^{\circ} \mathrm{C}$ en tubo sellado, posteriormente se evapora el disolvente y se obtiene $98 \mathrm{mg}(0,31 \mathrm{mmol}, 97 \%)$ del compuesto 74.

\section{$\underline{N, N \text {-dimetil-2,3-dimetoxi-5-(1-(4-metoxifenil)etenil)anilina (74): }}$}

RMN ${ }^{1} \mathbf{H}:\left(\mathrm{CD}_{3} \mathrm{OD}\right): 3,23(6 \mathrm{H}, \mathrm{s}) ; 3,76(3 \mathrm{H}, \mathrm{s}) ; 3,79(3 \mathrm{H}, \mathrm{s}) ; 4,12(3 \mathrm{H}, \mathrm{s}) ; 5,34(1 \mathrm{H}, \mathrm{s}) ; 5,38$ $(1 \mathrm{H}, \mathrm{s}) ; 6,81(2 \mathrm{H}, \mathrm{d}, 8,4) ; 6,89(1 \mathrm{H}, \mathrm{s}) ; 7,15(1 \mathrm{H}, \mathrm{s}) ; 7,18(2 \mathrm{H}, \mathrm{d}, 8,4)$.

RMN ${ }^{13} \mathrm{C}:\left(\mathrm{CD}_{3} \mathrm{OD}\right): 47,3(2)\left(\mathrm{CH}_{3}\right) ; 55,4\left(\mathrm{CH}_{3}\right) ; 56,4\left(\mathrm{CH}_{3}\right) ; 62,9\left(\mathrm{CH}_{3}\right) ; 111,4(\mathrm{CH}) ; 113,8$ $(\mathrm{CH}) ; 129,3\left(\mathrm{CH}_{2}\right) ; 132,4(\mathrm{C}) ; 133,5$ (2) (CH); 138,9 (2) (C); 140,4 (C); 147,3 (2) (CH); 152,5 (2) $(\mathrm{C}) ; 159,6(\mathrm{C})$.

IR (película): $1606 ; 1510 ; 1343 ; 1247 ; 1177 ; 838 \mathrm{~cm}^{-1}$.

HMRS (m/z): Obtenido 314,1746 $\left(\mathrm{M}+\mathrm{H}^{+}\right)$; esperado $314,1756\left(\mathrm{C}_{19} \mathrm{H}_{24} \mathrm{NO}_{3}{ }^{+}\right)$.

HPLC: Columna $\mathrm{C}_{18} \quad \mathrm{t}_{\mathrm{R}}: 20,1 \mathrm{~min}$.

\section{Preparación de la sal de amonio 75}
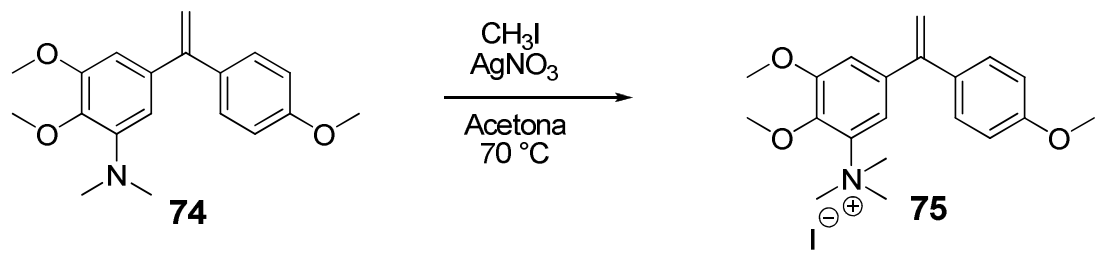

Se ponen en un tubo sellado $100 \mathrm{mg}(0,32 \mathrm{mmol})$ de $74 \mathrm{en} 5 \mathrm{ml}$ de acetona y se le añaden 108 $\mathrm{mg}(0,64 \mathrm{mmol})$ de $\mathrm{AgNO}_{3}$ y $400 \mu \mathrm{l}(6,38 \mathrm{mmol})$ de yodometano, apareciendo un precipitado blanco. La reacción se agita durante $24 \mathrm{~h}$ a $70{ }^{\circ} \mathrm{C}$, luego se filtra, se evapora el disolvente y se obtiene $90 \mathrm{mg}(0,27 \mathrm{mmol}, 84 \%)$ del compuesto 75.

Yoduro de $N, N$-dimetil-2,3-dimetoxi-5-(1-(4-metoxifenil)vinil)bencenamonio (75):

$\mathbf{R M N}^{1} \mathbf{H}: 3,85(3 \mathrm{H}, \mathrm{s}) ; 3,92(9 \mathrm{H}, \mathrm{s}) ; 4,21(3 \mathrm{H}, \mathrm{s}) ; 5,45(1 \mathrm{H}, \mathrm{s}) ; 5,51(1 \mathrm{H}, \mathrm{s}) ; 6,90$ (2H, d, 8,8); $7,07(1 \mathrm{H}, \mathrm{d}, 1,6) ; 7,12(1 \mathrm{H}, 1,6) ; 7,22(2 \mathrm{H}, \mathrm{d}, 8,8)$.

HMRS (m/z): obtenido 328, $1914\left(\mathrm{M}^{+}\right)$; esperado 328, $1913\left(\mathrm{C}_{20} \mathrm{H}_{26} \mathrm{NO}_{3}{ }^{+}\right)$. 


\section{Obtencion del compuesto secundario 76}

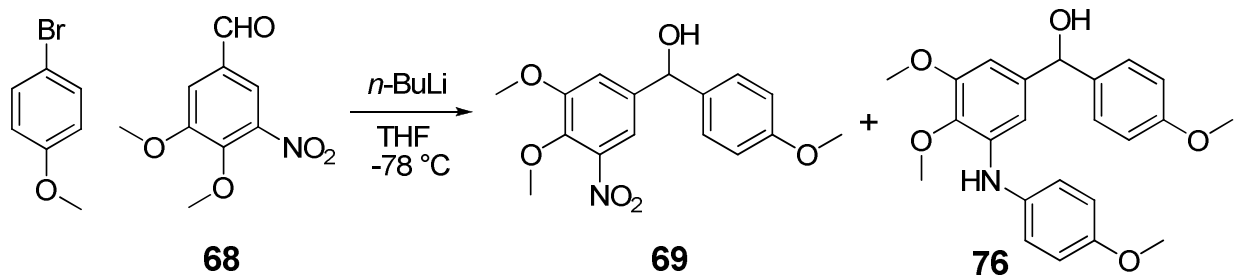

Se disuelven 4,00 g (21,39 mmol) de 4-bromoanisol en $30 \mathrm{ml}$ de THF seco, después se le añaden $8,9 \mathrm{ml}(14,24 \mathrm{mmol})$ de $n$-BuLi $1,6 \mathrm{M}$ en hexano a $-78{ }^{\circ} \mathrm{C}$, apareciendo un color amarillo. La mezcla se agita durante $1 \mathrm{~h} \mathrm{a}-78^{\circ} \mathrm{C}$ en atmósfera de nitrógeno, luego se añaden 1,5 g (7,10 mmol) del aldehído 68, el color cambia de amarillo a marrón. La reacción se agita durante $24 \mathrm{~h}$ a temperatura ambiente, posteriormente se trata con $\mathrm{NH}_{4} \mathrm{Cl}$ y AcOEt, se evapora el THF y se extrae con AcOEt obteniéndose 3,80 g de una mezcla del compuesto 69 y del compuesto 76, que se utiliza directamente para la siguiente reacción de oxidación.

\section{Obtención de la fenstatina 77}

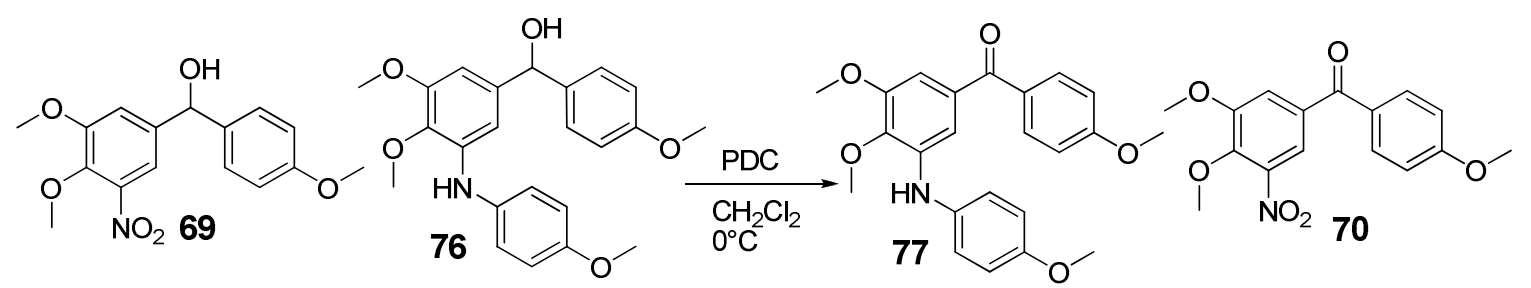

Se disuelven 3,80 g (11,90 mmol) de la mezcla 69+76 en $30 \mathrm{ml} \mathrm{de} \mathrm{CH}_{2} \mathrm{Cl}_{2}$ y se le añaden 4,50 g $(11,96 \mathrm{mmol})$ de dicromato de piridinio a $0^{\circ} \mathrm{C}$ apareciendo un color marrón. La reacción se agita durante $6 \mathrm{~h}$ a temperatura ambiente, posteriormente se filtra sobre Celita, se eluye con $\mathrm{CH}_{2} \mathrm{Cl}_{2}$ y se evapora el disolvente obteniéndose $2,85 \mathrm{~g}$ de crudo de reacción.

El crudo se purifica por cromatografía flash (Hex/AcOEt 7:3) y se obtienen $260 \mathrm{mg}(1,73$ mmol, $37 \%)$ del compuesto 70 y $170 \mathrm{mg}(0,43 \mathrm{mmol}, 4 \%)$ del compuesto $\mathbf{7 7}$ en forma de aceite naranja. 


\section{(3,4-dimetoxi-5-(4-metoxifenilamino)fenil)(4-metoxifenil)metanona (77):}

$\mathbf{R M N}^{1} \mathbf{H}: 3,74(3 \mathrm{H}, \mathrm{s}) ; 3,83(3 \mathrm{H}, \mathrm{s}) ; 3,90(3 \mathrm{H}, \mathrm{s}) ; 3,94(3 \mathrm{H}, \mathrm{s}) ; 6,19(1 \mathrm{H}, \mathrm{s}) ; 6,81$ (2H, d, 8,8); $6,89(2 \mathrm{H}, \mathrm{d}, 8,8) ; 7,06(1 \mathrm{H}, \mathrm{s}) ; 7,09(2 \mathrm{H}, \mathrm{d}, 8,4) ; 7,78(2 \mathrm{H}, \mathrm{d}, 8,4)$.

RMN ${ }^{13} \mathbf{C}: 55,4\left(\mathrm{CH}_{3}\right) ; 55,5\left(\mathrm{CH}_{3}\right) ; 55,9\left(\mathrm{CH}_{3}\right) ; 60,3\left(\mathrm{CH}_{3}\right) ; 104,3(\mathrm{CH}) ; 108,7(\mathrm{CH}) ; 113,4$ (2) $(\mathrm{CH}) ; 114,6(2)(\mathrm{CH}) ; 123,1$ (2) $(\mathrm{CH}) ; 130,3(\mathrm{C}) ; 132,4$ (2) $(\mathrm{CH}) ; 133,8(\mathrm{C}) ; 134,5(\mathrm{C})$; 138,9 (C); 139,1 (C); 152,3 (C); 155,7 (C); 163,0 (C); 195,0 (C).

IR (KBr): 3371; 1647; 1594; 1508; 1349; 1253;1169; $1033 \mathrm{~cm}^{-1}$.

HMRS (m/z): Obtenido 394,1647 $\left(\mathrm{M}+\mathrm{H}^{+}\right)$; esperado 394,1654 $\left(\mathrm{C}_{23} \mathrm{H}_{24} \mathrm{NO}_{5}{ }^{+}\right)$. 


\section{B. Análogos de combretastatina}

\section{Preparación de la nitrocombretastatina 78}
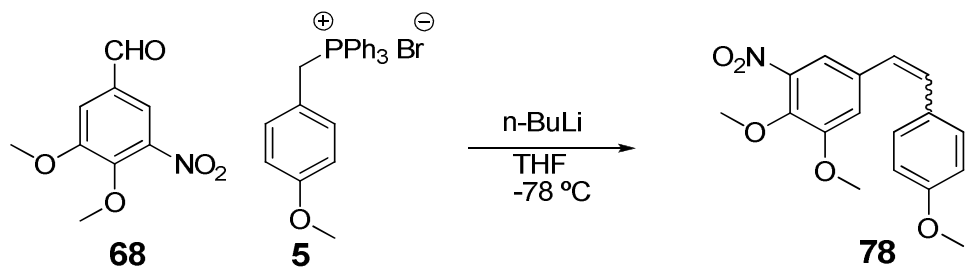

Se disuelven 4,80 g (10,36 mmol) de la sal de fosfonio 5 en $40 \mathrm{ml}$ de THF seco, después se le añaden $5,3 \mathrm{ml}(8,52 \mathrm{mmol})$ de $n$-BuLi a $-78{ }^{\circ} \mathrm{C}$ y aparece un color naranja. La mezcla se agita durante 1 h, después se añaden 1,20 g (5,68 mmol) de aldehído 68 disueltos en THF seco. La reacción se deja agitar durante 24 h a temperatura ambiente y en atmósfera de nitrógeno, luego se trata con $\mathrm{NH}_{4} \mathrm{Cl}$ y se extrae con AcOEt obteniéndose 4,85 g de $\mathbf{7 8}$ como una mezcla que contiene isómeros $Z / E$ en proporción 1:2.

El crudo se purifica por cromatografía flash (Hex/AcOEt 7:3), separándose $90 \mathrm{mg}(0,28$ mmol, 5\%) del isómero $Z, 950 \mathrm{mg}$ (3,01 mmol, 53\%) del isómero $E$ y $650 \mathrm{mg}$ de la mezcla de ambos.

\section{$\underline{(Z)-2,3-d i m e t o x i-5-(2-(4-m e t o x i f e n i l) e t e n i l) n i t r o b e n c e n o ~(78): ~}$}

RMN ${ }^{1} \mathbf{H}: 3,65$ (3H, s); 3,82 (3H, s); 3,83 (3H, s); 6,35 (1H, d, 12,2); 6,61 (1H, d, 12,2); 6,80 $(2 \mathrm{H}, \mathrm{d}, 6,6) ; 6,99(1 \mathrm{H}, \mathrm{d}, 2,4) ; 7,17(2 \mathrm{H}, \mathrm{d}, 6,6) ; 7,20(1 \mathrm{H}, \mathrm{d}, 2,4)$.

RMN ${ }^{13} \mathbf{C}: 55,3\left(\mathrm{CH}_{3}\right) ; 56,1\left(\mathrm{CH}_{3}\right) ; 62,1\left(\mathrm{CH}_{3}\right) ; 113,8(2)(\mathrm{CH}) ; 116,2(2)(\mathrm{CH}) ; 116,4(\mathrm{C})$; 126,3 (CH); 130,1 (2) (CH); 130,5 (C); 131,5 (CH); 141,4 (C); 153,4 (2) (C); 159,1 (C).

\section{$\underline{(E)-2,3-d i m e t o x i-5-(2-(4-m e t o x i f e n i l) e t e n i l) n i t r o b e n c e n o ~(78): ~}$}

RMN ${ }^{1} \mathbf{H}: 3,84(3 \mathrm{H}, \mathrm{s}) ; 3,97$ (3H, s); 3,98 (3H, s); 6,82 (1H, d, 16,0); 6,89 (2H, d, 7); 6,99 $(1 \mathrm{H}, \mathrm{d}, 16,0) ; 7,17(1 \mathrm{H}, \mathrm{d}, 2,0) ; 7,42(2 \mathrm{H}, \mathrm{d}, 7,0) ; 7,46(1 \mathrm{H}, \mathrm{d}, 2,0)$. 
RMN ${ }^{13} \mathbf{C}: 55,3\left(\mathrm{CH}_{3}\right) ; 56,4\left(\mathrm{CH}_{3}\right) ; 62,0\left(\mathrm{CH}_{3}\right) ; 113,2(\mathrm{CH}) ; 113,5(\mathrm{C}) ; 114,0(\mathrm{CH}) ; 114,5(2)$ $(\mathrm{CH}) ; 123,9(\mathrm{CH}) ; 127,9$ (2) (CH); 127,9 (C); 130,2 (CH); 133,0 (C); 141,7 (C); 154,1 (C); $159,8(\mathrm{C})$.

IR (película): $1600 ; 1508 ; 1236 ; 1127 \mathrm{~cm}^{-1}$.

Pf $\left(\mathrm{Hexano} / \mathrm{CH}_{2} \mathrm{Cl}_{2}\right): 139-140{ }^{\circ} \mathrm{C}$

HMRS (m/z): Obtenido 316,1184 $\left(\mathrm{M}+\mathrm{H}^{+}\right)$; esperado 316,1185 $\left(\mathrm{C}_{17} \mathrm{H}_{18} \mathrm{NO}_{5}{ }^{+}\right)$.

\section{Preparación de la combretastatina 79}

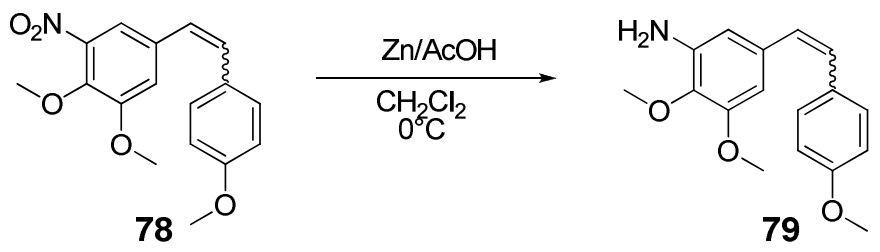

Se disuelven $500 \mathrm{mg}(1,58 \mathrm{mmol})$ de la mezcla de isómeros del compuesto 78 en $15 \mathrm{ml}$ de $\mathrm{CH}_{2} \mathrm{Cl}_{2}$ y se le añaden $630 \mathrm{mg}(9,51 \mathrm{mmol})$ de Zinc y $2,0 \mathrm{ml}$ de ácido acético a $0^{\circ} \mathrm{C}$, apareciendo un color marrón. La mezcla se agita durante $4 \mathrm{~h}$ a temperatura ambiente, luego se filtra sobre celita y se obtienen $836 \mathrm{mg}$ de una mezcla $Z / E$ del compuesto 79 en proporción $1: 3$.

El crudo se purifica por cromatografía flash (Hex/AcOEt 1:1) y se aíslan $88 \mathrm{mg}(0,31 \mathrm{mmol}$, $20 \%)$ del isómero $Z, 154 \mathrm{mg}(0,54 \mathrm{mmol}, 34 \%)$ del isómero $E$ y se recuperan $200 \mathrm{mg}$ de mezcla.

\section{$\underline{(Z)-2,3-d i m e t o x i-5-(2-(4-m e t o x i f e n i l) e t e n i l) a n i l i n a ~(79): ~}$}

RMN ${ }^{1} \mathbf{H}: 3,64(3 \mathrm{H}, \mathrm{s}) ; 3,78(3 \mathrm{H}, \mathrm{s}) ; 3,81(3 \mathrm{H}, \mathrm{s}) ; 6,30(1 \mathrm{H}, \mathrm{d}, 12,0) ; 6,32(1 \mathrm{H}, \mathrm{s}) ; 6,38(1 \mathrm{H}$, s); 6,44 (1H, d, 12,0); 6,77 (2H, d, 8,6); 7,24 (2H, d, 8,6).

RMN ${ }^{13} \mathbf{C}: 54,7\left(\mathrm{CH}_{3}\right) ; 55,2\left(\mathrm{CH}_{3}\right) ; 59,5\left(\mathrm{CH}_{3}\right) ; 100,0(\mathrm{CH}) ; 106,4(\mathrm{CH}) ; 113,6(2)(\mathrm{CH})$; 126,2 (CH); 126,8 (CH); 127,1 (2) (CH); 129,7 (C); 133,3 (C); 135,1 (C); 140,1 (C); 152,5 (C); 158,7 (C). 


\section{$\underline{(E)-2,3-d i m e t o x i-5-(2-(4-m e t o x i f e n i l) e t e n i l) a n i l i n a ~(79): ~}$}

RMN ${ }^{1} \mathbf{H}: 3,82(3 \mathrm{H}, \mathrm{s}) ; 3,84(3 \mathrm{H}, \mathrm{s}) ; 3,89$ (3H, s); 6,49 (1H, d, 2,0); 6,55 (1H, d, 2,0); 6,80 $(1 \mathrm{H}, \mathrm{d}, 16,2) ; 6,88(2 \mathrm{H}, \mathrm{d}, 8,6) ; 6,98(1 \mathrm{H}, \mathrm{d}, 16,2) ; 7,41(1 \mathrm{H}, \mathrm{d}, 8,6)$.

RMN ${ }^{13} \mathbf{C}: 55,6(2)\left(\mathrm{CH}_{3}\right) ; 60,0\left(\mathrm{CH}_{3}\right) ; 100,5(\mathrm{CH}) ; 106,8(\mathrm{CH}) ; 114,1$ (2) $(\mathrm{CH}) ; 127,0$ (2) $(\mathrm{CH}) ; 127,5(2)(\mathrm{CH}) ; 130,2(\mathrm{C}) ; 135,5(2)(\mathrm{C}) ; 152,9(\mathrm{C}) ; 159,1(2)(\mathrm{C})$.

IR (pelicula): $3470 ; 1604 ; 1507 ; 1245 ; 1125 \mathrm{~cm}^{-1}$.

HMRS (m/z): Obtenido 286,1427 $\left(\mathrm{M}+\mathrm{H}^{+}\right)$; esperado 286,1443 $\left(\mathrm{C}_{17} \mathrm{H}_{20} \mathrm{NO}_{3}{ }^{+}\right)$.

HPLC: Columna $\mathrm{C}_{18} \quad \mathrm{t}_{\mathrm{R}}: 14,9 \mathrm{~min} ; \mathrm{t}_{\mathrm{R}}: 15,6 \mathrm{~min}$.

\section{Preparación de la combretastatina 80 por metilación de 79}
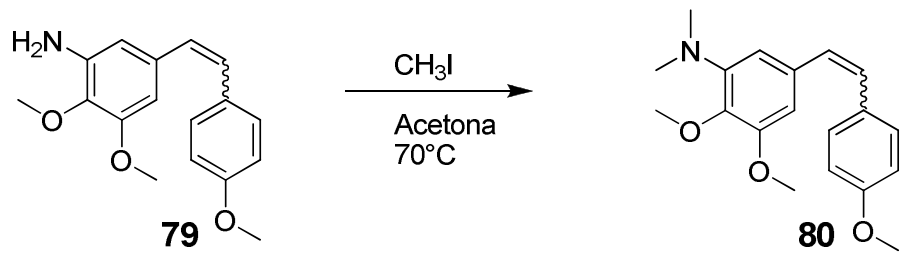

Se disuelven $110 \mathrm{mg}(0,39 \mathrm{mmol})$ de 79 en $10 \mathrm{ml}$ de acetona y se le añaden 1,2 $\mathrm{ml}(19 \mathrm{mmol})$ de yodometano, apareciendo un color marrón. La reacción se agita durante 24 h a $70{ }^{\circ} \mathrm{C}$ en un tubo sellado, posteriormente se evapora la acetona y se obtienen $172 \mathrm{mg}$ de una mezcla Z/E del compuesto 80 en proporción 1:3.

El crudo se purifica por cromatografía flash (Hex/AcOEt 1:1), se aíslan $15 \mathrm{mg}(0,05 \mathrm{mmol}$, $13 \%)$ del isómero $Z$ puro, $17 \mathrm{mg}(0,06 \mathrm{mmol}, 14 \%)$ del isómero $E$ y $74 \mathrm{mg}(0,24 \mathrm{mmol}, 61$ $\%)$ de la mezcla $Z / E$ en proporción 1:1. 


\section{Preparación de la combretastatina 81}

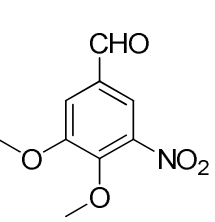

68
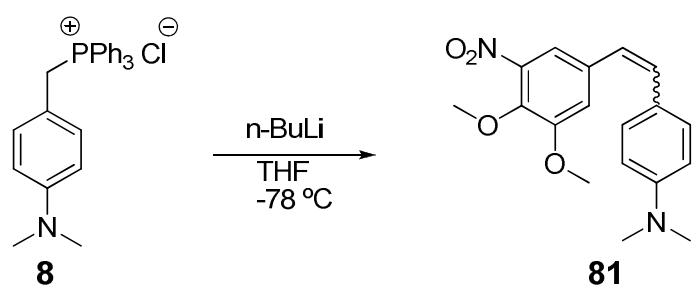

81

Se disuelven 2,70 g (5,64 mmol) de la sal de fosfonio 8 en $50 \mathrm{ml}$ de THF seo y se le añaden 3,3 $\mathrm{ml}(5,23 \mathrm{mmol})$ de $n$-BuLi 1,6 $\mathrm{M}$ en hexano apareciendo un color naranja. La mezcla se agita durante $1 \mathrm{~h} \mathrm{a}-78^{\circ} \mathrm{C}$ en atmósfera de nitrógeno, después se añaden $850 \mathrm{mg}(4,03 \mathrm{mmol})$ del aldehído $\mathbf{6 8}$ disuelto en THF seco también y el color pasa de naranja a amarillo. La reacción se agita durante $24 \mathrm{~h}$ a temperatura ambiente, luego se trata con $\mathrm{NH}_{4} \mathrm{Cl}$ y AcOEt, y por el procedimiento habitual se obtienen 1,80 g como mezcla de isómeros $\mathrm{Z} / \mathrm{E}$ en proporcion $1: 3$.

El crudo se purifica por cromatografía flash (Hex/AcOEt 9:1) aíslándose $163 \mathrm{mg}$ (0,50 mol, $12 \%)$ del isómero $Z$ como aceite naranja y $464 \mathrm{mg}(1,41 \mathrm{mmol}, 35 \%)$ del isómero $E$ como un sólido de color naranja, que se cristaliza en $\mathrm{Hex} / \mathrm{CH}_{2} \mathrm{Cl}_{2}$.

\section{$\underline{(Z)-N, N \text {-dimetil-4-(2-(3,4-dimetoxi-5-nitrofenil)etenil)anilina (81): }}$}

$\mathbf{R M N}^{1} \mathbf{H}: 2,92(6 \mathrm{H}, \mathrm{s}) ; 3,67$ (3H, s); 3,94 (3H, s); 6,24 (1H, d, 12,4); 6,55 (1H, d, 12,4); 6,59 $(2 \mathrm{H}, \mathrm{d}, 8,8) ; 7,08(1 \mathrm{H}, \mathrm{d}, 2,0) ; 7,13(2 \mathrm{H}, \mathrm{d}, 8,8) ; 7,26(1 \mathrm{H}, \mathrm{d}, 2,0)$.

RMN ${ }^{13} \mathbf{C}: 40,3(2)\left(\mathrm{CH}_{3}\right) ; 56,1\left(\mathrm{CH}_{3}\right) ; 62,0\left(\mathrm{CH}_{3}\right) ; 111,9$ (2) $(\mathrm{CH}) ; 116,2(2)(\mathrm{CH}) ; 123,9$ (C); 124,1 (CH); 129,9 (2) (CH); 132,2 (CH); 134,2 (C); 141,2 (C); 144,8 (C); 149,9 (C); $153,4(\mathrm{C})$

\section{$\underline{(E)-N, N \text {-dimetil-4-(2-(3,4-dimetoxi-5-nitrofenil)etenil)anilina (81): }}$}

RMN ${ }^{1} \mathbf{H}: 2,95(6 \mathrm{H}, \mathrm{s}) ; 3,69(3 \mathrm{H}, \mathrm{s}) ; 3,97(3 \mathrm{H}, \mathrm{s}) ; 6,70(2 \mathrm{H}, \mathrm{d}, 8,8) ; 6,78(1 \mathrm{H}, \mathrm{d}, 16,0) ; 6,98$ $(1 \mathrm{H}, \mathrm{d}, 16,0) ; 7,16(1 \mathrm{H}, \mathrm{s}) ; 7,39(2 \mathrm{H}, \mathrm{d}, 8,8) ; 7,42(1 \mathrm{H}, \mathrm{s})$.

RMN ${ }^{13} \mathbf{C}: 39,5(2)\left(\mathrm{CH}_{3}\right) ; 55,6\left(\mathrm{CH}_{3}\right) ; 61,2\left(\mathrm{CH}_{3}\right) ; 111,5(2)(\mathrm{CH}) ; 112,1(\mathrm{CH}) ; 120,7$ (2) $(\mathrm{CH}) ; 123,7(\mathrm{C}) ; 127,1(2)(\mathrm{CH}) ; 130,0(\mathrm{CH}) ; 133,9$ (C); 140,3 (C); 144,2 (C); 149,7 (C); $153,3(\mathrm{C})$. 
IR (película): 1604; 1532; 1453; 1358; $1287 ; 1167 \mathrm{~cm}^{-1}$.

Pf $\left(\mathrm{Hexano} / \mathrm{CH}_{2} \mathrm{Cl}_{2}\right): 84-85{ }^{\circ} \mathrm{C}$

HMRS (m/z): Obtenido 329,1499 $\left(\mathrm{M}+\mathrm{H}^{+}\right)$; esperado 329,1501 $\left(\mathrm{C}_{18} \mathrm{H}_{21} \mathrm{~N}_{2} \mathrm{O}_{4}{ }^{+}\right)$.

\section{Preparación de la combretastatina 82}
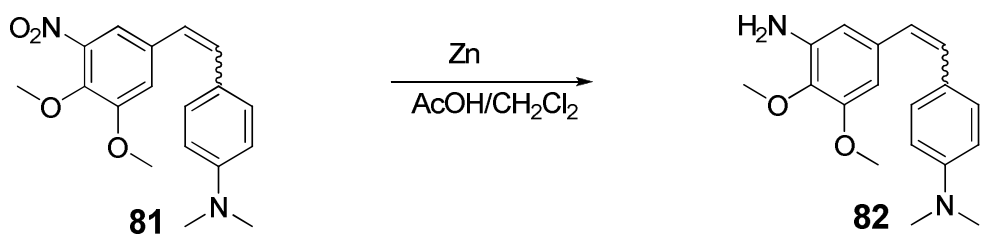

Se disuelven $120 \mathrm{mg}(0,36 \mathrm{mmol})$ del compuesto 81 en $15 \mathrm{ml} \mathrm{de} \mathrm{CH}_{2} \mathrm{Cl}_{2}$, después se le añaden $145 \mathrm{mg}(2,22 \mathrm{mmol})$ de zinc y 4 gotas de $\mathrm{AcOH}$ apareciendo un color verde. La mezcla se agita durante $16 \mathrm{~h}$ a temperatura ambiente, posteriormente se evapora el disolvente obteniéndose $120 \mathrm{mg}$ de una mezcla de isómeros Z/E del compuesto 82 en proporción 3:1.

El crudo se purifica por cromatografía flash (Hex/AcOEt 7:3) y se aíslan $63 \mathrm{mg}(0,21 \mathrm{mmol}$, $59 \%$ ) del compuesto 82 de configuración $Z$ y $11 \mathrm{mg}$ de isómero $E$.

\section{$\underline{(Z)-N, N \text {-dimetil-4-(2-(3-amino-4,5-dimetoxifenil)etenil)anilina (82): }}$}

RMN ${ }^{1} \mathbf{H}: 2,93(6 \mathrm{H}, \mathrm{s}) ; 3,68(3 \mathrm{H}, \mathrm{s}) ; 3,83(3 \mathrm{H}, \mathrm{s}) ; 6,27$ (1H, d, 12,0); 6,34 (1H, d, 2,0); 6,38 $(1 \mathrm{H}, \mathrm{d}, 2,0) ; 6,39(1 \mathrm{H}, \mathrm{d}, 12,0) ; 6,63(2 \mathrm{H}, \mathrm{d}, 8,8) ; 7,22(2 \mathrm{H}, \mathrm{d}, 8,8)$.

RMN ${ }^{13} \mathbf{C}: 40,7(2)\left(\mathrm{CH}_{3}\right) ; 55,6\left(\mathrm{CH}_{3}\right) ; 59,9\left(\mathrm{CH}_{3}\right) ; 100,3(\mathrm{CH}) ; 106,6(\mathrm{CH}) ; 112,8(2)(\mathrm{CH})$; 124,8 (C); 127,2 (2) (CH); 127,4 (2) (CH); 134,3 (C); 135,0 (C); 140,5 (C); 149,3 (C); 153,0 (C).

\section{(E)-N,N-dimetil-4-(2-(3-amino-4,5-dimetoxifenil)etenil)anilina (82):}

RMN ${ }^{1} \mathbf{H}: 2,98(6 \mathrm{H}, \mathrm{s}) ; 3,68(3 \mathrm{H}, \mathrm{s}) ; 3,89(3 \mathrm{H}, \mathrm{s}) ; 6,48(1 \mathrm{H}, \mathrm{d}, 2,0) ; 6,53(1 \mathrm{H}, \mathrm{d}, 2,0) ; 6,74$ $(2 \mathrm{H}, \mathrm{d}, 6,8) ; 6,76(1 \mathrm{H}, \mathrm{d}, 16,0) ; 6,89(1 \mathrm{H}, \mathrm{d}, 16,0) ; 7,38(2 \mathrm{H}, \mathrm{d}, 6,8)$. 
RMN ${ }^{13} \mathbf{C}: 40,7(2)\left(\mathrm{CH}_{3}\right) ; 55,7\left(\mathrm{CH}_{3}\right) ; 60,0\left(\mathrm{CH}_{3}\right) ; 103,1(\mathrm{CH}) ; 109,2(\mathrm{CH}) ; 112,7(2)(\mathrm{CH})$; 127,8 (C); 129,5 (2) (CH); 130,1 (2) (CH); 134,0 (C); 134,8 (C); 140,1 (C); 149,2 (C); 152,5 (C).

IR (película): 3365; 1607; 1517; 1231; $1128 \mathrm{~cm}^{-1}$.

HMRS (m/z): Obtenido 299,1758 $\left(\mathrm{M}+\mathrm{H}^{+}\right)$; esperado 299,1760 $\left(\mathrm{C}_{18} \mathrm{H}_{23} \mathrm{~N}_{2} \mathrm{O}_{2}{ }^{+}\right)$.

HPLC: Columna $\mathrm{C}_{18} \quad \mathrm{t}_{\mathrm{R}}: 15,9 \mathrm{~min}$.

\section{Protección del aldehído 68 en diclorometano}

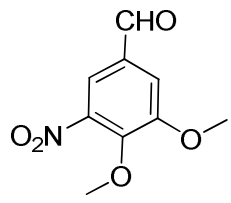

68

$$
\begin{aligned}
& \stackrel{\mathrm{HO}\left(\mathrm{CH}_{2}\right)_{2} \mathrm{OH}}{\mathrm{TMSCl}} \\
& \underset{\mathrm{CH}_{2} \mathrm{Cl}_{2}}{\longrightarrow}
\end{aligned}
$$<smiles>COc1cc(C2OCCO2)cc([N+](=O)[O-])c1OC</smiles>

83

Se disuelven $800 \mathrm{mg}(3,79 \mathrm{mmol})$ de aldehído 68 en $20 \mathrm{ml}$ de $\mathrm{CH}_{2} \mathrm{Cl}_{2}$, después se le añade 1 $\mathrm{ml}(7,6 \mathrm{mmol})$ de cloruro de trimetilsililo y $700 \mu \mathrm{l}(11,4 \mathrm{mmol})$ de etilénglicol. La reacción se agita durante $24 \mathrm{~h}$ a temperatura ambiente, después se extrae con agua y $\mathrm{CH}_{2} \mathrm{Cl}_{2}$, se seca con $\mathrm{Na}_{2} \mathrm{SO}_{4}$, se filtra y se evapora el disolvente obteniéndose 1,20 g de crudo de reacción.

El crudo se purifica por cromatografía flash (Hex/AcOEt 7:3) y se aíslan $505 \mathrm{mg}$ (1,98 mmol, $52 \%$ ) del compuesto $\mathbf{8 3}$ como un aceite naranja.

\section{2-(3,4-dimetoxi-5-nitrofenil)-1,3-dioxolano (83):}

$\mathbf{R M N}^{1} \mathbf{H}: 3,92(3 \mathrm{H}, \mathrm{s}) ; 3,97(3 \mathrm{H}, \mathrm{s}) ; 4,02(2 \mathrm{H}, \mathrm{m}) ; 4,08(2 \mathrm{H}, \mathrm{m}) ; 5,75(1 \mathrm{H}, \mathrm{s}) ; 7,20(1 \mathrm{H}, \mathrm{d}$, $2,0) ; 7,42(1 \mathrm{H}, \mathrm{d}, 2,0)$.

RMN ${ }^{13} \mathrm{C}: 56,4\left(\mathrm{CH}_{3}\right) ; 62,2\left(\mathrm{CH}_{3}\right) ; 65,3(2)\left(\mathrm{CH}_{2}\right) ; 102,1(\mathrm{CH}) ; 113,7(\mathrm{CH}) ; 114,0(\mathrm{CH})$; 119,3 (C); 134,2 (C); 143,1 (C); 154,1 (C).

IR (película): $1608 ; 1537 ; 1287 ; 1149 \mathrm{~cm}^{-1}$. 


\section{Protección del aldehído 68 en tolueno}
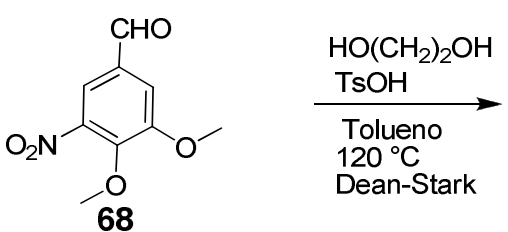<smiles>COc1cc(C2OCCO2)cc([N+](=O)[O-])c1OC</smiles>

Se disuelven 8,50 g (40,2 mmol) de aldehído 68 en $200 \mathrm{ml}$ de tolueno seco y se le añaden 7,0 ml (125 mmol) de etilénglicol y 1,10 g (6,40 mmol) del ácido p-toluensulfónico. La reacción se agita durante $24 \mathrm{~h}$ a reflujo, después se trata con $\mathrm{NaHCO}_{3}$ anhidro, se evapora el tolueno y se extrae con agua/AcOEt, se seca con $\mathrm{Na}_{2} \mathrm{SO}_{4}$, se filtra y se evapora el disolvente obteniéndose 9,88 g (38,7 mmol, $96 \%)$ del compuesto $\mathbf{8 3}$ en forma de aceite naranja.

\section{Reducción del nitroderivado 8}<smiles>COc1cc(C2OCCO2)cc([N+](=O)[O-])c1OC</smiles>

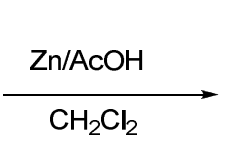<smiles>COc1cc(C2OCCO2)cc(N)c1OC</smiles>

Se disuelven $500 \mathrm{mg}(1,96 \mathrm{mmol})$ de $\mathbf{8 3}$ en $20 \mathrm{ml} \mathrm{de} \mathrm{CH}_{2} \mathrm{Cl}_{2}$ y se le añaden $770 \mathrm{mg}(11,75$ mmol) de zinc en polvo y 4 gotas de ácido acético apareciendo un color marrón. La reacción se agita durante $15 \mathrm{~h}$ a temperatura ambiente, luego se extrae con agua/ $\mathrm{CH}_{2} \mathrm{Cl}_{2}$, se seca con $\mathrm{Na}_{2} \mathrm{SO}_{4}$ y se evapora el disolvente obteniéndose $404 \mathrm{mg}(1,79 \mathrm{mmol} ; 92 \%)$ del compuesto 84.

\section{5-(1,3-dioxolan-2-il)-2,3-dimetoxianilina (84):}

RMN ${ }^{1} \mathbf{H}: 3,79(3 \mathrm{H}, \mathrm{s}) ; 3,84(3 \mathrm{H}, \mathrm{s}) ; 4,00(2 \mathrm{H}, \mathrm{m}) ; 4,09(2 \mathrm{H}, \mathrm{m}) ; 5,72(1 \mathrm{H}, \mathrm{s}) ; 6,46(1 \mathrm{H}, \mathrm{d}$, $2,0) ; 6,51(1 \mathrm{H}, \mathrm{d}, 2,0)$.

RMN ${ }^{13} \mathbf{C}: 56,4\left(\mathrm{CH}_{3}\right) ; 60,5\left(\mathrm{CH}_{3}\right) ; 65,9(2)\left(\mathrm{CH}_{2}\right) ; 100,7(\mathrm{CH}) ; 104,4(\mathrm{CH}) ; 107,7(\mathrm{CH})$; 130,7 (C); 134,5 (C); 141,4 (C); 153,6 (C). 
IR (película): 3368; 1597; 1457; 1350; $1232 ; 1143 \mathrm{~cm}^{-1}$.

\section{Metilación del compuesto 84}
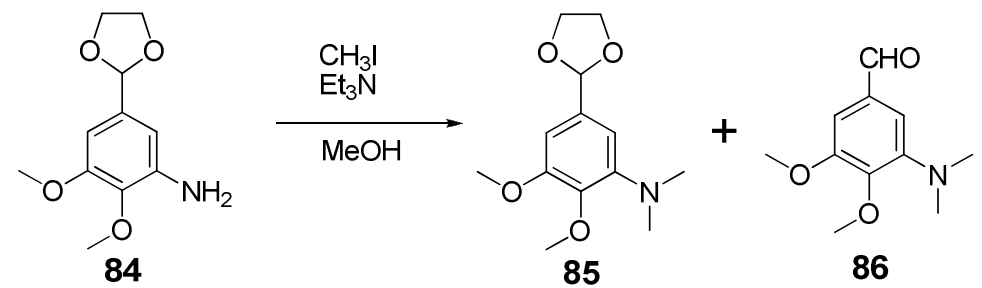

Se disuelven 1,70 g (7,55 mmol) de 84 en $30 \mathrm{ml}$ de $\mathrm{MeOH}$ y se le añaden 7,0 $\mathrm{ml}$ (113 mmol) de yodometano y 2,7 $\mathrm{ml}$ (19 mmol) de trietilamina, adquiriendo un color marrón. La reacción se agita durante $24 \mathrm{~h}$ a temperatura ambiente en atmosfera de nitrógeno. Posteriormente se evapora el metanol y se extrae con agua/AcOEt, se seca con $\mathrm{Na}_{2} \mathrm{SO}_{4}$ y se evapora el disolvente, obteniéndose 1,80 g (7,11 mmol; $94 \%)$ de una mezcla de 85 y 86 . El crudo de esta reacción se pone a hidrolizar en medio ácido.

\section{$\underline{\text { 5-(1,3-dioxolan-2-il)-2,3-dimetoxi- } N, N \text {-dimetilanilina (85): }}$}

Datos obtenidos de la mezcla:

$\mathbf{R M N}^{1} \mathbf{H}: 2,84(6 \mathrm{H}, \mathrm{s}) ; 3,75(3 \mathrm{H}, \mathrm{s}) ; 3,82(3 \mathrm{H}, \mathrm{s}) ; 4,00-4,10(4 \mathrm{H}, \mathrm{m}) ; 5,65(1 \mathrm{H}, \mathrm{s}) ; 6,75(1 \mathrm{H}$, $\mathrm{d}, 2,0) ; 6,81(1 \mathrm{H}, \mathrm{d}, 2,0)$.

IR (película): 1599; 1458; 1144; $1006 \mathrm{~cm}^{-1}$.

\section{Desprotección del dioxolano 85:}<smiles>COc1cc(C2OCCO2)cc(N(C)C)c1OC</smiles>

85<smiles>COc1cc(C=O)cc(N(C)C)c1OC</smiles>

86

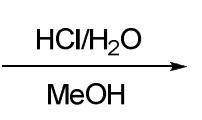<smiles>COc1cc(C=O)cc(N(C)C)c1OC</smiles>

86 
Se disuelven 1,8 g (7,11 mmol) de la mezcla $85+86$ en $20 \mathrm{ml}$ de $\mathrm{MeOH}$ y se le añaden $4 \mathrm{ml}$ de agua y 6 gotas de acido clorhídrico concentrado a $0^{\circ} \mathrm{C}$. La mezcla se agita durante $8 \mathrm{~h}$ a temperatura ambiente, luego se evapora el metanol, se extrae con agua/ $\mathrm{CH}_{2} \mathrm{Cl}_{2}$ y después de la evaporación del disolvente se obtienen 980 mg (4,68 mmol, 66\%) del compuesto 86 puro.

\section{3-(dimetilamino)-4,5-dimetoxibenzaldehído (86):}

$\mathbf{R M N}^{1} \mathbf{H}: 2,90(6 \mathrm{H}, \mathrm{s}) ; 3,87(3 \mathrm{H}, \mathrm{s}) ; 3,90(3 \mathrm{H}, \mathrm{s}) ; 6,81(1 \mathrm{H}, \mathrm{d}, 2,0) ; 6,86(1 \mathrm{H}, \mathrm{d}, 2,0) ; 9,84$ $(1 \mathrm{H}, \mathrm{s})$.

RMN ${ }^{13} \mathbf{C}: 42,5(2)\left(\mathrm{CH}_{3}\right) ; 55,8\left(\mathrm{CH}_{3}\right) ; 59,9\left(\mathrm{CH}_{3}\right) ; 102,4(\mathrm{CH}) ; 105,3(\mathrm{CH}) ; 123,9(\mathrm{C}) ; 132,4$

(C); 143,7 (C); 152,3 (C); 192,0 (CH).

IR (película): 1679; 1602; 1509; 1245; $1140 \mathrm{~cm}^{-1}$.

\section{Preparación de la combretastatina 80 por reacción de Wittig}

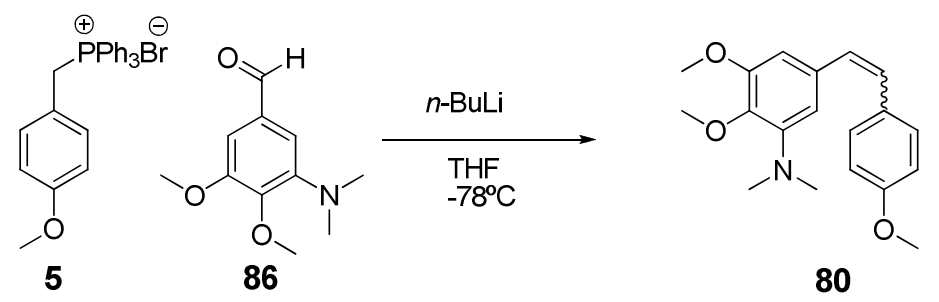

A una suspensión de 3,58 g (7,74 mmol) de la sal de fosfonio 5 en $40 \mathrm{ml}$ de THF seco, se le añaden 4,1 $\mathrm{ml}(6,5 \mathrm{mmol})$ de $n$-BuLi 1,6 $\mathrm{M}$ de hexano a $-78^{\circ} \mathrm{C}$ en atmósfera de nitrógeno. La reacción se agita durante $1 \mathrm{~h}$ y luego se le añade $900 \mathrm{mg}(4,30 \mathrm{mmol})$ del aldehído 86 disuelto en $10 \mathrm{ml}$ de THF, pasando de color naranja a marrón. La mezcla se agita durante $24 \mathrm{~h}$ a temperatura ambiente, posteriormente se trata con $\mathrm{NH}_{4} \mathrm{Cl} / \mathrm{AcOEt}$, se evapora el $\mathrm{THF}$ y se extrae con agua/AcOEt y se obtienen 3,30 g del compuesto 80 como una mezcla de los isómeros $Z / E$ en proporción 1:1.

La mezcla se separa por cromatografía flash (Hex/AcOEt 6:4) y se aíslan $150 \mathrm{mg}(0,48 \mathrm{mmol}$, $11 \%$ ) del isómero $Z$ y $700 \mathrm{mg}$ de la mezcla $Z / E$ en proporción 1:1.

$\underline{(Z)-N, N \text {-dimetil-2,3-dimetoxi-5-(2-(4-metoxifenil)etenil)anilina (80): }}$ 
$\mathbf{R M N}^{1} \mathbf{H}: 2,72(6 \mathrm{H}, \mathrm{s}) ; 3,65(3 \mathrm{H}, \mathrm{s}) ; 3,84(3 \mathrm{H}, \mathrm{s}) ; 3,90(3 \mathrm{H}, \mathrm{s}) ; 6,40(1 \mathrm{H}, \mathrm{d}, 12,0) ; 6,48(1 \mathrm{H}$, $\mathrm{d}, 12,0) ; 6,51(2 \mathrm{H}, \mathrm{s}) ; 6,79(2 \mathrm{H}, \mathrm{d}, 8,8) ; 7,24(2 \mathrm{H}, \mathrm{d}, 8,8)$.

RMN ${ }^{13} \mathbf{C}: 42,9(2)\left(\mathrm{CH}_{3}\right) ; 55,2\left(\mathrm{CH}_{3}\right) ; 55,7\left(\mathrm{CH}_{3}\right) ; 59,5\left(\mathrm{CH}_{3}\right) ; 106,4(\mathrm{CH}) ; 111,7(\mathrm{CH})$; 113,5 (2) (CH); 128,8 (C); 129,1 (2) (CH); 129,9 (C); 130,2 (2) (CH); 132,5 (C); 140,2 (C); $152,9(\mathrm{C}) ; 158,6(\mathrm{C})$.

HPLC: Columna $\mathrm{C}_{18} \mathrm{t}_{\mathrm{R}}: 19,8 \mathrm{~min}$.

\section{$\underline{(E)-N, N \text {-dimetil-2,3-dimetoxi-5-(2-(4-metoxifenil)etenil)anilina (80): }}$}

RMN ${ }^{1} \mathbf{H}: 2,88(6 \mathrm{H}, \mathrm{s}) ; 3,80(3 \mathrm{H}, \mathrm{s}) ; 3,85(3 \mathrm{H}, \mathrm{s}) ; 3,91(3 \mathrm{H}, \mathrm{s}) ; 6,27(1 \mathrm{H}, \mathrm{d}, 16,4) ; 6,38(1 \mathrm{H}$, d, 16,4); 6,48 (1H, d, 16,4); 6,75 (2H, d, 8,6); 6,85 (1H, d, 16,4); 7,47 (2H, d, 8,6).

RMN ${ }^{13} \mathbf{C}: 43,0(2)\left(\mathrm{CH}_{3}\right) ; 55,3\left(\mathrm{CH}_{3}\right) ; 56,1\left(\mathrm{CH}_{3}\right) ; 59,5\left(\mathrm{CH}_{3}\right) ; 103,3(\mathrm{CH}) ; 109,2(\mathrm{CH})$; 114,1 (2) $(\mathrm{CH}) ; 126,9(\mathrm{C}) ; 129,1$ (2) $(\mathrm{CH}) ; 127,6$ (2) (CH); $130(\mathrm{C}) ; 133,1(\mathrm{C}) ; 140,6(\mathrm{C})$; 153,5 (C); 159,2 (C).

IR (película): 1576; 1458; 1253; 1175; $1086 \mathrm{~cm}^{-1}$.

HMRS (m/z): Obtenido 336,1564 $\left(\mathrm{M}+\mathrm{Na}^{+}\right)$; esperado 336, $1576\left(\mathrm{C}_{19} \mathrm{H}_{23} \mathrm{NNaO}_{3}{ }^{+}\right)$.

\section{Preparación de la sal de amonio de la combretastatina 80}
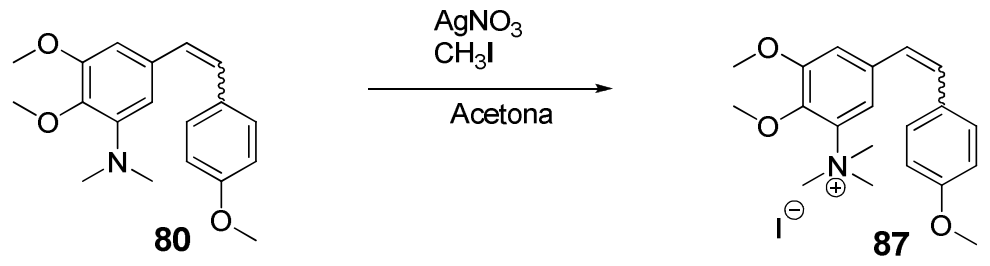

Se disuelven $200 \mathrm{mg}(0,63 \mathrm{mmol})$ de una mezcla de isómeros Z/E del compuesto 80 en $15 \mathrm{ml}$ de acetona, después se le añaden $320 \mathrm{mg}(1,85 \mathrm{mmol})$ de $\mathrm{AgNO}_{3}$ y $600 \mu \mathrm{l}(9,25 \mathrm{mmol}) \mathrm{de}$ yodometano, apareciendo un precipitado amarillo. La mezcla se deja agitando en un tubo sellado $24 \mathrm{~h}$ a temperatura ambiente, posteriormente se filtra sobre celita y se evapora el disolvente, obteniéndose $100 \mathrm{mg}(0,31 \mathrm{mmol}, 49$ \%) del isómero $Z$ del compuesto 87. 
Yoduro de (Z)-N,N-dimetil-2,3-dimetoxi-5-(2-(4-metoxifenil)etenil)bencenamonio (87):

RMN ${ }^{1} \mathbf{H}: 3,59(9 \mathrm{H}, \mathrm{s}) ; 3,67(3 \mathrm{H}, \mathrm{s}) ; 3,70(3 \mathrm{H}, \mathrm{s}) ; 3,74(3 \mathrm{H}, \mathrm{s}) ; 6,50(1 \mathrm{H}, \mathrm{d}, 12,0) ; 6,70(1 \mathrm{H}$, d, 12,0); 6,87 (2H, d, 8,4); 7,15 (1H, s); 7,18 (1H, s); 7,21 (2H, d, 8,4).

RMN ${ }^{13} \mathbf{C}: 55,5\left(\mathrm{CH}_{3}\right) ; 57,6\left(\mathrm{CH}_{3}\right) ; 58,0(3)\left(\mathrm{CH}_{3}\right) ; 61,8\left(\mathrm{CH}_{3}\right) ; 113,4(\mathrm{CH}) ; 113,9(2)(\mathrm{CH})$; 115,2 (CH); 127,1 (CH); 128,8 (C); 130,1 (2) (CH); 131,7 (CH); 133,5 (C); 137,8 (C); 140,8 (C); 153,7 (C); 159,0 (C).

IR (película): $1603 ; 1508 ; 1459 ; 1252 ; 1177 ; 1060 \mathrm{~cm}^{-1}$.

$\operatorname{HMRS}(\mathbf{m} / \mathbf{z})$ : Obtenido 328,1911 $\left(\mathrm{M}^{+}\right)$; esperado $328,1913\left(\mathrm{C}_{20} \mathrm{H}_{26} \mathrm{NO}_{3}{ }^{+}\right)$.

HPLC: Columna $\mathrm{C}_{18} \quad \mathrm{t}_{\mathrm{R}}: 7,1 \mathrm{~min}$.

\section{Obtención de 89}<smiles>COc1cc(C2OCCO2)cc(N)c1O</smiles><smiles>COCOc1cc(C=O)cc(N)c1Br</smiles>

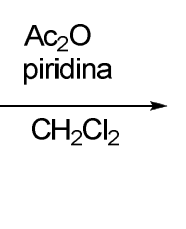

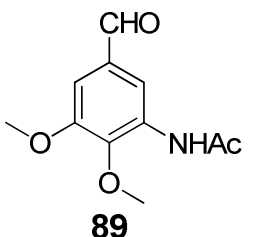

La desprotección de $320 \mathrm{mg}(1,42 \mathrm{mmol})$ del compuesto 84 siguiendo el método de la reacción 10 produce $250 \mathrm{mg}(1,38 \mathrm{mmol}, 97 \%)$ de 3-amino-4,5-dimetoxibenzaldehído (88), que se disuelven en $20 \mathrm{ml}$ de $\mathrm{CH}_{2} \mathrm{Cl}_{2}$, se le añaden $260 \mu \mathrm{l}(2,76 \mathrm{mmol})$ de anhídrido acético y $230 \mu \mathrm{l}(2,77 \mathrm{mmol})$ de piridina. La mezcla se deja $2 \mathrm{~h}$ a temperatura ambiente, posteriormente se añade agua y extrae con $\mathrm{CH}_{2} \mathrm{Cl}_{2}$. Se obtienen $223 \mathrm{mg}(1,00 \mathrm{mmol}, 72 \%)$ del compuesto acetilado 89.

\section{3-amino-4,5-dimetoxibenzaldehído (88):}

$\mathbf{R M N}^{1} \mathbf{H}: 3,87(3 \mathrm{H}, \mathrm{s}) ; 3,89(3 \mathrm{H}, \mathrm{s}) ; 6,92(1 \mathrm{H}, \mathrm{d}, 2,0) ; 6,97$ (1H, d, 2,0); 9,78 (1H, s).

IR (película): 3362; 1688; 1582; 1458; $1088 \mathrm{~cm}^{-1}$.

\section{$\underline{N \text {-(5-formil-2,3-dimetoxifenil)acetamida (89): }}$}


$\mathbf{R M N}^{1} \mathbf{H}: 2,21(3 \mathrm{H}, \mathrm{s}) ; 3,85(3 \mathrm{H}, \mathrm{s}) ; 3,95(3 \mathrm{H}, \mathrm{s}) ; 7,20(1 \mathrm{H}, \mathrm{s}) ; 8,52(1 \mathrm{H}, \mathrm{s}) ; 9,84(1 \mathrm{H}, \mathrm{s})$.

\section{Preparación de la combretastatina 90}
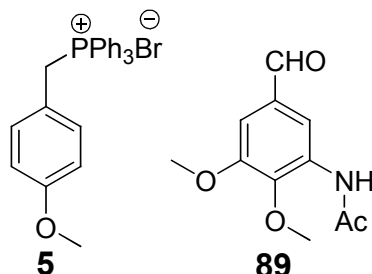

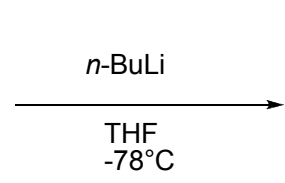

89

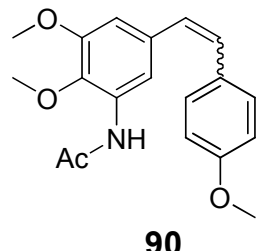

90

A $950 \mathrm{mg}$ (2,04 mmol) de la sal de fosfonio 5 en $30 \mathrm{ml}$ de THF seco se le añaden 1,1 $\mathrm{ml}(1,61$ mmol) de $n$-BuLi 1,6 $\mathrm{M}$ en hexano a $-78^{\circ} \mathrm{C}$ en atmósfera de nitrógeno, apareciendo un color naranja, la mezcla se agita $1 \mathrm{~h}$ a $-78{ }^{\circ} \mathrm{C}$, después se añaden $240 \mathrm{mg}(1,07 \mathrm{mmol})$ del aldehído 89 disuelto en $10 \mathrm{ml}$ de THF y el color pasa de naranja a marrón. La reacción se deja agitando $24 \mathrm{~h}$ a temperatura ambiente y siguiendo el procedimiento habitual se obtienen $926 \mathrm{mg}$ de una mezcla de isómeros $Z / E$ del compuesto 90 en proporción 1:3.

El crudo se purifica por cromatografía flash (Hex/AcOEt 7:3) y se separan $20 \mathrm{mg}(0,06 \mathrm{mmol}$, $6 \%)$ del isómero $Z, 33 \mathrm{mg}(0,1 \mathrm{mmol}, 10 \%)$ del isómero $E$ y $137 \mathrm{mg}(0,42 \mathrm{mmol}, 39 \%)$ de la mezcla $Z / E$ en proporción 1:1

\section{$\underline{(Z)-N \text {-(2,3-dimetoxi-5-(2-(4-metoxifenil)etenil)acetamida (90): }}$}

RMN ${ }^{1} \mathbf{H}: 2,19$ (3H, s); 3,55 (3H, s); 3,78 (3H, s); 3,89 (3H, s); 6,45 (1H, d, 12,0); 6,49 (1H, d, 12,0); 6,59 (1H, d, 1,6); 6,78 (2H, d, 9,2); 7,21 (2H, d, 9,2); 7,90 (1H, d, 1,6).

RMN ${ }^{13} \mathbf{C}: 25,0\left(\mathrm{CH}_{3}\right) ; 55,2\left(\mathrm{CH}_{3}\right) ; 55,5\left(\mathrm{CH}_{3}\right) ; 60,8\left(\mathrm{CH}_{3}\right) ; 107,7(\mathrm{CH}) ; 113,5(2)(\mathrm{CH})$; $114,1(\mathrm{CH}) ; 127,6(\mathrm{C}) ; 128,8(\mathrm{CH}) ; 129,5(\mathrm{CH}) ; 129,7(\mathrm{C}) ; 130,2$ (2) $(\mathrm{CH}) ; 131,7(\mathrm{C}) ; 133,5$ (C); 151,1 (C); 158,6 (C); 168,2 (C).

HPLC: Columna $\mathrm{C}_{18} \quad \mathrm{t}_{\mathrm{R}}: 14,8 \mathrm{~min}$.

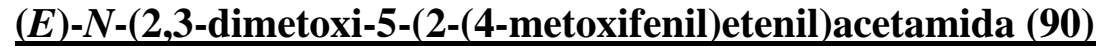

RMN ${ }^{1} \mathbf{H}: 2,22(3 \mathrm{H}, \mathrm{s}) ; 3,84(3 \mathrm{H}, \mathrm{s}) ; 3,87$ (3H, s); 3,91 (3H, s); 6,78 (1H, d, 1,6); 6,87 (2H, d, 8,8); 6,89 (1H, d, 16,0); 6,97 (1H, d, 16,0); 7,42 (2H, d, 8,8); 8,17 (1H, d, 1,6).

IR (película): 3326; 1684; 1591; 1248; $1105 \mathrm{~cm}^{-1}$. 
HMRS (m/z): Obtenido 328,1543 $\left(\mathrm{M}+\mathrm{H}^{+}\right)$; esperado 328, $1549\left(\mathrm{C}_{19} \mathrm{H}_{22} \mathrm{NO}_{4}{ }^{+}\right)$.

\section{Obtención de la combretastatina 91}
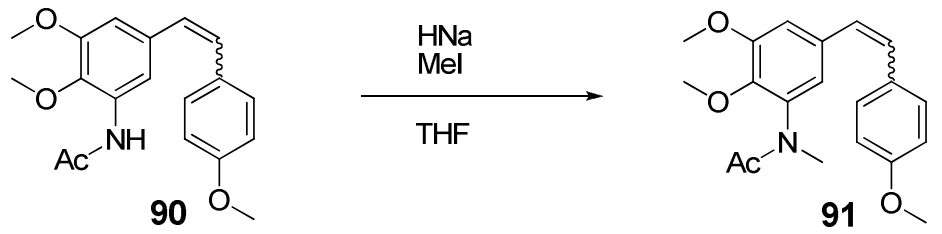

Se disuelven $140 \mathrm{mg}(0,42 \mathrm{mmol})$ de una mezcla de isómeros $Z / E$ del compuesto 90 en $10 \mathrm{ml}$ de THF y se le añaden poco a poco $31 \mathrm{mg}(1,28 \mathrm{mmol})$ de hidruro sodio y $140 \mu \mathrm{l}(2,13 \mathrm{mmol})$ de yodometano a $0^{\circ} \mathrm{C}$. La mezcla se deja agitando $15 \mathrm{~h}$ a temperatura ambiente en atmósfera de nitrógeno, posteriormente se evapora el THF y se extrae con agua/AcOEt, obteniéndose $145 \mathrm{mg}$ del compuesto 91 como una mezcla de isómeros $Z / E$ en proporción 2:1.

El crudo se purifica por cromatografía flash (Hex/AcOEt 6:4), se aíslan $60 \mathrm{mg}$ (0,18 mmol, $43 \%$ ) del isómero $Z$ y 44 mg de la mezcla de los dos isómeros.

\section{$\underline{(Z)-N \text {-metil-[2,3-dimetoxi-5-(2-(4-metoxifenil)etenil)]acetamida (91): }}$}

RMN ${ }^{1} \mathbf{H}: 1,81(3 \mathrm{H}, \mathrm{s}) ; 3,13(3 \mathrm{H}, \mathrm{s}) ; 3,72(3 \mathrm{H}, \mathrm{s}) ; 3,78(3 \mathrm{H}, \mathrm{s}) ; 3,81(3 \mathrm{H}, \mathrm{s}) ; 6,38(1 \mathrm{H}, \mathrm{d}$, $12,0) ; 6,54(1 \mathrm{H}, \mathrm{d}, 12,0) ; 6,64(1 \mathrm{H}, \mathrm{d}, 2,0) ; 6,75(2 \mathrm{H}, \mathrm{d}, 8,8) ; 6,81(1 \mathrm{H}, \mathrm{d}, 2,0) ; 7,17(2 \mathrm{H}, \mathrm{d}$, $8,8)$.

RMN ${ }^{13} \mathbf{C}: 21,4\left(\mathrm{CH}_{3}\right) ; 36,1\left(\mathrm{CH}_{3}\right) ; 54,8\left(\mathrm{CH}_{3}\right) ; 55,4\left(\mathrm{CH}_{3}\right) ; 60,6\left(\mathrm{CH}_{3}\right) ; 111,9(\mathrm{CH}) ; 113,3$ (2) $(\mathrm{CH}) ; 120,6(\mathrm{CH}) ; 127,0(\mathrm{CH}) ; 128,8(\mathrm{C}) ; 129,7$ (2) $(\mathrm{CH}) ; 130,0(\mathrm{CH}) ; 133,3(\mathrm{C}) ; 137,2$ (C); 143,3 (C); 152,7 (C); 158,5 (C); 170,6 (C).

HPLC: Columna $\mathrm{C}_{18} \quad \mathrm{t}_{\mathrm{R}}: 17,4 \mathrm{~min}$.

\section{$\underline{(E)-N \text {-metil-[2,3-dimetoxi-5-(2-(4-metoxifenil)etenil)]acetamida (91): }}$}

RMN ${ }^{1} \mathrm{H}: 1,87(3 \mathrm{H}, \mathrm{s}) ; 3,21(3 \mathrm{H}, \mathrm{s}) ; 3,72(3 \mathrm{H}, \mathrm{s}) ; 3,78(3 \mathrm{H}, \mathrm{s}) ; 3,81(3 \mathrm{H}, \mathrm{s}) ; 6,85(1 \mathrm{H}, \mathrm{d}$, $16,0) ; 6,86(2 \mathrm{H}, \mathrm{d}, 8,8) ; 6,87(1 \mathrm{H}, \mathrm{d}, 2,4) ; 6,94(1 \mathrm{H}, \mathrm{d}, 16,0) 7,00(1 \mathrm{H}, \mathrm{d}, 2,4) ; 7,40(2 \mathrm{H}, \mathrm{d}$, $8,8)$. 
RMN ${ }^{13} \mathbf{C}: 21,8\left(\mathrm{CH}_{3}\right) ; 36,6\left(\mathrm{CH}_{3}\right) ; 55,3\left(\mathrm{CH}_{3}\right) ; 56,0\left(\mathrm{CH}_{3}\right) ; 61,1\left(\mathrm{CH}_{3}\right) ; 109,3(\mathrm{CH}) ; 114,2$

(2) $(\mathrm{CH}) ; 125,1(\mathrm{CH}) ; 127,4(2)(\mathrm{CH}) ; 129,5(\mathrm{C}) ; 130,4$ (2) $(\mathrm{CH}) ; 134,2$ (C); 138,0 (C); 143,7

(C); 153,1 (C); 159,5 (C); 171,0 (C).

IR (película): $1661 ; 1596 ; 1572 ; 1511 ; 1254 ; 1063 \mathrm{~cm}^{-1}$.

HMRS (m/z): Obtenido 364,1522 $\left(\mathrm{M}+\mathrm{Na}^{+}\right)$; esperado 364,1525 $\left(\mathrm{C}_{20} \mathrm{H}_{23} \mathrm{NNaO}_{4}{ }^{+}\right)$.

\section{Protección de 84 como $N$-Boc}

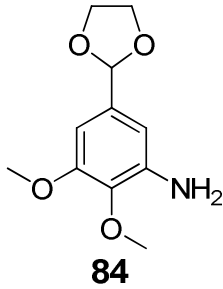

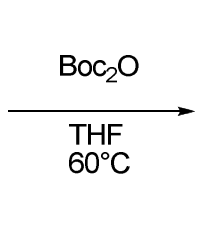

84<smiles>COc1cc(C2OCCO2)cc(NC(=O)OC(C)(C)C)c1OC</smiles>

92<smiles>COc1cc(C=O)cc(NC(=O)OC(C)(C)C)c1OC</smiles>

93

Se disuelven 2,80 g (12,43 mmol) del compuesto 84 en $60 \mathrm{ml}$ THF seco, después se le añaden 4,10 g (18,65 mmol) de $\mathrm{Boc}_{2} \mathrm{O}$. La reacción se deja agitando 48 h a $60{ }^{\circ} \mathrm{C}$ en atmósfera de nitrógeno, posteriormente se evapora el THF y se extrae con agua y AcOEt, después de secar con $\mathrm{Na}_{2} \mathrm{SO}_{4}$, filtrar y evaporar el disolvente, se obtienen 3,20 g $(9,85 \mathrm{mmol}, 80 \%)$ de un aceite naranja de una mezcla de 92 y 93 en proporción 3:1. Por cristalización en $\mathrm{CH}_{2} \mathrm{Cl}_{2}$ se aísla 92 en forma cristales amarillos.

\section{(5-(1,3-dioxolan-2-il)-2,3-dimetoxifenil)carbamato de terc-butilo (92):}

RMN ${ }^{1} \mathbf{H}: 1,52(9 \mathrm{H}, \mathrm{s}) ; 3,84(3 \mathrm{H}, \mathrm{s}) ; 3,88(3 \mathrm{H}, \mathrm{s}) ; 4,01(2 \mathrm{H}, \mathrm{m}) ; 4,13(2 \mathrm{H}, \mathrm{m}) ; 5,72(1 \mathrm{H}, \mathrm{s})$; $6,75(1 \mathrm{H}, \mathrm{d}, 2,0) ; 7,17(1 \mathrm{H}, \mathrm{d}, 2,0)$.

RMN ${ }^{13} \mathbf{C}: 28,2(3)\left(\mathrm{CH}_{3}\right) ; 55,7\left(\mathrm{CH}_{3}\right) ; 60,5\left(\mathrm{CH}_{3}\right) ; 65,2$ (2) $\left(\mathrm{CH}_{2}\right) ; 80,4(\mathrm{C}) ; 103,6(\mathrm{CH})$; 103,7 (CH); 109,2 (CH); 132,4 (C); 133,7 (C); 137,1 (C); 151,9 (C); 152,4 (C).

IR (película): 3425; 1731; 1533; 1240; $1152 ; 1002 \mathrm{~cm}^{-1}$.

Pf $\left(\mathrm{CH}_{2} \mathrm{Cl}_{2}\right): 97-98{ }^{\circ} \mathrm{C}$

\section{(5-formil-2,3-dimetoxifenil)carbamato de terc-butilo (93):}


RMN ${ }^{1} \mathbf{H}: 1,54(9 \mathrm{H}, \mathrm{s}) ; 3,92(3 \mathrm{H}, \mathrm{s}) ; 3,95(3 \mathrm{H}, \mathrm{s}) ; 7,17(1 \mathrm{H}, \mathrm{d}, 1,6) ; 7,20(1 \mathrm{H}, \mathrm{d}, 1,6) ; 9,88$ $(1 \mathrm{H}, \mathrm{s})$.

RMN ${ }^{13} \mathbf{C}: 28,8(3)\left(\mathrm{CH}_{3}\right) ; 56,4\left(\mathrm{CH}_{3}\right) ; 61,3\left(\mathrm{CH}_{3}\right) ; 81,6(\mathrm{C}) ; 104,4(\mathrm{CH}) ; 116,4(\mathrm{CH}) ; 132,7$ (C); 133,9 (C); 141,9 (C); 152,9 (C); 153,0 (C); 192,2 (CH).

IR (película): 3432; 1727; 1604; 1534; 1242; 1156; $1048 \mathrm{~cm}^{-1}$.

\section{Metilación de 92 y 93}

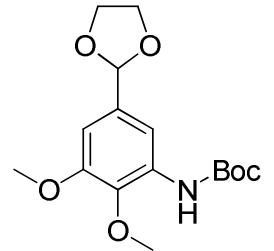

92<smiles>COc1cc(C=O)cc(NC(=O)OCc2ccccc2)c1OC</smiles>

93

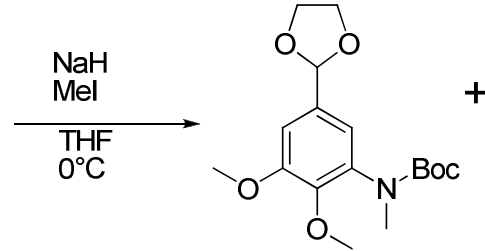

94<smiles>COc1cc(C=O)cc(N(C)C(=O)OCc2ccccc2)c1OC</smiles>

95

Se disuelven 1,70 g (5,23 mmol) de la mezcla de 92 y 93 en $30 \mathrm{ml}$ THF seco, después se le añaden $380 \mathrm{mg}(15,70 \mathrm{mmol})$ de hidruro sódico a $0{ }^{\circ} \mathrm{C}$, la mezcla se agita durante $30 \mathrm{~min}$ y se le añaden $1,7 \mathrm{ml}$ (26 mmol) de yodometano. La reacción se agita $15 \mathrm{~h}$ a temperatura ambiente en presencia de atmósfera de nitrógeno, posteriormente se evapora el THF y se extrae con agua y AcOEt, después de secar con $\mathrm{Na}_{2} \mathrm{SO}_{4}$, filtrar y evaporar el disolvente, se obtiene 1,60 g de la mezcla 94+95 en proporción 6:4.

El crudo se cromatografía flash eluyendole con Hex/AcOEt 8:2, se aíslan 800 mg (2,36 mmol, $45 \%)$ del compuesto 94 como aceite amarillo y $600 \mathrm{mg}$ (2,03 mmol, $39 \%)$ del compuesto 95 como aceite naranja.

\section{(5-(1,3-dioxolan-2-il)-2,3-dimetoxifenil)(metil)carbamato de terc-butilo (94):}

RMN ${ }^{1} \mathbf{H}: 1,47$ (9H, s); 3,14 (3H, s); 3,82 (3H, s); 3,88 (3H, s); 4,01 (2H, m); 4,13 (2H, m); $5,73(1 \mathrm{H}, \mathrm{s}) ; 6,84(1 \mathrm{H}, \mathrm{d}, 2,0) ; 6,95(1 \mathrm{H}, \mathrm{d}, 2,0)$.

RMN ${ }^{13} \mathbf{C}: 27,8\left(\mathrm{CH}_{3}\right) ; 28,3(3)\left(\mathrm{CH}_{3}\right) ; 55,9\left(\mathrm{CH}_{3}\right) ; 60,5\left(\mathrm{CH}_{3}\right) ; 65,2(2)\left(\mathrm{CH}_{2}\right) ; 79,9(\mathrm{C})$; 103,2 (CH); 108,6 (CH); 119,2 (CH); 133,0 (C); 137,1 (C); 145,8 (C); 153,3 (C); 155,1 (C).

IR (película): 1786; 1591; 1256; 1152; $1074 \mathrm{~cm}^{-1}$. 


\section{(5-formil-2,3-dimetoxifenil)(metil)carbamato de terc-butilo (95):}

RMN ${ }^{1} \mathbf{H}: 1,25(9 \mathrm{H}, \mathrm{s}) ; 2,91(3 \mathrm{H}, \mathrm{s}) ; 3,88(3 \mathrm{H}, \mathrm{s}) ; 3,91(3 \mathrm{H}, \mathrm{s}) ; 6,81(1 \mathrm{H}, \mathrm{d}, 1,6) ; 6,87(1 \mathrm{H}, \mathrm{d}$, $1,6) ; 9,85(1 \mathrm{H}, \mathrm{s})$.

RMN ${ }^{13} \mathbf{C}: 28,1\left(\mathrm{CH}_{3}\right) ; 28,6(3)\left(\mathrm{CH}_{3}\right) ; 56,5\left(\mathrm{CH}_{3}\right) ; 61,1\left(\mathrm{CH}_{3}\right) ; 80,7(\mathrm{C}) ; 109,6(\mathrm{CH}) ; 125,7$ (CH); 130,0 (C); 132,1 (C); 137,8 (C); 154,2 (C); 156,0 (C); 190,9 (CH).

IR (película): 1730; 1697; 1582; 1256; $1152 ; 1073 \mathrm{~cm}^{-1}$.

\section{Metilación de 92}<smiles>COc1cc(C2OCCO2)cc(NC(C)(C)C)c1OC</smiles>

92

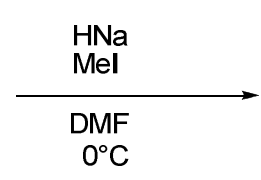

$0^{\circ} \mathrm{C}$

Se disuelven 6,60 g (20,30 mmol) del compuesto 92 en $100 \mathrm{ml}$ de DMF, después se le añaden $975 \mathrm{mg}(40,6 \mathrm{mmol})$ de hidruro sódico a $0{ }^{\circ} \mathrm{C}$, la mezcla se agita durante $30 \mathrm{~min}$ y se le añade 4,0 $\mathrm{ml}(64 \mathrm{mmol})$ de yodometano. La reacción se mantiene $4 \mathrm{~h}$ a temperatura ambiente en atmósfera de nitrógeno, luego se trata con agua y hielo y se extrae con AcOEt, se seca con $\mathrm{Na}_{2} \mathrm{SO}_{4}$, se filtra y se evapora, obteniéndose 6,20 g (18,27 mmol, $\left.90 \%\right)$ de 94 como un aceite de color naranja.

\section{Preparación de la combretastatina 96}<smiles>COc1ccc(CP)cc1</smiles><smiles>COc1cc(C=O)cc(N(C)C(=O)OC(C)(C)C)c1OC</smiles><smiles>CCCCCCCCCCCCC</smiles><smiles>COc1ccc(-c2ccc(OC)c(N(C)C(=O)OC(C)(C)C)c2)cc1</smiles> 
Se disuelven $630 \mathrm{mg}(1,36 \mathrm{mmol})$ de la sal de fosfonio 5 en $20 \mathrm{ml}$ de THF seco y se le añaden $640 \mu \mathrm{l}(1,02 \mathrm{mmol})$ de $n$-BuLi 1,6 M en hexano a $-78{ }^{\circ} \mathrm{C}$ en atmósfera de nitrógeno, el color pasa de blanco a naranja, la mezcla se agita $1 \mathrm{~h}$ a $-78{ }^{\circ} \mathrm{C}$, después se añaden $200 \mathrm{mg}(0,67$ mmol) del aldehído 95 disuelto en $10 \mathrm{ml}$ de THF seco y el color pasa de naranja a amarillo. La reacción se deja agitando $24 \mathrm{~h}$ a temperatura ambiente, luego se trata con $\mathrm{NH}_{4} \mathrm{Cl}$ y AcOEt, se evapora el THF, se extrae con agua/AcOEt, se seca con $\mathrm{Na}_{2} \mathrm{SO}_{4}$, se filtra y se evapora el disolvente, obteniéndose $930 \mathrm{mg}$ del compuesto 96 como una mezcla de isómeros $Z / E$ en proporción 1:2.

El crudo se purifica por cromatografía flash (Hex/AcOEt 8:2) separándose 76 mg (0,19 mmol, $28 \%)$ del isómero $Z, 142 \mathrm{mg}(0,35 \mathrm{mmol}, 53 \%)$ del isómero $E$ y $42 \mathrm{mg}$ de la mezcla $Z / E$ en proporción 3:1

\section{$\underline{(Z)-2,3-d i m e t o x i-5-(2-(4-m e t o x i f e n i l) e t e n i l)(N-m e t i l) c a r b a m a t o ~ d e ~ t e r c-b u t i l o ~(96): ~}$}

RMN ${ }^{1} \mathbf{H}: 1,43(9 \mathrm{H}, \mathrm{s}) ; 3,07(3 \mathrm{H}, \mathrm{s}) ; 3,64(3 \mathrm{H}, \mathrm{s}) ; 3,76(3 \mathrm{H}, \mathrm{s}) ; 3,80(3 \mathrm{H}, \mathrm{s}) ; 6,36(1 \mathrm{H}, \mathrm{d}$, 12,0); 6,46 (1H, d, 12,0); 6,72 (1H, d, 2,0); 6,75 (2H, d, 8,0); 7,77 (1H, d, 2,0); 7,21 (2H, d, $8,0)$.

RMN ${ }^{13} \mathbf{C}: 27,9\left(\mathrm{CH}_{3}\right) ; 28,3(3)\left(\mathrm{CH}_{3}\right) ; 55,2\left(\mathrm{CH}_{3}\right) ; 55,7\left(\mathrm{CH}_{3}\right) ; 60,6\left(\mathrm{CH}_{3}\right) ; 79,8(\mathrm{C}) ; 111,4$ $(\mathrm{CH}) ; 113,5(2)(\mathrm{CH}) ; 114,3(\mathrm{CH}) ; 127,8(\mathrm{C}) ; 128,0(\mathrm{CH}) ; 129,4(\mathrm{CH}) ; 129,6(\mathrm{C}) ; 130,1$ (2) (CH); 132,8 (C); 137,0 (C); 152,7 (C); 155,1 (C); 158,7 (C).

HPLC: Columna $\mathrm{C}_{18} \quad \mathrm{t}_{\mathrm{R}}: 21,1 \mathrm{~min}$.

\section{(E)-2,3-dimetoxi-5-(2-(4-metoxifenil)etenil)(N-metil)carbamato de terc-butilo (96):}

RMN ${ }^{1} \mathbf{H}: 1,40(9 \mathrm{H}, \mathrm{s}) ; 3,15(3 \mathrm{H}, \mathrm{s}) ; 3,81(6 \mathrm{H}, \mathrm{s}) ; 3,89$ (3H, s); 6,85 (1H, d, 16,4); 6,88 (2H, d, 8,4); 6,90 (1H, d, 2,0); 6,93 (1H, d, 16,4); 6,65 (1H, d, 2,0); 7,42 (2H, d, 8,4).

RMN ${ }^{13} \mathbf{C}: 28,1\left(\mathrm{CH}_{3}\right) ; 28,1(3)\left(\mathrm{CH}_{3}\right) ; 55,1\left(\mathrm{CH}_{3}\right) ; 55,7\left(\mathrm{CH}_{3}\right) ; 60,5\left(\mathrm{CH}_{3}\right) ; 79,7$ (C); 108,1 $(\mathrm{CH}) ; 113,3(\mathrm{CH}) ; 113,9(2)(\mathrm{CH}) ; 118,8(\mathrm{C}) ; 125,6(\mathrm{CH}) ; 127,4(2)(\mathrm{CH}) ; 127,6(\mathrm{CH}) ; 129,7$ (C); 130,0 (C); 137,2 (C); 152,7 (C); 155,0 (C); 159,1 (C).

IR (película): 1700; 1606; 1511; 1367; 1254; $1153 \mathrm{~cm}^{-1}$.

HMRS (m/z): Obtenido 400,2123 $\left(\mathrm{M}+\mathrm{H}^{+}\right)$; esperado 400,2124 $\left(\mathrm{C}_{23} \mathrm{H}_{30} \mathrm{NO}_{5}{ }^{+}\right)$. 


\section{Desprotección del grupo $N$-Boc del isómero $Z$ de 96}
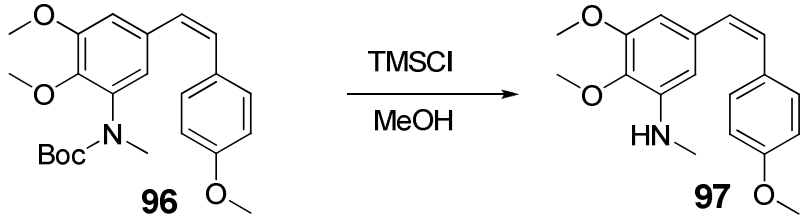

Se disuelven $70 \mathrm{mg}(0,17 \mathrm{mmol})$ la $(Z)$-combretastatina 96 en $3 \mathrm{ml}$ de $\mathrm{MeOH}$ seco y se le añaden $67 \mu \mathrm{l}(0,53 \mathrm{mmol})$ del cloruro de trimetilsililo, pasando el color de amarillo a violeta. La mezcla se mantiene agitando durante $24 \mathrm{~h}$ a temperatura ambiente, luego se evapora el $\mathrm{MeOH}$ y se extrae con $\mathrm{NaHCO}_{3} / \mathrm{AcOEt}$ y se obtiene $100 \mathrm{mg}$ de la mezcla Z/E en proporción 6:4. El crudo se purifica por cromatografía flash (Hex/AcOEt 8:2), se aíslan 25 mg (0,08 mmol, $49 \%$ ) del isómero $Z$ y $30 \mathrm{mg}$ de la mezcla $Z / E$ en proporción 3:1.

\section{$\underline{(Z)-N-m e t i l-[2,3-d i m e t o x i-5-(2-(4-m e t o x i f e n i l) e t e n i l)] a n i l i n a ~(97): ~}$}

RMN ${ }^{1} \mathbf{H}: 2,61(3 \mathrm{H}, \mathrm{s}) ; 3,55(3 \mathrm{H}, \mathrm{s}) ; 3,68(6 \mathrm{H}, \mathrm{s}) ; 6,15(1 \mathrm{H}, \mathrm{d}, 2,8) ; 6,33$ (1H, d, 12,0); 6,35 $(1 \mathrm{H}, \mathrm{d}, 2,8) ; 6,37(1 \mathrm{H}, \mathrm{d}, 12,0) ; 6,67(2 \mathrm{H}, \mathrm{d}, 8,4) ; 7,16(2 \mathrm{H}, \mathrm{d}, 8,4)$.

RMN ${ }^{13} \mathbf{C}: 30,4\left(\mathrm{CH}_{3}\right) ; 55,2\left(\mathrm{CH}_{3}\right) ; 55,7\left(\mathrm{CH}_{3}\right) ; 60,0\left(\mathrm{CH}_{3}\right) ; 102,0(\mathrm{CH}) ; 104,5(\mathrm{CH}) ; 113,4$ (2) $(\mathrm{CH}) ; 128,8(\mathrm{CH}) ; 129,4(\mathrm{CH}) ; 130,0(\mathrm{C}) ; 130,3$ (2) $(\mathrm{CH}) ; 133,5(\mathrm{C}) ; 134,3(\mathrm{C}) ; 143,0$ (C); 151,7 (C); 158,5 (C).

IR (KBr): 3387; 1590; 1512; 1459; 1254; $1176 \mathrm{~cm}^{-1}$.

HMRS (m/z): Obtenido 300,1583 $\left(\mathrm{M}+\mathrm{H}^{+}\right)$; esperado 300,1600 $\left(\mathrm{C}_{18} \mathrm{H}_{22} \mathrm{NO}_{3}{ }^{+}\right)$.

HPLC: Columna $\mathrm{C}_{18} \quad \mathrm{t}_{\mathrm{R}}: 18,2 \mathrm{~min}$.

\section{Desprotección del grupo $N$-Boc del isómero $E$ de 96}
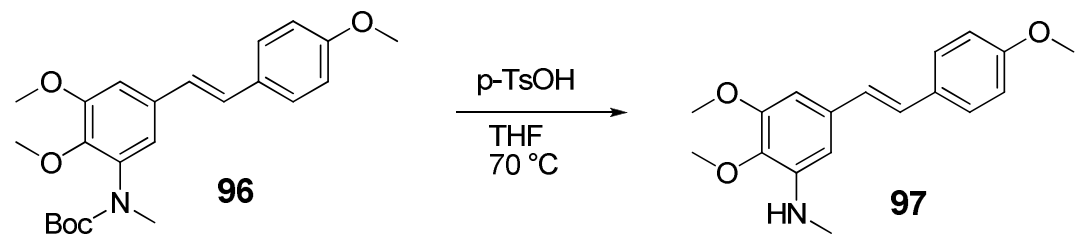
Se disuelven $140 \mathrm{mg}(0,35 \mathrm{mmol})$ la $(E)$-combretastatina 96 en $5 \mathrm{ml}$ de THF seco y se le añaden $121 \mathrm{mg}(0,70 \mathrm{mmol})$ de ácido p-toluensulfónico, pasando el color de amarillo a violeta. La mezcla se mantiene agitando durante $24 \mathrm{~h}$ a $70{ }^{\circ} \mathrm{C}$, luego se evapora el THF y se extrae con $\mathrm{NaHCO}_{3} / \mathrm{CH}_{2} \mathrm{Cl}_{2}$ y se obtiene $120 \mathrm{mg}$ de crudo de reacción.

El crudo se purifica por cromatografía flash (Hex/AcOEt 9:1), se aíslan $60 \mathrm{mg}$ (0,20 mmol, 57 $\%$ ) del compuesto 97 como isómero trans en forma de un sólido amarillo

\section{$\underline{(E)-N-m e t i l-[2,3-d i m e t o x i-5-(2-(4-m e t o x i f e n i l) e t e n i l)] a n i l i n a ~(97): ~}$}

RMN ${ }^{1} \mathbf{H}: 2,90(3 \mathrm{H}, \mathrm{s}) ; 3,80(3 \mathrm{H}, \mathrm{s}) ; 3,83(3 \mathrm{H}, \mathrm{s}) ; 3,90(3 \mathrm{H}, \mathrm{s}) ; 6,44(1 \mathrm{H}, \mathrm{d}, 2,0) ; 6,47$ (1H, d, 2,0); 6,88 (2H, d, 8,4); 6,92 (1H, d, 16,4); 6,95 (1H, d, 16,4); 7,43 (2H, d, 8,4).

RMN ${ }^{13} \mathbf{C}: 29,6\left(\mathrm{CH}_{3}\right) ; 54,4\left(\mathrm{CH}_{3}\right) ; 54,9\left(\mathrm{CH}_{3}\right) ; 59,1\left(\mathrm{CH}_{3}\right) ; 98,5(\mathrm{CH}) ; 100,8(\mathrm{CH}) ; 113,2(2)$ $(\mathrm{CH}) ; 126,4(\mathrm{CH}) ; 126,6(\mathrm{CH}) ; 127,3$ (2) (CH); 129,4 (C); 133,1 (C); 134,0 (C); 142,5 (C); $151,3(\mathrm{C}) ; 158,2(\mathrm{C})$.

IR (KBr): 3387; 1590; 1512; 1459; 1254; $1176 \mathrm{~cm}^{-1}$.

HMRS (m/z): Obtenido 300,1583 $\left(\mathrm{M}+\mathrm{Na}^{+}\right)$; esperado 300,1600 $\left(\mathrm{C}_{18} \mathrm{H}_{21} \mathrm{NNaO}_{3}{ }^{+}\right)$. 


\section{Compuestos con indol como anillo B}

\section{Metilación de 5-bromo-1H-indol}

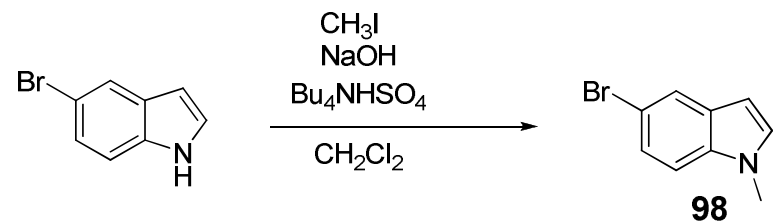

Se disuelven 2,00 g (10,2 mmol) de 5-bromo- $1 \mathrm{H}$-indol en $50 \mathrm{ml} \mathrm{de} \mathrm{CH}_{2} \mathrm{Cl}_{2}$ y se le añaden 820 mg de $\mathrm{NaOH}$ triturada, $35 \mathrm{mg}(0,10 \mathrm{mmol})$ de bisulfato de tetrabutilamonio y $2 \mathrm{ml}(30 \mathrm{mmol})$ de yodometano. La mezcla se pone de color rosa, la reacción se agita durante $72 \mathrm{~h}$ a temperatura ambiente controlándose por capa fina.

Al final se extrae con una disolución saturada de $\mathrm{NaCl}$ hasta $\mathrm{pH}$ neutro y se obtienen 2,10 $\mathrm{g}$ (10,00 mmol, $98 \%)$ de producto 98.

\section{$\underline{\text { 5-bromo-1-metil-1H-indol }(98)}$}

RMN ${ }^{1} \mathbf{H}: 3,67(3 \mathrm{H}, \mathrm{s}) ; 6,58(1 \mathrm{H}, \mathrm{d}, 3,2) ; 7,09(1 \mathrm{H}, \mathrm{d}, 3,2) ; 7,16(1 \mathrm{H}, \mathrm{d}, 8,4) ; 7,45(1 \mathrm{H}, \mathrm{dd}$, $8,4,2,0) ; 7,95(1 \mathrm{H}, \mathrm{d}, 2,0)$.

RMN ${ }^{13} \mathbf{C}: 33,0\left(\mathrm{CH}_{3}\right) ; 100,7(\mathrm{CH}) ; 111,1(\mathrm{CH}) ; 112,8(\mathrm{C}) ; 123,4(\mathrm{CH}) ; 124,3(\mathrm{CH}) ; 130,3$ $(\mathrm{CH}) ; 130,4$ (C); 135,5 (C).

IR (película): $1607 ; 1561 ; 1511 ; 1276 ; 896 \mathrm{~cm}^{-1}$.

\section{Preparación del alcohol 99}<smiles>COc1cc(C=O)cc([N+](=O)[O-])c1OC</smiles><smiles>Cn1ccc2cc(Br)ccc21</smiles>
98

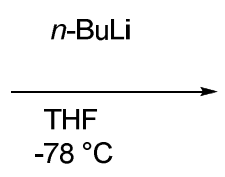

$-78^{\circ} \mathrm{C}$<smiles>COc1cc(C(O)c2ccc3c(ccn3C)c2)cc([N+](=O)[O-])c1OC</smiles> 
Se disuelven 4,20 g (19,90 mmol) de 98 en $50 \mathrm{ml}$ de THF seco y se le añaden 12,8 $\mathrm{ml}$ (20,5 mmol) de $n$-BuLi 1,6 $\mathrm{M}$ en hexano a $-78{ }^{\circ} \mathrm{C}$, apareciendo un color naranja. Después de una hora de reacción a $-78^{\circ} \mathrm{C}$ en atmósfera de nitrógeno, se añaden $1,50 \mathrm{~g}(7,11 \mathrm{mmol}) \mathrm{de}$ aldehído 68 disuelto en $10 \mathrm{ml}$ de THF y el color pasa de naranja a marrón. La mezcla se agita durante $24 \mathrm{~h}$ a temperatura ambiente, luego se trata con $\mathrm{NH}_{4} \mathrm{Cl} / \mathrm{AcOEt}$, se evapora el THF y se extrae con agua/AcOEt y se obtienen 4,20 g de producto de reacción, que se utiliza en la oxidación sin purificar.

\section{(3,4-dimetoxi-5-nitrofenil)(1-metil-1H-indol-5-il)metanol (99):}

RMN ${ }^{1} \mathrm{H}: 3,63(3 \mathrm{H}, \mathrm{s}) ; 3,68(3 \mathrm{H}, \mathrm{s}) ; 3,73(3 \mathrm{H}, \mathrm{s}) ; 5,76(1 \mathrm{H}, \mathrm{s}) ; 6,32(1 \mathrm{H}, \mathrm{d}, 3,2) ; 6,78(1 \mathrm{H}, \mathrm{d}$, 8,8); 7,03 (1H, s); 7,06 (1H, d, 3,2); 7,60 (1H, d, 8,8); 7,75 (1H, s); 8,11 (1H, s).

\section{Obtencion de la fenstatina $\mathbf{1 0 0}$}<smiles>COc1cc(C(O)c2ccc3c(ccn3C)c2)cc([N+](=O)[O-])c1OC</smiles><smiles>COc1cc(C(=O)c2ccc3c(ccn3C)c2)cc([N+](=O)[O-])c1OC</smiles>

Se disuelven 4,00 g (11,68 mmol) de la mezcla que contiene el alcohol 99 en $100 \mathrm{ml}$ de $\mathrm{CH}_{2} \mathrm{Cl}_{2}$ y se le añaden $4,50 \mathrm{~g}(11,68 \mathrm{mmol})$ de dicromato de piridinio a $0{ }^{\circ} \mathrm{C}$. La mezcla se agita $24 \mathrm{~h}$ a temperatura ambiente, posteriormente se extrae con agua/ $\mathrm{CH}_{2} \mathrm{Cl}_{2}$ y se obtienen 2,00 g de crudo de reacción.

El crudo se purifica por cromatografía flash (Hex/AcOEt 7:3) obteniéndose $50 \mathrm{mg}(0,15$ mmol, $2 \%$ ) de $\mathbf{1 0 0 .}$

\section{(3,4-dimetoxi-5-nitrofenil)(1-metil-1H-indol-5-il)metanona (100):}

RMN ${ }^{1} \mathbf{H}: 3,83(3 \mathrm{H}, \mathrm{s}) ; 3,96(3 \mathrm{H}, \mathrm{s}) ; 4,06(3 \mathrm{H}, \mathrm{s}) ; 6,60(1 \mathrm{H}, \mathrm{d}, 3,2) ; 7,14(1 \mathrm{H}, \mathrm{d}, 3,2) ; 7,38$ $(1 \mathrm{H}, \mathrm{d}, 8,8) ; 7,63(1 \mathrm{H}, \mathrm{s}) ; 7,71(1 \mathrm{H}, \mathrm{s}) ; 7,73(1 \mathrm{H}, \mathrm{d}, 8,8) ; 8,09(1 \mathrm{H}, \mathrm{s})$.

RMN ${ }^{13} \mathbf{C}: 33,1\left(\mathrm{CH}_{3}\right) ; 56,6\left(\mathrm{CH}_{3}\right) ; 62,2\left(\mathrm{CH}_{3}\right) ; 103,1(\mathrm{CH}) ; 109,4(\mathrm{CH}) ; 116,6(\mathrm{CH}) ; 118,2$ $(\mathrm{CH}) ; 123,5(\mathrm{CH}) ; 125,1(\mathrm{CH}) ; 128,0(\mathrm{C}) ; 130,8(\mathrm{CH}) ; 134,3(\mathrm{C}) ; 138,6(\mathrm{C}) ; 143,9(\mathrm{C}) ; 145,5$ (C); 154,0 (2) (C); 194,1 (C). 
IR (pelicula): $1647 ; 1603 ; 1535 ; 1288 ; 1164 \mathrm{~cm}^{-1}$.

HMRS (m/z): Obtenido 341,1131 $\left(\mathrm{M}+\mathrm{H}^{+}\right)$; esperado 341,1137 $\left(\mathrm{C}_{18} \mathrm{H}_{17} \mathrm{~N}_{2} \mathrm{O}_{5}{ }^{+}\right)$.

\section{Obtención de la isocombretastatina 101}
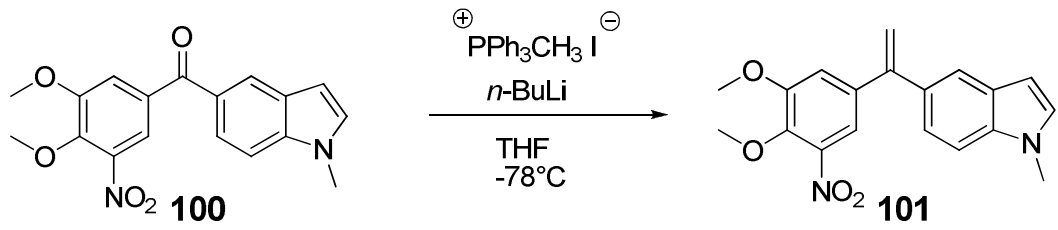

Se disuelven $150 \mathrm{mg}(0,35 \mathrm{mmol})$ de la sal de fosfonio 1 en $15 \mathrm{ml}$ de THF seco y se le añaden $200 \mu \mathrm{l}(0,29 \mathrm{mmol})$ de $n$-BuLi $1,6 \mathrm{M}$ en hexano a $-78^{\circ} \mathrm{C}$, apareciendo un color amarillo. La mezcla se mantiene en agitación durante $1 \mathrm{~h}$ a la misma temperatura, luego se le añaden 40 mg (0,11 mmol) de cetona 100 disuelta en $10 \mathrm{ml}$ de THF. La reacción se deja agitando 24 h a temperatura ambiente, posteriormente se trata con $\mathrm{NH}_{4} \mathrm{Cl} / \mathrm{AcOEt}$, se evapora el THF y se extrae con agua/AcOEt, obteniéndose 70 mg de crudo de reacción.

El crudo se purifica por cromatografía flash (Hex/AcOEt 8:2) y se aíslan $10 \mathrm{mg}(0,03 \mathrm{mmol}$, $27 \%$ ) del compuesto 101.

\section{5-(1-(3,4-dimetoxi-5-nitrofenil)etenil)-1-metil-1H-indol (101):}

$\mathbf{R M N}^{1} \mathbf{H}: 3,74(3 \mathrm{H}, \mathrm{s}) ; 3,77(3 \mathrm{H}, \mathrm{s}) ; 3,94(3 \mathrm{H}, \mathrm{s}) ; 5,34(1 \mathrm{H}, \mathrm{s}) ; 5,44(1 \mathrm{H}, \mathrm{s}) ; 6,41(1 \mathrm{H}, \mathrm{d}, 3,2)$; 7,02 (1H, d, 3,2); 7,03 (1H, d, 2,0); 7,10 (1H, d, 8,4); 7,22 (1H, d, 8,4); 7,29 (1H, d, 2,0); 7,50 $(1 \mathrm{H}, \mathrm{s})$.

IR (película): $1605 ; 1534 ; 1340 ; 1259 ; 1061 ; 870 \mathrm{~cm}^{-1}$. 


\section{Preparación del alcohol 102}<smiles>Cn1ccc2cc(Br)ccc21</smiles>

98<smiles>COc1cc(C=O)cc(N(C)C(=O)OCc2ccccc2)c1OC</smiles><smiles>CCCCCCCCCCCC</smiles><smiles>COc1cc(C(O)c2ccc3c(ccn3C)c2)cc(N(C(=O)O)C(=O)OCc2ccccc2)c1OC</smiles>

Se disuelven 1,30 g (5,72 mmol) del compuesto 98 en $30 \mathrm{ml}$ de THF seco, después se le añaden 3,1 $\mathrm{ml}(4,85 \mathrm{mmol})$ de $n$-BuLi a $-78{ }^{\circ} \mathrm{C}$, apareciendo un color naranja. La mezcla se agita durante $1 \mathrm{~h} \mathrm{a}-78^{\circ} \mathrm{C}$ y en atmósfera de nitrógeno, luego se añade $1,20 \mathrm{~g}(4,40 \mathrm{mmol}) \mathrm{de}$ aldehído 95 disuelto en $10 \mathrm{ml}$ de THF y de color pasa de naranja a marrón. La reacción se agita durante $24 \mathrm{~h}$ a temperatura ambiente, posteriormente se trata con $\mathrm{NH}_{4} \mathrm{Cl}$ y AcOEt, se evapora el THF y se extrae con AcOEt obteniéndose 2,02 g de crudo de reacción.

El crudo se purifica por cromatografía flash (Hex/AcOEt 7:3) y se aíslan $420 \mathrm{mg}$ (0,98 mmol, $22 \%$ ) del compuesto $\mathbf{1 0 2}$ como un aceite naranja.

(5-(hidroxi(1-metil-1H-indol-5-il)metil)-2,3-dimetoxifenil)(metil) carbamato de tercbutilo (102)

$\mathbf{R M N}^{1} \mathbf{H}: 1,47$ (9H, s); 3,16 (3H, s); 3,76 (3H, s); 3,82 (6H, s); 5,73 (1H, s); 6,58 (1H, d, 3,2); 6,96 (1H, d, 2,0); 7,14 (1H, d, 3,2); 7,38 (1H, d, 2,0); 7,39 (1H, d, 8,4); 7,77 (1H, d, 8,4); 8,11 $(1 \mathrm{H}, \mathrm{s})$.

RMN ${ }^{13} \mathbf{C}: 28,7(3)\left(\mathrm{CH}_{3}\right) ; 33,4\left(\mathrm{CH}_{3}\right) ; 37,1\left(\mathrm{CH}_{3}\right) ; 56,5\left(\mathrm{CH}_{3}\right) ; 61,1\left(\mathrm{CH}_{3}\right) ; 65,7(\mathrm{CH}) ; 80,4$ (C); 103,2 (CH); 108,9 (CH); 113,8 (CH); 119,5 (CH); 124,1 (C); 124,5 (CH); 125,4 (CH); 127,9 (C); 129,5 (C); 130,3 (C); 130,8 (CH); 132,1 (C); 137,5 (C); 153,4 (C); 155,4 (C).

IR (pelicula): 3419; 1697; 1590; 1367; 1256; $1152 \mathrm{~cm}^{-1}$. 


\section{Oxidación del alcohol 102}<smiles>COC(=O)N(c1cc(C(O)c2ccc3c(ccn3C)c2)cc(OC)c1OC)C(C)(C)C</smiles>

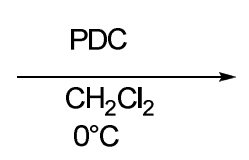<smiles>COc1cc(C(=O)c2ccc3c(ccn3C)c2)cc(N(C)C(=O)OC(C)(C)C)c1OC</smiles>

Se disuelven $300 \mathrm{mg}(0,71 \mathrm{mmol})$ del compuesto 102 en $20 \mathrm{ml} \mathrm{de} \mathrm{CH}_{2} \mathrm{Cl}_{2}$ y se le añade 318 $\mathrm{mg}(0,84 \mathrm{mmol}) \mathrm{de}$ dicromato piridinio a $0{ }^{\circ} \mathrm{C}$. La mezcla se agita $4 \mathrm{~h}$ a temperatura ambiente, posteriormente se extrae con agua/ $\mathrm{CH}_{2} \mathrm{Cl}_{2}$ y se obtienen $352 \mathrm{mg}$ de crudo de reacción.

El crudo se purifica por cromatografía flash (Hex/AcOEt 7:3) y se aíslan $250 \mathrm{mg}$ (0,59 mmol, $83 \%$ ) del compuesto $\mathbf{1 0 3 .}$

\section{(2,3-dimetoxi-5-(1-metil-1H-indol-5-carbonil)fenil)(metil)carbamato de terc-butilo (103):}

RMN ${ }^{1} \mathbf{H}: 1,43(9 \mathrm{H}, \mathrm{s}) ; 3,13(3 \mathrm{H}, \mathrm{s}) ; 3,74(3 \mathrm{H}, \mathrm{s}) ; 3,84(6 \mathrm{H}, \mathrm{s}) ; 6,57(1 \mathrm{H}, \mathrm{d}, 3,2) ; 7,14(1 \mathrm{H}, \mathrm{d}$, 3,2); 7,24 (1H, d, 2,0); 7,38 (1H, d, 8,8); 7,39 (1H, d, 2,0); 7,76 (1H, d, 8,8); 8,11 (1H, s).

RMN ${ }^{13} \mathbf{C}: 28,3(3)\left(\mathrm{CH}_{3}\right) ; 30,2\left(\mathrm{CH}_{3}\right) ; 33,1\left(\mathrm{CH}_{3}\right) ; 56,1\left(\mathrm{CH}_{3}\right) ; 60,7\left(\mathrm{CH}_{3}\right) ; 80,1(\mathrm{C}) ; 102,8$ $(\mathrm{CH}) ; 108,8(\mathrm{CH}) ; 112,1(\mathrm{CH}) ; 123,7(\mathrm{CH}) ; 123,9(\mathrm{C}) ; 124,2(\mathrm{CH}) ; 125,2(\mathrm{CH}) ; 127,6(\mathrm{C})$; 129,1 (C); 130,3 (C); 130,5 (CH); 133,9 (C); 138,8 (C); 153,1 (C); 154,9 (C); 195,8 (C).

IR (KBr): $1694 ; 1644 ; 1581 ; 1253 ; 1154 ; 1073 \mathrm{~cm}^{-1}$.

HMRS (m/z): Obtenido 425,2076 $\left(\mathrm{M}+\mathrm{H}^{+}\right)$; esperado 425,2076 $\left(\mathrm{C}_{24} \mathrm{H}_{29} \mathrm{~N}_{2} \mathrm{O}_{5}{ }^{+}\right)$.

\section{Obtención de la isocombretastatina 104}
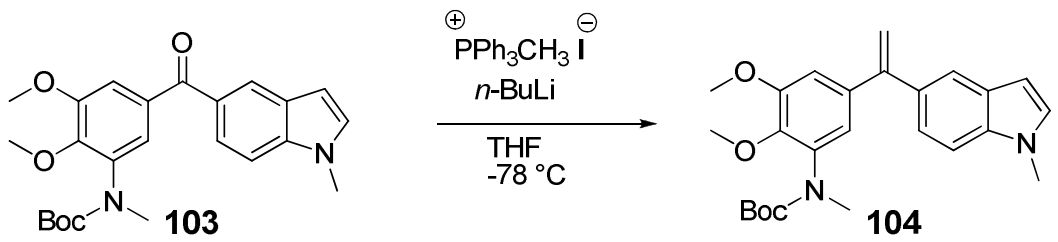

Se disuelven 1,70 g (4,24 mmol) de la sal de fosfonio 1 en $30 \mathrm{ml}$ de THF seco y se le añaden 2,2 $\mathrm{ml}(3,53 \mathrm{mmol})$ de $n$-BuLi 1,6 $\mathrm{M}$ en hexano a $-78^{\circ} \mathrm{C}$, apareciendo un color amarillo. La 
mezcla se mantiene agitando durante $1 \mathrm{~h}$ a $-78^{\circ} \mathrm{C}$ en atmósfera de nitrógeno, después se añaden $600 \mathrm{mg}$ (1,41 mmol) de la cetona 103 disuelta en $10 \mathrm{ml}$ de THF. La reacción se agita durante $24 \mathrm{~h}$ a temperatura ambiente, posteriormente se trata con $\mathrm{NH}_{4} \mathrm{Cl}$ y AcOEt, se evapora el THF y después de extracción líquido-líquido con agua/AcOEt se obtienen 1,10 g de crudo de reacción.

El crudo se purifica por cromatografía flash (Hex/AcOEt 7:3) y se aíslan $278 \mathrm{mg}(0,66 \mathrm{mmol}$, $47 \%$ ) del compuesto 104 en forma de aceite naranja.

\section{$\underline{\text { (2,3-dimetoxi-5-(1-(1-metil-1H-indol-5-il)etenil)fenil)(metil) } \text { carbamato de terc-butilo }}$} (104):

RMN ${ }^{1} \mathbf{H}: 1,40(9 \mathrm{H}, \mathrm{s}) ; 3,14(3 \mathrm{H}, \mathrm{s}) ; 3,81(6 \mathrm{H}, \mathrm{s}) ; 3,85(3 \mathrm{H}, \mathrm{s}) ; 5,36(1 \mathrm{H}, \mathrm{s}) ; 5,42(1 \mathrm{H}, \mathrm{s}) ; 6,46$ $(1 \mathrm{H}, \mathrm{d}, 3,2) ; 6,78(1 \mathrm{H}, \mathrm{d}, 2,0) ; 6,86(1 \mathrm{H}, \mathrm{d}, 2,0) ; 7,06(1 \mathrm{H}, \mathrm{d}, 3,2) ; 7,22(1 \mathrm{H}, \mathrm{d}, 8,4) ; 7,27(1 \mathrm{H}$, $\mathrm{d}, 8,4) ; 7,60(1 \mathrm{H}, \mathrm{s})$.

RMN ${ }^{13} \mathbf{C}: 28,7(3)\left(\mathrm{CH}_{3}\right) ; 30,8\left(\mathrm{CH}_{3}\right) ; 33,1\left(\mathrm{CH}_{3}\right) ; 56,3\left(\mathrm{CH}_{3}\right) ; 60,7\left(\mathrm{CH}_{3}\right) ; 80,1(\mathrm{C}) ; 101,7$ $(\mathrm{CH}) ; 109,1(\mathrm{CH}) ; 111,4(\mathrm{CH}) ; 112,9\left(\mathrm{CH}_{2}\right) ; 121,2(\mathrm{CH}) ; 121,6(\mathrm{CH}) ; 122,7(\mathrm{CH}) ; 128,7(2)$ (C); 129,6 (C); 129,8 (CH); 132,9 (C); 136,8 (C); 137,2 (C); 150,7 (C); 153,1 (C); 155,5 (C).

IR (película): 1699; 1577; 1495; 1246; $1153 ; 1075 \mathrm{~cm}^{-1}$.

HMRS (m/z): Obtenido 423,2274 $\left(\mathrm{M}+\mathrm{H}^{+}\right)$; esperado 423,2284 $\left(\mathrm{C}_{25} \mathrm{H}_{31} \mathrm{~N}_{2} \mathrm{O}_{4}{ }^{+}\right)$.

HPLC: Columna $\mathrm{C}_{18} \quad \mathrm{t}_{\mathrm{R}}: 21,6 \mathrm{~min}$.

\section{Obtención de la fenstatina $\mathbf{1 0 5}$}
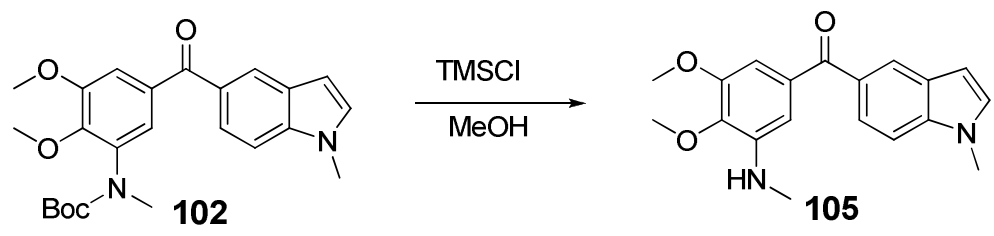

Se disuelven $45 \mathrm{mg}(0,11 \mathrm{mmol})$ de la cetona 102 en $4 \mathrm{ml}$ de $\mathrm{MeOH}$ y se le añaden $41 \mu \mathrm{l}$ (0,33 mmol) de cloruro de trimetilsililo, pasando el color de amarillo a rojo. La mezcla se 
mantiene agitando durante $24 \mathrm{~h}$ a temperatura ambiente, luego se evapora el $\mathrm{MeOH}$ y se extrae con $\mathrm{NaHCO}_{3} / \mathrm{CH}_{2} \mathrm{Cl}_{2}$, obteniéndose $48 \mathrm{mg}$ de crudo de reacción.

El crudo se purifica por cromatografía flash (Hex/AcOEt 6:4) y se aíslan $20 \mathrm{mg}$ (0,06 mmol, $56 \%$ ) del compuesto $\mathbf{1 0 5}$ en forma de aceite amarillo.

\section{(3,4-dimetoxi-5-(metilamino)fenil)(1-metil-1H-indol-5-il)metanona (105):}

RMN ${ }^{1} \mathbf{H}: 2,84(3 \mathrm{H}, \mathrm{s}) ; 3,85$ (2) (3H, s); 3,88 (3H, s); 6,59 (1H, d, 3,2); 6,76 (1H, d, 1,6); 6,81 $(1 \mathrm{H}, \mathrm{d}, 1,6) ; 7,13(1 \mathrm{H}, \mathrm{d}, 3,2) ; 7,38(1 \mathrm{H}, \mathrm{dd}, 8,4) ; 7,82(1 \mathrm{H}, \mathrm{dd}, 8,4,1,6) ; 8,17(1 \mathrm{H}, \mathrm{d}, 1,6)$.

RMN ${ }^{13} \mathbf{C}: 30,9\left(\mathrm{CH}_{3}\right) ; 33,3\left(\mathrm{CH}_{3}\right) ; 56,3\left(\mathrm{CH}_{3}\right) ; 60,7\left(\mathrm{CH}_{3}\right) ; 101,7(\mathrm{CH}) ; 104,1(\mathrm{CH}) ; 106,7$ $(\mathrm{CH}) ; 109,2(\mathrm{CH}) ; 120,4(\mathrm{C}) ; 124,2(\mathrm{CH}) ; 124,5(\mathrm{CH}) ; 126,8(\mathrm{C}) ; 128,2(\mathrm{CH}) ; 129,3(\mathrm{C})$; 135,4 (C); 139,9 (C); 143,2 (C); 151,9 (C); 197,5 (C).

IR (película): 3416; 1642; 1590; 1168; $1129 \mathrm{~cm}^{-1}$.

HMRS (m/z): Obtenido 325,1552 $\left(\mathrm{M}+\mathrm{H}^{+}\right)$; esperado 325,1552 $\left(\mathrm{C}_{19} \mathrm{H}_{21} \mathrm{~N}_{2} \mathrm{O}_{3}{ }^{+}\right)$.

HPLC: Columna $\mathrm{C}_{18} \mathrm{t}_{\mathrm{R}}: 15,1 \mathrm{~min}$.

\section{Obtención de la isocombretastatina 106}
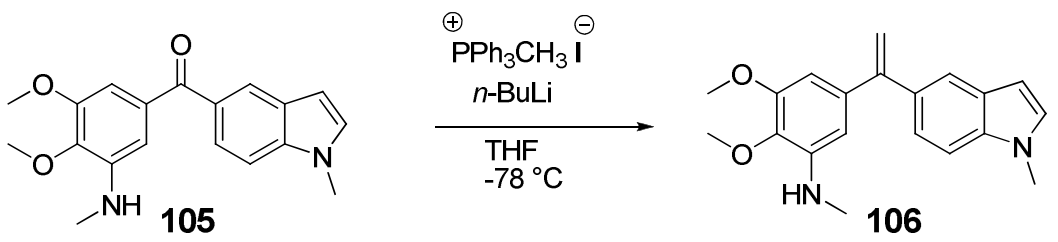

Se disuelven $675 \mathrm{mg}(1,67 \mathrm{mmol})$ de la sal de fosfonio 1 en $20 \mathrm{ml}$ de THF seco y se le añaden $870 \mu \mathrm{L}(1,39 \mathrm{mmol})$ de $n$-BuLi a $-78^{\circ} \mathrm{C}$, apareciendo un color amarillo. La mezcla se mantiene agitando durante $1 \mathrm{~h}$ a $-78^{\circ} \mathrm{C}$ en atmósfera de nitrógeno, después se añaden $180 \mathrm{mg}$ (0,55 mmol) del crudo de reacción de 105 disuelto en $10 \mathrm{ml}$ de el THF. La reacción se agita durante $24 \mathrm{~h}$ a temperatura ambiente, posteriormente se trata con $\mathrm{NH}_{4} \mathrm{Cl}$ y AcOEt, se evapora el THF, después se extrae con agua/AcOEt y se obtienen 320 g de crudo de reacción.

El crudo se purifica por cromatografía flash (Hex/AcOEt 7:3) y se aíslan $50 \mathrm{mg}(0,15 \mathrm{mmol}$, $27 \%$ ) del compuesto 106 en forma sólido blanco. 


\section{$\underline{N \text {-metil-2,3-dimetoxi-5-(1-(1-metil-1H-indol-5-il)etenil)anilina (106): }}$}

RMN ${ }^{1} \mathbf{H}: 2,66(3 \mathrm{H}, \mathrm{s}) ; 3,65(3 \mathrm{H}, \mathrm{s}) ; 3,69(3 \mathrm{H}, \mathrm{s}) ; 3,73(3 \mathrm{H}, \mathrm{s}) ; 5,17(1 \mathrm{H}, \mathrm{s}) ; 5,21(1 \mathrm{H}, \mathrm{s})$; $5,66(1 \mathrm{H}, \mathrm{s}) ; 6,19(1 \mathrm{H}, \mathrm{d}, 2,0) ; 6,23(1 \mathrm{H}, \mathrm{d}, 2,0) ; 7,10(1 \mathrm{H}, \mathrm{d}, 3,2) ; 7,37(1 \mathrm{H}, \mathrm{d}, 3,2) ; 7,40(1 \mathrm{H}$, dd, 8,8, 1,6); 7,58 (1H, dd, 8,4; 1,6); 7,63 (1H, d, 1,6).

IR (película): 3416; 1586; 1519; 1166; 1119; 1000; $910 \mathrm{~cm}^{-1}$. 


\section{Otras combretastatinas modificadas}

\section{A. Modificación en el puente etilénico}

\section{Modificaciones en el puente de la combretastatina 78}

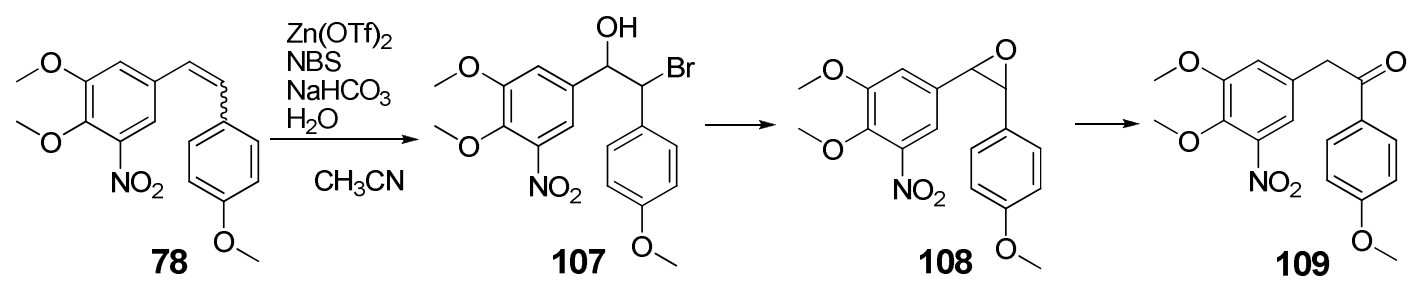

Se disuelven $70 \mathrm{mg}(0,22 \mathrm{mmol})$ de una mezcla de isómeros Z/E del compuesto 78 en $4 \mathrm{~mL}$ de acetonitrilo y se añaden $5 \mathrm{mg}(0,01 \mathrm{mmol})$ de triflato de zinc, $52 \mathrm{mg}(0,29 \mathrm{mmol}) \mathrm{de} \mathrm{N}$ bromosuccinimida, $25 \mathrm{mg}(0,29 \mathrm{mmol})$ de bicarbonato sódico y 2 gotas de agua, la reacción se pone de color verde claro. La mezcla se deja agitando 48 h controlándose por RMN 1H, viéndose la formación inicial de la halohidrina $\mathbf{1 0 7}$.

La reacción se deja agitando controlándose día a día por $\mathrm{RMN} 1 \mathrm{H}$ y se observa la transformación de $\mathbf{1 0 7}$ en el epóxido 108 y finalmente la cetona 109.

2-bromo-1-(3,4-dimetoxi-5-nitrofenil)-2-(4-metoxifenil)etanol (107):

RMN ${ }^{1} \mathbf{H}: 3,79$ (3H, s); 3,85 (3H, s); 3,97 (3H, s); 5,02 (1H, d, 5,6); 5,15 (1H, d, 5,6); 6,83 $(2 \mathrm{H}, \mathrm{d}, 8,4) ; 7,08(1 \mathrm{H}, \mathrm{d}, 2,4) ; 7,16(2 \mathrm{H}, \mathrm{d}, 8,4) ; 7,32(1 \mathrm{H}, \mathrm{d}, 2,4)$.

\section{2-(3,4-dimetoxi-5-nitrofenil)-3-(4-metoxifenil)oxirano (108):}

RMN ${ }^{1} \mathbf{H}: 3,80(3 \mathrm{H}, \mathrm{s}) ; 3,91(3 \mathrm{H}, \mathrm{s}) ; 3,96(3 \mathrm{H}, \mathrm{s}) ; 4,20(2 \mathrm{H}, \mathrm{s}) ; 6,88(2 \mathrm{H}, \mathrm{d}, 8,8) ; 7,03(1 \mathrm{H}, \mathrm{d}$, 2,0); 7,22 (2H, d, 8,8); 7,30 (1H, d, 2,0).

\section{2-(3,4-dimetoxi-5-nitrofenil)-1-(4-metoxifenil)etanona (109):}

RMN ${ }^{1} \mathbf{H}: 3,78(3 \mathrm{H}, \mathrm{s}) ; 3,90(3 \mathrm{H}, \mathrm{s}) ; 3,97$ (3H, s); 4,18 (2H, s); 6,86 (2H, d, 6,8); 7,15 (2H, d, 6,8); 7,72 (1H, d, 2,4); 7,98 (1H, d, 2,4). 
RMN ${ }^{13} \mathbf{C}: 44,4\left(\mathrm{CH}_{2}\right) ; 55,2\left(\mathrm{CH}_{3}\right) ; 56,5\left(\mathrm{CH}_{3}\right) ; 62,1\left(\mathrm{CH}_{3}\right) ; 114,2(2)(\mathrm{CH}) ; 114,9(\mathrm{CH})$; 117,1 (CH); 125,6 (C); 130,4 (2) (CH); 131,5 (C); 146,6 (C); 154,1 (C); 158,7 (C); 177,9 (C); 195,1 (C).

IR (pelicula): $3260 ; 2945 ; 1710 ; 1535 ; 1288 ; 1178 \mathrm{~cm}^{-1}$.

HMRS (m/z): Obtenido 332,1129 $\left(\mathrm{M}+\mathrm{H}^{+}\right)$; esperado 332,1134 $\left(\mathrm{C}_{17} \mathrm{H}_{18} \mathrm{NO}_{6}{ }^{+}\right)$.

\section{Obtención del compuesto 110:}
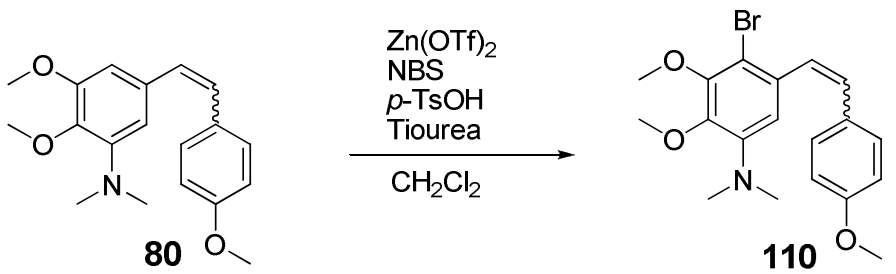

Se disuelven $100 \mathrm{mg}(0,32 \mathrm{mmol})$ de una mezcla de isómeros $(Z / E)$ de $\mathbf{8 0}$ en $5 \mathrm{~mL}$ de $\mathrm{CH}_{2} \mathrm{Cl}_{2}$ y se le añade $6 \mathrm{mg}(0,02 \mathrm{mmol})$ de $\mathrm{Zn}(\mathrm{OTf})_{2}, 70 \mathrm{mg}(0,39 \mathrm{mmol}) \mathrm{de} \mathrm{NBS}, 34 \mathrm{mg}(0,39$ mmol) de $\mathrm{NaHCO}_{3}$ y $30 \mathrm{mg}(0,39 \mathrm{mmol})$ de tiourea y el color pasa de amarillo a violeta. $\mathrm{La}$ reacción se agita durante $18 \mathrm{~h}$ a temperatura ambiente, después se extrae con agua/ $\mathrm{CH}_{2} \mathrm{Cl}_{2}$, se obtienen $120 \mathrm{mg}(0,30 \mathrm{mmol}, 93 \%)$ del compuesto 110 como un aceite naranja constituido por una mezcla de isómeros $Z / E$ en proporción 1:1.

Datos sacados del espectro de la mezcla $Z / E$

\section{(Z)-N,N-dimetil-2,3-dimetoxi-4-bromo-5-(2-(4-metoxifenil)etenil)anilina (110):}

$\mathbf{R M N}^{1} \mathbf{H}: 2,57(6 \mathrm{H}, \mathrm{s}) ; 3,76(3 \mathrm{H}, \mathrm{s}) ; 3,88(6 \mathrm{H}, \mathrm{s}) ; 6,45(1 \mathrm{H}, \mathrm{d}, 12,0) ; 6,54(1 \mathrm{H}, \mathrm{d}, 12,0) ; 6,58$ $(1 \mathrm{H}, \mathrm{s}) ; 6,72(2 \mathrm{H}, \mathrm{d}, 7,6) ; 7,12(2 \mathrm{H}, \mathrm{d}, 7,6)$.

RMN ${ }^{13} \mathbf{C}: 42,7(2)\left(\mathrm{CH}_{3}\right) ; 55,2\left(\mathrm{CH}_{3}\right) ; 59,7\left(\mathrm{CH}_{3}\right) ; 60,7\left(\mathrm{CH}_{3}\right) ; 110,6(\mathrm{CH}) ; 110,7(\mathrm{C}) ; 113,5$ (2) $(\mathrm{CH}) ; 127,9$ (2) (CH); 129,1 (C); 130,0 (C); 130,3 (2) (CH); 133,2 (C); 145,6 (C); 151,0 (C); 158,7 (C).

\section{$\underline{(E)-N, N \text {-dimetil-2,3-dimetoxi-4-bromo-5-(2-(4-metoxifenil)etenil)anilina (110): }}$}


RMN ${ }^{1} \mathbf{H}: 2,86(6 \mathrm{H}, \mathrm{s}) ; 3,81(3 \mathrm{H}, \mathrm{s}) ; 3,88(6 \mathrm{H}, \mathrm{s}) ; 6,89$ (2H, d, 7,2); 6,91 (1H, d, 15,2); 7,25 $(1 \mathrm{H}, \mathrm{s}) ; 7,27(1 \mathrm{H}, \mathrm{d}, 15,2) ; 7,47(2 \mathrm{H}, \mathrm{d}, 7,2)$.

RMN ${ }^{13} \mathbf{C}: 42,9$ (2) $\left(\mathrm{CH}_{3}\right) ; 55,3\left(\mathrm{CH}_{3}\right) ; 59,8\left(\mathrm{CH}_{3}\right) ; 60,8\left(\mathrm{CH}_{3}\right) ; 110,7(\mathrm{C}) ; 114,1(2)(\mathrm{CH})$; 115,3 (CH); 125,8 (2) (CH); 129,1 (C); 129,8 (2) (CH); 130,0 (C); 133,0 (C); 145,4 (C); 146,1 (C); 159,5 (C).

IR (película): 1606; 1574; 1252; 1066; $948 \mathrm{~cm}^{-1}$.

HMRS (m/z): Obtenido 392,0850 $\left(\mathrm{M}+\mathrm{H}^{+}\right)$; esperado 392,0861 $\left(\mathrm{C}_{19} \mathrm{H}_{23} \mathrm{BrNO}_{3}{ }^{+}\right)$. 


\section{B. Derivados de isocombretastatina con anillos alifáticos}

\section{Obtención de la fenstatina 111}

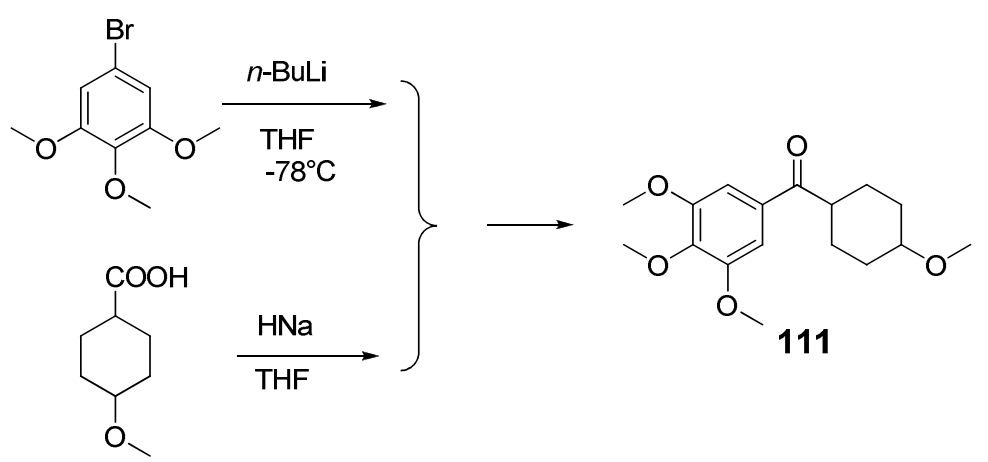

Se disuelven 11,7 g (47,4 mmol) de 5-bromo-1,2,3-trimetoxibenceno en $60 \mathrm{ml}$ de THF seco y después se le añaden 27,3 $\mathrm{mL}(43,6 \mathrm{mmol})$ de n-BuLi a $-78{ }^{\circ} \mathrm{C}$ apareciendo un color amarillo. La reacción se deja agitando durante $1 \mathrm{~h}$ a baja temperatura. En paralelo se disuelven en otro matraz 3,00 g (18,9 mmol) de una mezcla cis/trans en proporcion 2:1 del acido 4metoxiciclohexanocarboxílico en $60 \mathrm{ml}$ de THF seco y se le añaden poco a poco 2,30 g (95,9 mmol) de hidruro sodio a $0{ }^{\circ} \mathrm{C}$. Tras una hora de reacción se mezclan las dos reacciones y se deja agitando $24 \mathrm{~h}$ a temperatura ambiente. Se trata con $\mathrm{NH}_{4} \mathrm{Cl}$ y AcOEt, se evapora el THF, después se extrae con AcOEt, se seca con $\mathrm{Na}_{2} \mathrm{SO}_{4}$, se evapora el disolvente y se obtienen 12,5 g del crudo de reacción.

El crudo se purifica por cromatografía flash (Hex/AcOEt 1:1) y se aíslan 5,40 g (17,51 mmol, $92 \%$ ) del compuesto 111 como mezcla cis/trans en proporción 6:4.

\section{(4-metoxiciclohexil)(3,4,5-trimetoxifenil)metanona (111):}

\section{Isómero mayoritario:}

$\mathbf{R M N}^{1} \mathbf{H}: 1,25-2,12(9 \mathrm{H}, \mathrm{m}) ; 3,20(1 \mathrm{H}, \mathrm{m}) ; 3,28(3 \mathrm{H}, \mathrm{s}) ; 3,81(3 \mathrm{H}, \mathrm{s}) ; 3,85(6 \mathrm{H}, \mathrm{s}) ; 7,16(2 \mathrm{H}$, s).

RMN ${ }^{13} \mathbf{C}: 23,8(2)\left(\mathrm{CH}_{2}\right) ; 28,7(2)\left(\mathrm{CH}_{2}\right) ; 44,3(\mathrm{CH}) ; 55,4\left(\mathrm{CH}_{3}\right) ; 56,2(2)\left(\mathrm{CH}_{3}\right) ; 60,8\left(\mathrm{CH}_{3}\right)$; 74,4 (CH); 104,6 (2) (CH); 131,5 (C); 137,7 (C); 153,3 (2) (C); 202,0 (C). 


\section{Isómero minoritario:}

RMN ${ }^{1} \mathbf{H}:$ 1,25-2,12 (9H, m); 3,34 (3H, s); 3,45 (1H, m); 3,85 (3H, s); 3,87 (6H, s); 7,16 (2H, s).

RMN ${ }^{13} \mathbf{C}: 27,7(2)\left(\mathrm{CH}_{2}\right) ; 31,1(2)\left(\mathrm{CH}_{2}\right) ; 44,4(\mathrm{CH}) ; 56,7\left(\mathrm{CH}_{3}\right) ; 56,3(2)\left(\mathrm{CH}_{3}\right) ; 60,8\left(\mathrm{CH}_{3}\right)$; 78,5 (CH); 105,8 (2) (CH); 131,4 (C); 137,5 (C); 153,3 (2) (C); 202,0 (C).

IR (película): 1672; 1580; 1236; 1126; $1005 \mathrm{~cm}^{-1}$.

HMRS (m/z): Obtenido 331,1516 $\left(\mathrm{M}+\mathrm{Na}^{+}\right)$; esperado 331,1521 $\left(\mathrm{C}_{17} \mathrm{H}_{24} \mathrm{NaO}_{5}{ }^{+}\right)$.

HPLC: Columna $\mathrm{C}_{18} \quad \mathrm{t}_{\mathrm{R}}: 14,4 \mathrm{~min} ; \mathrm{t}_{\mathrm{R}}: 16,2 \mathrm{~min}$.

\section{Preparación de la isocombretastatina 112}<smiles>COc1cc(C(=O)C2CCC(OC)CC2)cc(OC)c1OC</smiles>

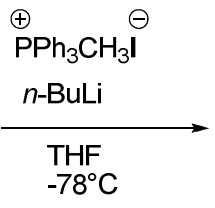<smiles>C=C(c1cc(OC)c(OC)c(OC)c1)C1CCC(OC)CC1</smiles>

Se disuelven $670 \mathrm{mg}(1,66 \mathrm{mmol})$ de la sal de fosfonio 1 en $40 \mathrm{ml}$ de THF seco y se le añaden $1,2 \mathrm{ml}(1,33 \mathrm{mmol})$ de $n$-BuLi a $-78{ }^{\circ} \mathrm{C}$ y aparece un color amarillo. La mezcla se mantiene agitando durante $1 \mathrm{~h} \mathrm{a}-78{ }^{\circ} \mathrm{C}$ en atmósfera de nitrógeno y después se añaden $170 \mathrm{mg}(0,55$ mmol) de la mezcla cis/trans de la cetona 111 disuelta en $10 \mathrm{ml}$ de THF. La reacción se agita durante $24 \mathrm{~h}$ a temperatura ambiente, posteriormente se trata con $\mathrm{NH}_{4} \mathrm{Cl}$ y AcOEt, se evapora el THF, se extrae con agua/AcOEt y se obtienen $453 \mathrm{mg}$ de crudo de reacción como una mezcla cis/trans en proporción 6:4.

El crudo se purifica por cromatografía flash (Hex/AcOEt 8:2) y se aíslan $64 \mathrm{mg}$ (0,21 mmol, $38 \%)$ del isómero trans y $35 \mathrm{mg}(0,11 \mathrm{mmol}, 21 \%)$ del isómero cis del compuesto 112 como un sólido blanco.

\section{1,2,3-trimetoxi-5-(1-(4-metoxiciclohexil)etenil)benceno (112):}

\section{Isómero cis:}


RMN ${ }^{1} \mathbf{H}: 1,43$ (4H, m); 1,90 (4H,m); 2,38 (1H, m); 3,29 (3H, s); 3,43 (1H, m); 3,83 (3H, s); $3,85(6 \mathrm{H}, \mathrm{s}) ; 5,02(1 \mathrm{H}, \mathrm{s}) ; 5,10(1 \mathrm{H}, \mathrm{s}) ; 6,51(2 \mathrm{H}, \mathrm{s})$.

RMN ${ }^{13} \mathbf{C}: 30,4(2)\left(\mathrm{CH}_{2}\right) ; 32,0(2)\left(\mathrm{CH}_{2}\right) ; 42,1(\mathrm{CH}) ; 55,7\left(\mathrm{CH}_{3}\right) ; 56,1(2)\left(\mathrm{CH}_{3}\right) ; 60,9\left(\mathrm{CH}_{3}\right)$; 79,3 (CH); 103,8 (2) (CH); 110,3 ( $\left.\mathrm{CH}_{2}\right) ; 137,3(\mathrm{C}) ; 138,7$ (C); 152,9 (2) (C); 154,0 (C).

IR (película): 1617; 1578; 1456; 1236; $1123 ; 1008 \mathrm{~cm}^{-1}$.

HMRS (m/z): Obtenido 307,1908 $\left(\mathrm{M}+\mathrm{H}^{+}\right)$; esperado 307,1909 $\left(\mathrm{C}_{18} \mathrm{H}_{27} \mathrm{O}_{4}{ }^{+}\right)$.

HPLC: Columna $\mathrm{C}_{18} \quad \mathrm{t}_{\mathrm{R}}: 18,6 \mathrm{~min}$.

\section{Isómero trans:}

RMN ${ }^{1} \mathbf{H}: 1,25$ (4H, m); 1,90 (2H, m); 2,14 (2H, m); 2,35 (1H, m); 3,18 (1H, m); 3,36 (3H, s); 3,85 (3H, s); 3,87 (6H, s); 4,97 (1H, s); 5,10 (1H, s); 6,51 (2H, s).

\section{Preparación de la oxima 113}<smiles>COc1cc(C(=O)C2CCC(OC)CC2)cc(OC)c1OC</smiles><smiles>O[Mg]O[Na]</smiles><smiles>COc1cc(/C(=N/O)C2CCC(OC)CC2)cc(OC)c1OC</smiles>

Se disuelven $50 \mathrm{mg}(0,16 \mathrm{mmol})$ de la cetona 111 en $5 \mathrm{ml}$ de $\mathrm{MeOH}$ y se le añaden $113 \mathrm{mg}$ (1,62 mmol) de clorohidrato de hidroxilamina. La reacción se agita durante 24 h a $70{ }^{\circ} \mathrm{C}$. Se evapora el metanol y se extrae con agua/AcOEt, se seca con $\mathrm{Na}_{2} \mathrm{SO}_{4}$ y se evapora el disolvente obteniéndose $143 \mathrm{mg}$ del crudo de reacción como mezcla cis/trans 2:1.

El crudo se purifica por cromatografía flash (Hex/AcOEt 8:2) y se aíslan $13 \mathrm{mg}$ (0,04 mmol, $25 \%)$ del isómero trans del compuesto $\mathbf{1 1 3}$ como un aceite transparente.

\section{Oxima de (4-metoxiciclohexil)(3,4,5-trimetoxifenil)metanona (113):}

\section{Isómero mayoritario: datos sacados de la mezcla}


RMN ${ }^{1} \mathbf{H}: 1,24-2,15(8 \mathrm{H}, \mathrm{m}) ; 2,45(1 \mathrm{H}, \mathrm{m}) ; 3,20(1 \mathrm{H}, \mathrm{m}) ; 3,38(3 \mathrm{H}, \mathrm{s}) ; 3,85(3 \mathrm{H}, \mathrm{s}) ; 3,87$ $(6 \mathrm{H}, \mathrm{s}) ; 6,61(2 \mathrm{H}, \mathrm{s})$.

\section{Isómero minoritario:}

RMN ${ }^{1} \mathbf{H}: 1,14(2 \mathrm{H}, \mathrm{m}) ; 1,28(2 \mathrm{H}, \mathrm{m}) ; 1,87(2 \mathrm{H}, \mathrm{m}) ; 2,05(2 \mathrm{H}, \mathrm{m}) ; 2,37(1 \mathrm{H}, \mathrm{m}) ; 3,03(1 \mathrm{H}$, $\mathrm{m}) ; 3,30(3 \mathrm{H}, \mathrm{s}) ; 3,80(3 \mathrm{H}, \mathrm{s}) ; 3,82(6 \mathrm{H}, \mathrm{s}) ; 6,42(2 \mathrm{H}, \mathrm{s})$.

RMN ${ }^{13} \mathbf{C}: 28,4(2)\left(\mathrm{CH}_{2}\right) ; 31,4(2)\left(\mathrm{CH}_{2}\right) ; 43,5(\mathrm{CH}) ; 55,6\left(\mathrm{CH}_{3}\right) ; 56,2(2)\left(\mathrm{CH}_{3}\right) ;$ 60,8 $\left(\mathrm{CH}_{3}\right)$; 78,8 (CH); 104,6 (2) (CH); 128,9 (C); 138,0 (C); 153,2 (2) (C); 162,0 (C).

IR (película): 3442; 1576; 1398; 1236; $1125 ; 1005 \mathrm{~cm}^{-1}$.

HMRS (m/z): Obtenido 324,1812 $\left(\mathrm{M}+\mathrm{H}^{+}\right)$; esperado 324,1811 $\left(\mathrm{C}_{17} \mathrm{H}_{26} \mathrm{NO}_{5}{ }^{+}\right)$.

HPLC: Columna $\mathrm{C}_{18} \quad \mathrm{t}_{\mathrm{R}}: 4,3 \mathrm{~min} ; \mathrm{t}_{\mathrm{R}}: 5,3 \mathrm{~min}$.

\section{Obtención del alcohol 114}<smiles>COc1cc(C(C)=O)cc(OC)c1OC</smiles>
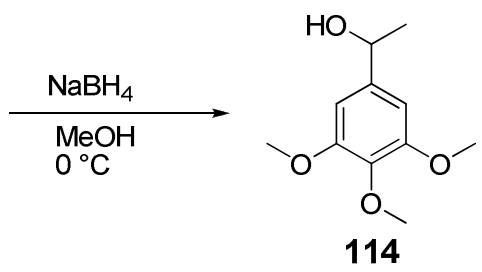

Se disuelven 2,00 g (9,51 mmol) de 3,4,5-trimetoxiacetofenona en $30 \mathrm{ml}$ de $\mathrm{MeOH}$ y se le añaden poco a poco $440 \mathrm{mg}(11,63 \mathrm{mmol})$ de borohidruro sódico a $0{ }^{\circ} \mathrm{C}$. La mezcla se mantiene en agitación 4 h, luego se evapora el metanol, se extrae con agua/AcOEt, se seca con $\mathrm{Na}_{2} \mathrm{SO}_{4}$, se evapora el disolvente y se obtienen 1,92 g (9,04 mmol, $\left.95 \%\right)$ del compuesto 114 como un aceite transparente.

\section{1-(3,4,5-trimetoxifenil)etanol (114):}

RMN ${ }^{1} \mathrm{H}: 1,48$ (3H, d, 6,4); 3,81 (3H, s); 3,86 (6H, s); 4,84 (1H, c, 6,4); 6,61 (2H, s).

RMN ${ }^{13} \mathbf{C}: 25,2\left(\mathrm{CH}_{3}\right) ; 56,1(2)\left(\mathrm{CH}_{3}\right) ; 60,7\left(\mathrm{CH}_{3}\right) ; 70,4(\mathrm{CH}) ; 102,1(2)(\mathrm{CH}) ; 136,9(\mathrm{C}) ;$ 141,8 (C); 153,2 (2) (C). 
IR (película): 3470; 1592; 1234; 1127; $1007 \mathrm{~cm}^{-1}$.

\section{Bromación del alcohol 114}

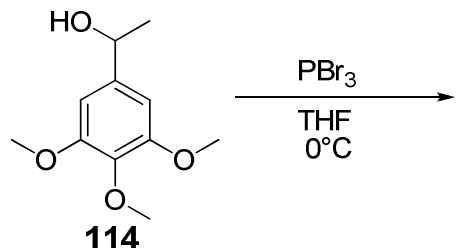

114

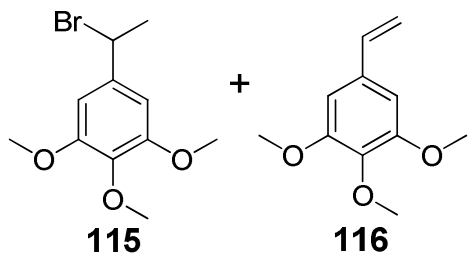

Se disuelven 1,92 g (8,95 mmol) de 114 en $30 \mathrm{~mL}$ de THF y después se añaden $950 \mu \mathrm{L}(10,10$ mmol) de tribromuro de fósforo a $0{ }^{\circ} \mathrm{C}$. La reacción se agita durante $2 \mathrm{~h}$, luego se evapora el THF, se extrae con agua/AcOEt, se seca con $\mathrm{Na}_{2} \mathrm{SO}_{4}$, se evapora el disolvente y se obtienen 2,40 g de crudo de reacción.

El crudo se purifica por cromatografía flash (Hex/AcOEt 8:2) separándose 2,00 g (7,27 mmol, $81 \%)$ del compuesto 115 y $150 \mathrm{mg}(0,77 \mathrm{mmol}, 9 \%)$ del compuesto 116.

\section{5-(1-bromoetil)-1,2,3-trimetoxibenceno (115):}

$\mathbf{R M N}^{1} \mathbf{H}: 2,01(3 \mathrm{H}, \mathrm{d}, 6,8) ; 3,83(3 \mathrm{H}, \mathrm{s}) ; 3,87(6 \mathrm{H}, \mathrm{s}) ; 5,11$ (1H, c, 6,8); 6,64 (2H, s).

RMN ${ }^{13} \mathbf{C}: 25,0\left(\mathrm{CH}_{3}\right) ; 55,6(2)\left(\mathrm{CH}_{3}\right) ; 60,4\left(\mathrm{CH}_{3}\right) ; 70,1(\mathrm{CH}) ; 101,9$ (2) $(\mathrm{CH}) ; 102,8(\mathrm{C})$; 141,6 (C); 152,8 (2) (C).

IR (película): $1591 ; 1461 ; 1327 ; 1235 ; 1127 ; 833 \mathrm{~cm}^{-1}$.

\section{1,2,3-trimetoxi-5-vinilbenceno (116):}

RMN ${ }^{1} \mathbf{H}: 3,84(3 \mathrm{H}, \mathrm{s}) ; 3,88(6 \mathrm{H}, \mathrm{s}) ; 5,20(1 \mathrm{H}, \mathrm{d}, 11,2) ; 5,64(1 \mathrm{H}, \mathrm{d}, 17,6) ; 6,60(1 \mathrm{H}, \mathrm{dd}$, $11,2,17,6) ; 6,63$ (2H, s).

RMN ${ }^{13} \mathbf{C}: 56,0(2)\left(\mathrm{CH}_{3}\right) ; 60,8\left(\mathrm{CH}_{3}\right) ; 103,2(2)(\mathrm{CH}) ; 113,2\left(\mathrm{CH}_{2}\right) ; 133,3(\mathrm{C}) ; 136,7(\mathrm{CH})$; 139,8 (C); 153,2 (2) (C).

IR (película): 1583; 1505; 1462; 1326; $1238 ; 1128 \mathrm{~cm}^{-1}$. 


\section{Preparación del compuesto 117}

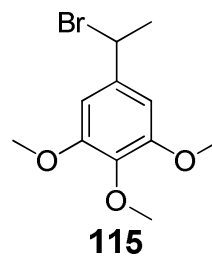<smiles></smiles><smiles>[3H][Tl]Oc1cc(C(C)N2CCCCC2)cc(OC)c1OC</smiles>

Se disuelven 1,00 g (3,63 mmol) de 115 en $15 \mathrm{ml}$ de DMF y después se le añaden $450 \mu \mathrm{l}$ (4,55 mmol) de piperidina. La reacción se agita durante $48 \mathrm{~h}$ a temperatura ambiente controlándose por cromatografía de capa fina, luego se calienta a $90{ }^{\circ} \mathrm{C}$, posteriormente se trata con hielo y agua, se extrae con AcOEt, se seca con $\mathrm{Na}_{2} \mathrm{SO}_{4}$, se evapora el disolvente y se obtienen $631 \mathrm{mg}$ (2,26 mmol, $62 \%)$ del compuesto 117 como un aceite naranja.

\section{$\underline{1-(1-(3,4,5-t r i m e t o x i f e n i l) e t i l) p i p e r i d i n a ~(117) ~}$}

RMN ${ }^{1} \mathbf{H}$ (MeOD): 1,33 (3H, d, 6,6); 1,39 (4H, m); 1,54 (2H, m); 2,33 (4H, m); 3,23 (1H, c, $6,6) ; 3,73(3 \mathrm{H}, \mathrm{s}) ; 3,81(6 \mathrm{H}, \mathrm{s}) ; 6,61(2 \mathrm{H}, \mathrm{s})$.

RMN ${ }^{13} \mathbf{C}$ (MeOD): 20,2 ( $\left(\mathrm{CH}_{3}\right) ; 25,4\left(\mathrm{CH}_{2}\right) ; 26,8$ (2) $\left(\mathrm{CH}_{2}\right) ; 53,0$ (2) $\left(\mathrm{CH}_{2}\right) ; 56,7$ (2) $\left(\mathrm{CH}_{3}\right)$; $61,1\left(\mathrm{CH}_{3}\right) ; 67,4(\mathrm{CH}) ; 106,2(2)(\mathrm{CH}) ; 138,2(\mathrm{C}) ; 140,6(\mathrm{C}) ; 154,4(2)(\mathrm{C})$.

IR (pelicula): $1590 ; 1503 ; 1125 ; 1012 \mathrm{~cm}^{-1}$.

HMRS (m/z): Obtenido 280,1894 $\left(\mathrm{M}+\mathrm{H}^{+}\right)$; esperado 280,1913 $\left(\mathrm{C}_{16} \mathrm{H}_{26} \mathrm{NO}_{3}{ }^{+}\right)$.

\section{Obtención del compuesto 118}<smiles>COc1cc(C(C)=O)cc(OC)c1OC</smiles><smiles>OC1CCNCC1</smiles><smiles>COc1ccccc1</smiles><smiles>COc1cc(C(C)N2CCC(O)CC2)cc(OC)c1OC</smiles>

Se disuelven $400 \mathrm{mg}$ (1,90 mmol) de 3,4,5-trimetoxiacetofenona en $20 \mathrm{ml}$ de $\mathrm{MeOH}$ y se le añaden $290 \mathrm{mg}$ (2,86 mmol) de 4-piperidinol, $155 \mathrm{mg}(0,73 \mathrm{mmol})$ de cianoborohidruro sódico y 3 gotas de ácido clorhídrico. La reacción se agita durante $1 \mathrm{~h} \mathrm{a} 0{ }^{\circ} \mathrm{C}$ y mantiene la 
agitación durante $24 \mathrm{~h}$ a de temperatura ambiente, posteriormente se evapora el $\mathrm{MeOH}$ y se obtiene 420 mg del crudo de reacción. En la RMN 1H no se observó evolución de la reacción. El mismo crudo se vuelve a poner en el microondas casero durante 3 min utilizando la sílice como soporte y se observó la evolución de esta reacción.

El crudo se purifica por cromatografía flash (Hex/AcOEt 6:4) aislándose 230 mg (0,78 mmol, $41 \%$ ) del compuesto 118 en forma de aceite amarillo.

\section{1-(1-(3,4,5-trimetoxifenil)etil)piperidin-4-ol (118):}

RMN ${ }^{1} \mathbf{H}: 1,23(3 \mathrm{H}, \mathrm{d}, 6,4) ; 1,41(2 \mathrm{H}, \mathrm{m}) ; 1,73(2 \mathrm{H}, \mathrm{m}) ; 1,99(1 \mathrm{H}, \mathrm{m}) ; 2,58(2 \mathrm{H}, \mathrm{m}) ; 2,78$ $(2 \mathrm{H}, \mathrm{m}) ; 3,18(1 \mathrm{H}, \mathrm{m}) ; 3,50(1 \mathrm{H}, \mathrm{sa}) ; 3,69(3 \mathrm{H}, \mathrm{s}) ; 3,72(6 \mathrm{H}, \mathrm{s}) ; 6,42(2 \mathrm{H}, \mathrm{s})$.

RMN ${ }^{13} \mathbf{C}: 20,5\left(\mathrm{CH}_{3}\right) ; 34,7(2)\left(\mathrm{CH}_{2}\right) ; 48,9(\mathrm{CH}) ; 56,6(2)\left(\mathrm{CH}_{3}\right) ; 61,3(\mathrm{CH}) ; 65,7$ (2) $\left(\mathrm{CH}_{2}\right)$; 68,1 (CH); 104,9 (2) (CH); 137,1 (C); 140,0 (C); 153,5 (2) (C). 


\section{Determinación de la solubilidad acuosa:}

Una vez sintetizados los compuestos se han realizado los ensayos de la solubilidad acuosa para completar los objetivos de este trabajo. Para ello se decidió medir la solubilidad en un tampón fosfato a $\mathrm{pH} 7$, ya que es el pH fisiológico y son las condiciones en las que se realizan los ensayos biológicos de estos compuestos.

Para la realización de los ensayos de la solubilidad se utilizó espectrofotómetro Helios Alpha Thermo Spectronic para medir la absorbancia de los compuestos.

En primer lugar se realiza un barrido en el espectrofotómetro desde 270 a $400 \mathrm{~nm}$ para determinar la $\lambda$ de absorbancia máxima de cada compuesto. A continuación se realizan las rectas de calibrado para cada compuesto.

Para la realización de la recta de calibrado se prepara una disolución del compuesto en DMSO con una concentración de $100 \mu \mathrm{g} / \mathrm{mL}$, a partir de la cual se preparan 6 cubetas de concentraciones que van desde 1 hasta $15 \mu \mathrm{g} / \mathrm{mL}$. Las cubetas se preparan con un volumen final de $300 \mu \mathrm{L}$, de los cuáles 270 serán de DMSO, disolvente orgánico muy polar utilizado por ser miscible con agua además de por su elevada capacidad para disolver compuestos orgánicos, y $30 \mu \mathrm{L}$ de tampón fosfato que va a mantener el $\mathrm{pH}$ de la disolución entorno a 7, a pH fisiológico.

Una vez preparadas las cubetas, se toma la muestra con menor concentración $(1 \mu \mathrm{g} / \mathrm{mL})$ y se lleva a cabo un scan o barrido entre los 270 y $400 \mathrm{~nm}$ para conocer la longitud de onda a la que el compuesto presenta un máximo de absorbancia y que será la longitud de onda a la que se realizarán el resto de medidas. En la mayoría de los casos ésta suele estar entorno a los 300 nm, característica de compuestos aromáticos con dobles enlaces conjugados. Después, a la longitud seleccionada, se mide la absorbancia de cada una de las cubetas, la cual se representa frente a la concentración de cada una. Los puntos obtenidos se ajustan a una recta, que es la recta patrón o de calibrado que posteriormente servirá para determinar la concentración de las muestras de estudio.

Para los ensayos de solubilidad se pesaron muestras de entre uno y dos miligramos de cada compuesto y se le añade $300 \mu \mathrm{L}$ del tampón fosfato y se pone en agitación 48 horas. Para saber la cantidad de compuesto que se ha disuelto en el tampón, se mide la absorbancia a una determinada longitud de onda que presenta el compuesto disuelto en el tampón y se compara con las absorbancias de una recta patrón o recta de calibrado realizada previamente. 
Se han determinado la solubilidad acuosa de varios compuestos sintetizados, familia de combretastatinas, fenstatinas e isocombretastatinas. Se han detallado los resultados obtenidos en la tabla siguiente:

\begin{tabular}{|c|c|c|c|}
\hline Compuesto & $\begin{array}{c}\text { Solubilidad } \\
(\boldsymbol{\mu g} / \mathbf{m l})\end{array}$ & Compuesto & $\begin{array}{c}\text { Solubilidad } \\
(\boldsymbol{\mu g} / \mathbf{m l})\end{array}$ \\
\hline $\mathbf{1 2}$ & 48 & $\mathbf{5 2}$ & 65 \\
\hline $\mathbf{1 3}$ & 30 & $\mathbf{5 4}$ & 11 \\
\hline $\mathbf{1 4}$ & 9 & $\mathbf{5 5}$ & 21 \\
\hline $\mathbf{1 5}$ & 11 & $\mathbf{5 7}$ & 153 \\
\hline $\mathbf{1 6}$ & 107 & $\mathbf{6 1}$ & $4,4 \mathrm{mg} / \mathrm{ml}$ \\
\hline $\mathbf{1 7}$ & 123 & $\mathbf{6 2}$ & $1,0 \mathrm{mg} / \mathrm{ml}$ \\
\hline $\mathbf{1 8}$ & 84 & $\mathbf{6 6}$ & $>5 \mathrm{mg} / \mathrm{ml}$ \\
\hline $\mathbf{2 0}$ & $2,5 \mathrm{mg} / \mathrm{ml}$ & $\mathbf{7 1}$ & 110 \\
\hline $\mathbf{2 1}$ & 74 & $\mathbf{7 3}$ & 102 \\
\hline $\mathbf{2 2}$ & $1,5 \mathrm{mg} / \mathrm{ml}$ & $\mathbf{8 0}$ & 71 \\
\hline $\mathbf{3 3}$ & 34 & $\mathbf{8 2}$ & 7 \\
\hline $\mathbf{3 4}$ & 583 & $\mathbf{8 7}$ & $1,0 \mathrm{mg} / \mathrm{ml}$ \\
\hline $\mathbf{3 5}$ & 136 & $\mathbf{9 0}$ & 48 \\
\hline $\mathbf{3 6}$ & 10 & $\mathbf{9 1}$ & 44 \\
\hline $\mathbf{3 7}$ & 13 & $\mathbf{9 7}$ & 52 \\
\hline $\mathbf{4 0}$ & 62 & $\mathbf{1 0 4}$ & 6 \\
\hline $\mathbf{5 0}$ & 44 & $\mathbf{1 0 5}$ & 10 \\
\hline $\mathbf{5 1}$ & 679 & & \\
\hline
\end{tabular}

Tabla 21: valores de solubilidad en un tampón de 10 mM NaPi a pH 7 de los compuestos sintetizados. 


\section{Actividad biológica}

Para realizar los ensayos de inhibición de la polimerización de la tubulina se han seguido los tres pasos siguientes:

- Aislamiento de la proteína microtubular a partir de cerebros de ternero.

- Ensayos de inhibición de polimerización de la tubulina, en el cual se hace un cribado con el fin de seleccionar los compuestos que den mejores resultados.

- Determinación de la $\mathbf{I C}_{\mathbf{5 0}}$, de los compuestos que presentan una inhibición de polimerización de la tubulina mayor del $50 \%$ a una concentración de $5 \mu \mathrm{M}$.

\section{Aislamiento de la proteína:}

Partiendo de cerebros de ternero sacrificados el mismo día del aislamiento, se extrae en una cámara fría a $4{ }^{\circ} \mathrm{C}$ la sustancia gris, rica en proteína microtubular o tubulina, evitando en la medida de lo posible tomar restos de otros tejidos. Se añade tampón de extracción (EB) en una relación de $1 \mathrm{~mL}$ por gramo de córtex pesado (unos 260 g) y se homogeniza con mucho cuidado con el potter, aún en la cámara fría.

A partir de este punto, se realizan una serie de incubaciones y centrifugaciones a $4{ }^{\circ} \mathrm{C}$ y $37^{\circ} \mathrm{C}$, alternativamente, que permiten aislar la proteína deseada, gracias a su capacidad de polimerizar y formar microtúbulos a $37{ }^{\circ} \mathrm{C}$ y despolimerizar a $4{ }^{\circ} \mathrm{C}$. Así, cuando se lleva a cabo la centrifugación a $4{ }^{\circ} \mathrm{C}$ la proteína se encuentra despolimerizada y permanece en el sobrenadante, mientras que a $37^{\circ} \mathrm{C}$, la tubulina se encuentra en forma de microtúbulos y forma parte del precipitado resultante.

En primer lugar, se centrifuga a $4{ }^{\circ} \mathrm{C}$ y $31 \mathrm{k} \mathrm{rpm}$ durante una hora. Después de este primer centrifugado el resultado es un precipitado muy abundante, homogéneo y de color crema que contiene restos celulares y de tejido, pero solo se utilizará el sobrenadante, que contiene la tubulina en forma de subunidades. A este sobrenadante se le añade lo necesario para que en el siguiente paso la tubulina sea capaz de formar los microtúbulos:

- Tampón de ensamblaje (que contiene iones magnesio y $\beta$-mercaptoetanol).

- Glicerol hasta una concentración de 3,5 M

- GTP (hasta una concentración de 0,5 mM)

- PMSF (hasta una concentración de $1 \mathrm{mM}$ ) 
El volumen resultante se mantiene a una temperatura de $37^{\circ} \mathrm{C}$ durante 45 minutos para que la proteína polimerice durante 45 minutos y después se centrifuga a $37^{\circ} \mathrm{C}$ durante 90 minutos a $31 \mathrm{k} \mathrm{rpm}$.

Después de este segundo centrifugado, al contrario que antes, se escoge el precipitado (gelatinoso) que contiene la proteína polimerizada y se resuspende en:

- Tampón de ensamblaje

- $1 \mathrm{mM}$ GTP $(200 \mu \mathrm{L}$ de $0,1 \mathrm{M}$ stock por cada $20 \mathrm{~mL}$ de volumen añadido)

Esta suspensión se homogeniza, se enfría en hielo para que despolimerice durante 30 minutos $\mathrm{y}$, posteriormente, se centrifuga a $32 \mathrm{k}$ rpm durante 30 minutos a $4{ }^{\circ} \mathrm{C}$.

Al igual que antes, al sobrenadante obtenido (bastante claro), se le añade lo necesario para una nueva formación de microtúbulos:

- $\quad$ GTP (hasta $0,5 \mathrm{mM}$ )

- PMSF (hasta $1 \mathrm{mM}$ )

Se polimeriza a $37^{\circ} \mathrm{C}$ durante 30 minutos y se centrifuga a $32 \mathrm{k}$ rpm durante 45 minutos y a 37 ${ }^{\circ} \mathrm{C}$.

Se recoge el precipitado de aspecto gelatinoso y se deja enfriar en hielo durante 5 minutos para después añadir el tampón 1XAB y el GTP $(0,5 \mathrm{mM})$. Este precipitado resuspendido proveniente del segundo ciclo de polimerización/despolimerización se alicuota en volúmenes de $250 \mu \mathrm{L}$ (obteniendo un volumen total entre 2,5 y $3 \mathrm{~mL}$ ), que se congelan rápidamente en nitrógeno líquido y se guardan en un congelador a $-80^{\circ} \mathrm{C}$, hasta su posterior uso.

De esta forma, se obtiene MTP o proteína microtubular, constituida por tubulina $\alpha$, tubulina $\beta$ y MAPs o proteínas asociadas a microtúbulos. El rendimiento promedio de cada purificación (utilizando como material de partida $300 \mathrm{~g}$ de tejido) fue de 0,3-0,5 $\mathrm{mg}$ de proteína microtubular (MTP) por gramo de tejido.

\section{Ensayo de actividad:}

Las alícuotas de proteína microtubular (MTP) se descongelan rápidamente en un baño de agua a $20{ }^{\circ} \mathrm{C}$ y se resuspenden en $1 \mathrm{~mL}$ de tampón de ensamblaje por alícuota. La suspensión se somete, cuidadosamente, a agitación magnética suave en hielo durante 30 miutos, se centrifuga 30 minutos a $4{ }^{\circ} \mathrm{C}$ y $50000 \mathrm{rpm}$ (para completar el segundo ciclo de polimerización/despolimerización). Se recoge el sobrenadante y se realiza el ensayo de Bradford para determinar la concentración de proteína total; típicamente $4,0 \mathrm{mg} / \mathrm{mL}$ (valor 
medio por preparación). Para esta concentración de proteína, se toma $125 \mu \mathrm{L}$ de MTP, $5 \mu \mathrm{l}$ de disolución $2 \mathrm{mM}$ de los ligandos en DMSO (para una concentración de compuesto $20 \mu \mathrm{M}$ ), $15 \mu \mathrm{L}$ de DMSO y $355 \mu \mathrm{l}$ de tampón (ensamblaje + 1,5 mM GTP), hasta completar los 500 $\mu \mathrm{L}$ del volumen final.

Las muestras se incuban a $20{ }^{\circ} \mathrm{C}$ durante 30 minutos, permitiendo la interacción de los ligandos con la proteína microtubular. A continuación, se enfrían en un baño de hielo durante 10 minutos y se introducen en el espectrofotómetro. La absorbancia se registra a $450 \mathrm{~nm}$ durante todo el proceso. Tras un periodo de estabilización a $4{ }^{\circ} \mathrm{C}$, aproximadamente 5 minutos, la temperatura se eleva a $37^{\circ} \mathrm{C}$. Cuando la absorbancia se estabiliza, se vuelve a cambiar la temperatura a $4{ }^{\circ} \mathrm{C}$ y la absorbancia vuelve a disminuir.

\section{Determinación de la $\mathrm{IC}_{50}$ de la inhibición de la polimerización de la tubulina:}

La $\mathrm{IC}_{50}$ es la concentración a la cual el compuesto inhibe la polimerización de la proteína en un $50 \%$.

El procedimiento seguido en el ensayo de IPT es exactamente igual al explicado anteriormente, variando únicamente la concentración del ligando para el que se quiere calcular la $\mathrm{IC}_{50}$. Generalmente cada ligando se ensaya al menos a las concentraciones $0,5,2$, 4, 6 y $10 \mu \mathrm{M}$, aunque pueden variar en función del comportamiento de cada compuesto. 
En la tabla siguiente se resumen los ensayos de inhibición de la polimerización de la tubulina y se indican la concentración probada y el porcentaje de inhibición producida. Todos los resultados son para una concentración final de proteína $1 \mathrm{mg} / \mathrm{mL}$.

\begin{tabular}{|c|c|c|c|c|c|c|c|}
\hline COMP & $\begin{array}{l}\text { CONC } \\
(\mu \mathrm{M})\end{array}$ & \% INHIB & $\mathrm{IC}_{50}$ & COMP & $\begin{array}{l}\text { CONC } \\
(\mu \mathrm{M})\end{array}$ & \% INHIB & $\mathrm{IC}_{50}$ \\
\hline \multirow{6}{*}{13} & 0,5 & 16 & \multirow{6}{*}{1,9} & \multirow{6}{*}{79} & 2 & 20 & \multirow{6}{*}{6,2} \\
\hline & 1 & 28 & & & 4 & 36 & \\
\hline & 2 & 52 & & & 5 & 40 & \\
\hline & 4 & 84 & & & 6 & 40 & \\
\hline & 5 & 90 & & & 10 & 74 & \\
\hline & 20 & 100 & & & 20 & 83 & \\
\hline \multirow{6}{*}{50} & 2 & 22 & \multirow{6}{*}{5,1} & \multirow{4}{*}{80} & 0,5 & 20 & \multirow{4}{*}{1,1} \\
\hline & 4 & 45 & & & 1 & 43 & \\
\hline & 5 & 55 & & & 2 & 79 & \\
\hline & 10 & 65 & & & 5 & 92 & \\
\hline & 15 & 85 & & \multirow{5}{*}{$97 Z$} & 0,5 & 43 & \multirow{5}{*}{0,8} \\
\hline & 20 & 92 & & & 1 & 49 & \\
\hline \multirow{5}{*}{73} & 2 & 39 & \multirow{5}{*}{2,5} & & 2 & 79 & \\
\hline & 4 & 70 & & & 4 & 84 & \\
\hline & 5 & 63,5 & & & 5 & 85 & \\
\hline & 10 & 76 & & \multirow{5}{*}{105} & 0,5 & 20 & \multirow{5}{*}{1,2} \\
\hline & 20 & 80 & & & 1 & 36 & \\
\hline \multirow{5}{*}{74} & 2 & 9 & \multirow{5}{*}{6,0} & & 2 & 37 & \\
\hline & 4 & 36 & & & 4 & 78 & \\
\hline & 5 & 47 & & & 5 & 97 & \\
\hline & 10 & 64 & & & & & \\
\hline & 20 & 78 & & & & & \\
\hline
\end{tabular}

Tabla 22: Valores de inhibición de la polimerización de la tubulina de los compuestos seleccionados a distintas concentraciones e $\mathrm{IC}_{50}$ obtenidas. 


\section{CONCLUSIONES}





\section{CONCLUSIONES}

En este trabajo de Tesis Doctoral se ha llevado a cabo la síntesis y evaluación de nuevos análogos nitrogenados de combretastatinas. Así se han obtenido y evaluado compuestos que incorporan modificaciones tanto en el anillo A como en el anillo B como en el puente.

Los resultados obtenidos se resumen en las siguientes conclusiones:

La reacción de Wittig y el empleo de derivados organometálicos constituyen la metodología sintética empleada para la obtención con buenos rendimientos de los derivados de combretastatina, fenstatina e isocombretastatina.

$>$ Se han sintetizado 52 compuestos que incorporan un grupo nitrogenado en el anillo B y 30 compuestos que lo hacen en el anillo A.

Los resultados de los ensayos de solubilidad acuosa muestran que, en general, los compuestos sintetizados son más solubles que el compuesto de referencia, Combretastatina A-4.

Los compuestos en forma de sal de amonio han resultado ser los más solubles que se han obtenido. Sin embargo, estos compuestos no han mostrado una elevada inhibición de la polimerización de tubulina a las concentraciones ensayadas.

$>$ De las modificaciones llevadas a cabo en el anillo B, solamente la isocombretastatina con un anillo de p-dimetilaminofenilo tiene una actividad comparable a la de la CA-4.

La sustitución de uno de los metoxilos del anillo A por un grupo amino, metilamino o dimetilamino, ha dado lugar a compuestos a compuestos que inhiben la polimerización de tubulina con una potencia semejante a la de CA-4. Esto implica que, a pesar de la importancia que tiene el anillo de 3,4,5-trimetoxifenilo para la actividad, es posible introducir algunas modificaciones.

Se han combinado el anillo A de 3,4,5-trimetoxifenilo y el anillo B de piridina sustituida con dimetilamino, pirrolidina o sin sustituyentes, unidos por puentes de combrestastatina, fenstatina o isocombretastatina. Se han obtenido compuestos menos potentes pero muy solubles en agua. 



\section{ESPECTROS}





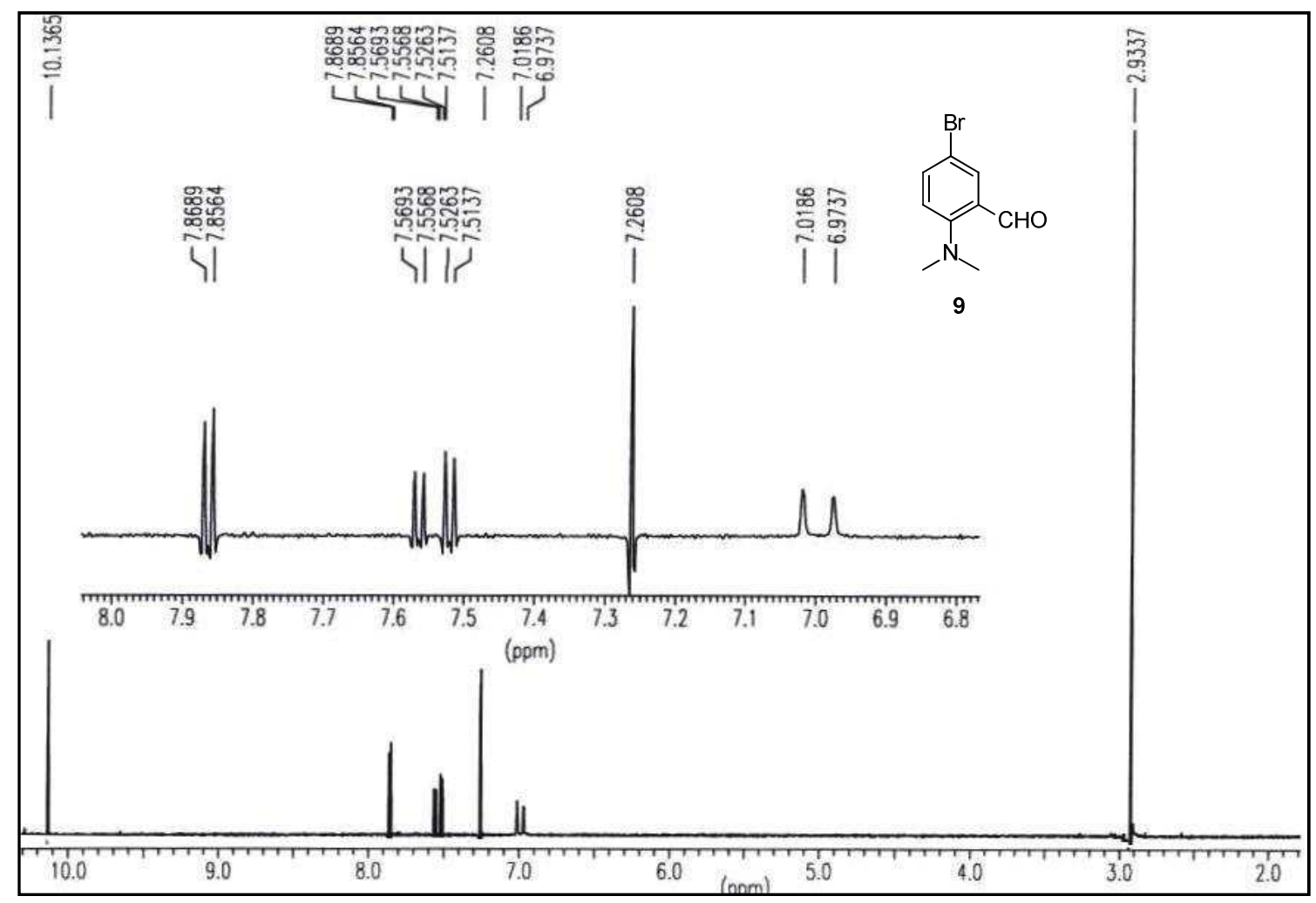

Figura Ia: Espectro de RMN ${ }^{1} \mathrm{H}$ del compuesto 9.

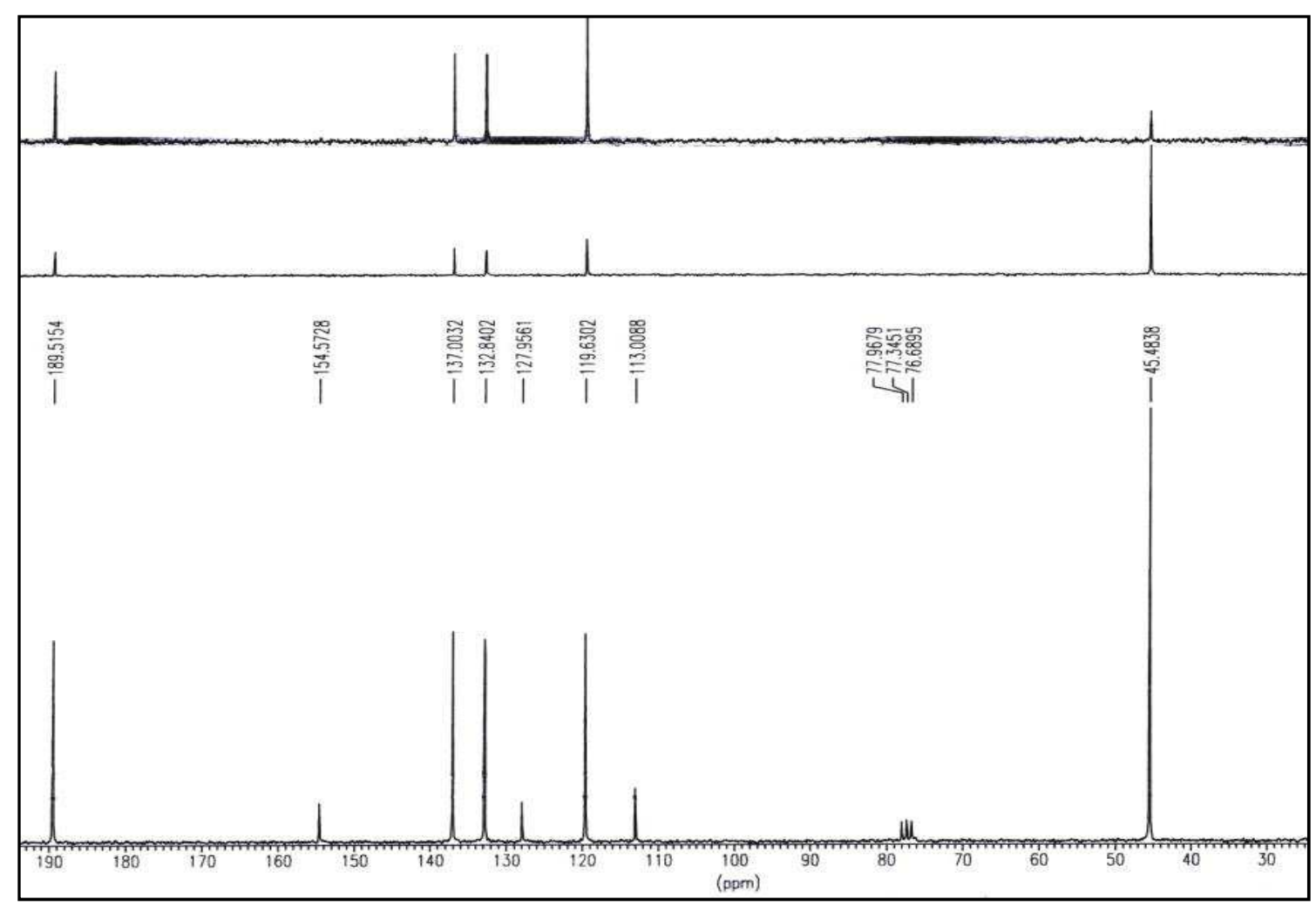

Figura Ib: Espectro de RMN ${ }^{13} \mathrm{C}$ del compuesto 9. 


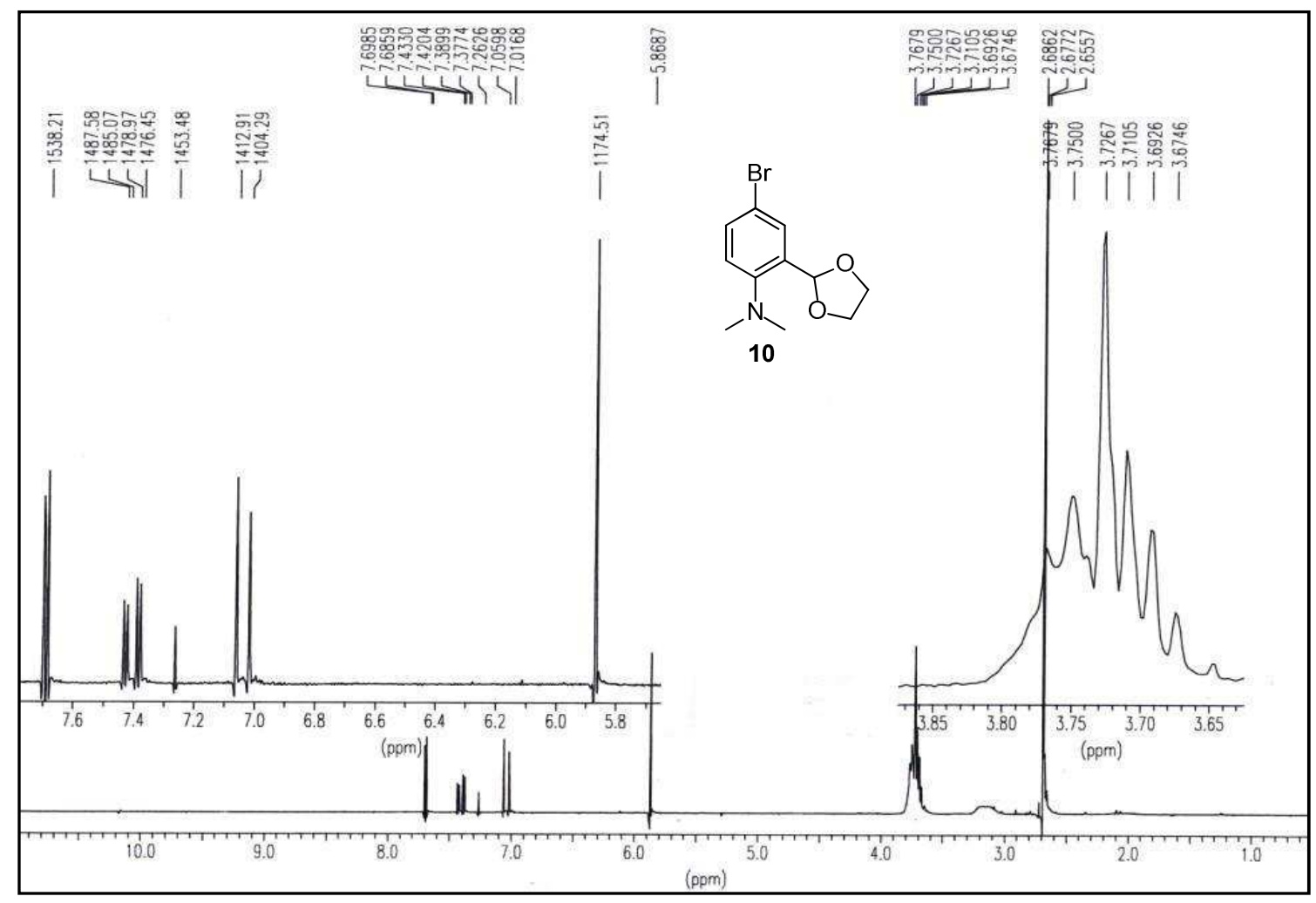

Figura IIa: Espectro de RMN ${ }^{1} \mathrm{H}$ del compuesto 10.

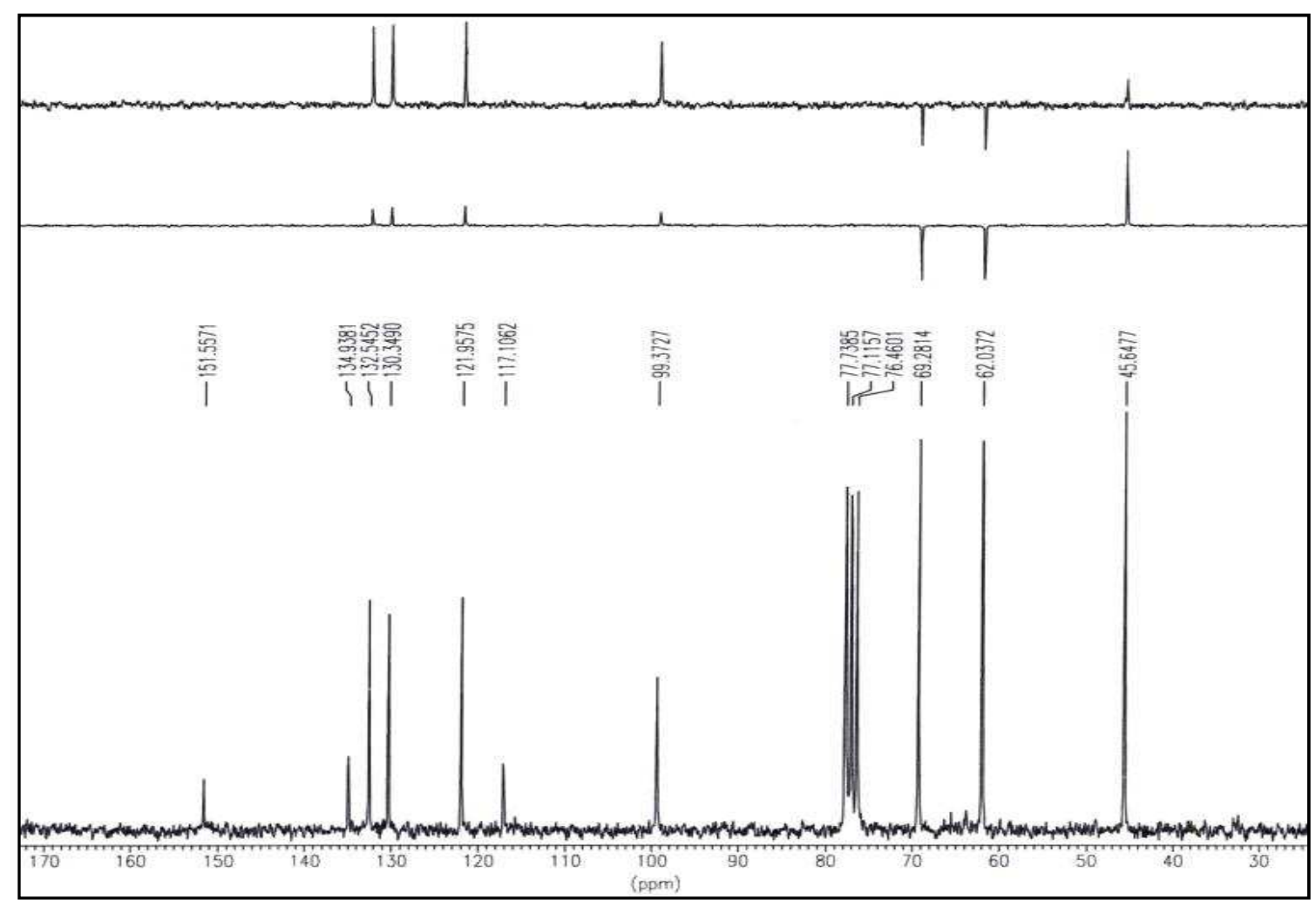

Figura IIb: Espectro de RMN ${ }^{13} \mathrm{C}$ del compuesto 10. 


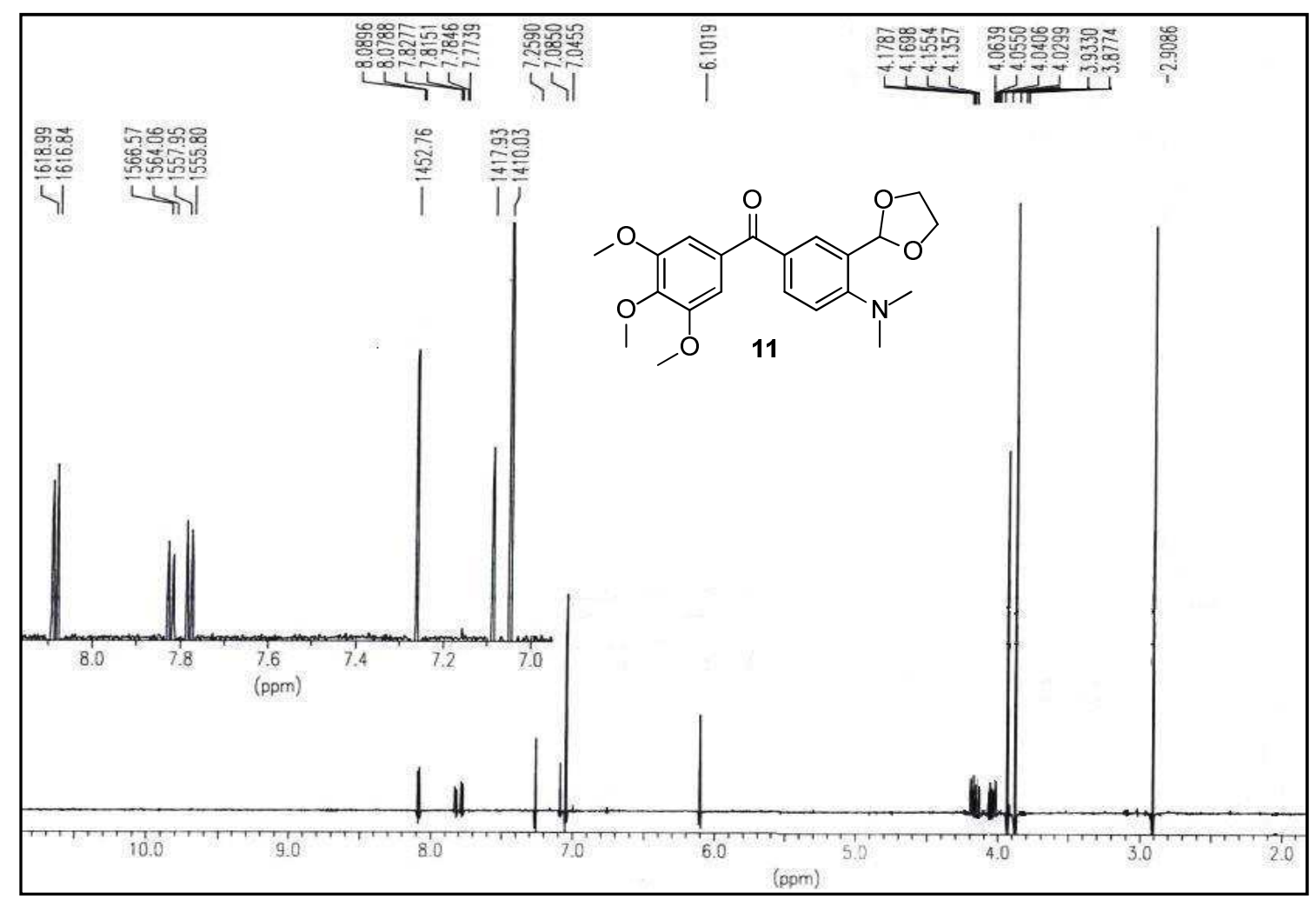

Figura IIIa: Espectro de RMN ${ }^{1} \mathrm{H}$ del compuesto 11.

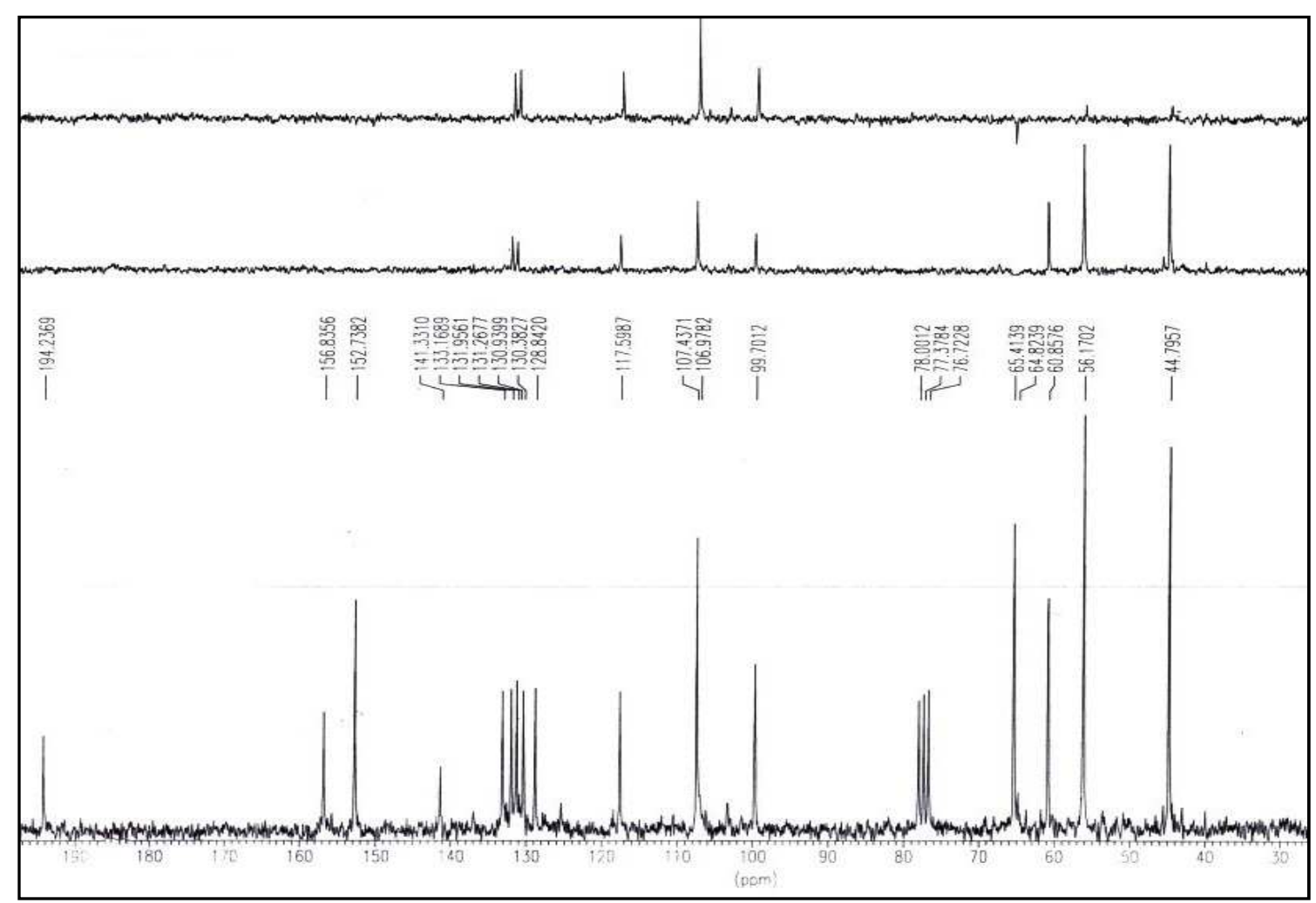

Figura IIIb: Espectro de RMN ${ }^{13} \mathrm{C}$ del compuesto 11. 


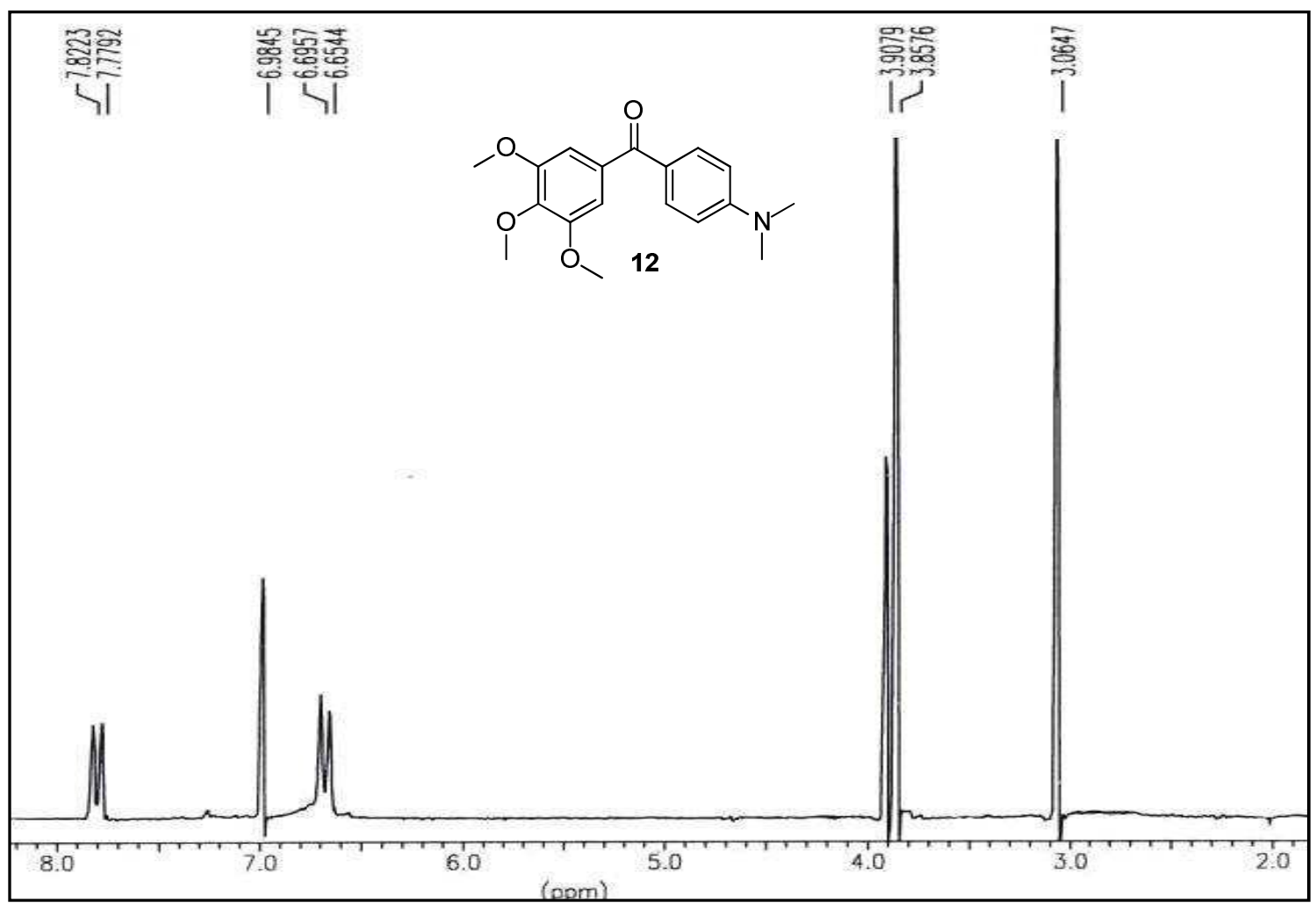

Figura IVa: Espectro de RMN ${ }^{1} \mathrm{H}$ del compuesto 12.

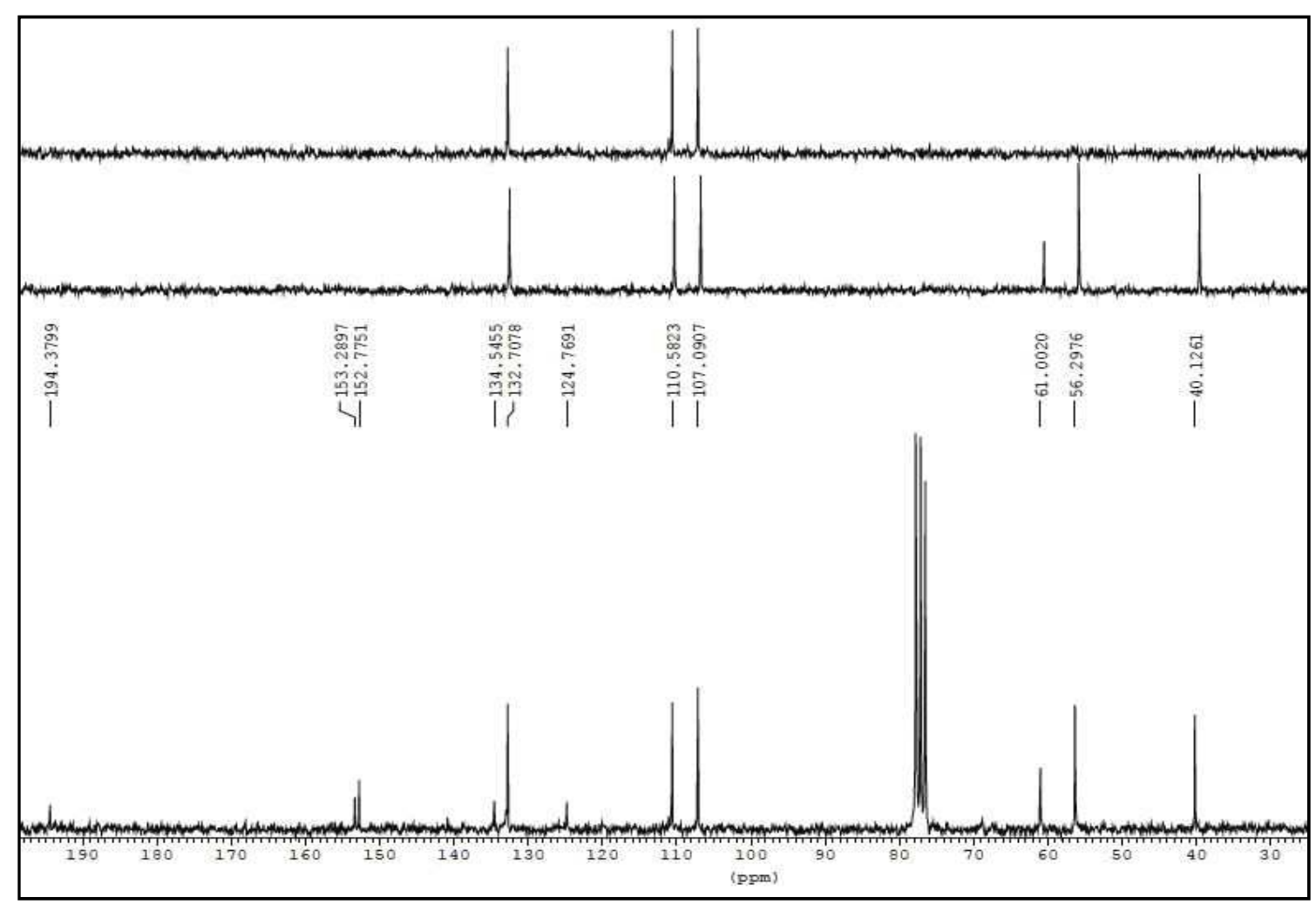

Figura IVb: Espectro de RMN ${ }^{13} \mathrm{C}$ del compuesto $\mathbf{1 2}$. 


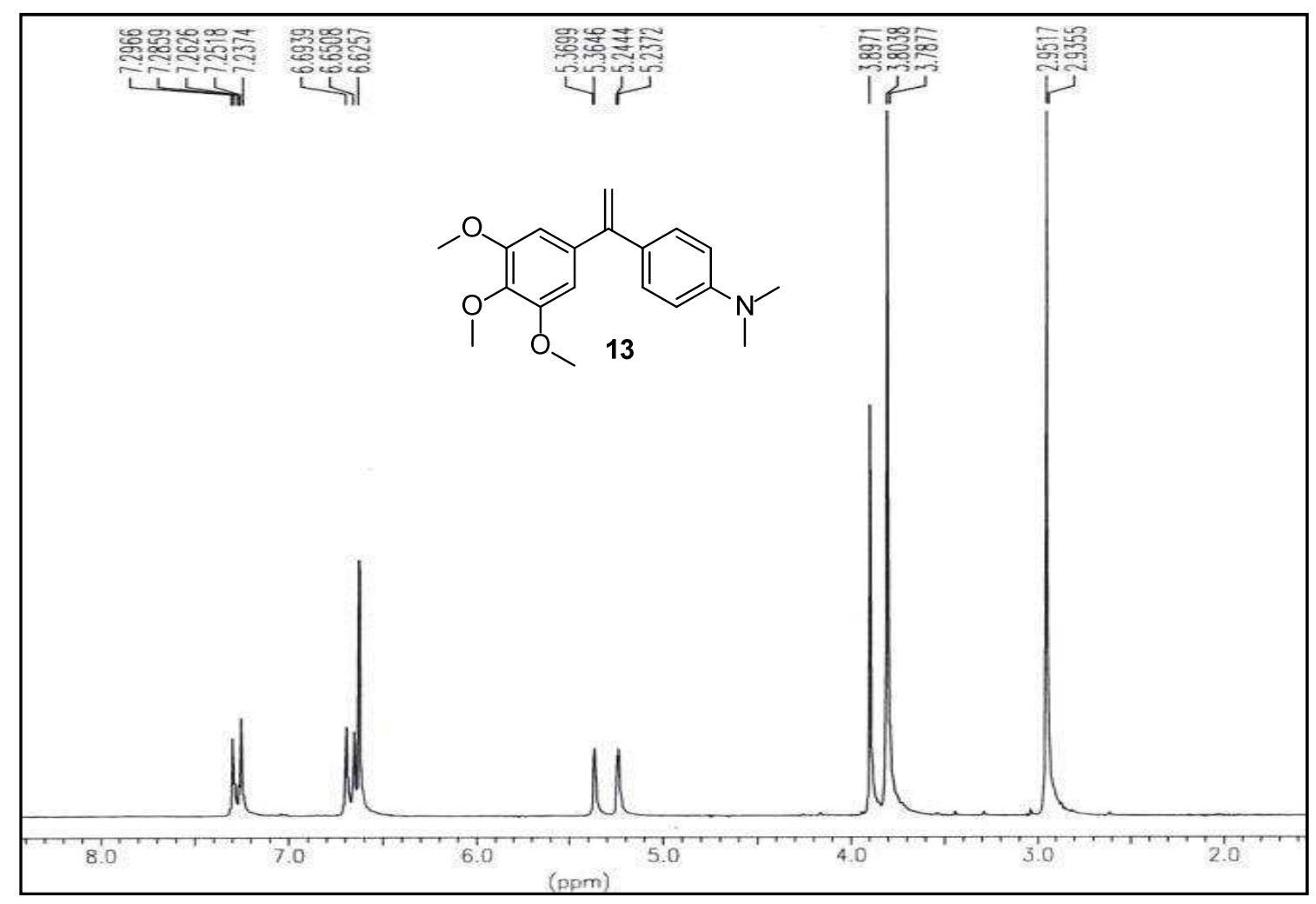

Figura Va: Espectro de RMN ${ }^{1} \mathrm{H}$ del compuesto 13.

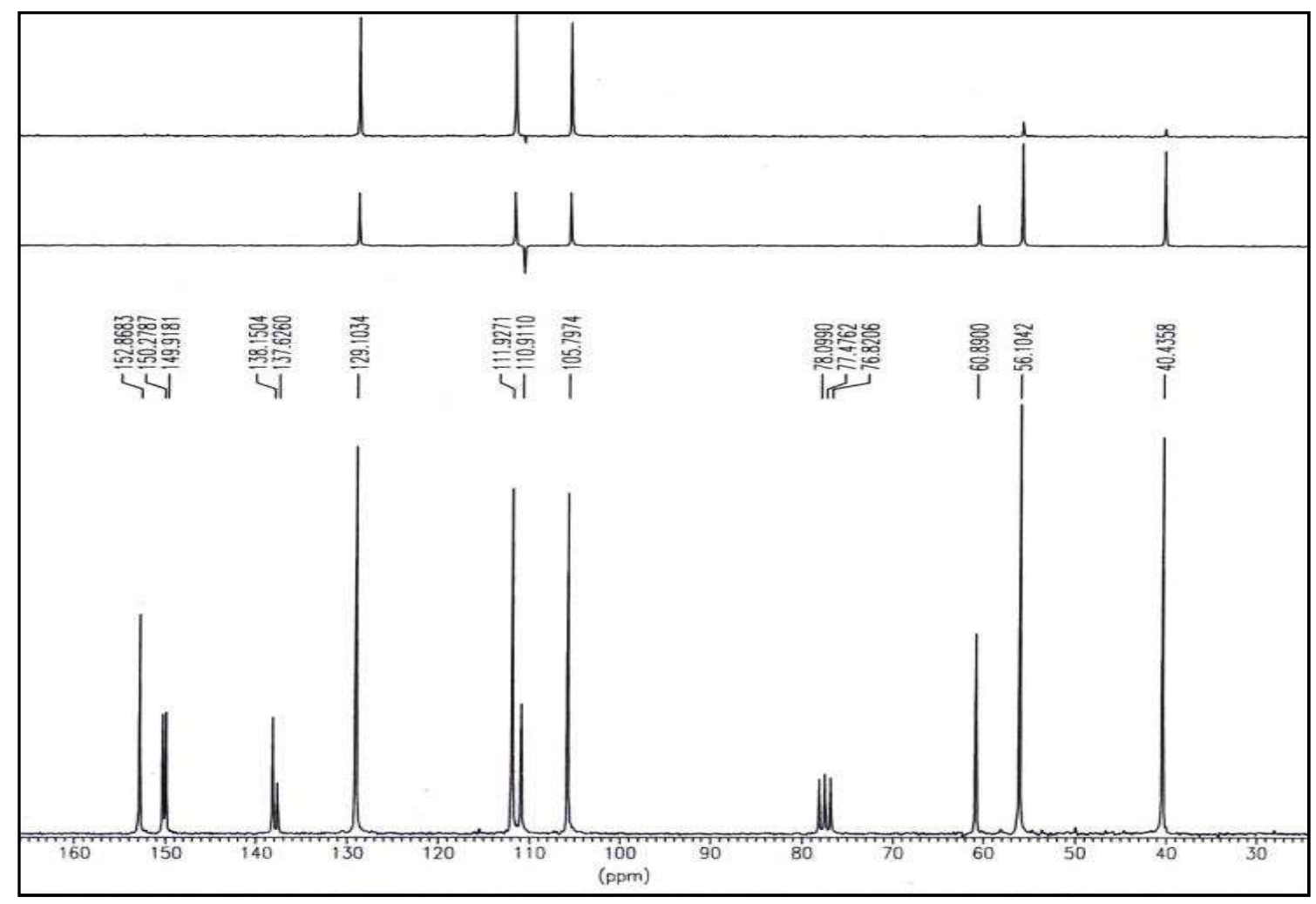

Figura Vb: Espectro de RMN ${ }^{13} \mathrm{C}$ del compuesto 13. 


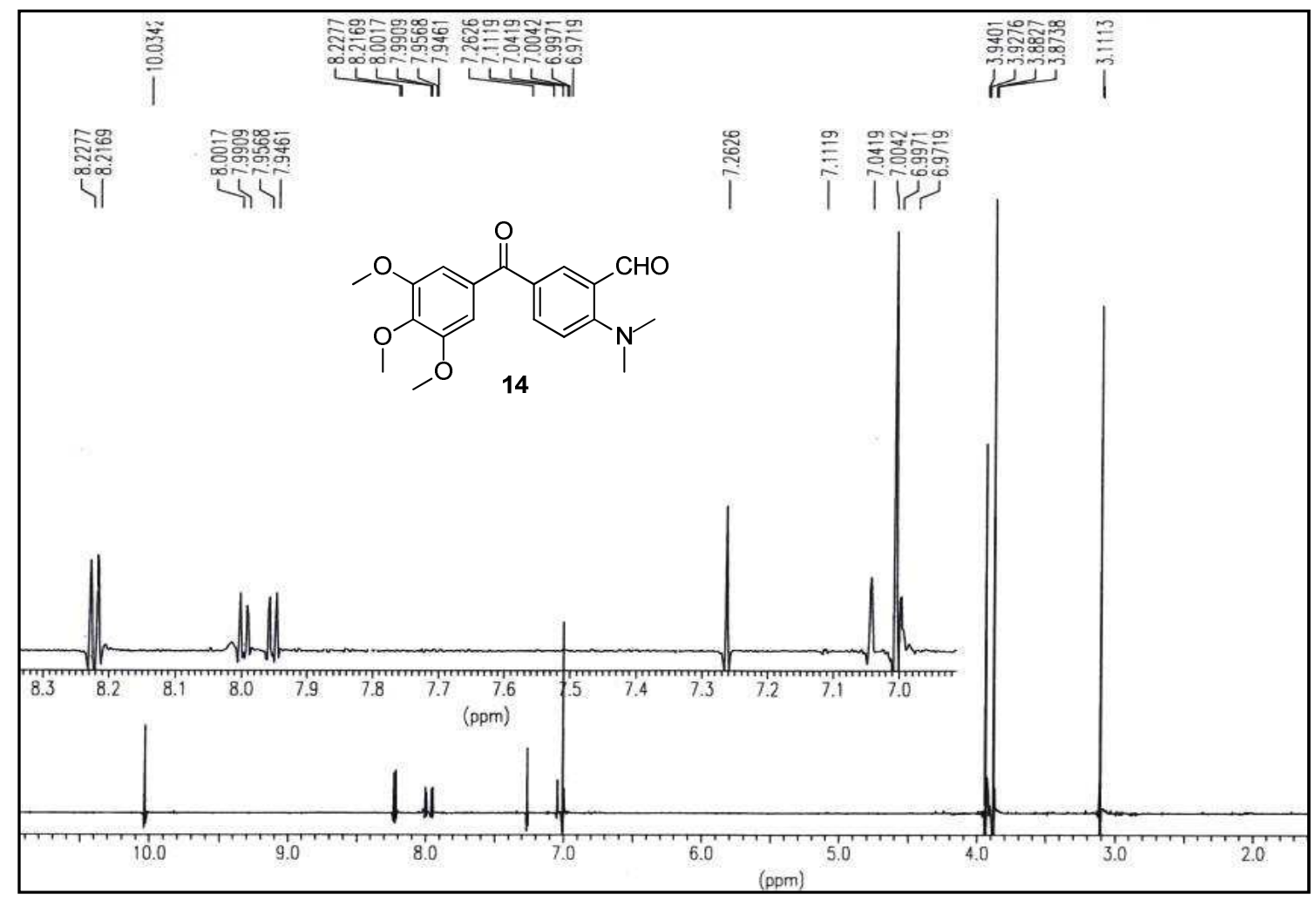

Figura VIa: Espectro de RMN ${ }^{1} \mathrm{H}$ del compuesto 14.

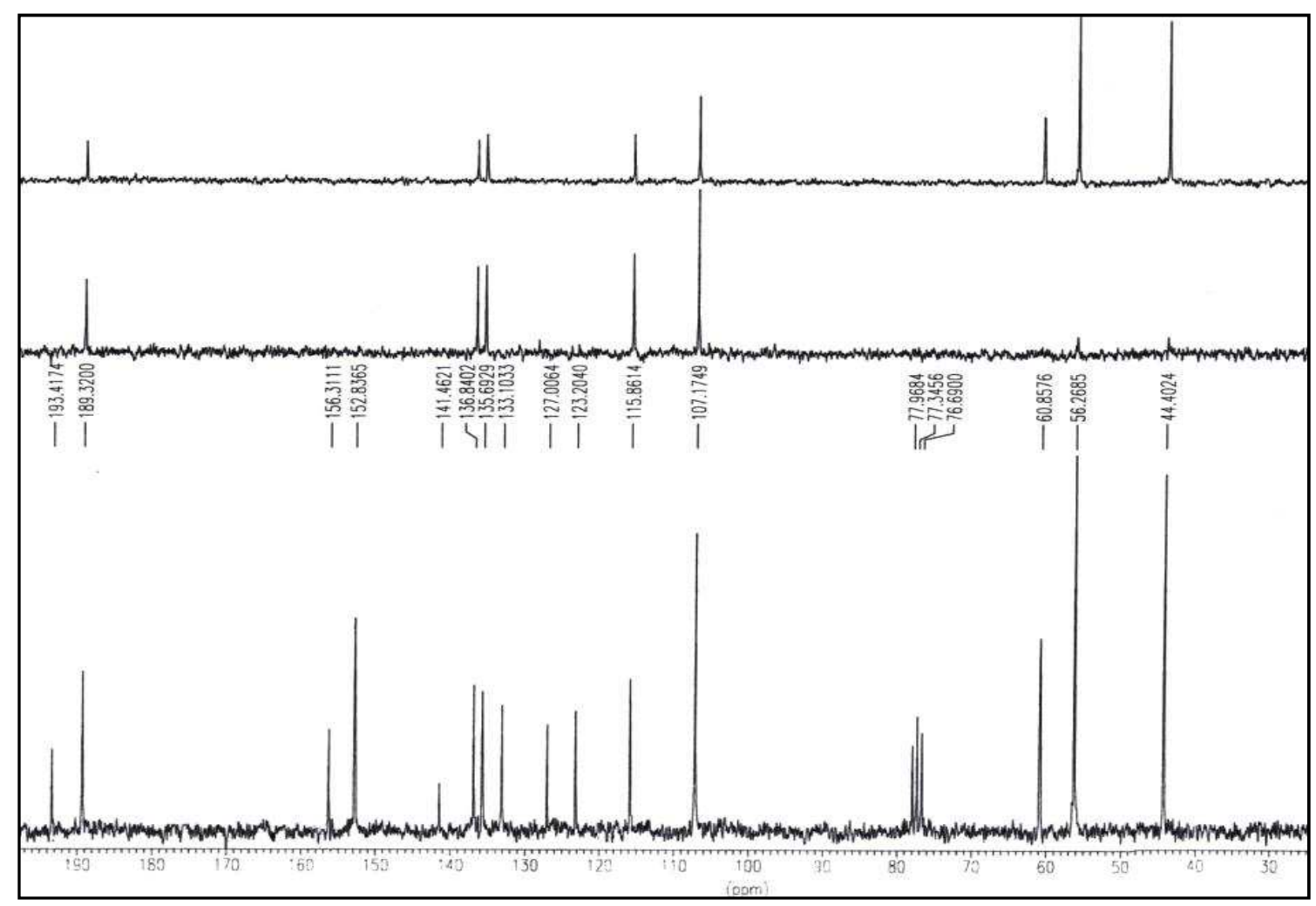

Figura VIb: Espectro de RMN ${ }^{13} \mathrm{C}$ del compuesto 14. 


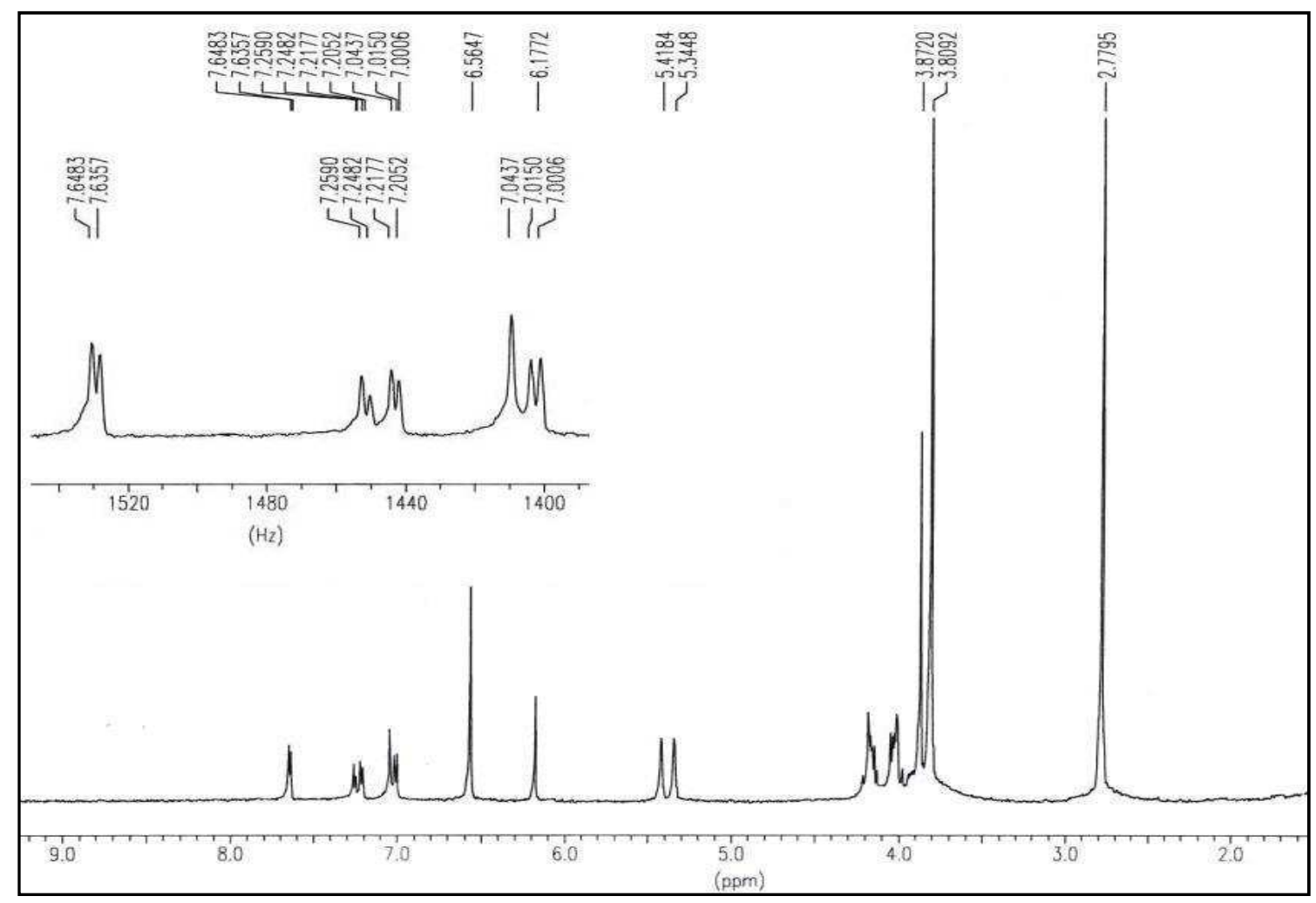

Figura VIIa: Espectro de RMN ${ }^{1} \mathrm{H}$ del compuesto 15.

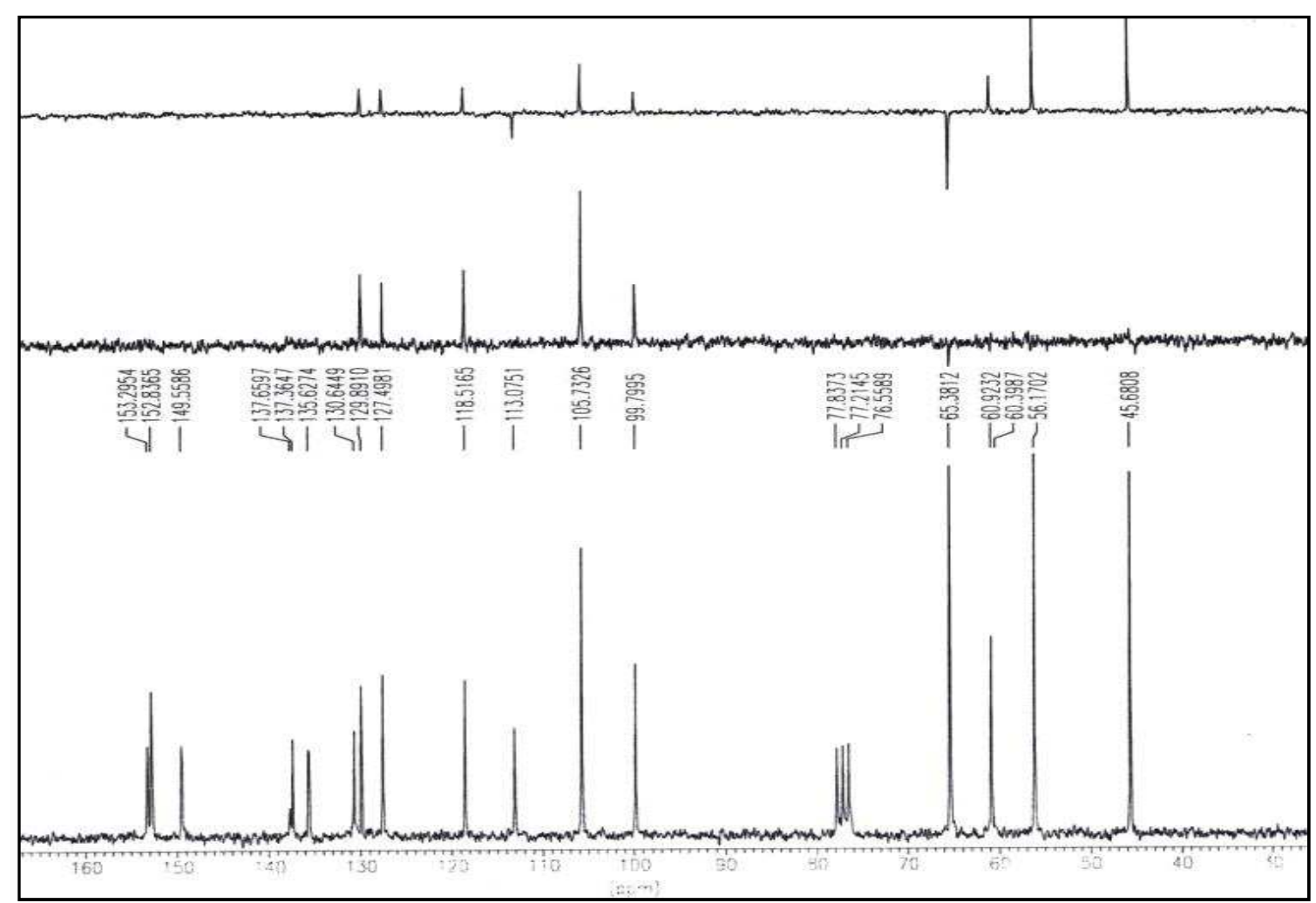

Figura VIIb: Espectro de RMN ${ }^{13} \mathrm{C}$ del compuesto 15. 


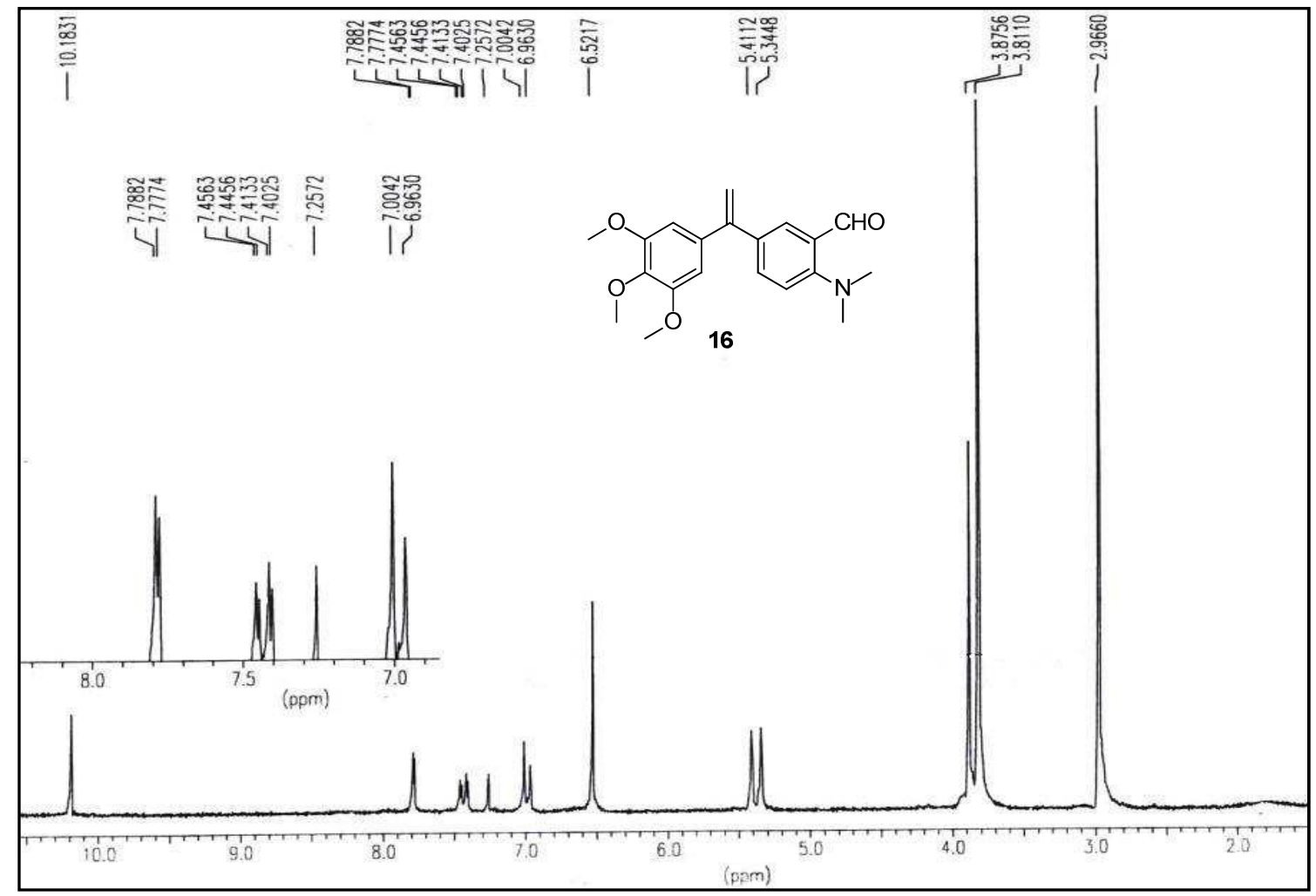

Figura VIIIa: Espectro de RMN ${ }^{1} \mathrm{H}$ del compuesto 16.

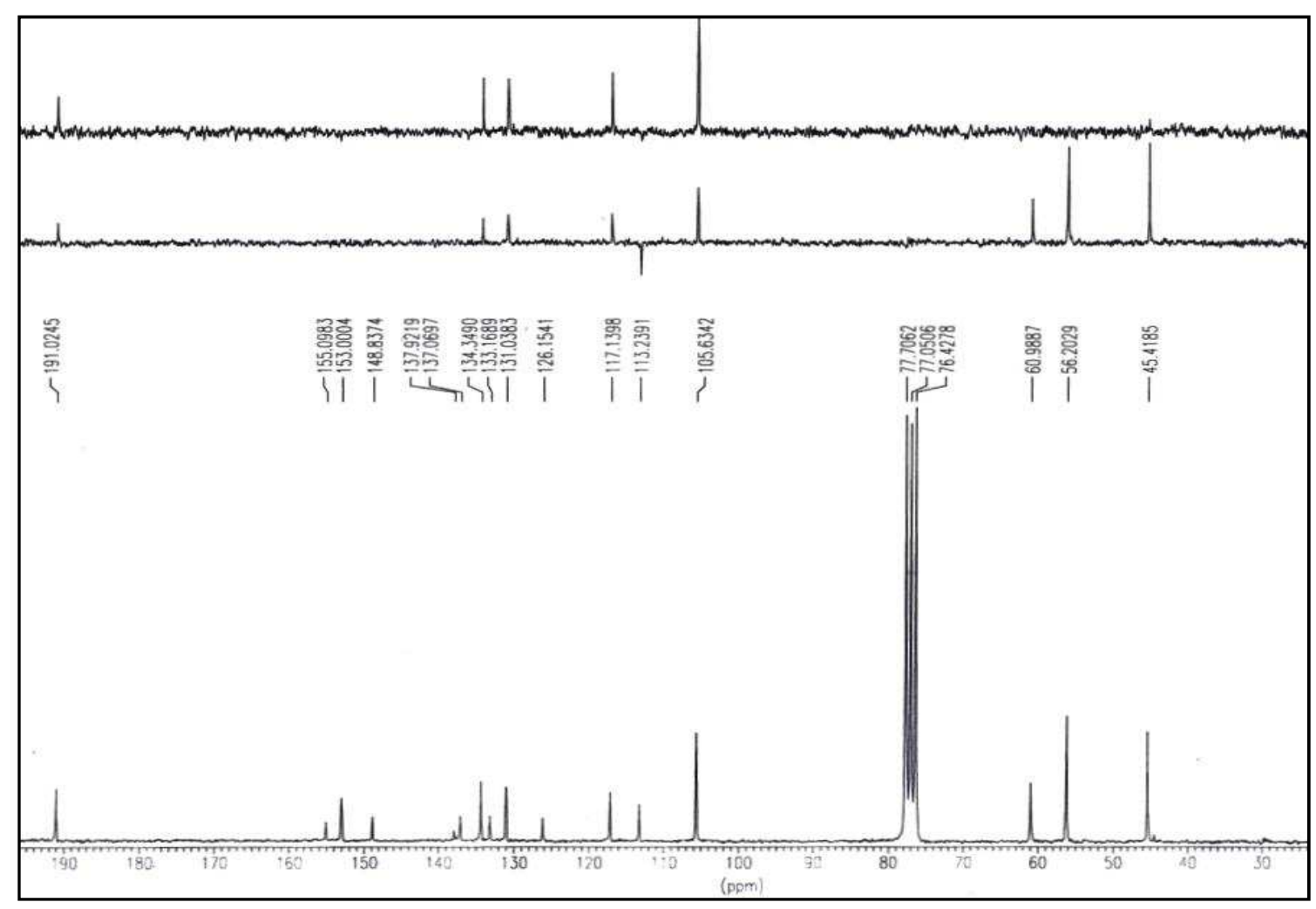

Figura VIIIb: Espectro de RMN ${ }^{13} \mathrm{C}$ del compuesto 16. 


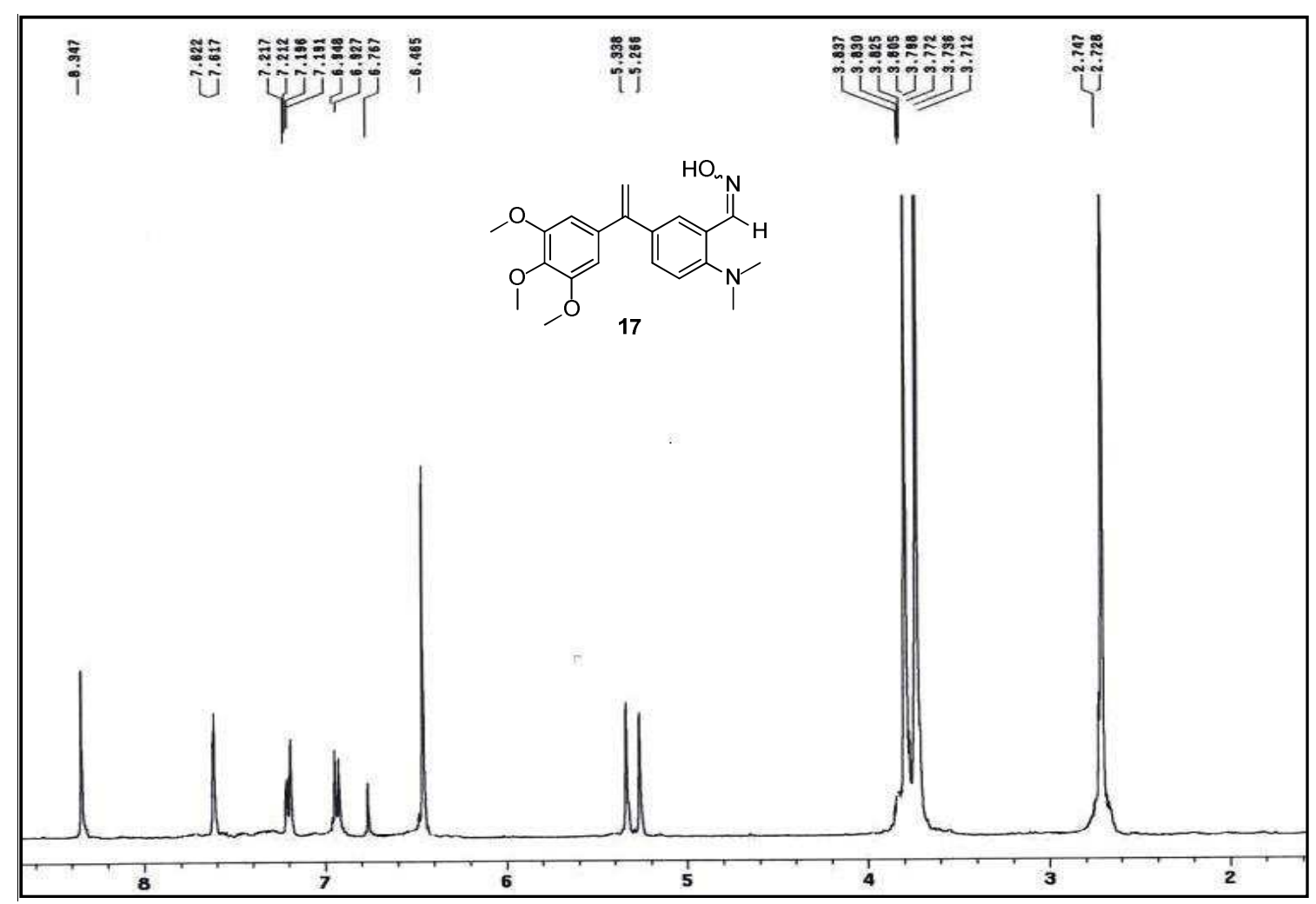

Figura IXa: Espectro de RMN ${ }^{1} \mathrm{H}$ del compuesto 17.

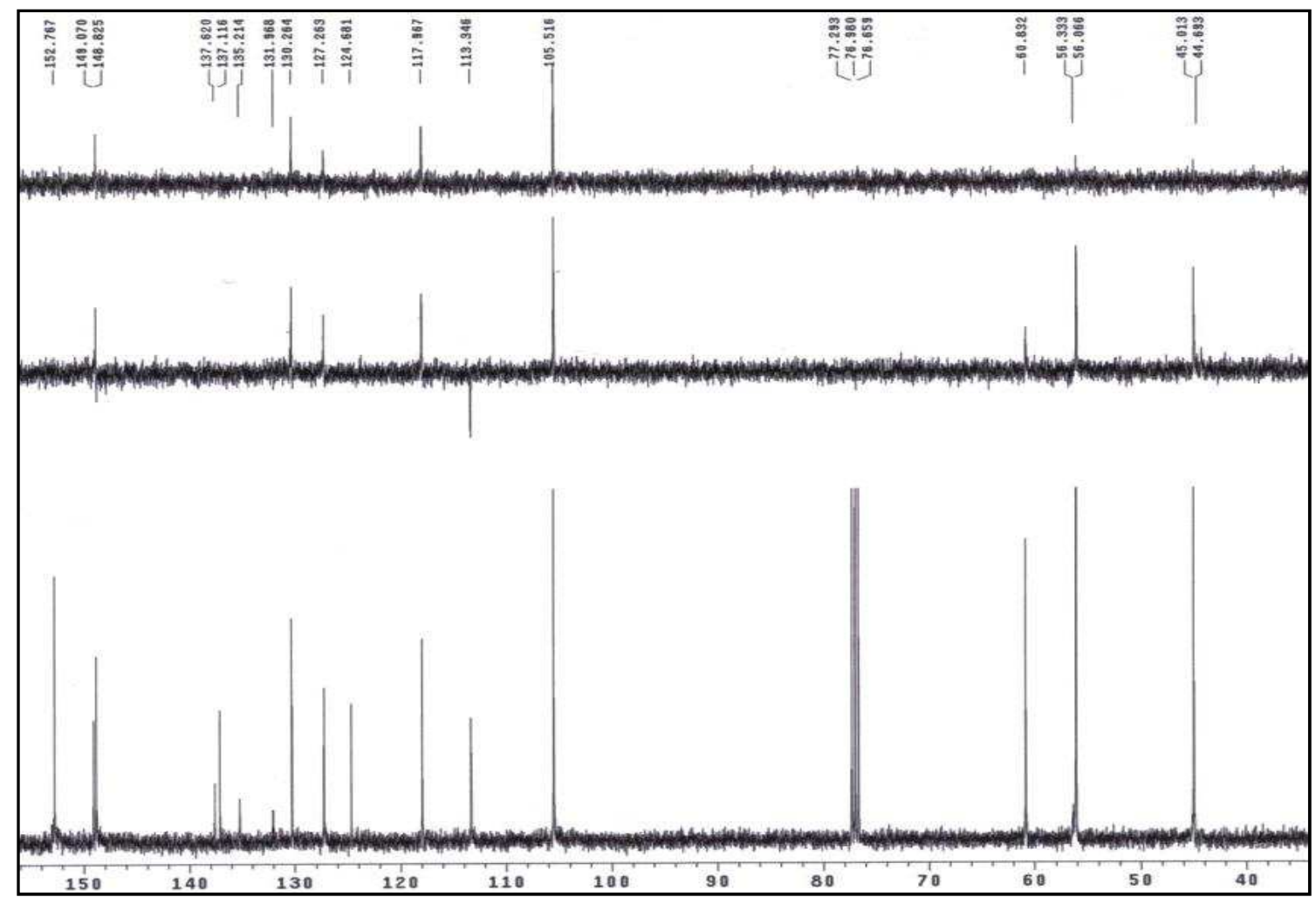

Figura IXb: Espectro de RMN ${ }^{13} \mathrm{C}$ del compuesto 17. 


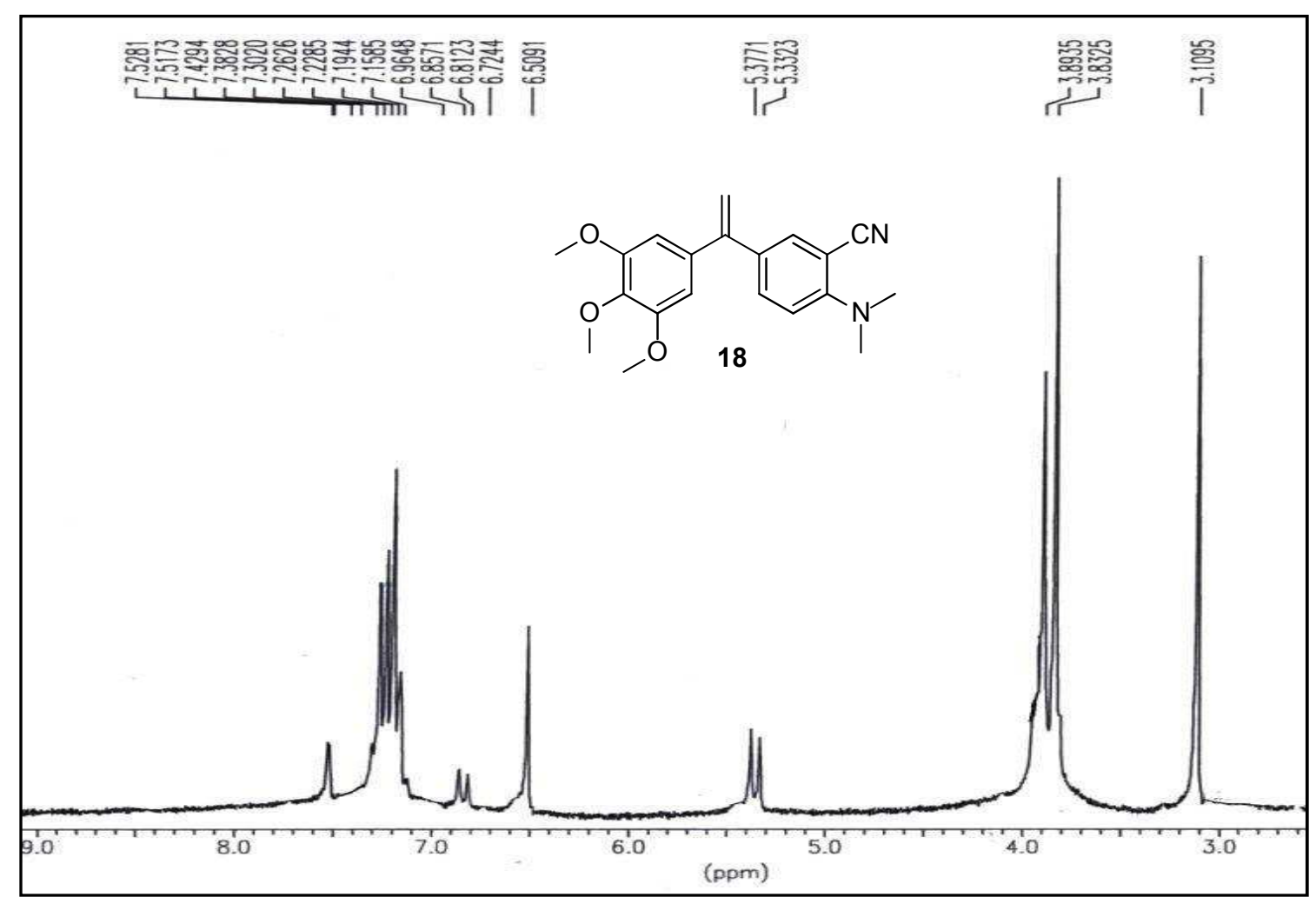

Figura Xa: Espectro de RMN ${ }^{1} \mathrm{H}$ del compuesto 18.

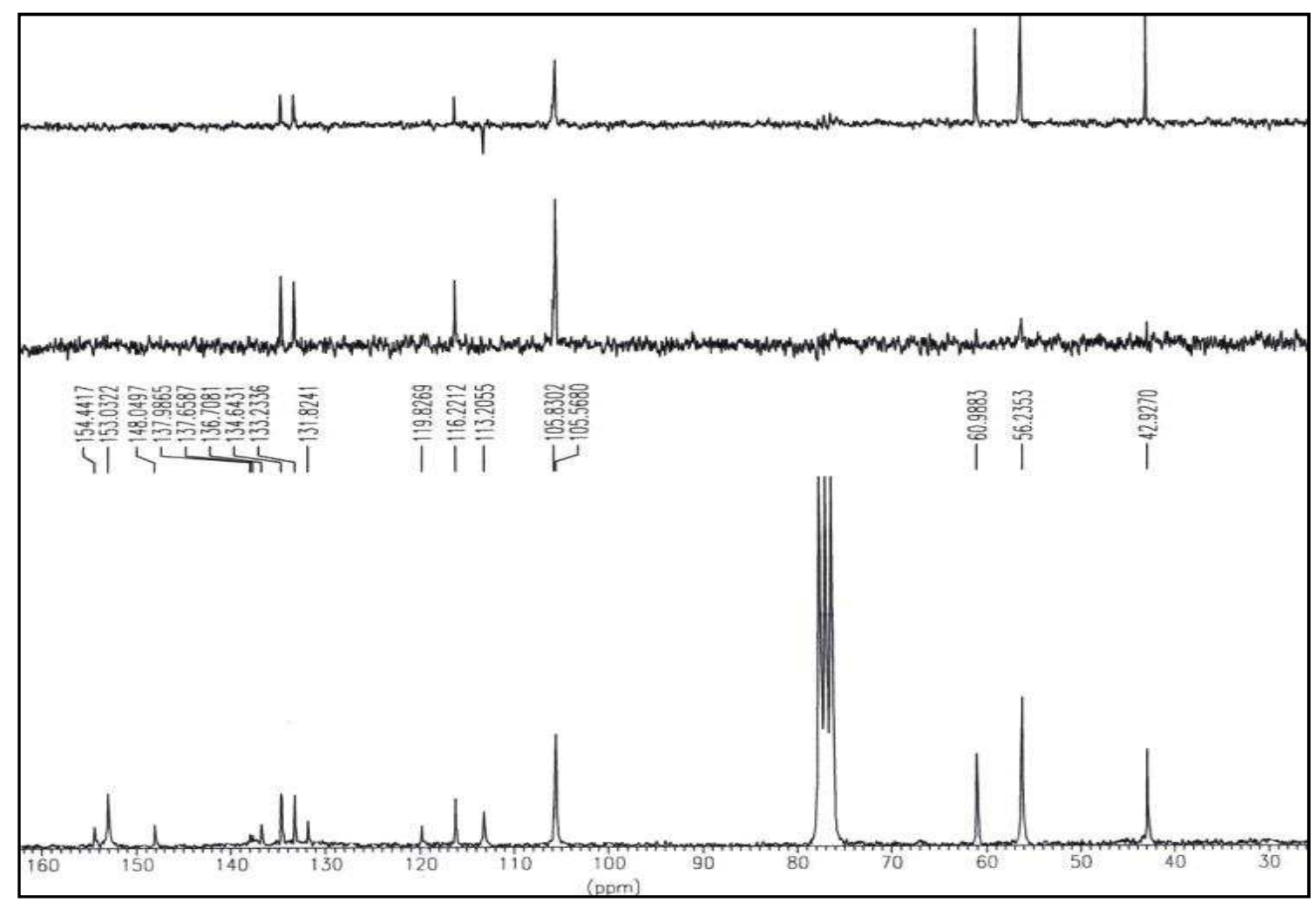

Figura Xb: Espectro de RMN ${ }^{13} \mathrm{C}$ del compuesto 18. 


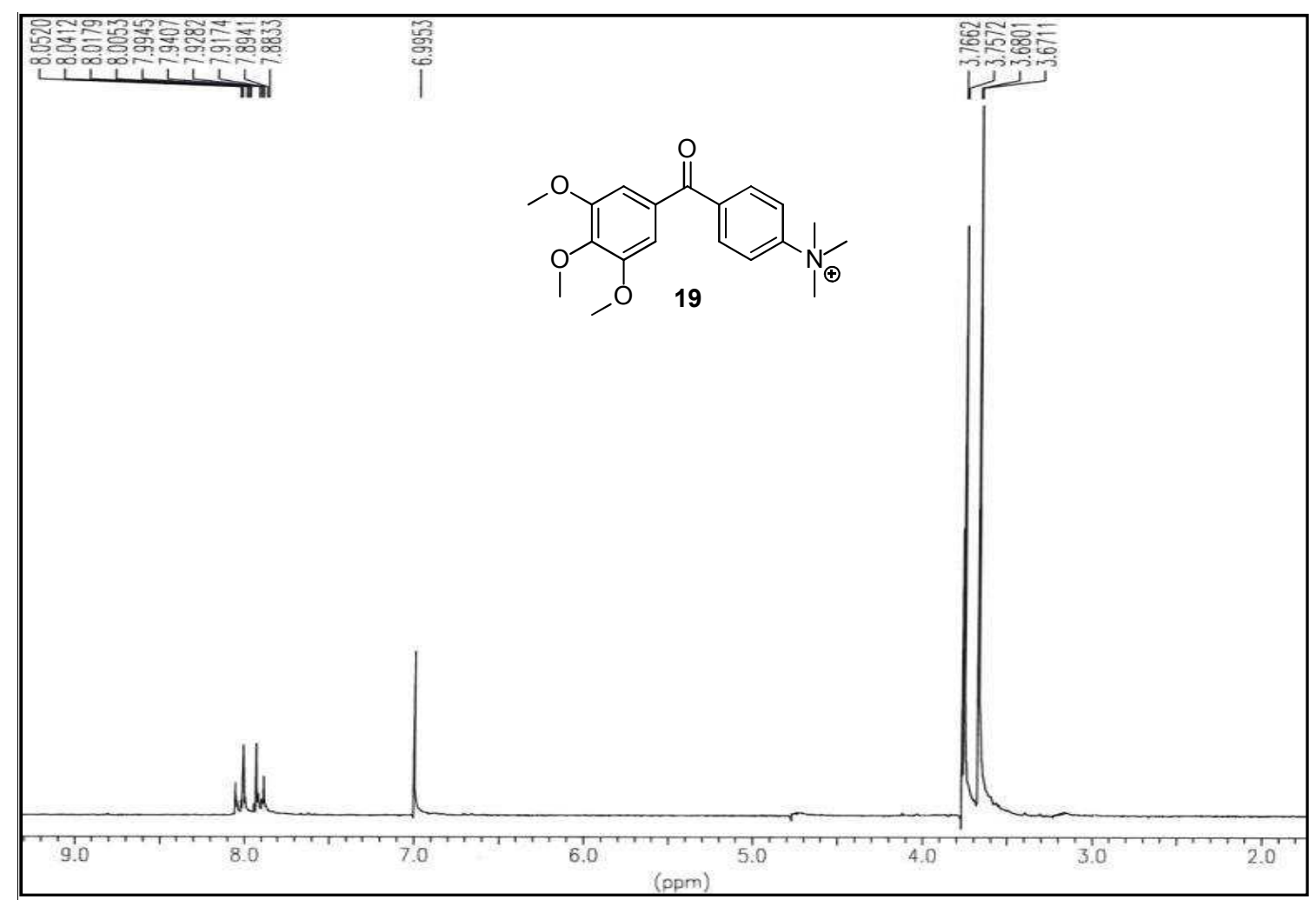

Figura XIa: Espectro de RMN ${ }^{1} \mathrm{H}$ del compuesto 19.

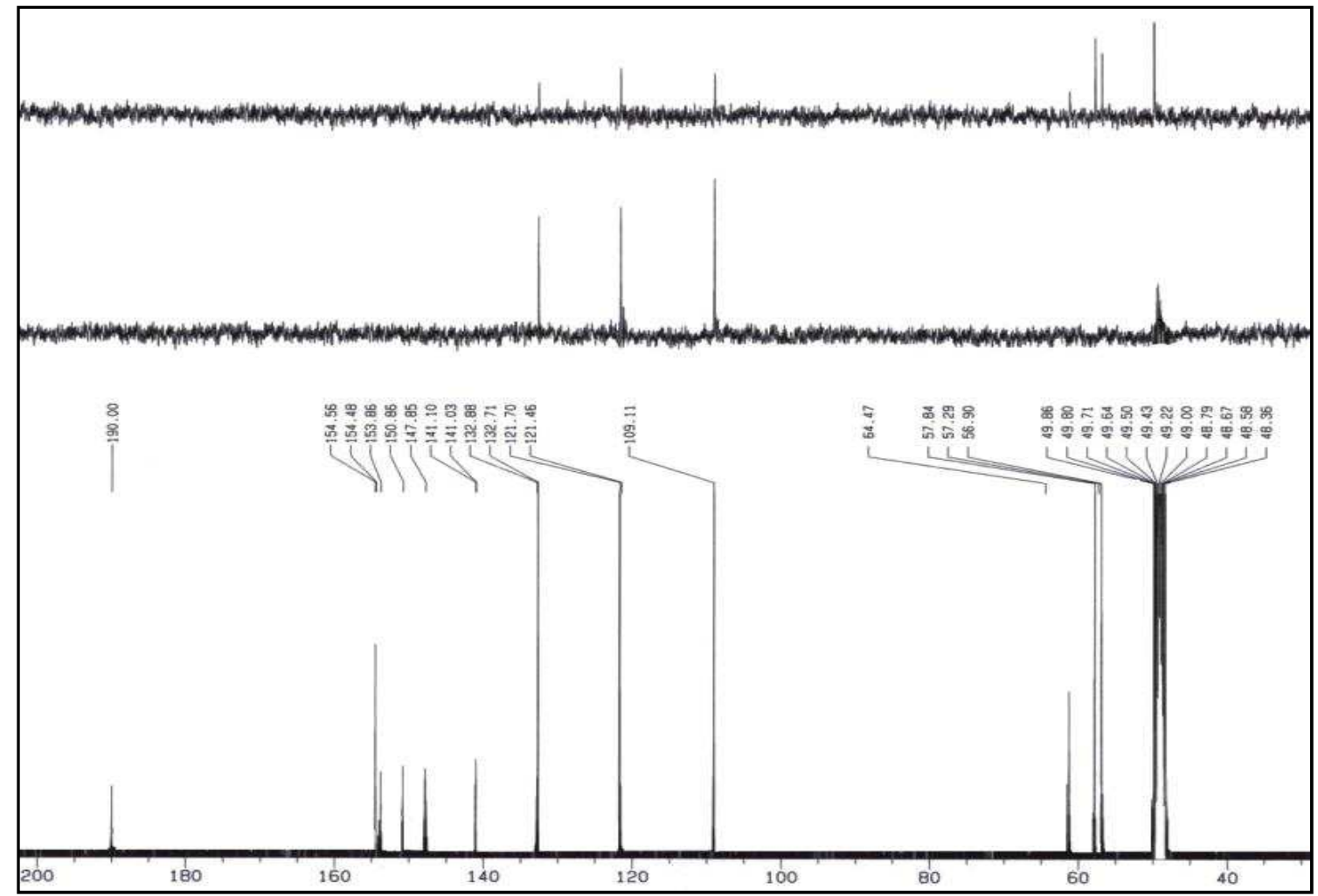

Figura XIb: Espectro de RMN ${ }^{13} \mathrm{C}$ del compuesto 19. 


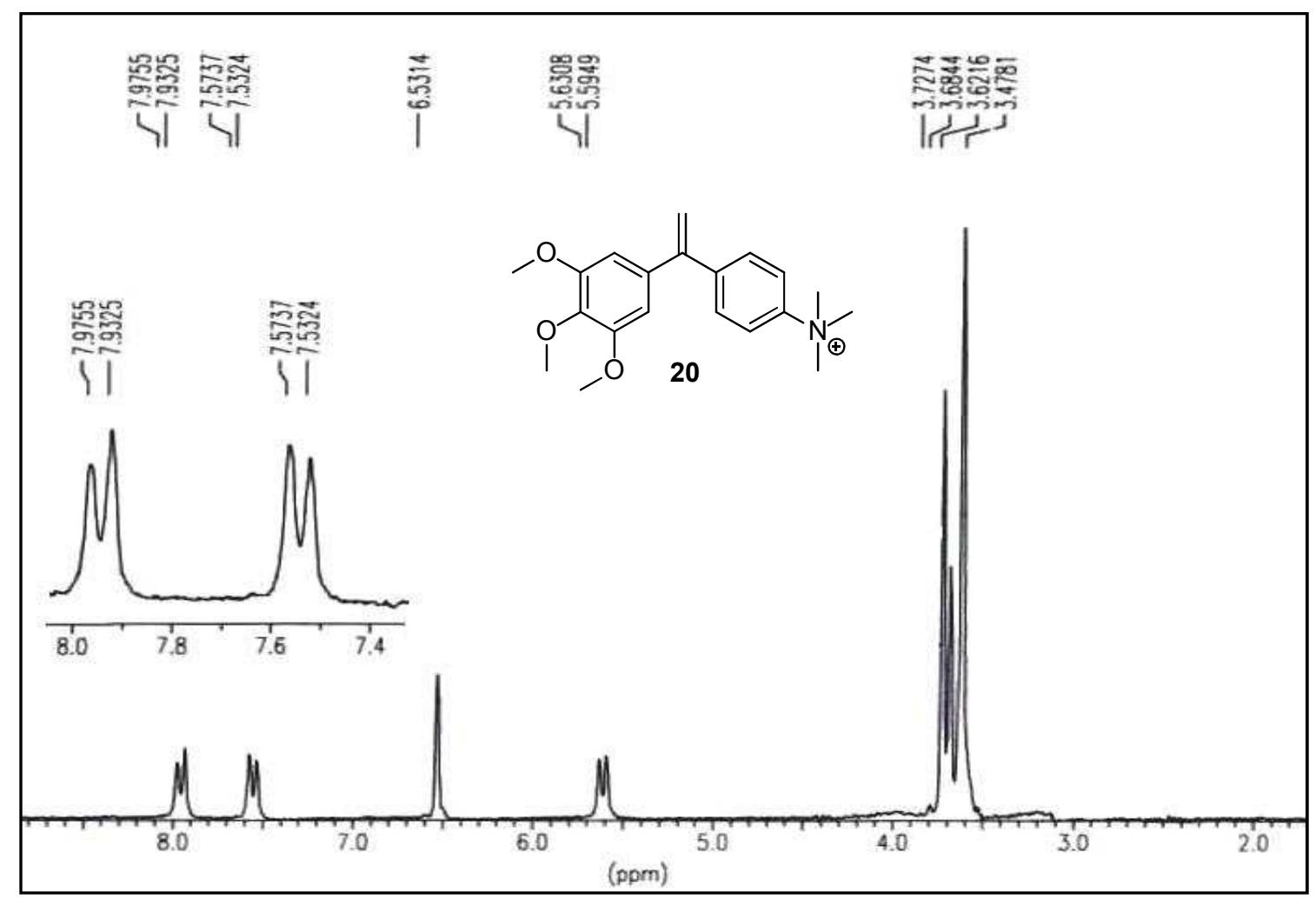

Figura XIIa: Espectro de RMN ${ }^{1} \mathrm{H}$ del compuesto 20.

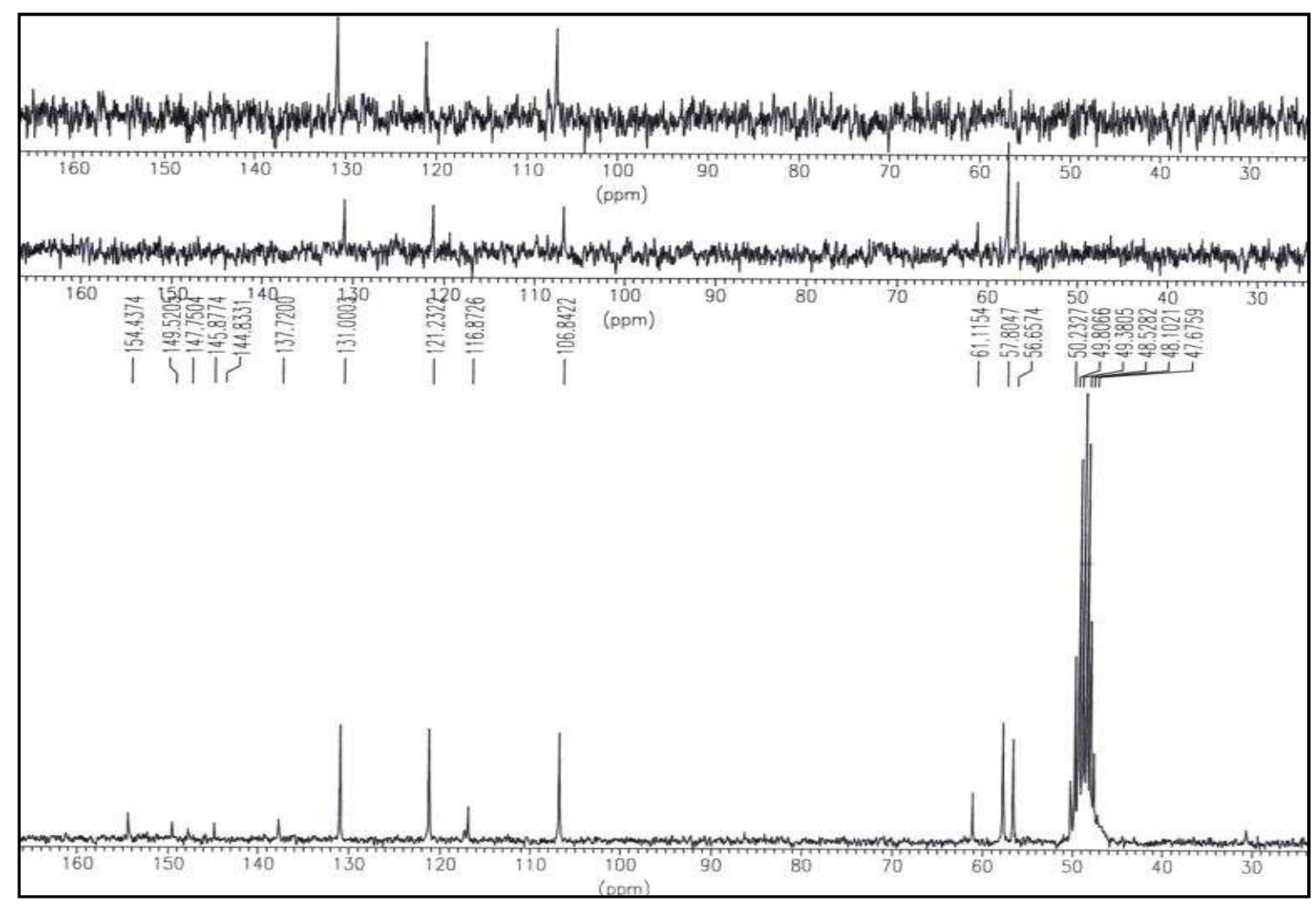

Figura XIIb: Espectro de RMN ${ }^{13} \mathrm{C}$ del compuesto 20. 


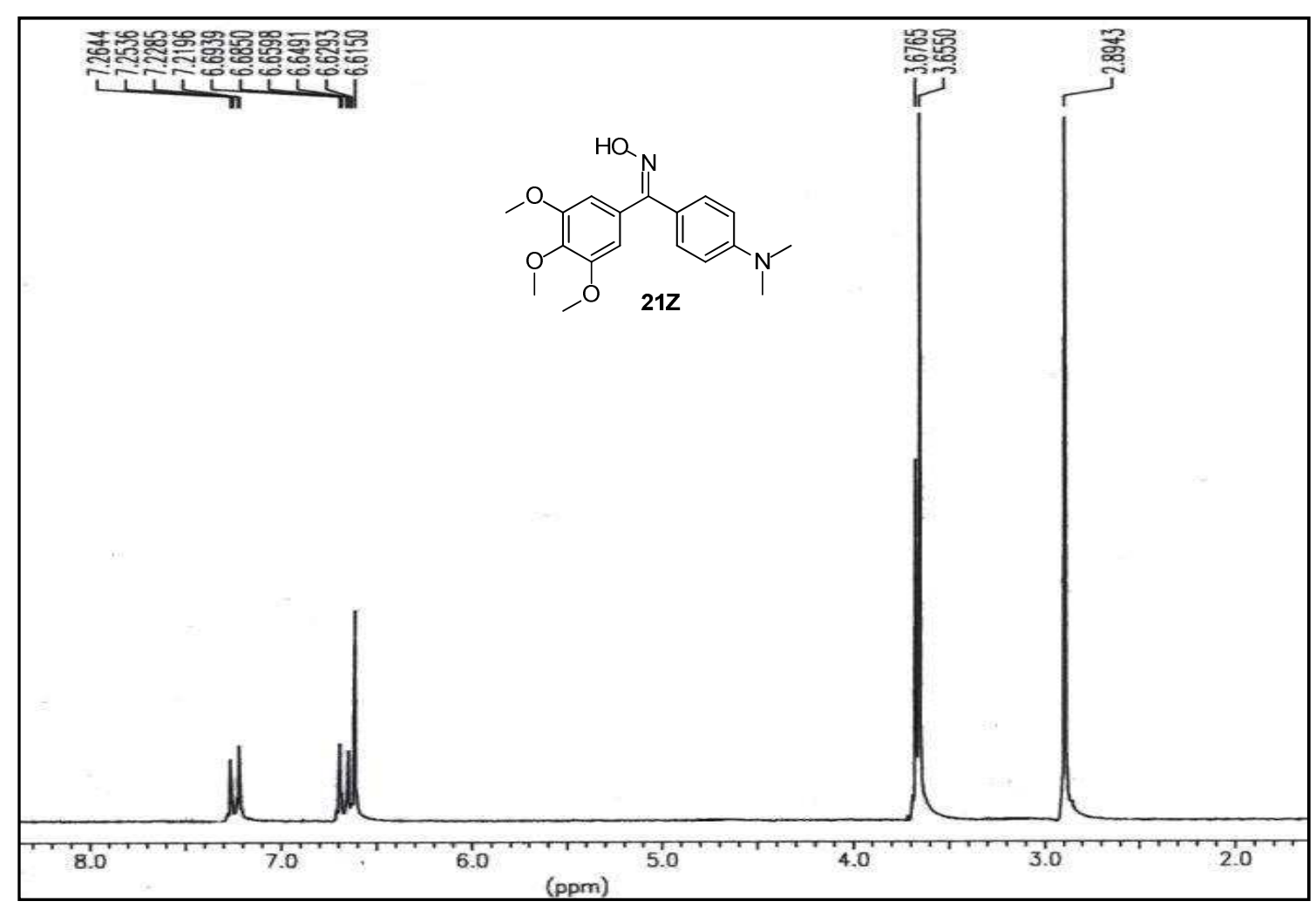

Figura XIIIa: Espectro de RMN ${ }^{1} \mathrm{H}$ del compuesto $\mathbf{2 1 Z}$.

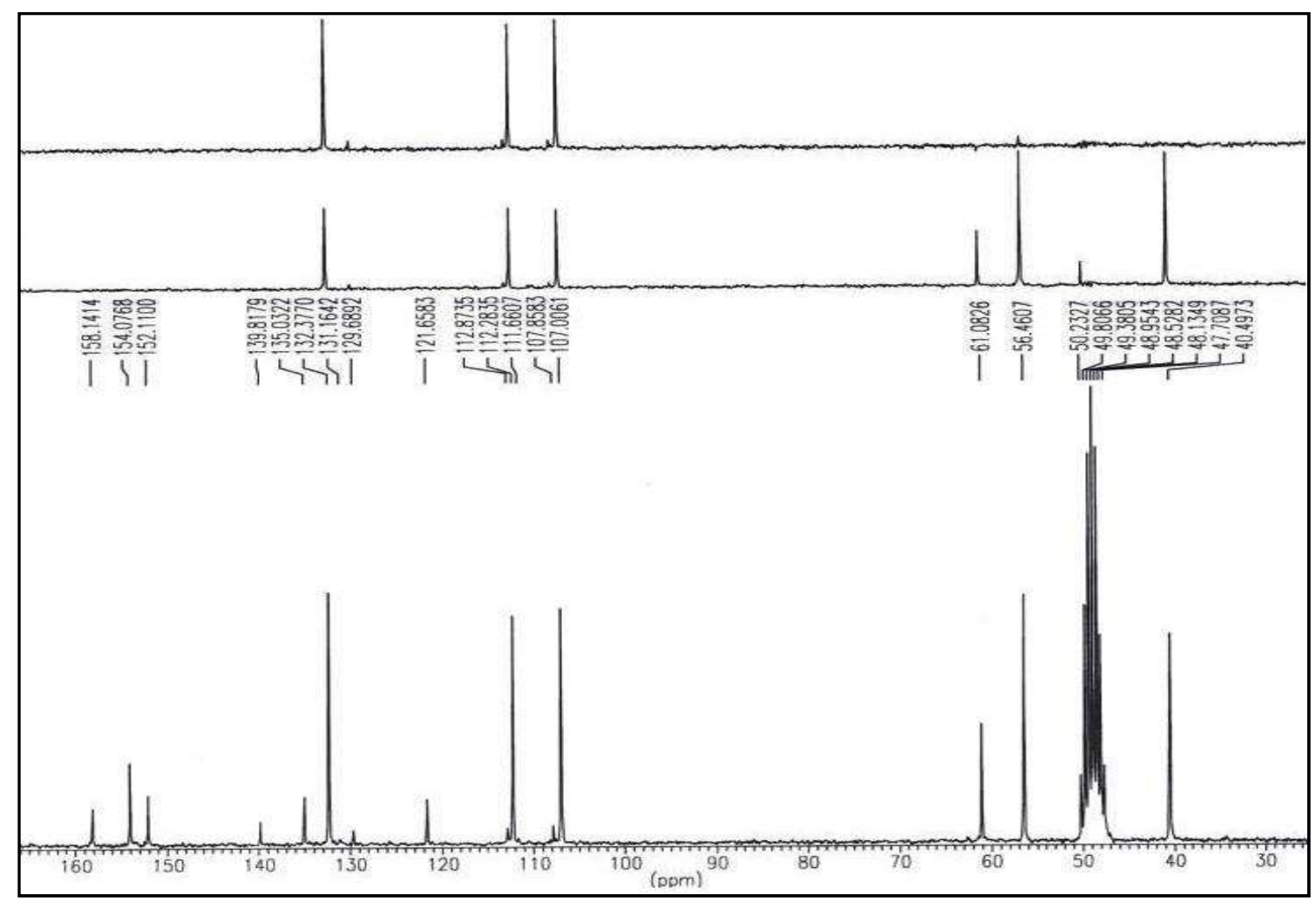

Figura XIIIb: Espectro de RMN ${ }^{13} \mathrm{C}$ del compuesto $\mathbf{2 1 Z}$. 


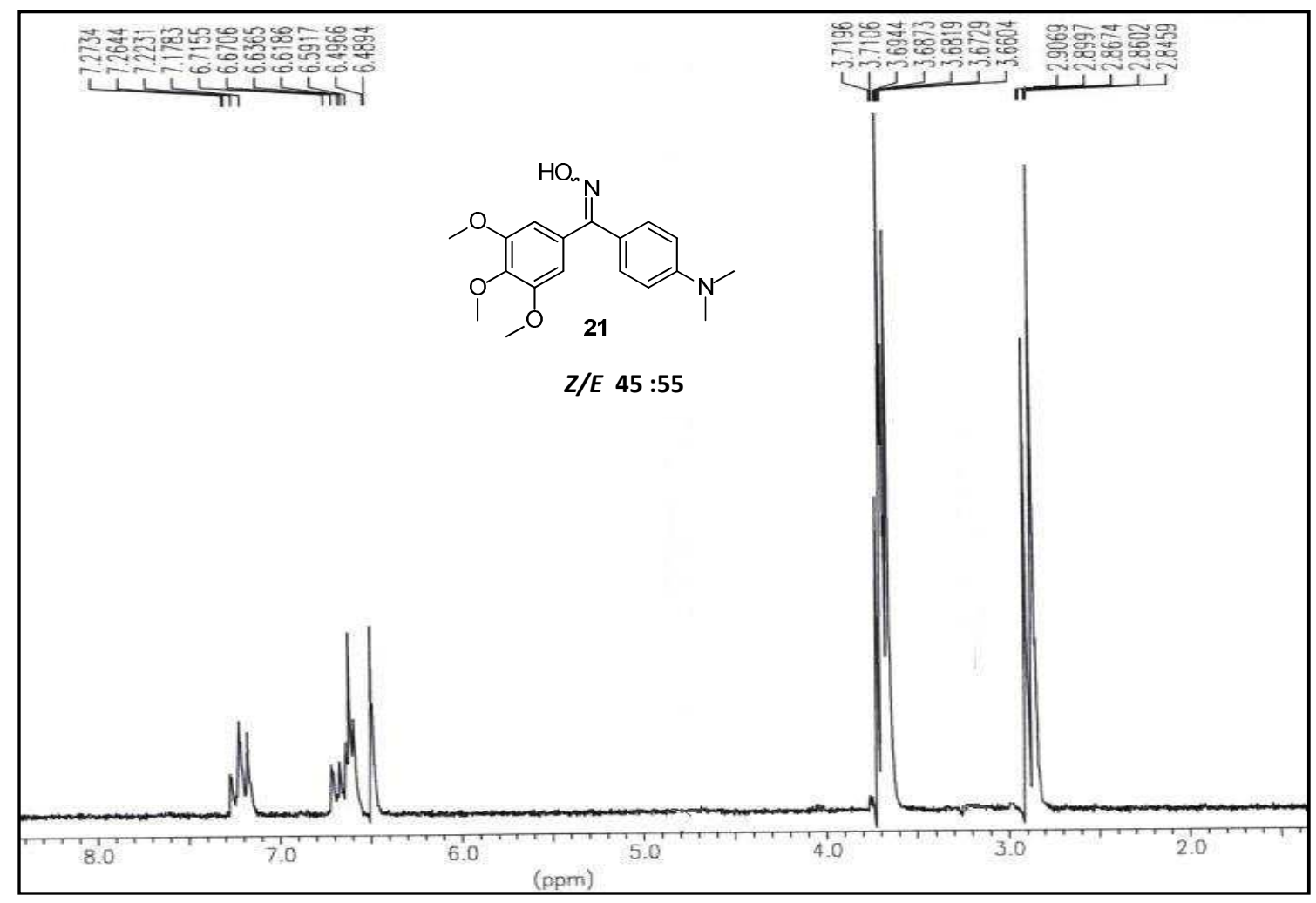

Figura XIIIc: Espectro de RMN ${ }^{1} \mathrm{H}$ del compuesto 21(Z/E). 


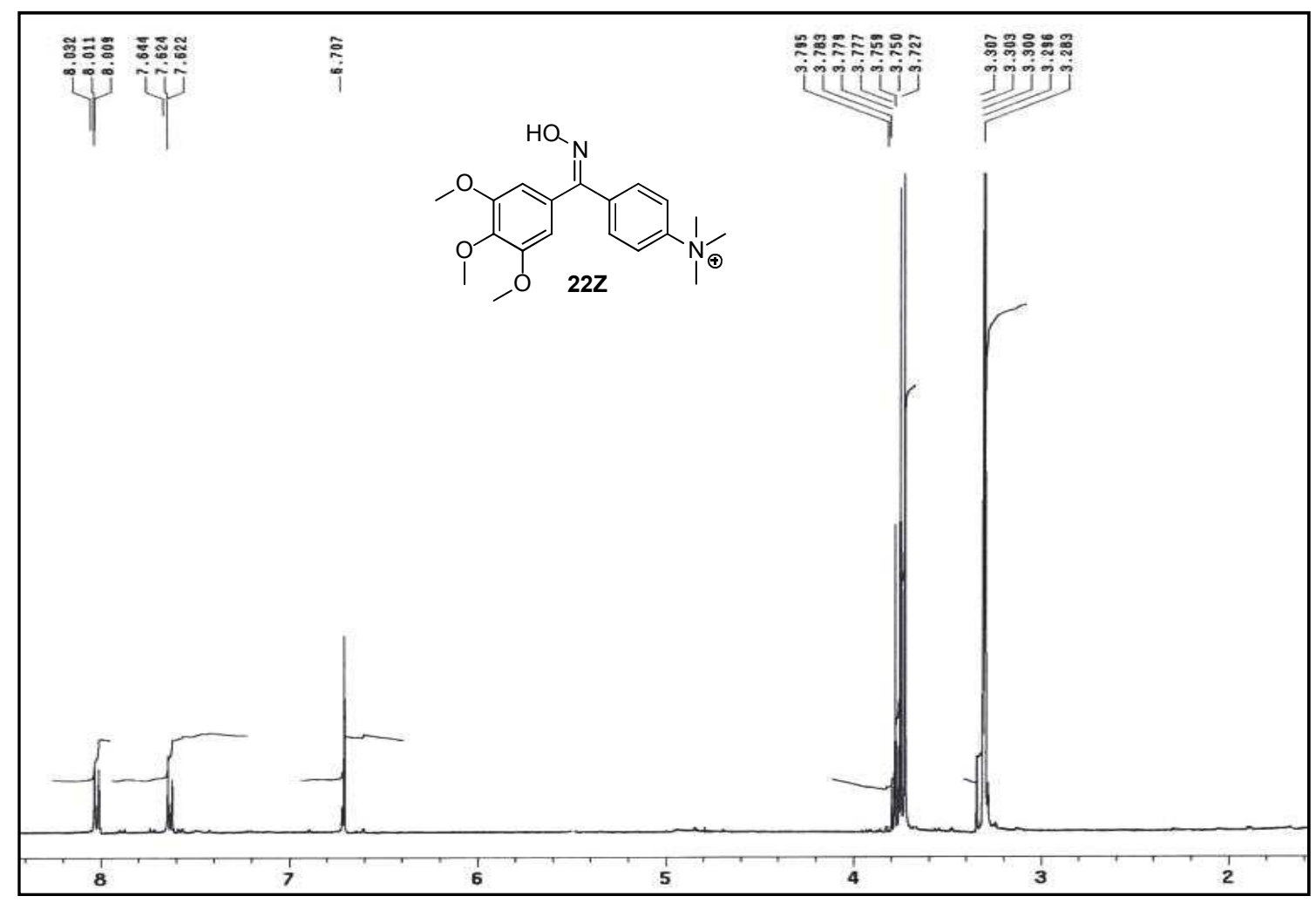

Figura XIVa: Espectro de RMN ${ }^{1} \mathrm{H}$ del compuesto $\mathbf{2 2 Z}$.

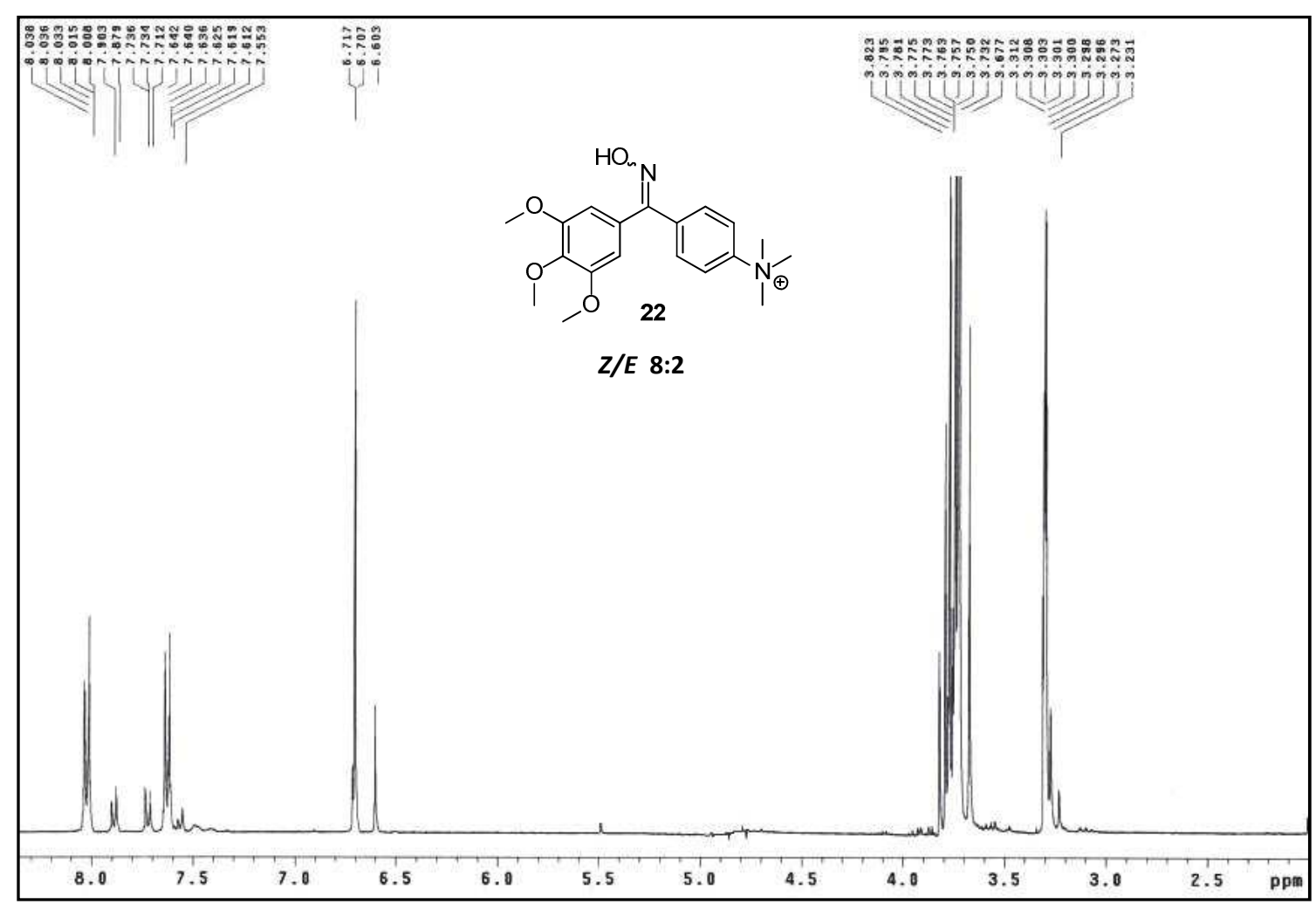

Figura XIVb: Espectro de RMN ${ }^{1} \mathrm{H}$ del compuesto (22Z/E). 


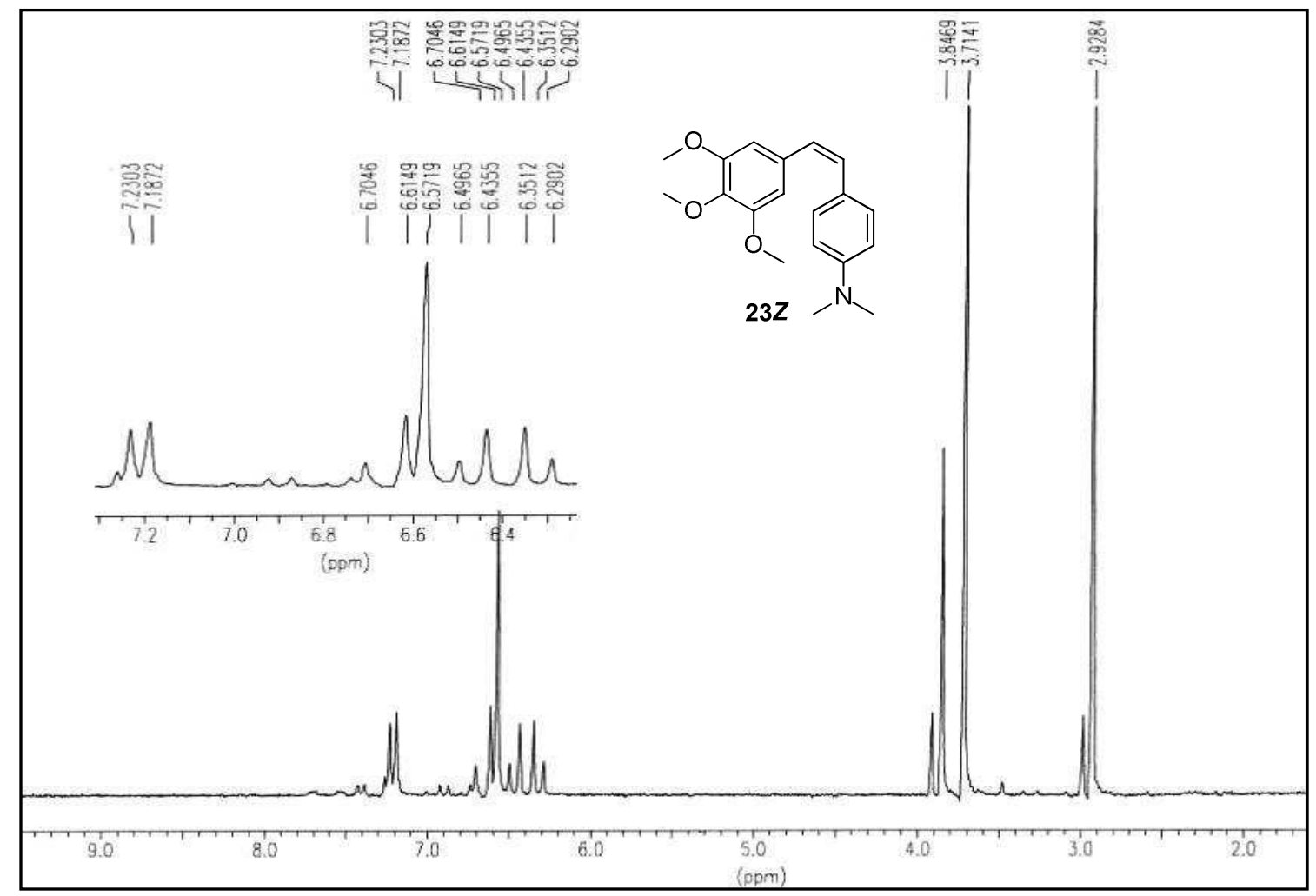

Figura XVa: Espectro de RMN ${ }^{1} \mathrm{H}$ del compuesto $\mathbf{2 3 Z}$.

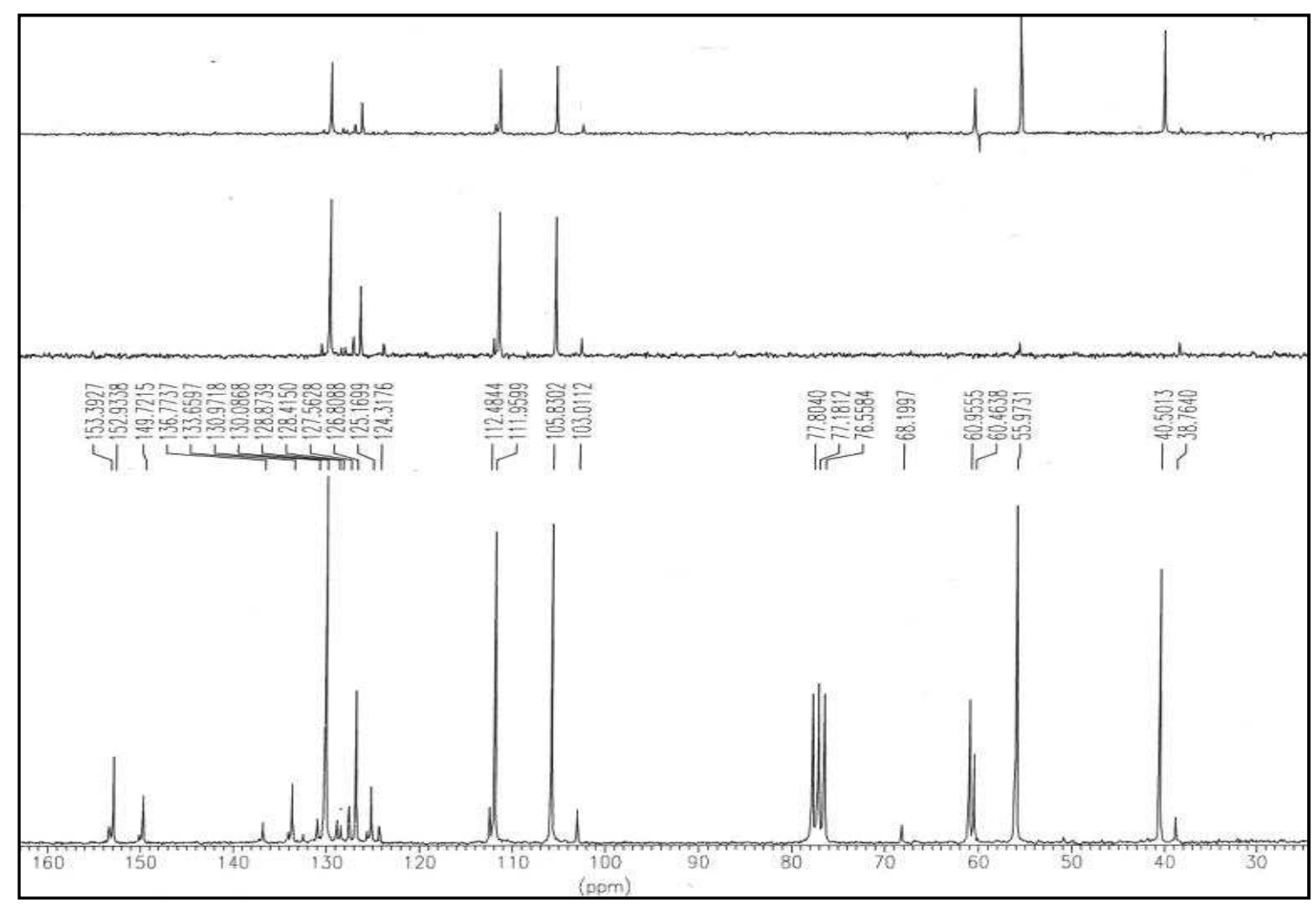

Figura XVb: Espectro de RMN ${ }^{13} \mathrm{C}$ del compuesto $\mathbf{2 3 Z}$. 


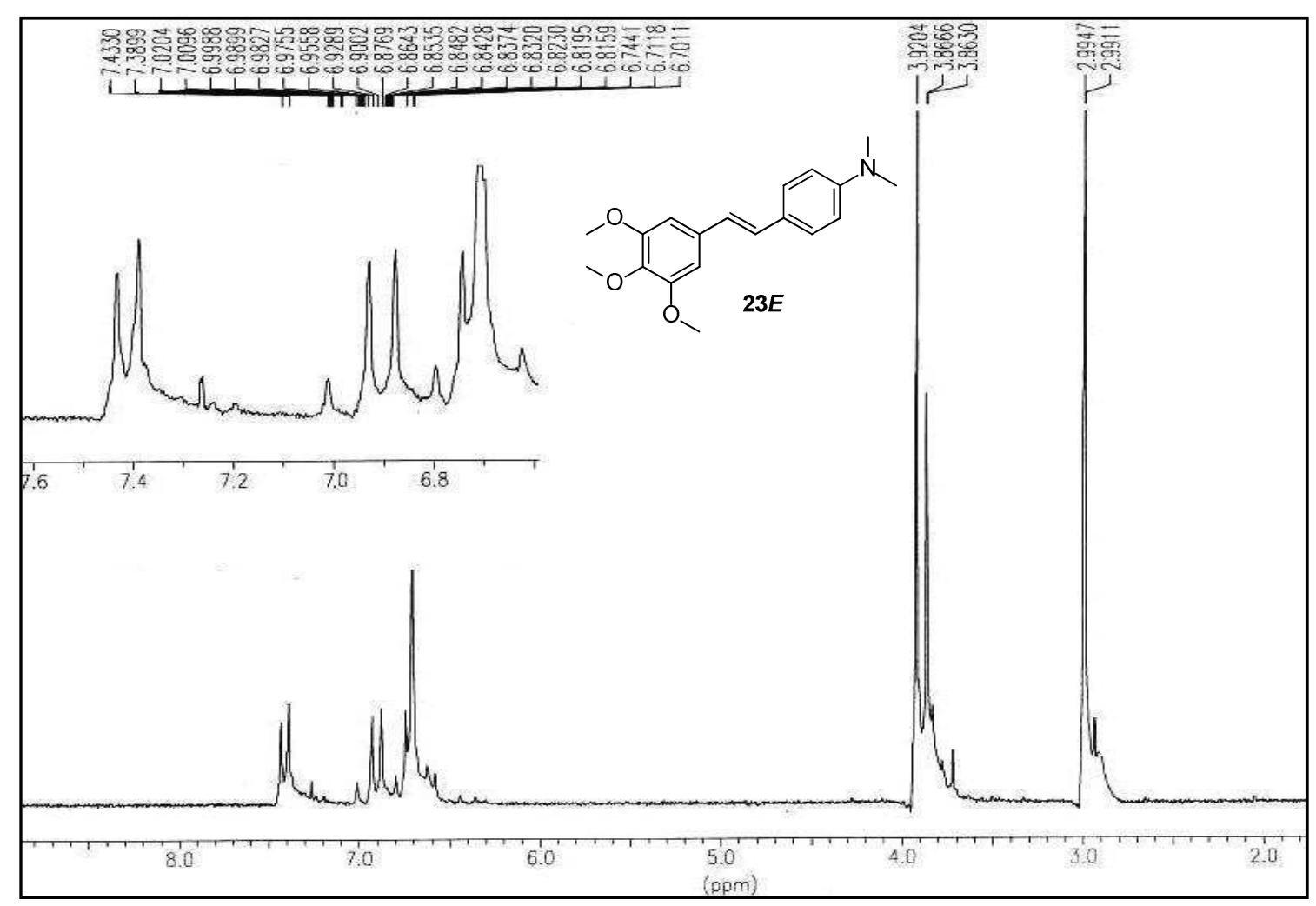

Figura XVIa: Espectro de $\mathrm{RMN}{ }^{1} \mathrm{H}$ del compuesto $\mathbf{2 3} \boldsymbol{E}$.

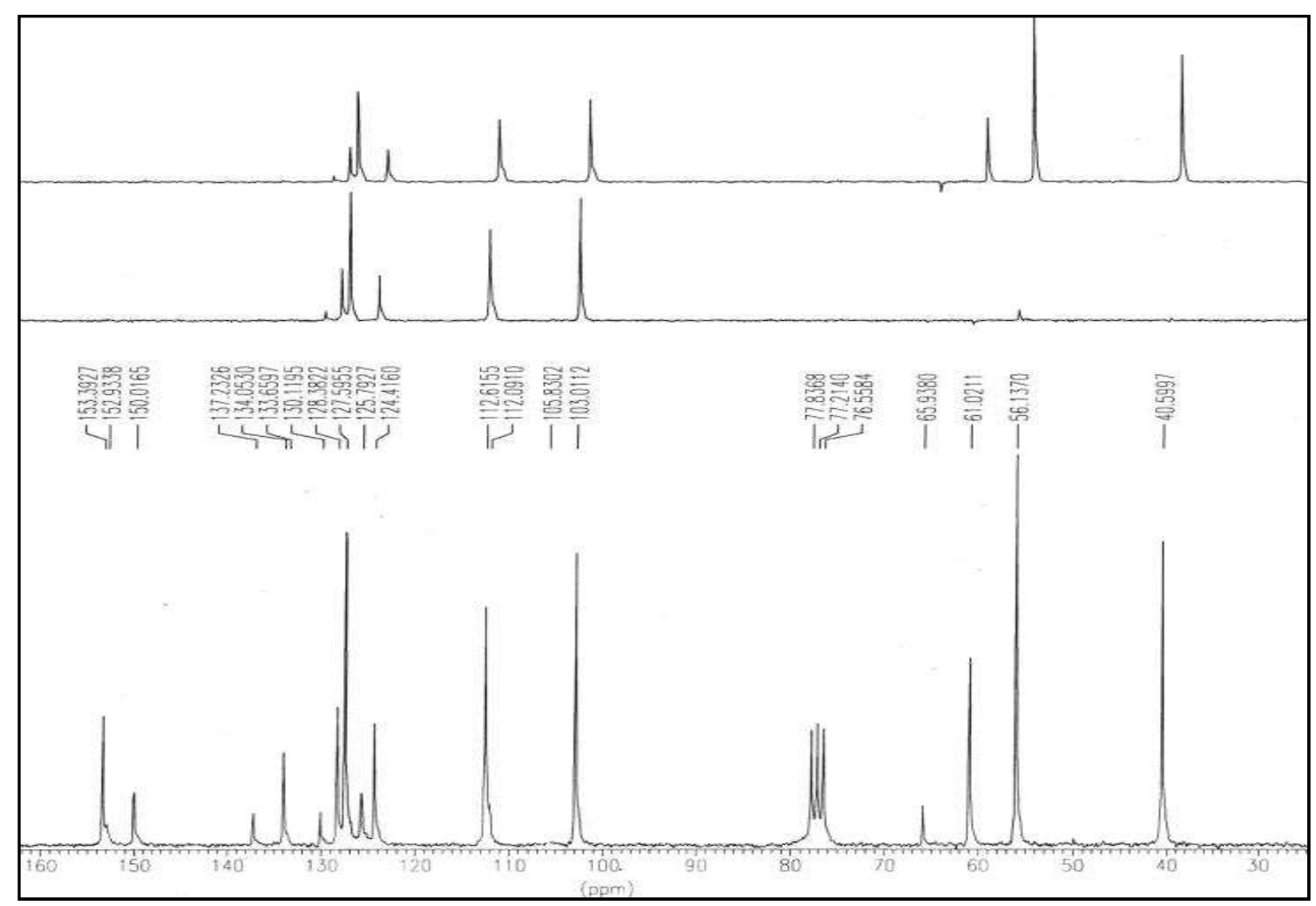

Figura XVIb: Espectro de RMN ${ }^{13} \mathrm{C}$ del compuesto $\mathbf{2 3 E}$. 


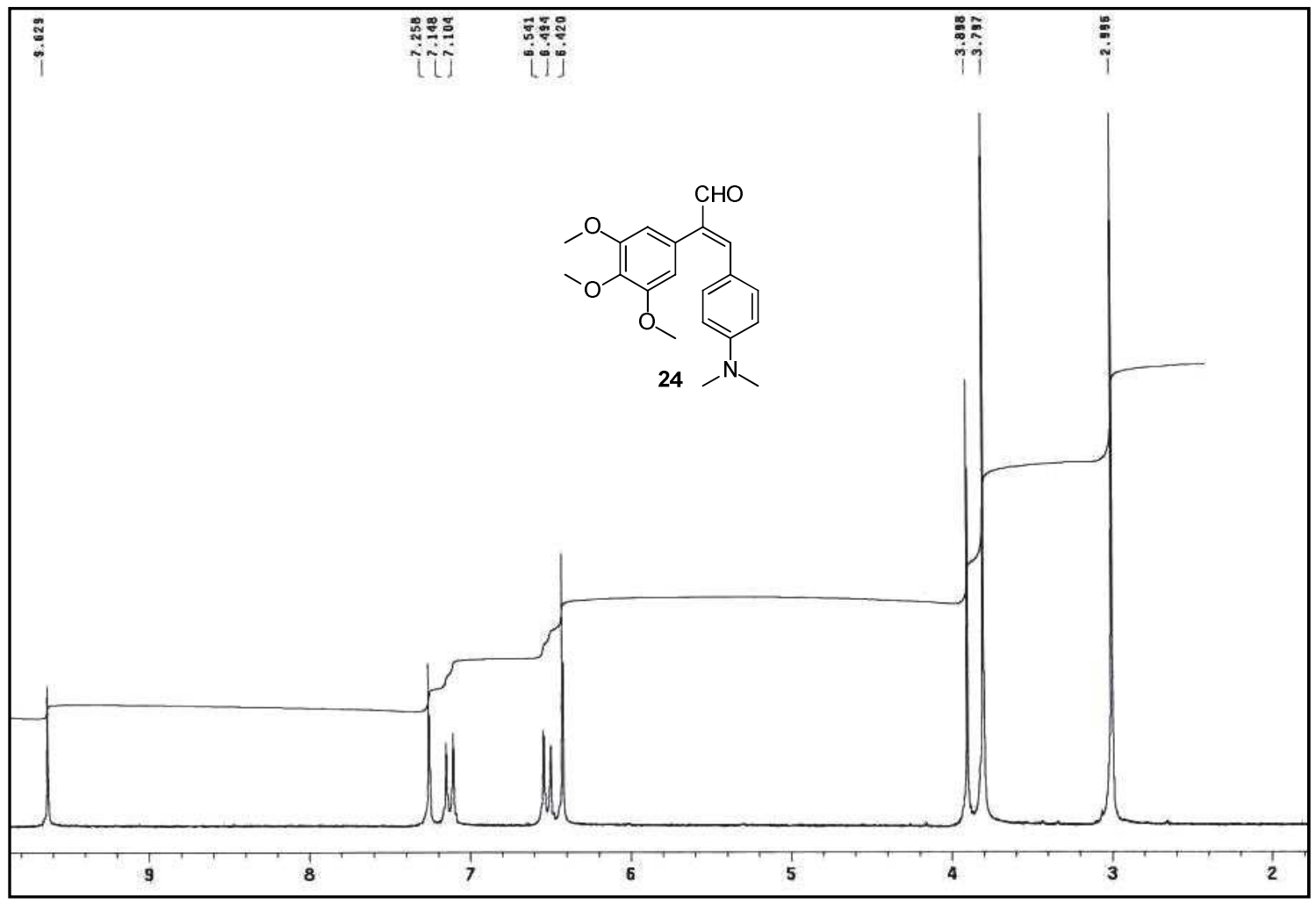

Figura XVIIa: Espectro de RMN ${ }^{13} \mathrm{C}$ del compuesto 24 .

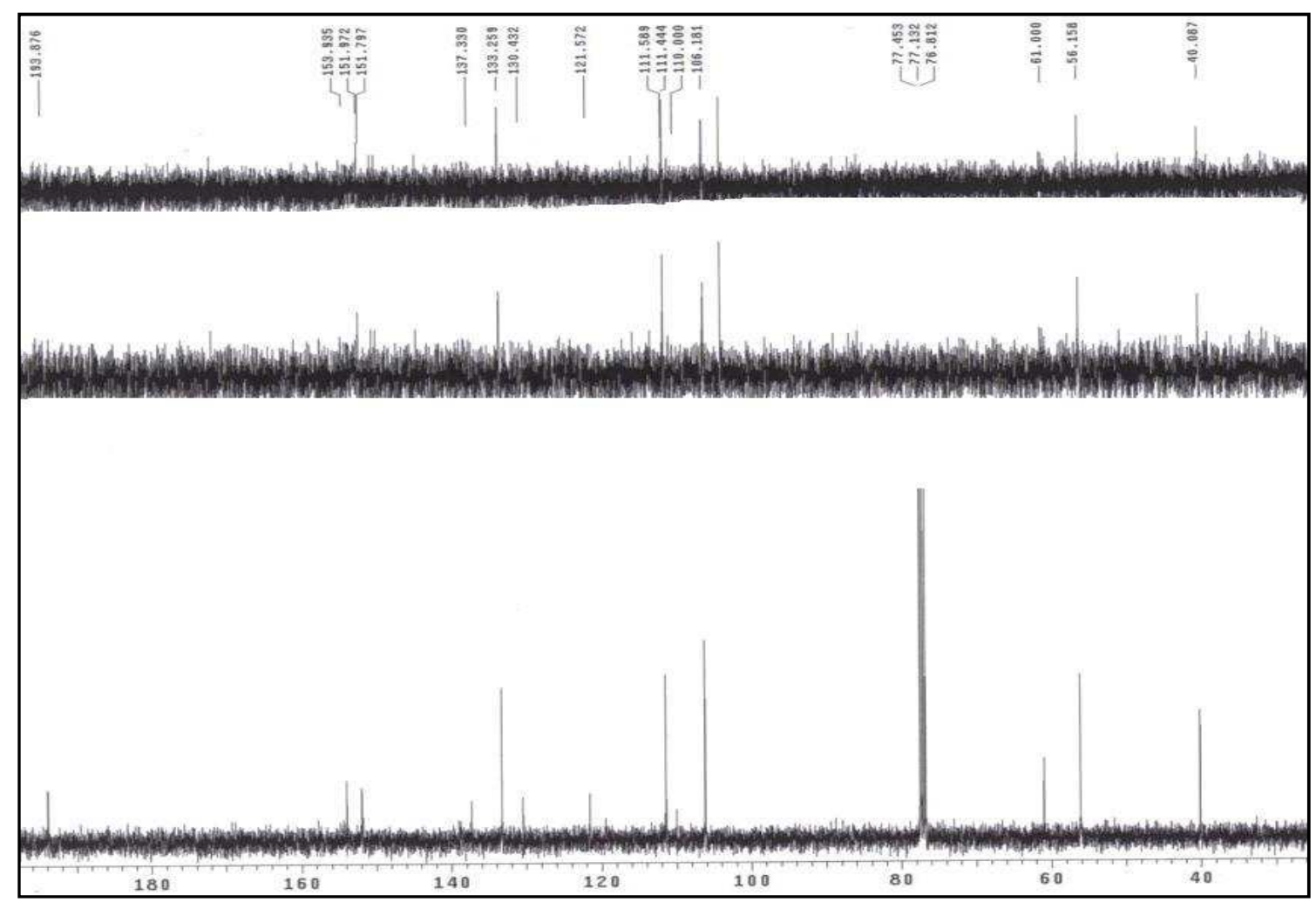

Figura XVIIb: Espectro de RMN ${ }^{13} \mathrm{C}$ del compuesto 24 . 


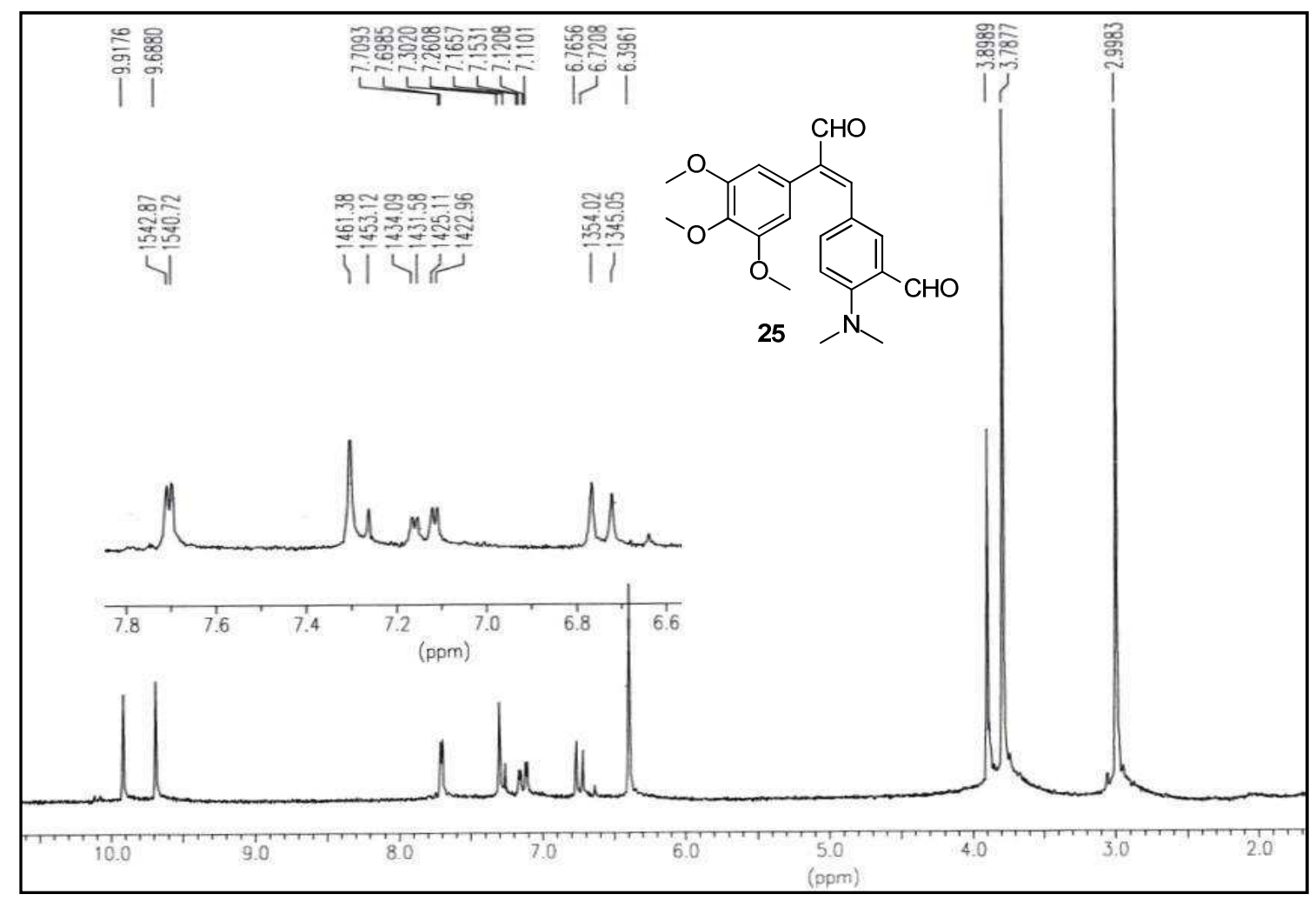

Figura XVIIIa: Espectro de RMN ${ }^{1} \mathrm{H}$ del compuesto 25.

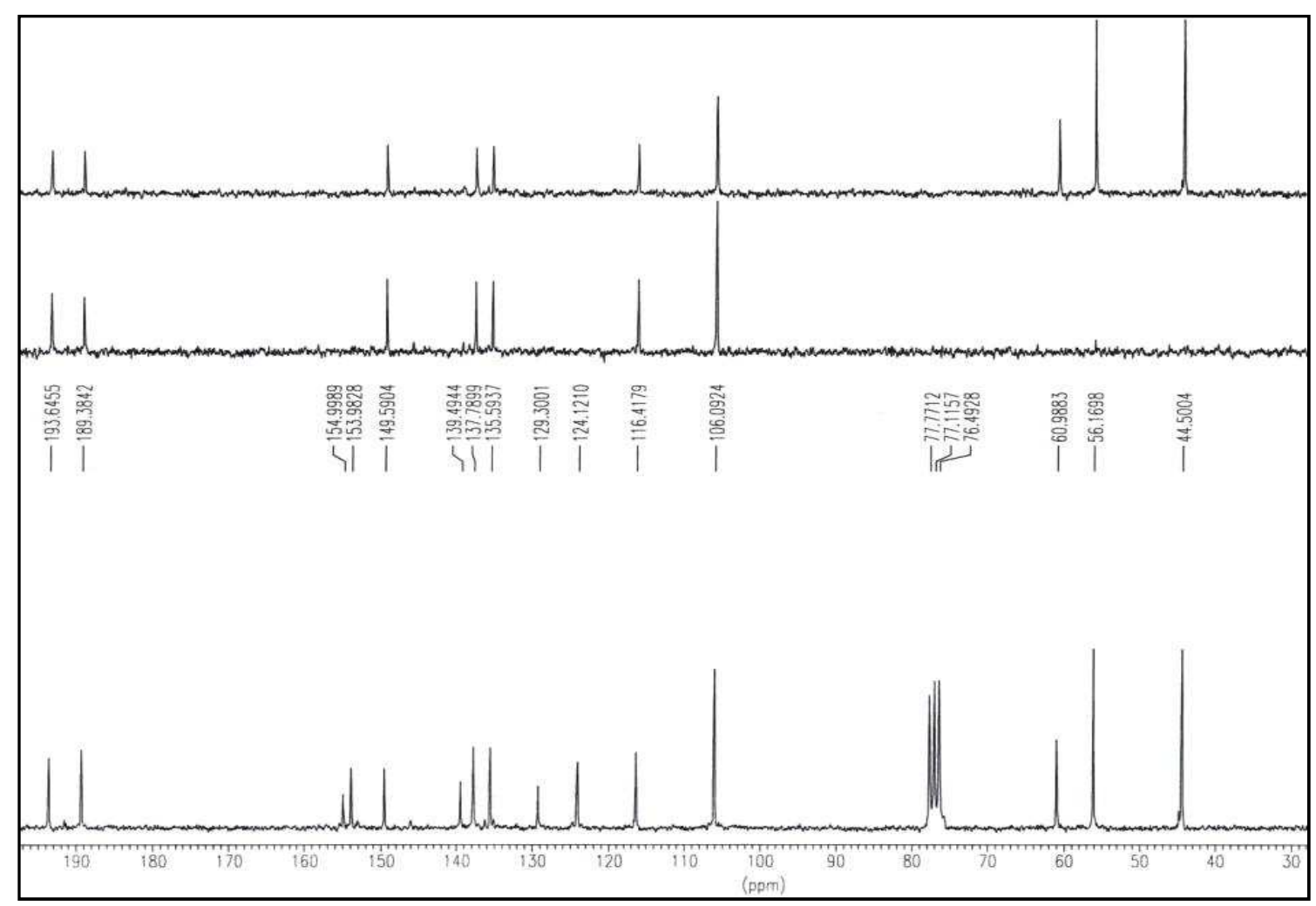

Figura XVIIIb: Espectro de RMN ${ }^{13} \mathrm{C}$ del compuesto 25 


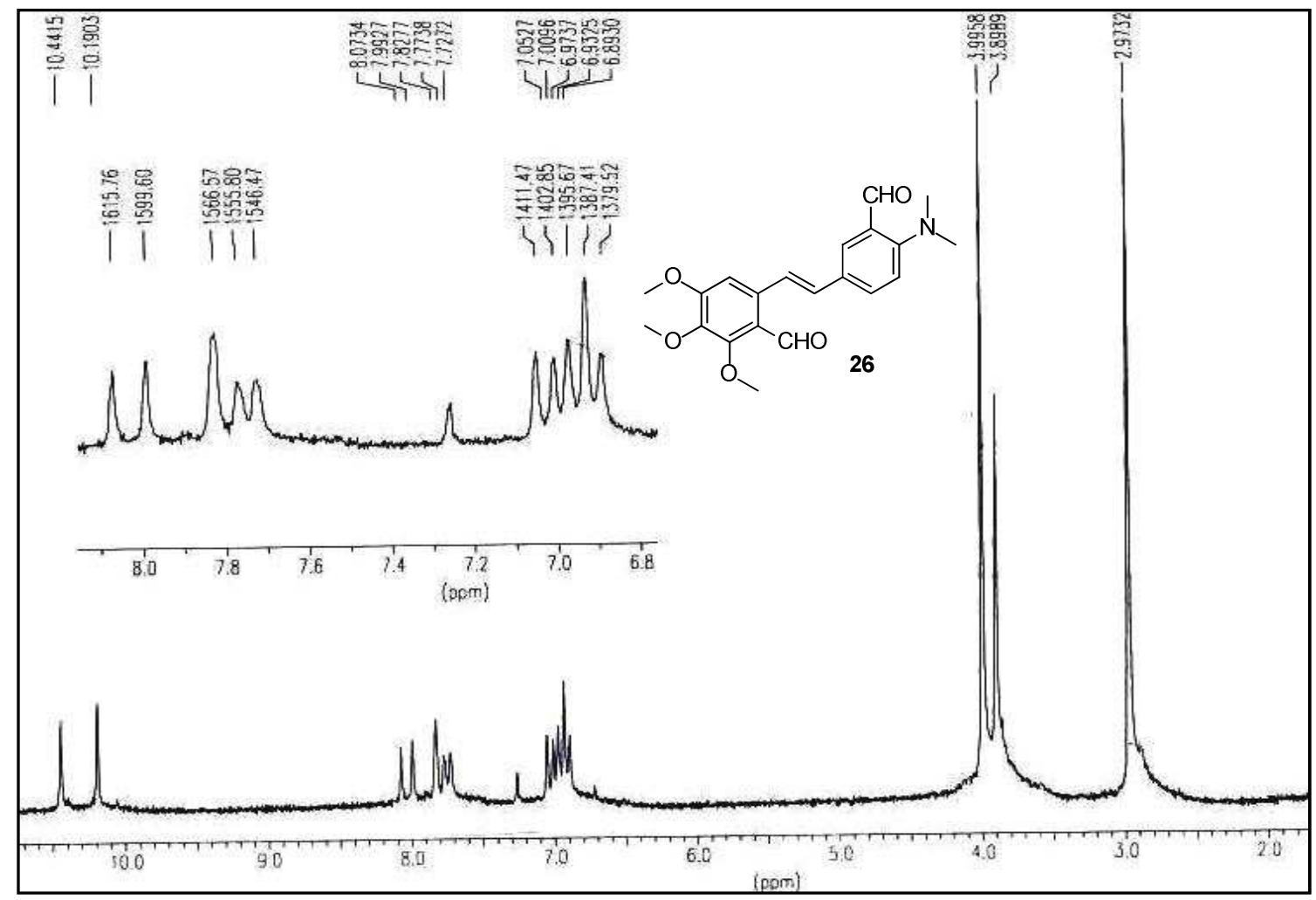

Figura XIXa: Espectro de RMN ${ }^{1} \mathrm{H}$ del compuesto 26.

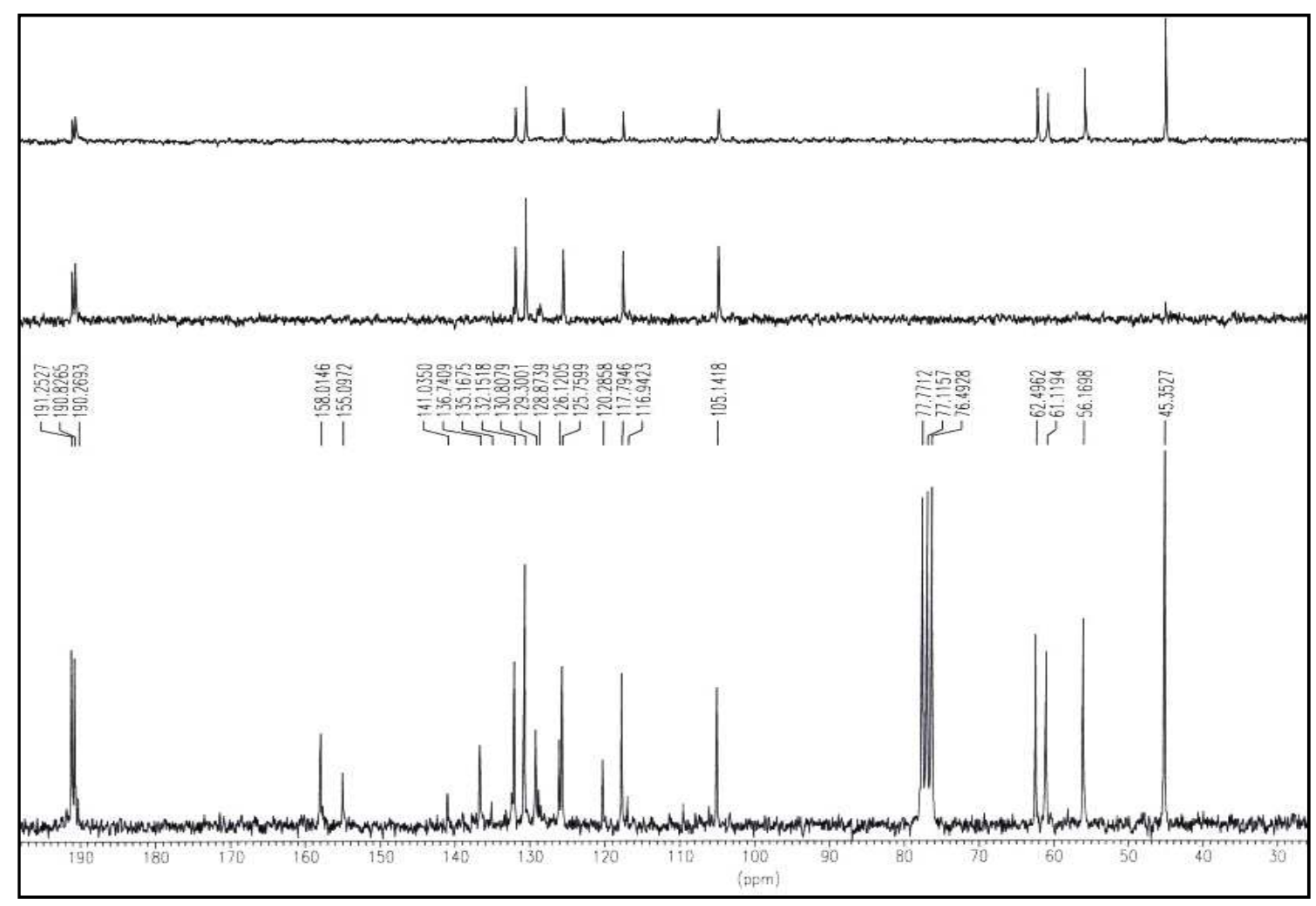

Figura XIXb: Espectro de RMN ${ }^{13} \mathrm{C}$ del compuesto 26. 


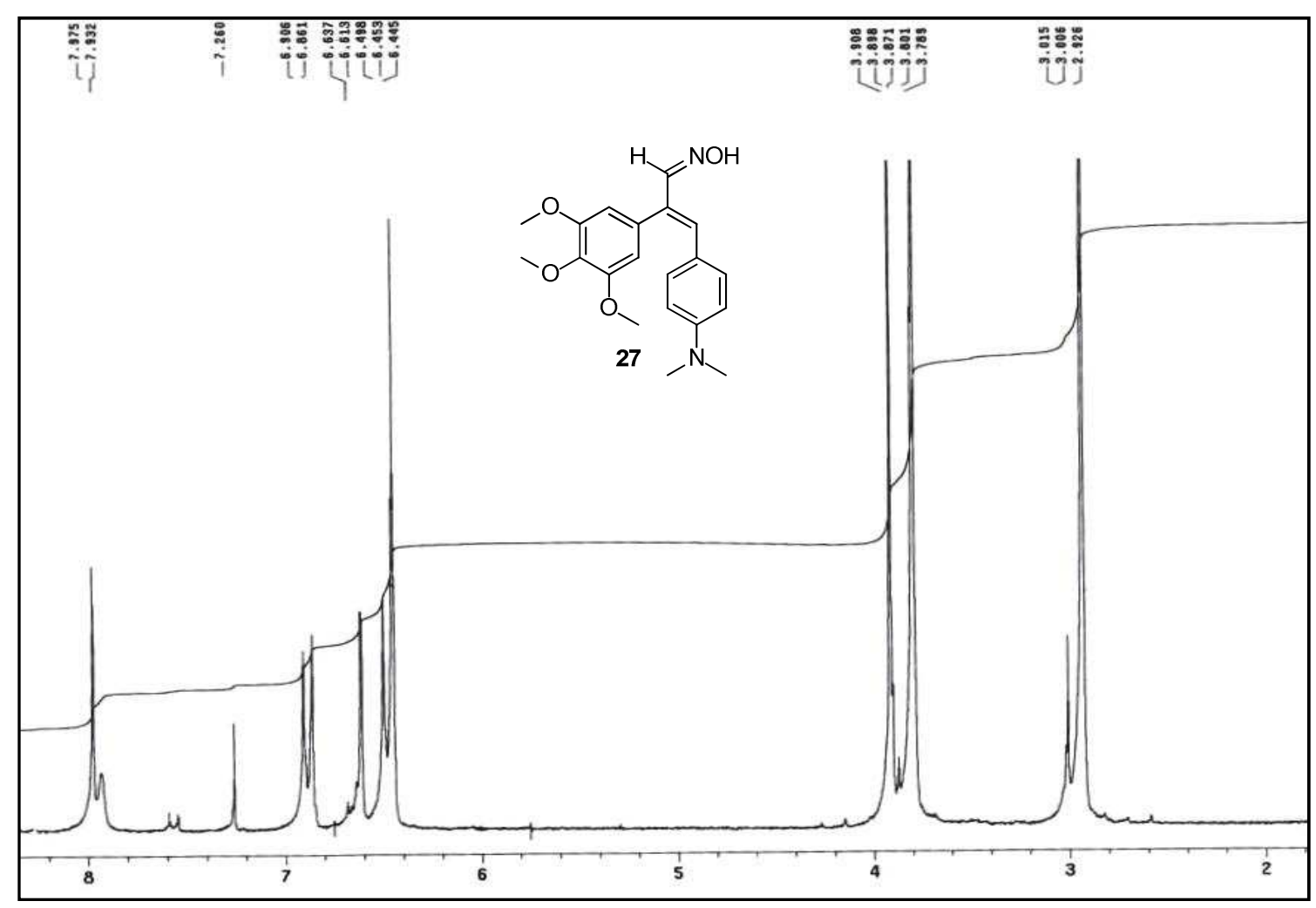

Figura XX: Espectro de RMN ${ }^{1} \mathrm{H}$ del compuesto 27. 


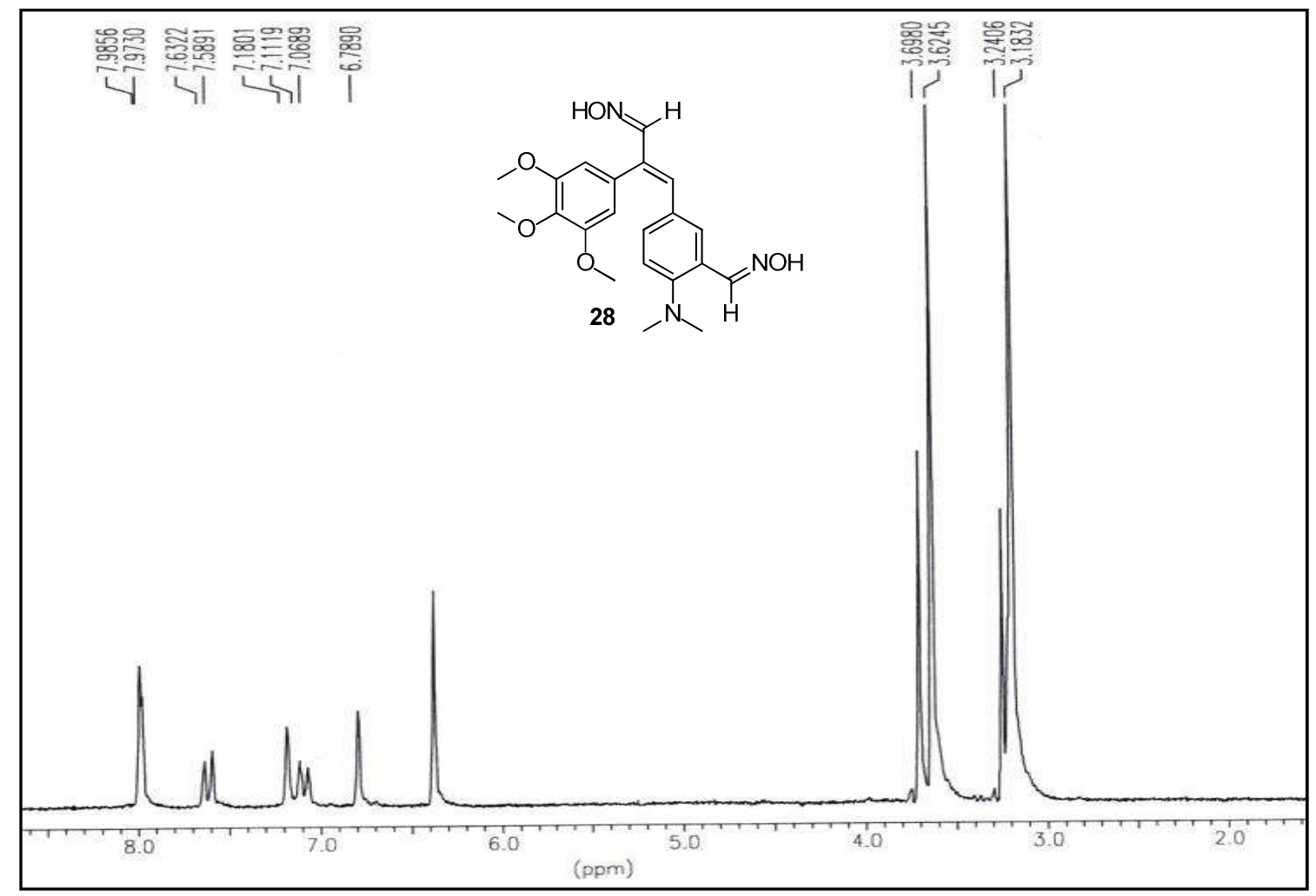

Figura XXIa: Espectro de RMN ${ }^{1} \mathrm{H}$ del compuesto 28.

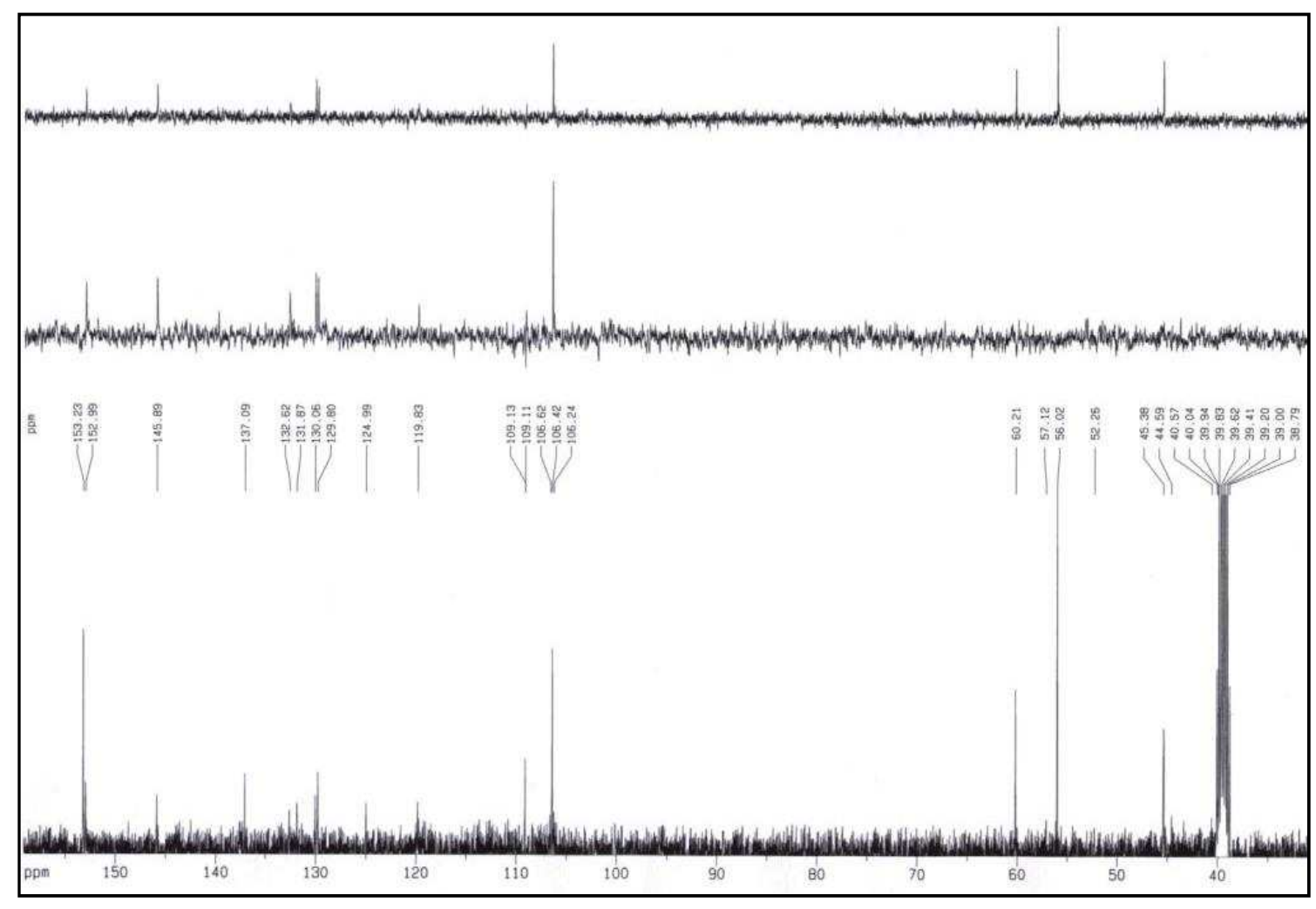

Figura XXIb: Espectro de RMN ${ }^{13} \mathrm{C}$ del compuesto 28. 


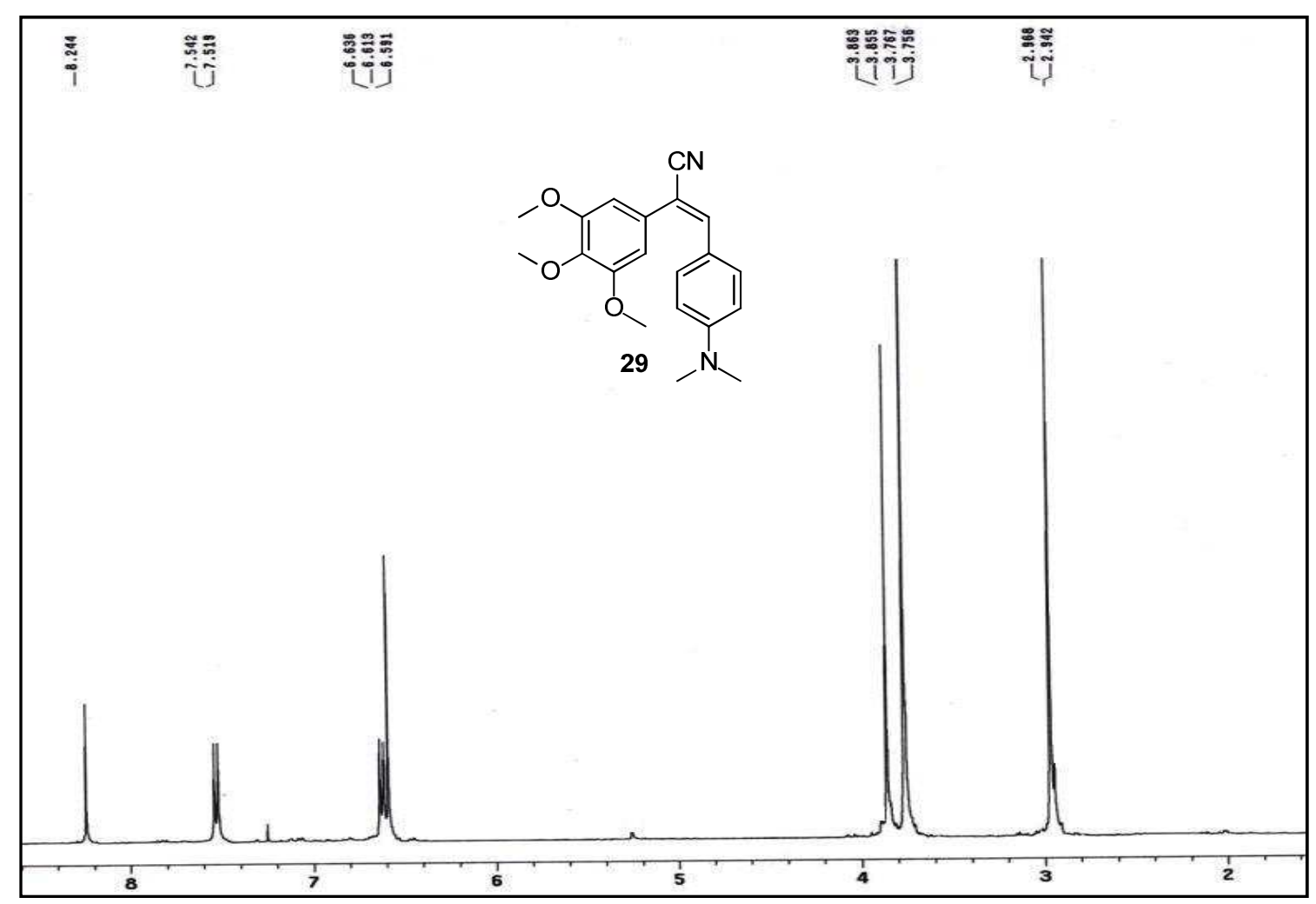

Figura XXIIa: Espectro de RMN ${ }^{1} \mathrm{H}$ del compuesto 29.

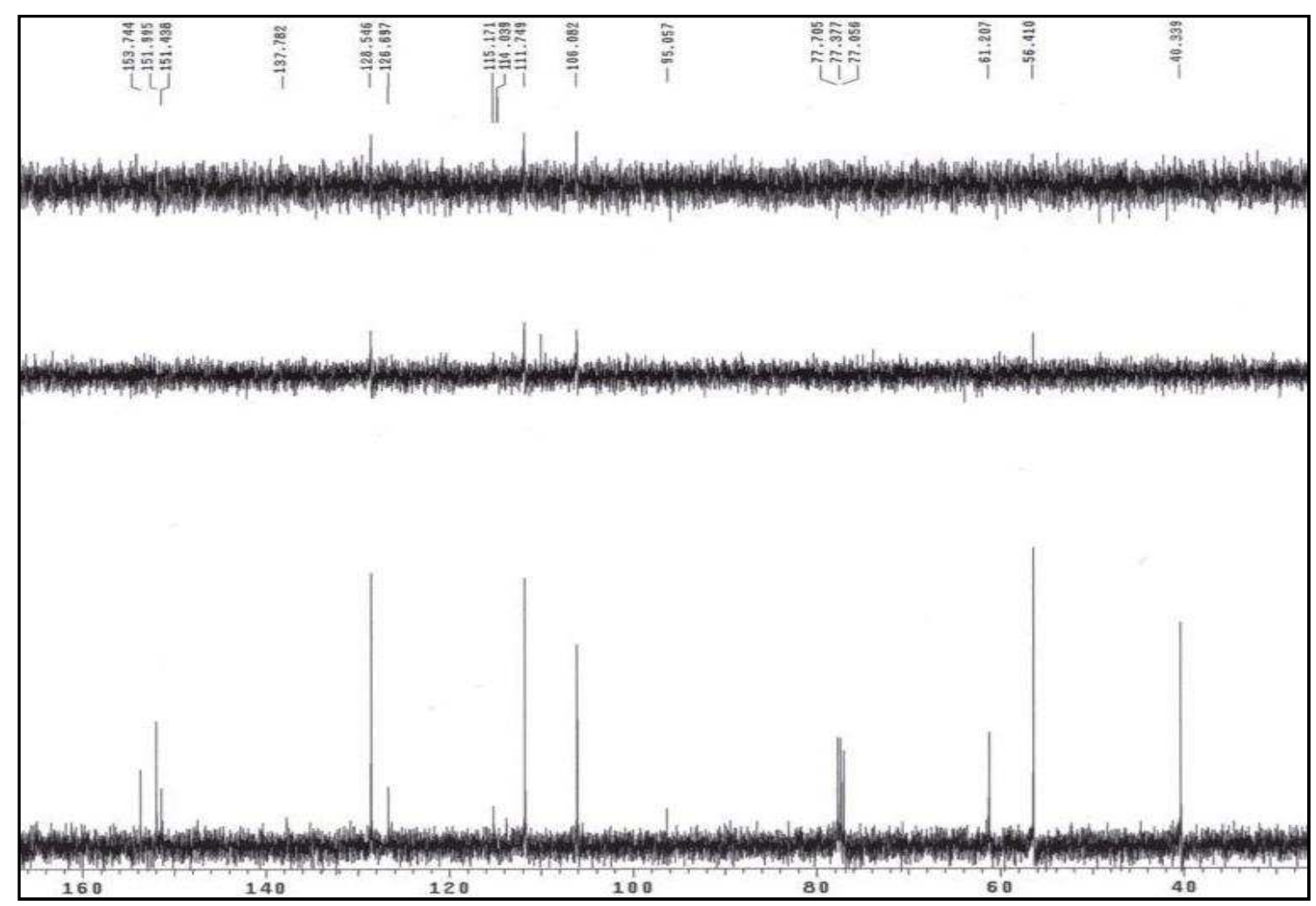

Figura XXIIb: Espectro de RMN ${ }^{13} \mathrm{C}$ del compuesto 29. 


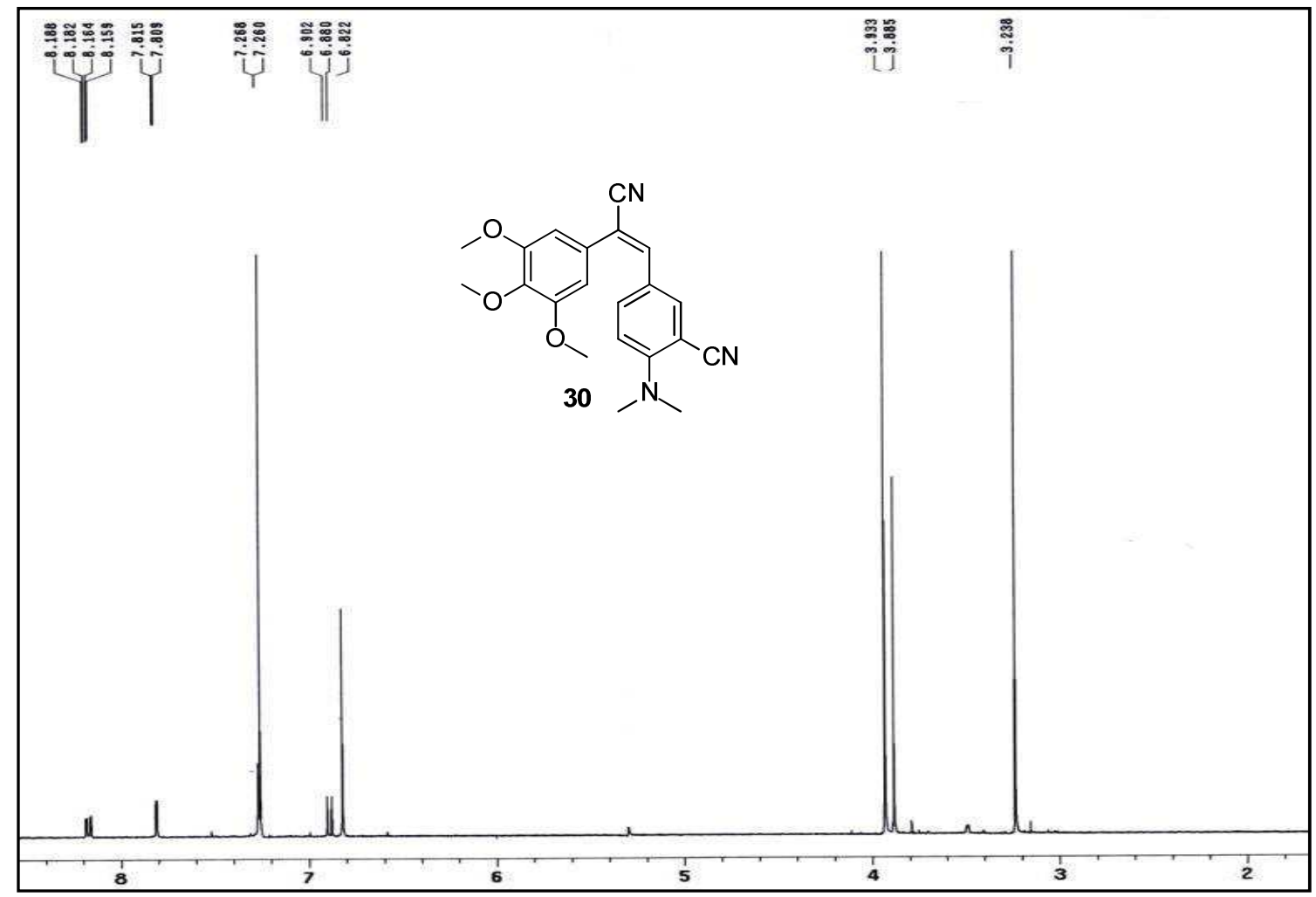

Figura XXIIIa: Espectro de RMN ${ }^{1} \mathrm{H}$ del compuesto 30.

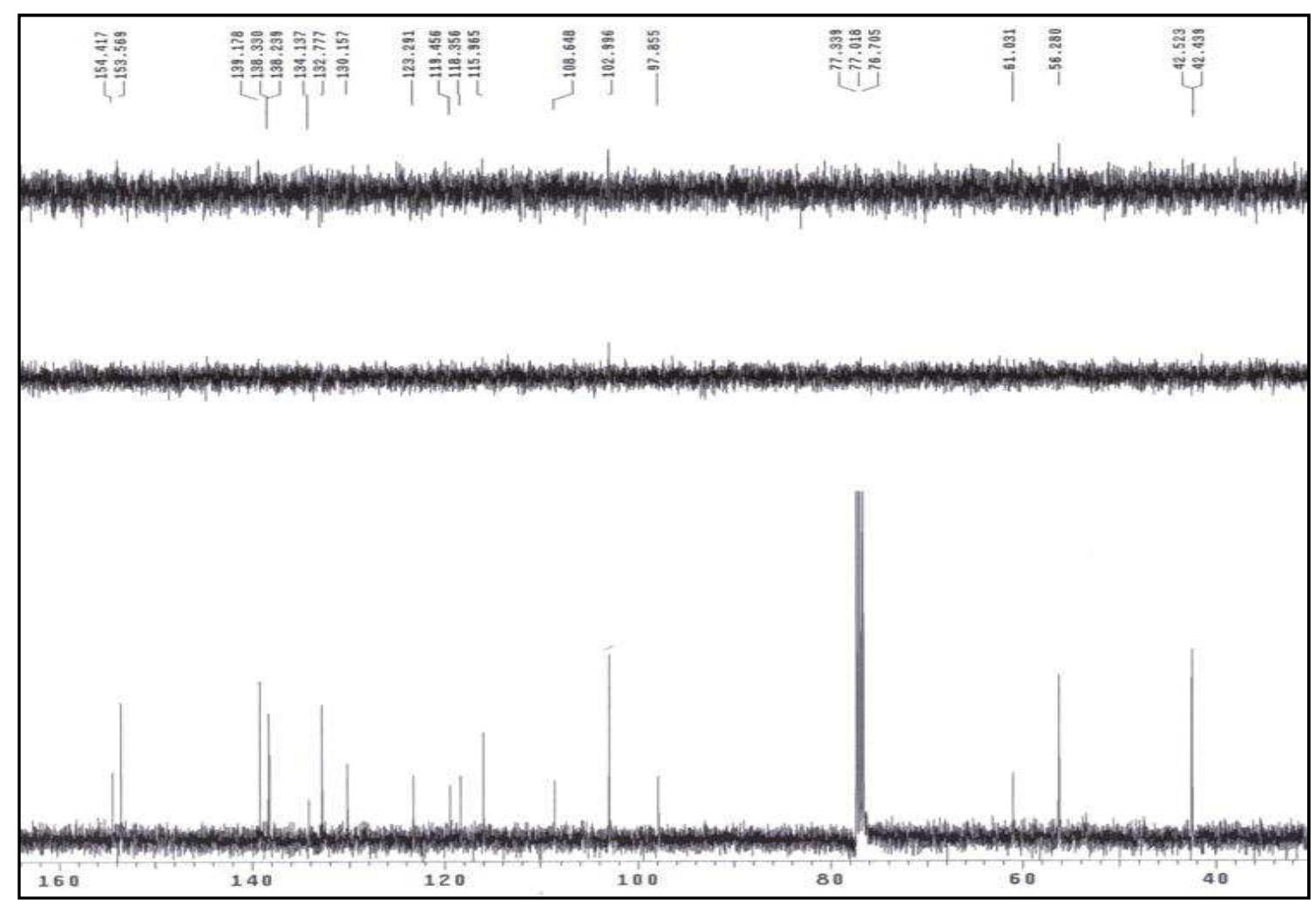

Figura XXIIIb: Espectro de RMN ${ }^{13} \mathrm{C}$ del compuesto 30. 


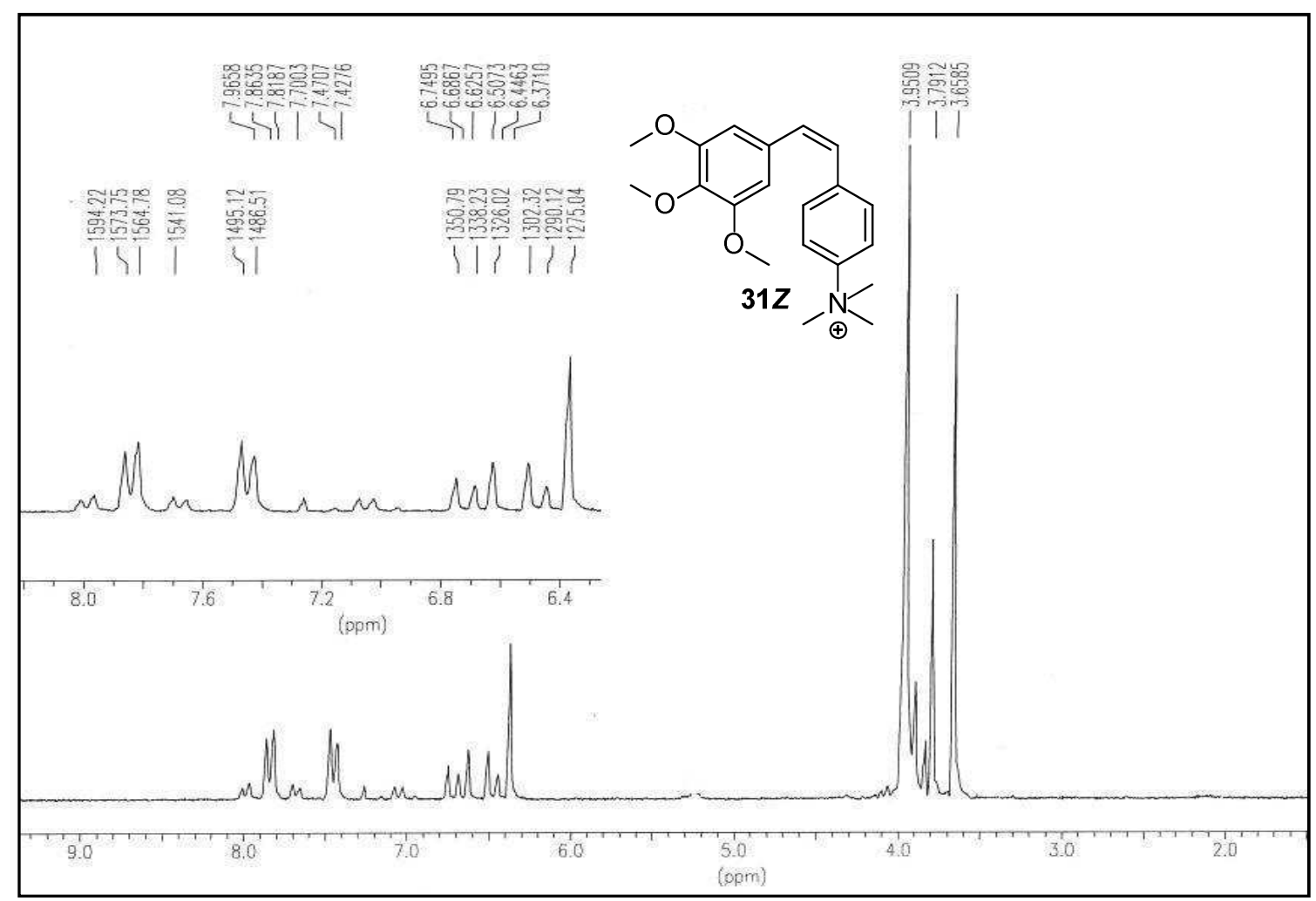

Figura XXIVa: Espectro de RMN ${ }^{1} \mathrm{H}$ del compuesto $\mathbf{3 1 Z}$.

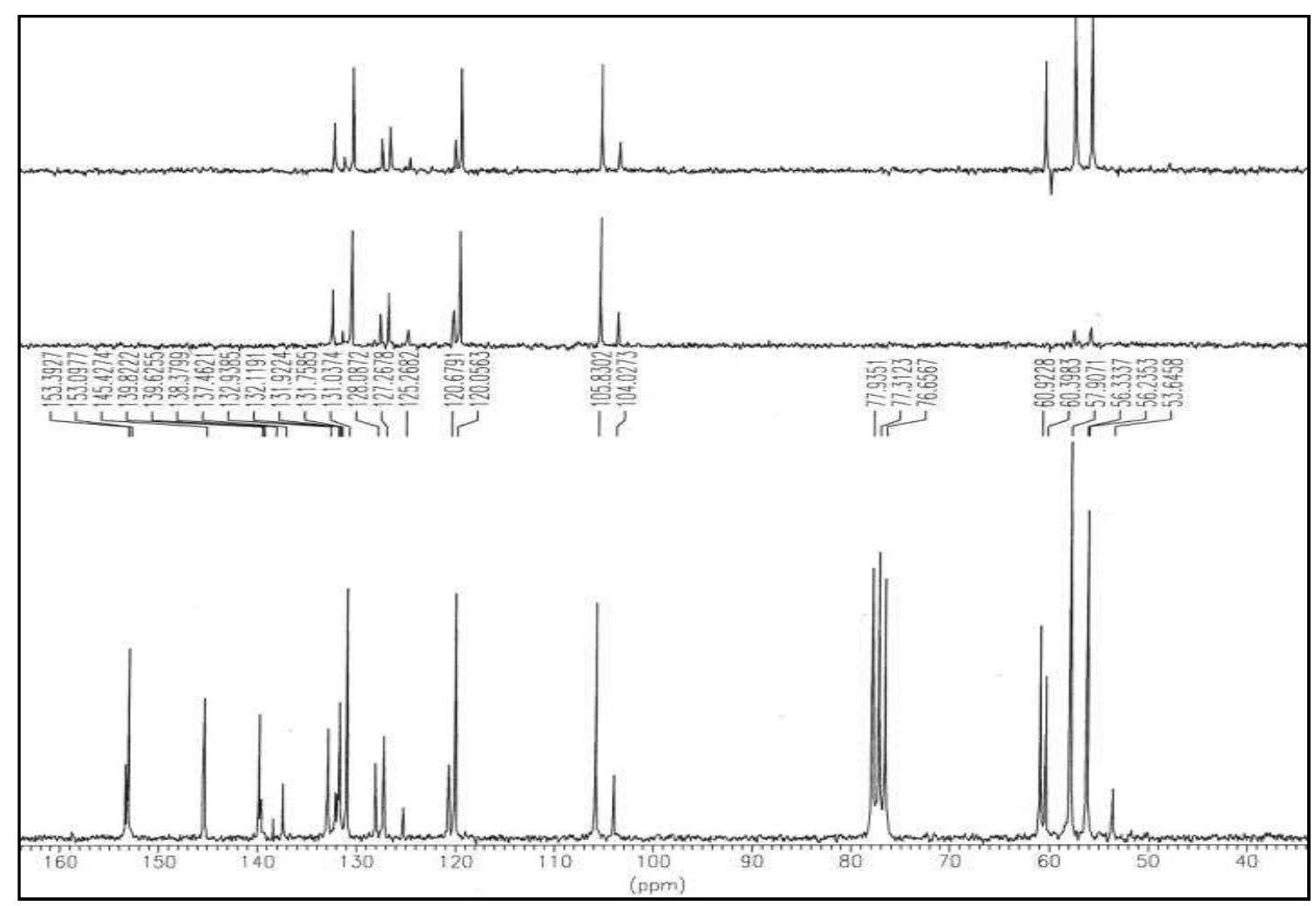

Figura XXIVb: Espectro de RMN ${ }^{13} \mathrm{C}$ del compuesto $\mathbf{3 1 Z}$. 


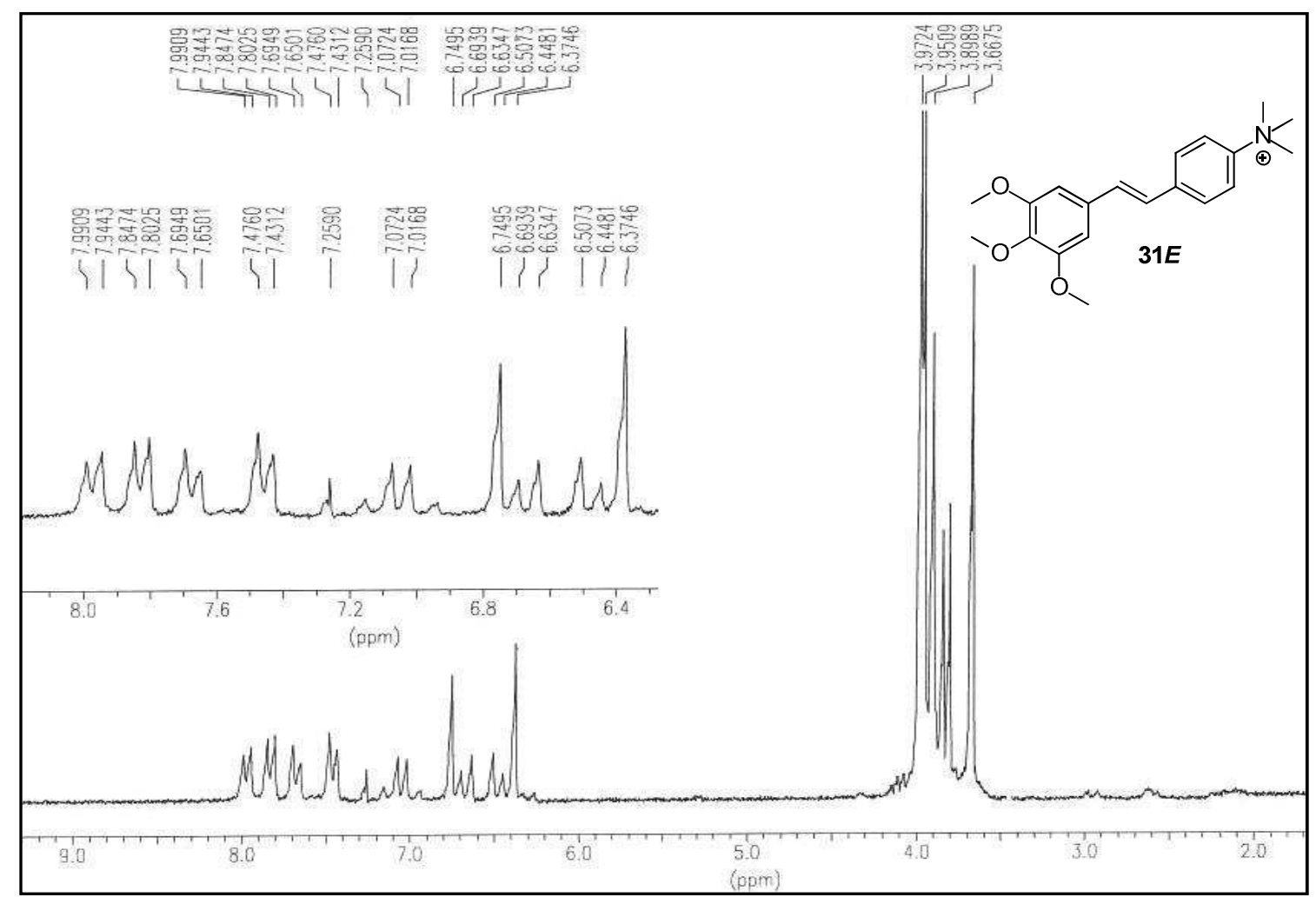

Figura XXIVc: Espectro de RMN ${ }^{1} \mathrm{H}$ del compuesto $31 \boldsymbol{E}$. 


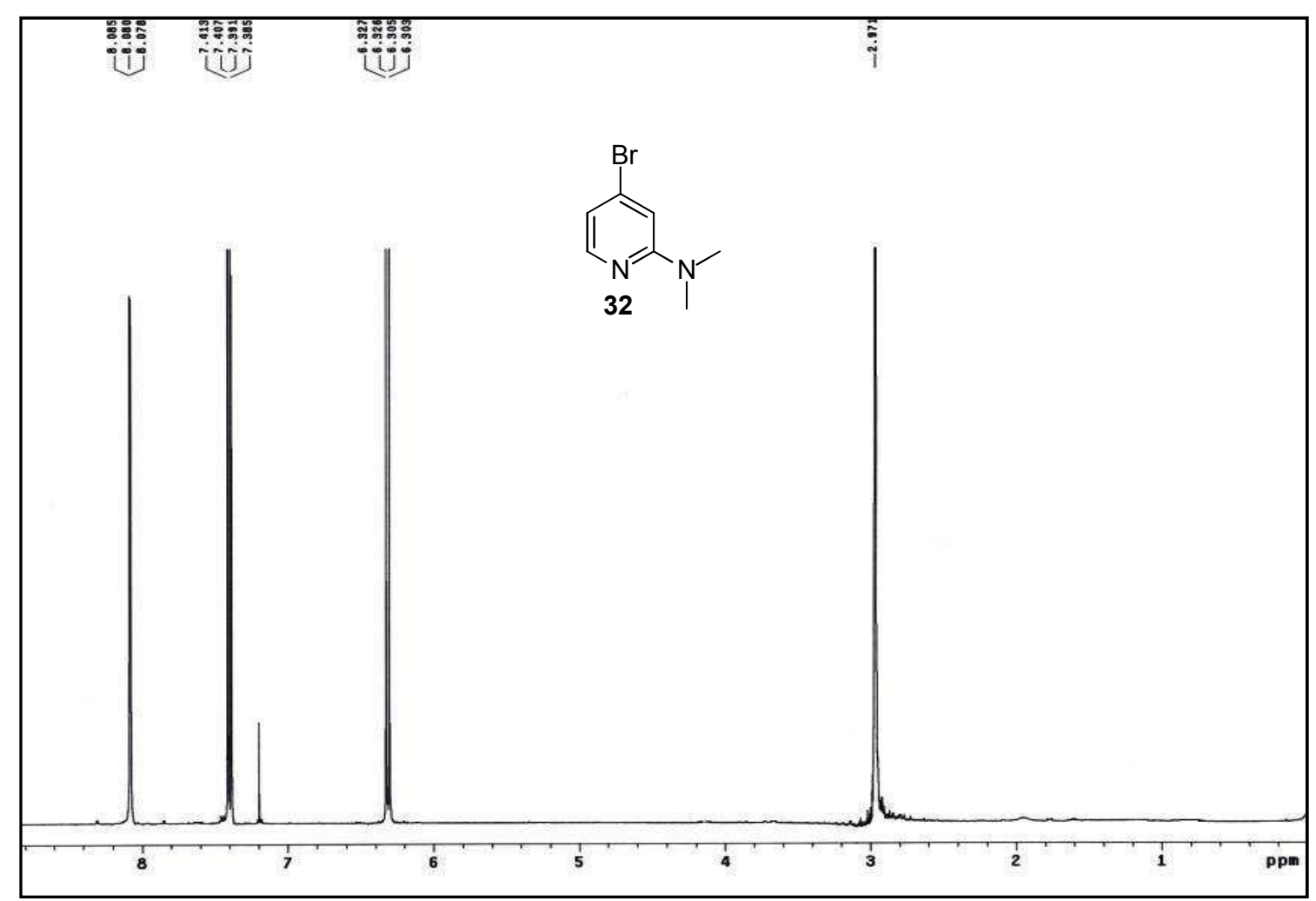

Figura XXVa: Espectro de RMN ${ }^{1} \mathrm{H}$ del compuesto 32 .

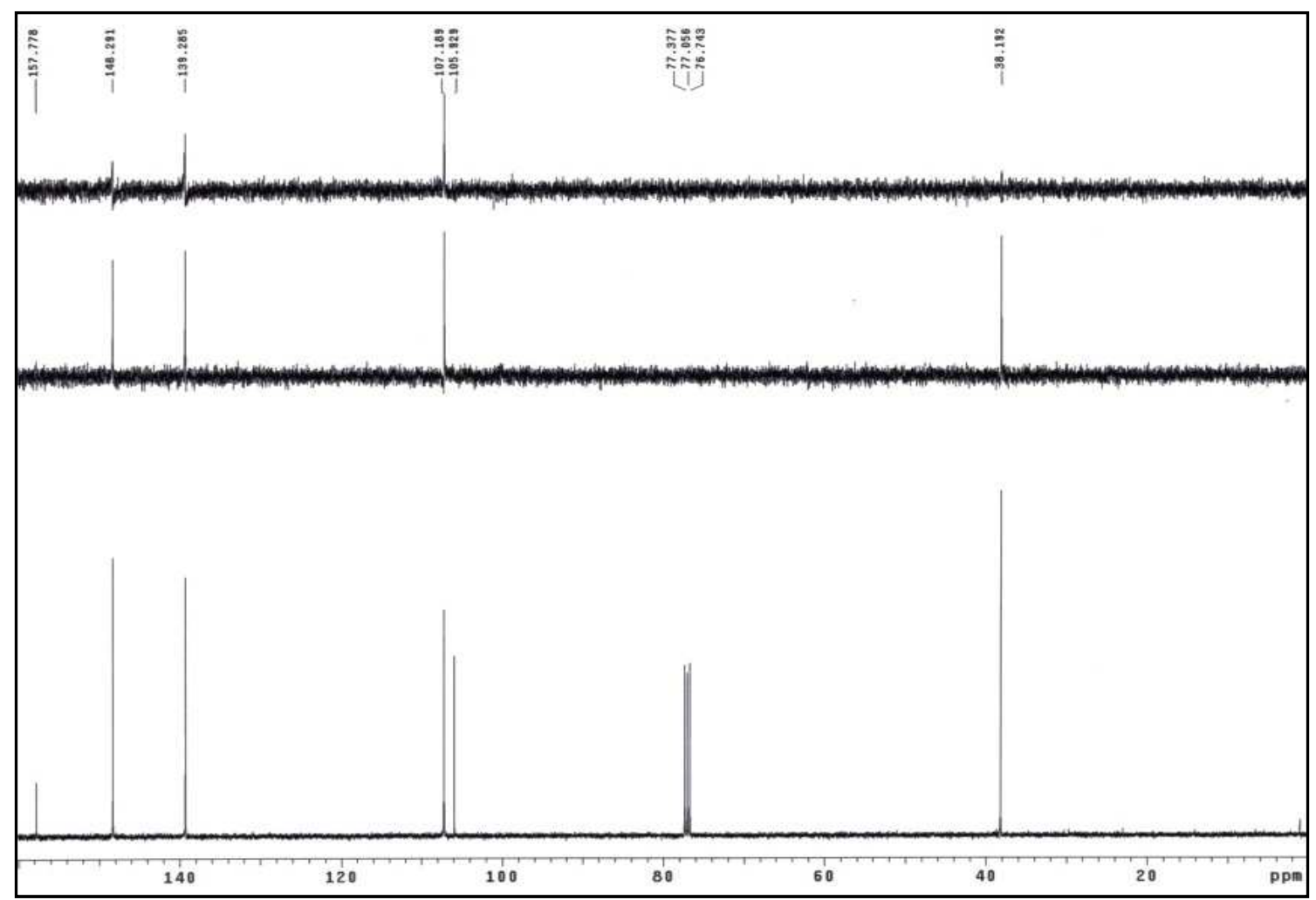

Figura XXVb: Espectro de $\mathrm{RMN}{ }^{13} \mathrm{C}$ del compuesto 32 . 


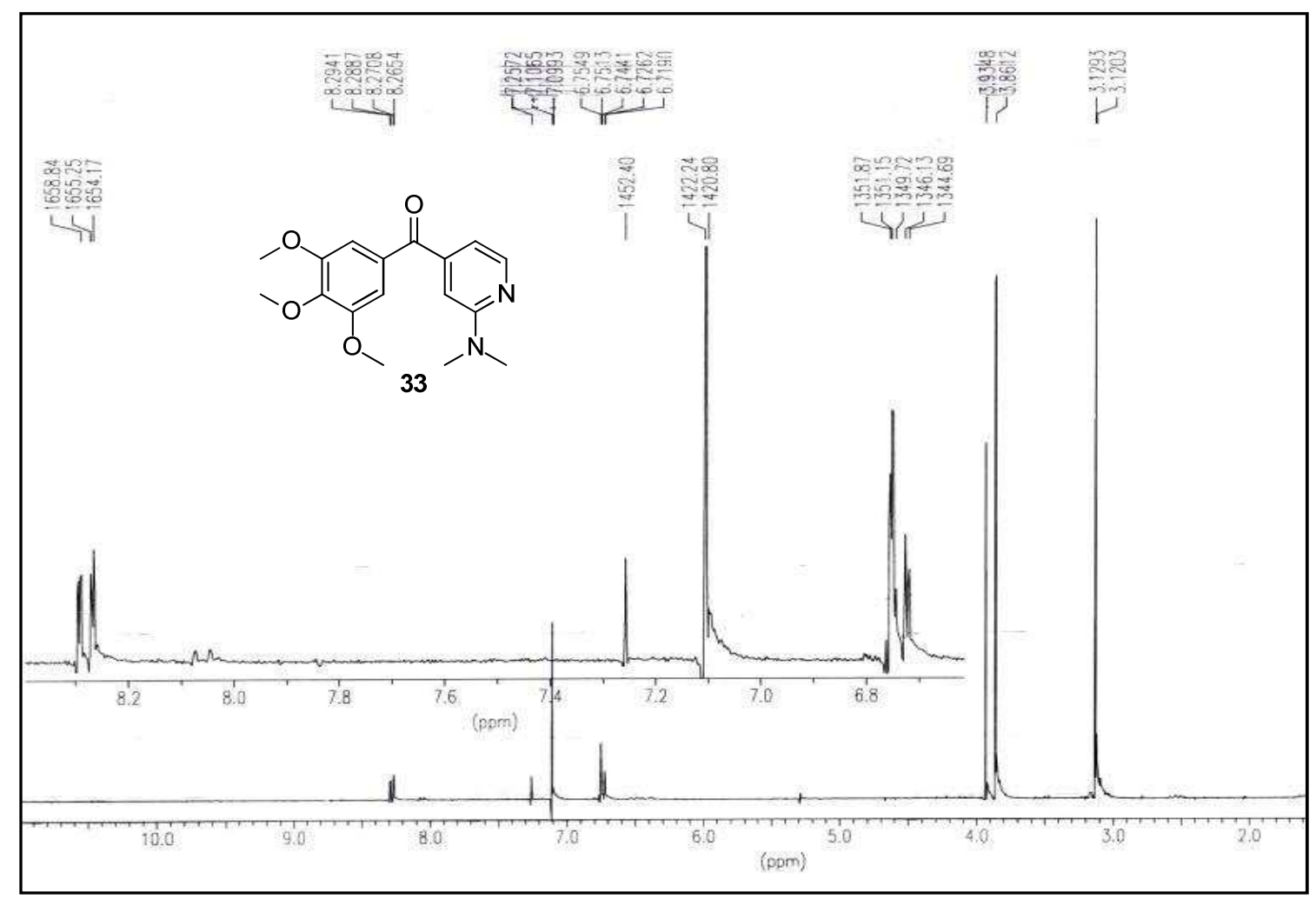

Figura XXVIa: Espectro de RMN ${ }^{1} \mathrm{H}$ del compuesto 33.

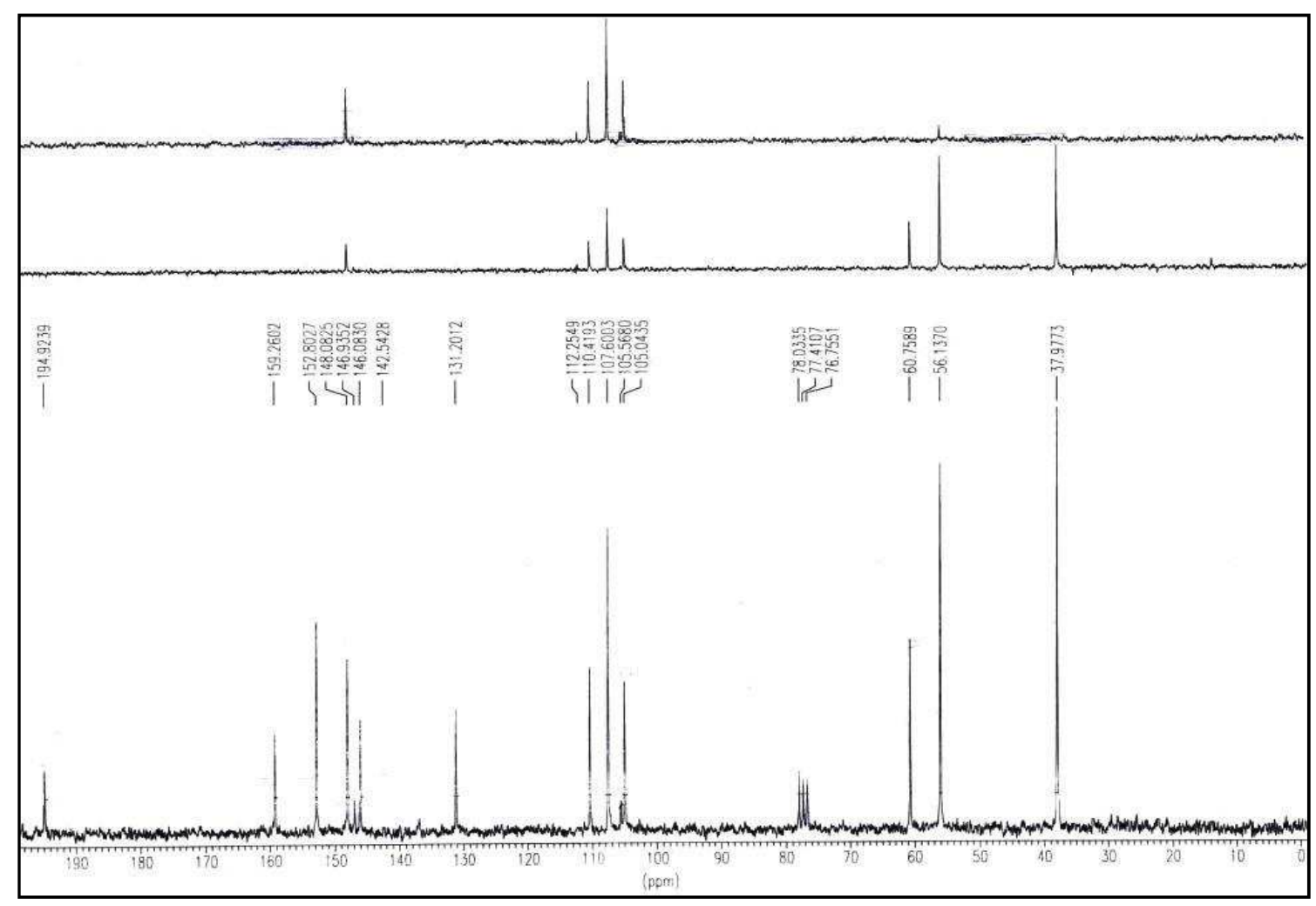

Figura XXVIb: Espectro de RMN ${ }^{13} \mathrm{C}$ del compuesto 33 . 


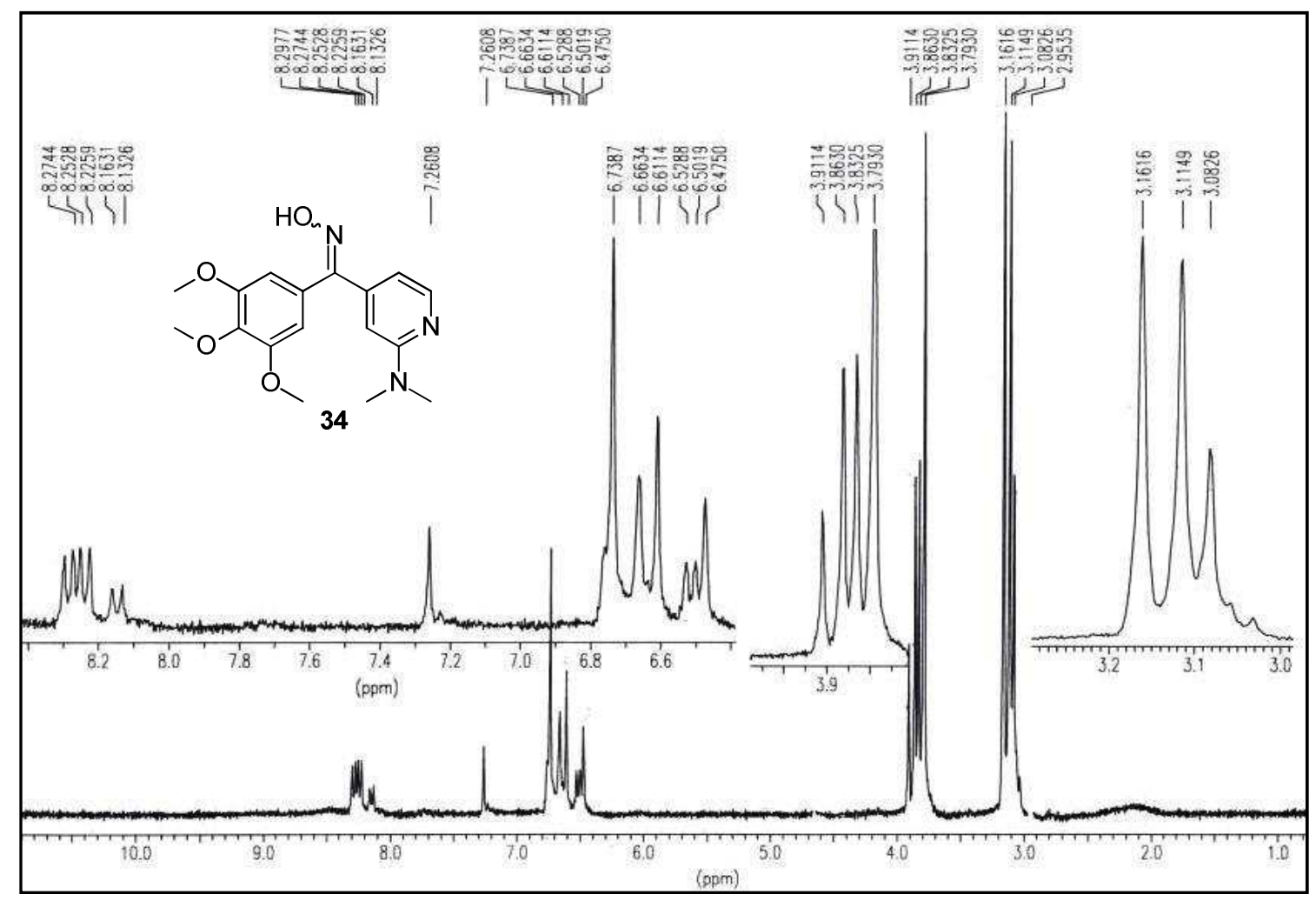

Figura XXVIIa: Espectro de RMN ${ }^{1} \mathrm{H}$ del compuesto 34 .

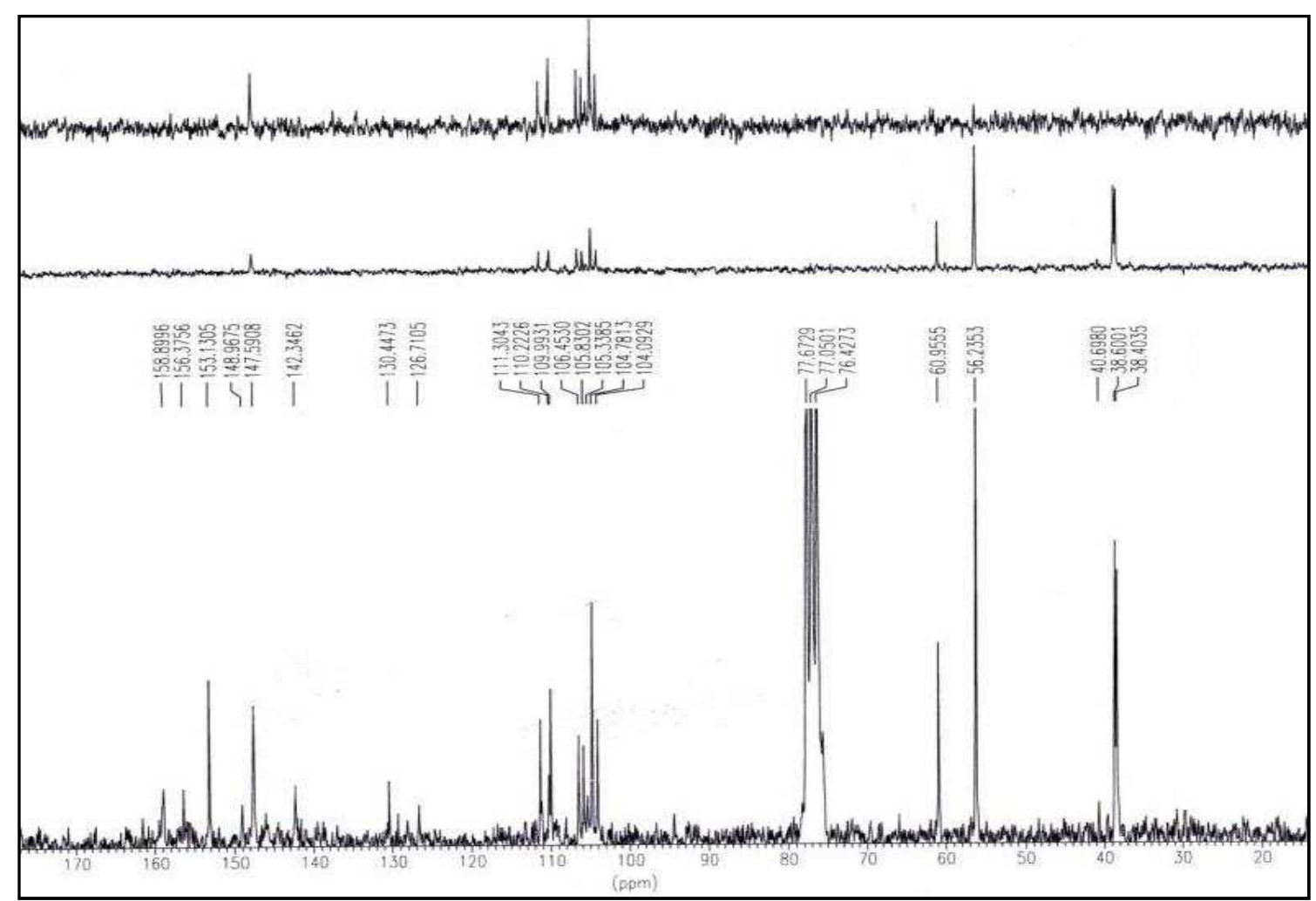

Figura XXVIIb: Espectro de RMN ${ }^{13} \mathrm{C}$ del compuesto 34. 


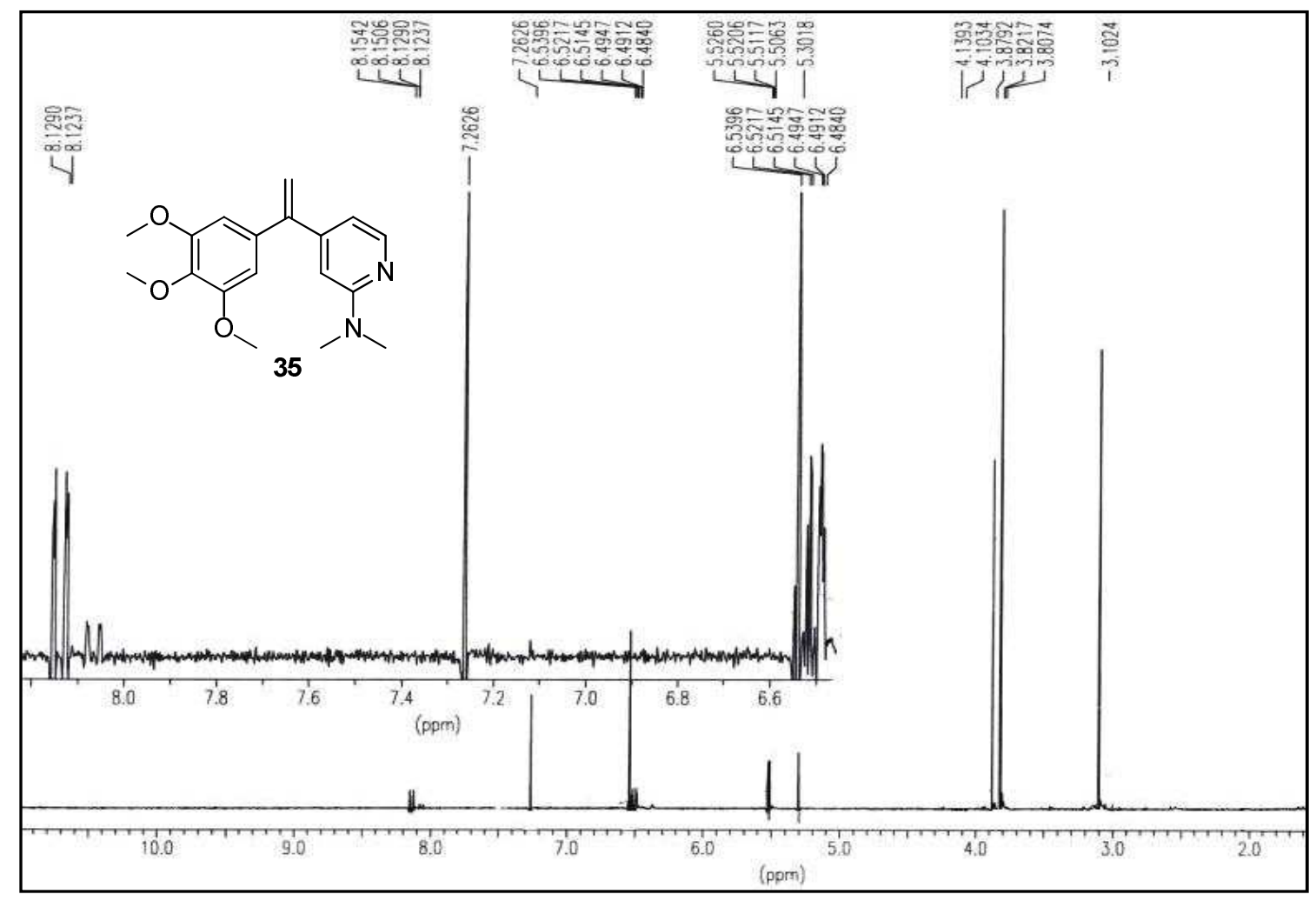

Figura XXVIIIa: Espectro de RMN ${ }^{1} \mathrm{H}$ del compuesto 35.

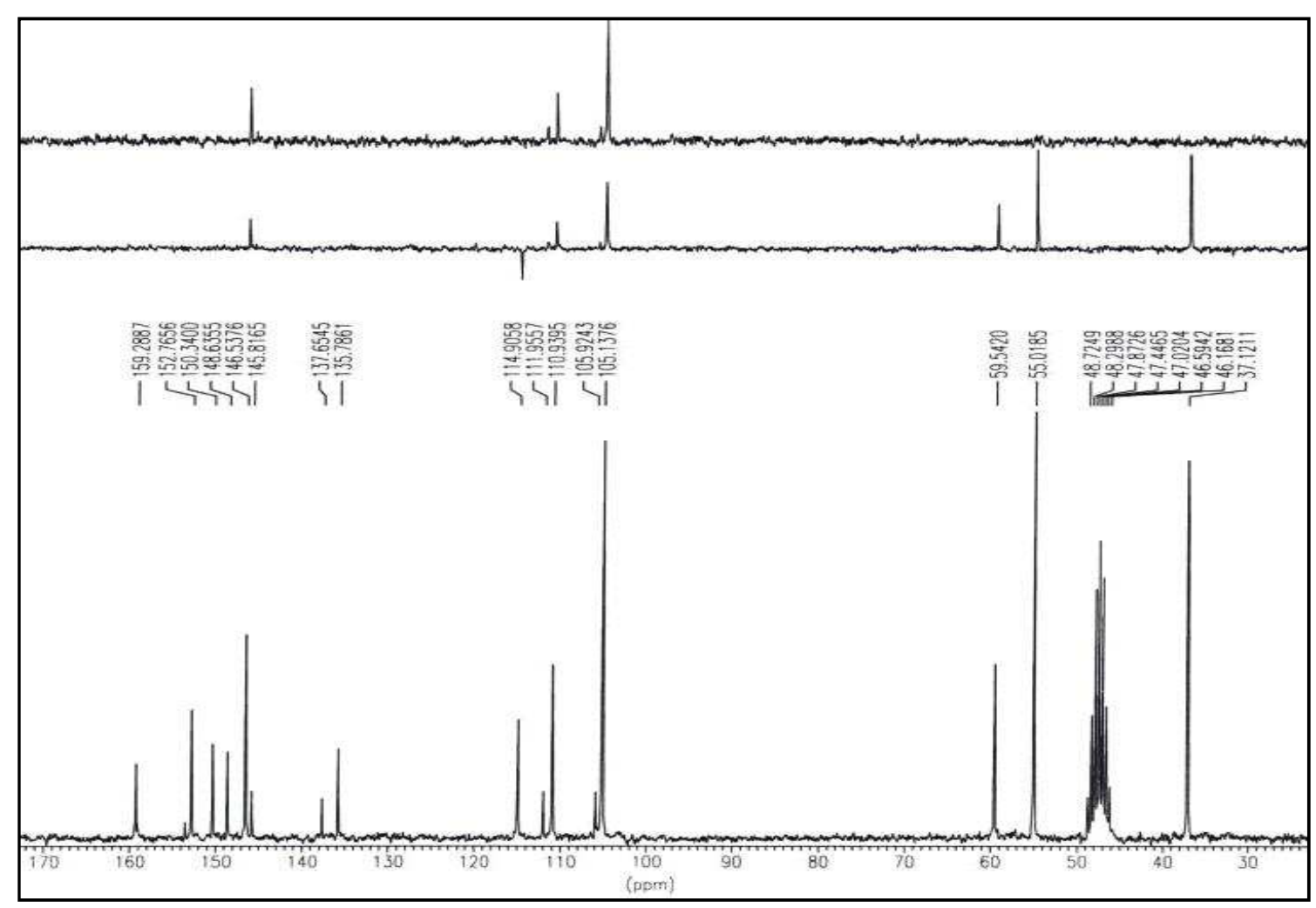

Figura XXVIIIb: Espectro de RMN ${ }^{13} \mathrm{C}$ del compuesto 35. 


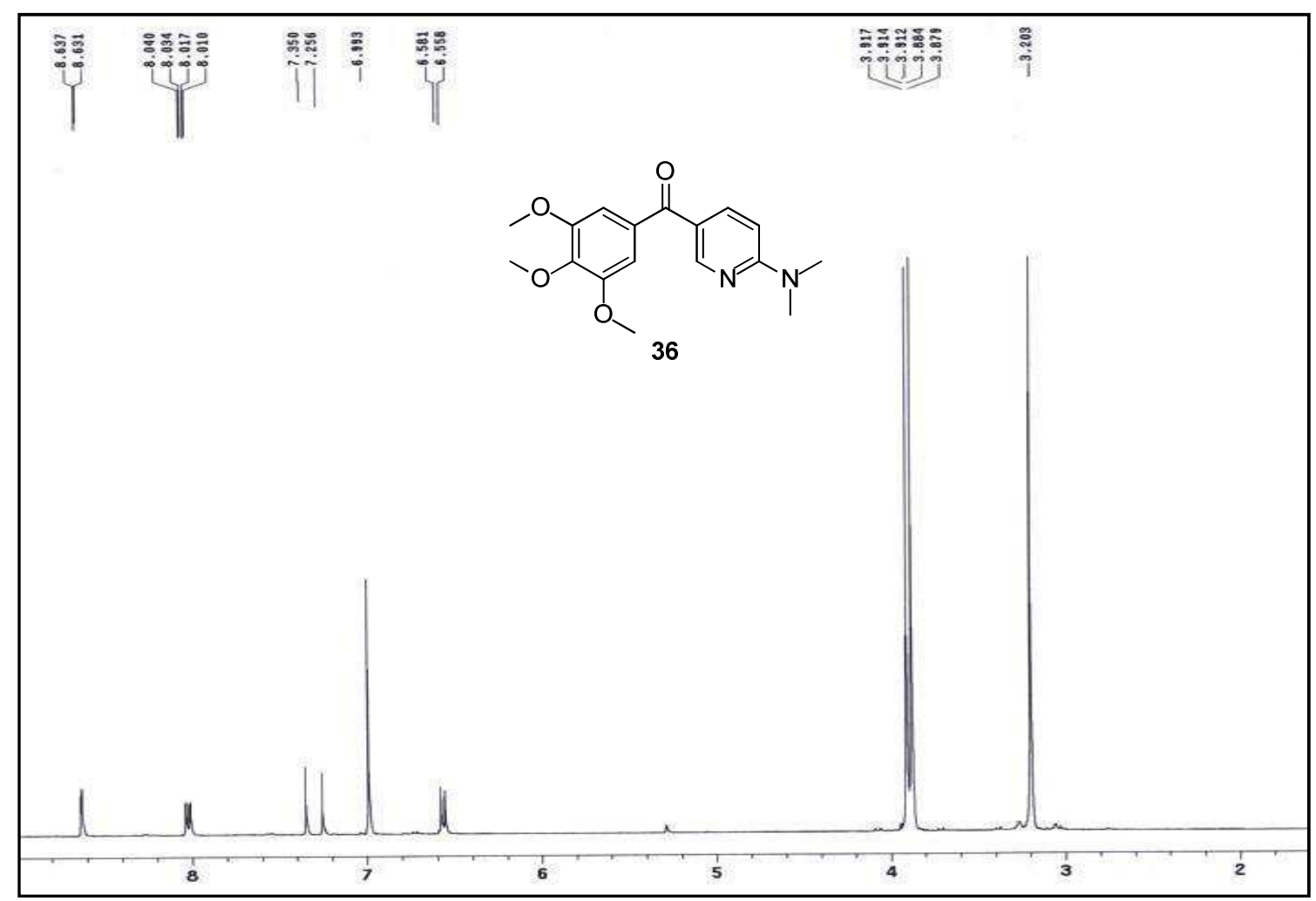

Figura XXIXa: Espectro de RMN ${ }^{1} \mathrm{H}$ del compuesto 36.

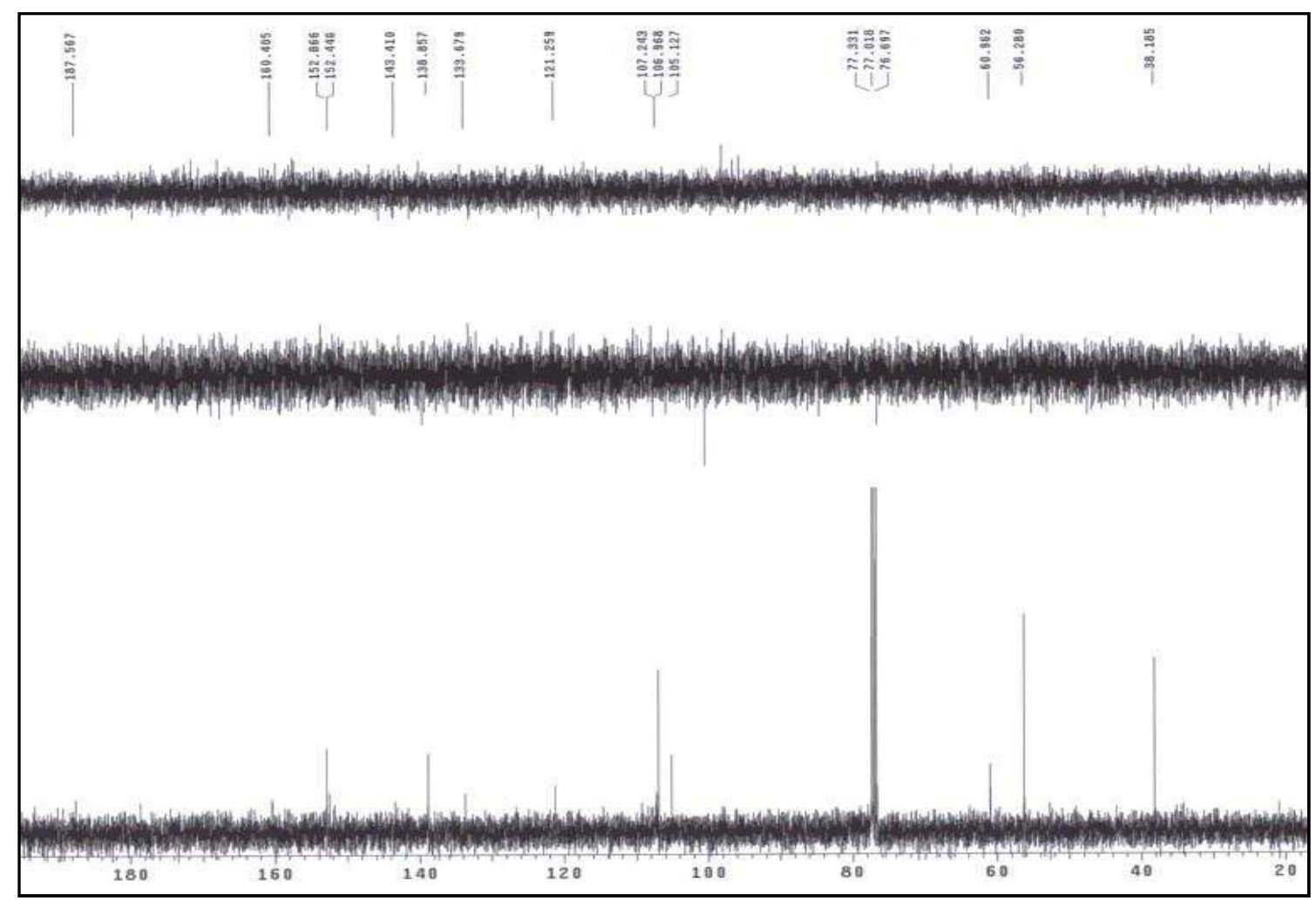

Figura XXIXb: Espectro de RMN ${ }^{13} \mathrm{C}$ del compuesto 36. 


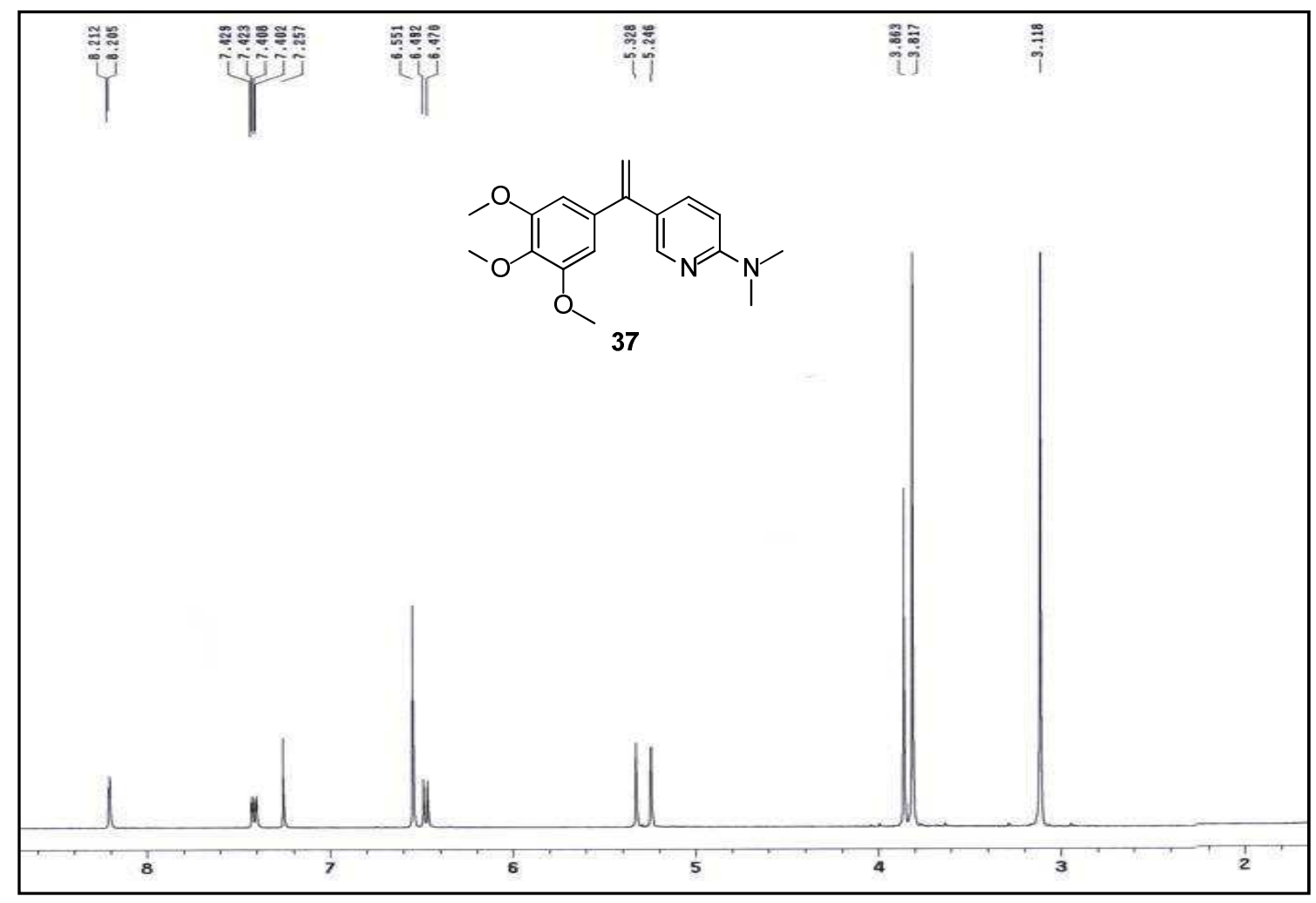

Figura XXXa: Espectro de RMN ${ }^{1} \mathrm{H}$ del compuesto 37.

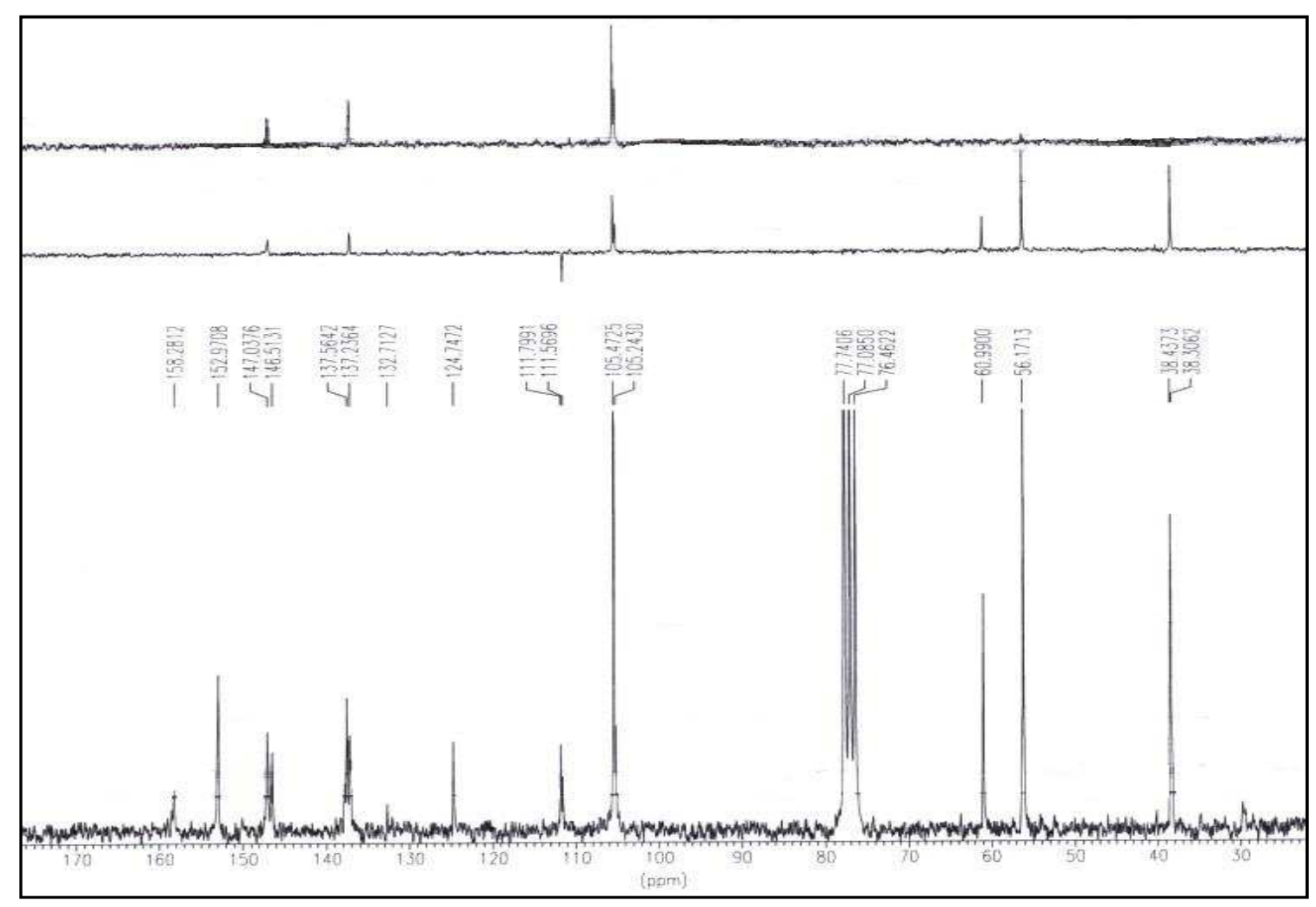

Figura XXXb: Espectro de RMN ${ }^{13} \mathrm{C}$ del compuesto 37 . 


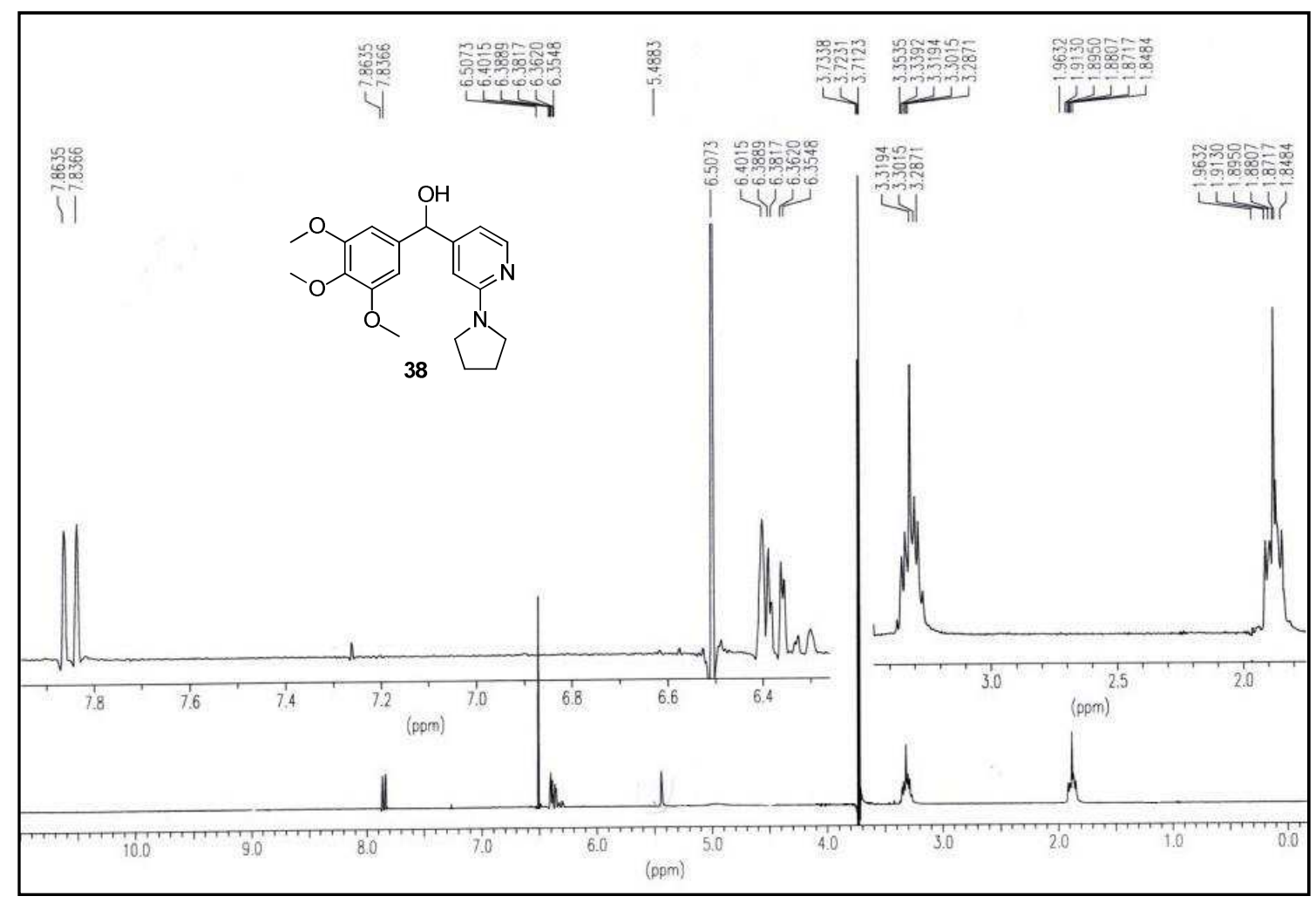

Figura XXXIa: Espectro de RMN ${ }^{1} \mathrm{H}$ del compuesto 38 .

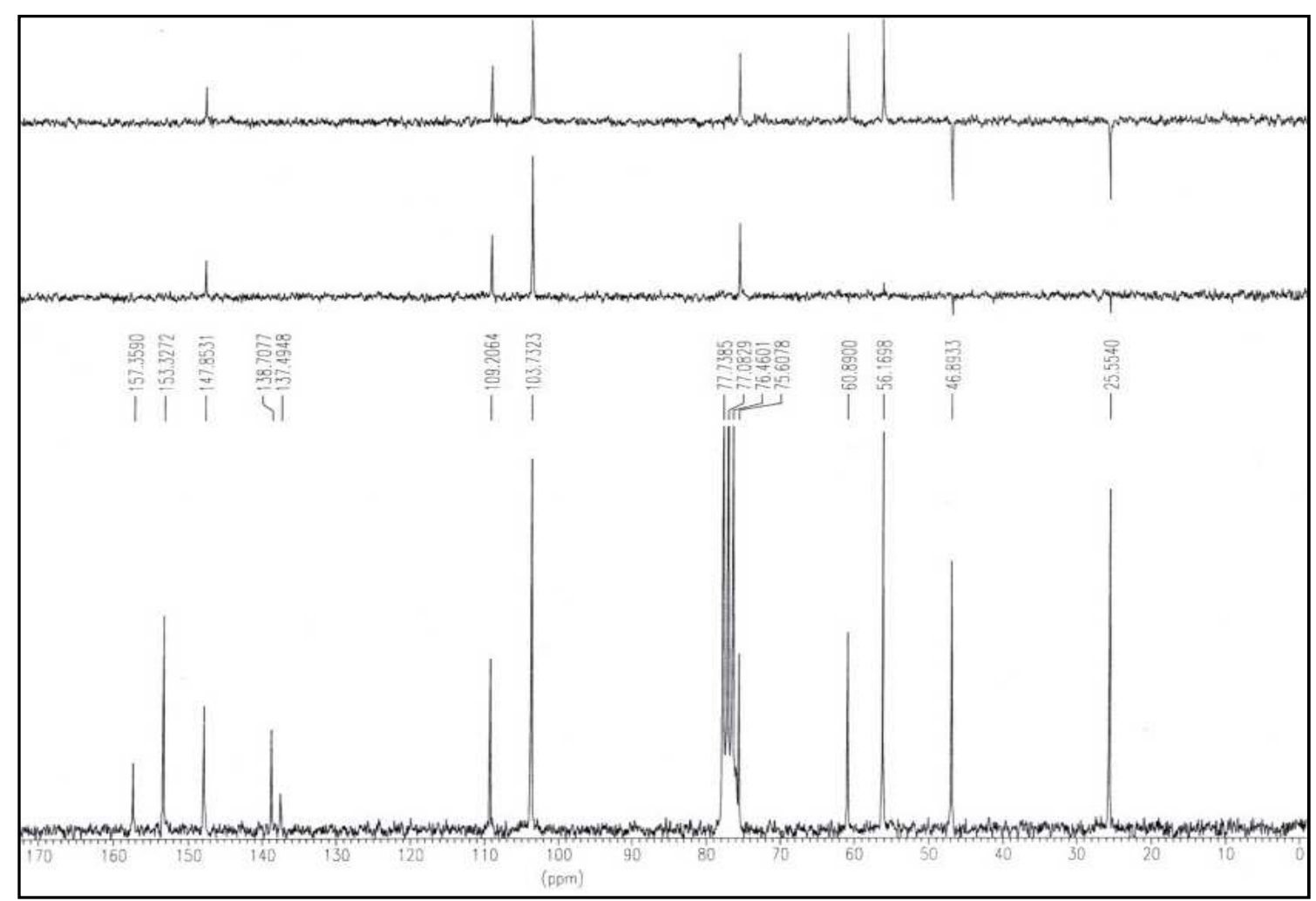

Figura XXXIb: Espectro de RMN ${ }^{13} \mathrm{C}$ del compuesto 38 . 


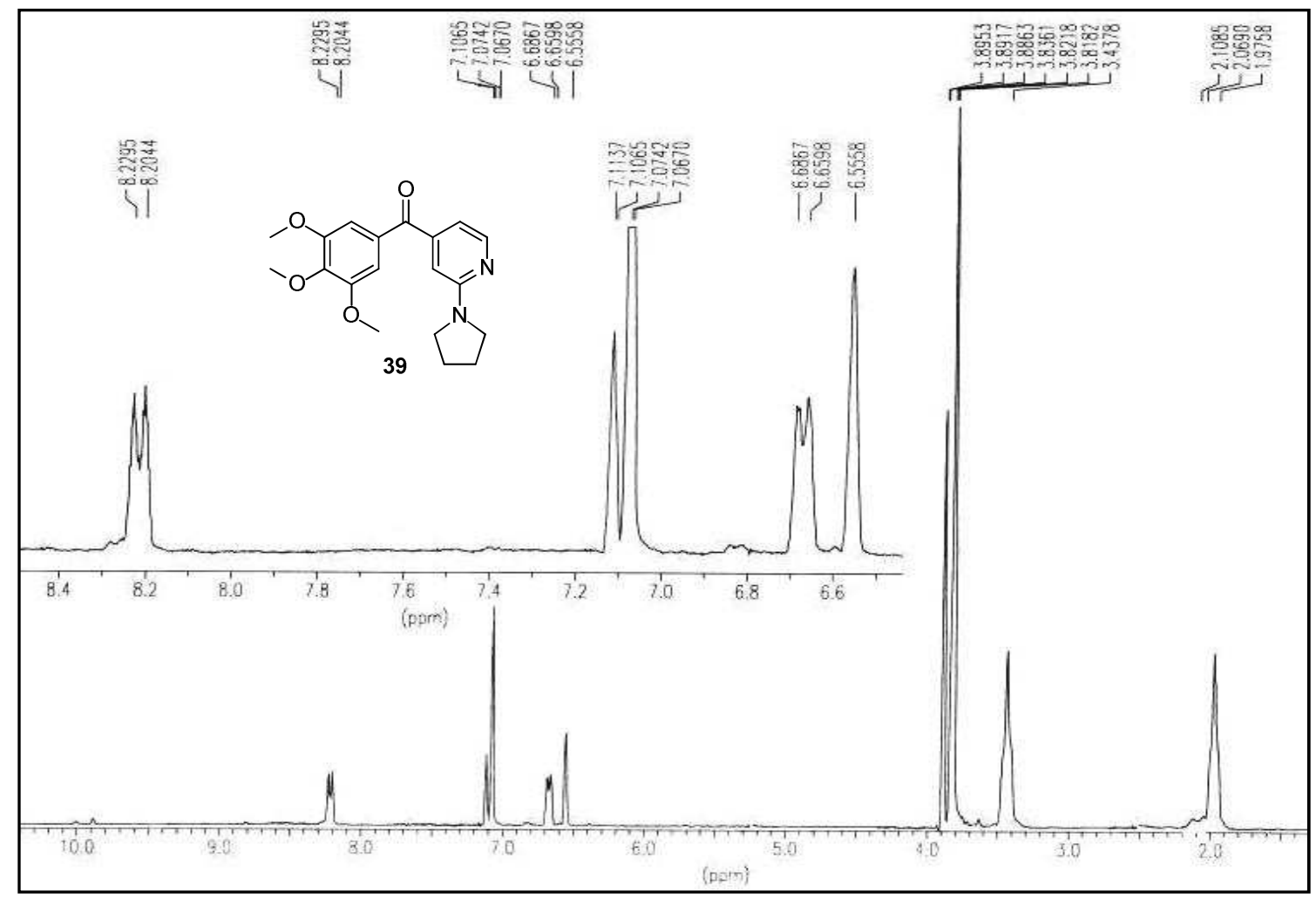

Figura XXXIIa: Espectro de RMN ${ }^{1} \mathrm{H}$ del compuesto 39.

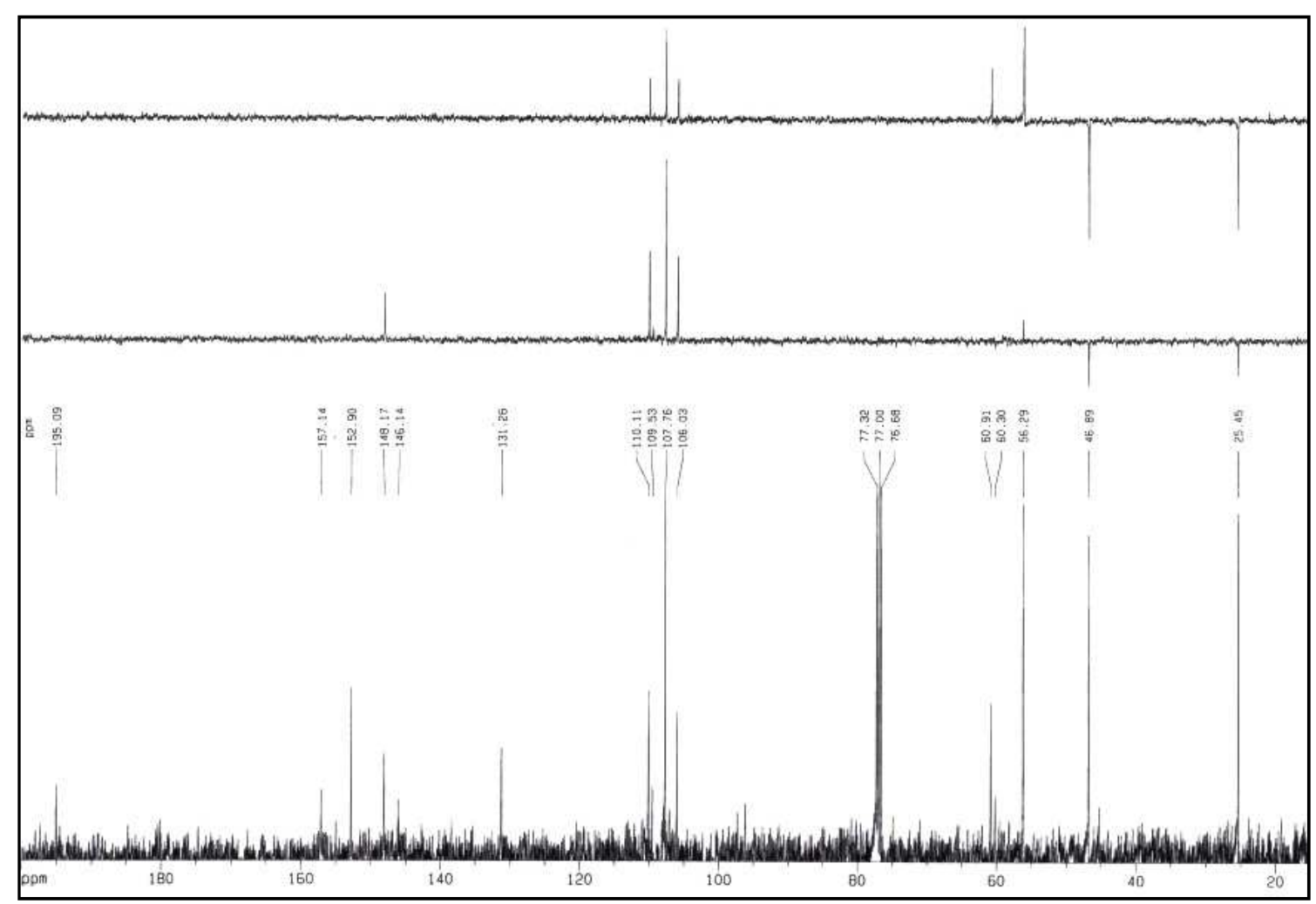

Figura XXXIIb: Espectro de RMN ${ }^{13} \mathrm{C}$ del compuesto 39 . 


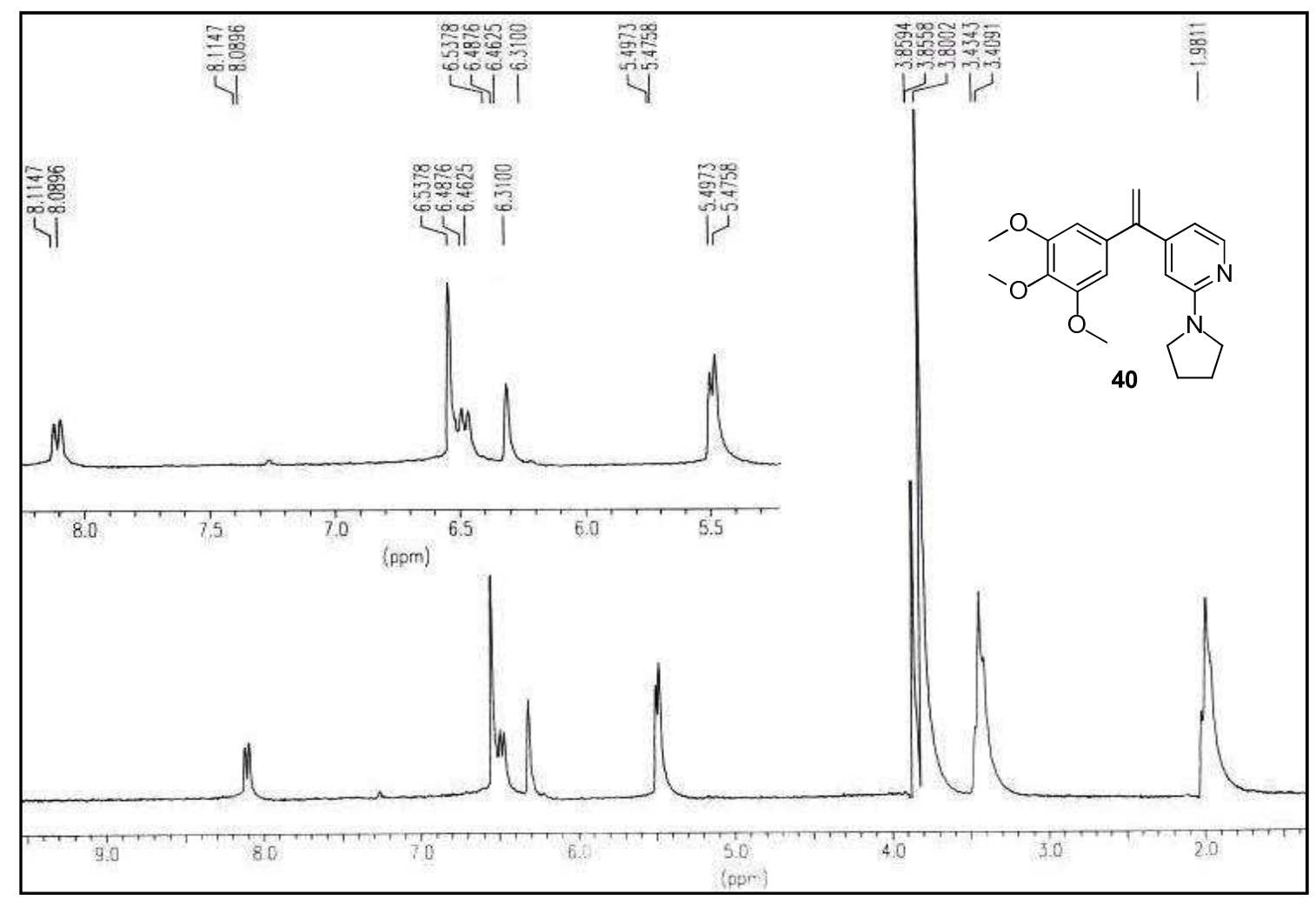

Figura XXXIIIa: Espectro de RMN ${ }^{1} \mathrm{H}$ del compuesto $\mathbf{4 0 .}$

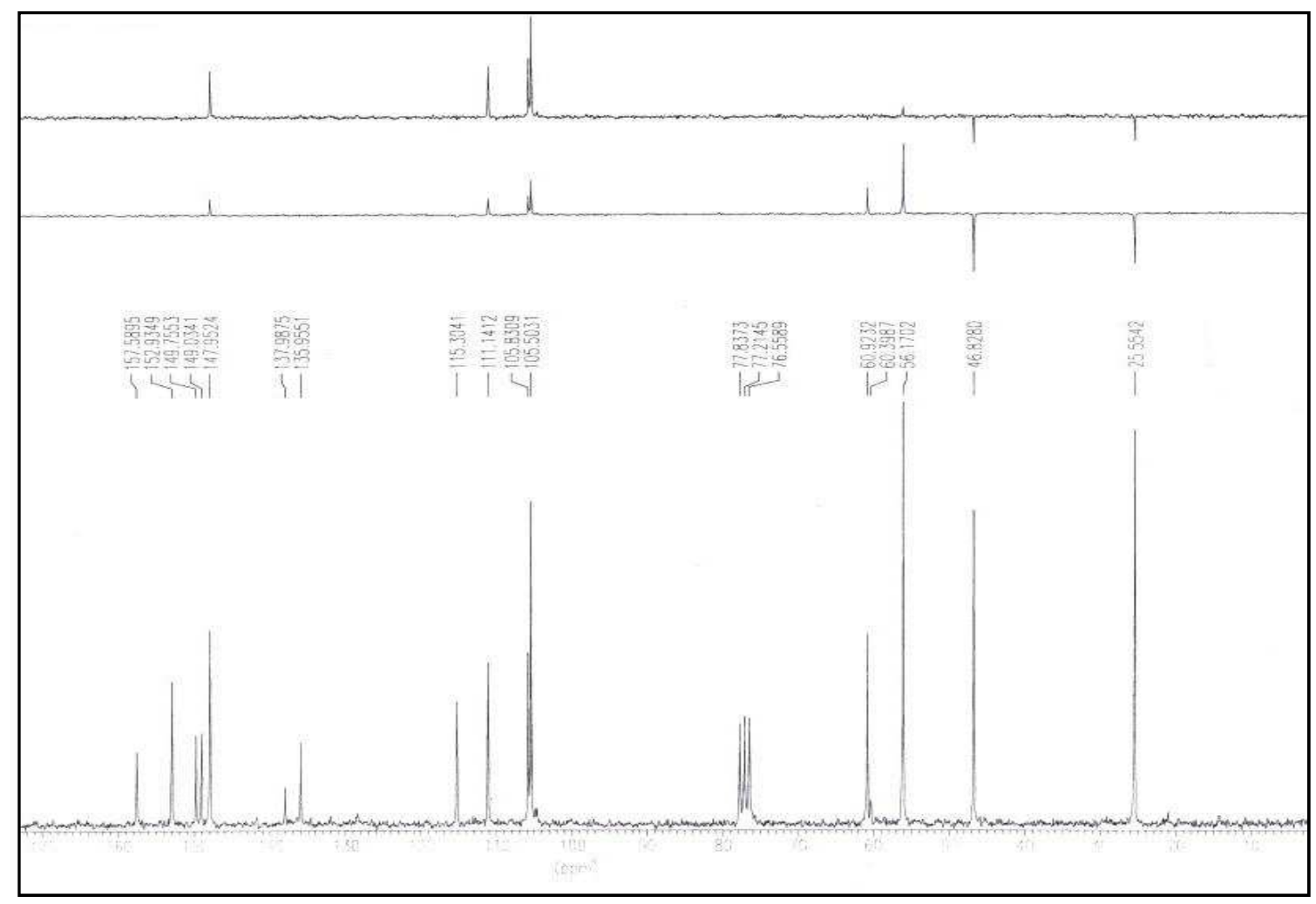

Figura XXXIIIb: Espectro de RMN ${ }^{13} \mathrm{C}$ del compuesto 40. 


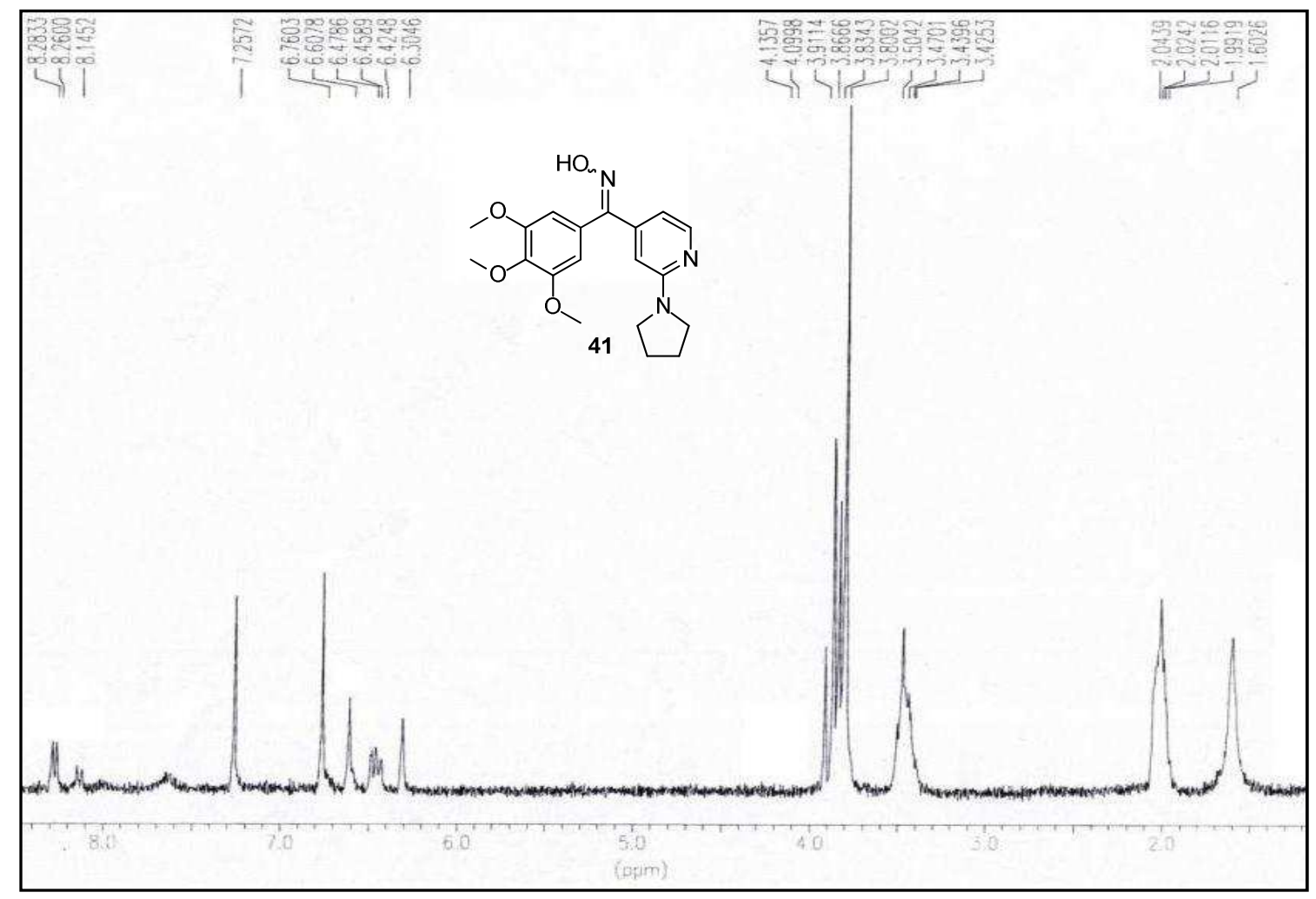

Figura XXXIVa: Espectro de RMN ${ }^{1} \mathrm{H}$ del compuesto 41.

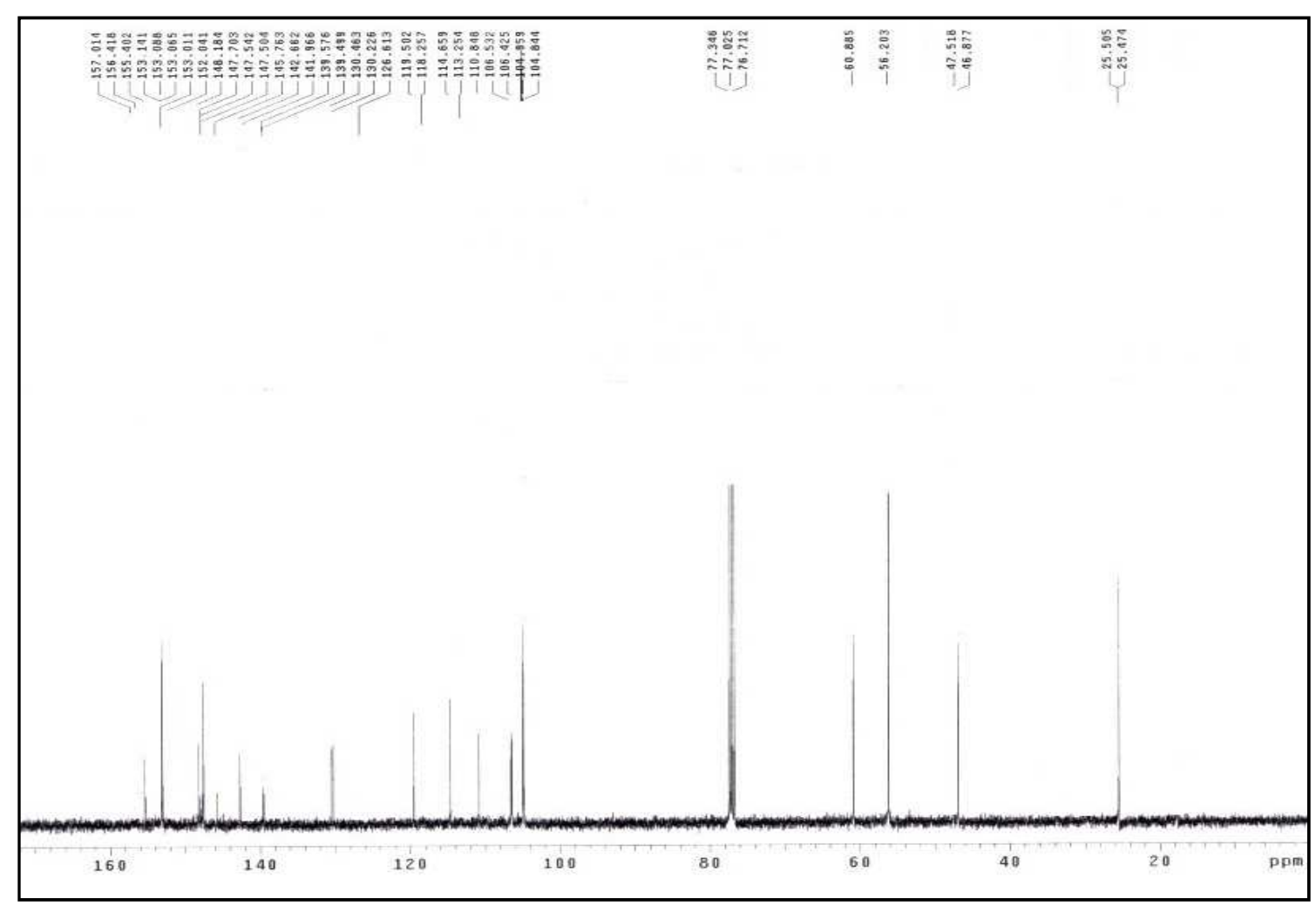

Figura XXXIVb: Espectro de RMN ${ }^{13} \mathrm{C}$ del compuesto 41. 


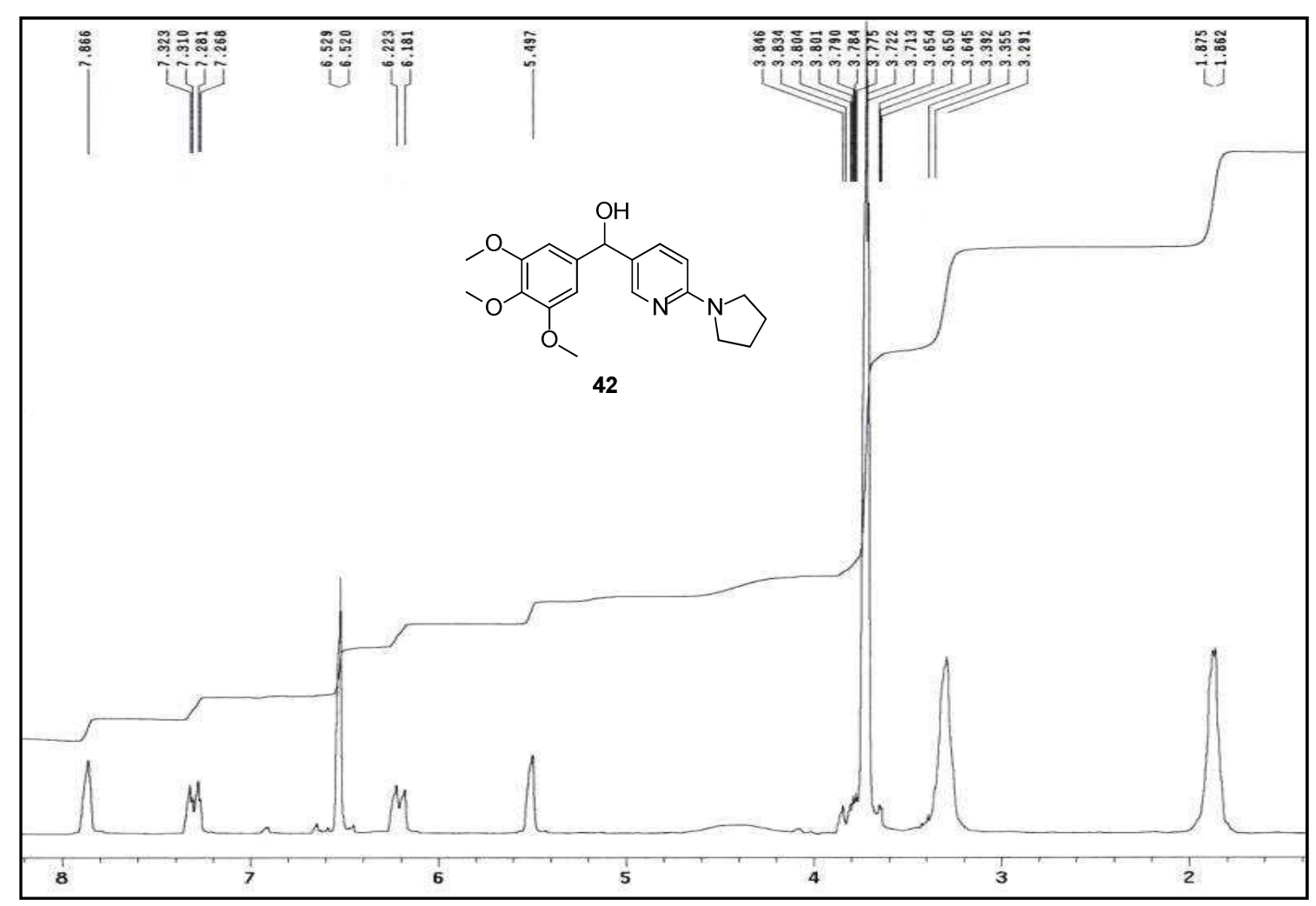

Figura XXXV: Espectro de RMN ${ }^{1} \mathrm{H}$ del compuesto $\mathbf{4 2}$. 


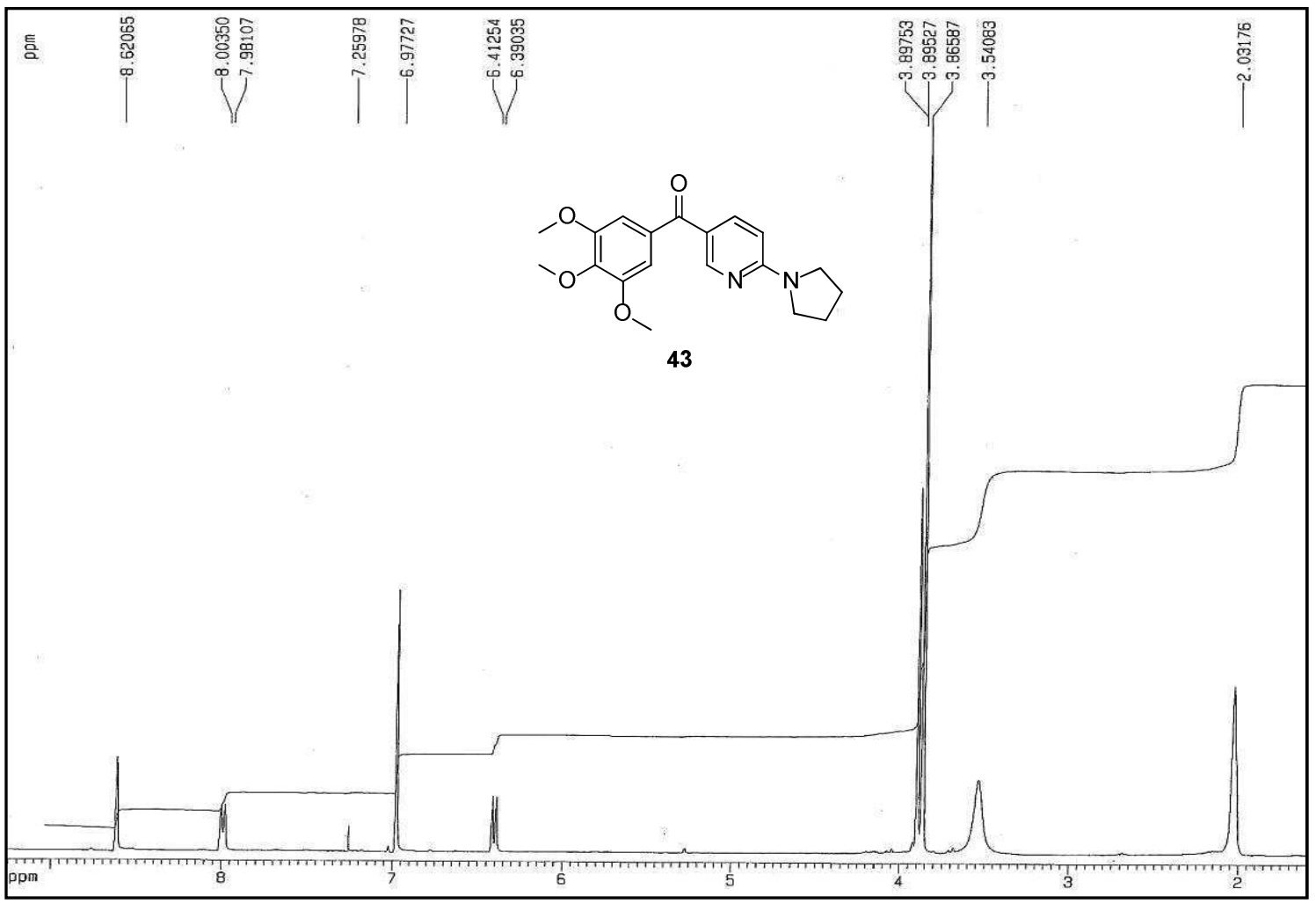

Figura XXXVIa: Espectro de RMN ${ }^{1} \mathrm{H}$ del compuesto 43.

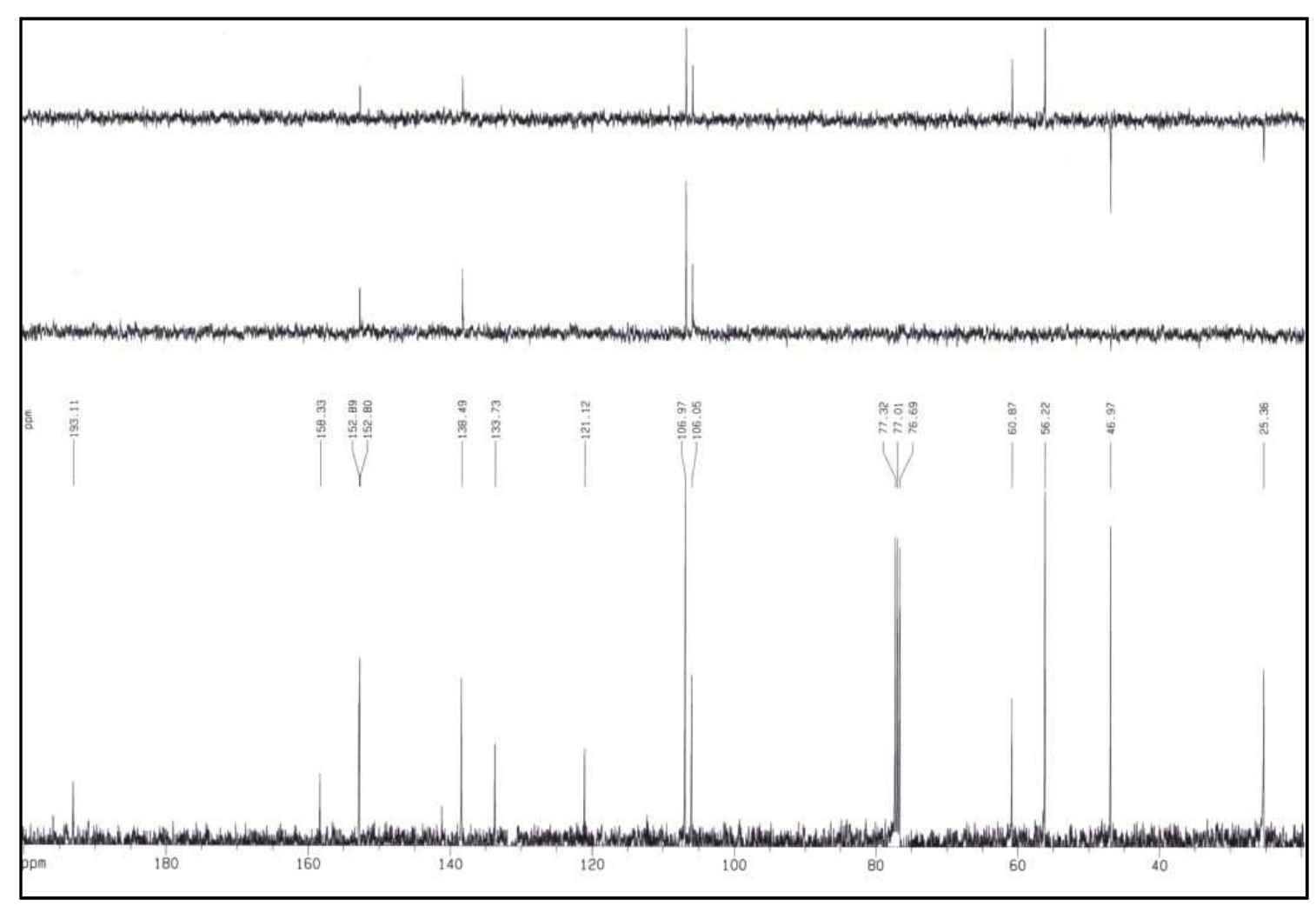

Figura XXXVIb: Espectro de RMN ${ }^{13} \mathrm{C}$ del compuesto $\mathbf{4 3}$. 


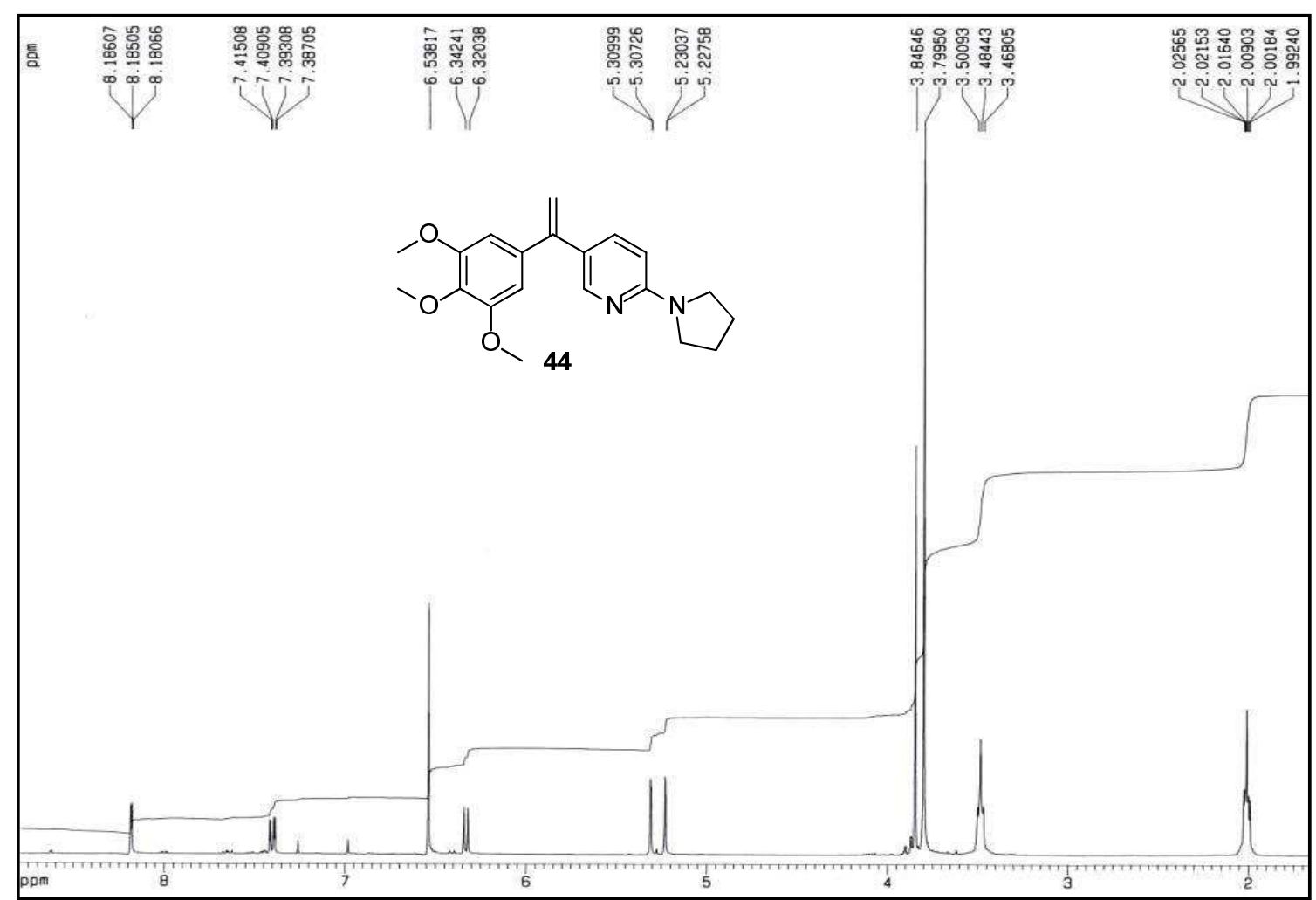

Figura XXXVIIa: Espectro de RMN ${ }^{1} \mathrm{H}$ del compuesto 44.

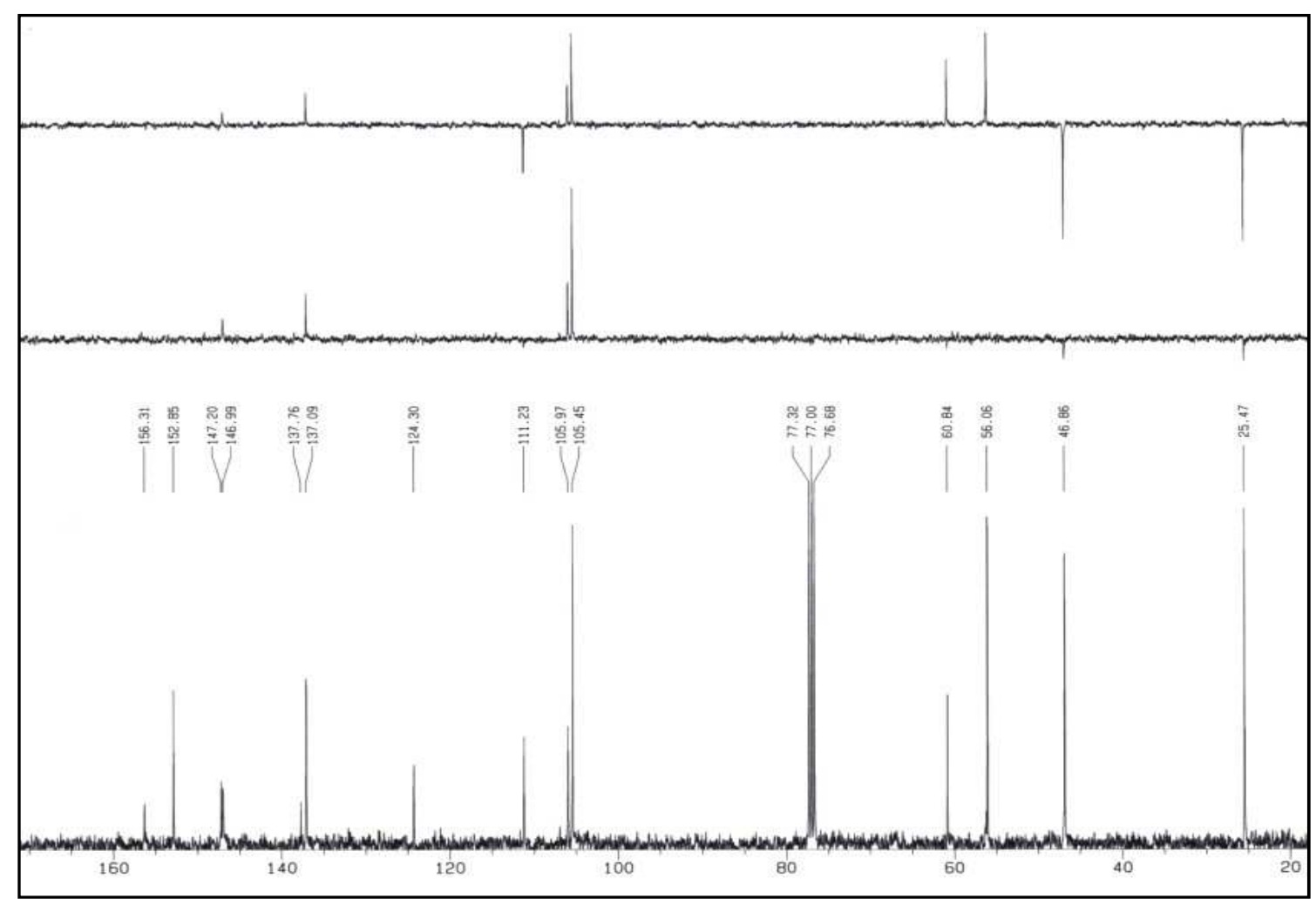

Figura XXXVIIb: Espectro de RMN ${ }^{13} \mathrm{C}$ del compuesto 44. 


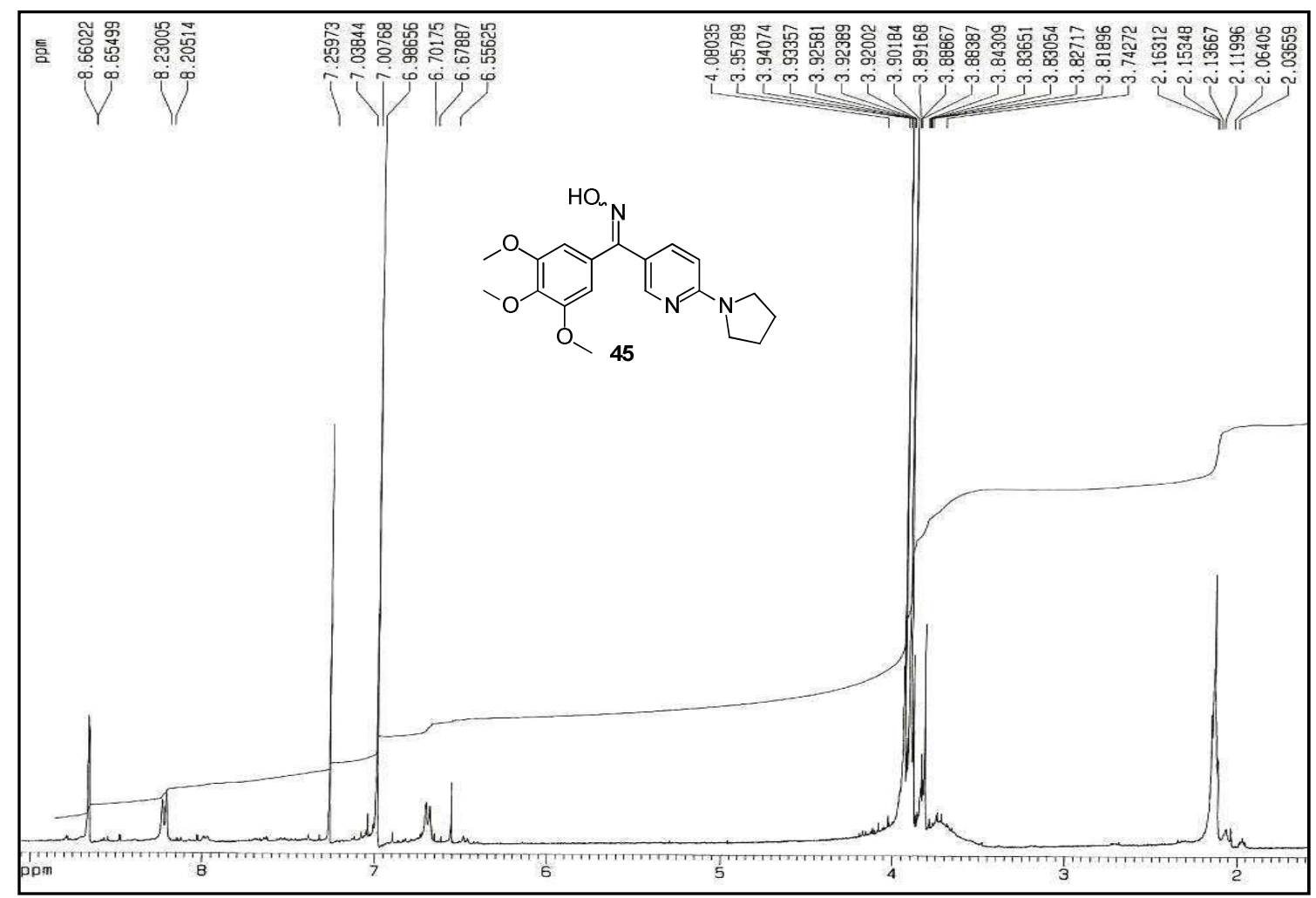

Figura XXXVIII: Espectro de RMN ${ }^{1} \mathrm{H}$ del compuesto 45.

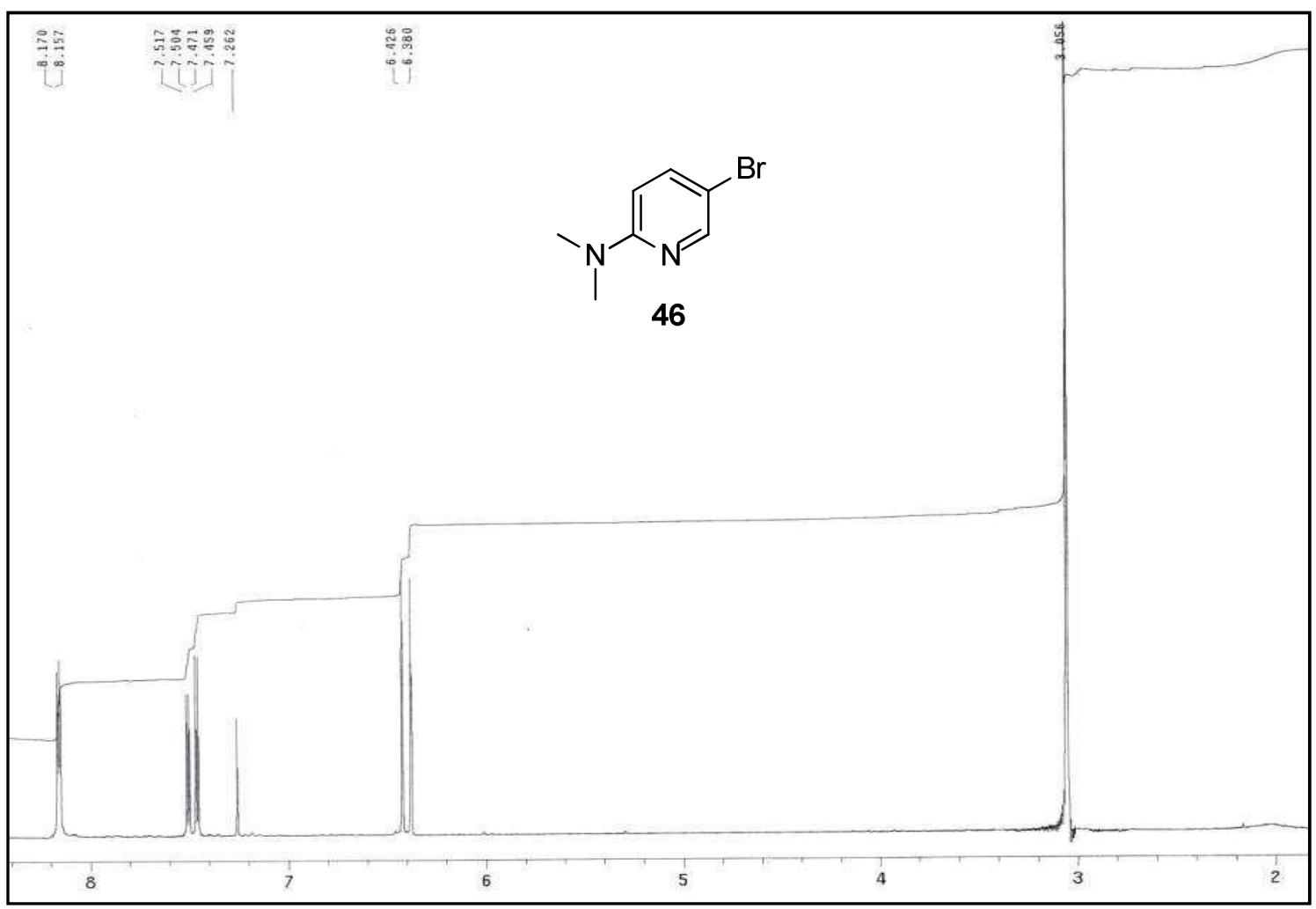

Figura XXXIX: Espectro de RMN ${ }^{1} \mathrm{H}$ del compuesto 46. 


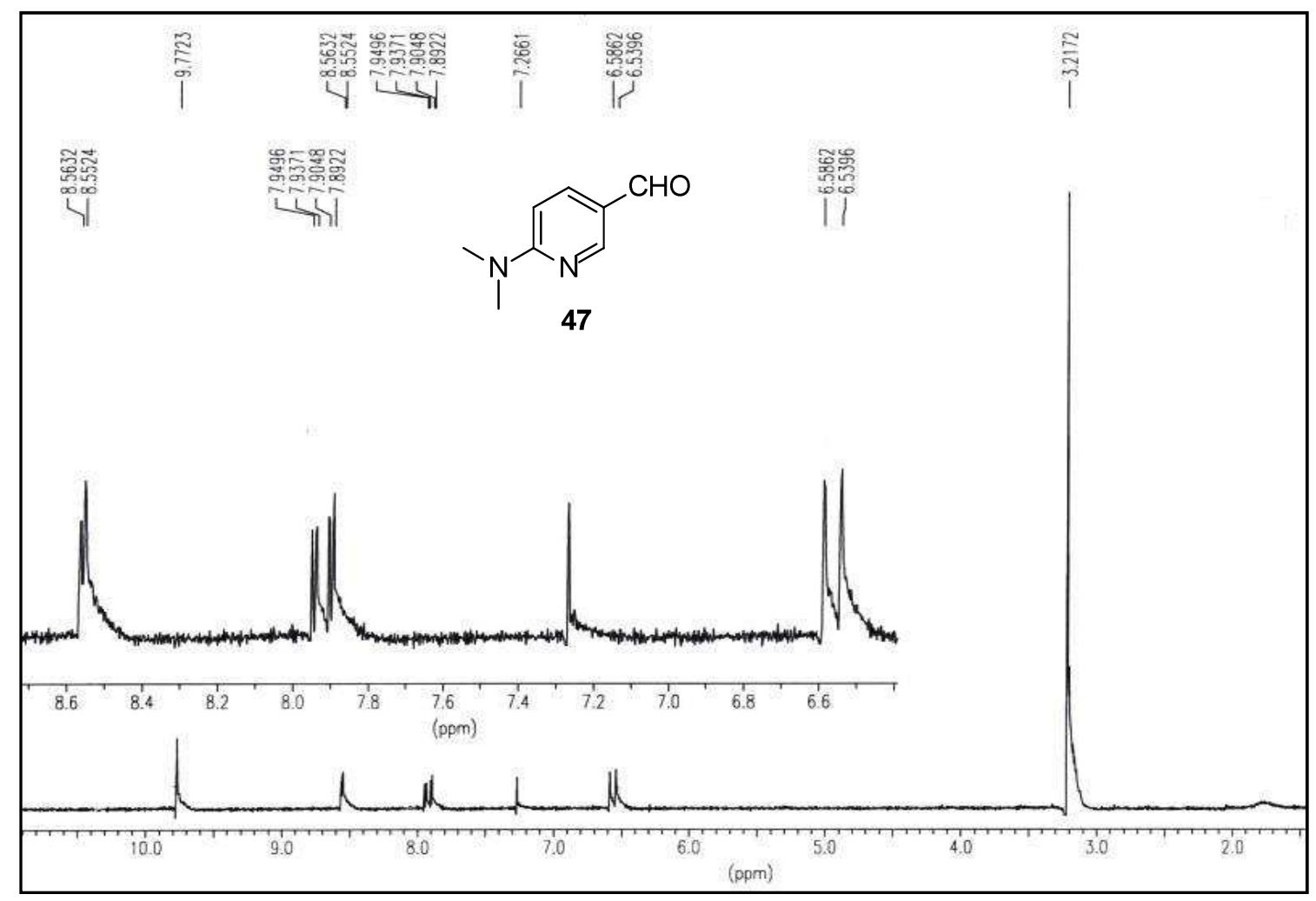

Figura XLa: Espectro de RMN ${ }^{1} \mathrm{H}$ del compuesto 47.

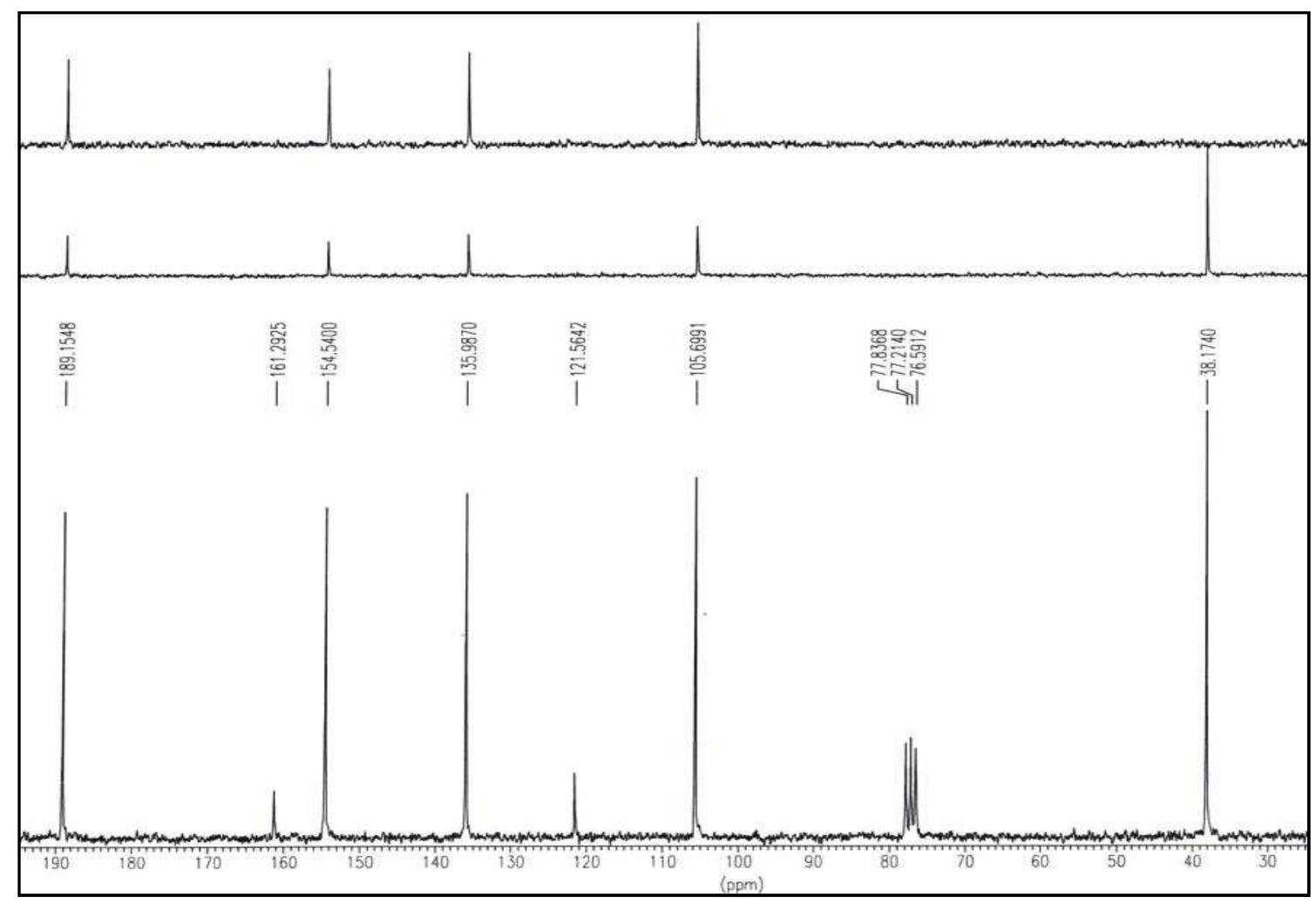

Figura XLb: Espectro de RMN ${ }^{13} \mathrm{C}$ del compuesto 47. 


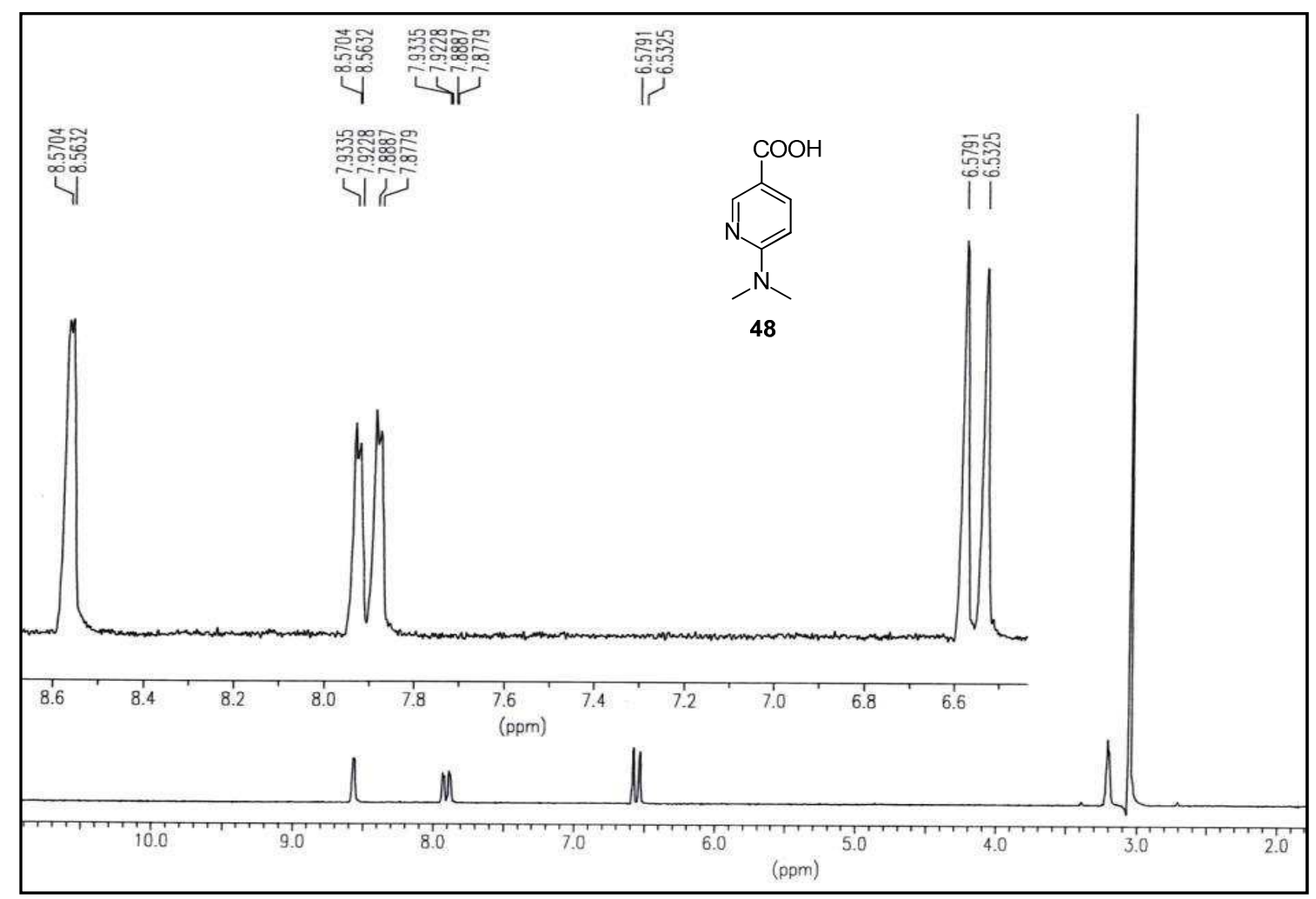

Figura XLIa: Espectro de RMN ${ }^{1} \mathrm{H}$ del compuesto 48.

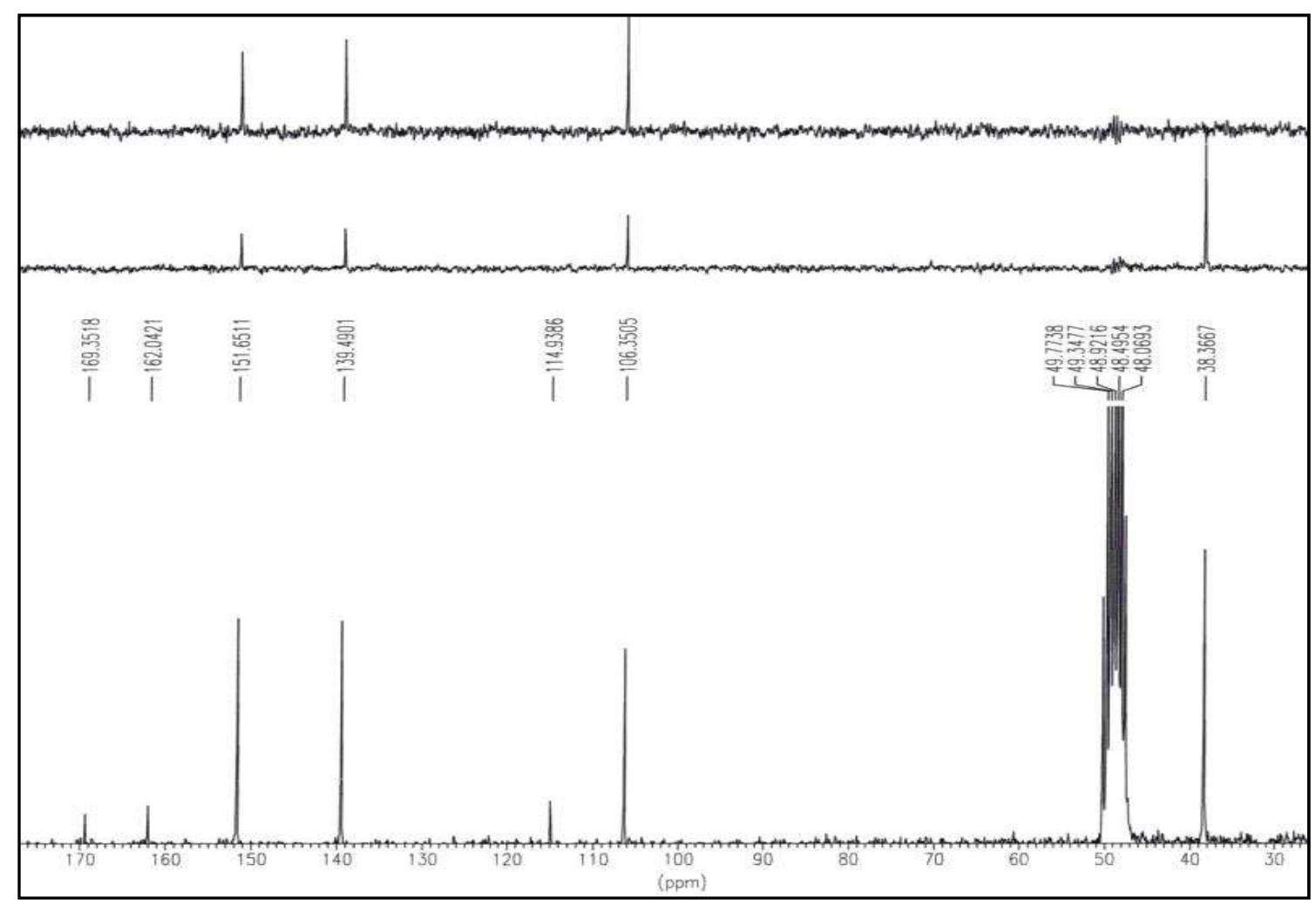

Figura XLIb: Espectro de RMN ${ }^{13} \mathrm{C}$ del compuesto 48. 


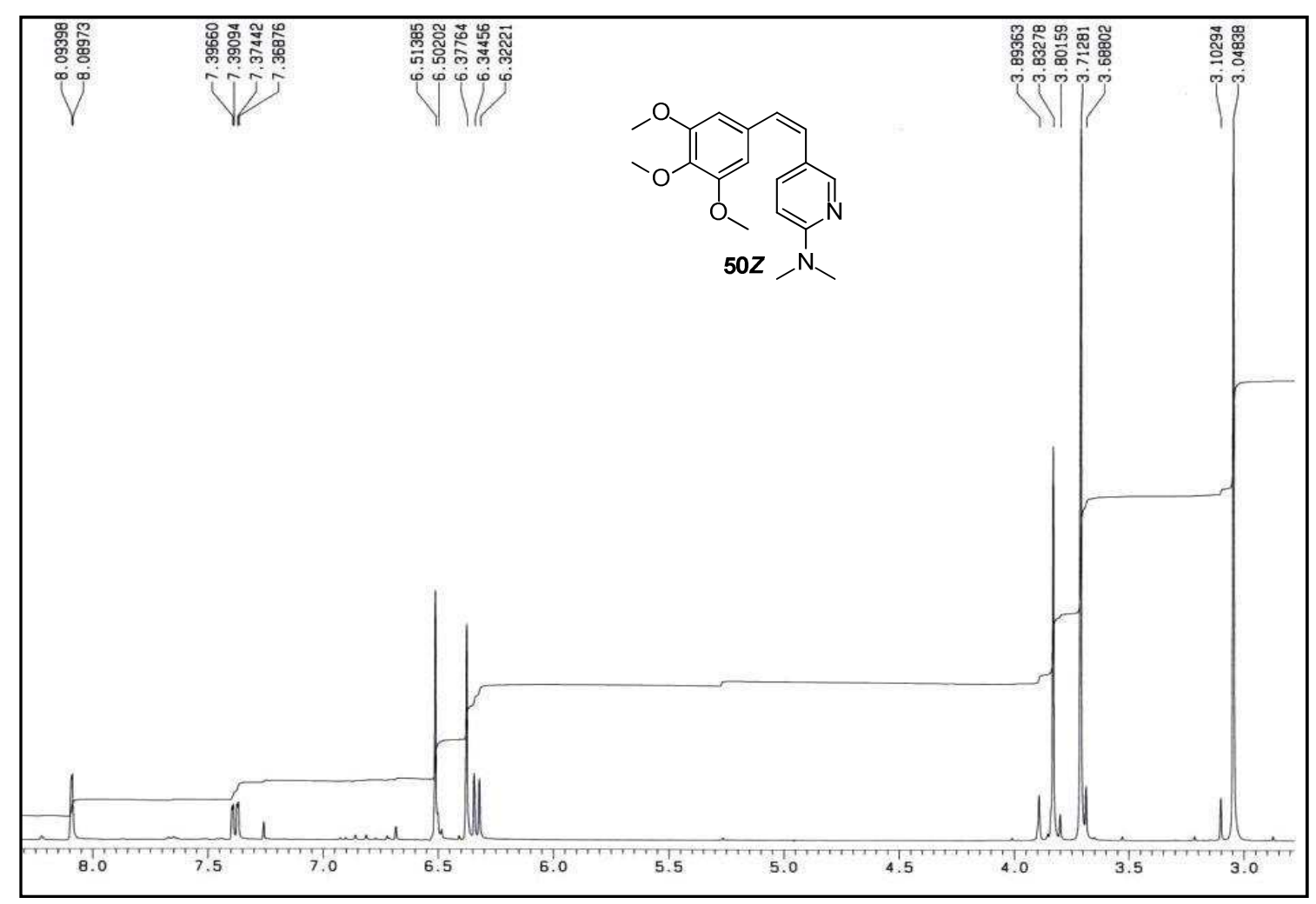

Figura XLIIa: Espectro de RMN ${ }^{1} \mathrm{H}$ del compuesto $\mathbf{5 0 Z}$.

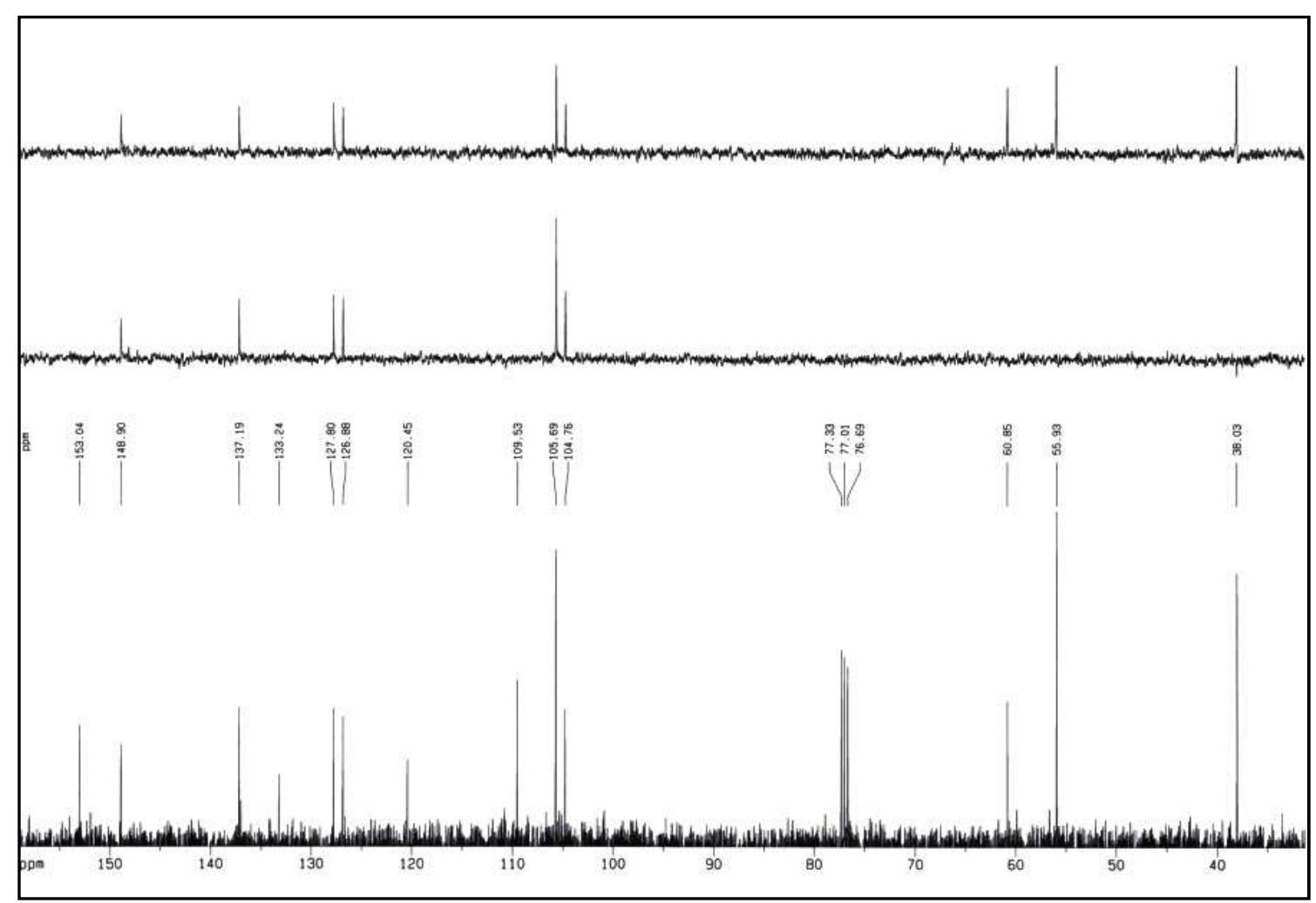

Figura XLIIb: Espectro de RMN ${ }^{13} \mathrm{C}$ del compuesto $\mathbf{5 0 Z}$. 


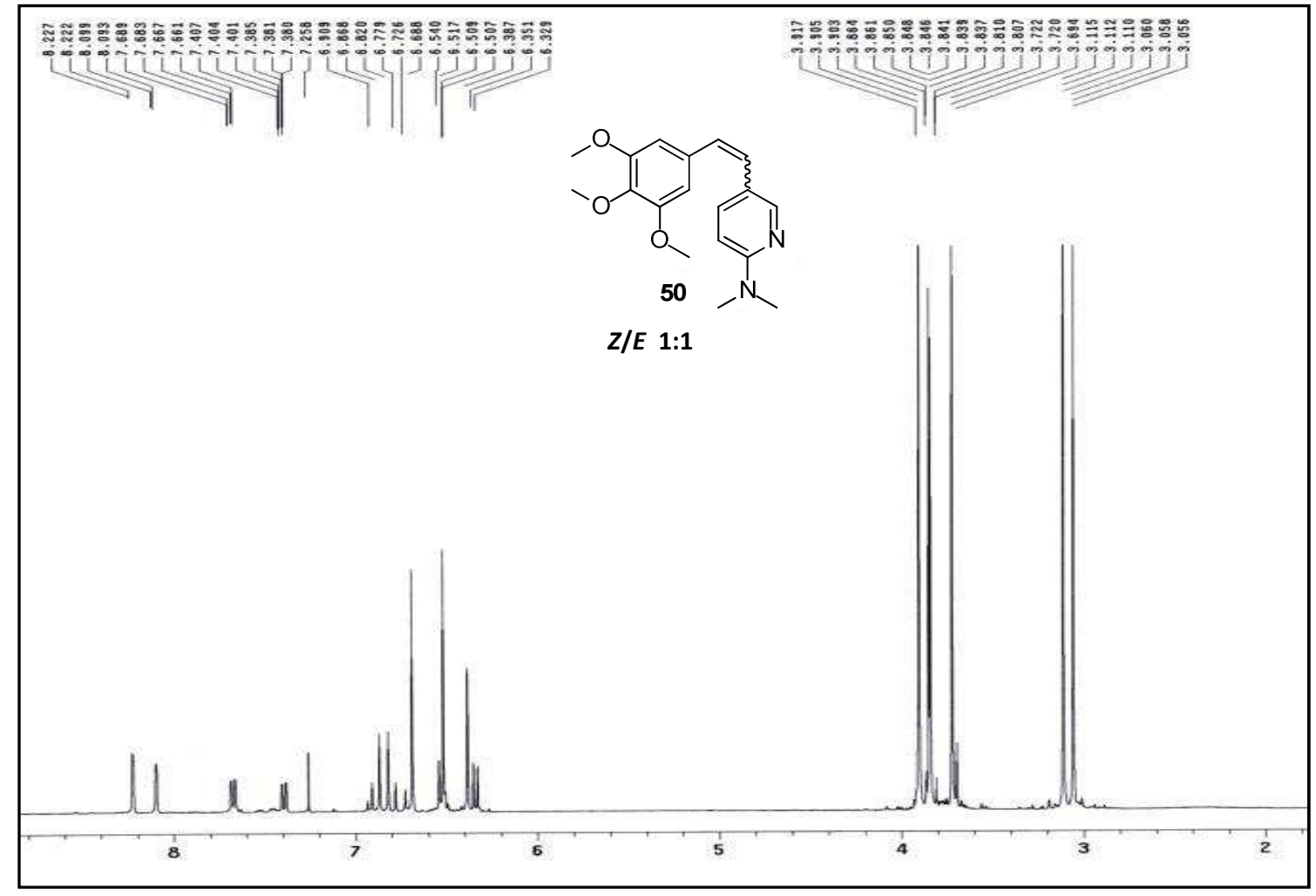

Figura XLIIc: Espectro de RMN ${ }^{1} \mathrm{H}$ del compuesto 50.

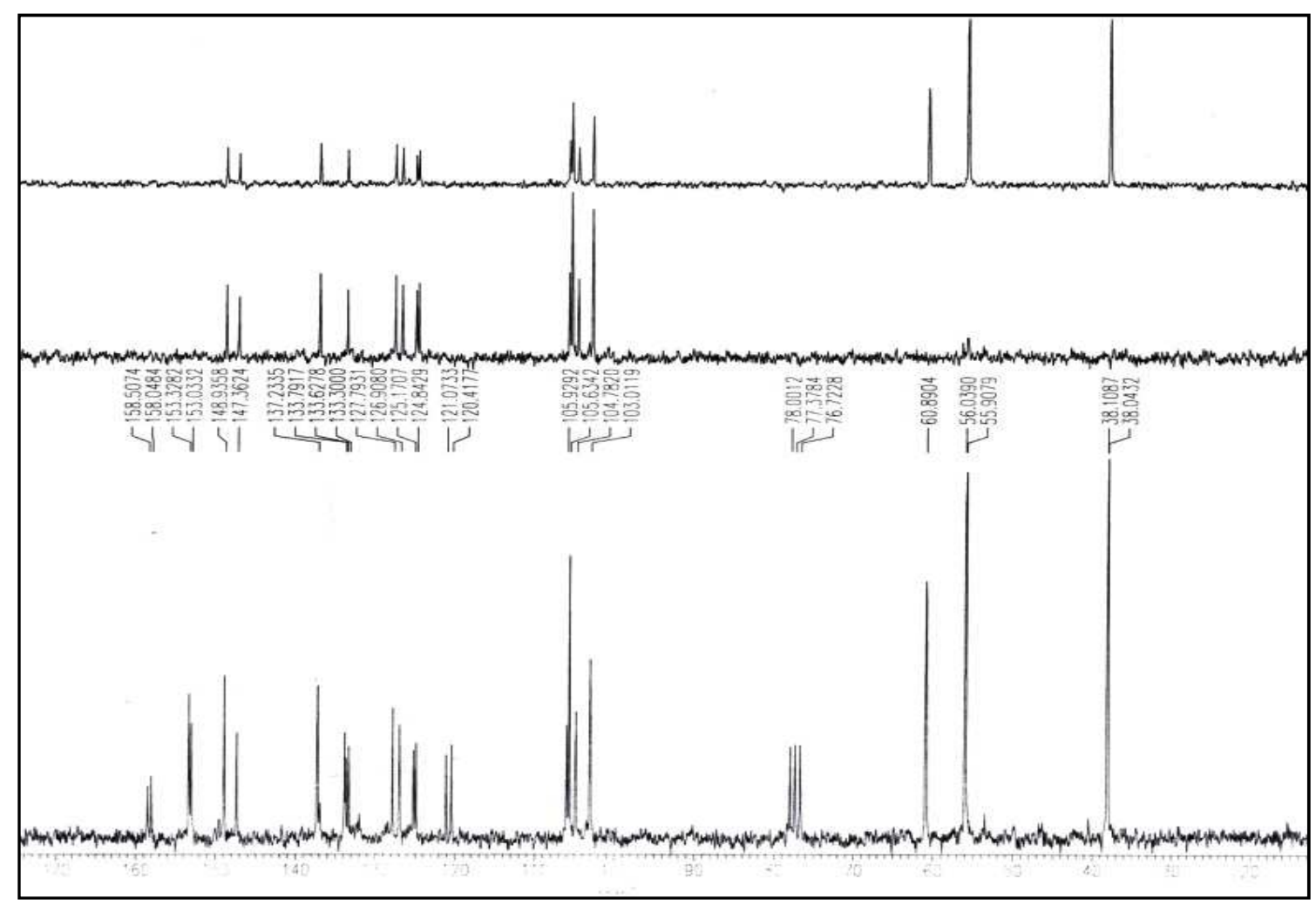

Figura XLIId: Espectro de RMN ${ }^{13} \mathrm{C}$ del compuesto 50. 


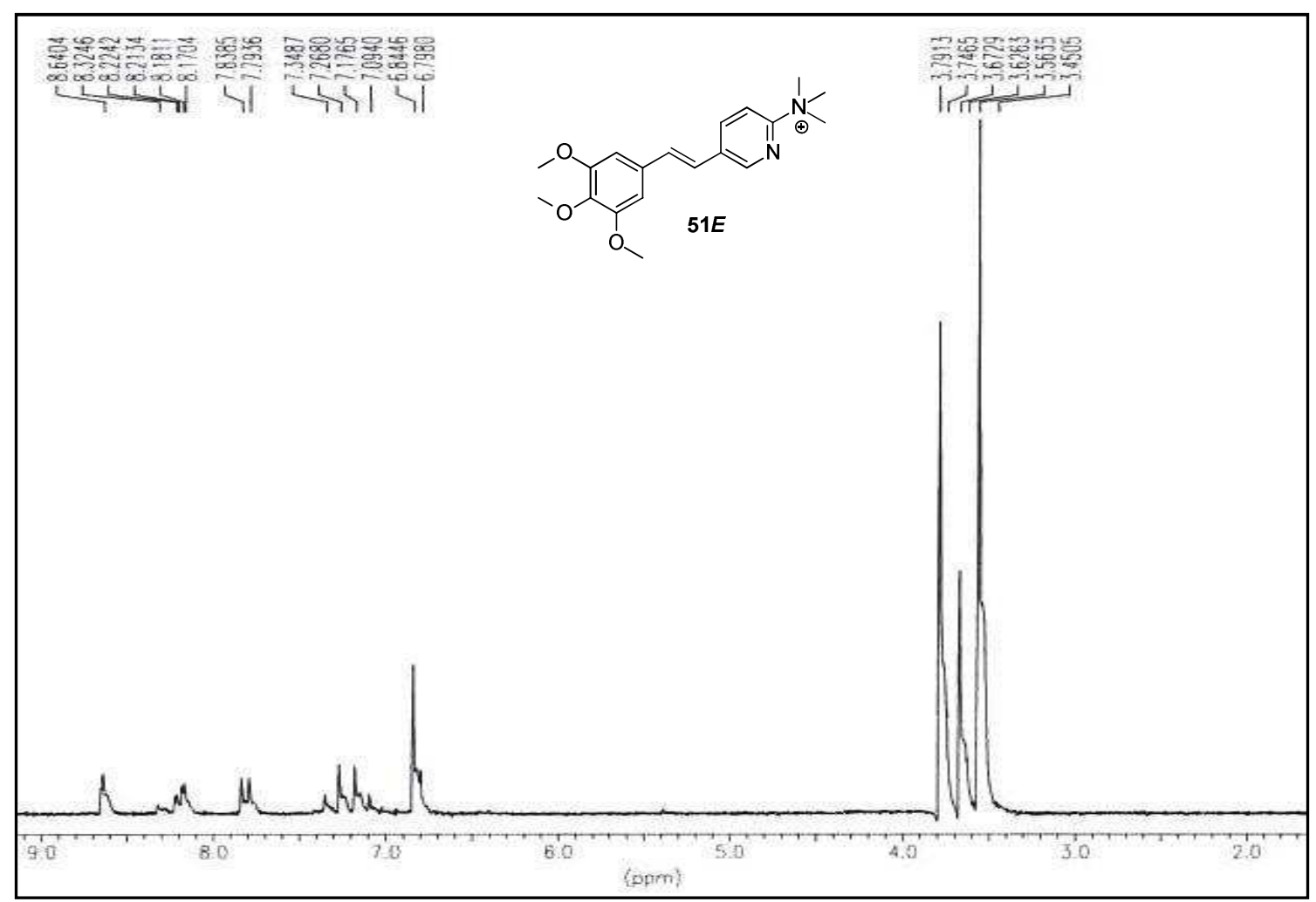

Figura XLIII: Espectro de RMN ${ }^{1} \mathrm{H}$ del compuesto $\mathbf{5 1 E}$. 


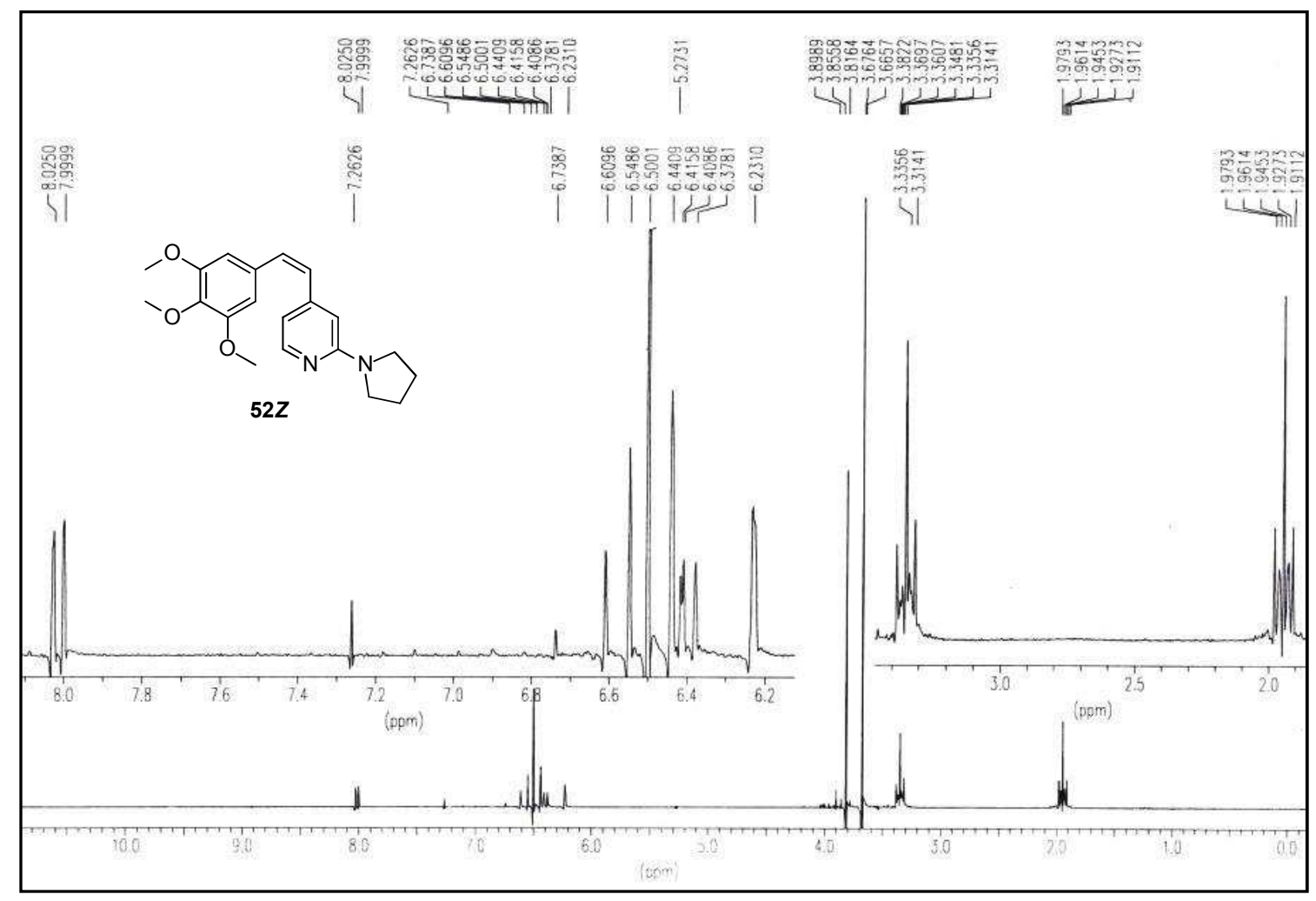

Figura XLIVa: Espectro de RMN ${ }^{1} \mathrm{H}$ del compuesto $\mathbf{5 2 Z}$.

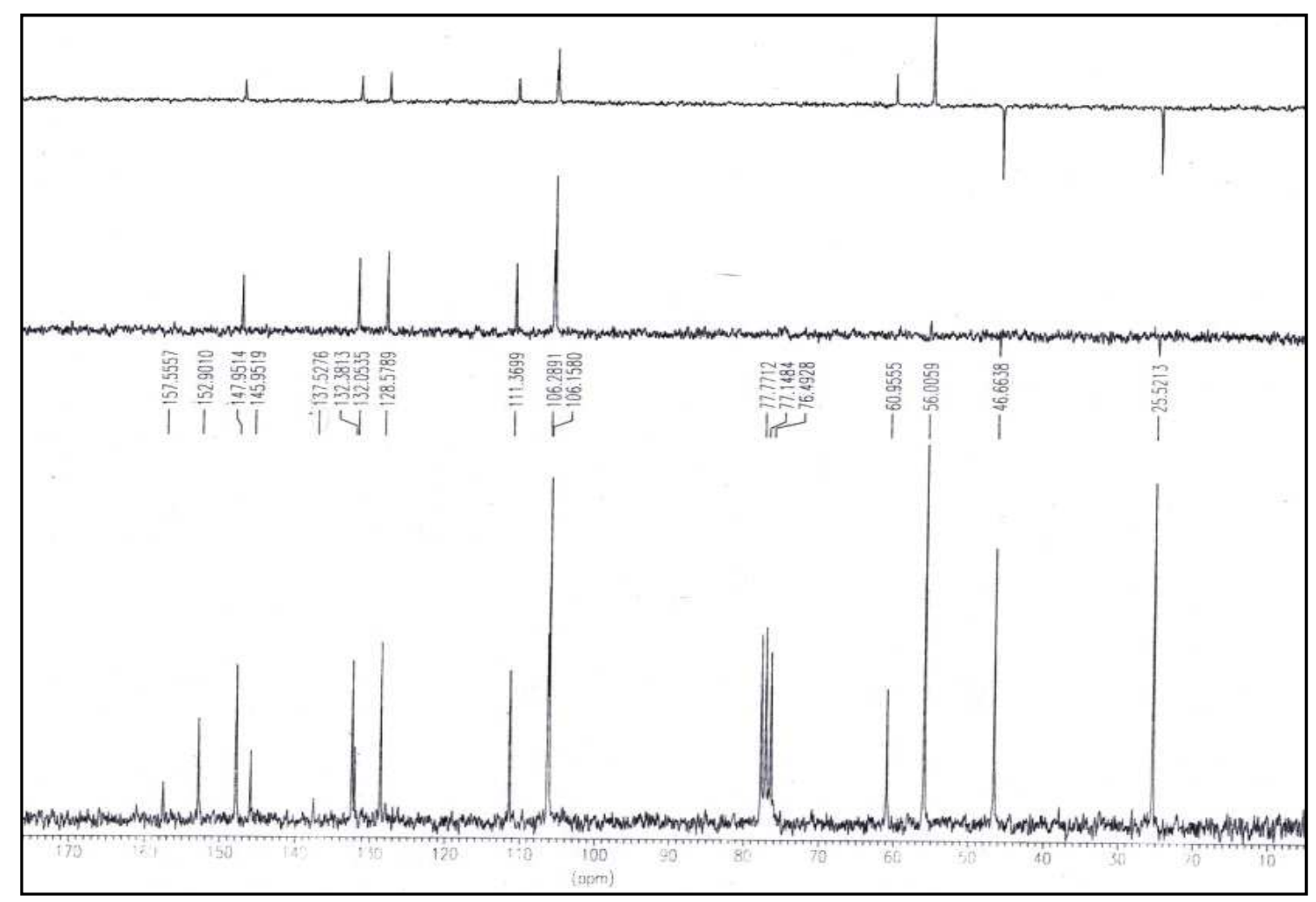

Figura XLIVb: Espectro de RMN ${ }^{13} \mathrm{C}$ del compuesto $\mathbf{5 2 Z}$. 


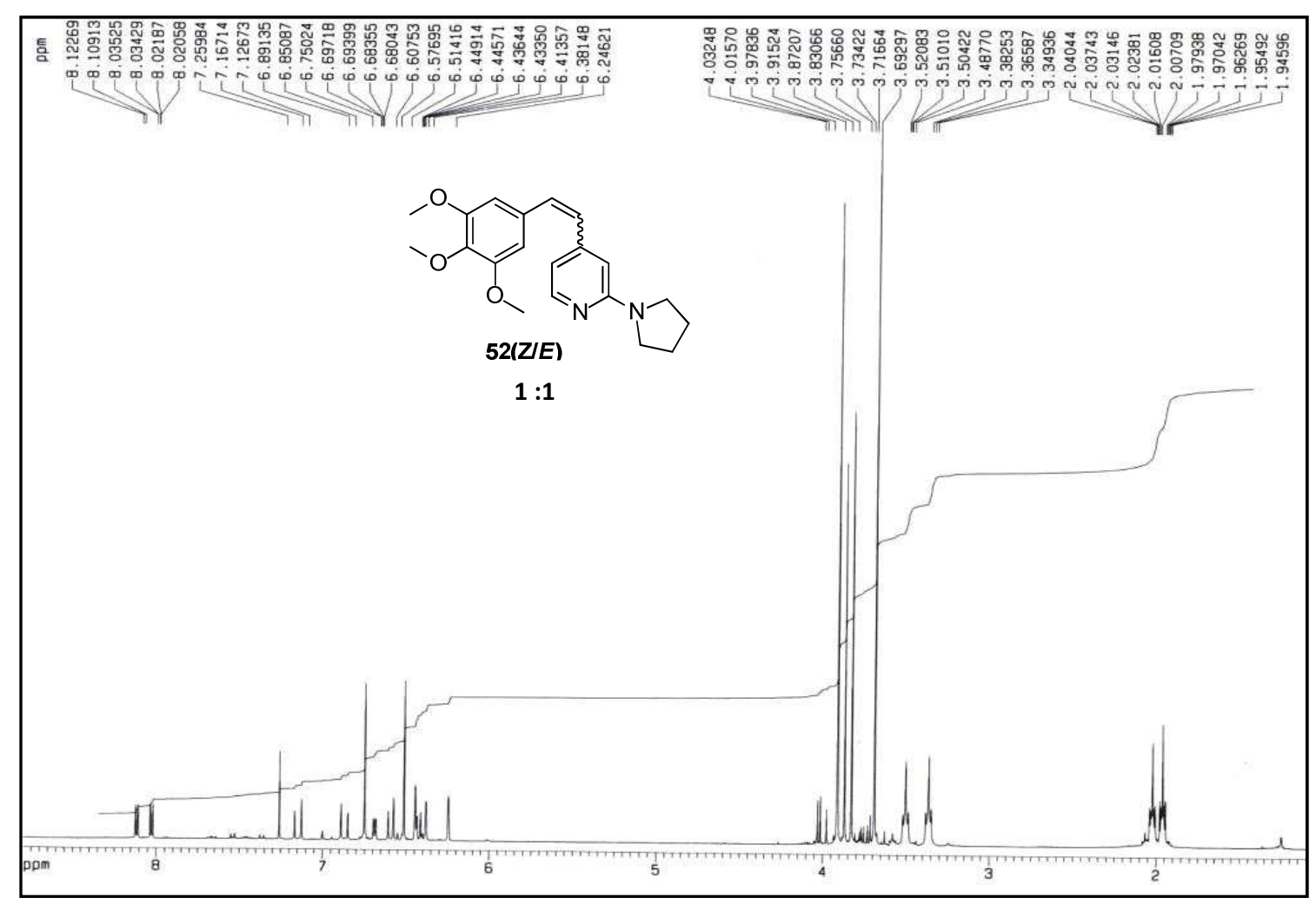

Figura XLIVc: Espectro de RMN ${ }^{1} \mathrm{H}$ del compuesto 52(Z/E).

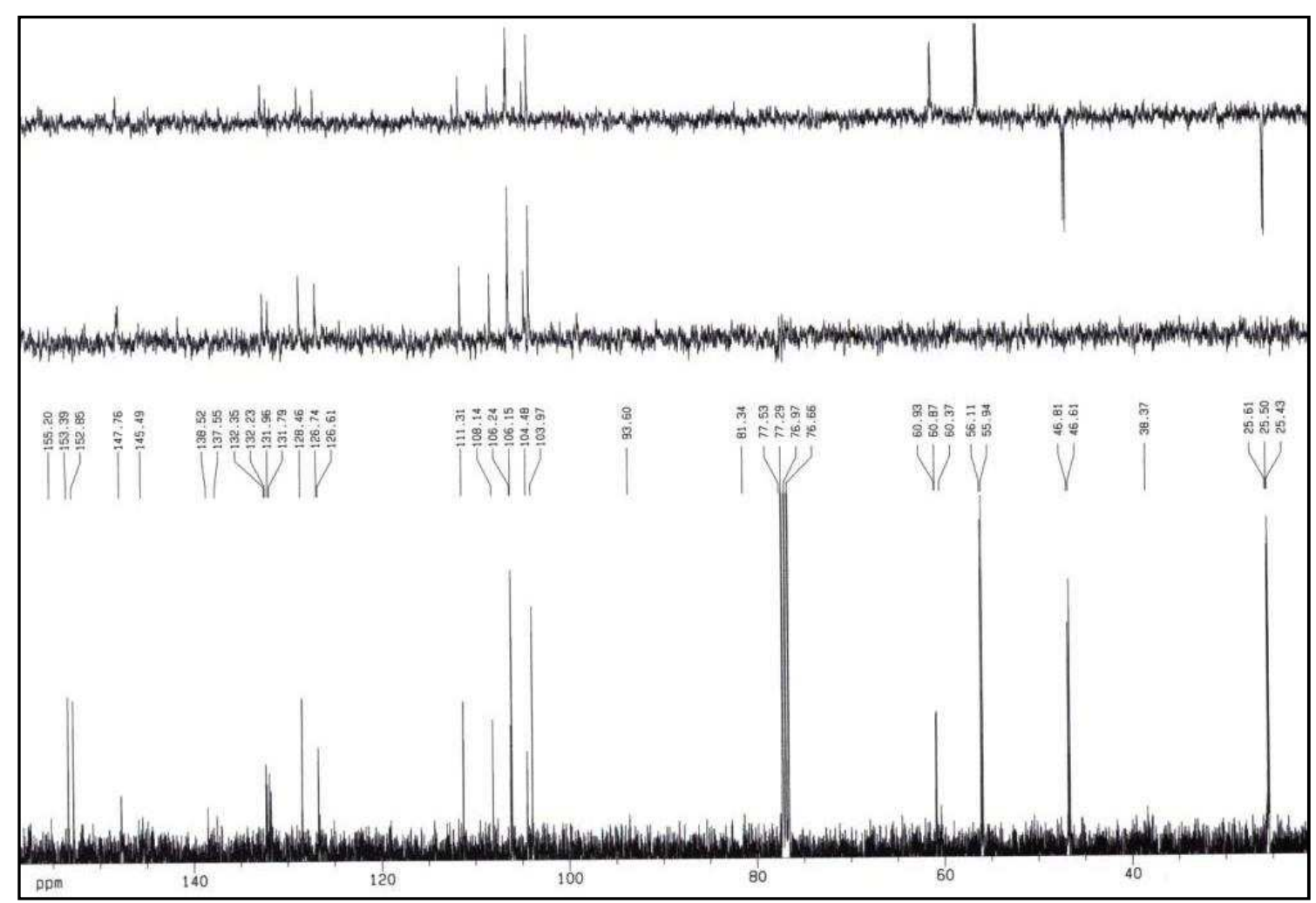

Figura XLIVd: Espectro de RMN ${ }^{13} \mathrm{C}$ del compuesto 52(Z/E). 


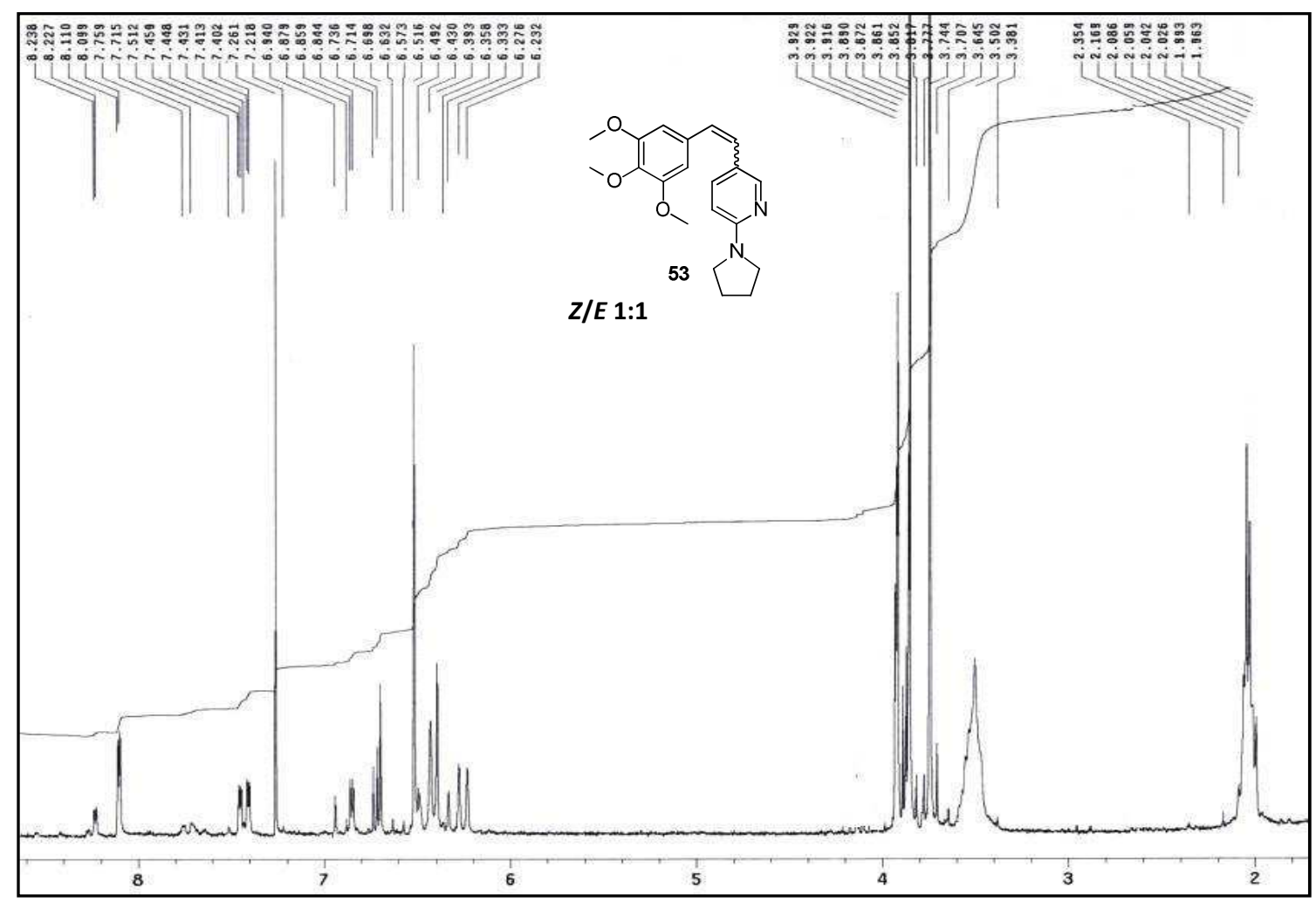

Figura XLV: Espectro de RMN ${ }^{1} \mathrm{H}$ del compuesto $\mathbf{5 3}(\boldsymbol{Z} / \boldsymbol{E})$. 


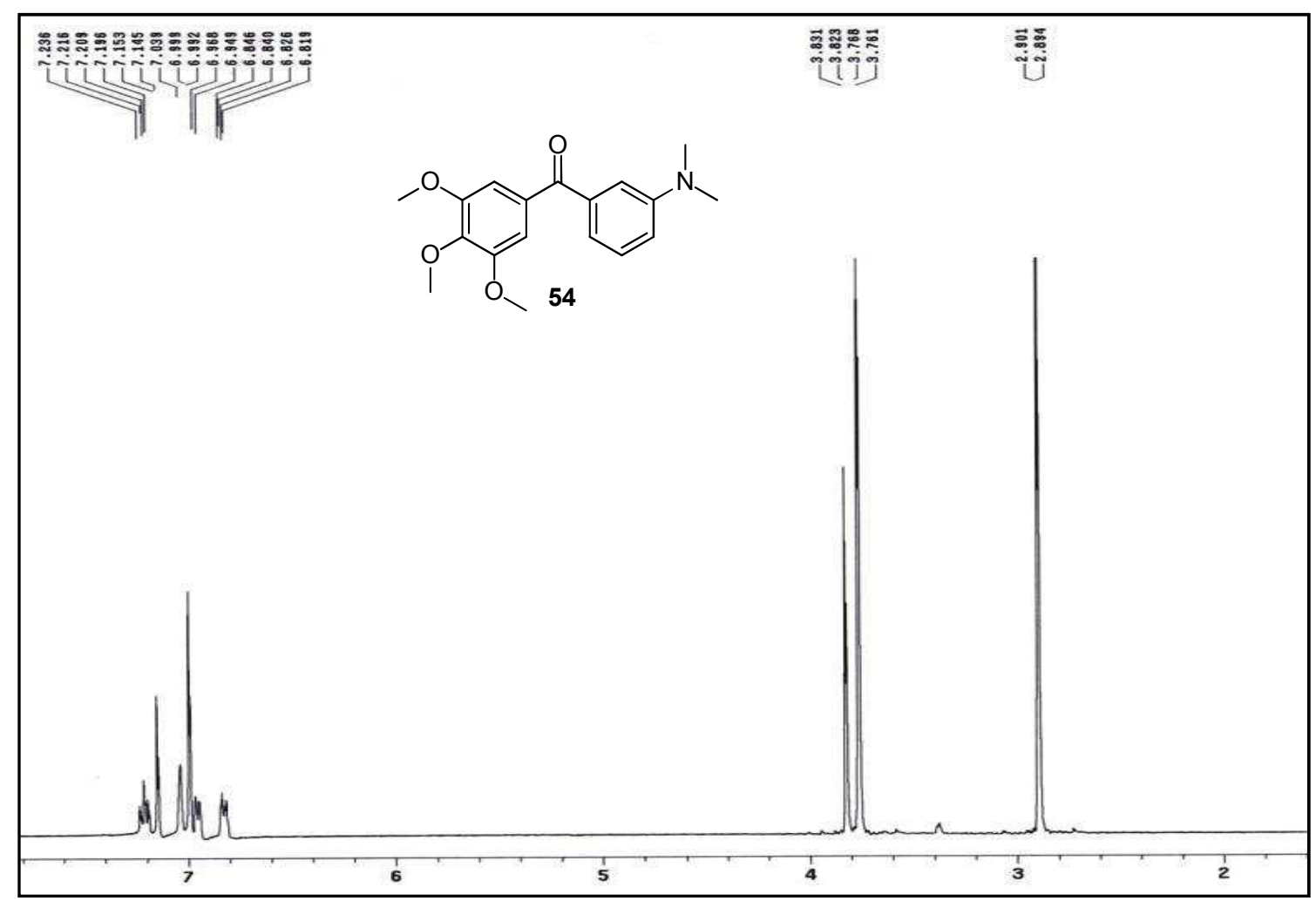

Figura XLVIa: Espectro de RMN ${ }^{1} \mathrm{H}$ del compuesto 54.

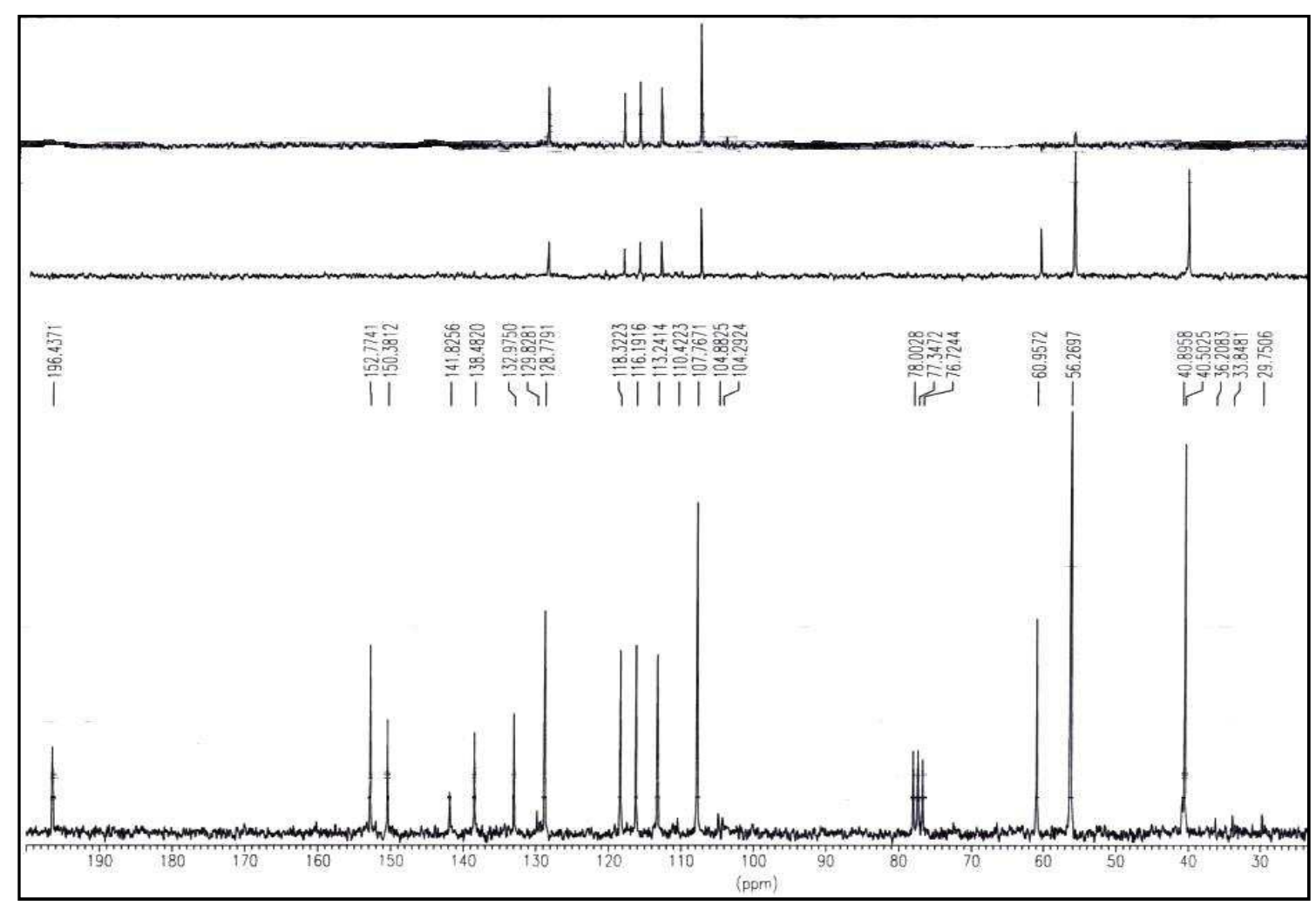

Figura XLVIb: Espectro de RMN ${ }^{13} \mathrm{C}$ del compuesto 54. 


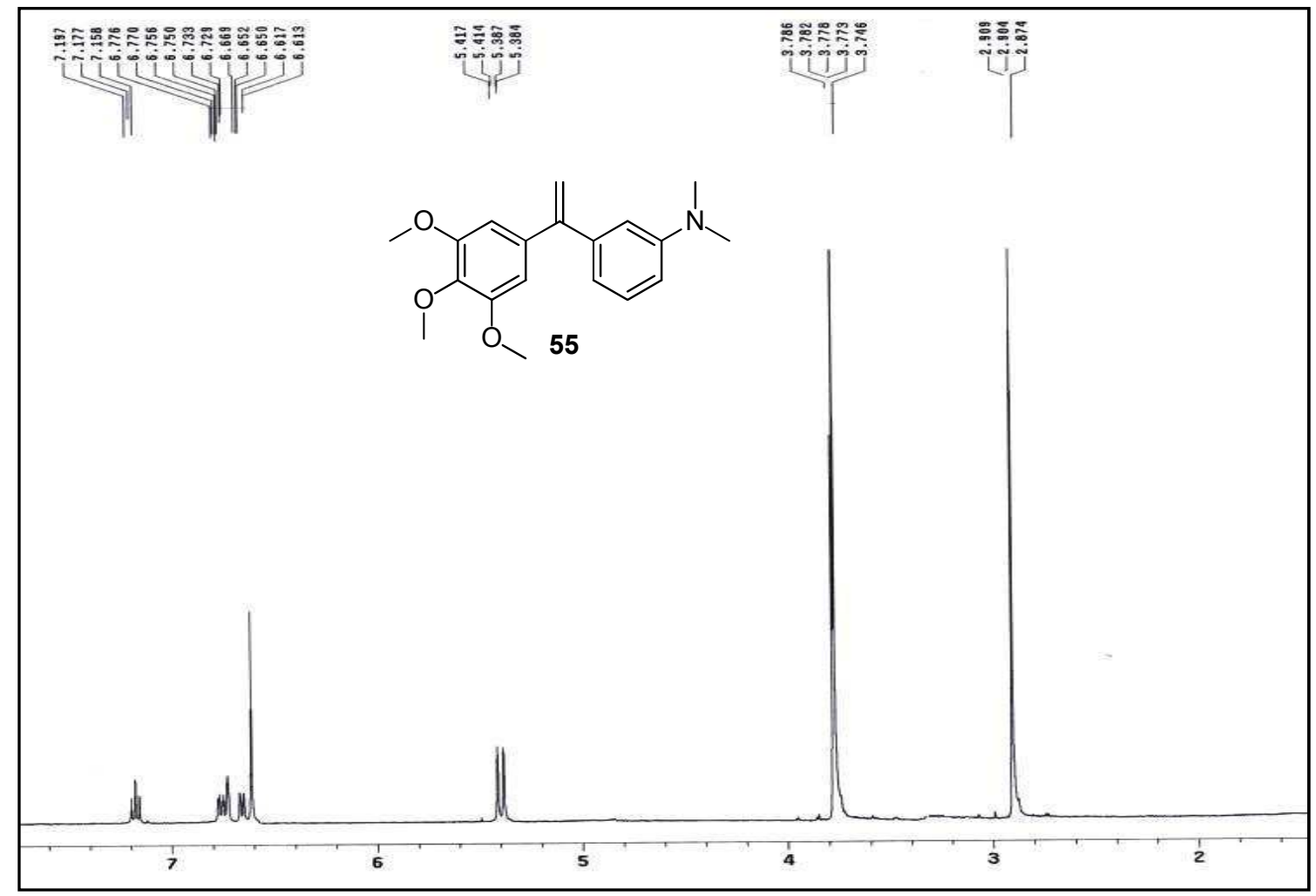

Figura XLVIIa: Espectro de RMN ${ }^{1} \mathrm{H}$ del compuesto 55.

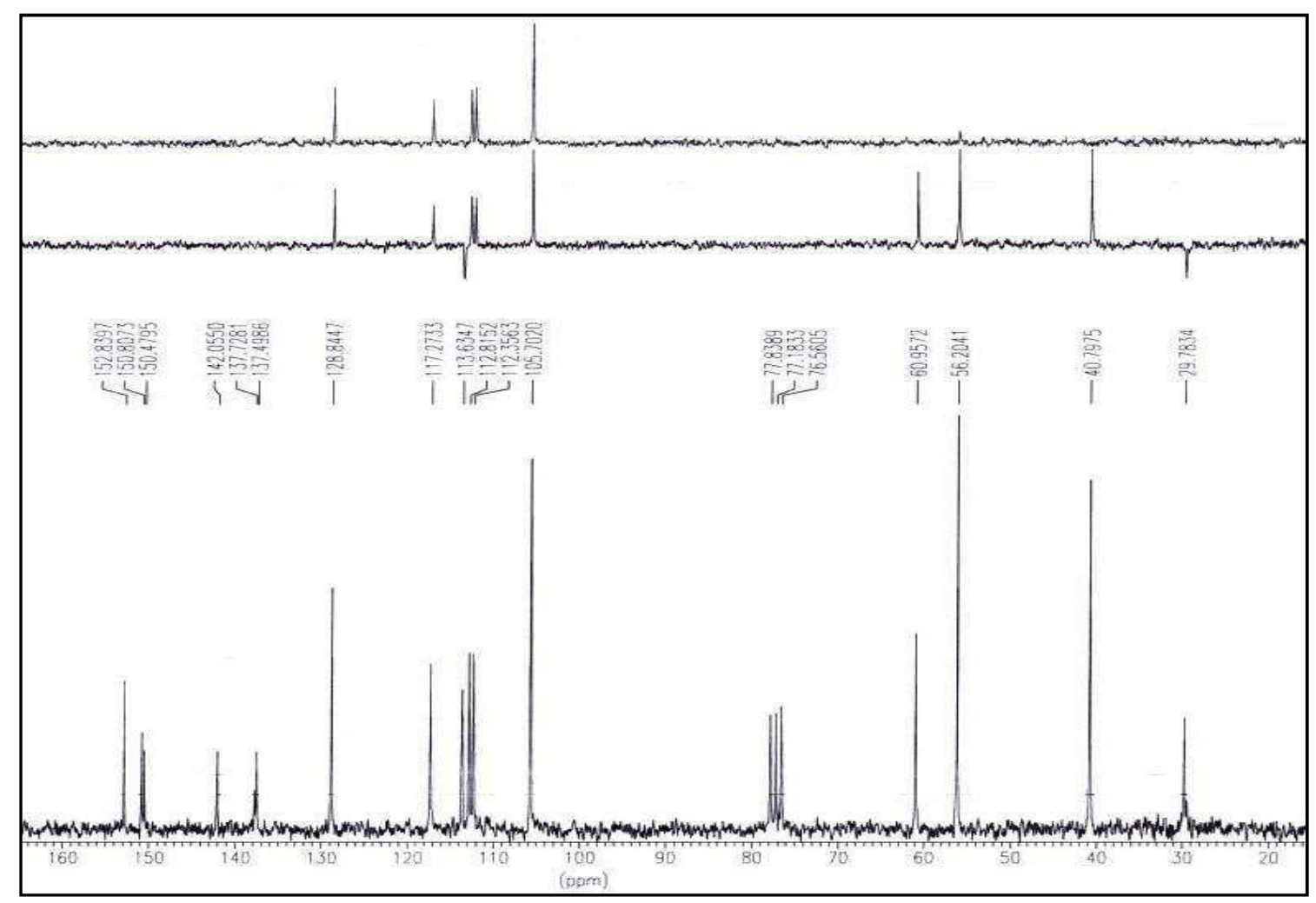

Figura XLVIIb: Espectro de RMN ${ }^{13} \mathrm{C}$ del compuesto 55. 


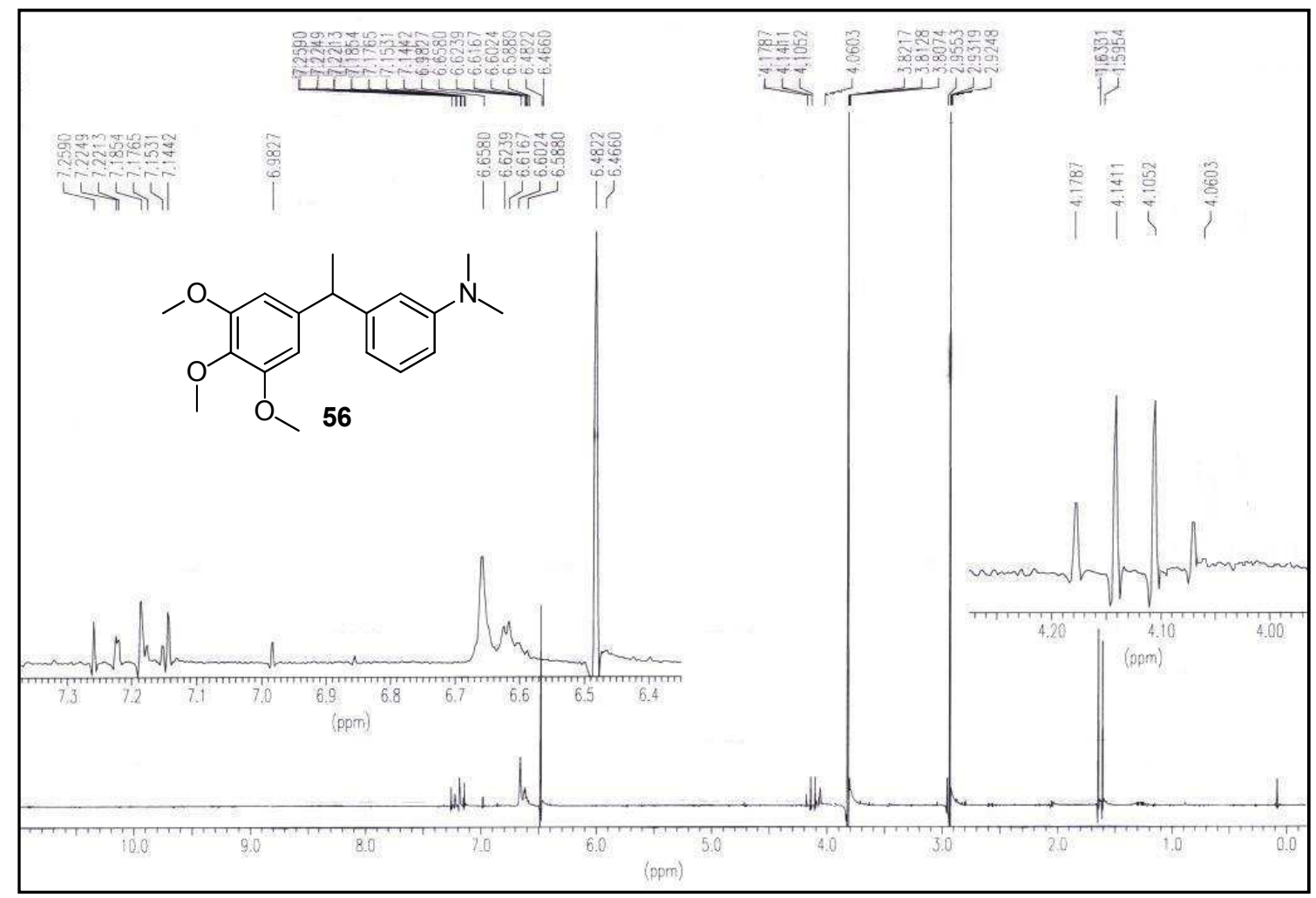

Figura XLVIIIa: Espectro de RMN ${ }^{1} \mathrm{H}$ del compuesto 56.

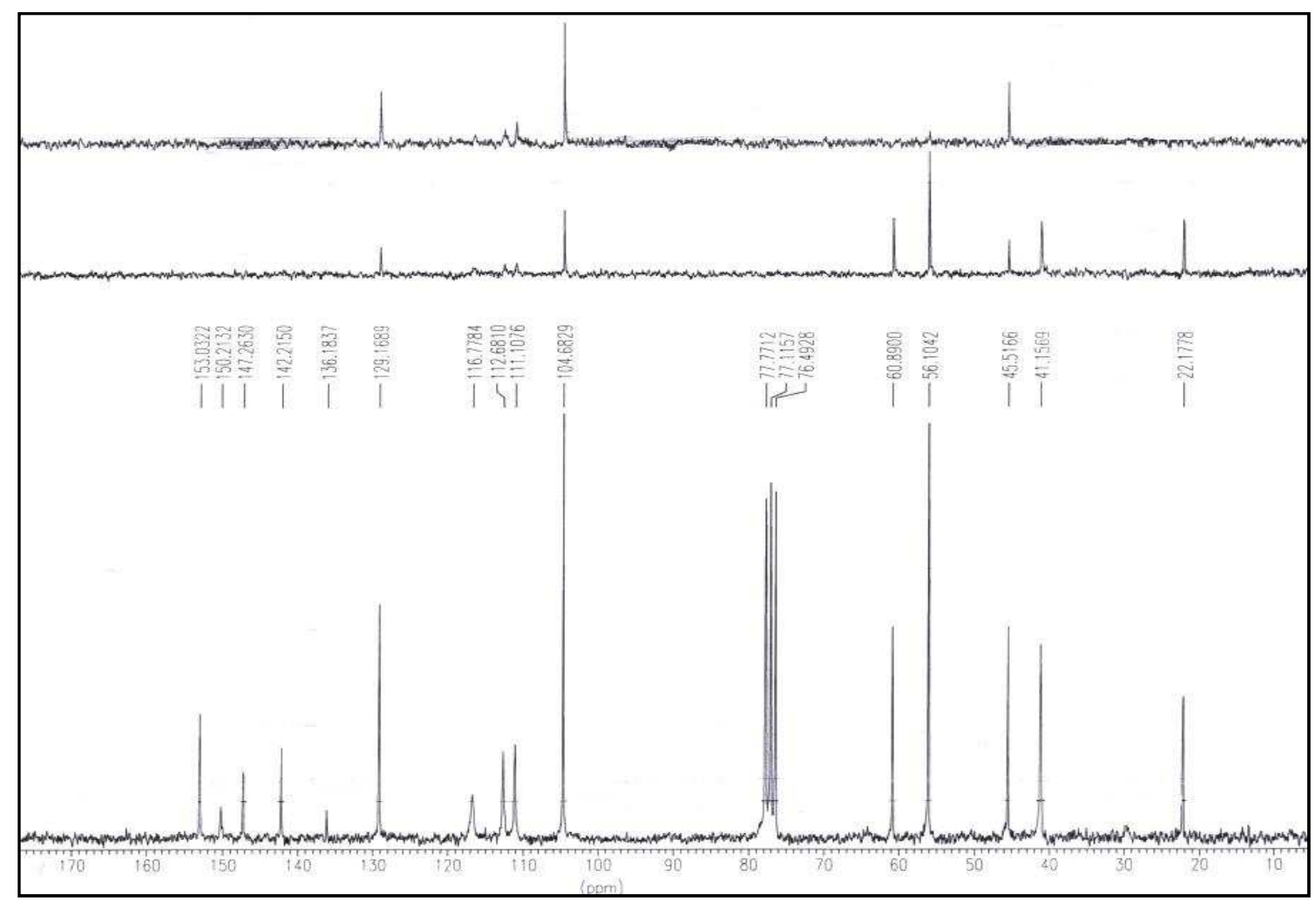

Figura XLVIIIb: Espectro de RMN ${ }^{13} \mathrm{C}$ del compuesto 56. 


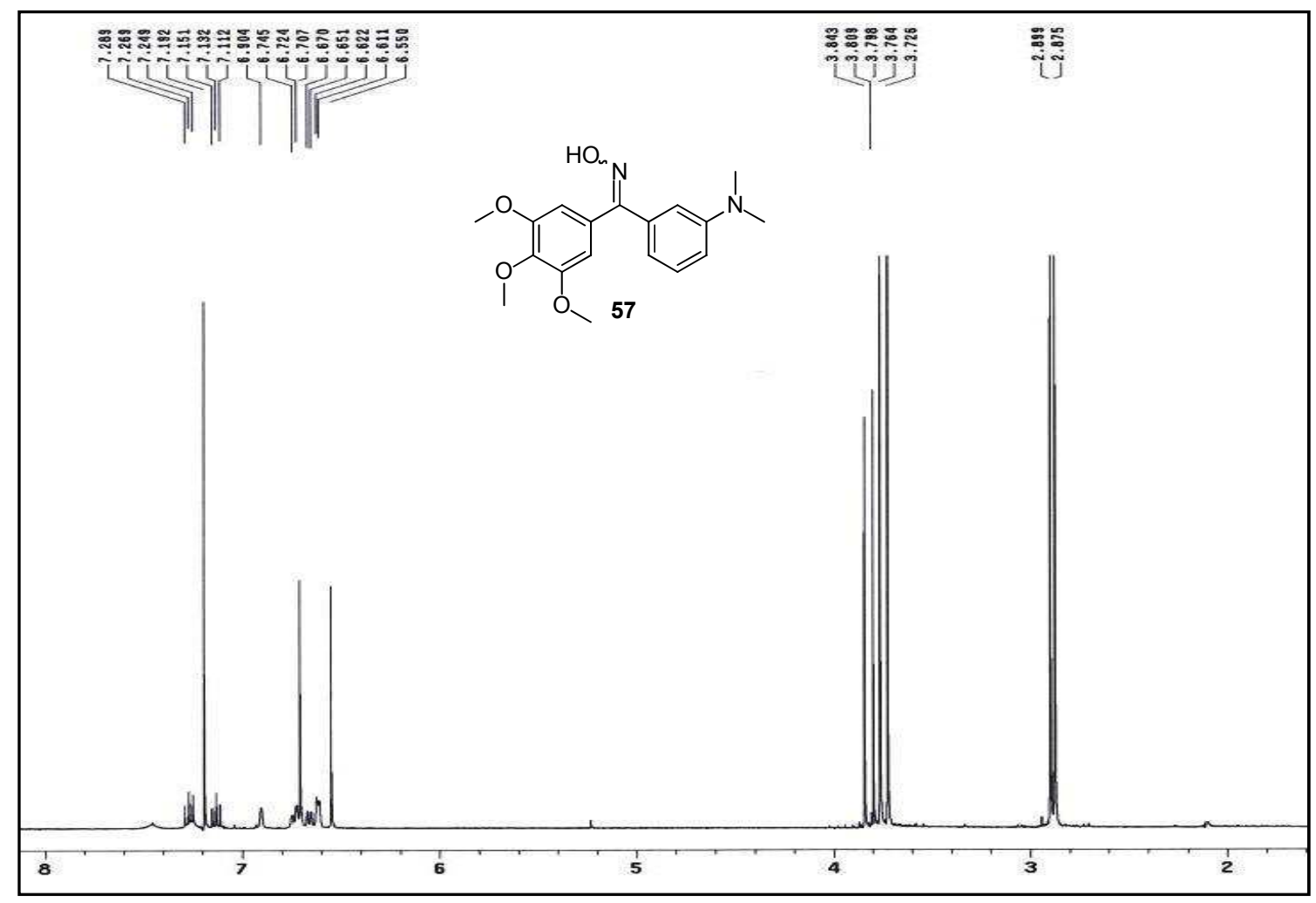

Figura XLIXa: Espectro de RMN ${ }^{1} \mathrm{H}$ del compuesto 57.

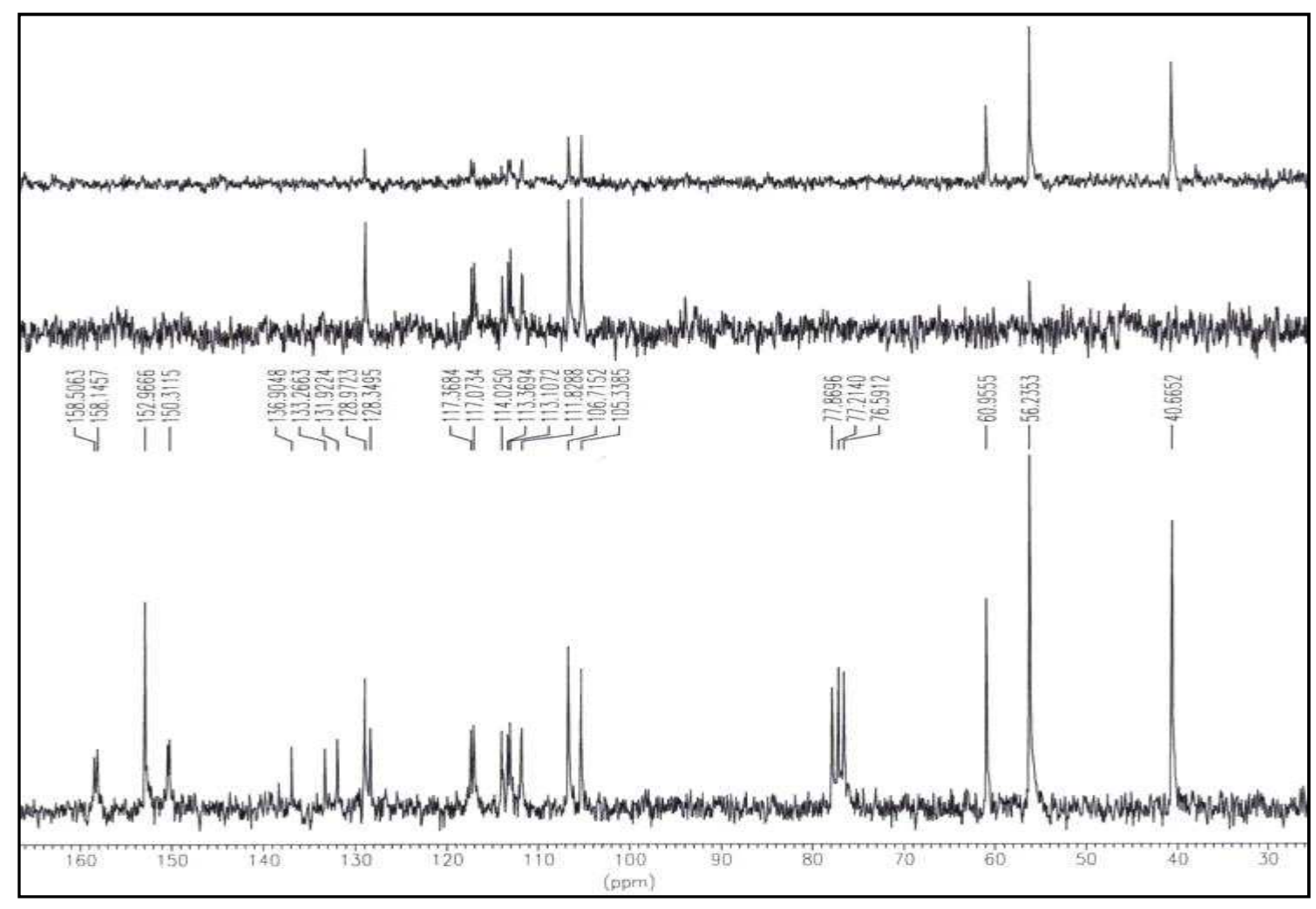

Figura XLIXb: Espectro de RMN ${ }^{13} \mathrm{C}$ del compuesto 57. 


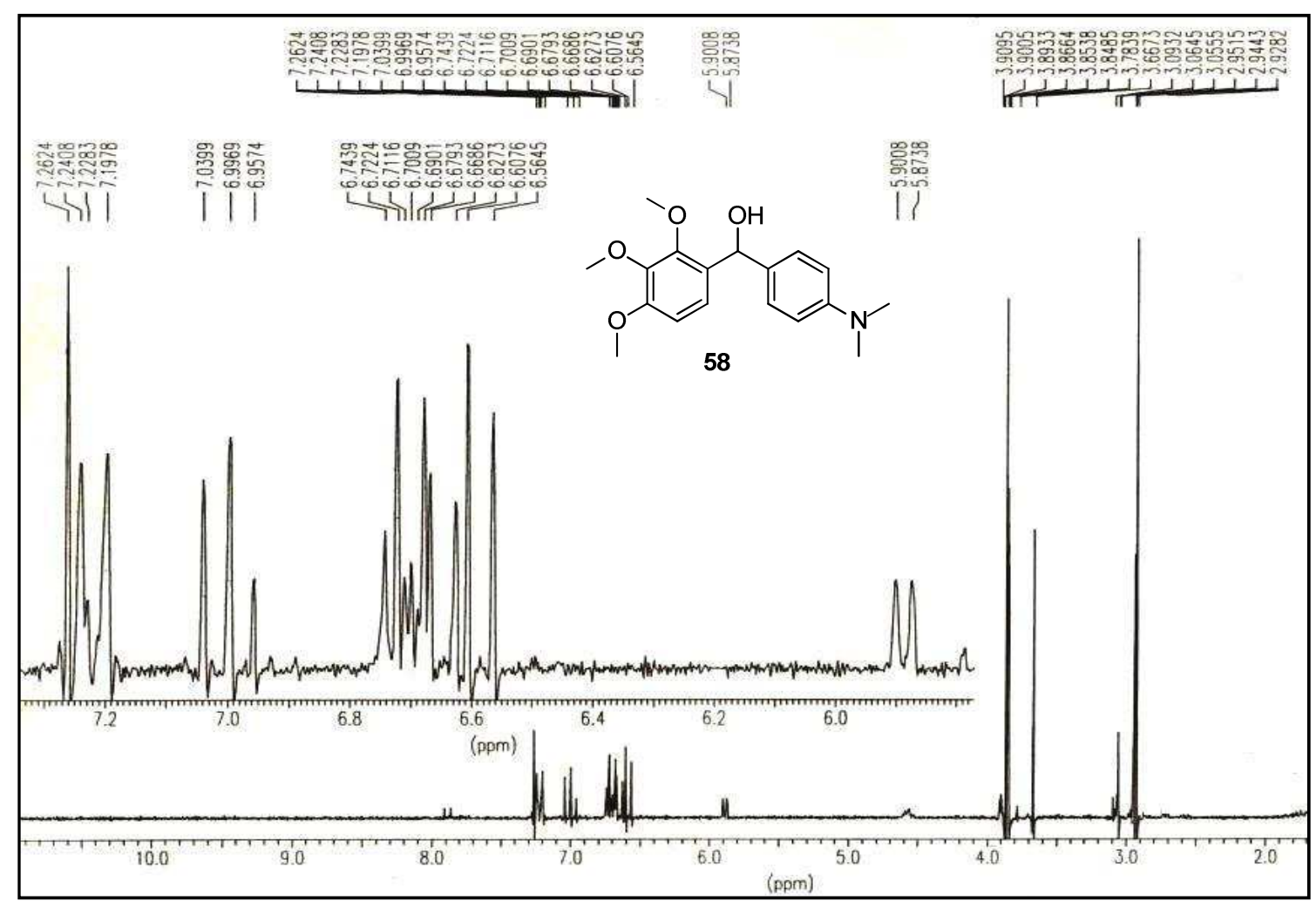

Figura L: Espectro de RMN ${ }^{1} \mathrm{H}$ del compuesto 58. 


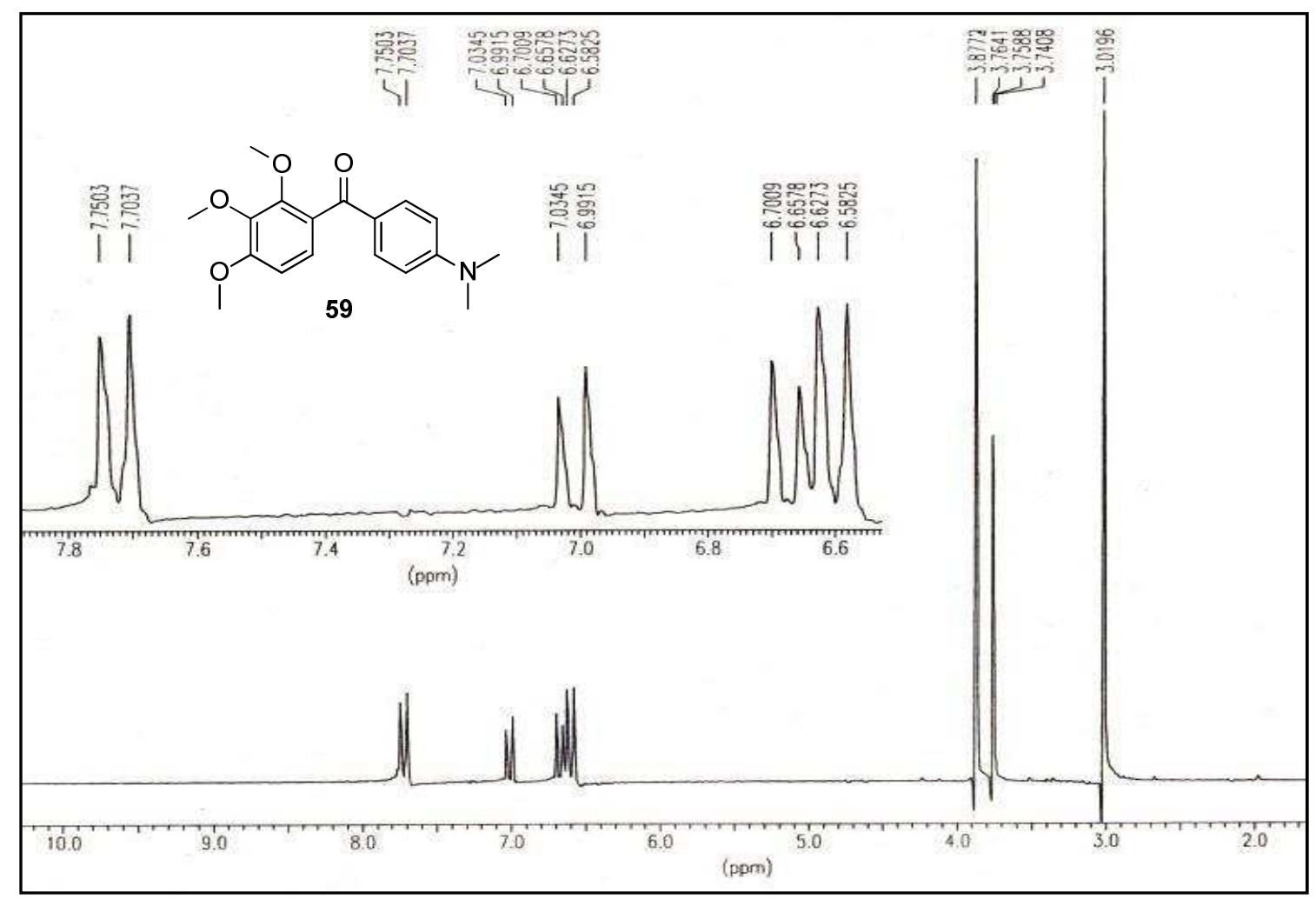

Figura LIa: Espectro de RMN ${ }^{1} \mathrm{H}$ del compuesto 59.

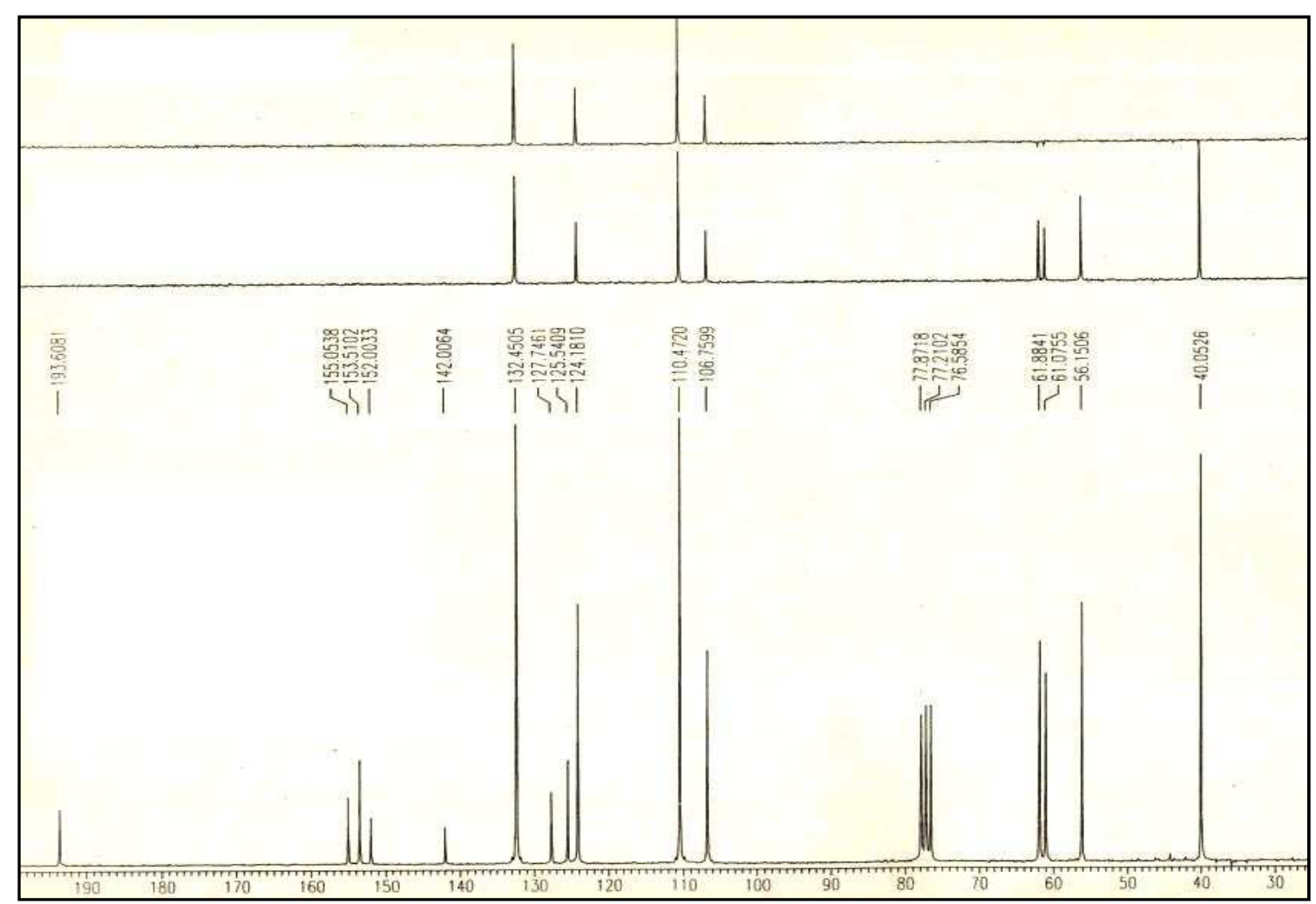

Figura LIb: Espectro de RMN ${ }^{1} \mathrm{H}$ del compuesto 59. 


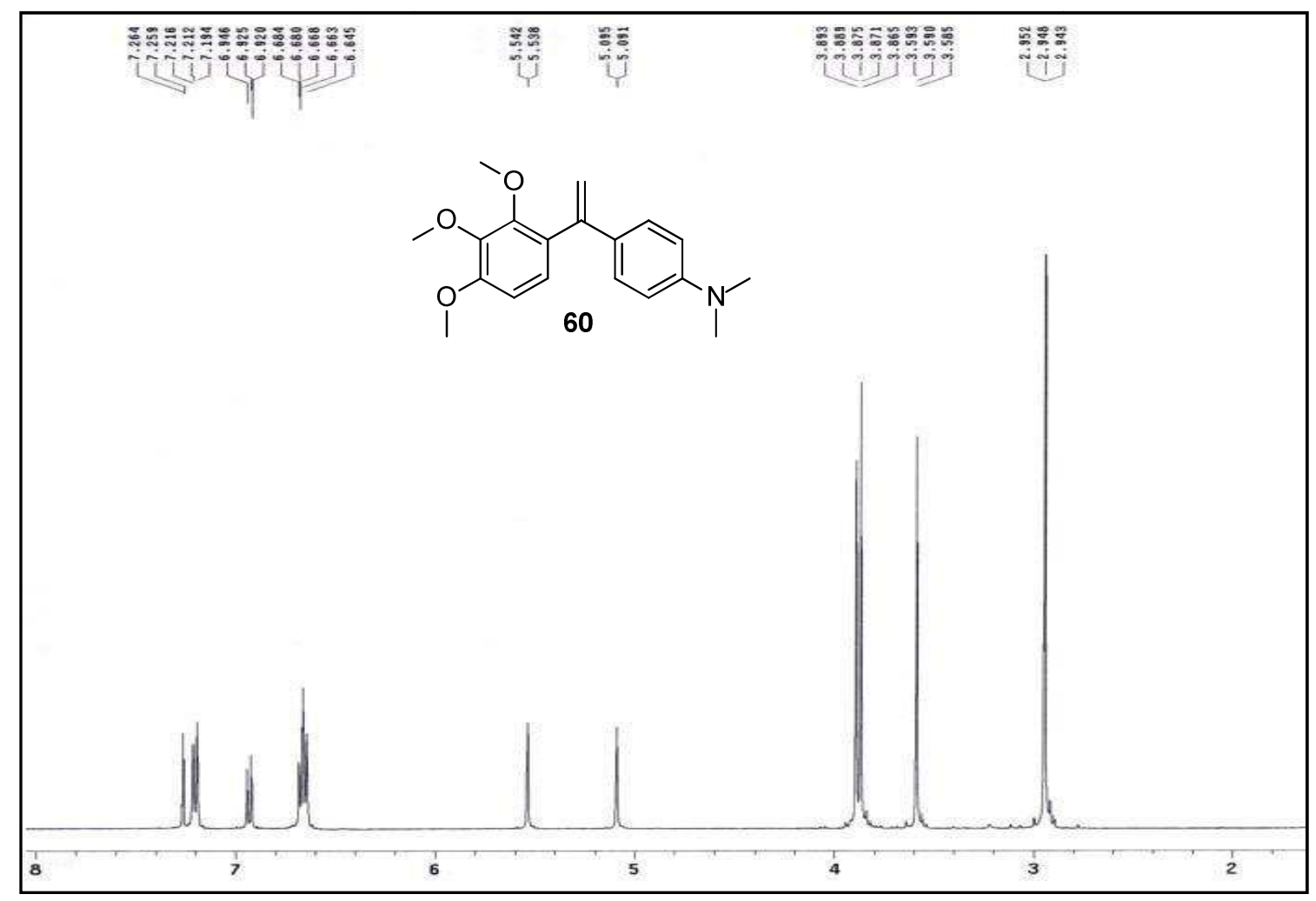

Figura LIIa: Espectro de RMN ${ }^{1} \mathrm{H}$ del compuesto 60.

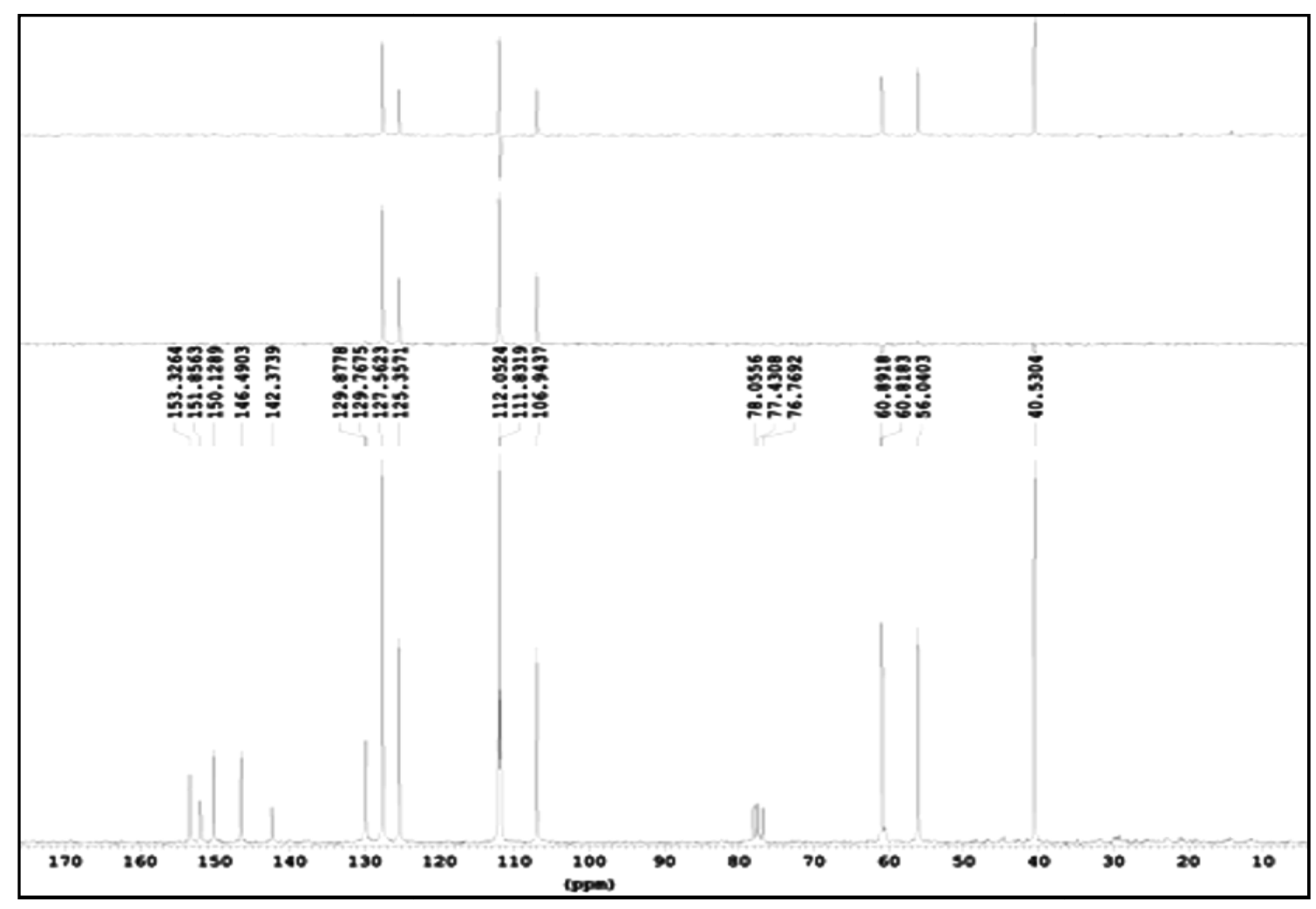

Figura LIIb: Espectro de RMN ${ }^{1} \mathrm{H}$ del compuesto 60. 


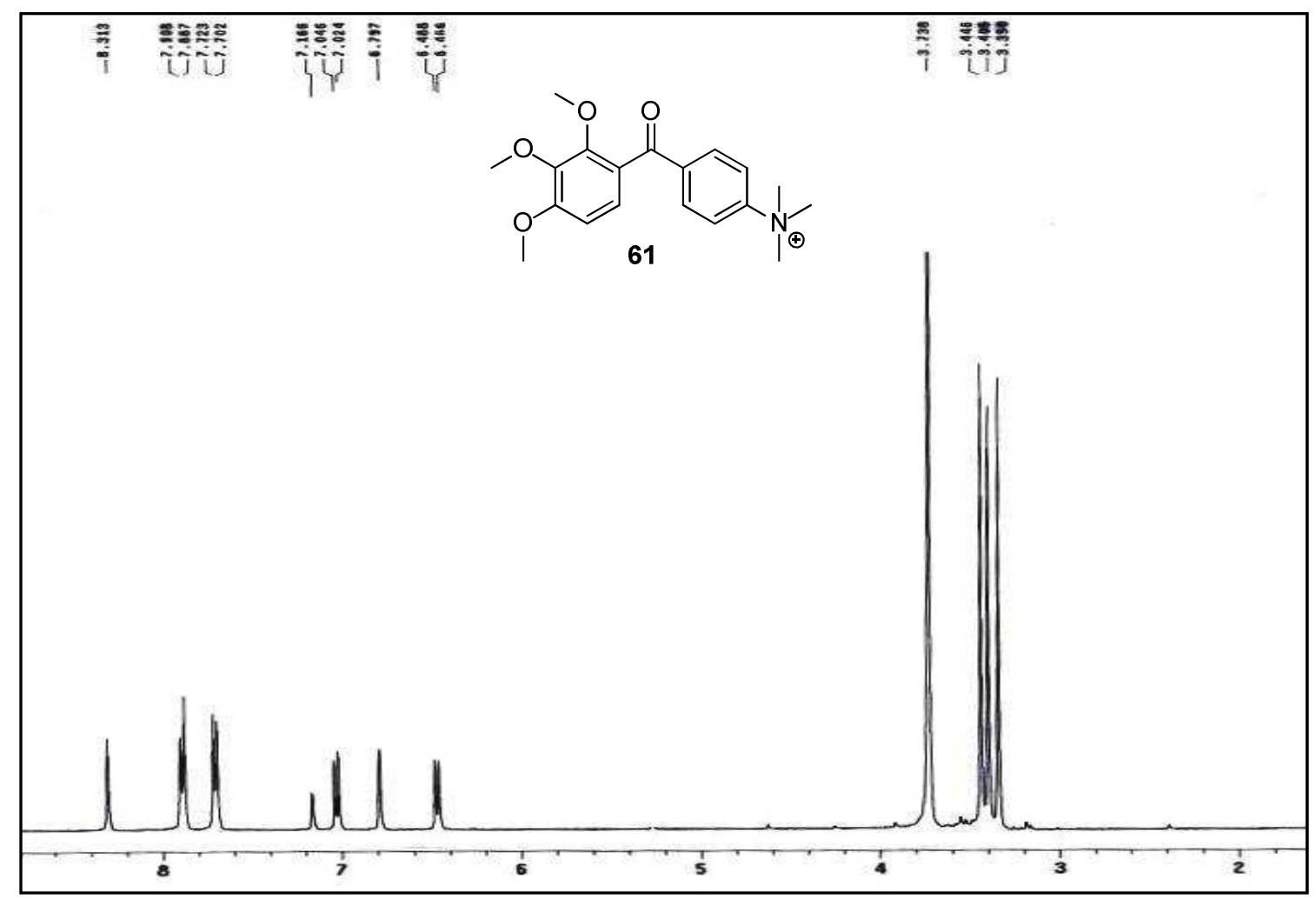

Figura LIIIa: Espectro de RMN ${ }^{1} \mathrm{H}$ del compuesto 61.

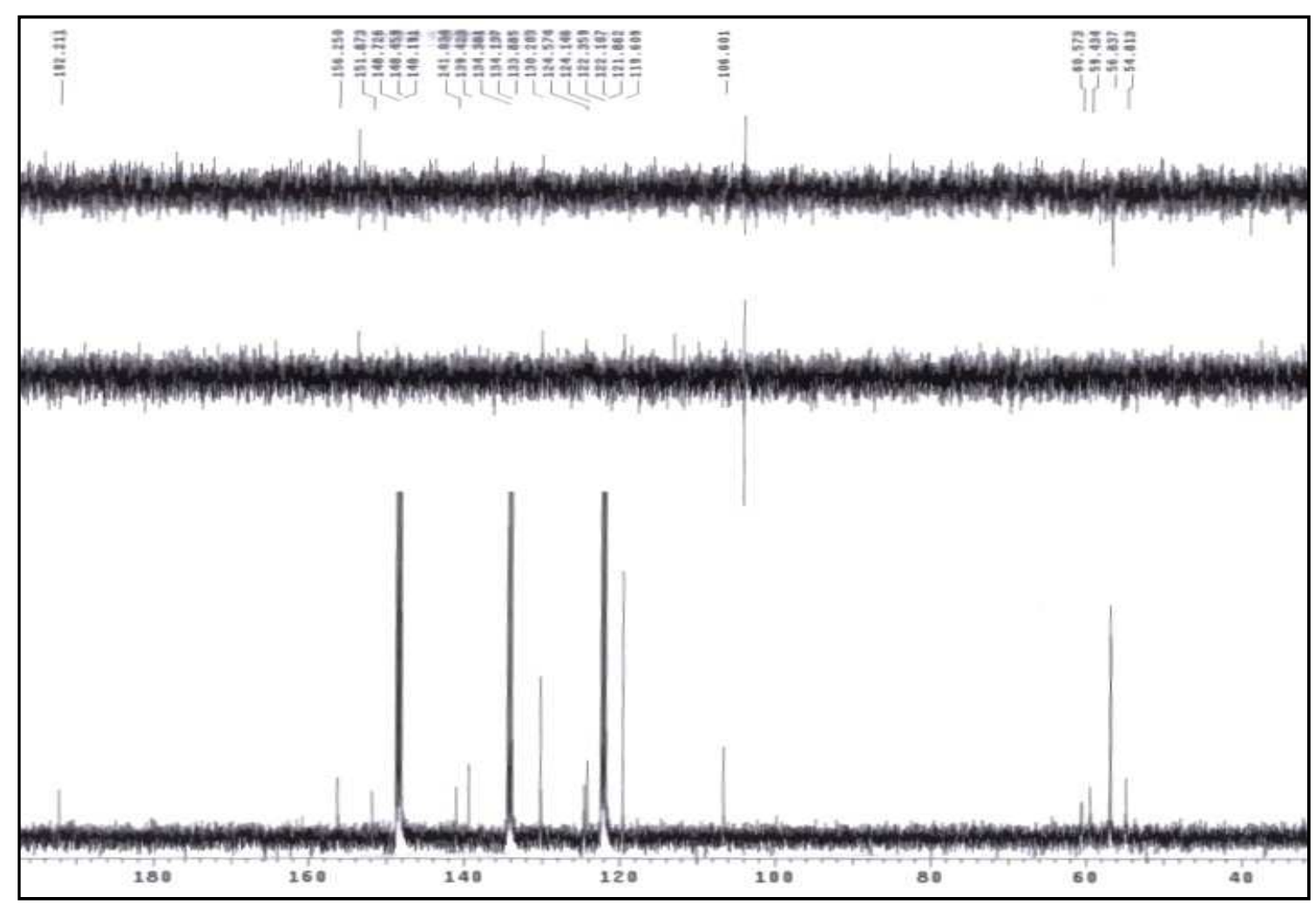

Figura LIIIb: Espectro de RMN ${ }^{1} \mathrm{H}$ del compuesto 61. 


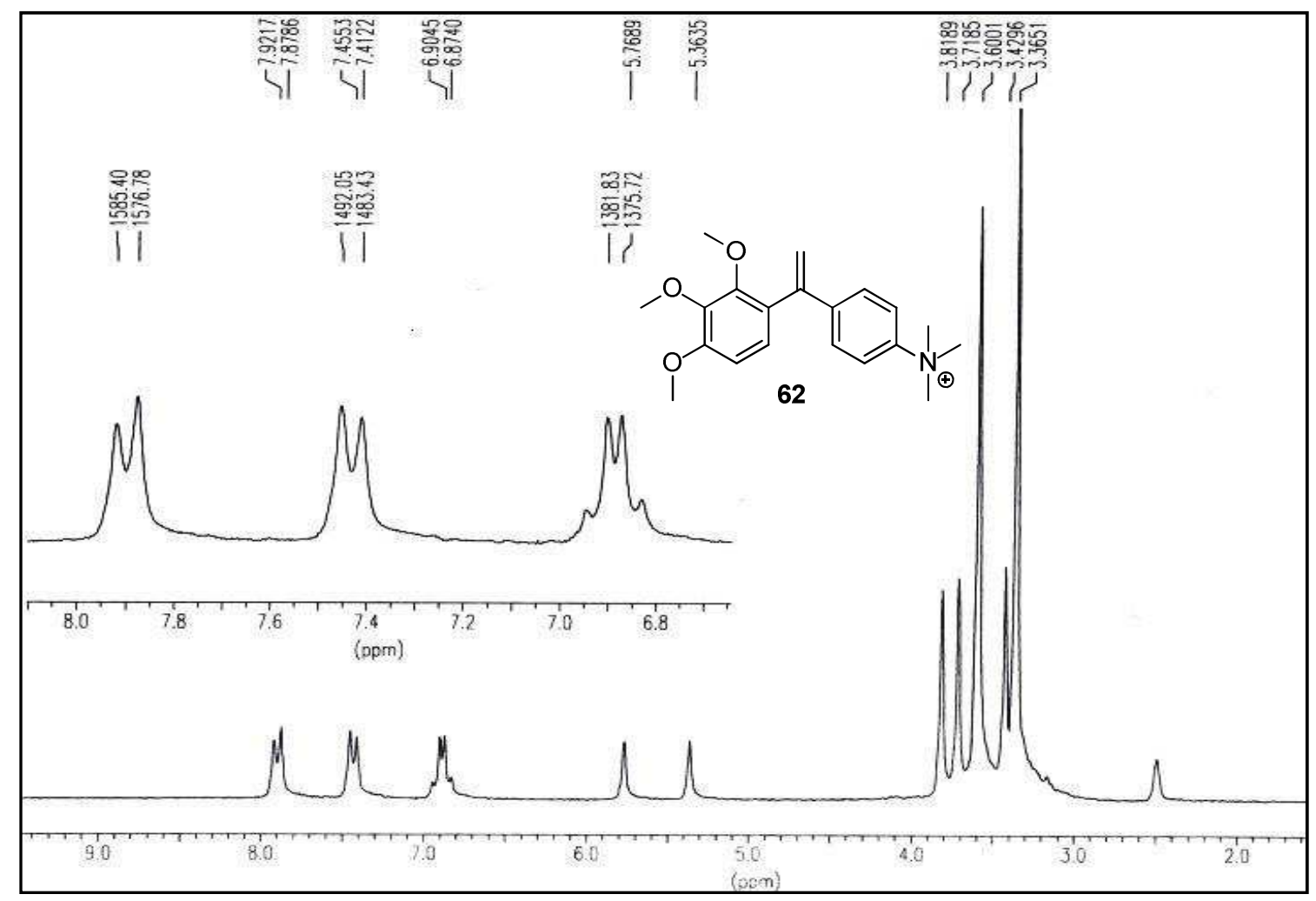

Figura LIVa: Espectro de RMN ${ }^{1} \mathrm{H}$ del compuesto 62.

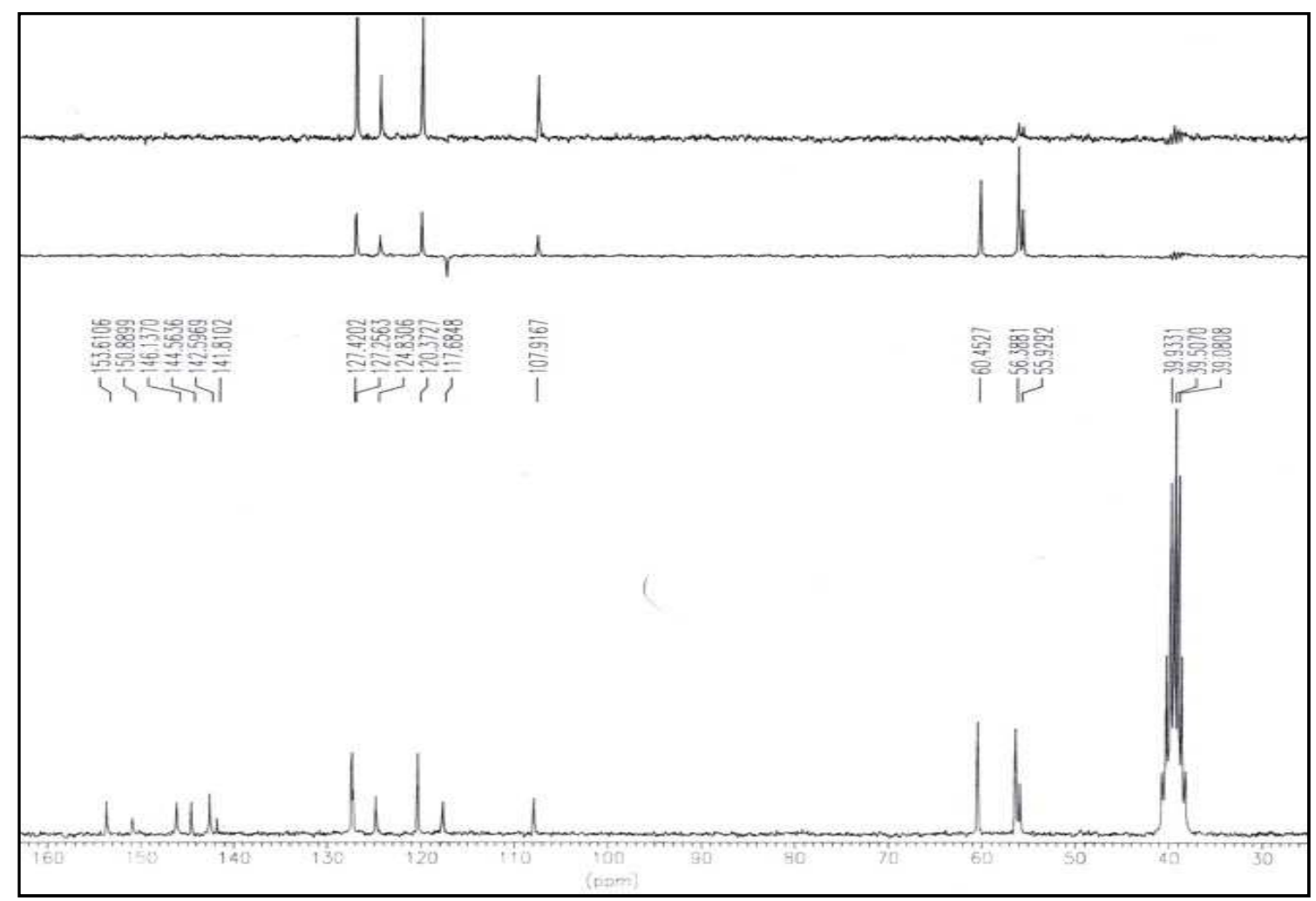

Figura LIVb: Espectro de RMN ${ }^{1} \mathrm{H}$ del compuesto 62. 


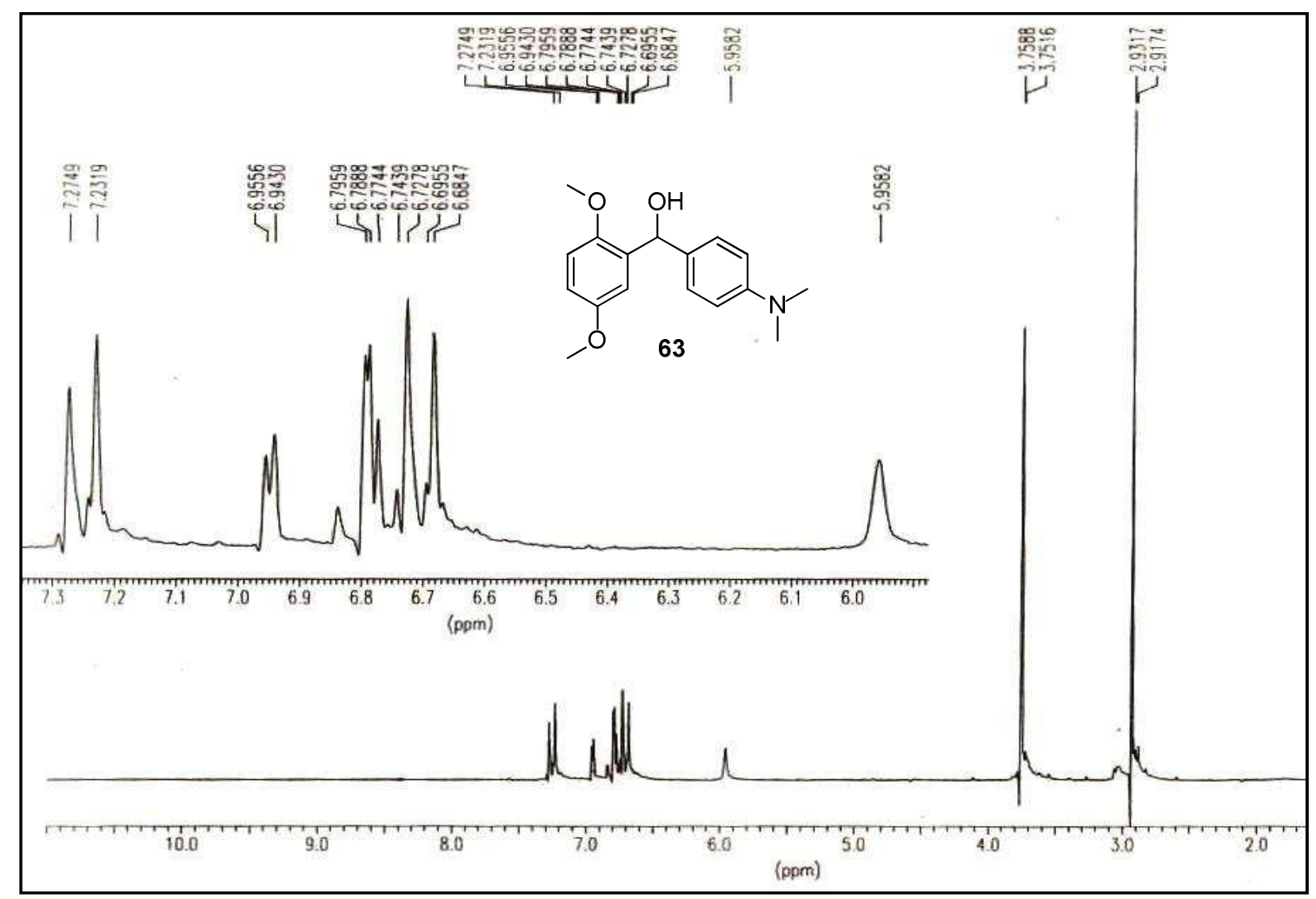

Figura LVa: Espectro de RMN ${ }^{1} \mathrm{H}$ del compuesto 63.

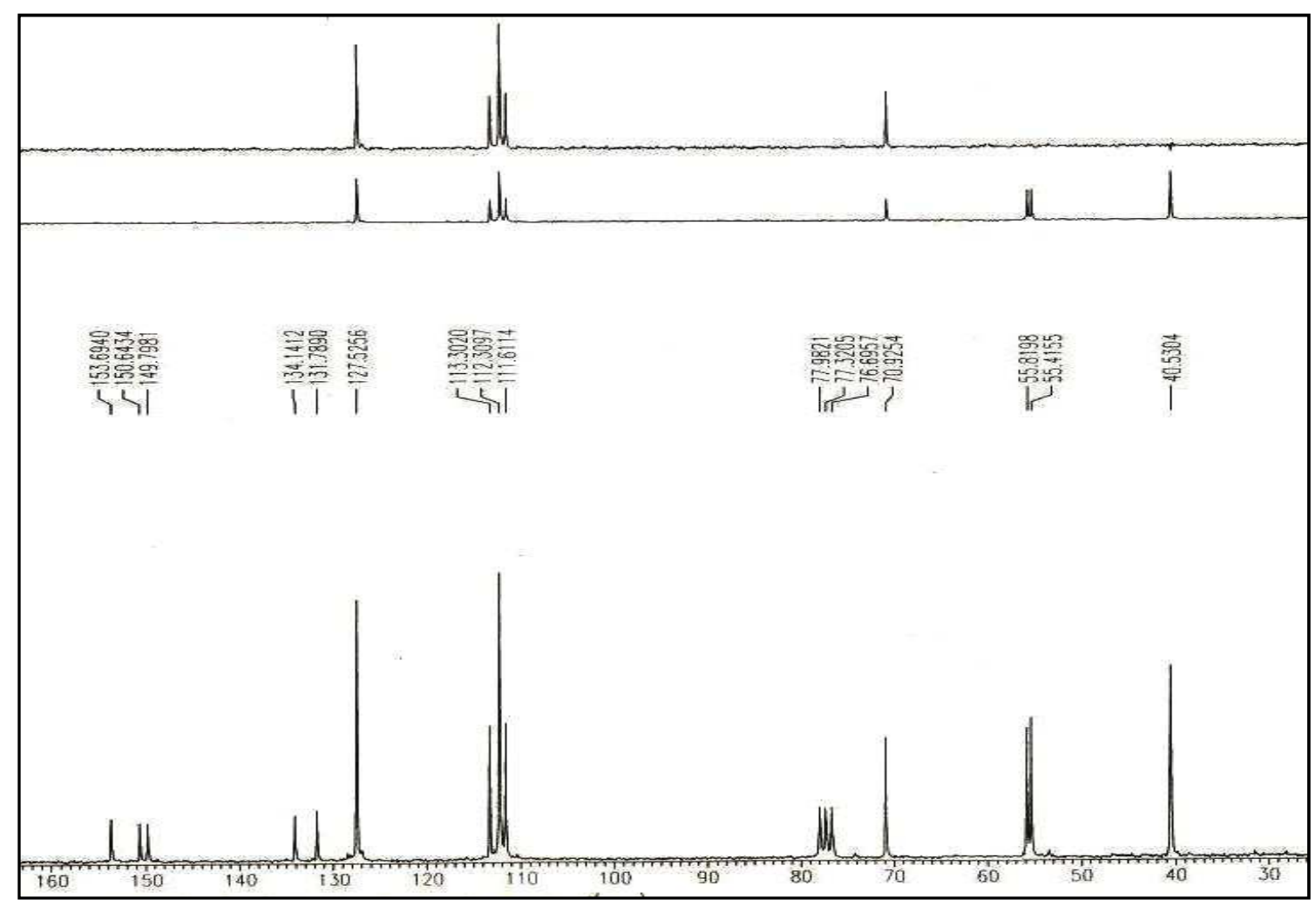

Figura LVb: Espectro de RMN ${ }^{1} \mathrm{H}$ del compuesto 63 . 


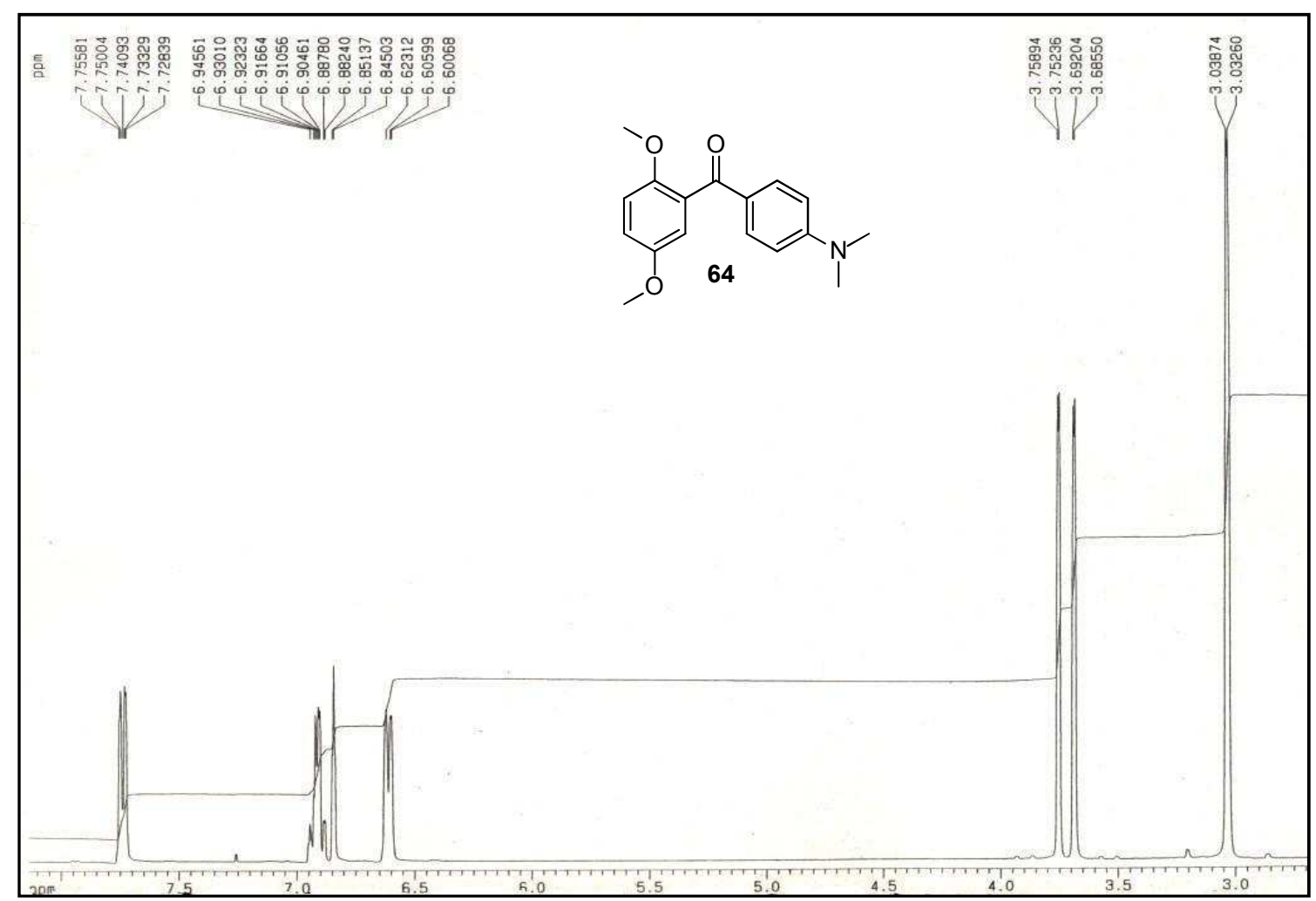

Figura LVIa: Espectro de RMN ${ }^{1} \mathrm{H}$ del compuesto 64.

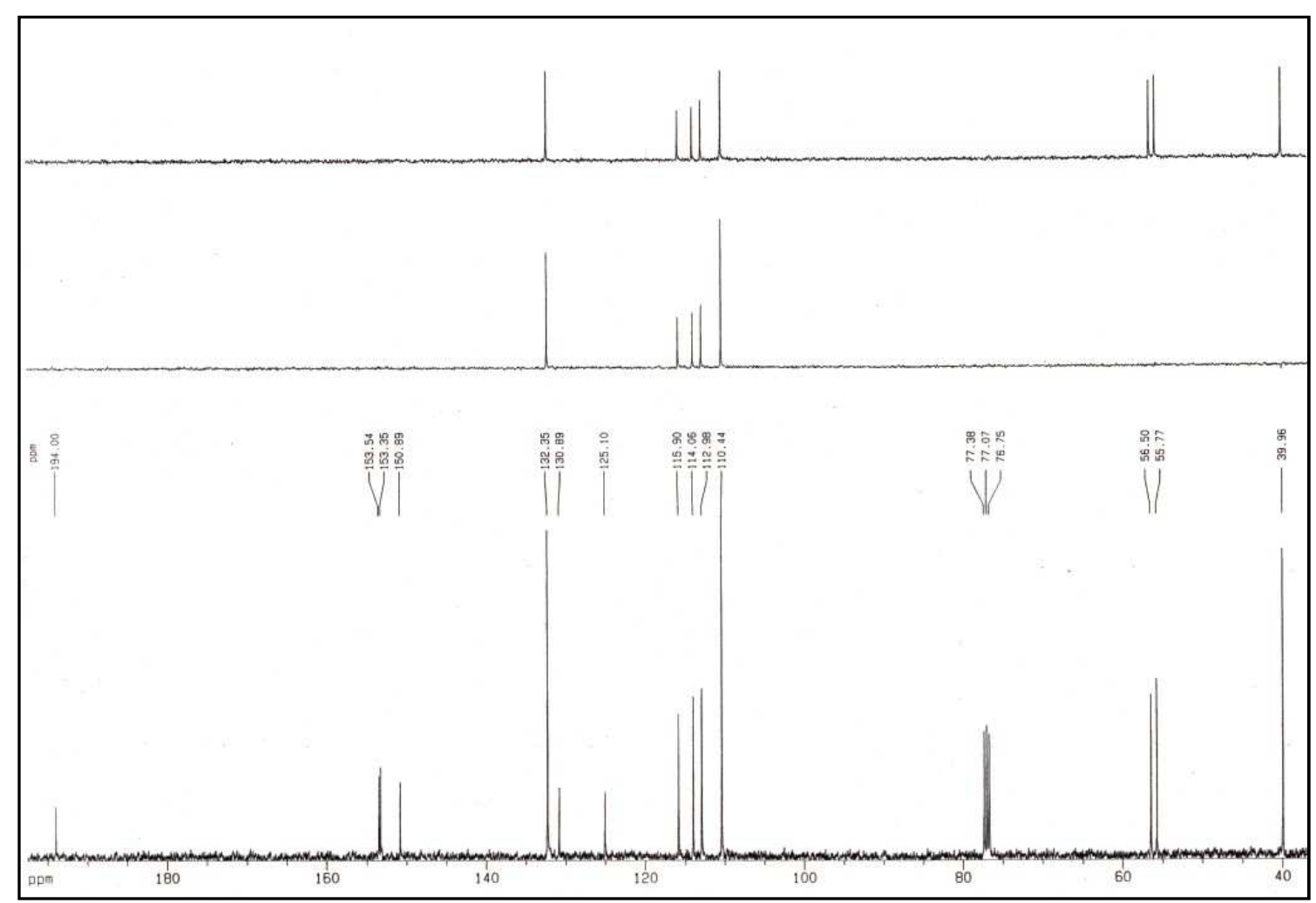

Figura LVIb: Espectro de RMN ${ }^{1} \mathrm{H}$ del compuesto 64. 


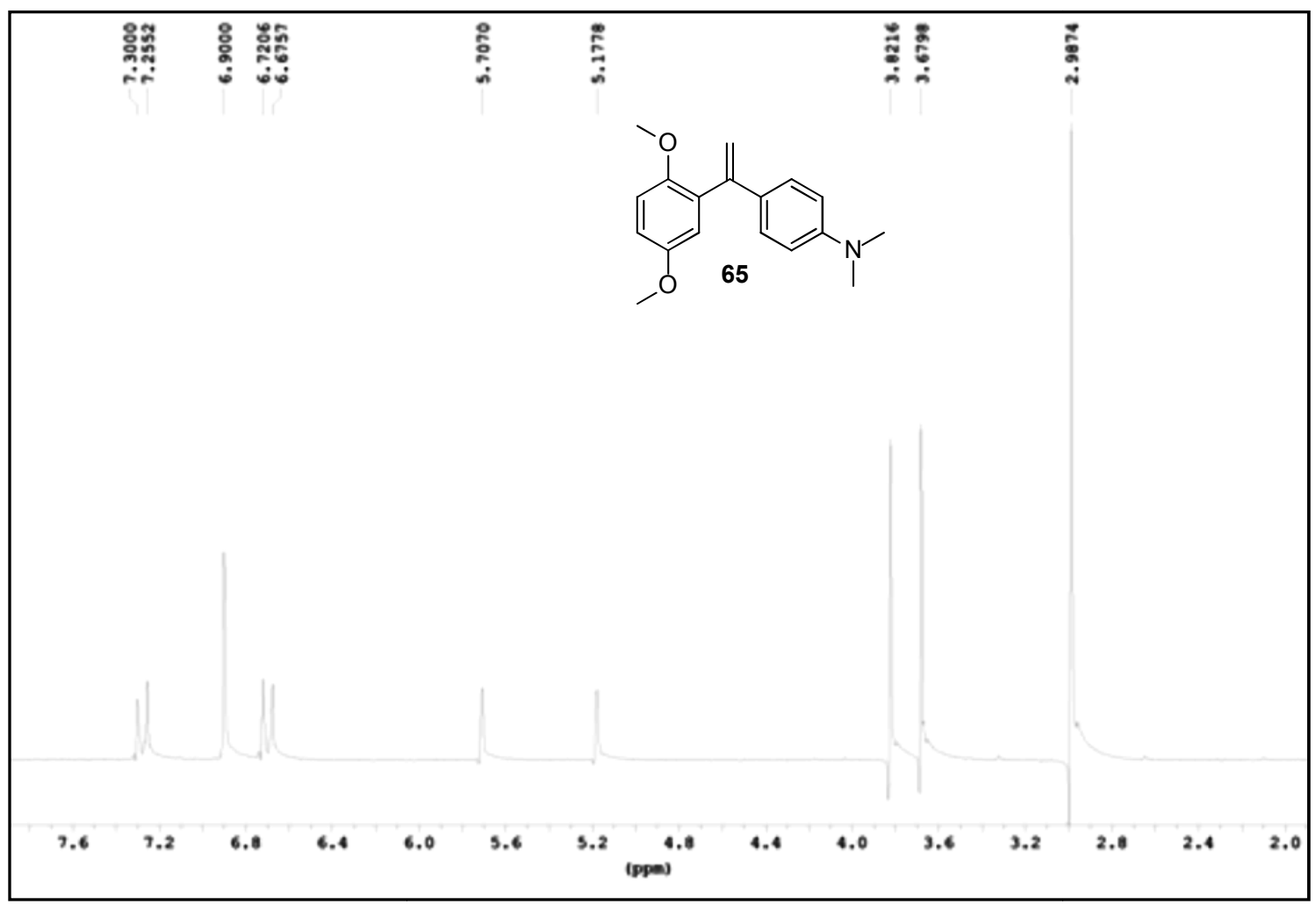

Figura LVIIa: Espectro de RMN ${ }^{1} \mathrm{H}$ del compuesto 65.

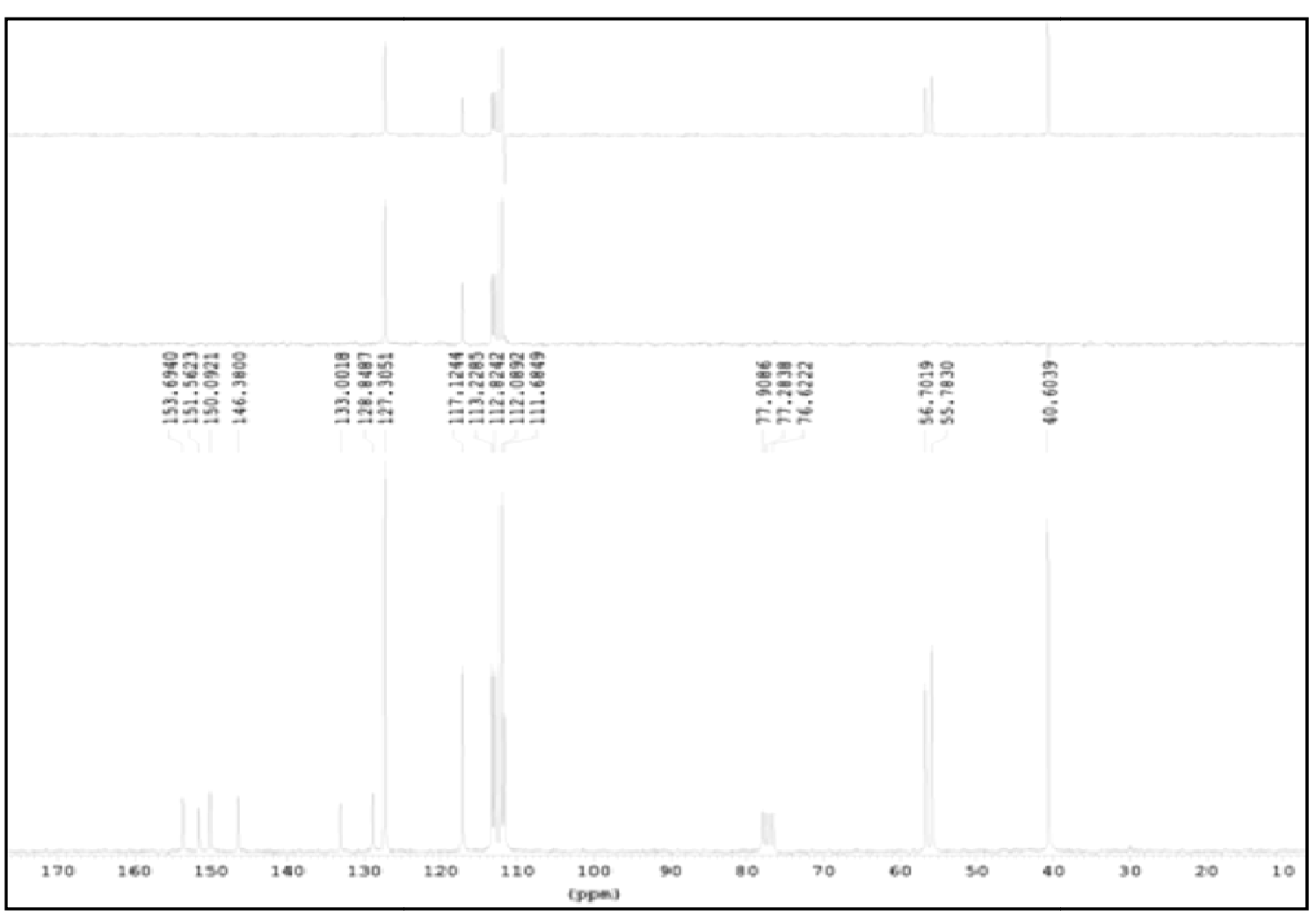

Figura LVIIb: Espectro de RMN ${ }^{1} \mathrm{H}$ del compuesto 65. 


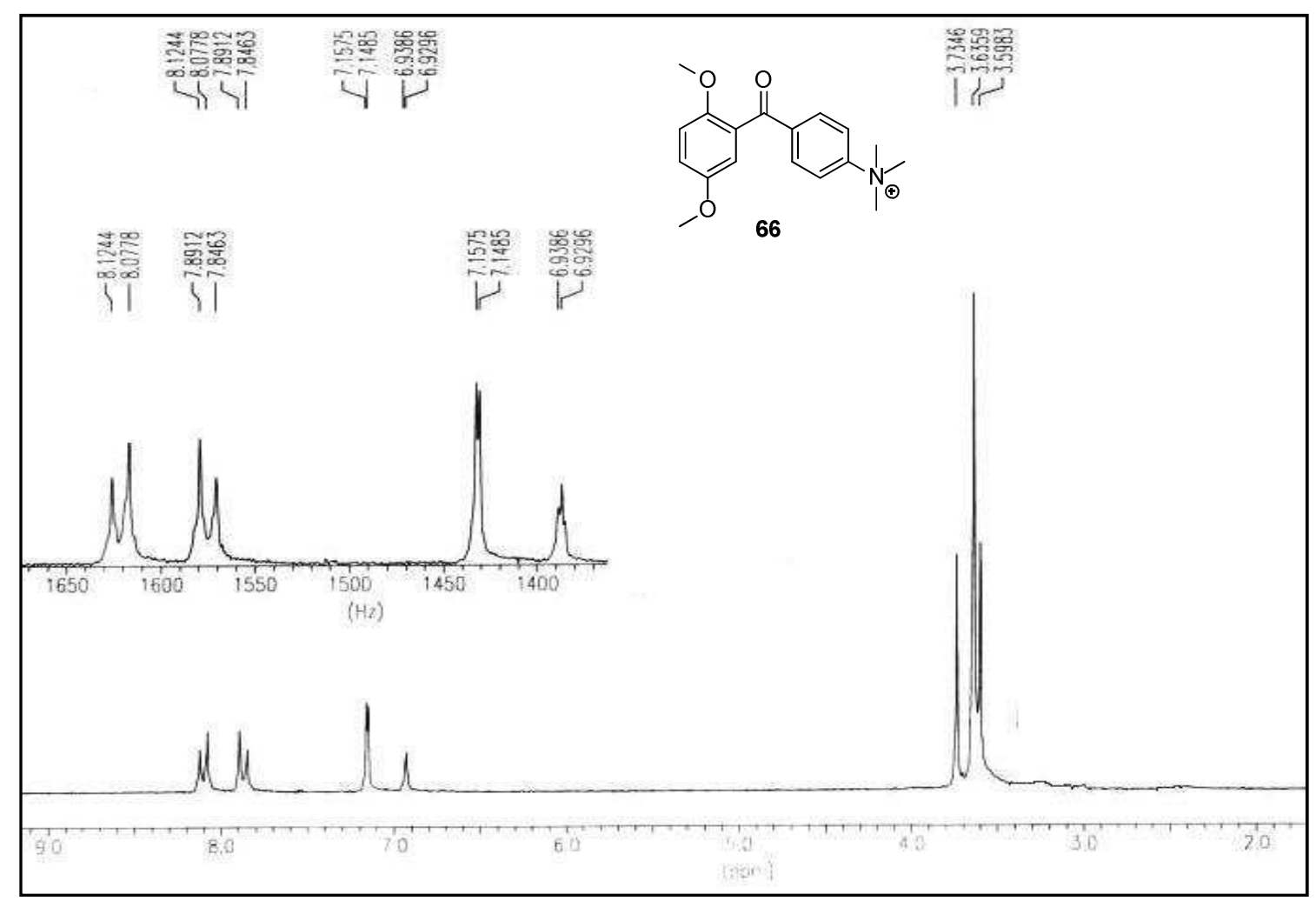

Figura LVIIIa: Espectro de RMN ${ }^{1} \mathrm{H}$ del compuesto 66.

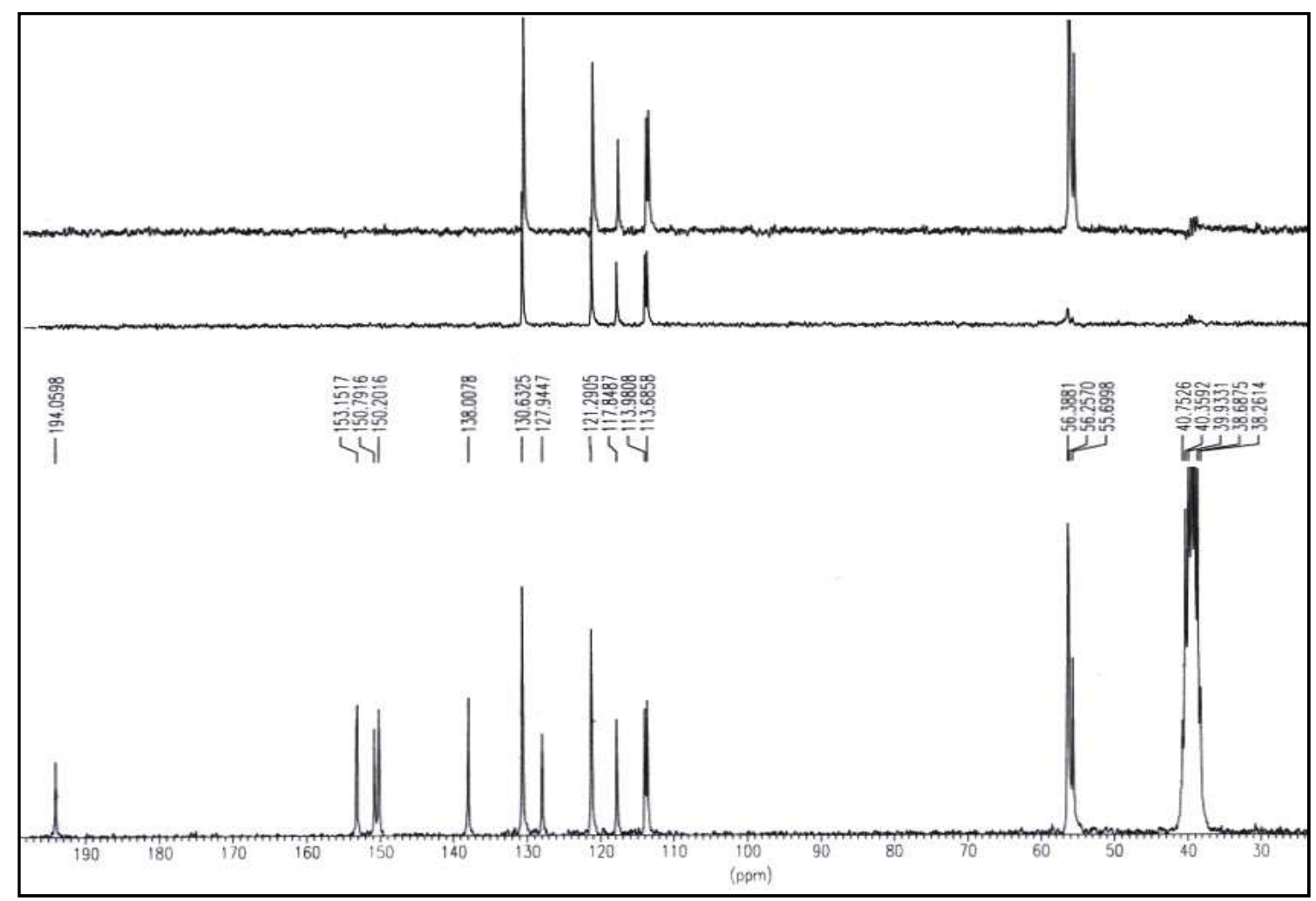

Figura LVIIIb: Espectro de RMN ${ }^{1} \mathrm{H}$ del compuesto 66. 


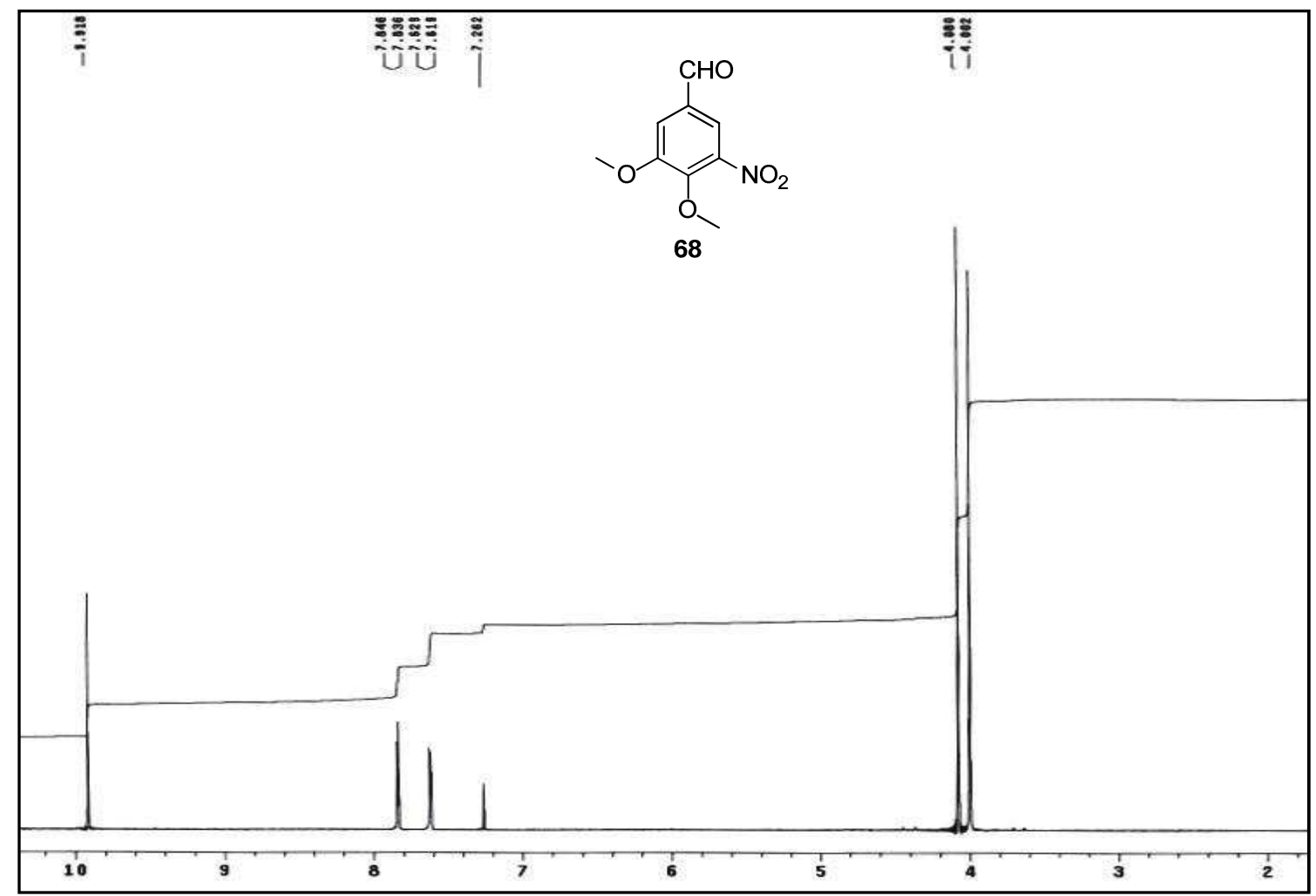

Figura LIXa: Espectro de RMN ${ }^{1} \mathrm{H}$ del compuesto 68.

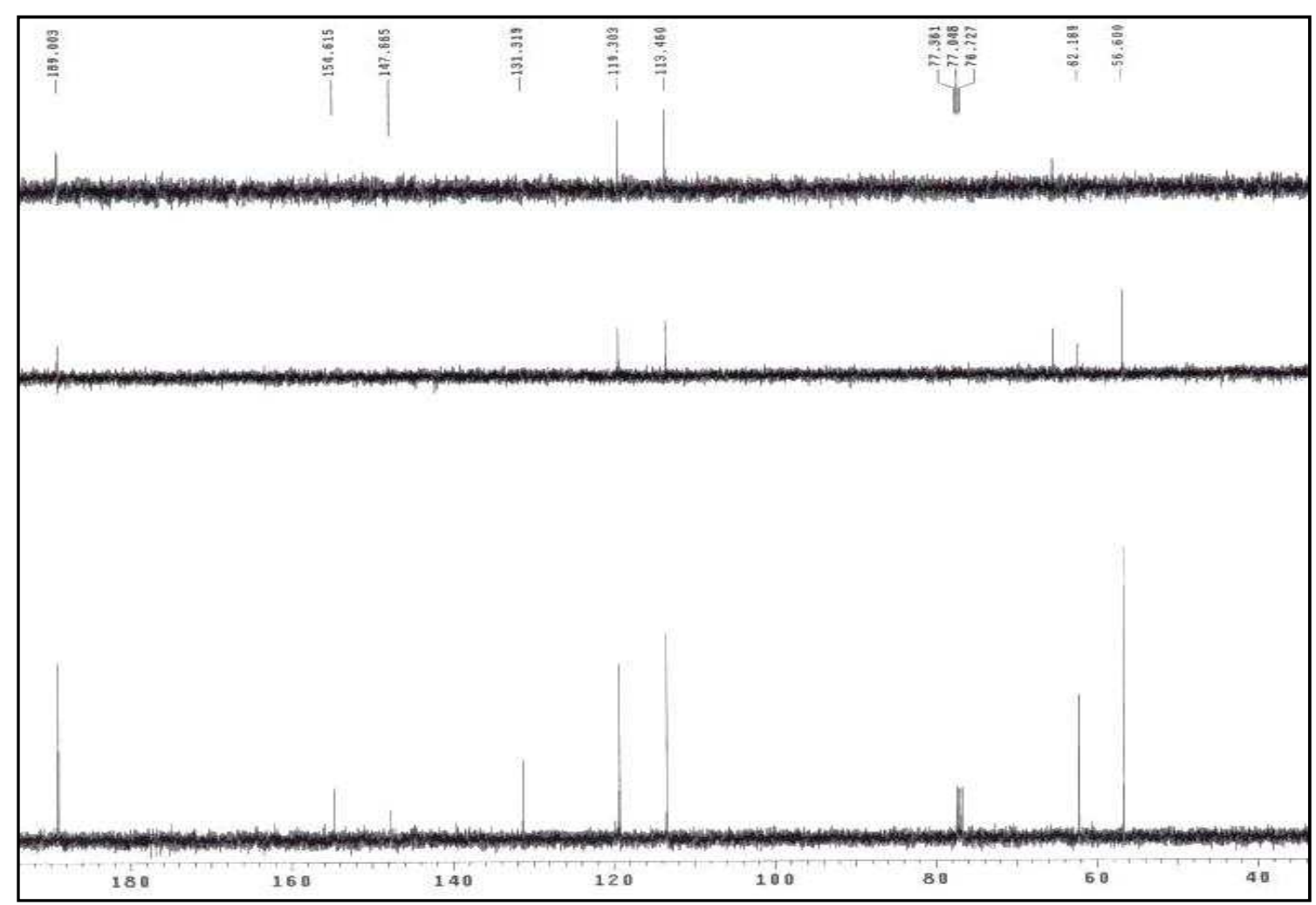

Figura LIXb: Espectro de RMN ${ }^{1} \mathrm{H}$ del compuesto 68. 


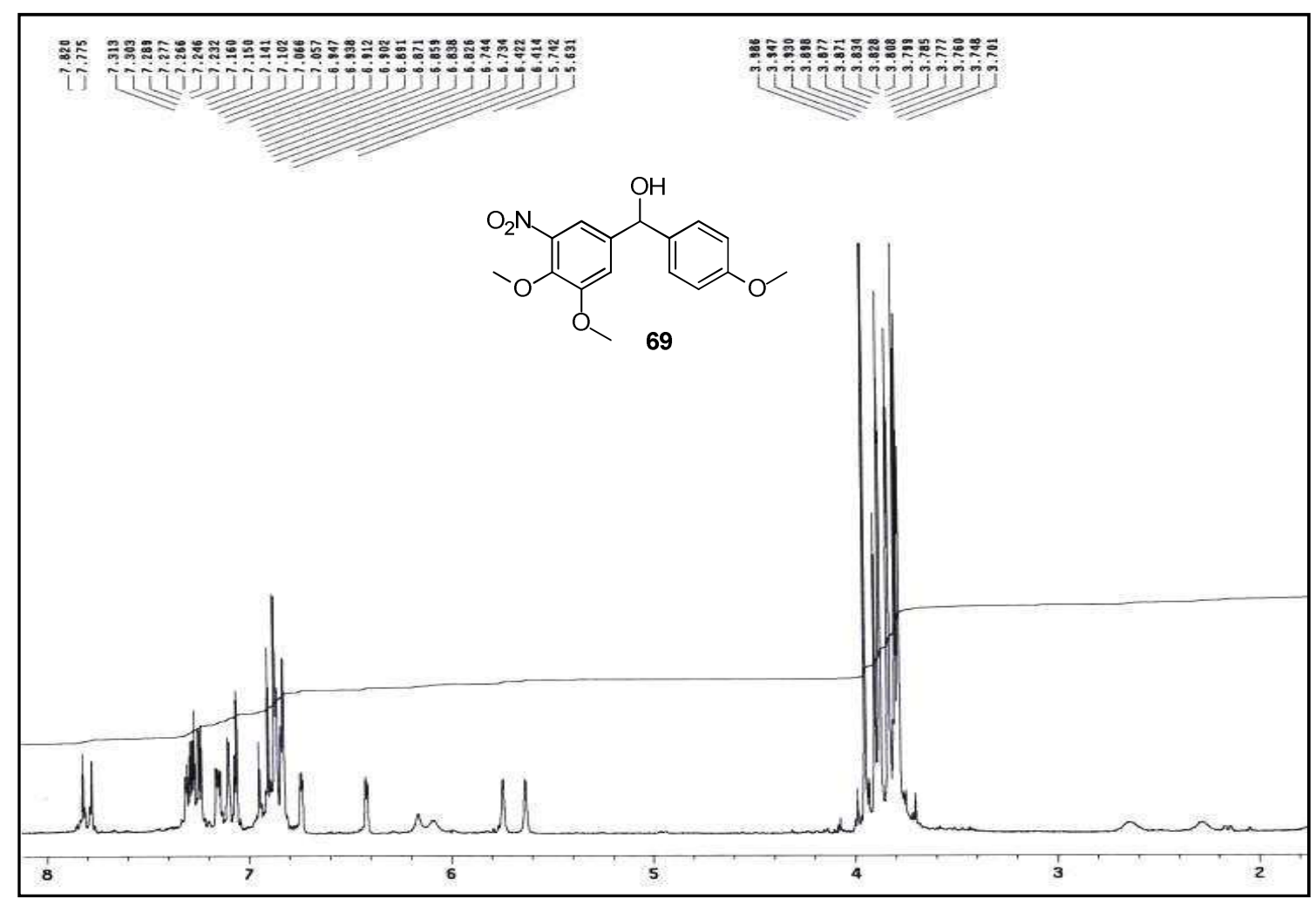

Figura LX: Espectro de RMN ${ }^{1} \mathrm{H}$ del compuesto 69. 


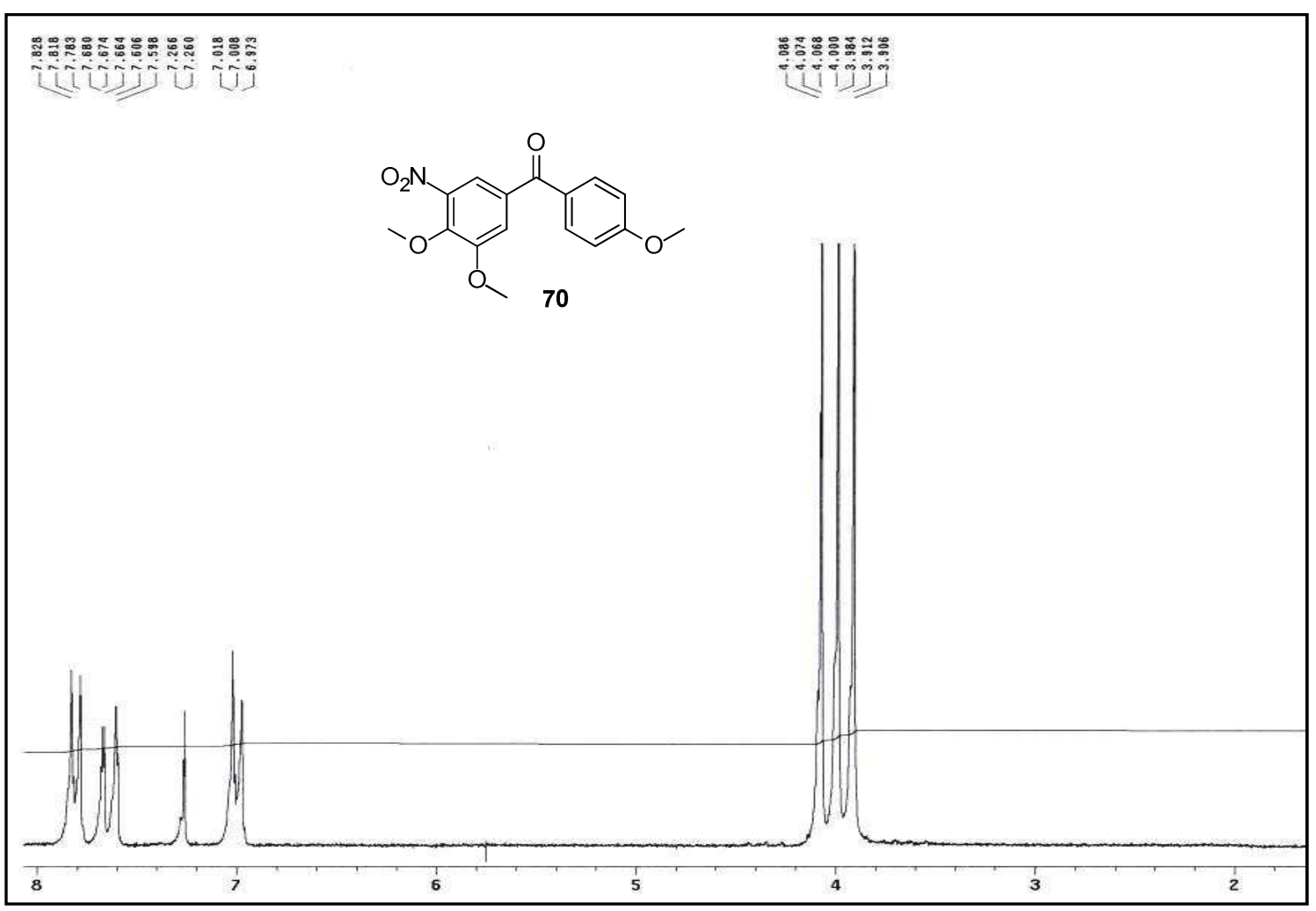

Figura LXIa: Espectro de RMN ${ }^{1} \mathrm{H}$ del compuesto 70.

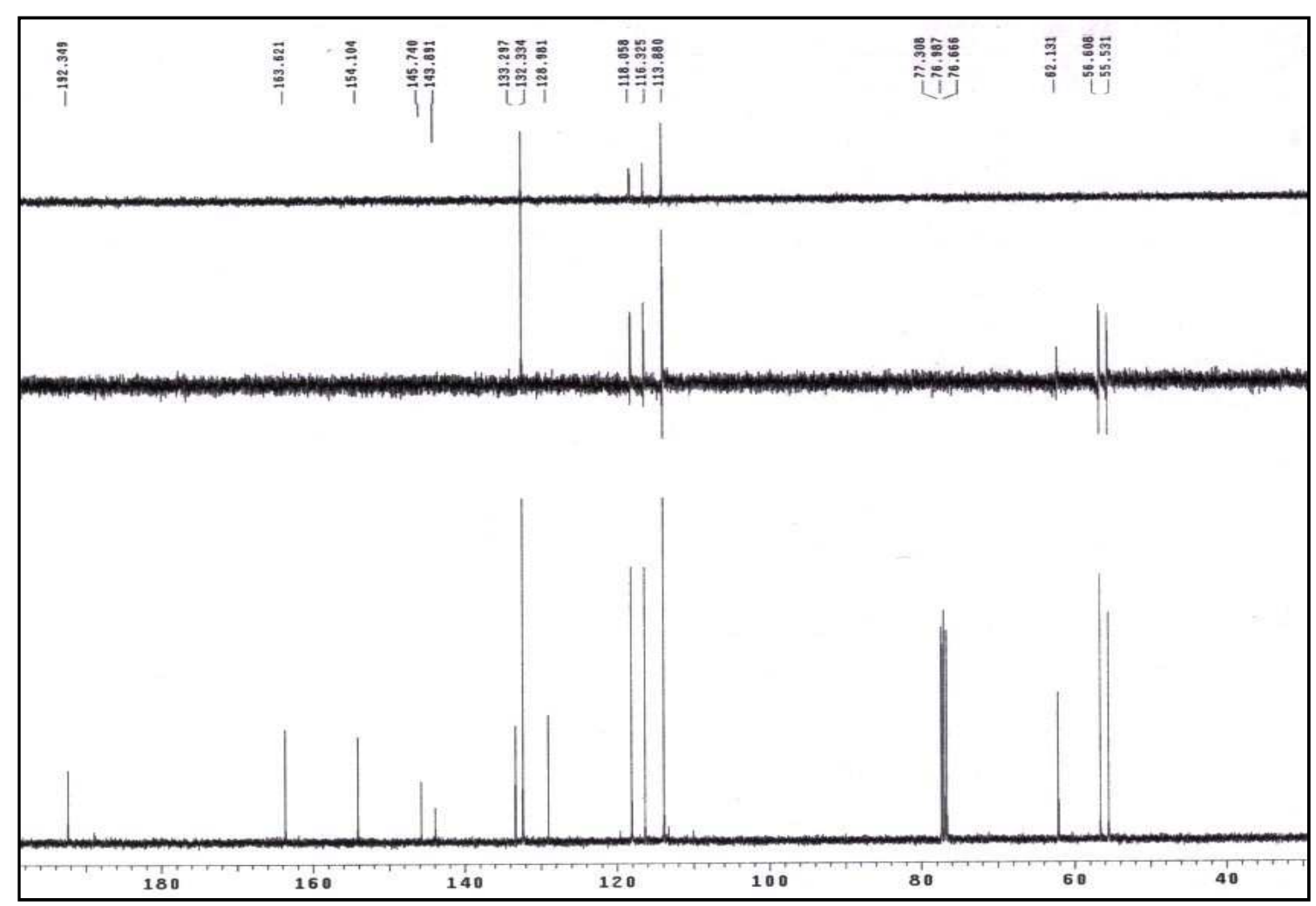

Figura LXIb: Espectro de RMN ${ }^{13} \mathrm{C}$ del compuesto 70. 


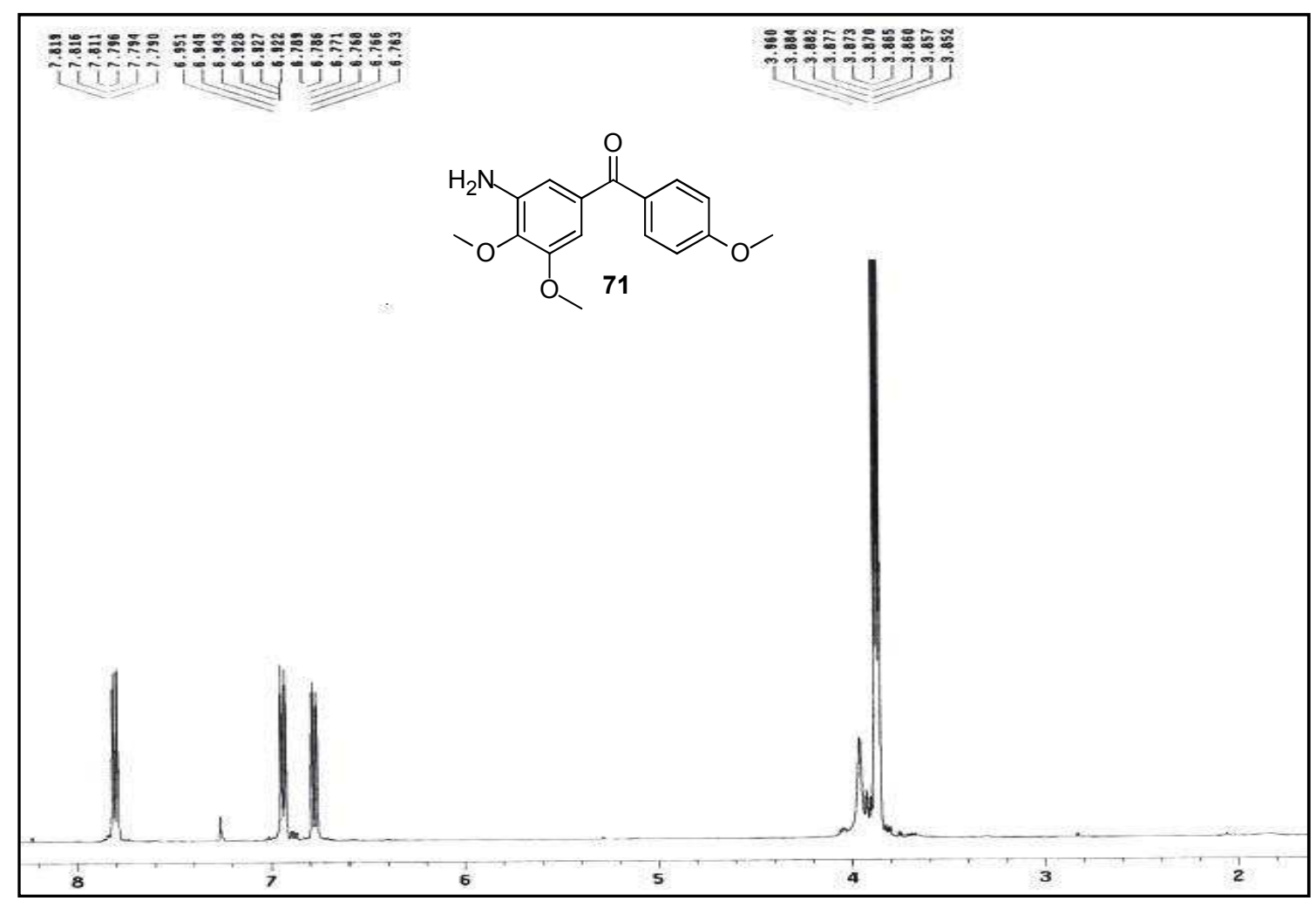

Figura LXIIa: Espectro de RMN ${ }^{1} \mathrm{H}$ del compuesto 71.

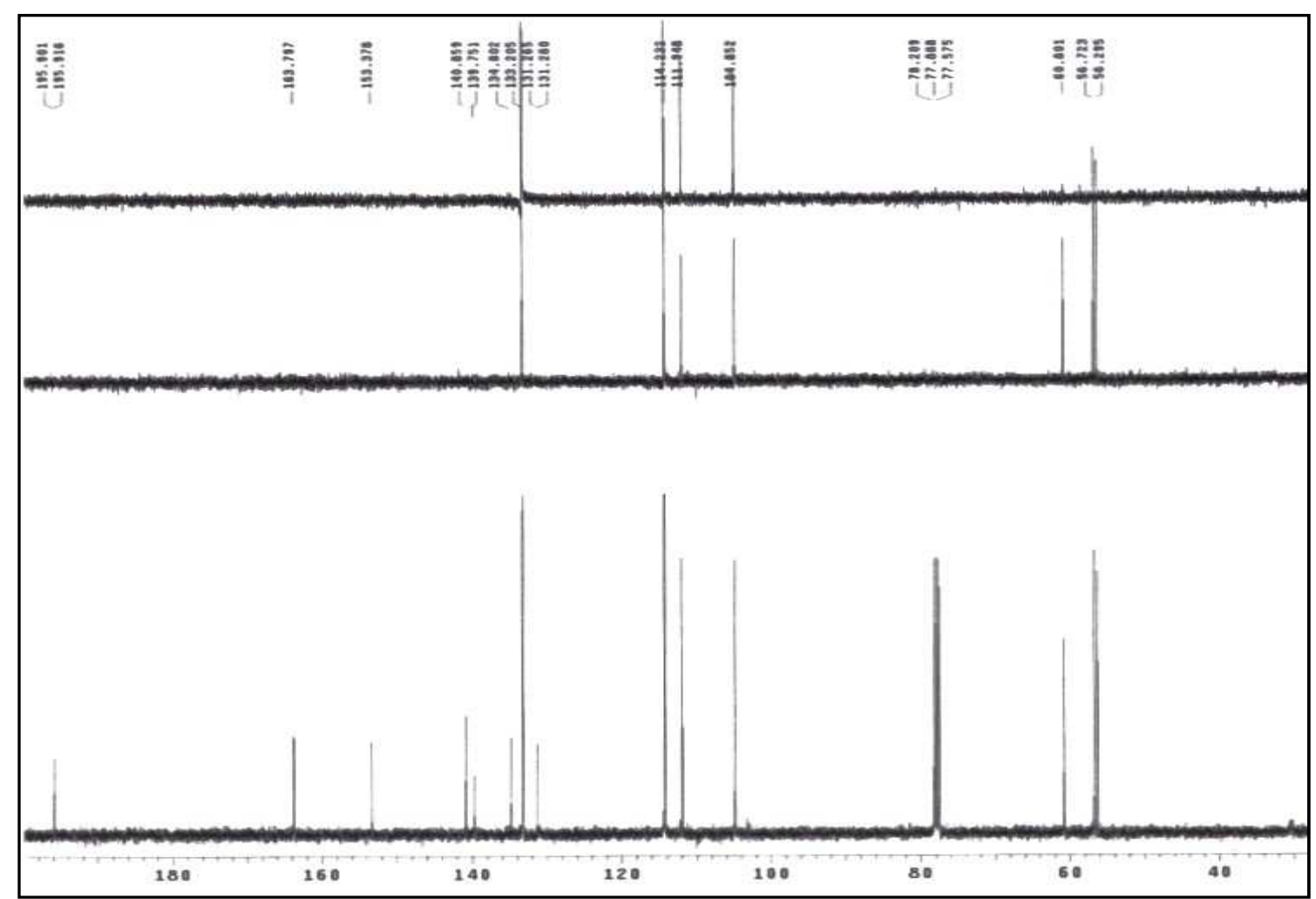

Figura LXIIb: Espectro de RMN ${ }^{13} \mathrm{C}$ del compuesto 71. 


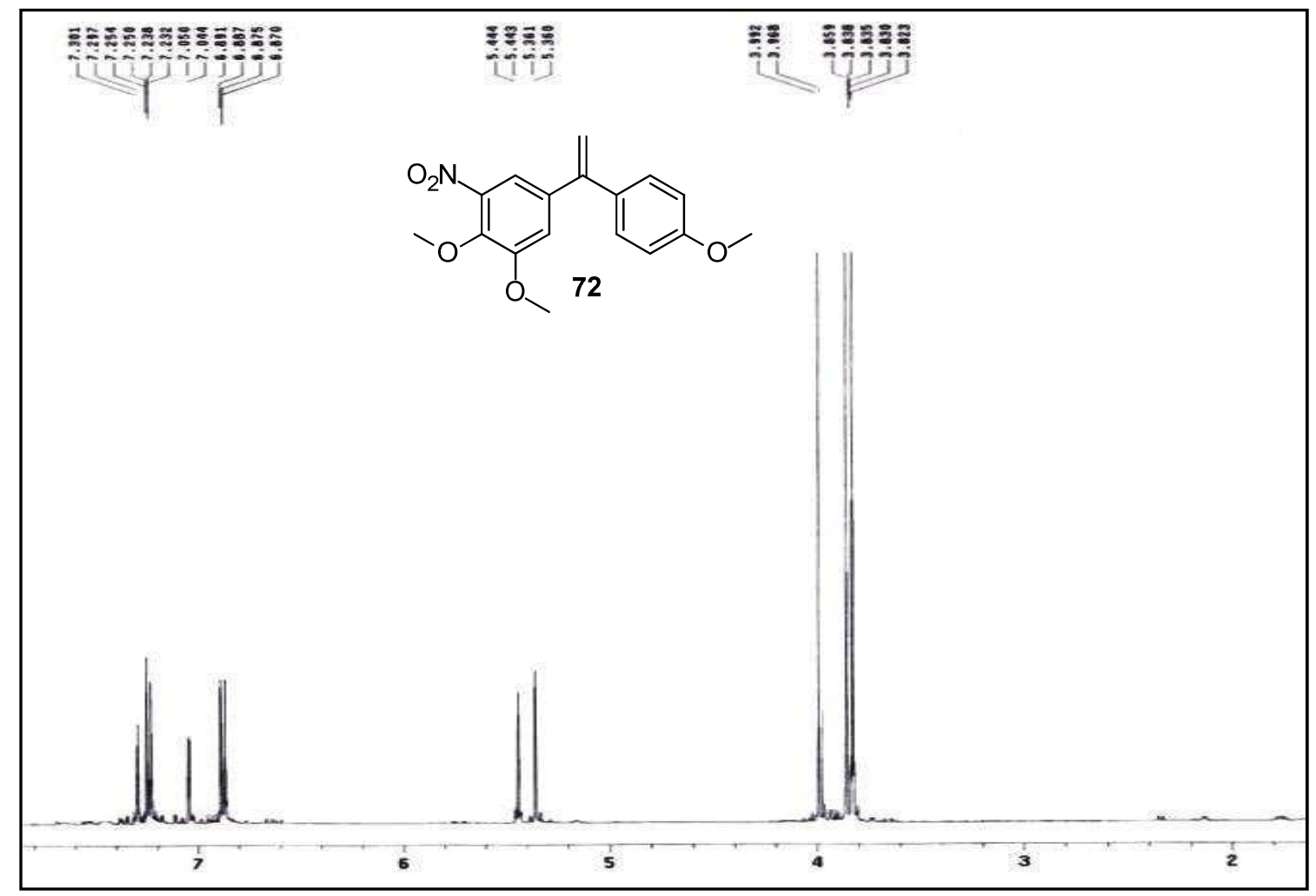

Figura LXIIIa: Espectro de RMN ${ }^{1} \mathrm{H}$ del compuesto 72.

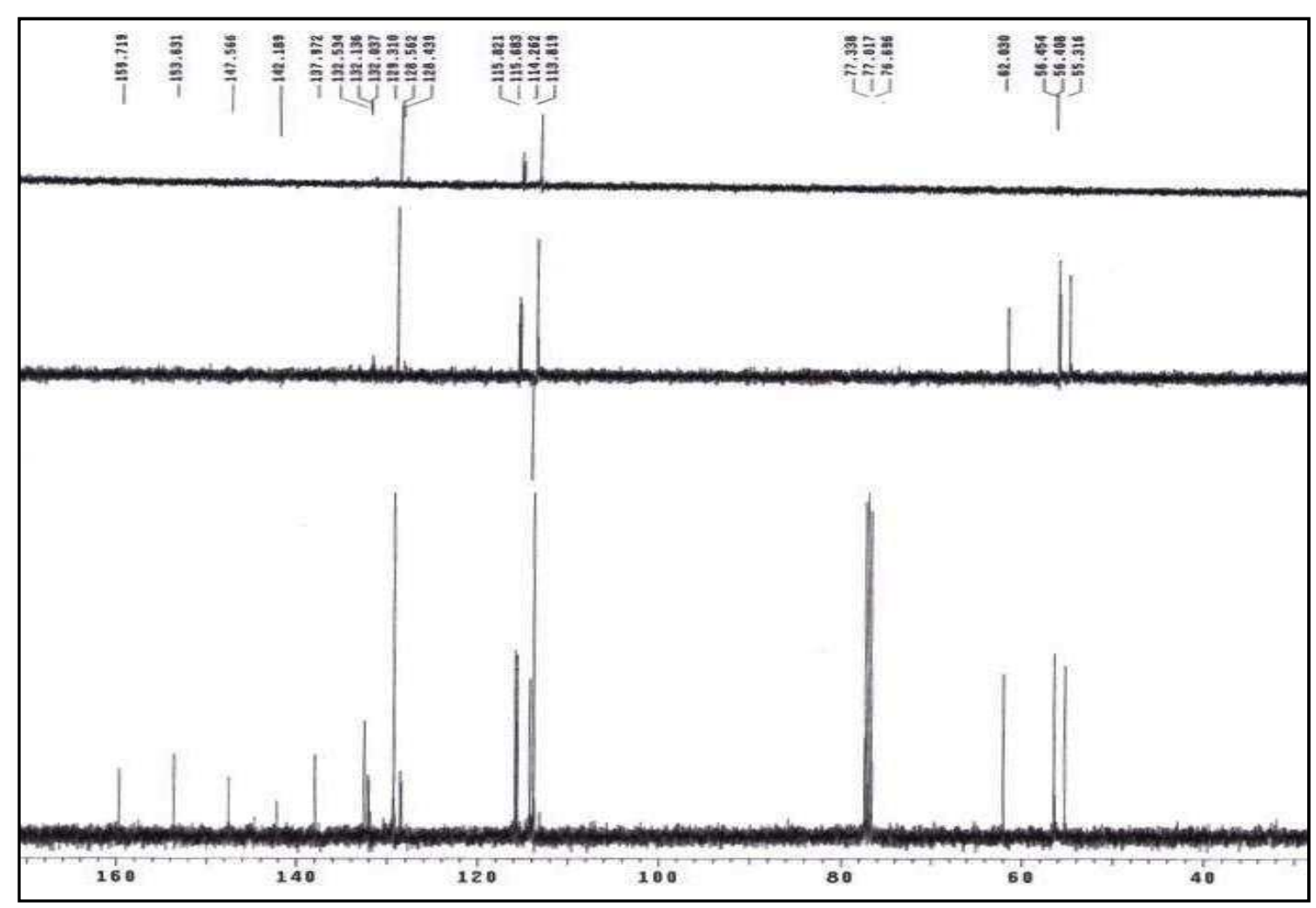

Figura LXIIIb: Espectro de RMN ${ }^{13} \mathrm{C}$ del compuesto 72. 


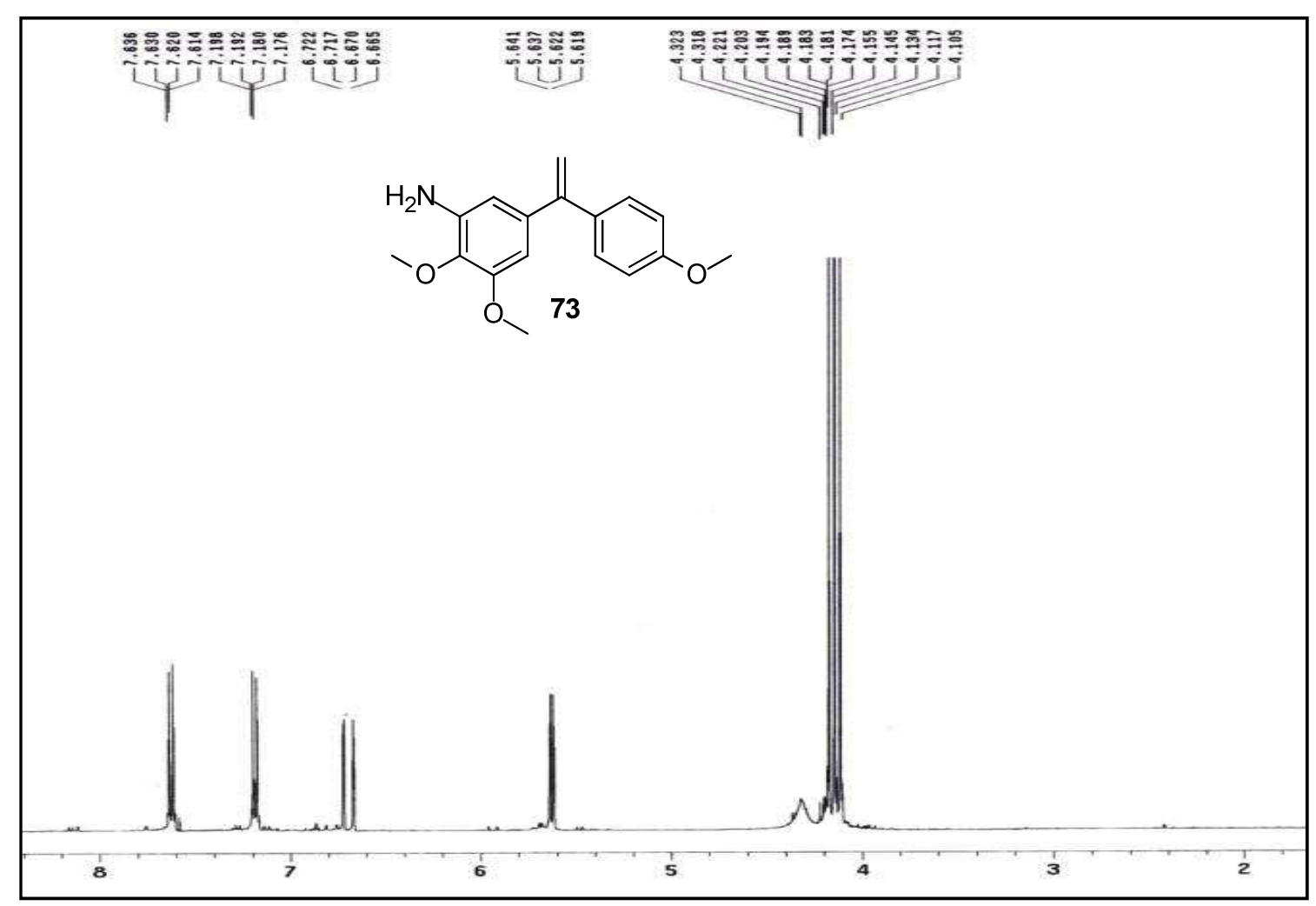

Figura LXIVa: Espectro de RMN ${ }^{1} \mathrm{H}$ del compuesto 73.

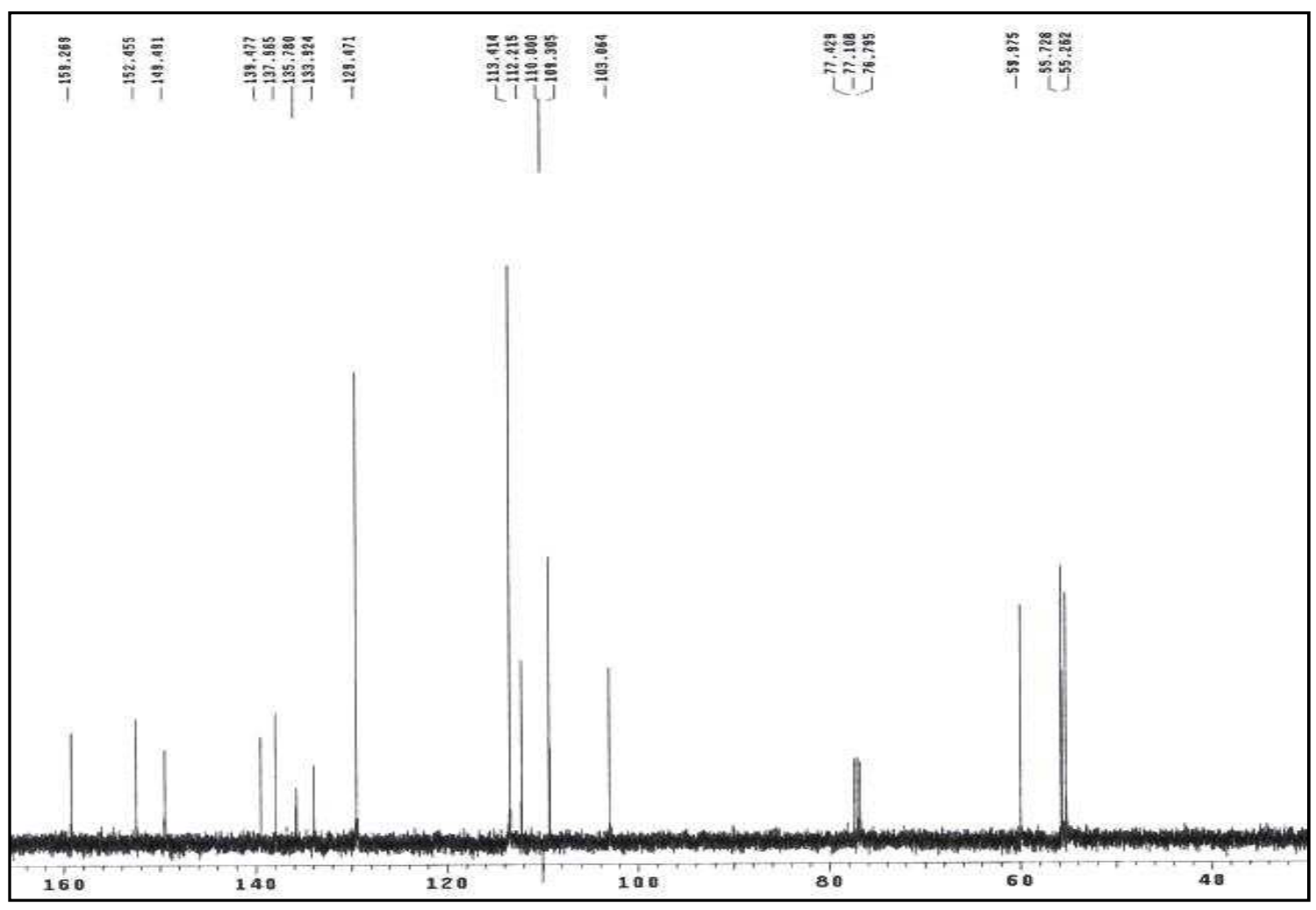

Figura LXIVb: Espectro de RMN ${ }^{13} \mathrm{C}$ del compuesto 73. 


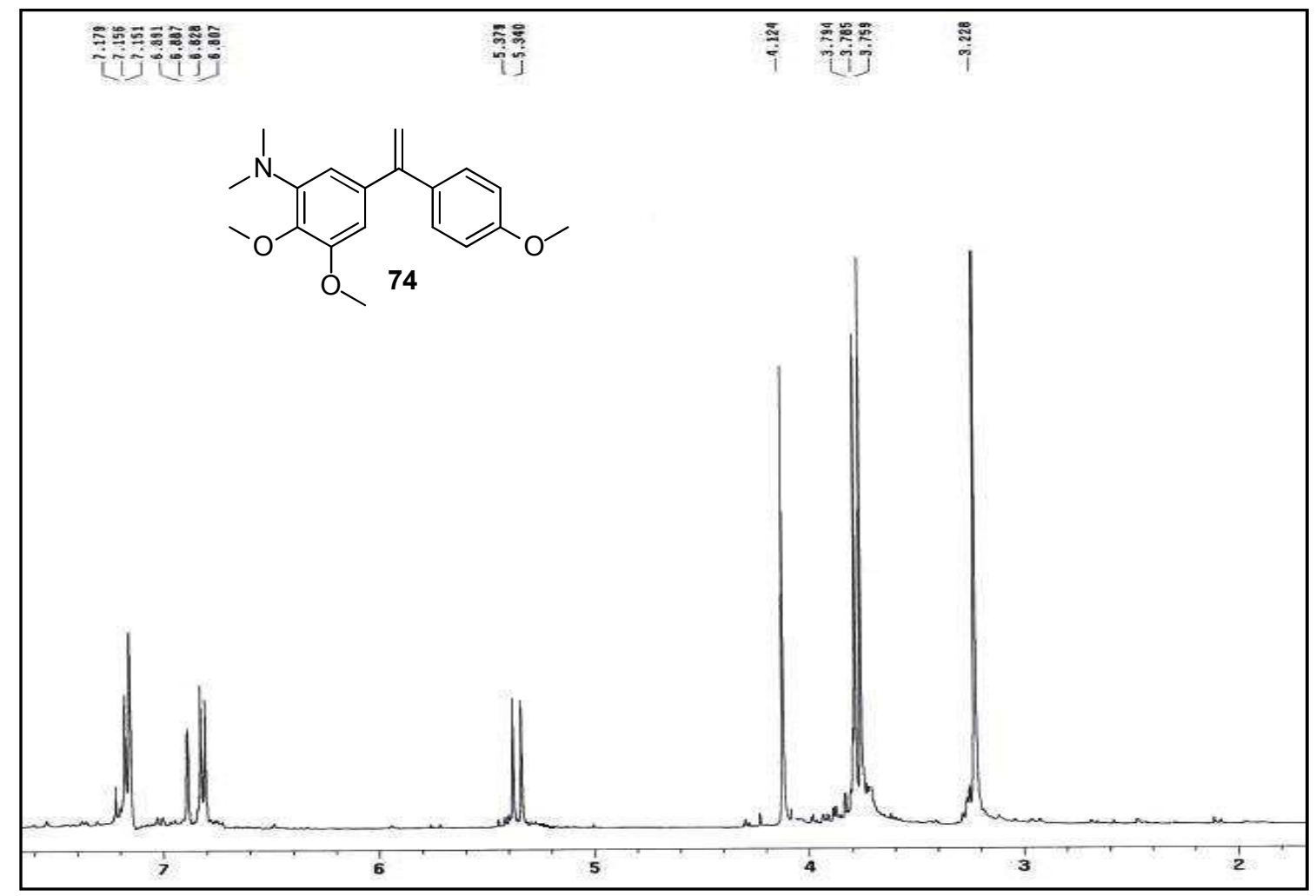

Figura LXVa: Espectro de RMN ${ }^{1} \mathrm{H}$ del compuesto 74.

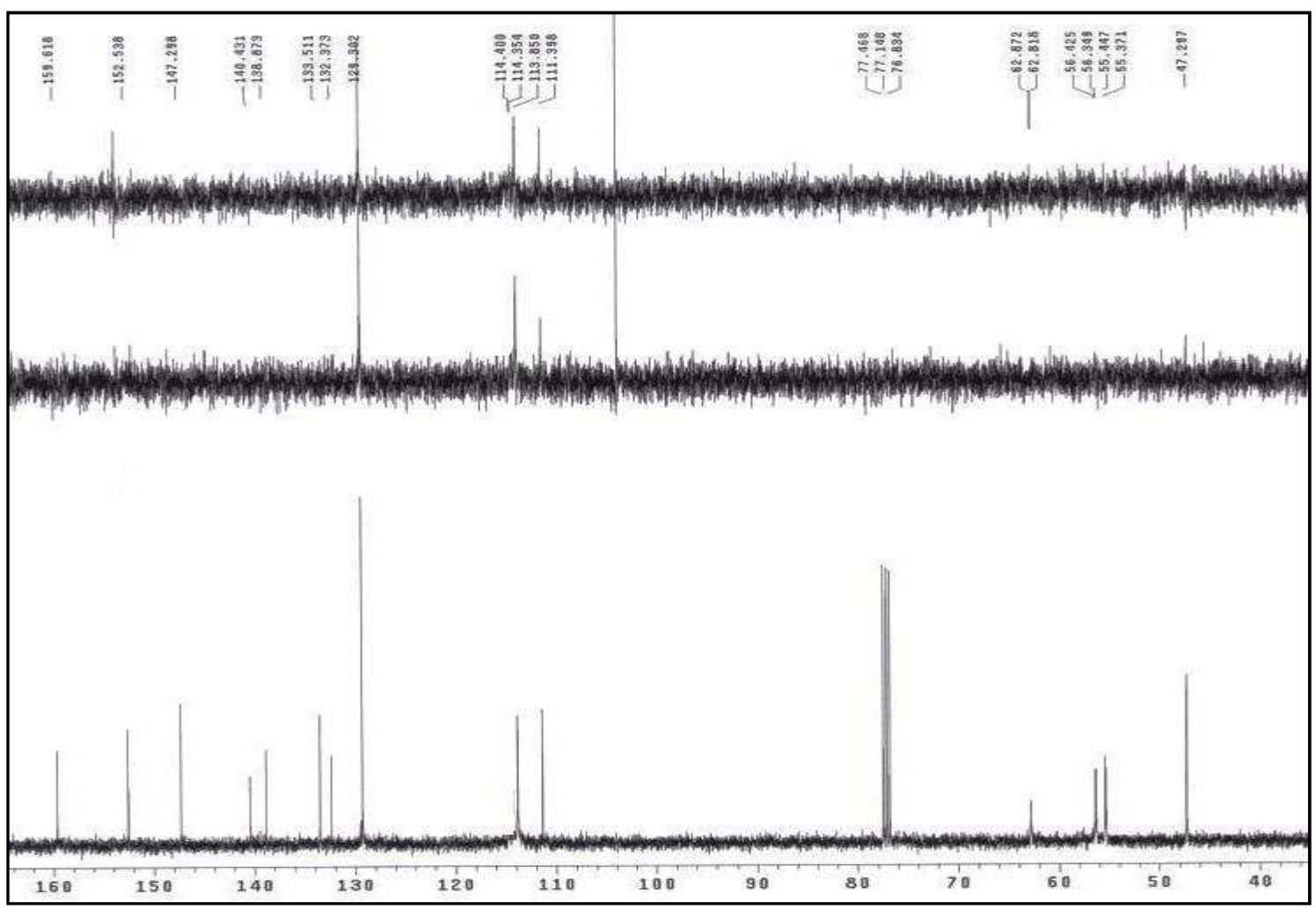

Figura LXVb: Espectro de RMN ${ }^{13} \mathrm{C}$ del compuesto 74. 


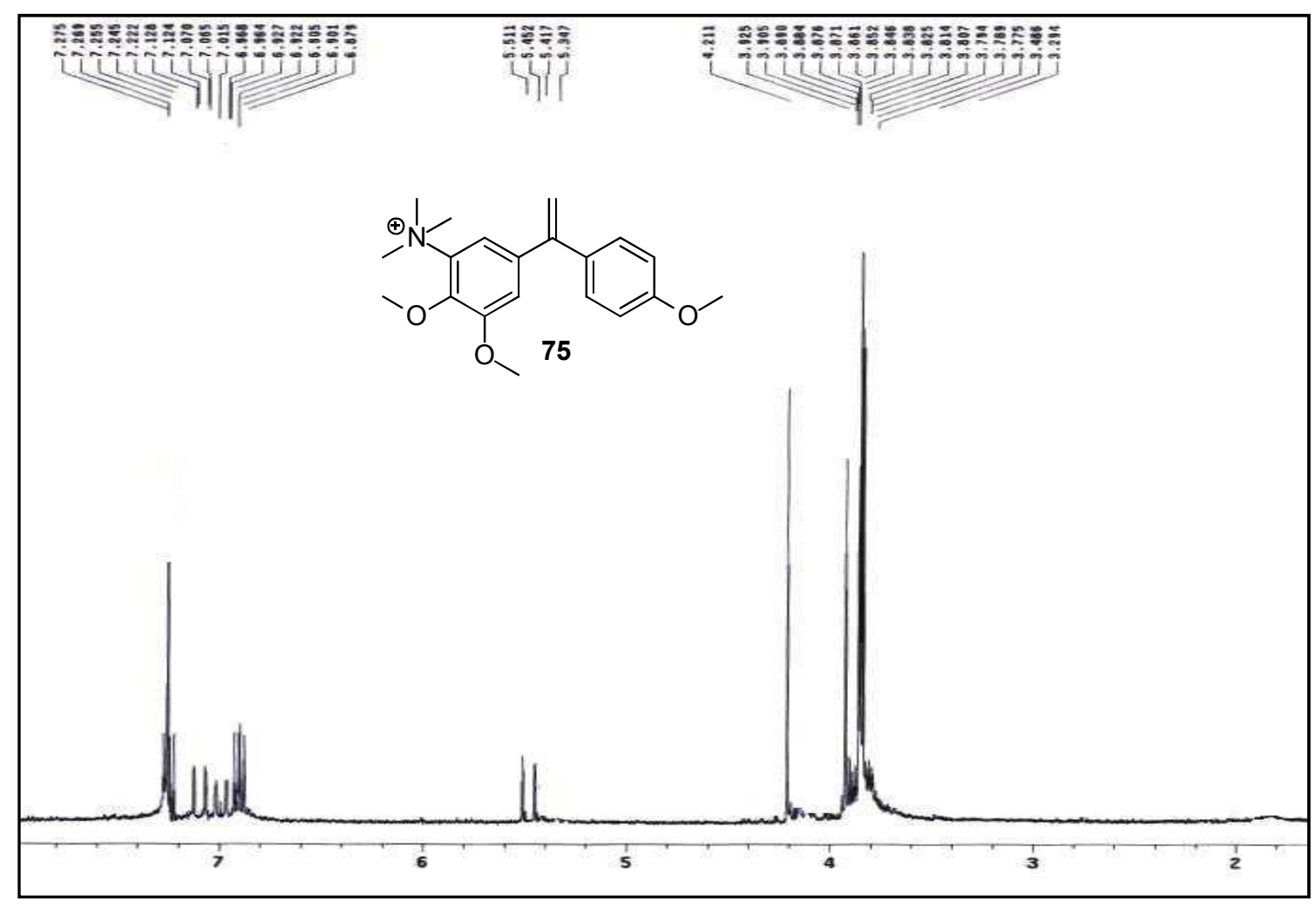

Figura LXVI: Espectro de RMN ${ }^{1} \mathrm{H}$ del compuesto 75. 


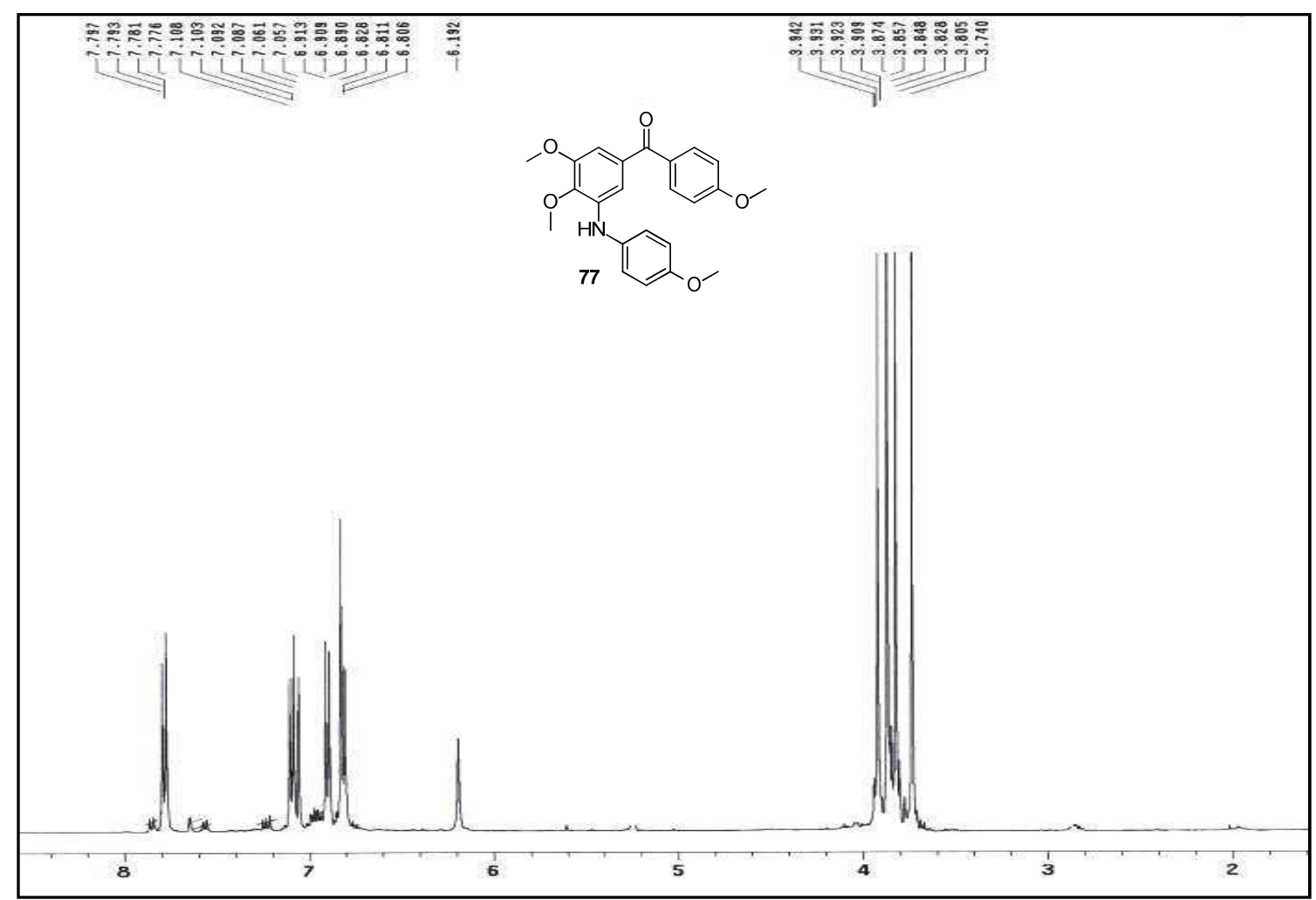

Figura LXVIIa: Espectro de RMN ${ }^{1} \mathrm{H}$ del compuesto 77.

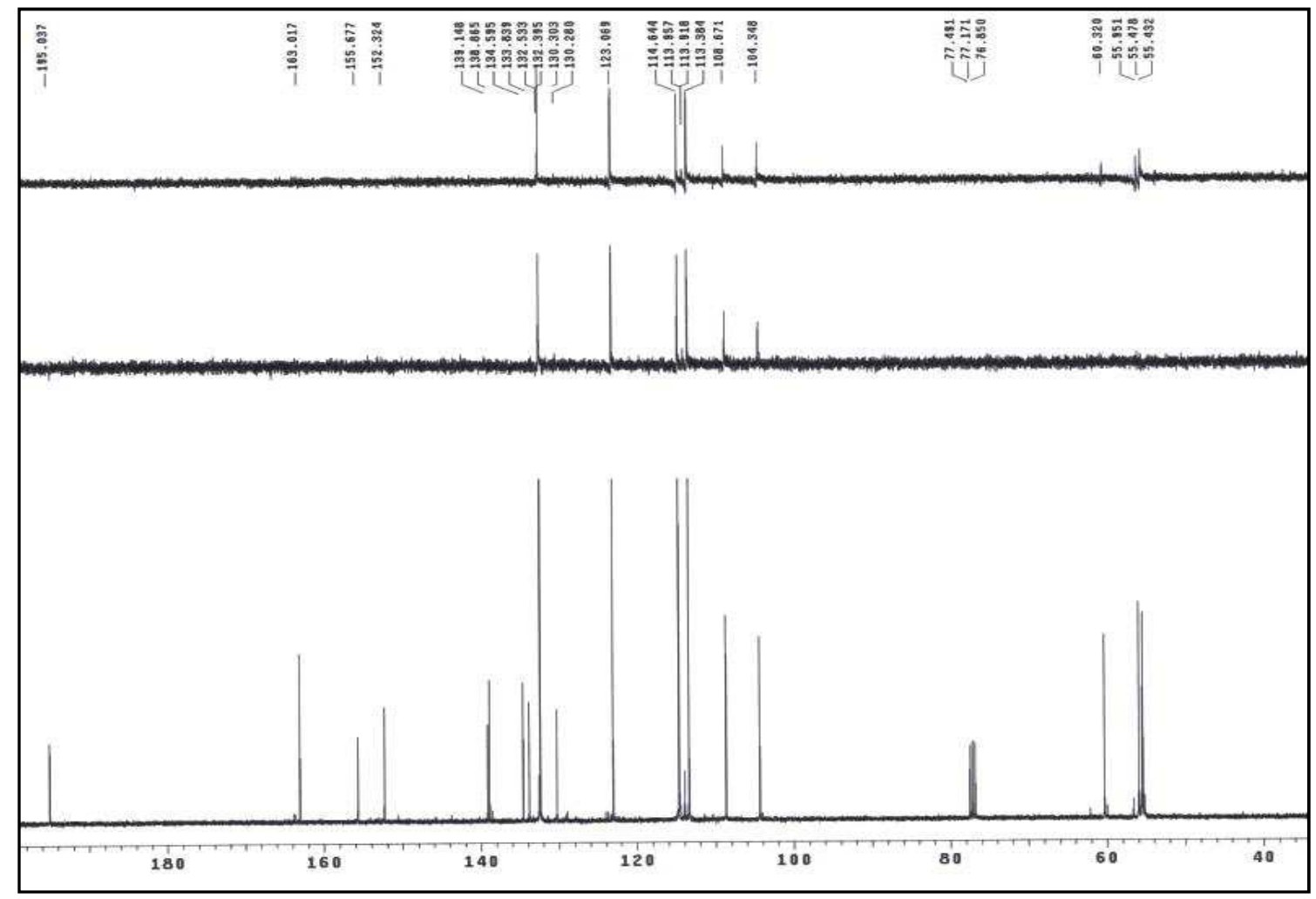

Figura LXVIIb: Espectro de RMN ${ }^{13} \mathrm{C}$ del compuesto 77. 


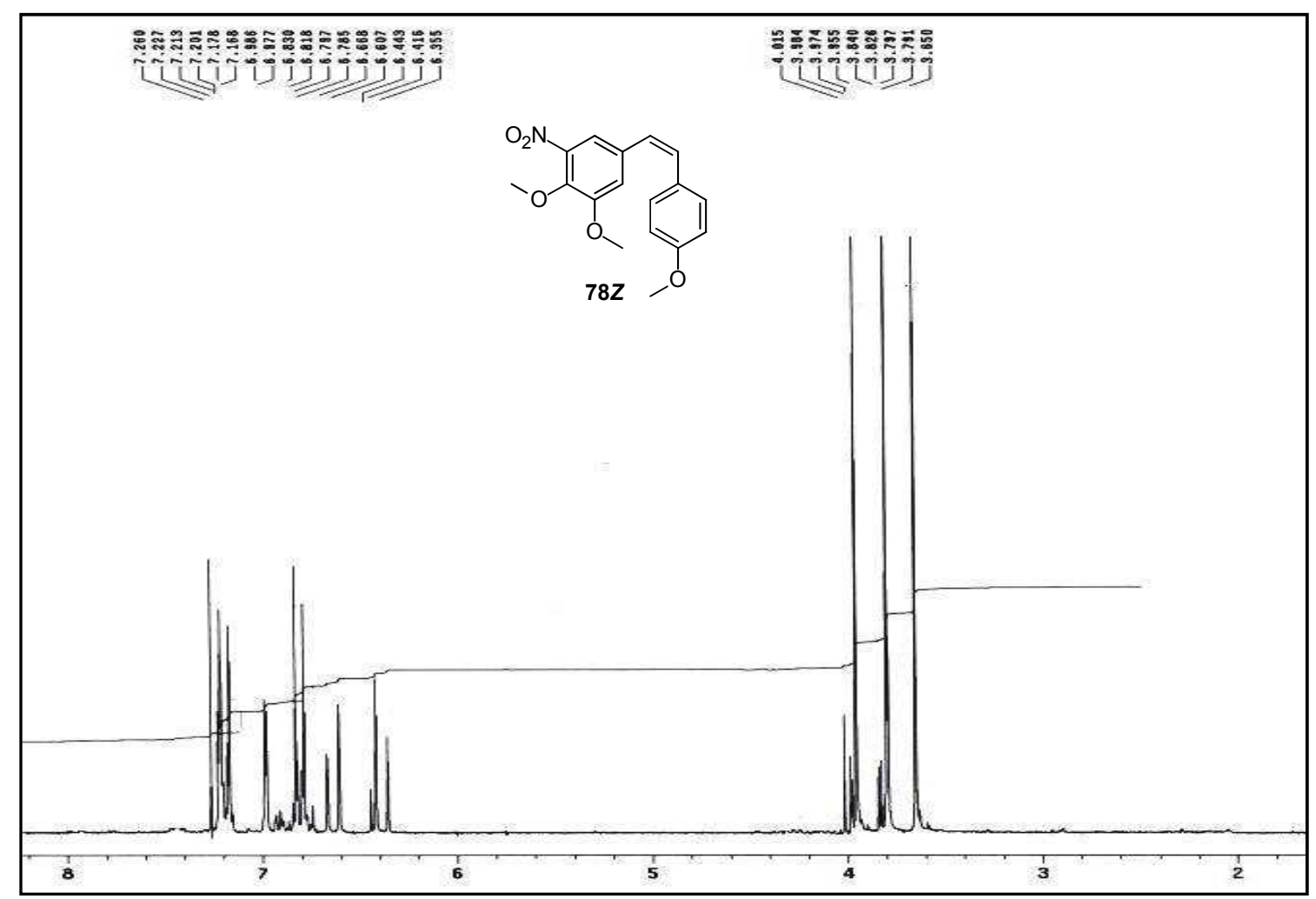

Figura LXVIIIa: Espectro de RMN ${ }^{1} \mathrm{H}$ del compuesto $\mathbf{7 8 Z}$.

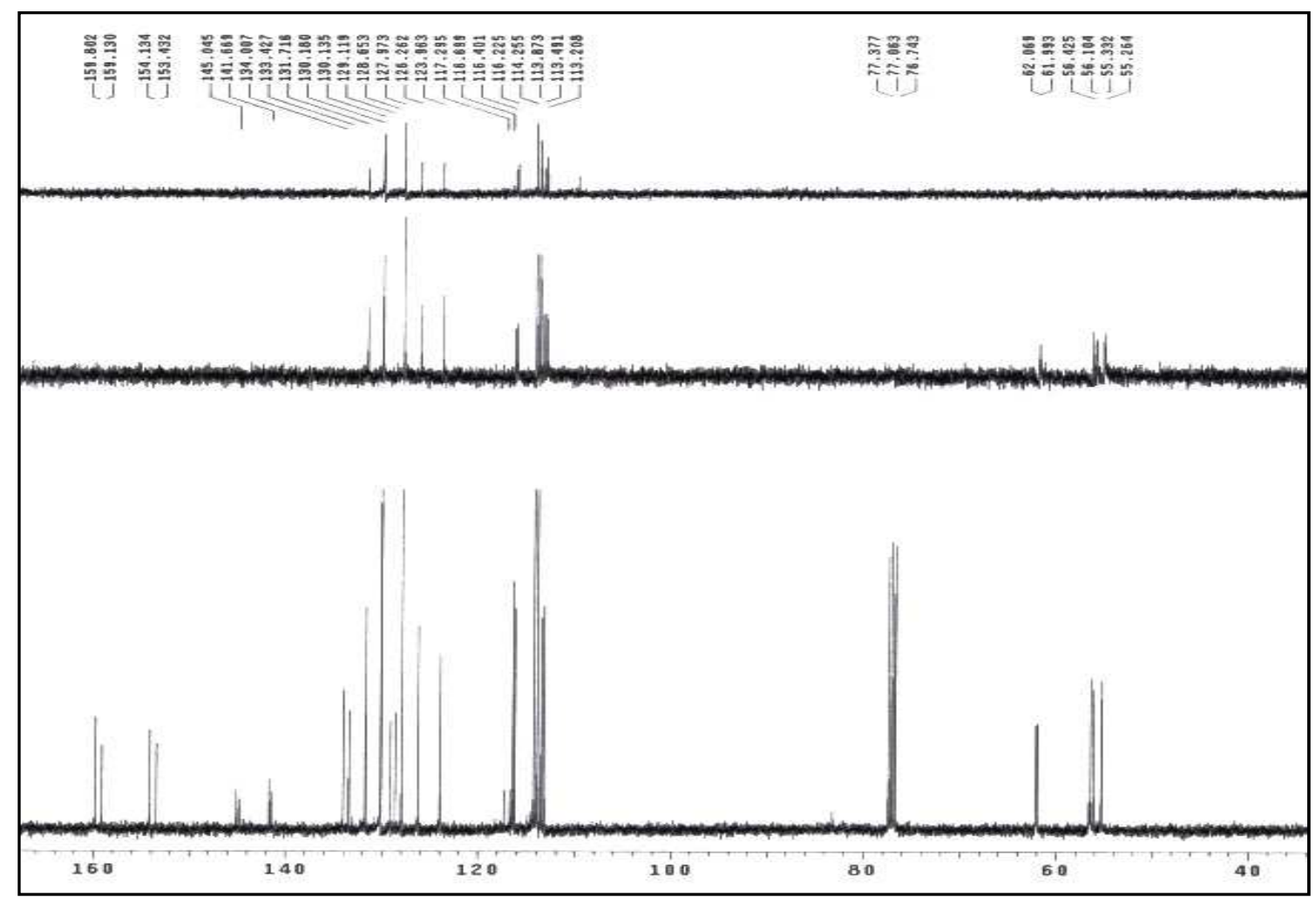

Figura LXVIIIa: Espectro de RMN ${ }^{13} \mathrm{C}$ del compuesto $\mathbf{7 8 Z}$. 


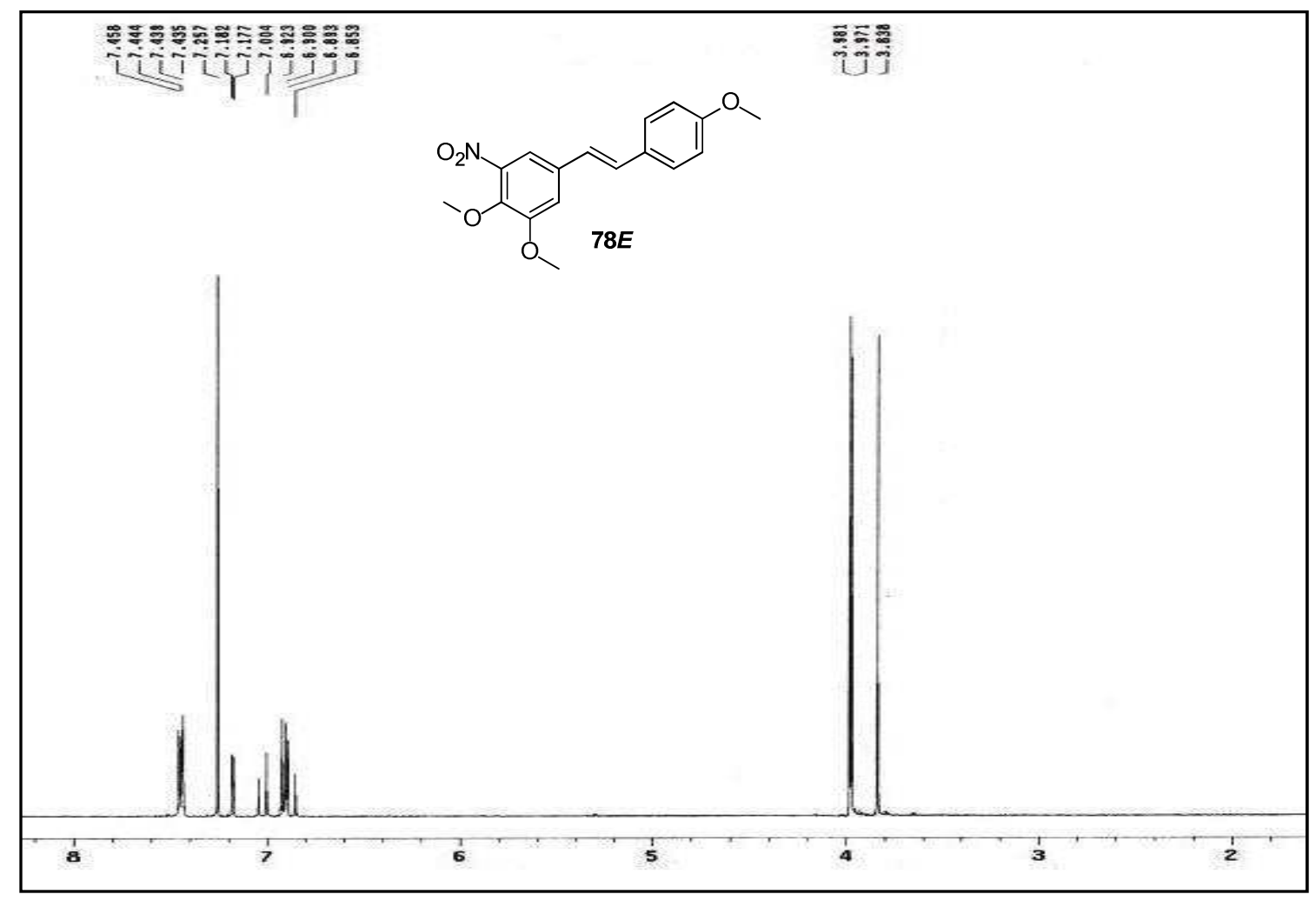

Figura LXVIIIc: Espectro de RMN ${ }^{1} \mathrm{H}$ del compuesto $\mathbf{7 8 E}$.

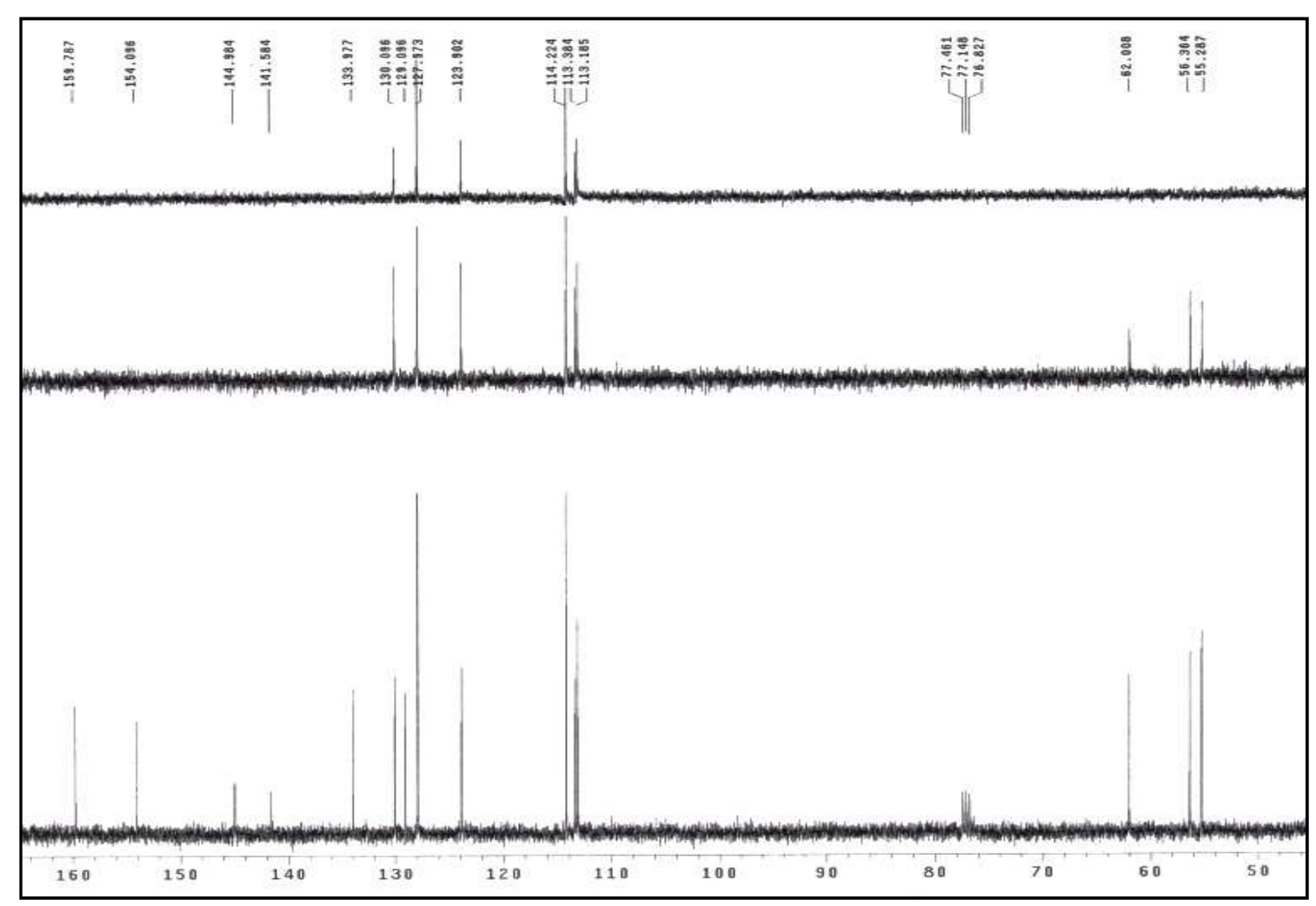

Figura LXVIIId: Espectro de RMN ${ }^{13} \mathrm{C}$ del compuesto $\mathbf{7 8 E}$. 


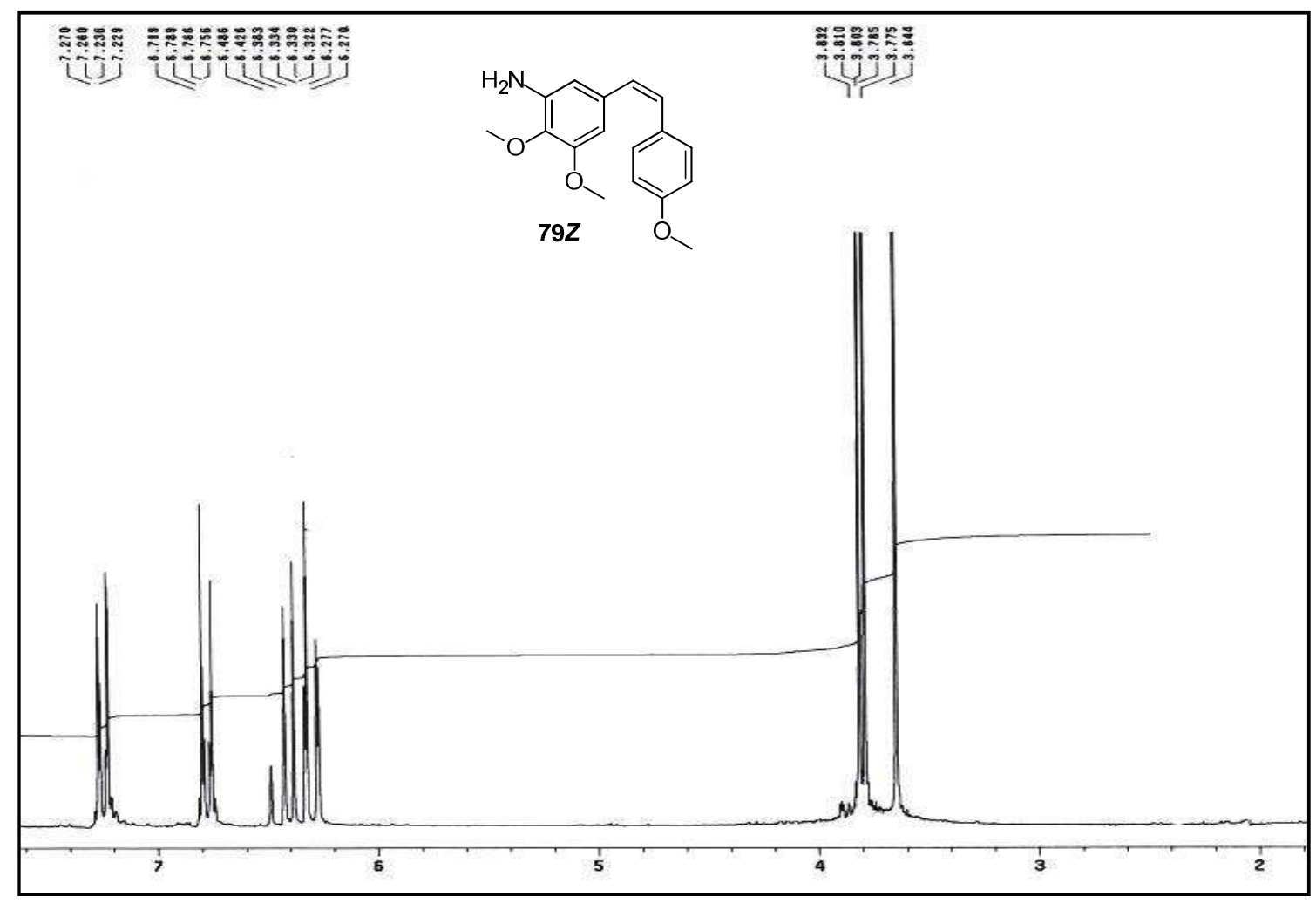

Figura LXIXa: Espectro de RMN ${ }^{1} \mathrm{H}$ del compuesto $79 Z$.

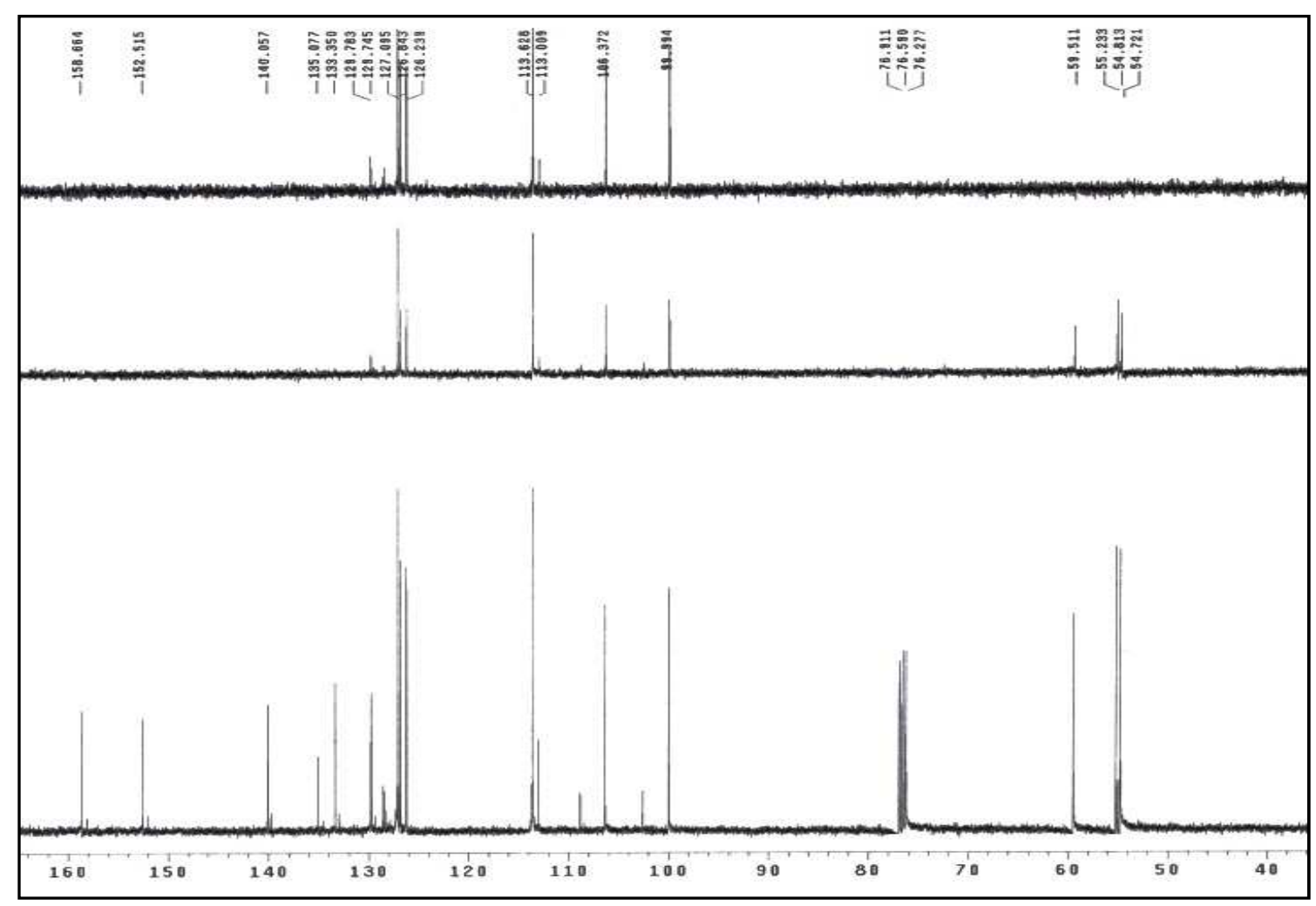

Figura LXIXb: Espectro de RMN ${ }^{13} \mathrm{C}$ del compuesto $79 Z$. 


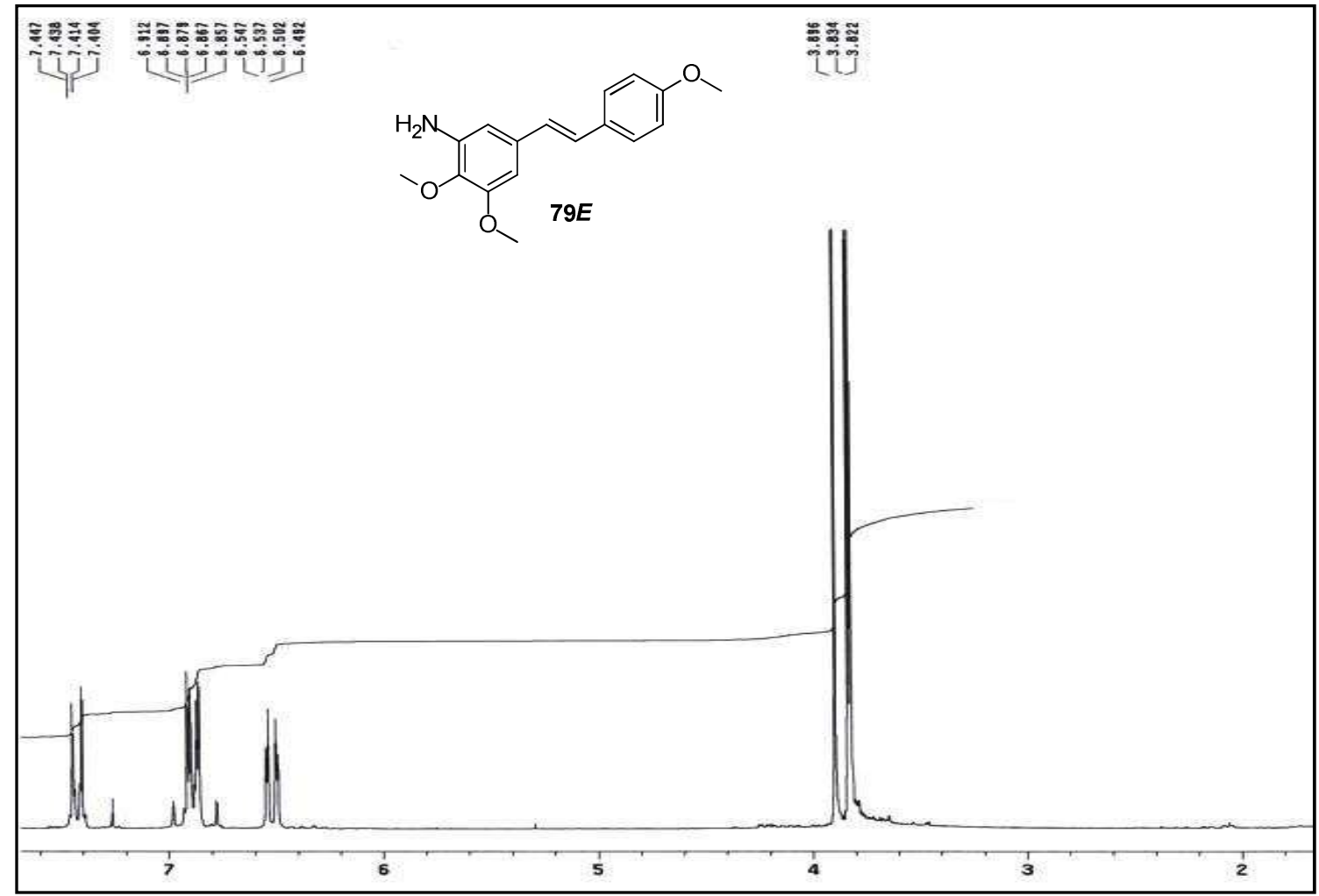

Figura LXIXc: Espectro de RMN ${ }^{1} \mathrm{H}$ del compuesto $\mathbf{7 9 E}$. 


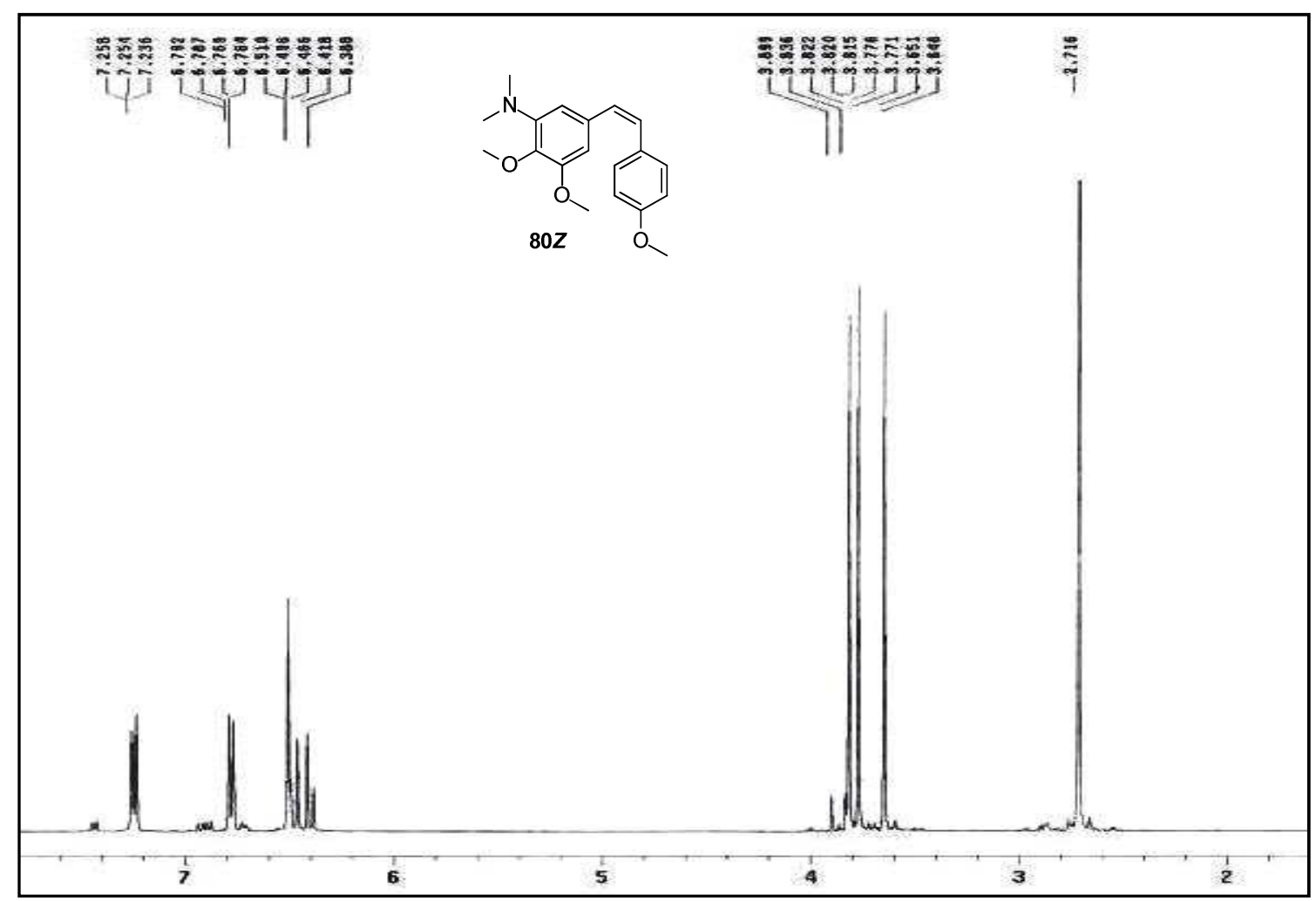

Figura LXXa: Espectro de RMN ${ }^{1} \mathrm{H}$ del compuesto $\mathbf{8 0 Z}$.

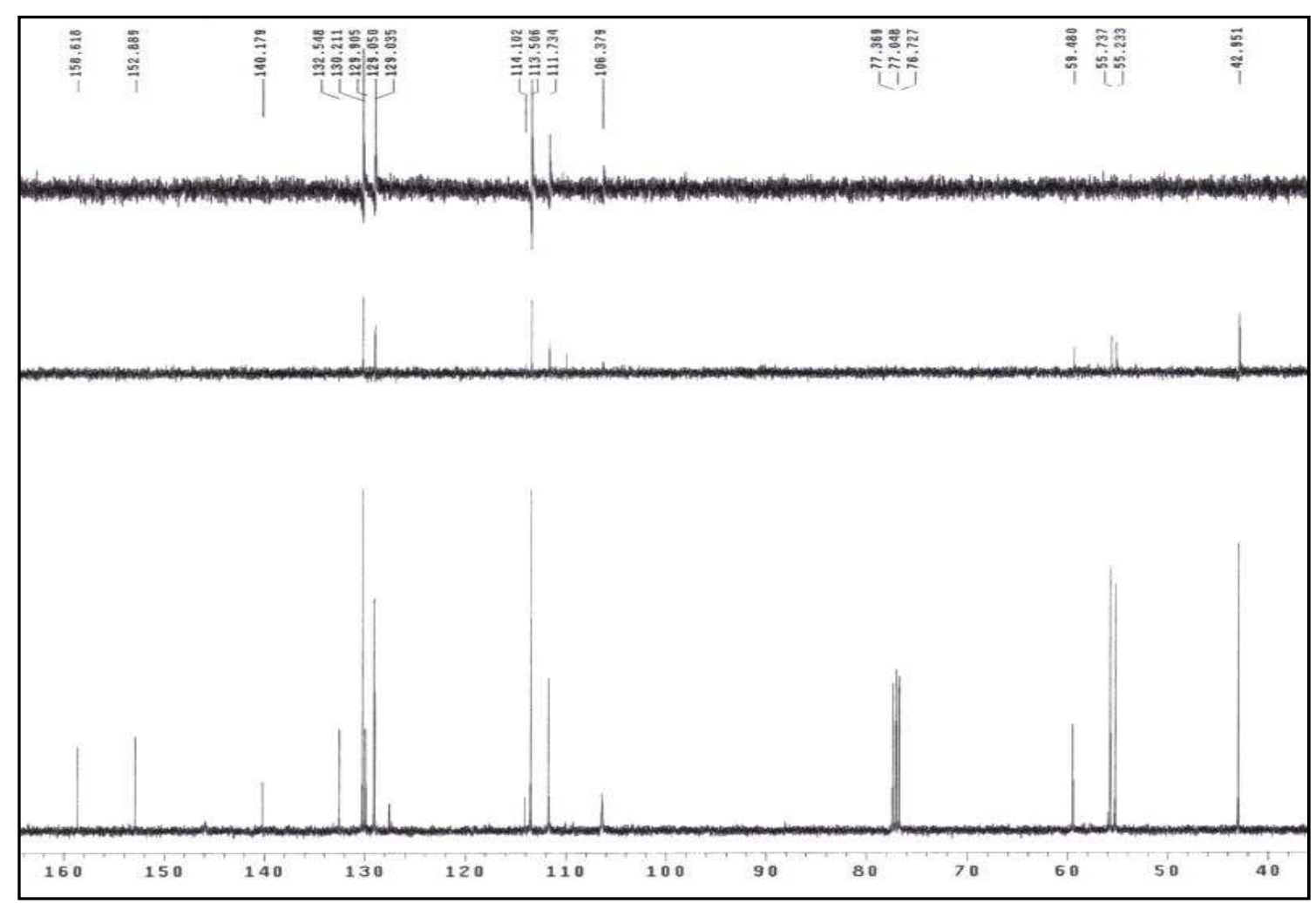

Figura LXXb: Espectro de RMN ${ }^{13} \mathrm{C}$ del compuesto $\mathbf{8 0 Z}$. 


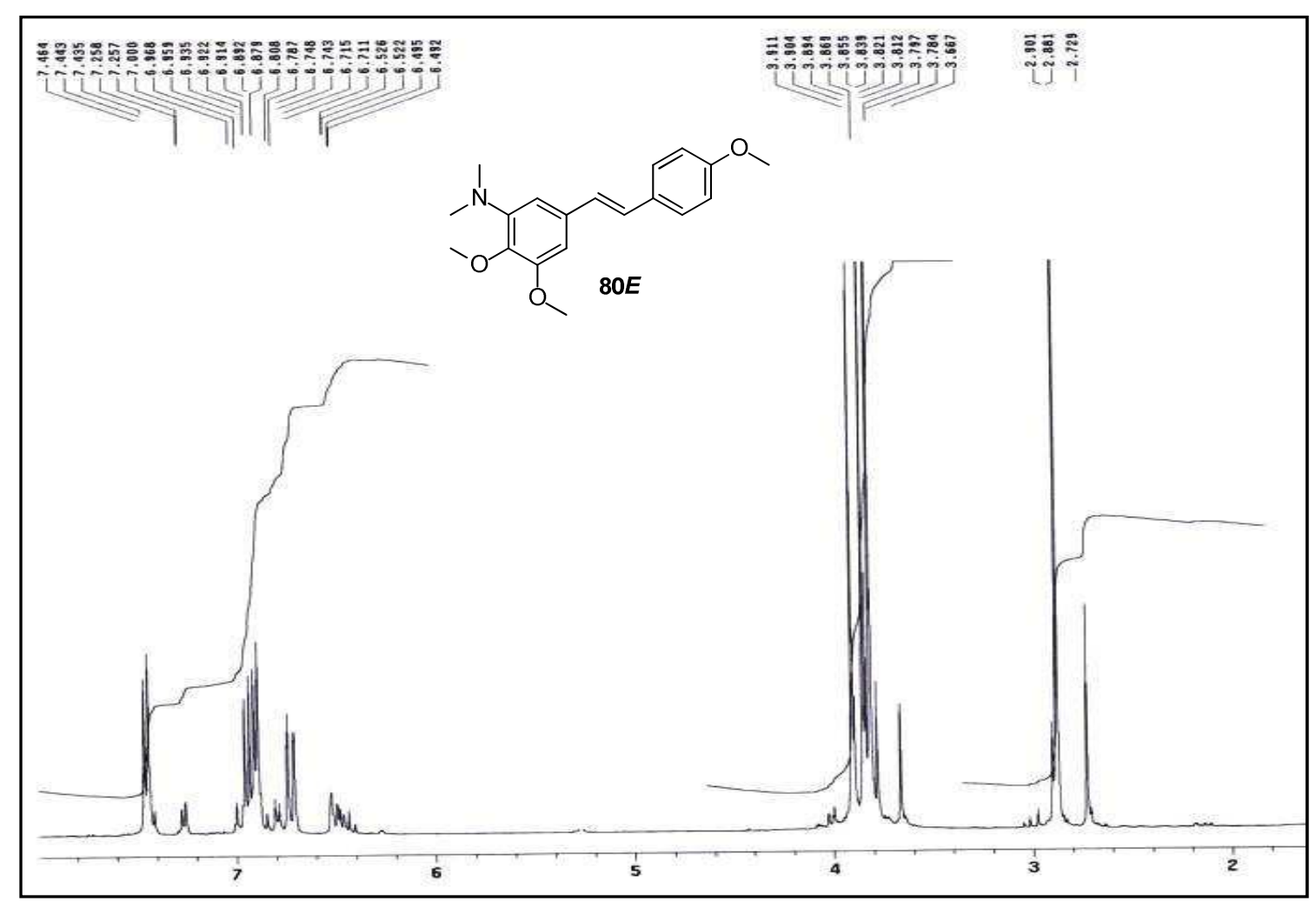

Figura LXXc: Espectro de RMN ${ }^{1} \mathrm{H}$ del compuesto $80 \boldsymbol{E}$.

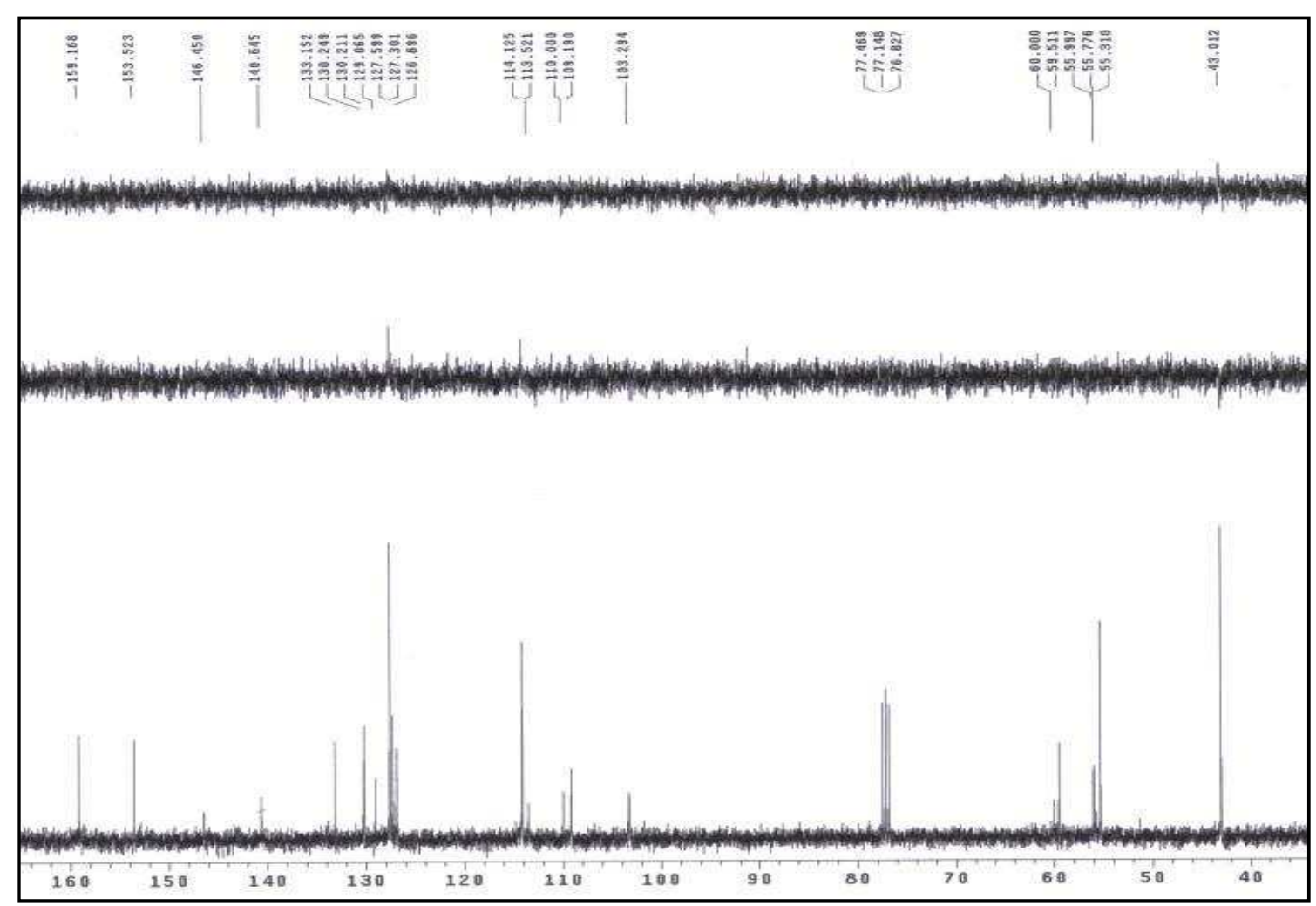

Figura LXXd: Espectro de RMN ${ }^{13} \mathrm{C}$ del compuesto $\mathbf{8 0 E}$. 


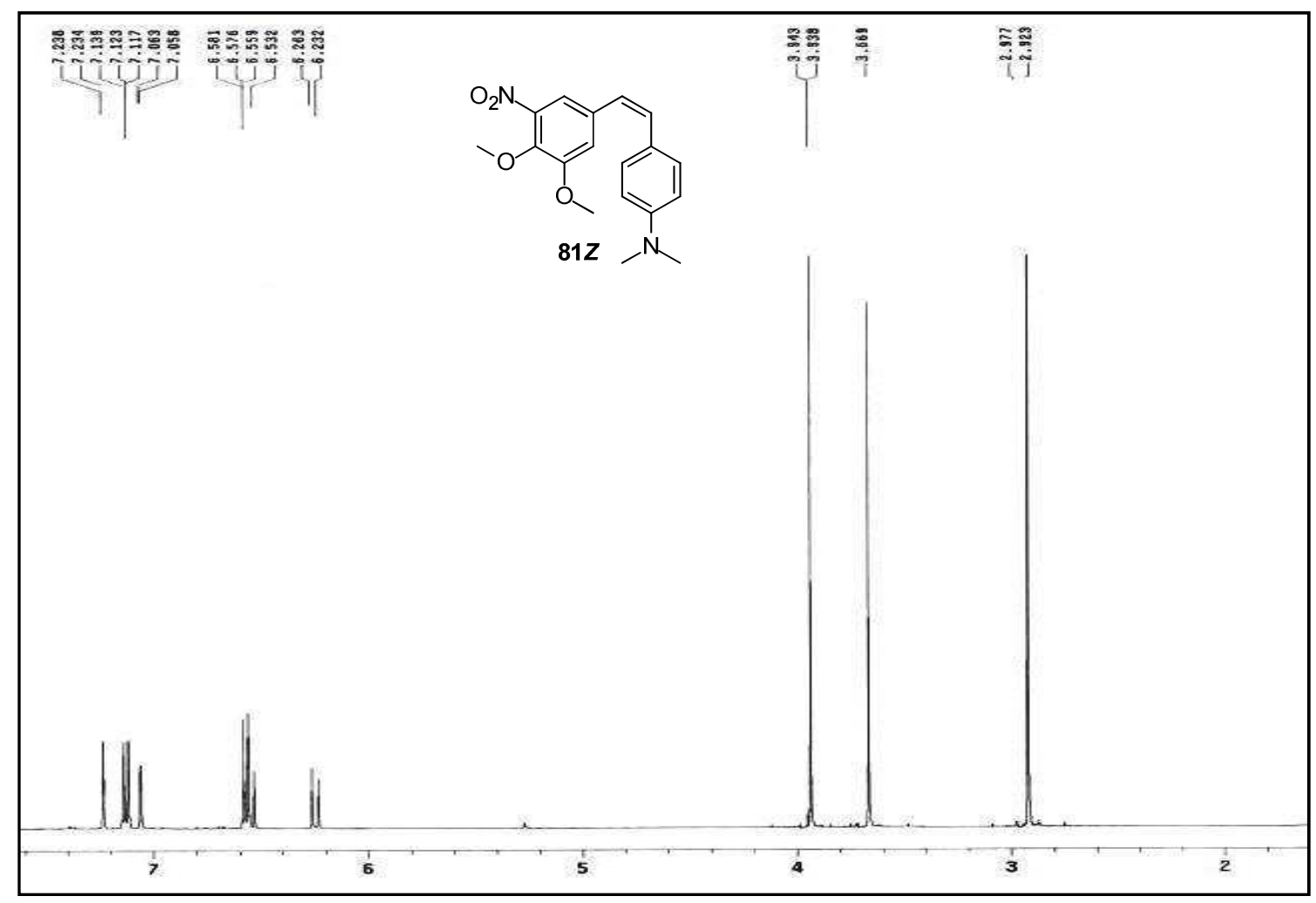

Figura LXXIa: Espectro de RMN ${ }^{1} \mathrm{H}$ del compuesto $\mathbf{8 1 Z}$.

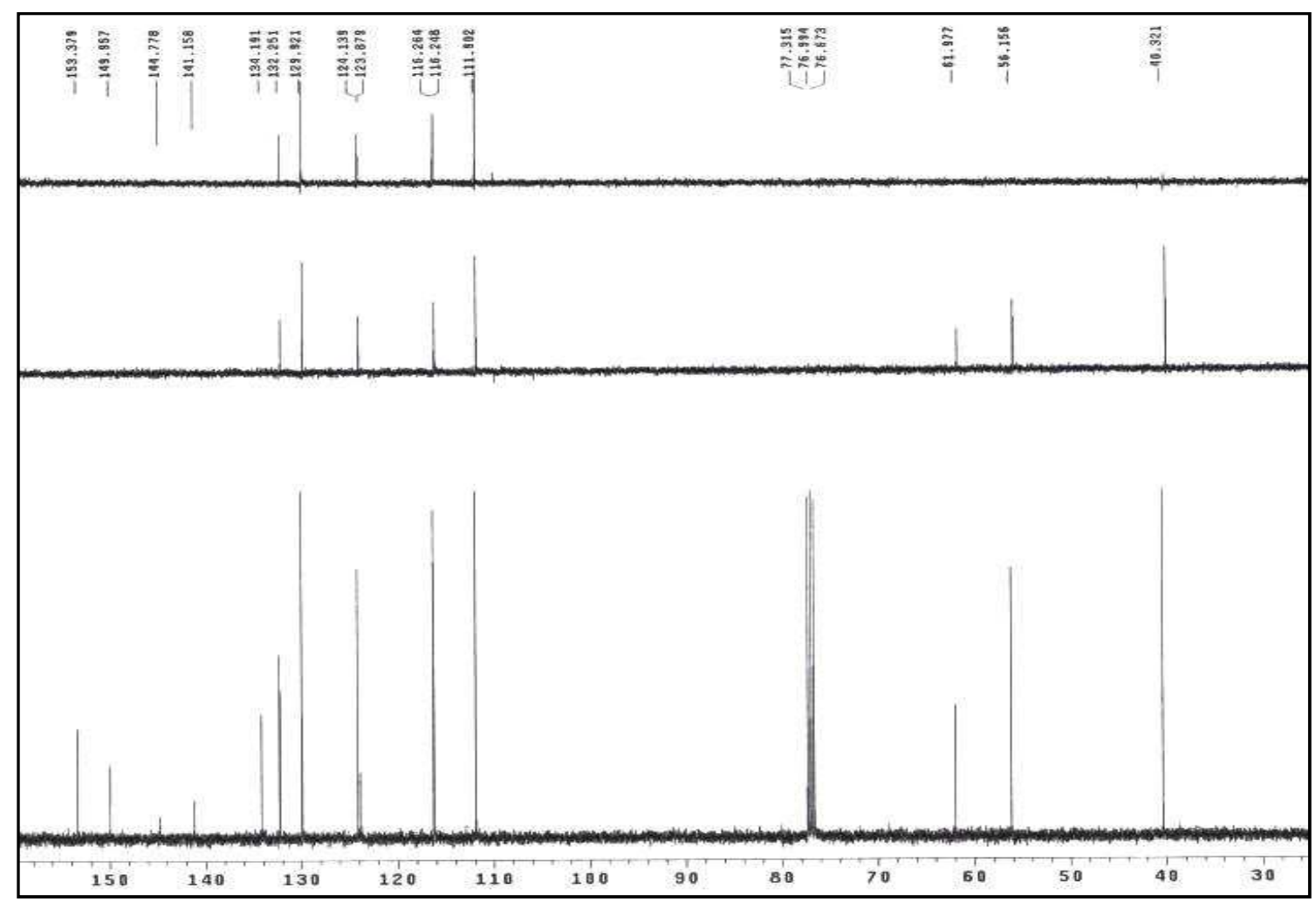

Figura LXXIb: Espectro de RMN ${ }^{13} \mathrm{C}$ del compuesto $81 Z$. 


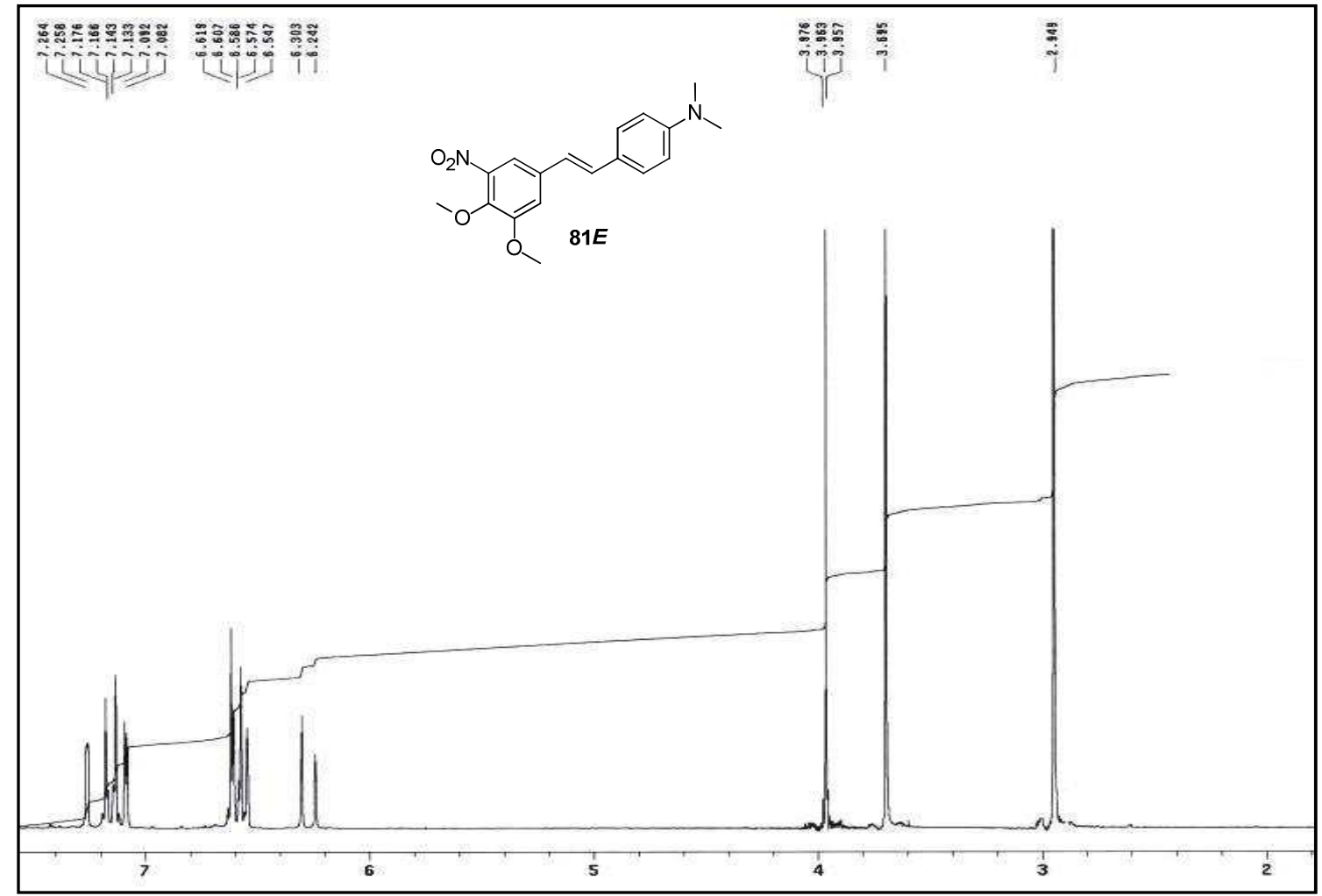

Figura LXXIc: Espectro de RMN ${ }^{1} \mathrm{H}$ del compuesto $\mathbf{8 1 E}$.

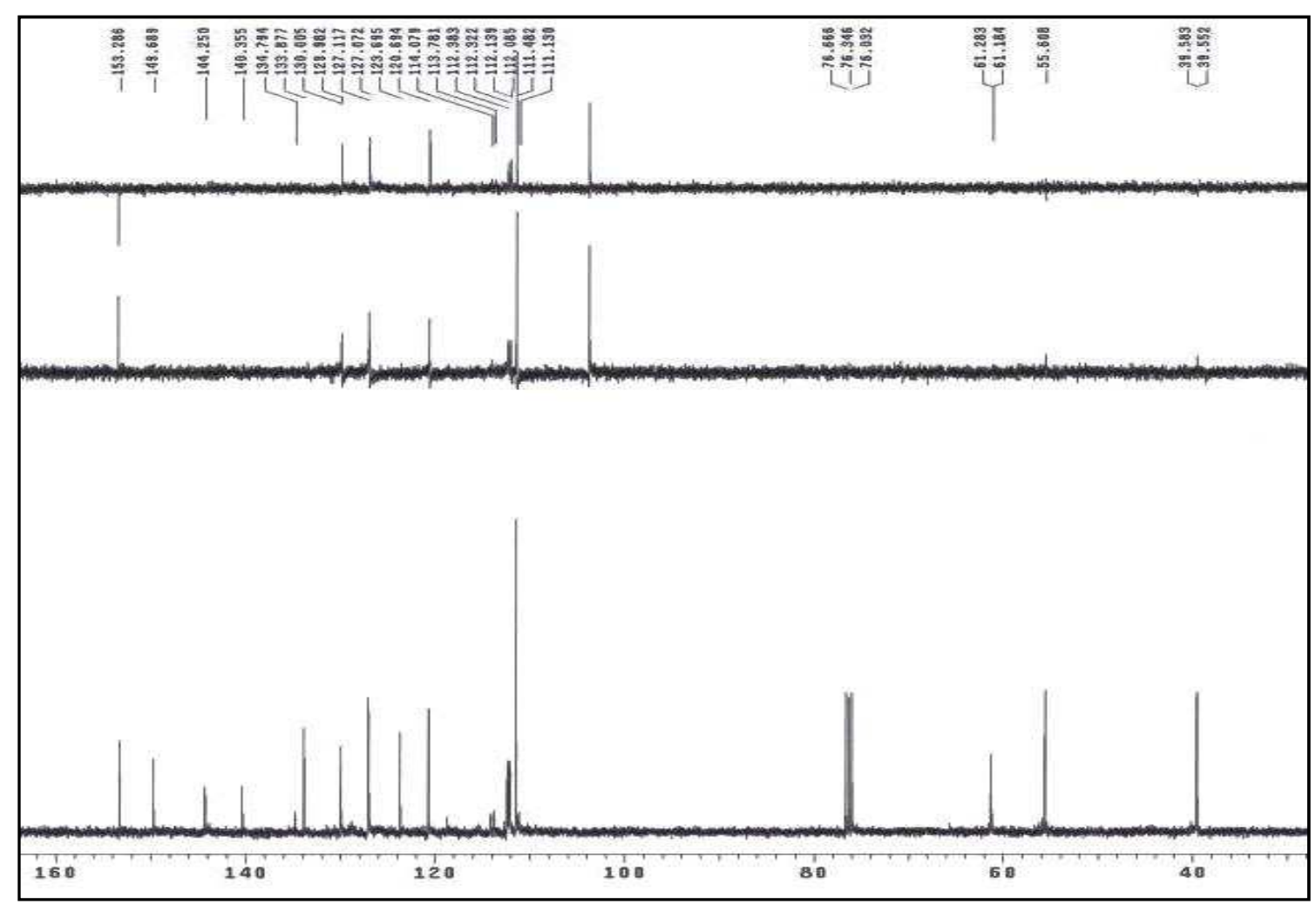

Figura LXXId: Espectro de RMN ${ }^{13} \mathrm{C}$ del compuesto $\mathbf{8 1 E}$. 


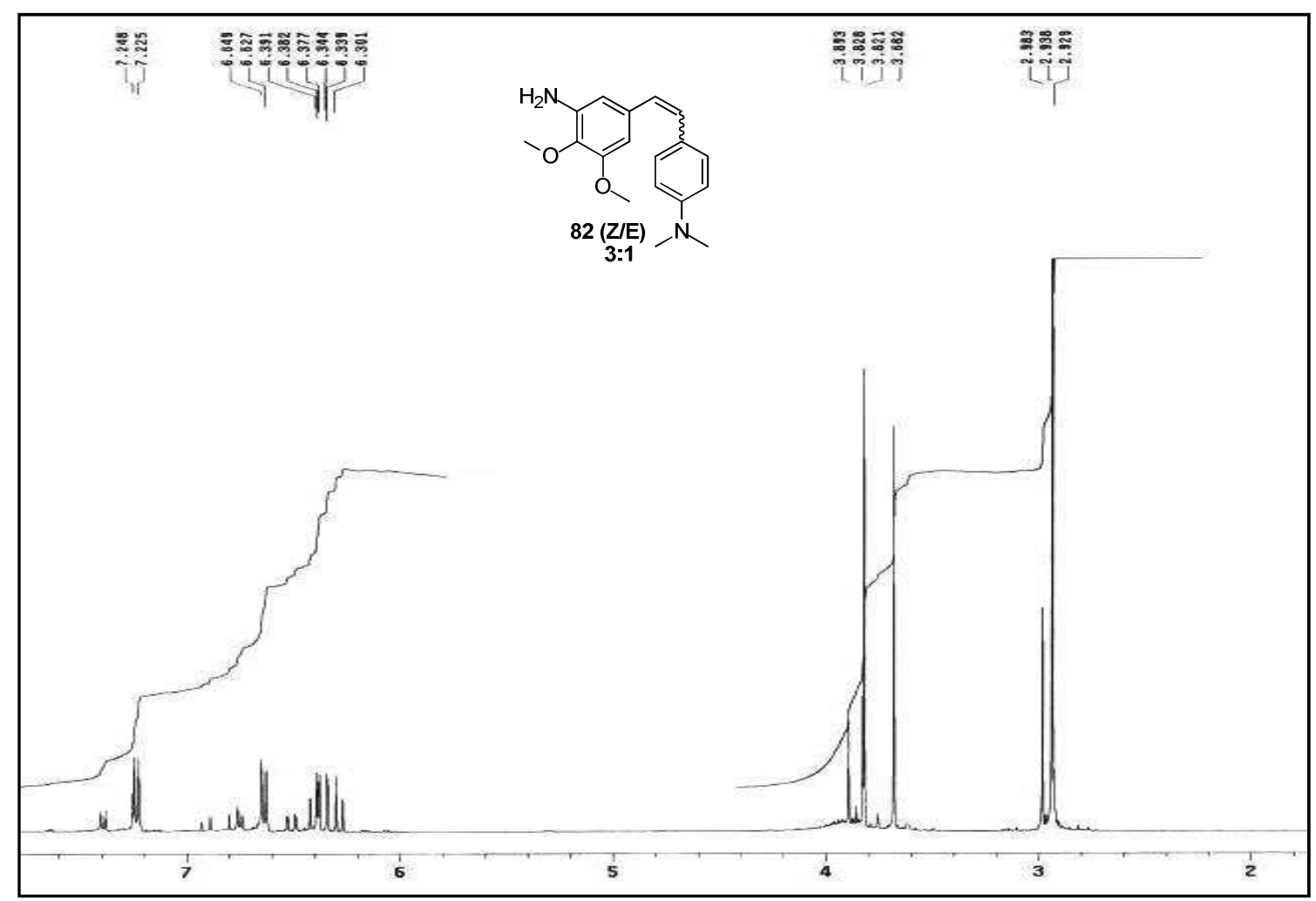

Figura LXXIIa: Espectro de RMN ${ }^{1} \mathrm{H}$ del compuesto 82(Z/E).

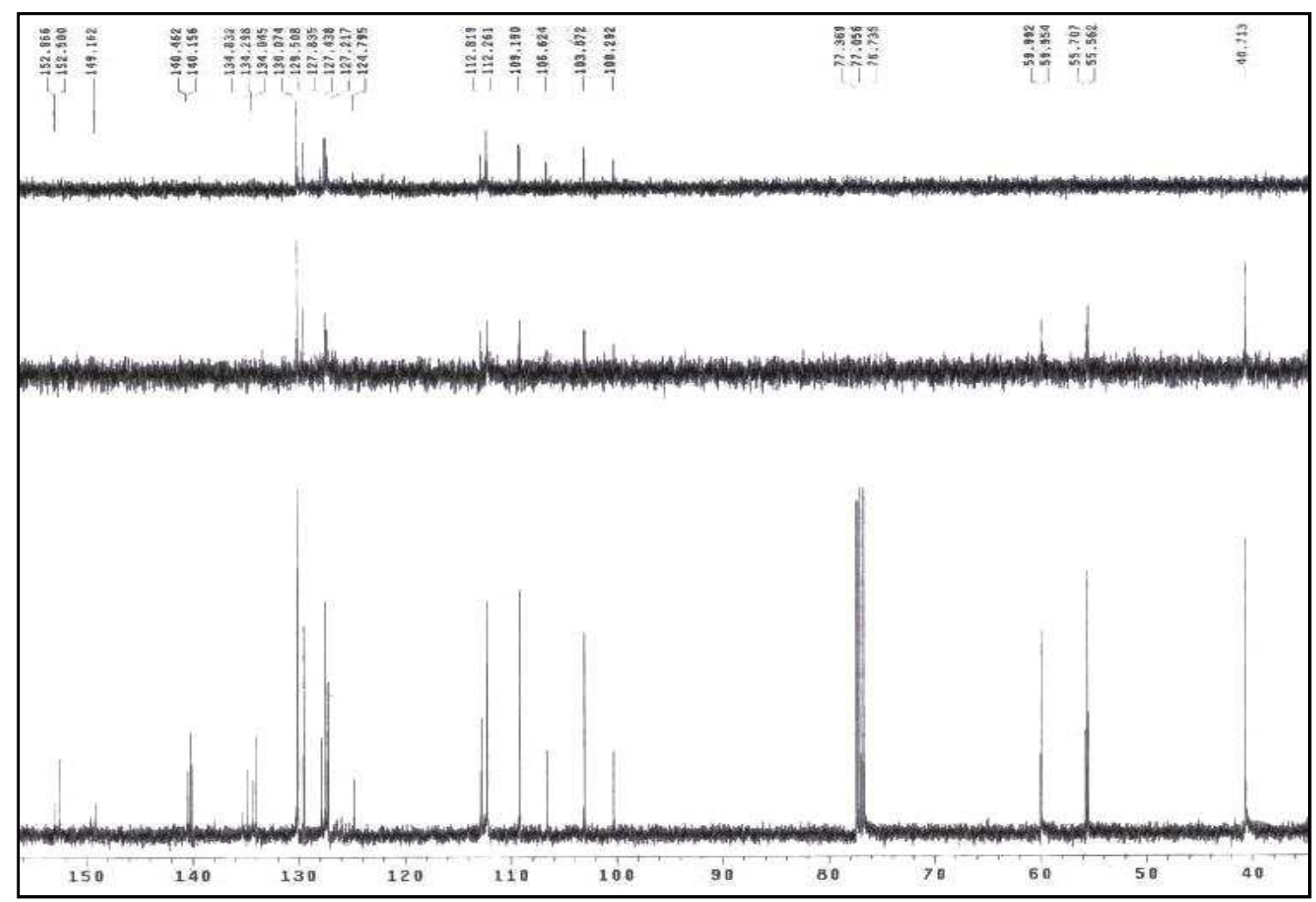

Figura LXXIIb: Espectro de RMN ${ }^{13} \mathrm{C}$ del compuesto $82(\mathrm{Z} / \boldsymbol{E})$. 


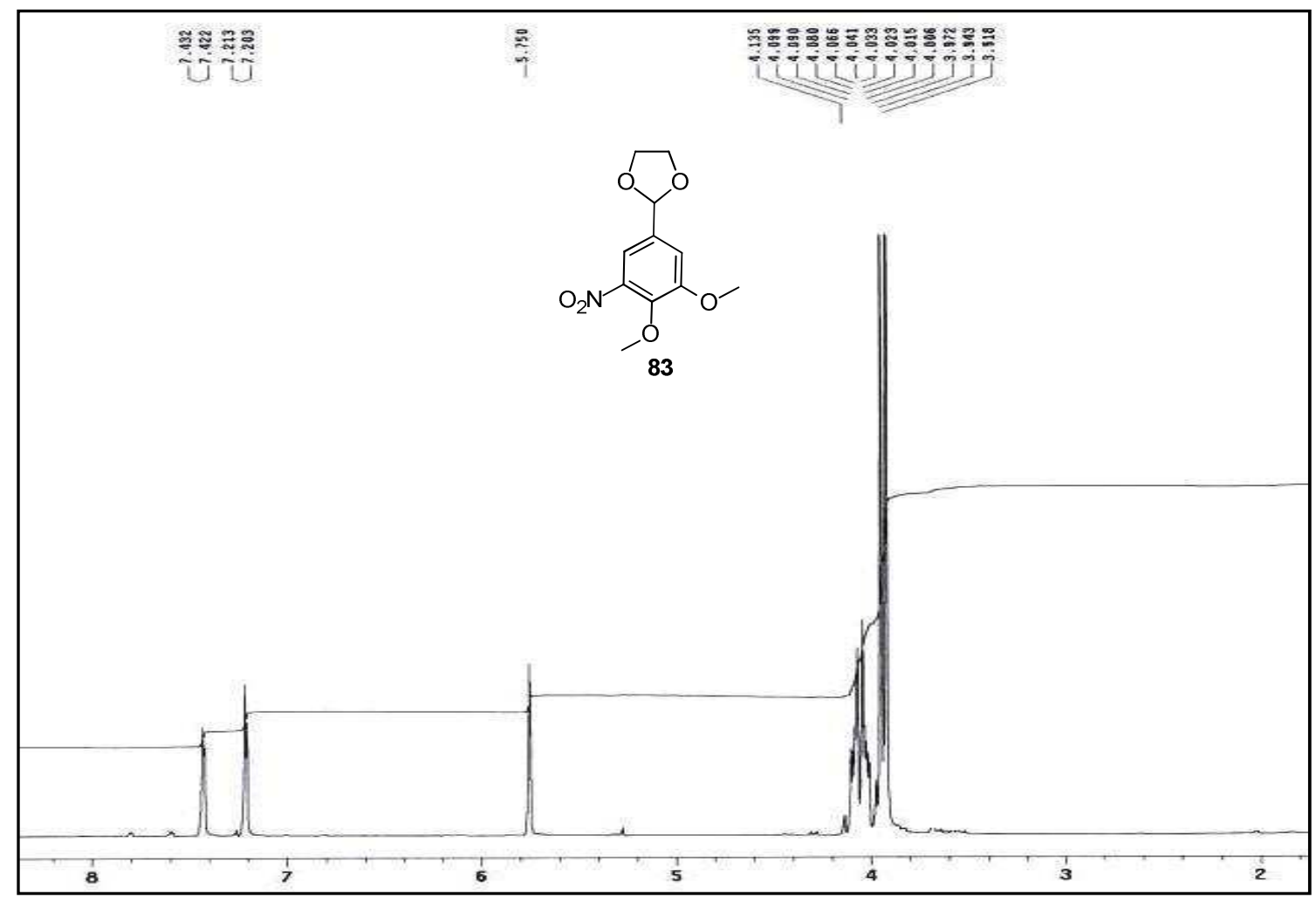

Figura LXXIIIa: Espectro de RMN ${ }^{1} \mathrm{H}$ del compuesto 83.

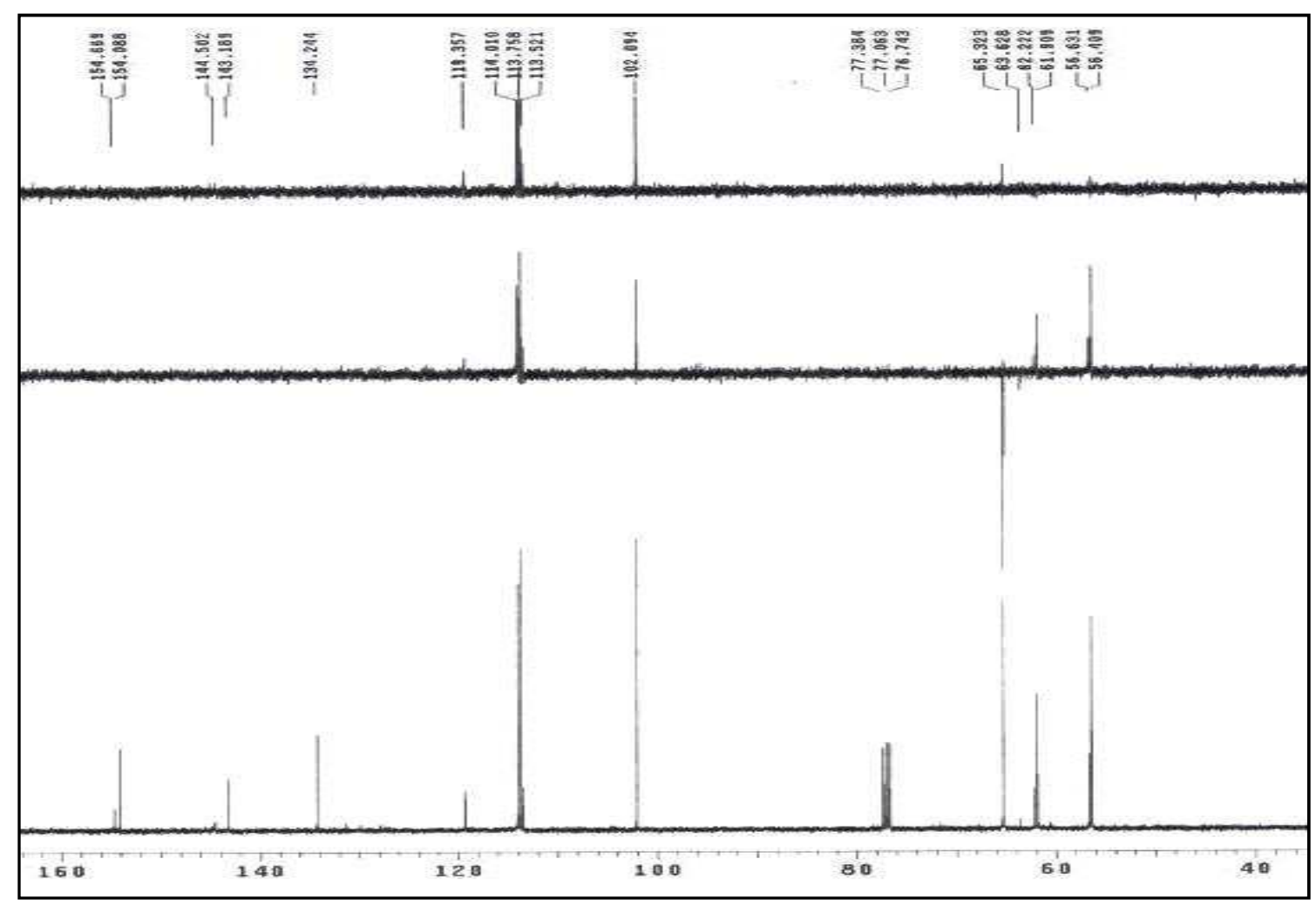

Figura LXXIIIb: Espectro de RMN ${ }^{13} \mathrm{C}$ del compuesto 83. 


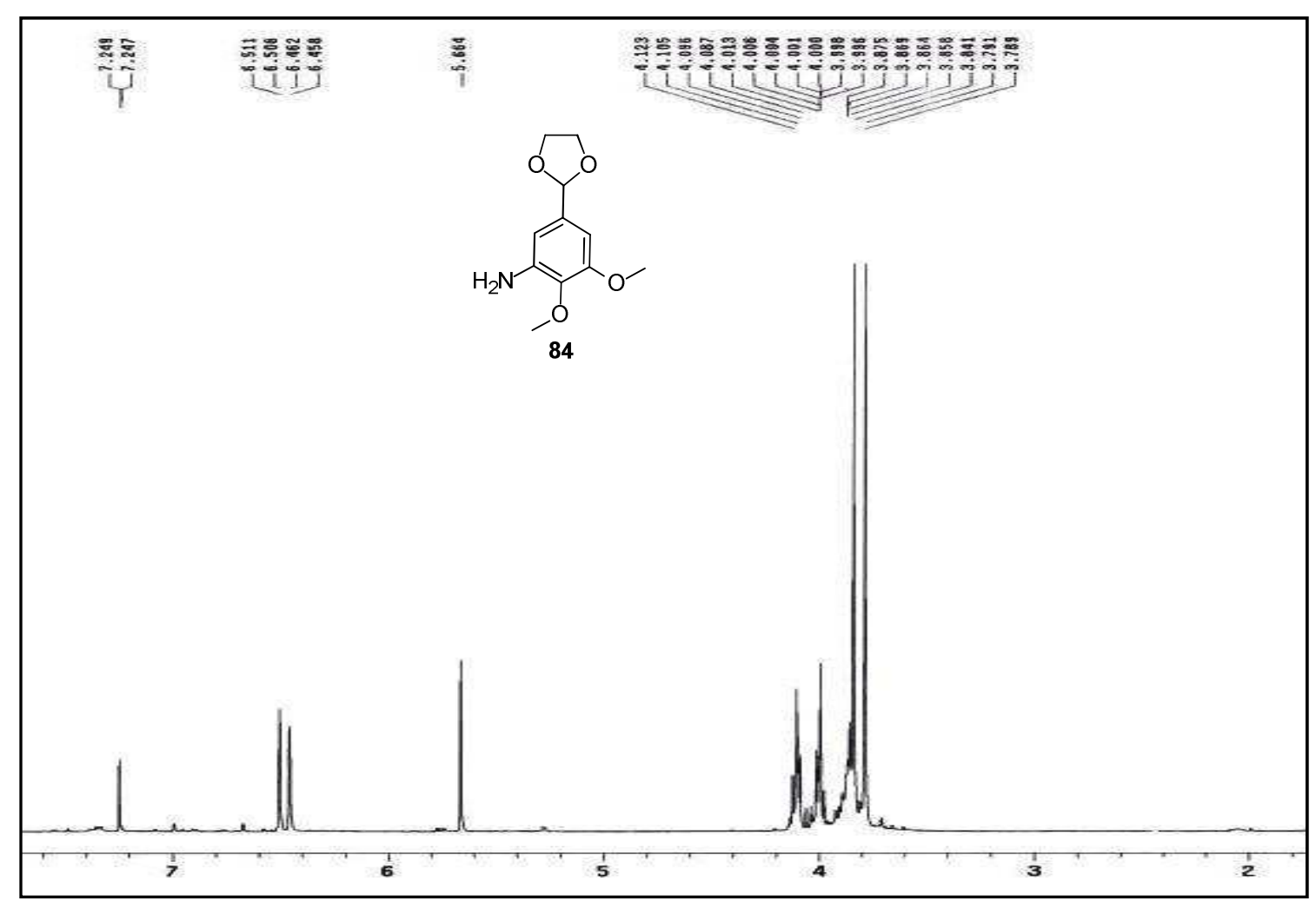

Figura LXXIVa: Espectro de RMN ${ }^{1} \mathrm{H}$ del compuesto 84.

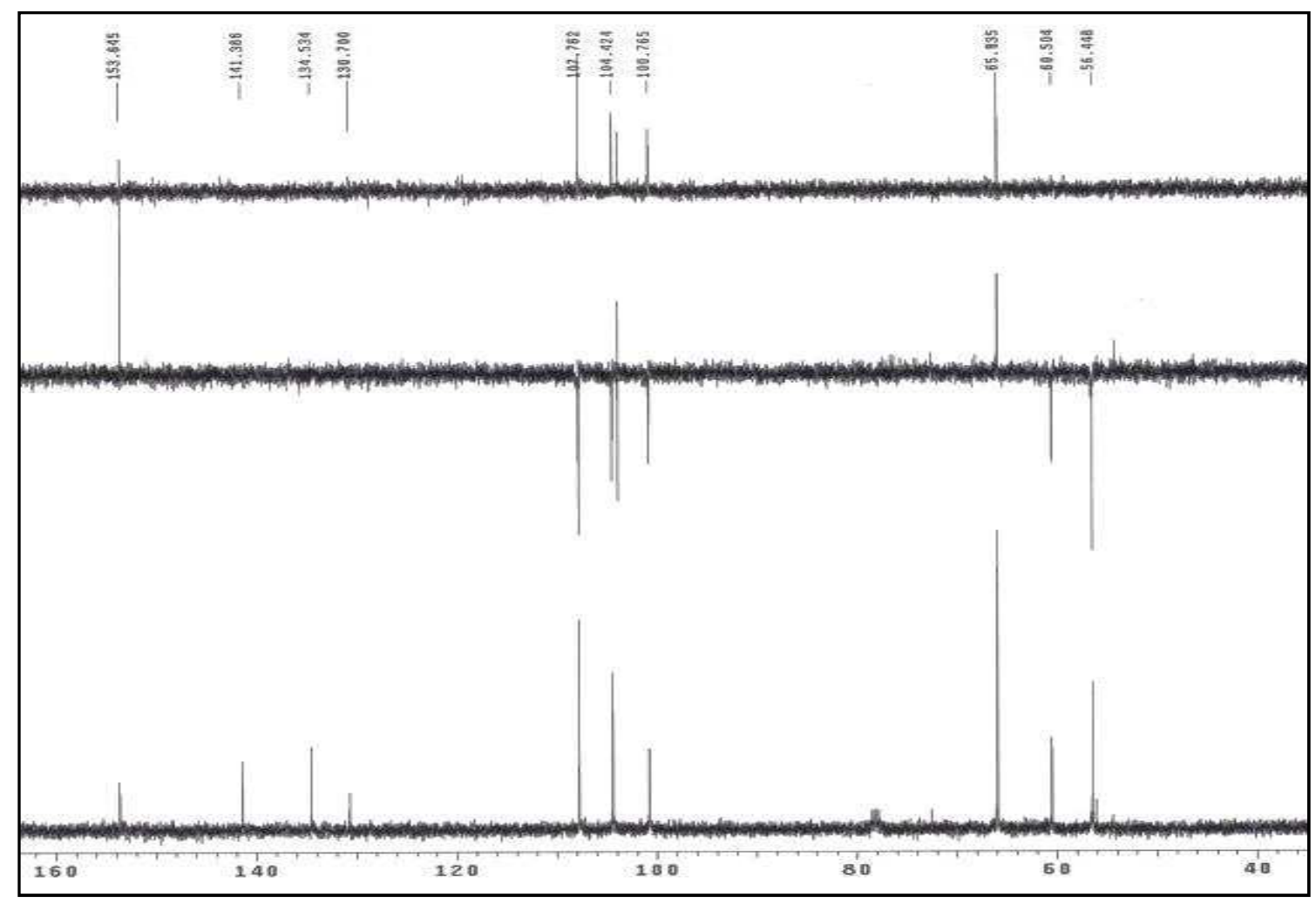

Figura LXXIVb: Espectro de RMN ${ }^{13} \mathrm{C}$ del compuesto 84 . 


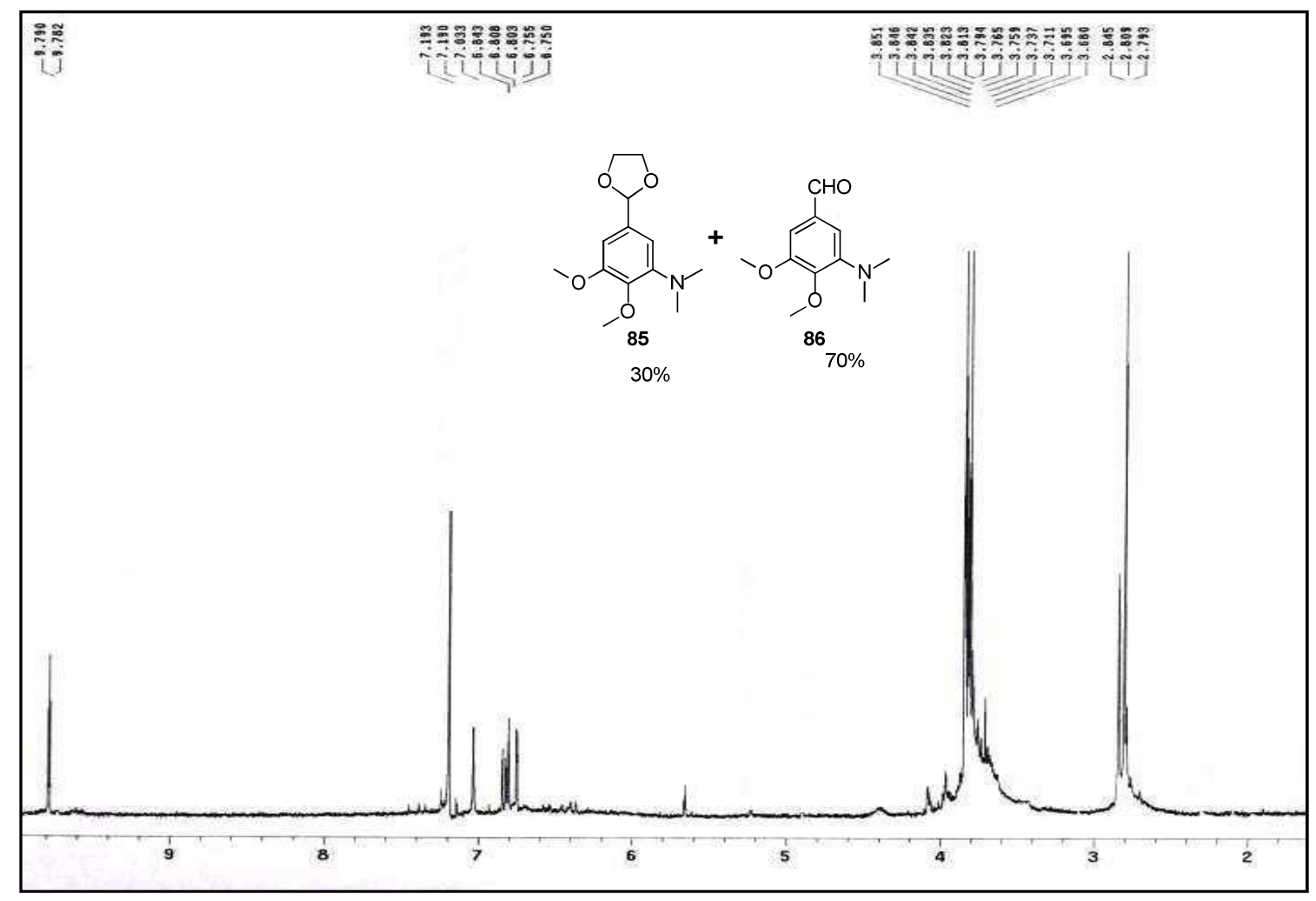

Figura LXXV: Espectro de RMN ${ }^{1} \mathrm{H}$ del compuesto 85. 


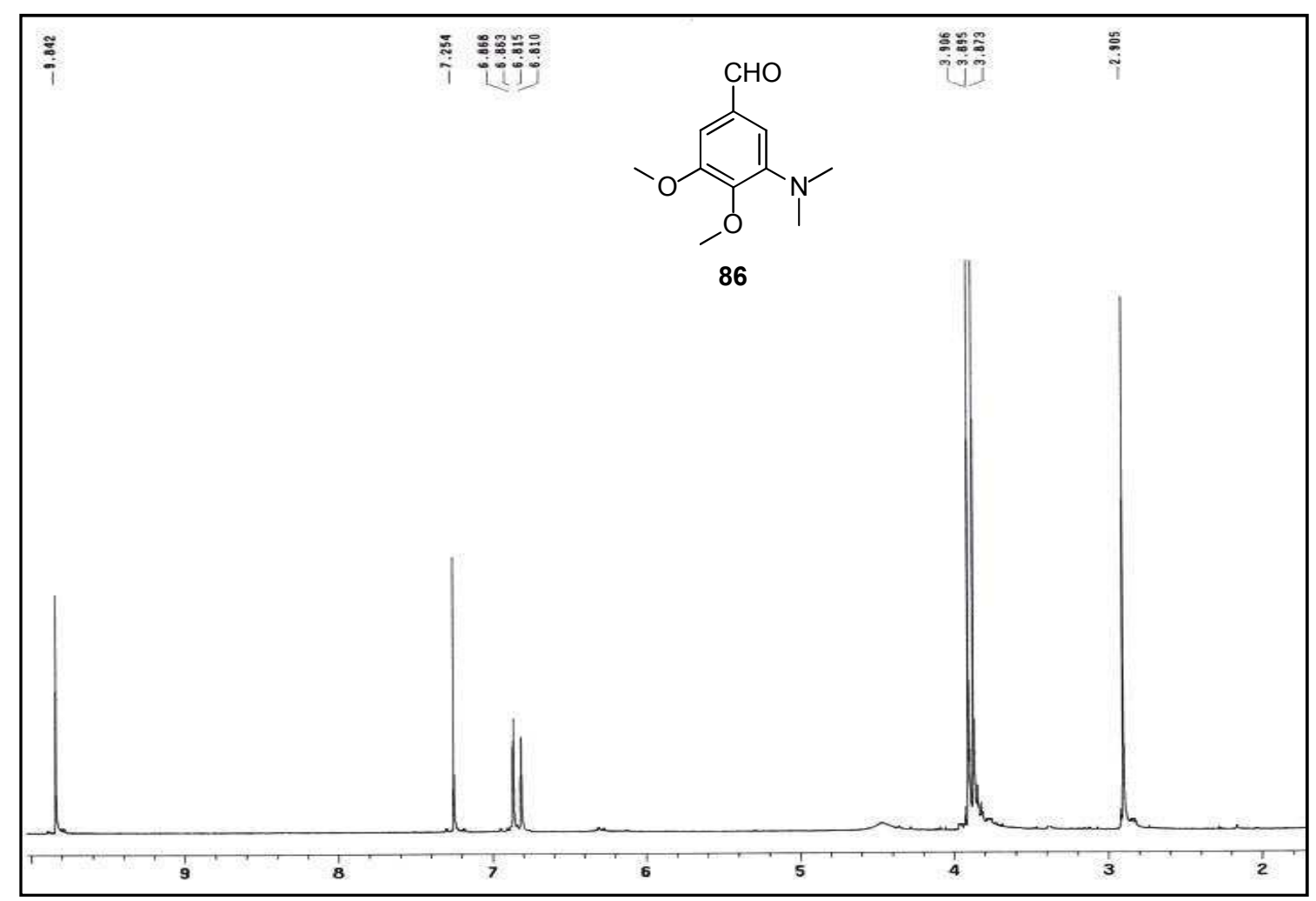

Figura LXXVIa: Espectro de RMN ${ }^{1} \mathrm{H}$ del compuesto 86.

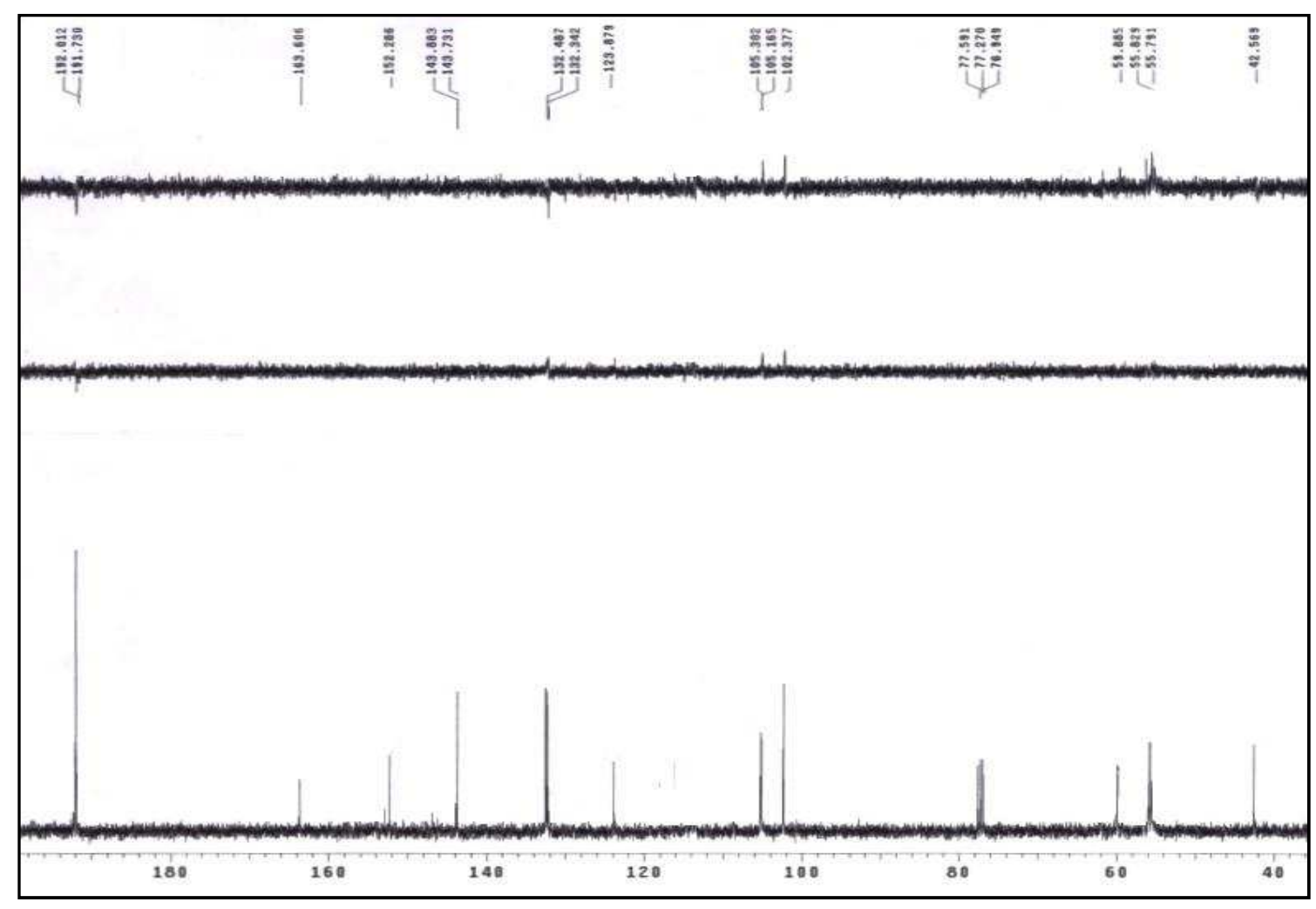

Figura LXXVIb: Espectro de RMN ${ }^{13} \mathrm{C}$ del compuesto 86. 


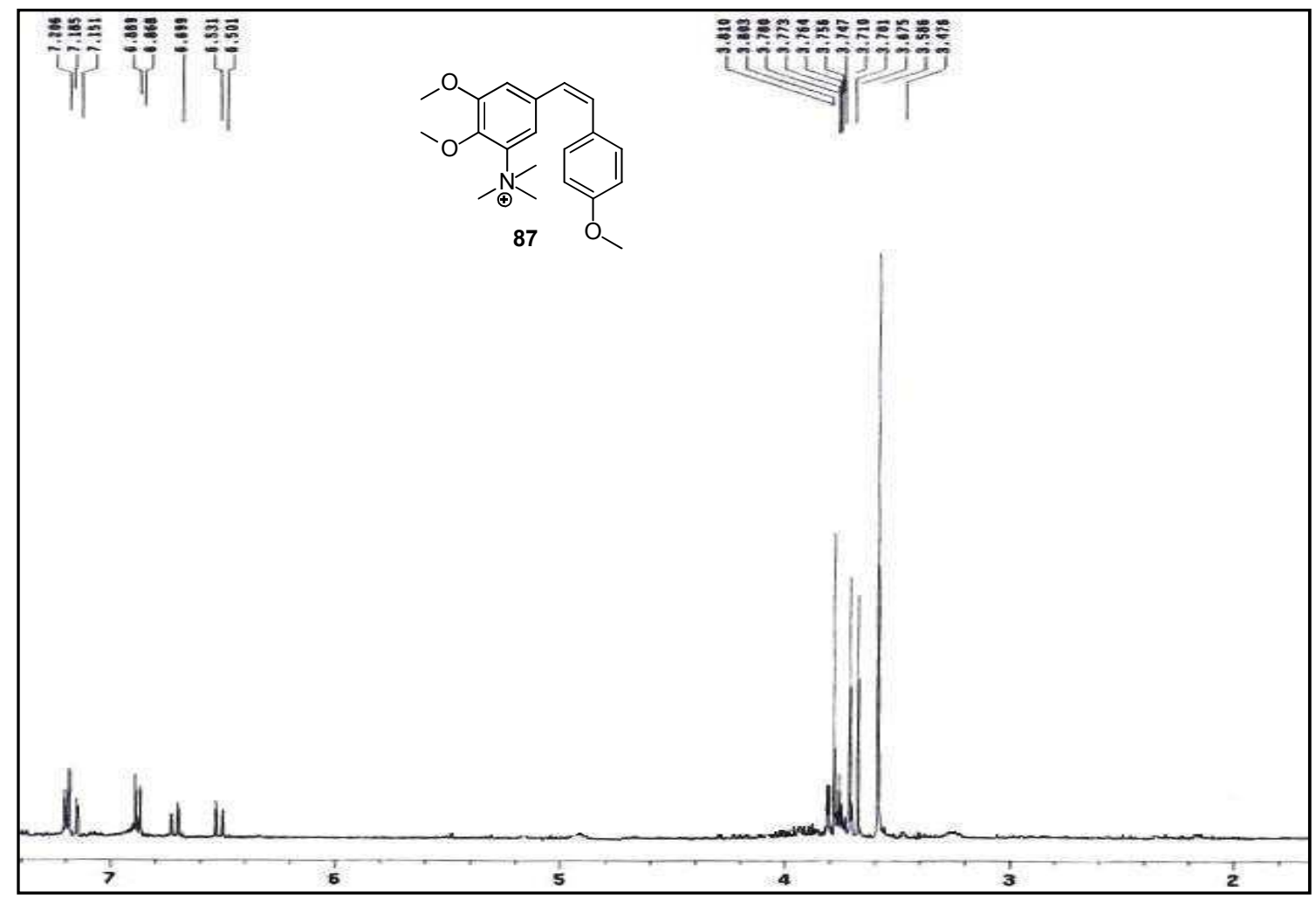

Figura LXXVIIa: Espectro de RMN ${ }^{1} \mathrm{H}$ del compuesto 87.

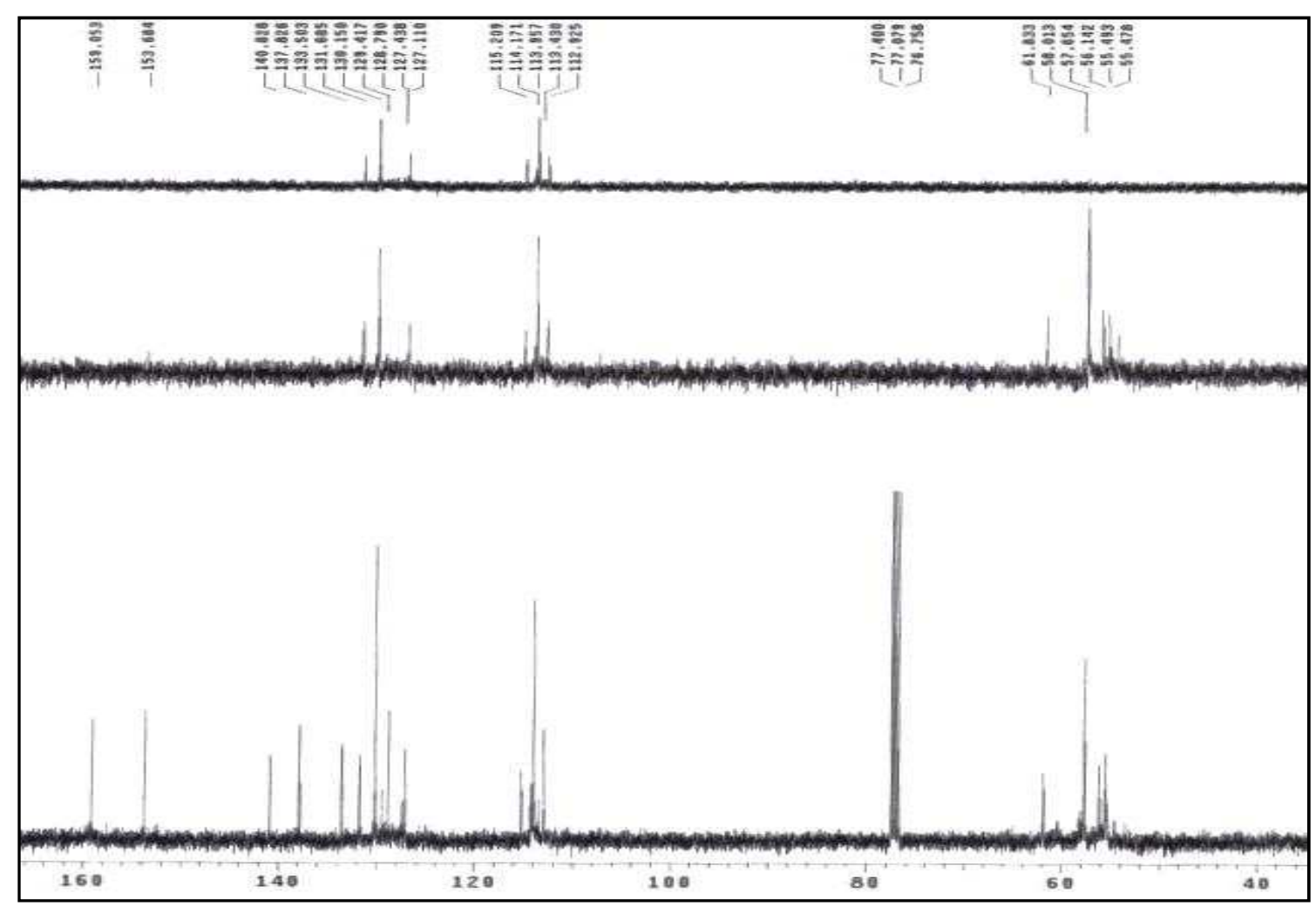

Figura LXXVIIb: Espectro de RMN ${ }^{13} \mathrm{C}$ del compuesto 87. 


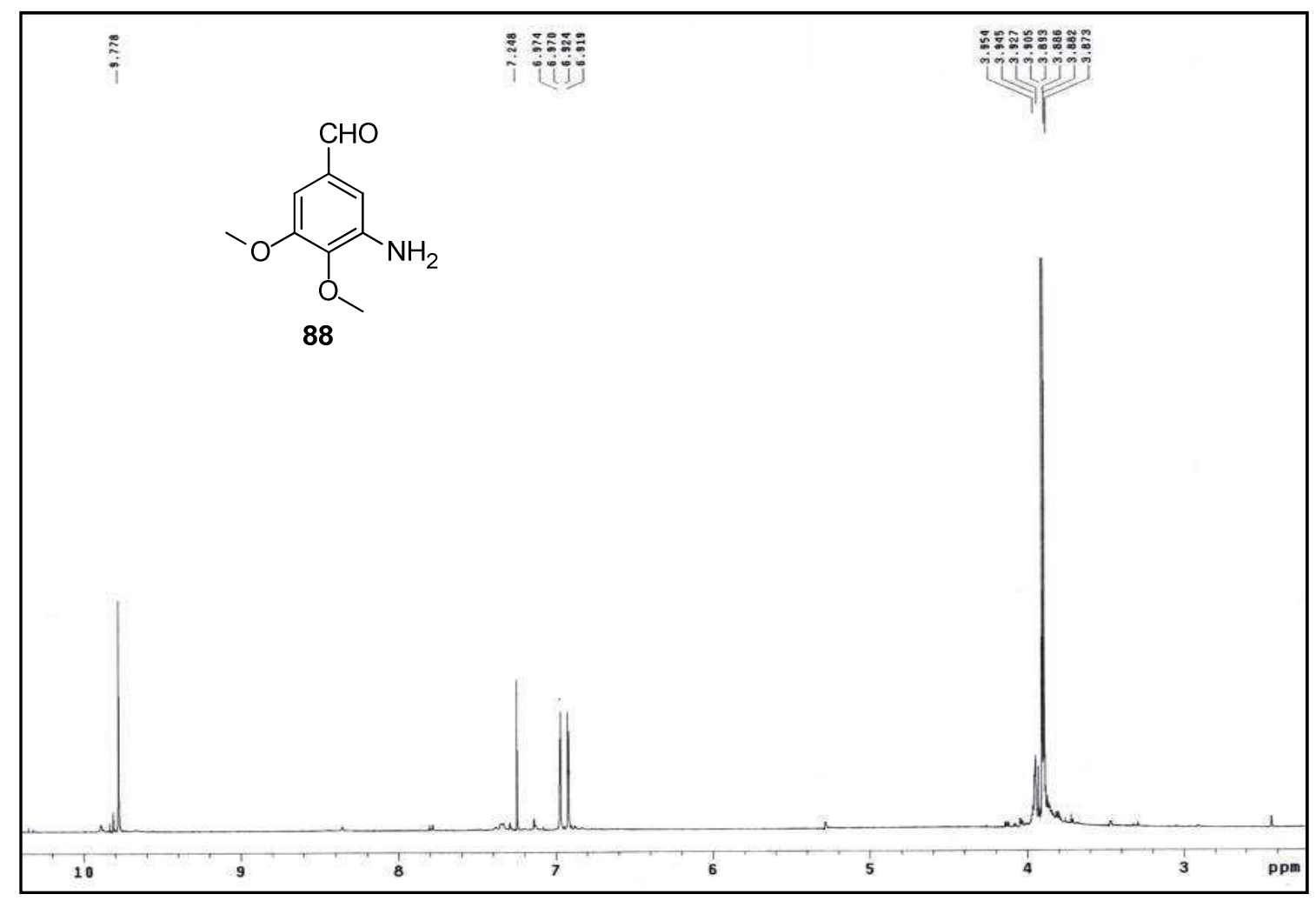

Figura LXXVIII: Espectro de RMN ${ }^{1} \mathrm{H}$ del compuesto 88 .

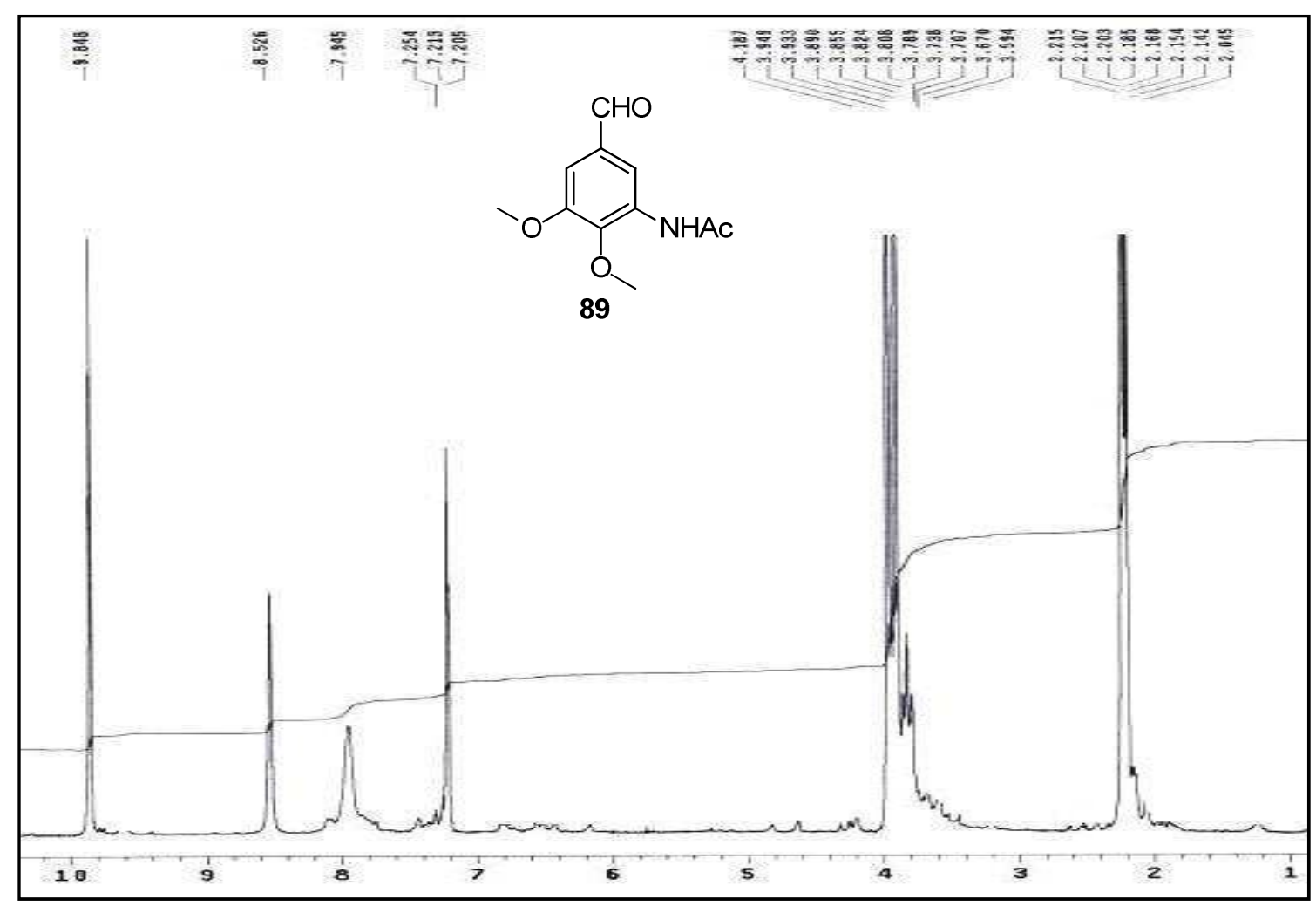

Figura LXXIX: Espectro de RMN ${ }^{1} \mathrm{H}$ del compuesto 89. 


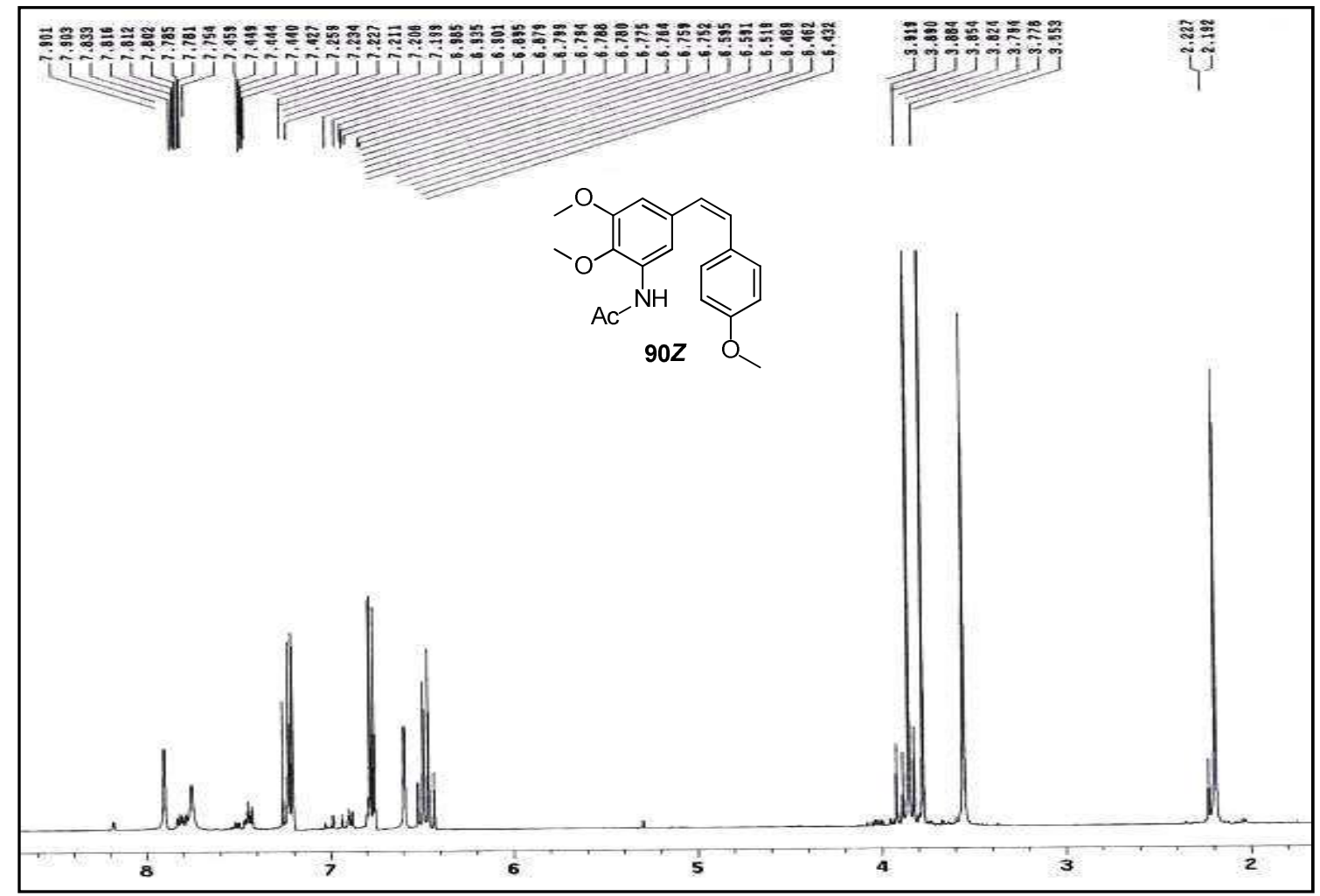

Figura LXXXa: Espectro de RMN ${ }^{1} \mathrm{H}$ del compuesto $\mathbf{9 0 Z}$.

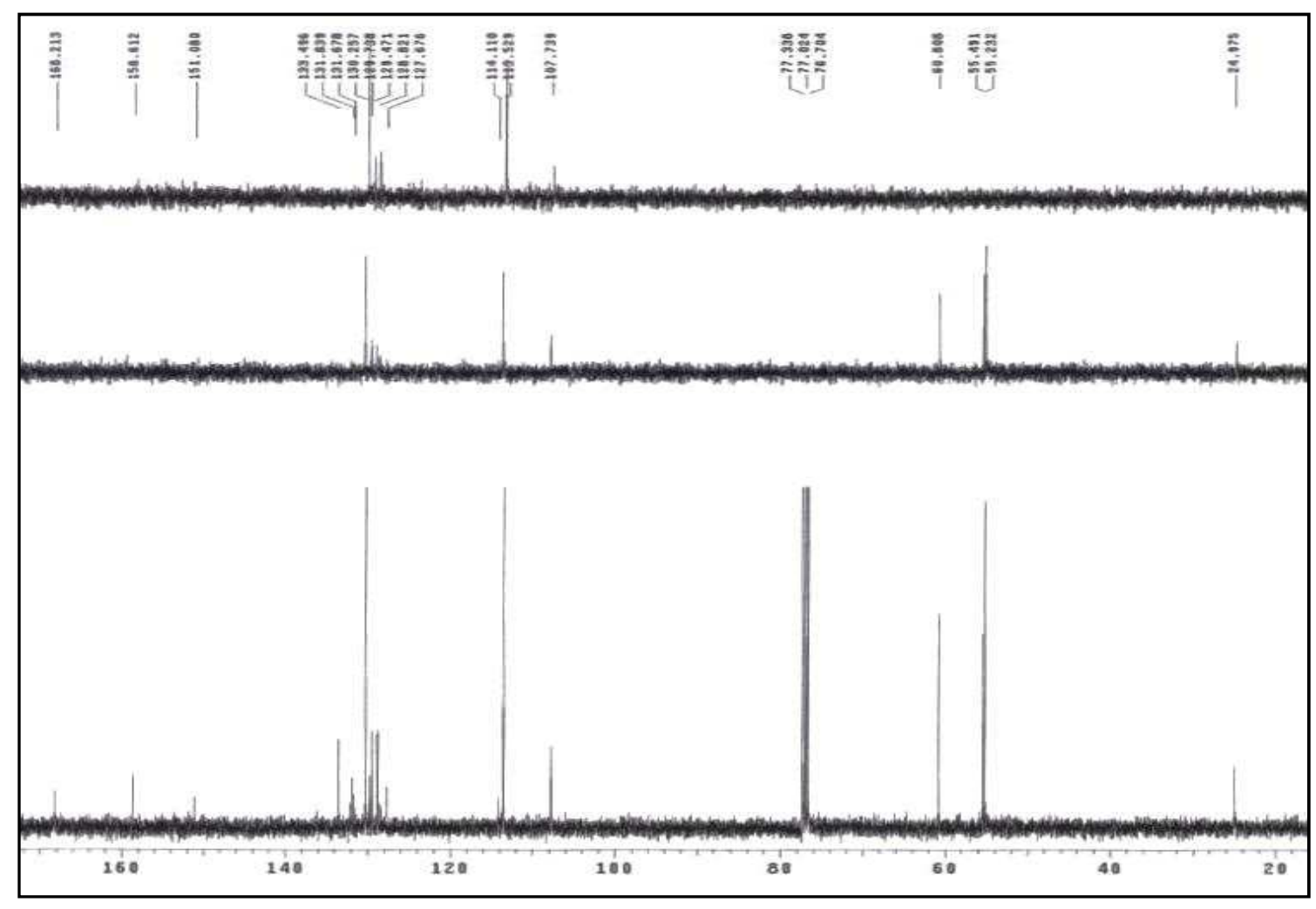

Figura LXXXb: Espectro de RMN ${ }^{13} \mathrm{C}$ del compuesto $\mathbf{9 0 Z}$. 


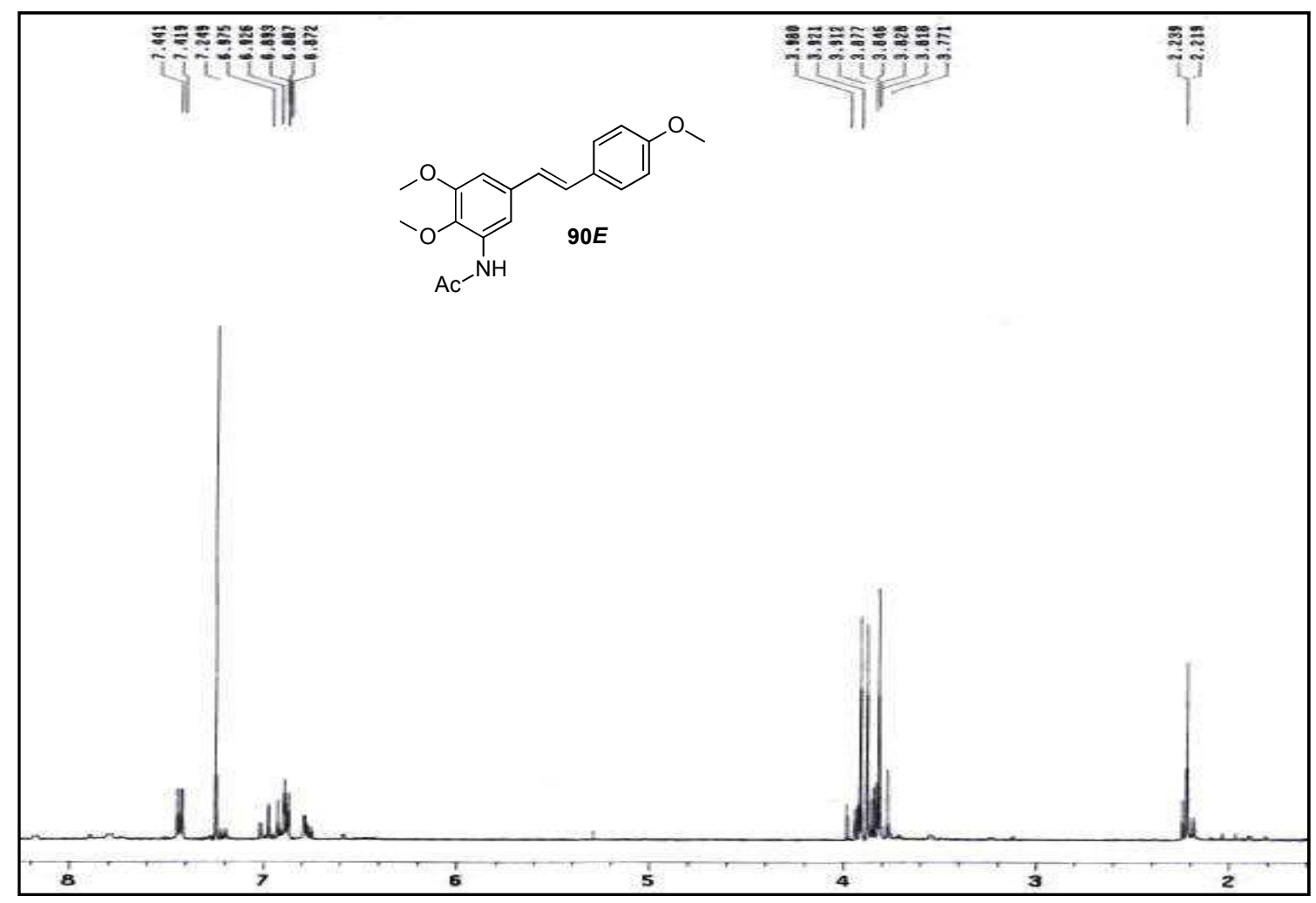

Figura LXXXc: Espectro de RMN ${ }^{1} \mathrm{H}$ del compuesto $\mathbf{9 0 E}$. 


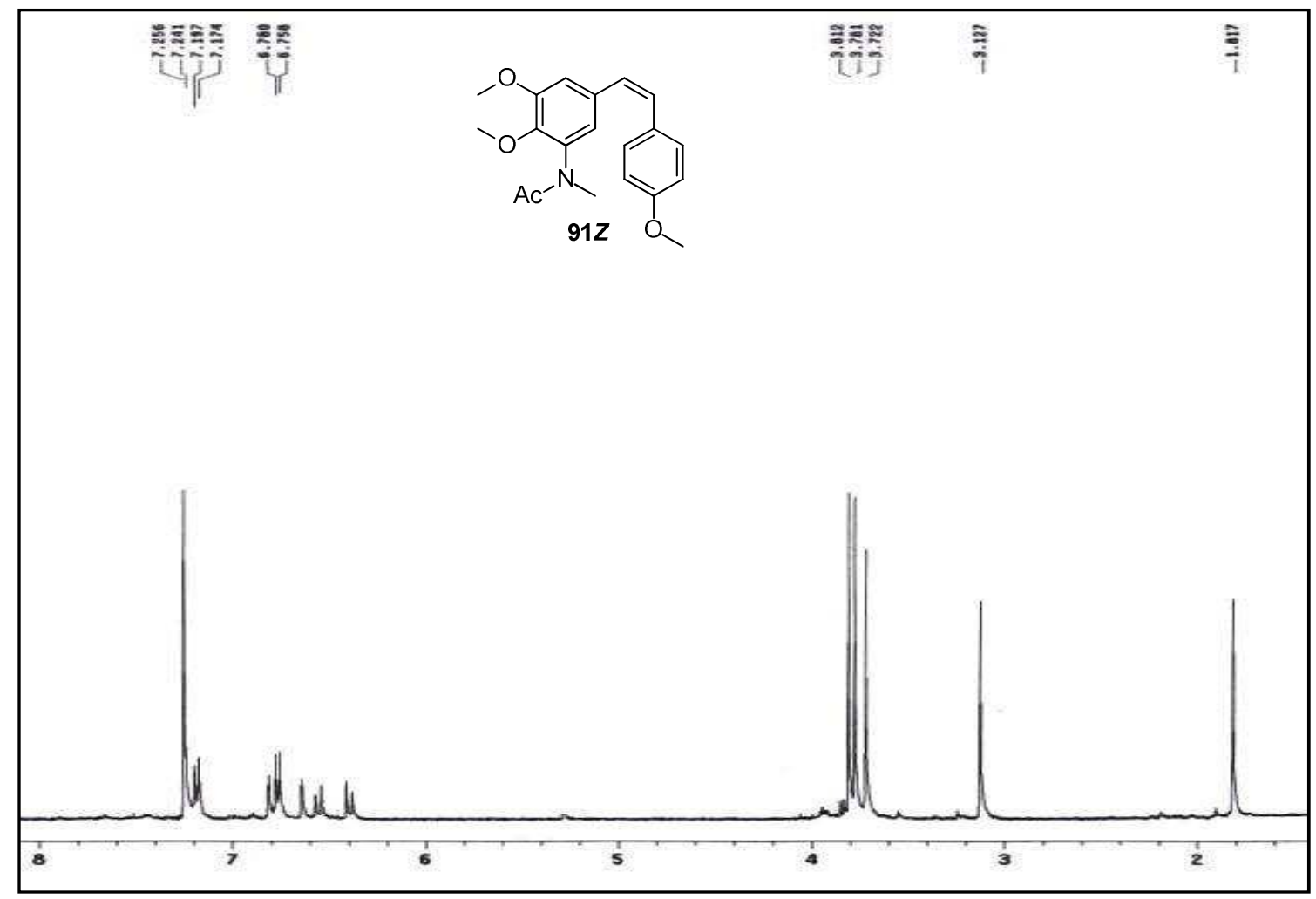

Figura LXXXIa: Espectro de RMN ${ }^{1} \mathrm{H}$ del compuesto $91 Z$.

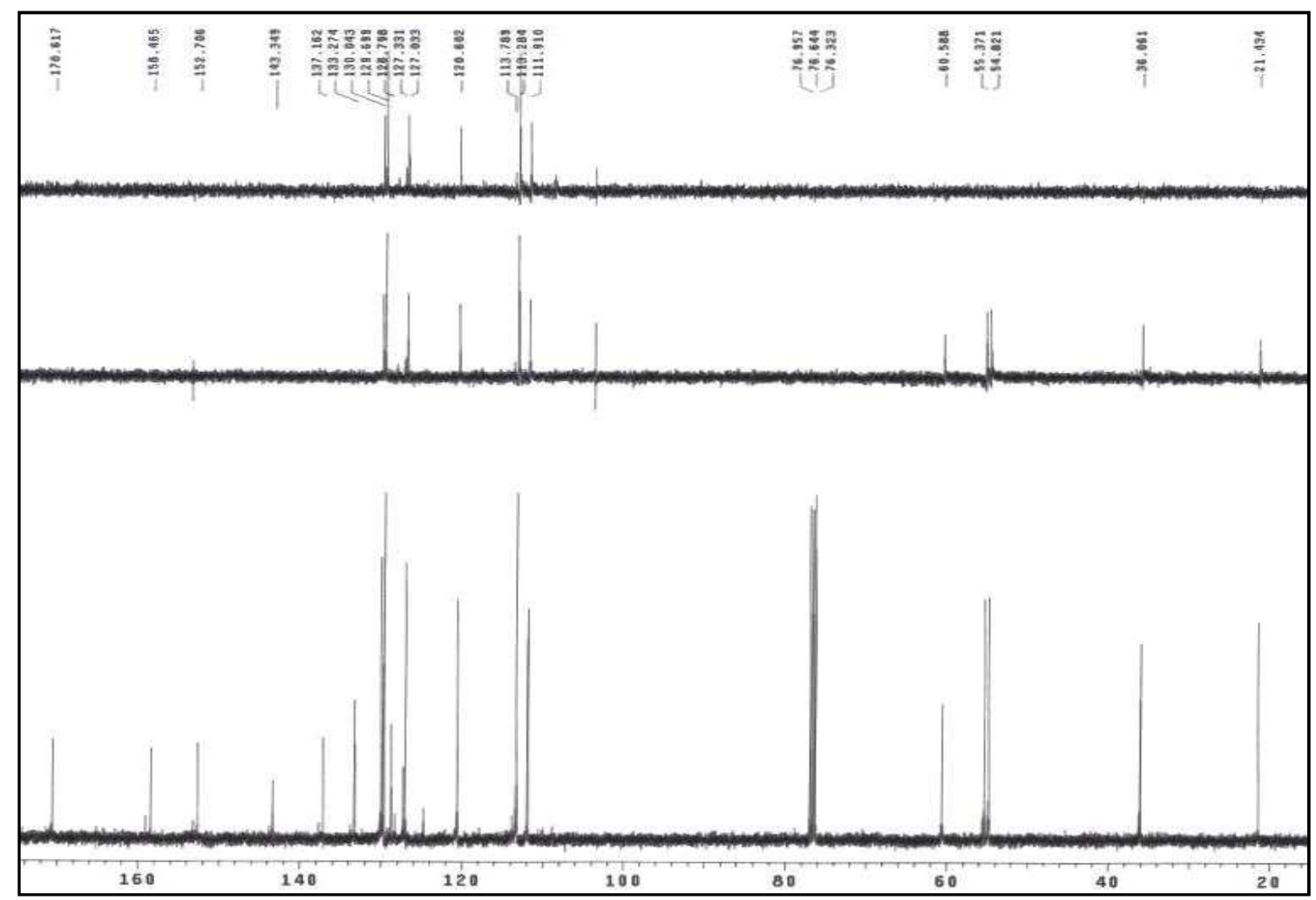

Figura LXXXIb: Espectro de RMN ${ }^{13} \mathrm{C}$ del compuesto $\mathbf{9 1 Z}$. 


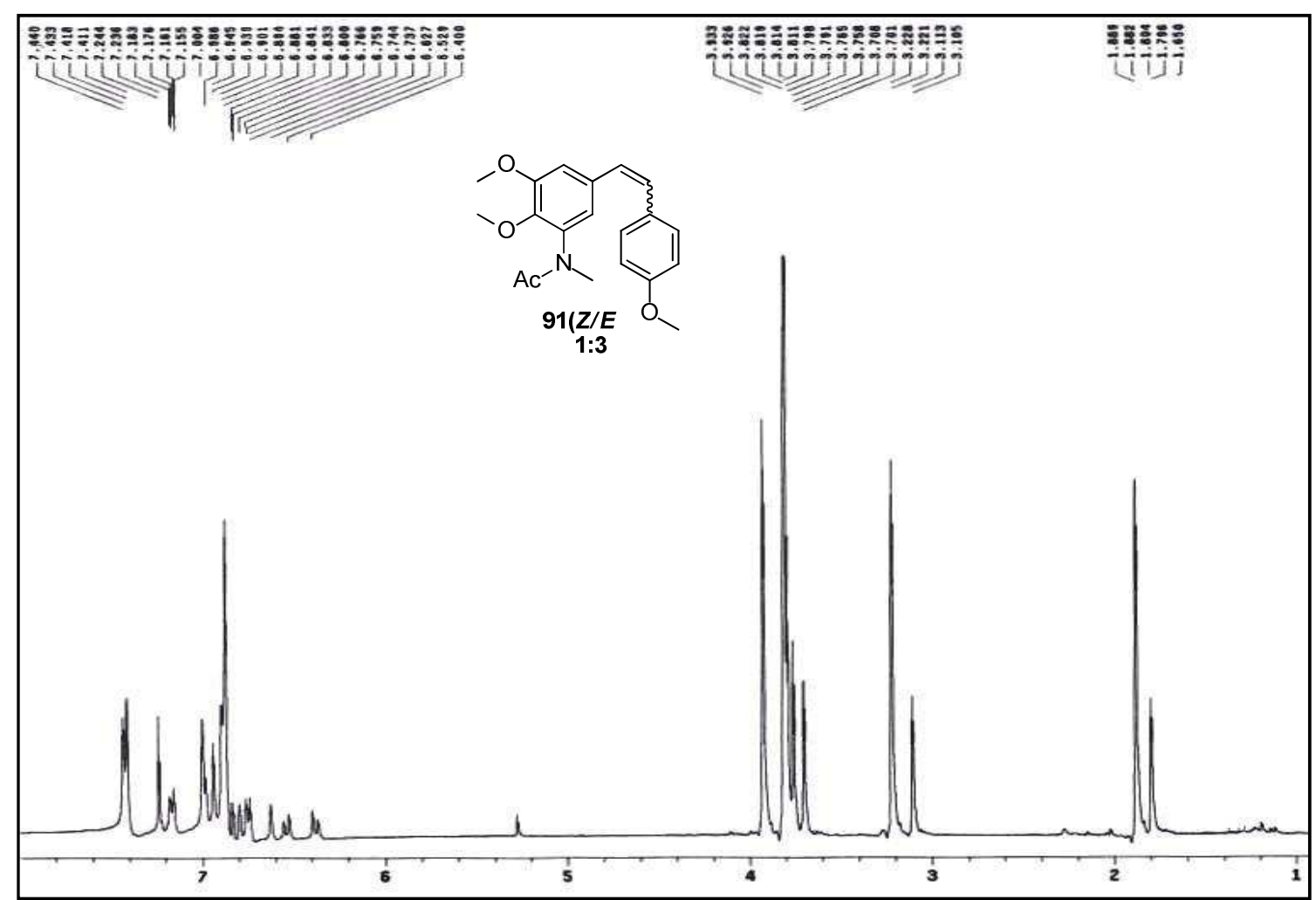

Figura LXXXIc: Espectro de RMN ${ }^{1} \mathrm{H}$ del compuesto 91(Z/E).

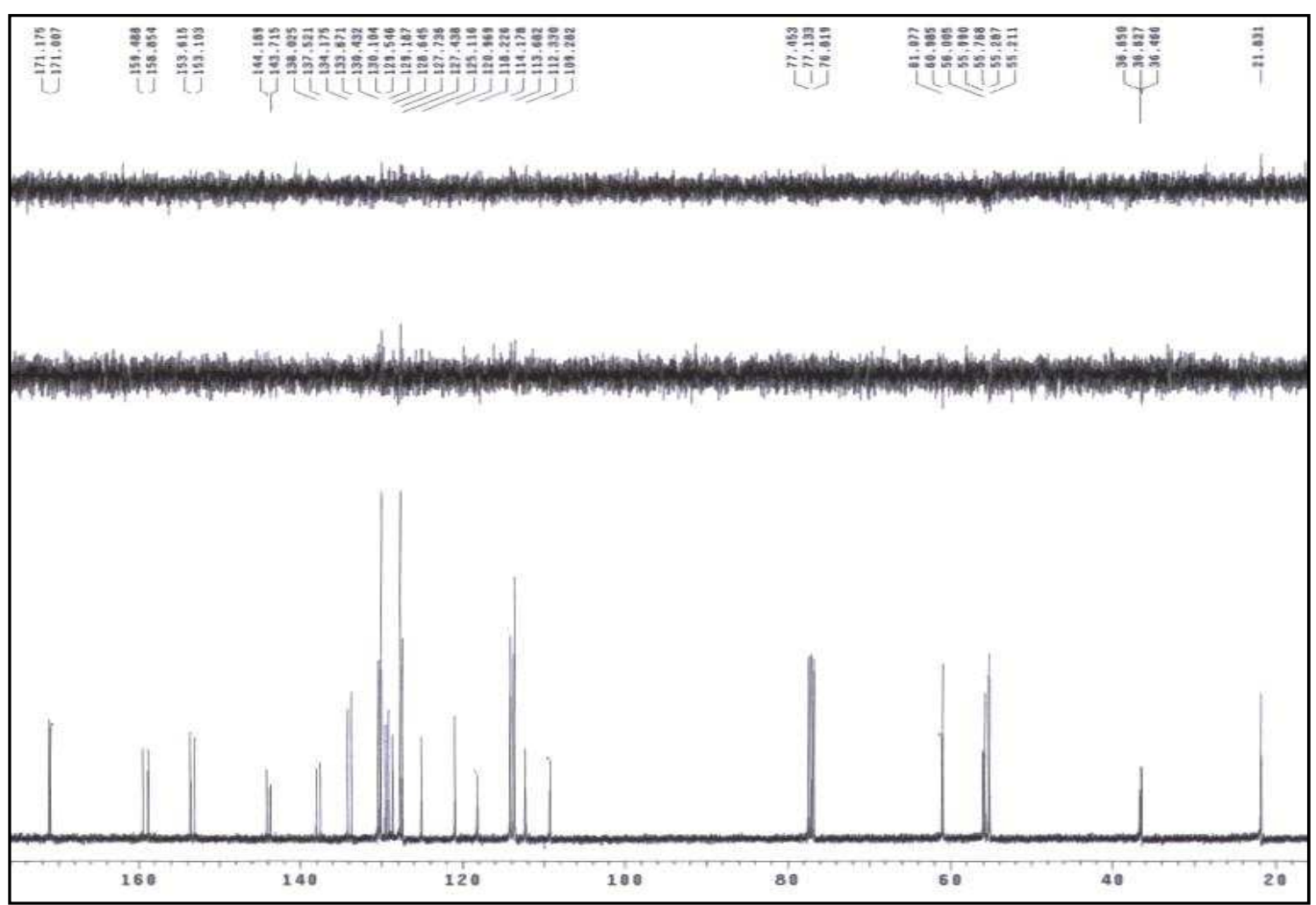

Figura LXXXId: Espectro de RMN ${ }^{13} \mathrm{C}$ del compuesto $91(\boldsymbol{Z} / \boldsymbol{E})$. 


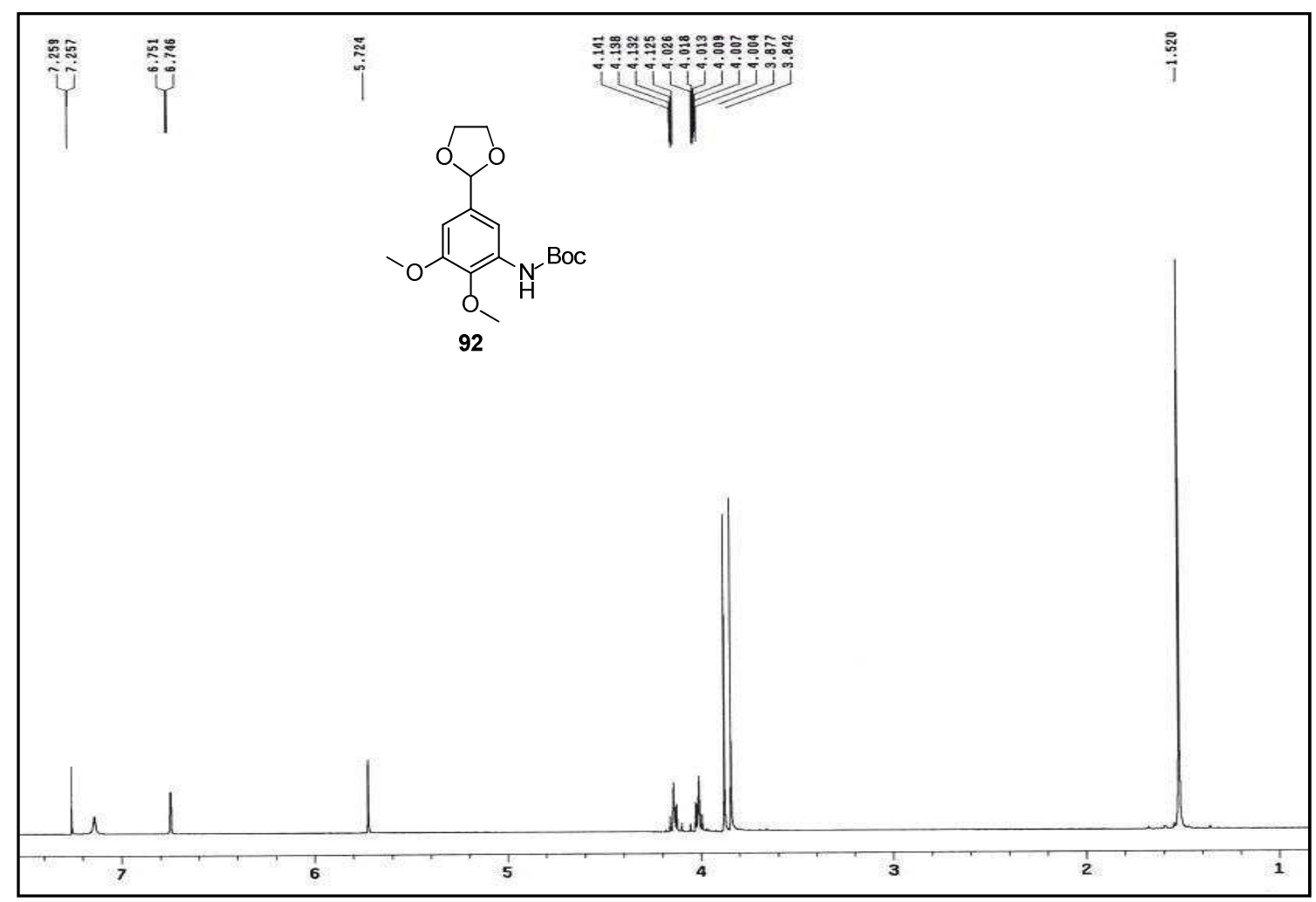

Figura LXXXIIa: Espectro de RMN ${ }^{1} \mathrm{H}$ del compuesto 92.

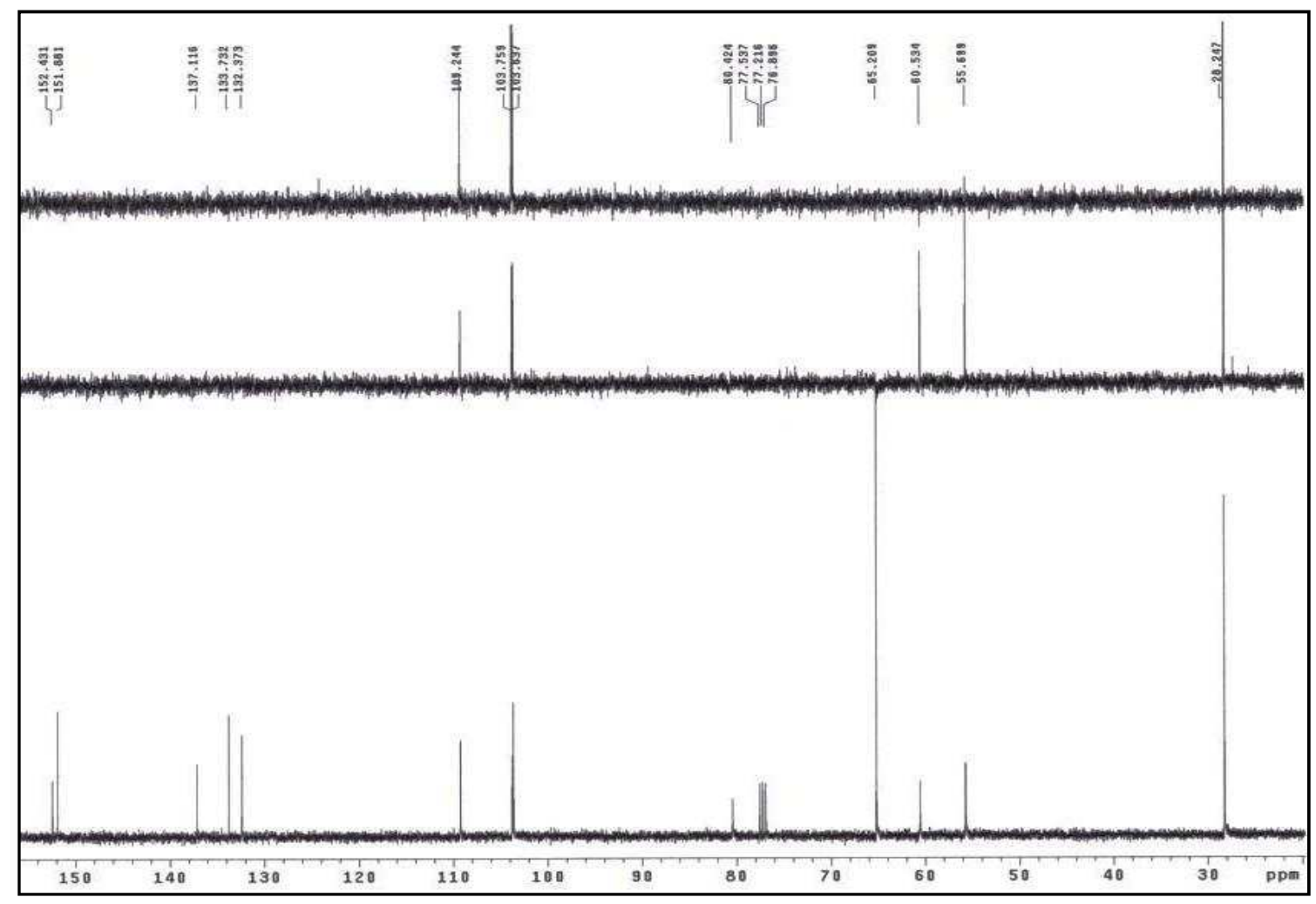

Figura LXXXIIb: Espectro de RMN ${ }^{13} \mathrm{C}$ del compuesto 92. 


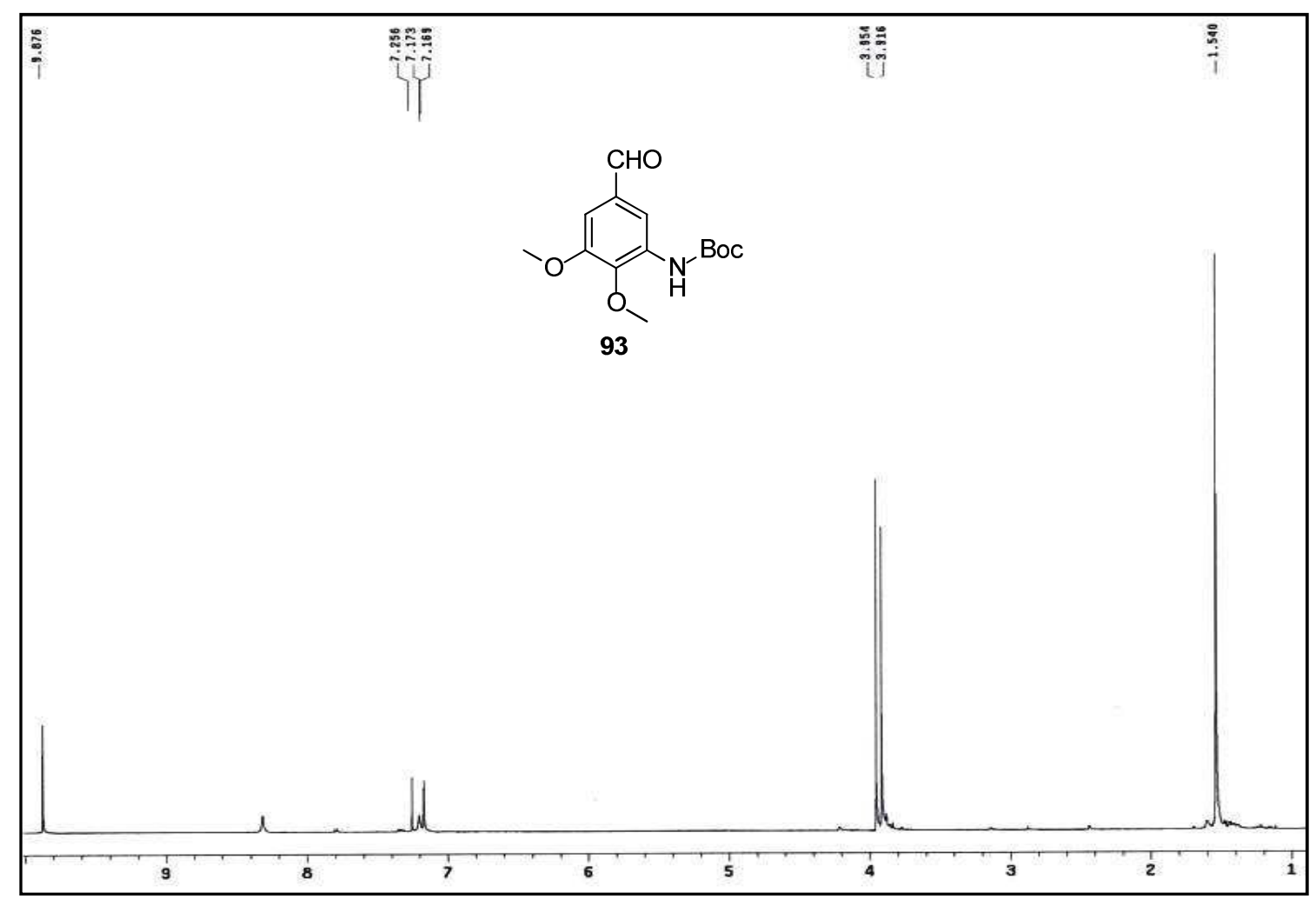

Figura LXXXIIIa: Espectro de RMN ${ }^{1} \mathrm{H}$ del compuesto 93.

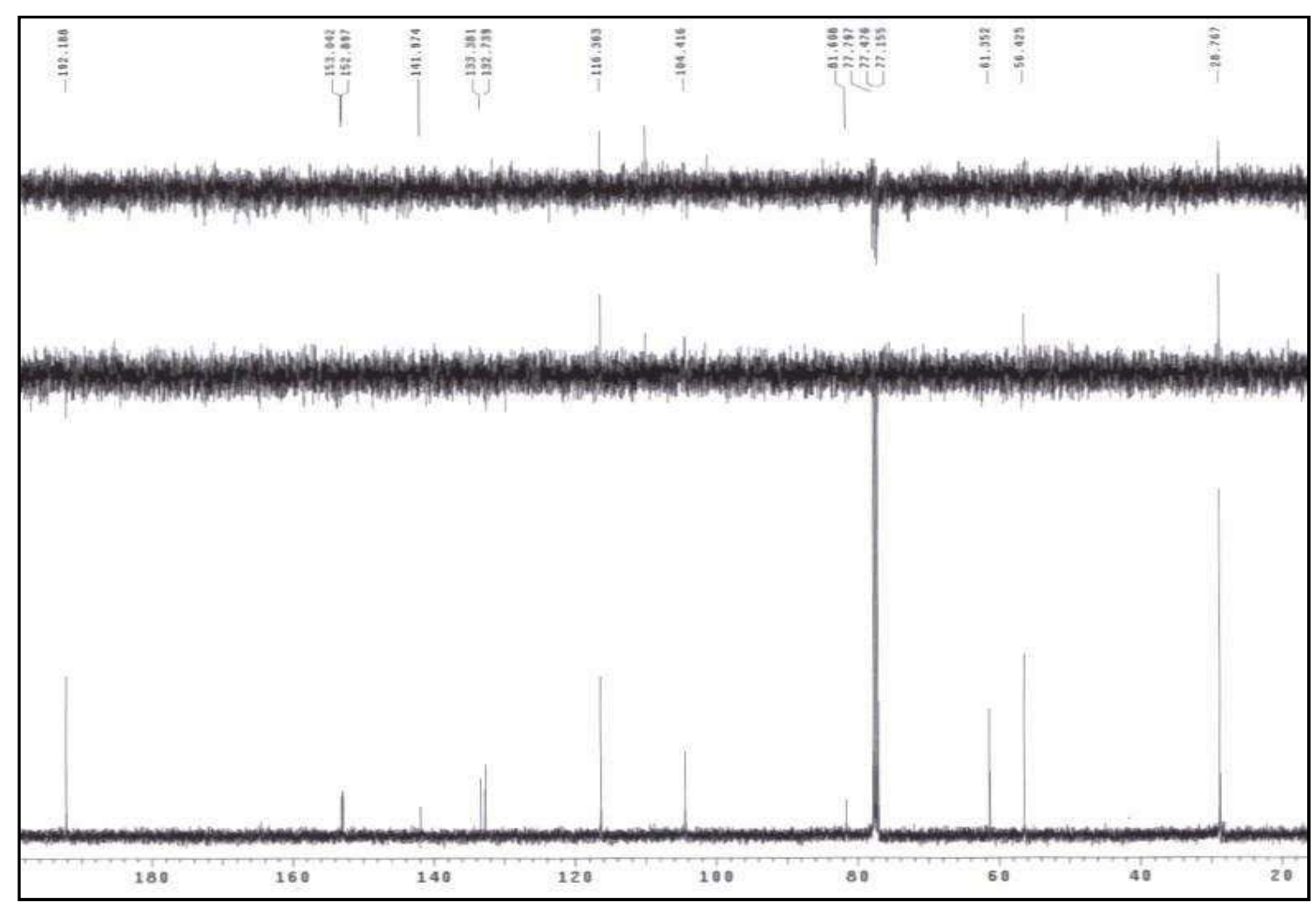

Figura LXXXIIIb: Espectro de RMN ${ }^{13} \mathrm{C}$ del compuesto 93. 


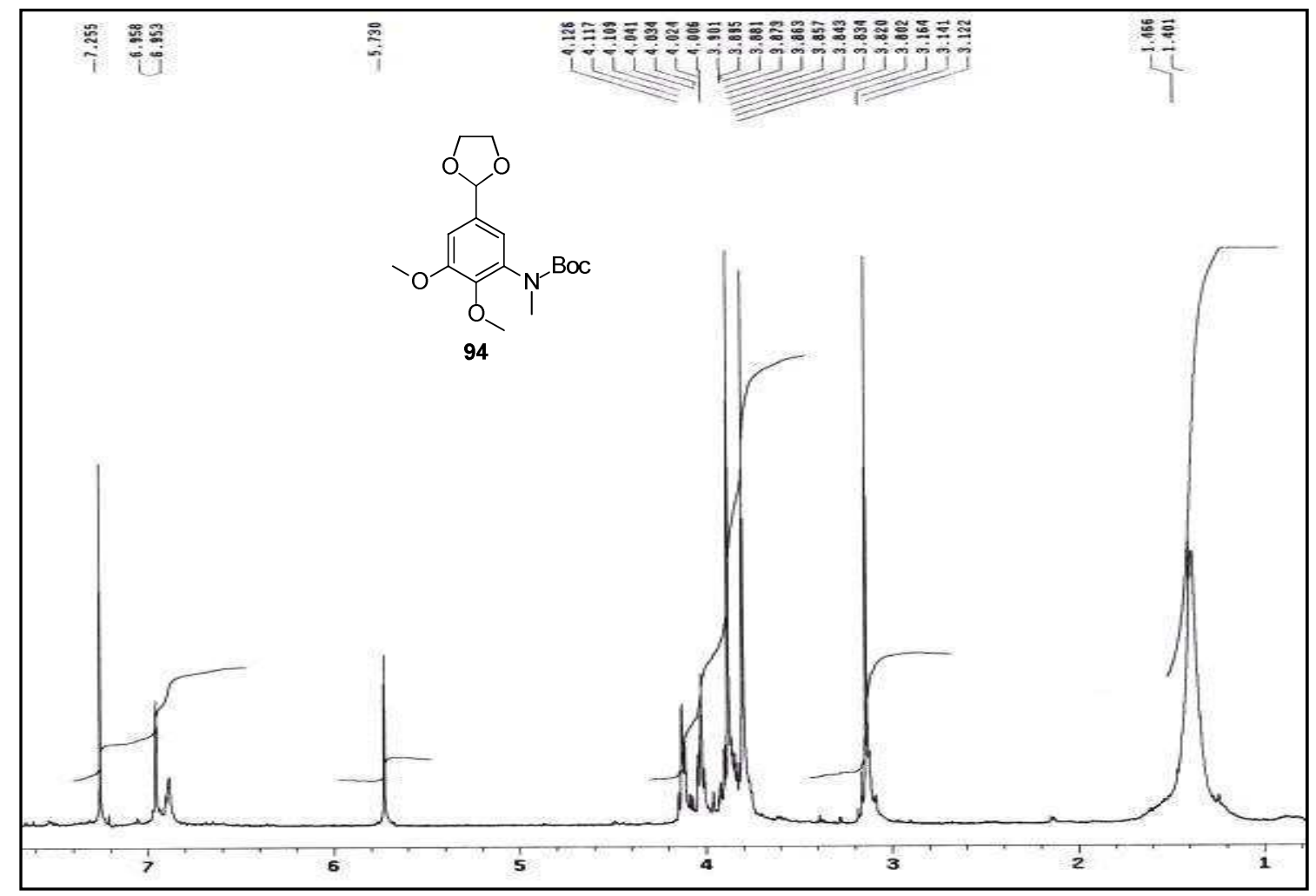

Figura LXXXIVa: Espectro de RMN ${ }^{1} \mathrm{H}$ del compuesto 94.

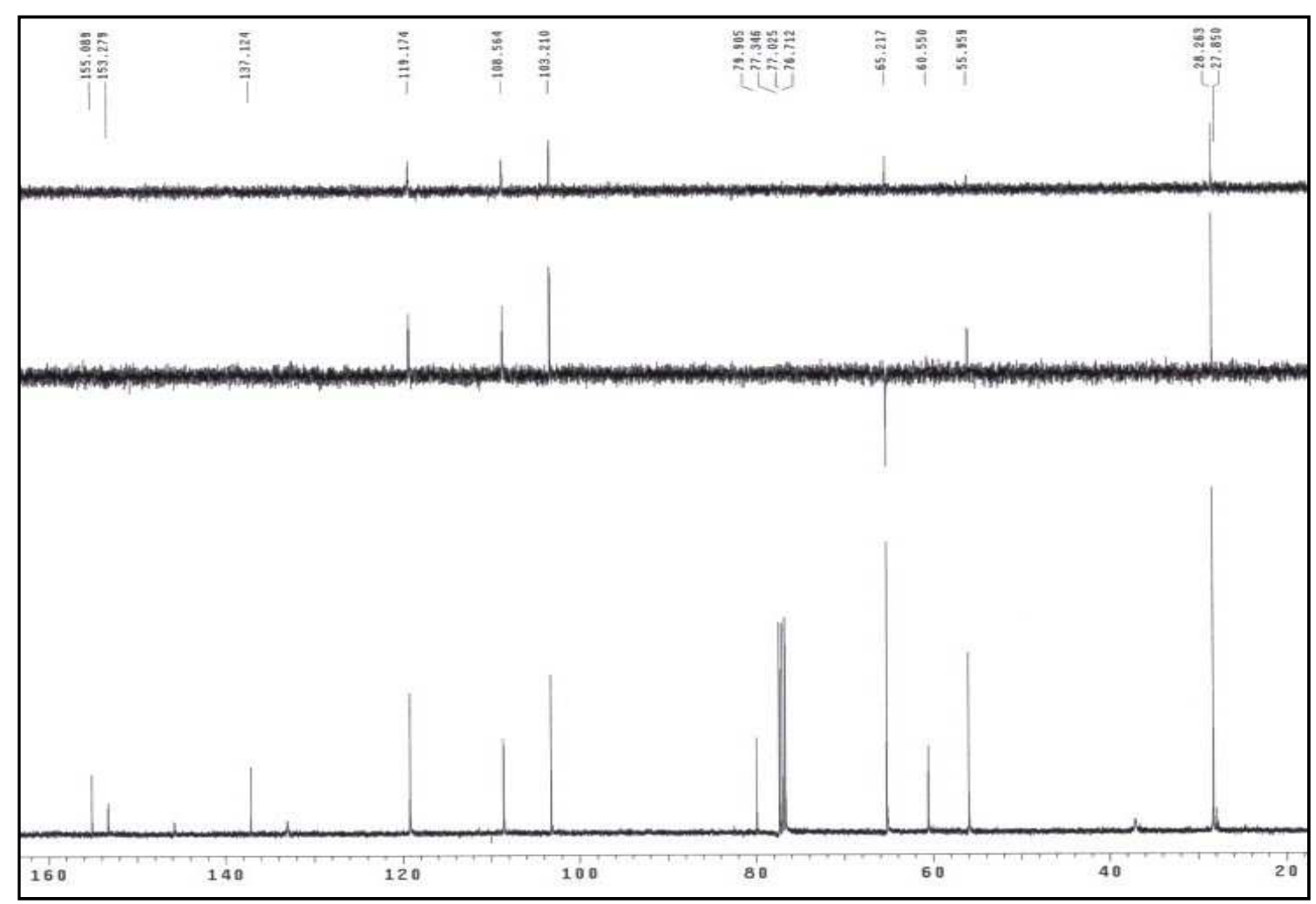

Figura LXXXIVb: Espectro de RMN ${ }^{13} \mathrm{C}$ del compuesto 94. 


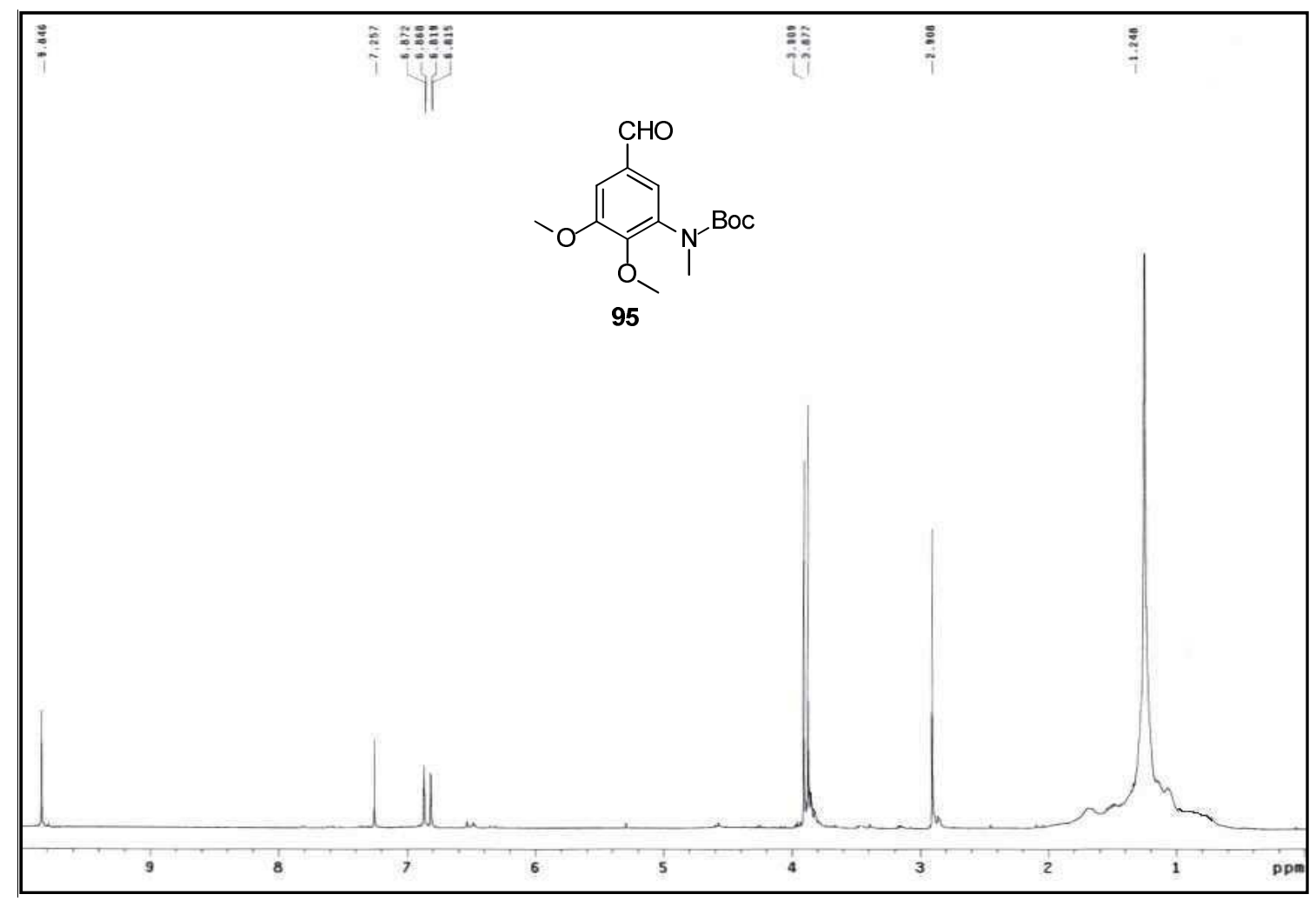

Figura LXXXVa: Espectro de RMN ${ }^{1} \mathrm{H}$ del compuesto 95.

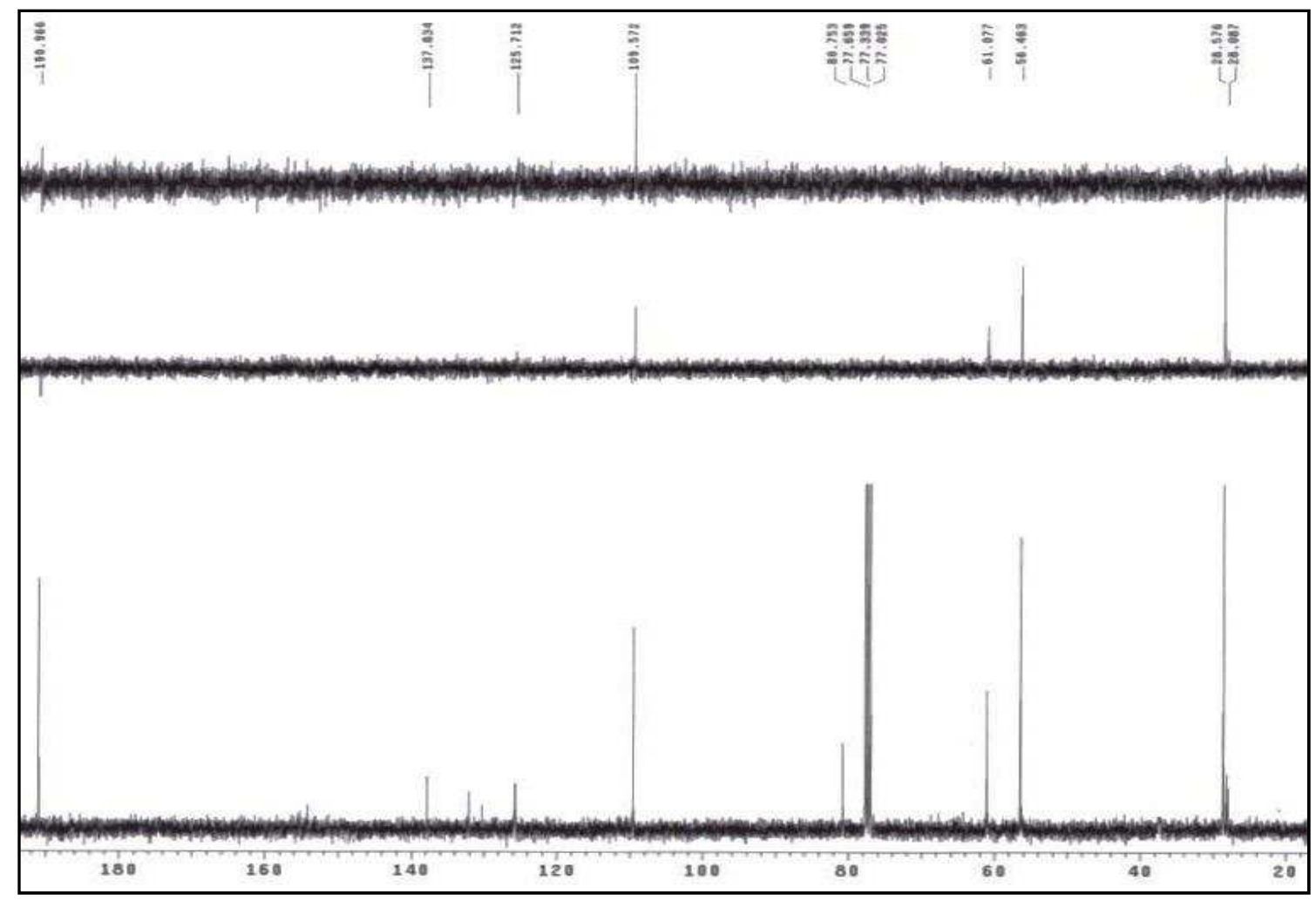

Figura LXXXVb: Espectro de RMN ${ }^{13} \mathrm{C}$ del compuesto 95. 


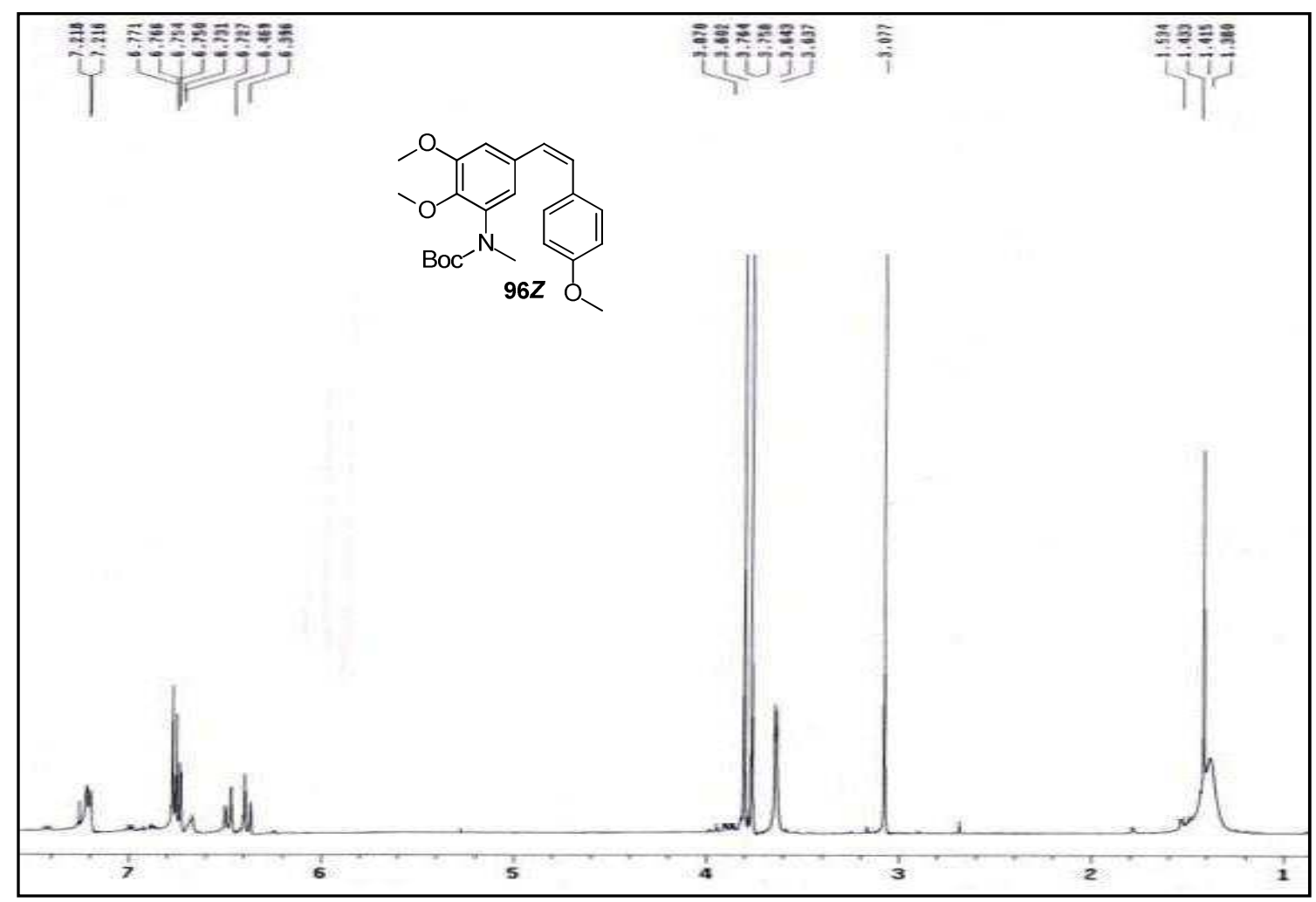

Figura LXXXVIa: Espectro de RMN ${ }^{1} \mathrm{H}$ del compuesto $96 Z$.

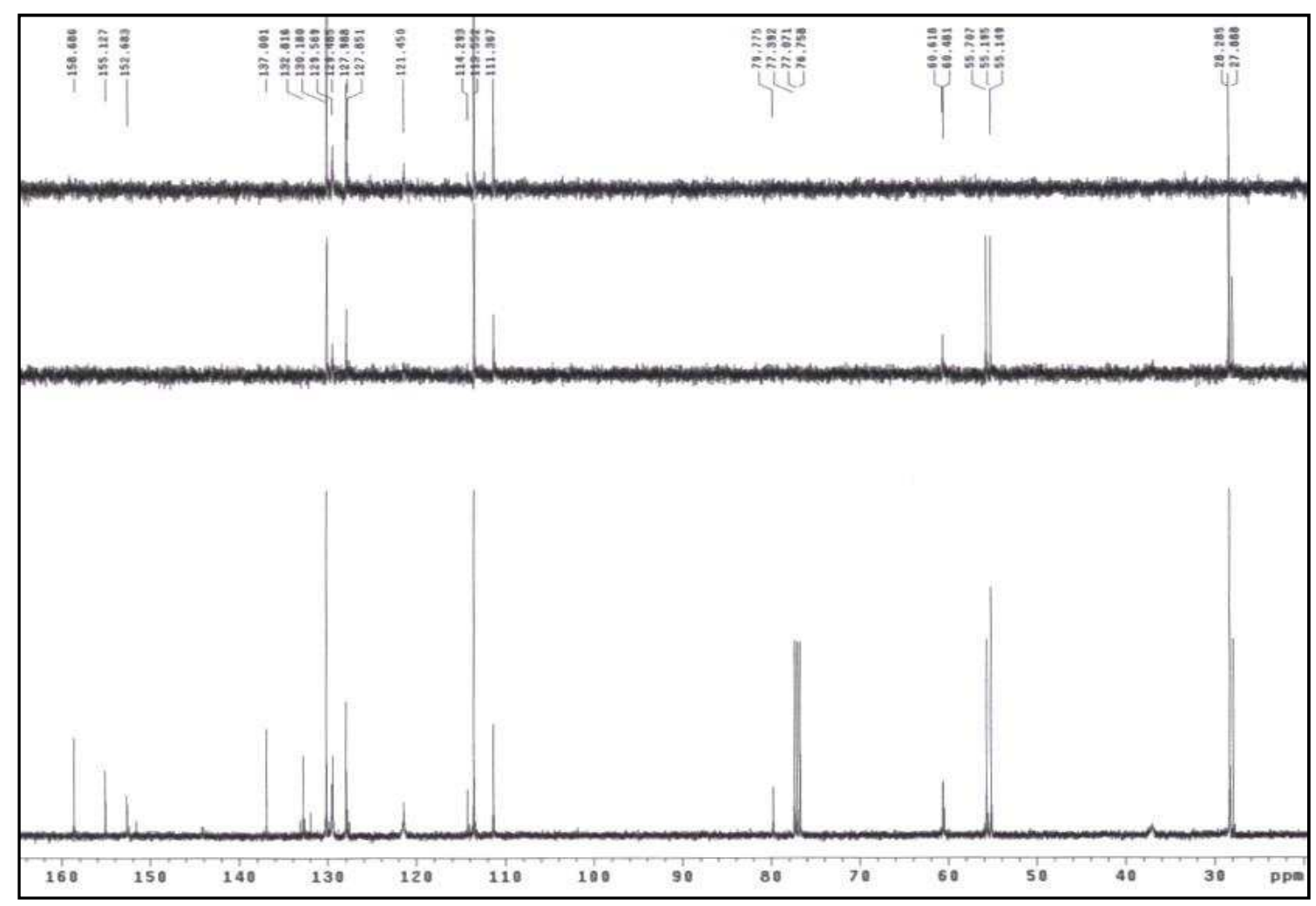

Figura LXXXVIb: Espectro de RMN ${ }^{13} \mathrm{C}$ del compuesto $96 Z$. 


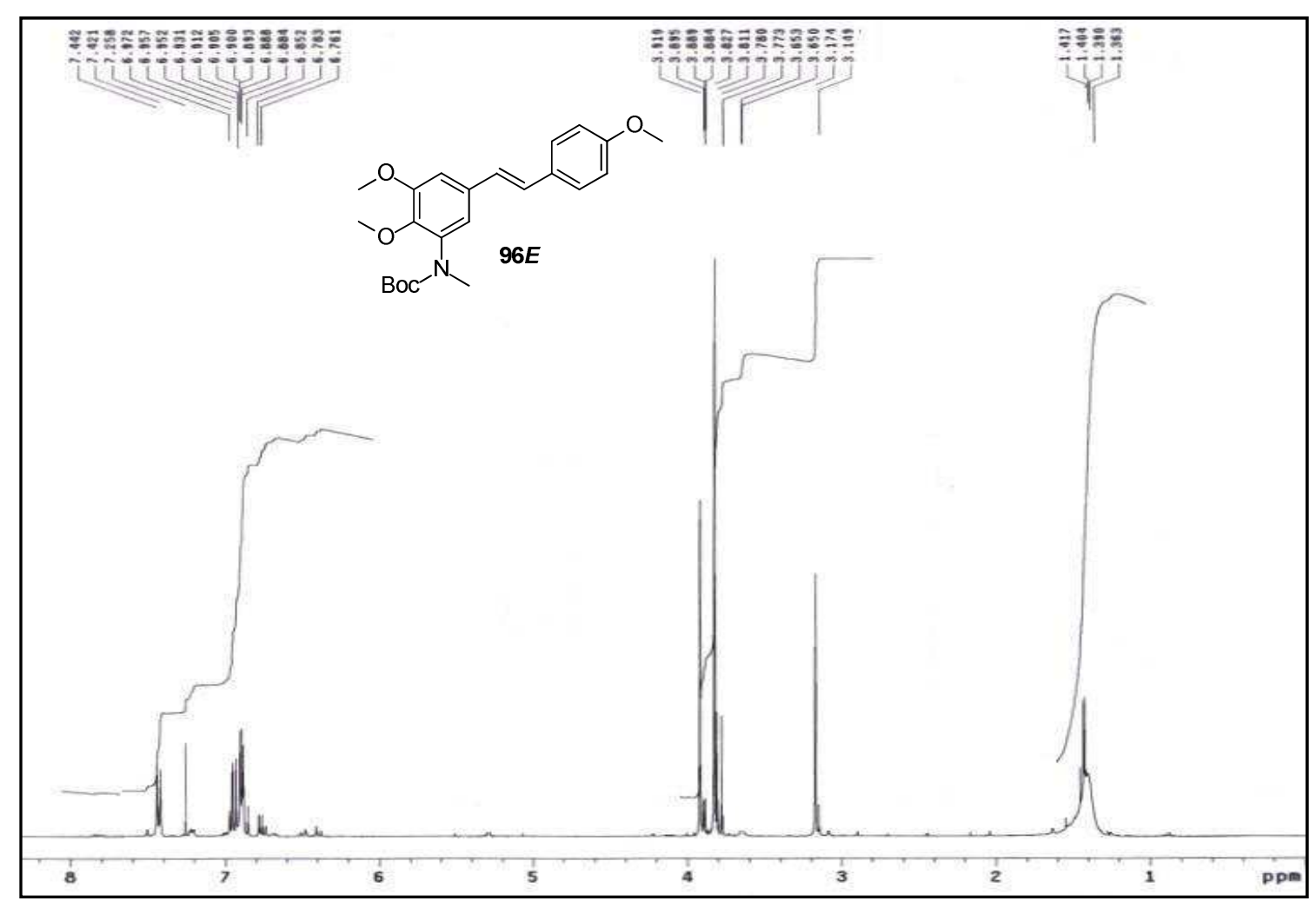

Figura LXXXVIc: Espectro de RMN ${ }^{1} \mathrm{H}$ del compuesto $96 \boldsymbol{E}$.

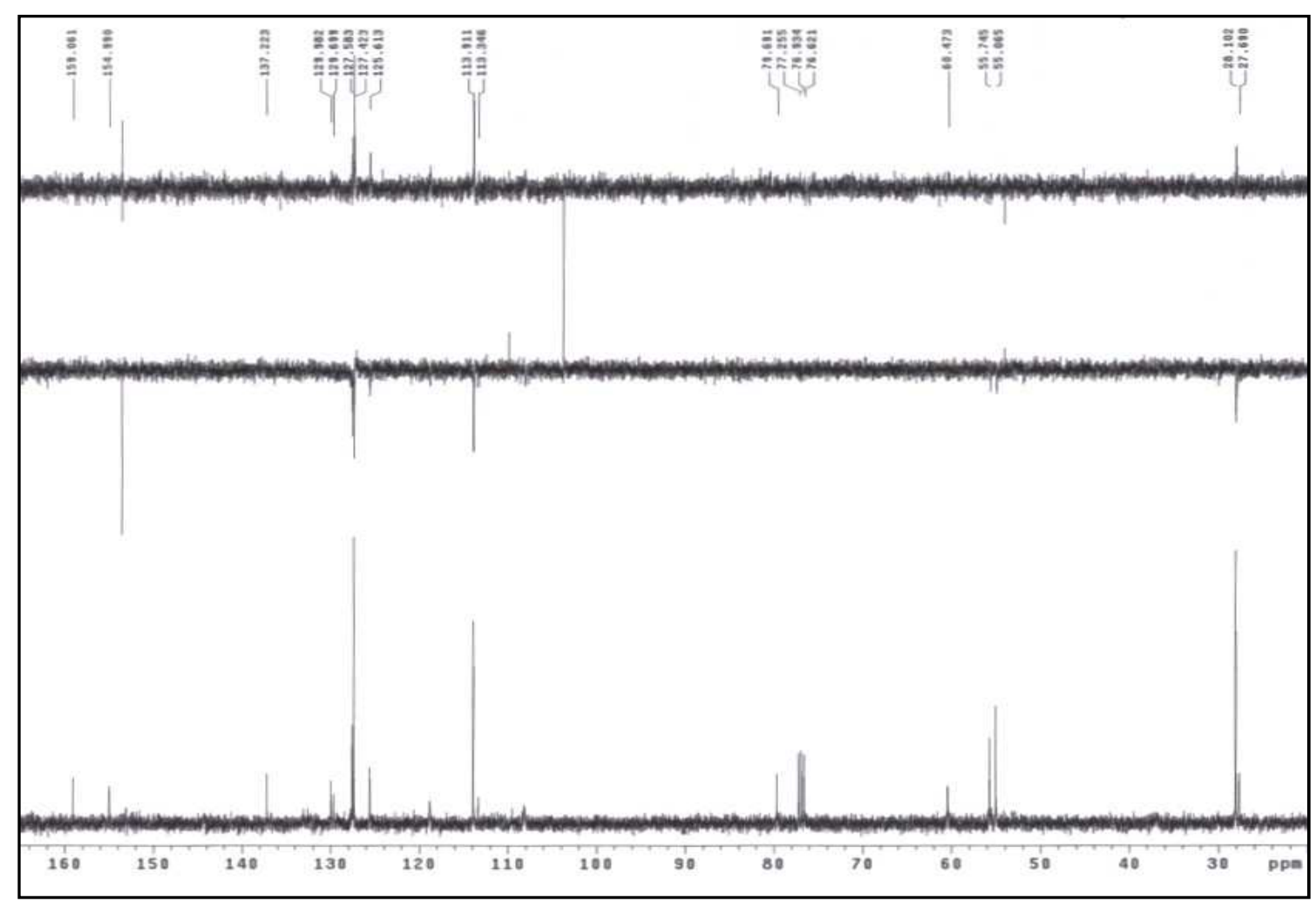

Figura LXXXVId: Espectro de RMN ${ }^{13} \mathrm{C}$ del compuesto $96 \boldsymbol{E}$. 


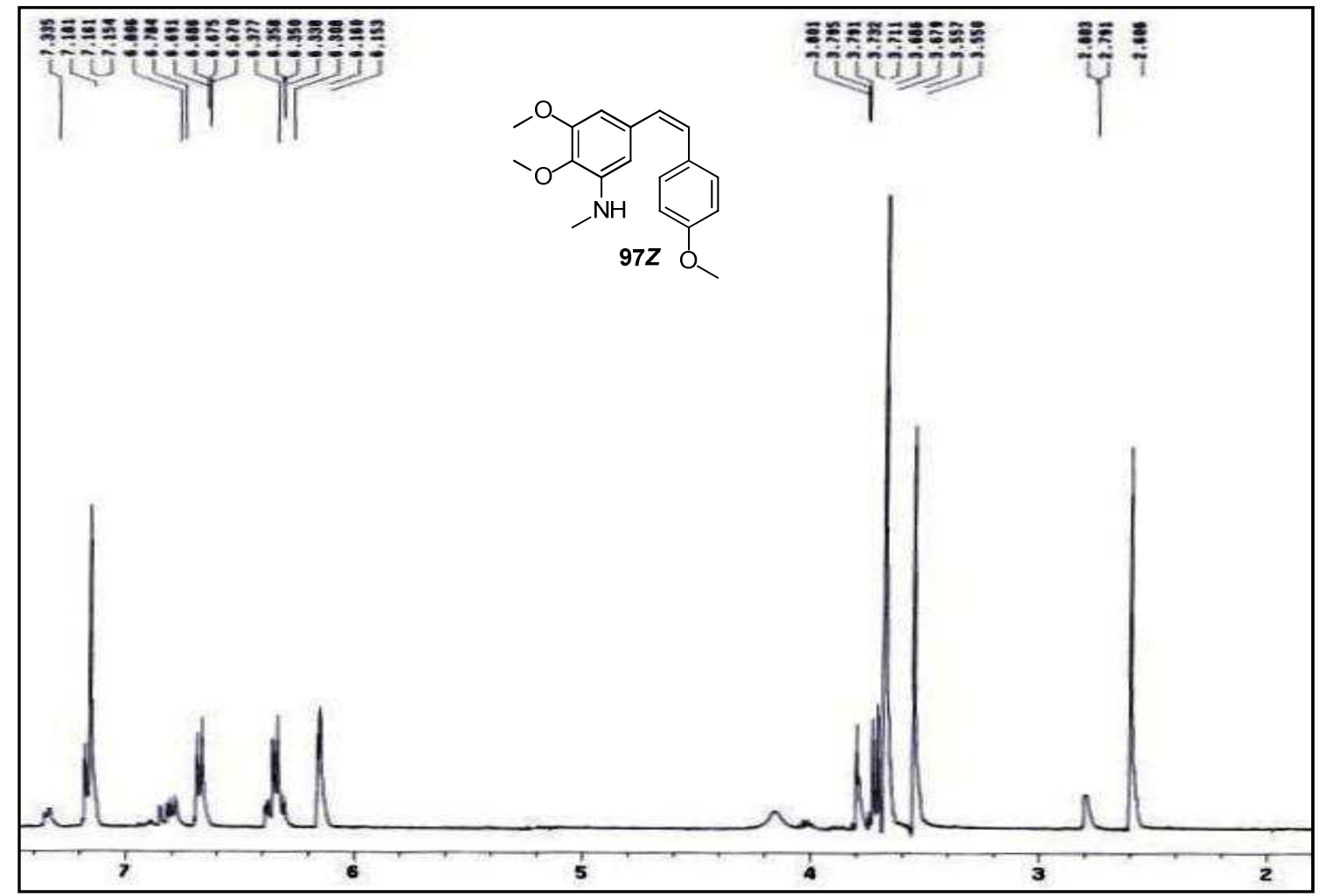

Figura LXXXVIIa: Espectro de RMN ${ }^{1} \mathrm{H}$ del compuesto $\mathbf{9 7 Z . ~}$

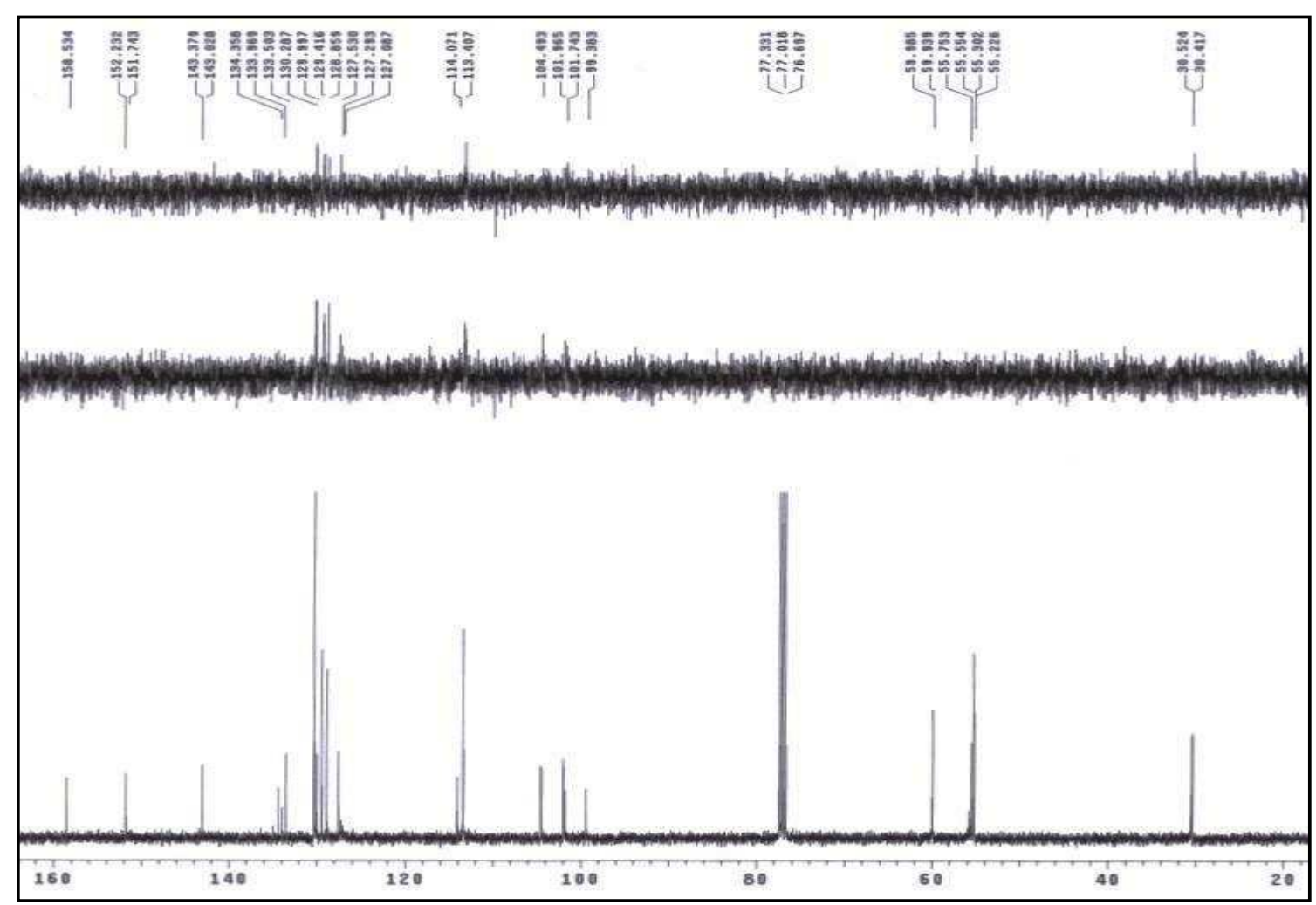

Figura LXXXVIIb: Espectro de RMN ${ }^{13} \mathrm{C}$ del compuesto $\mathbf{9 7 Z}$. 


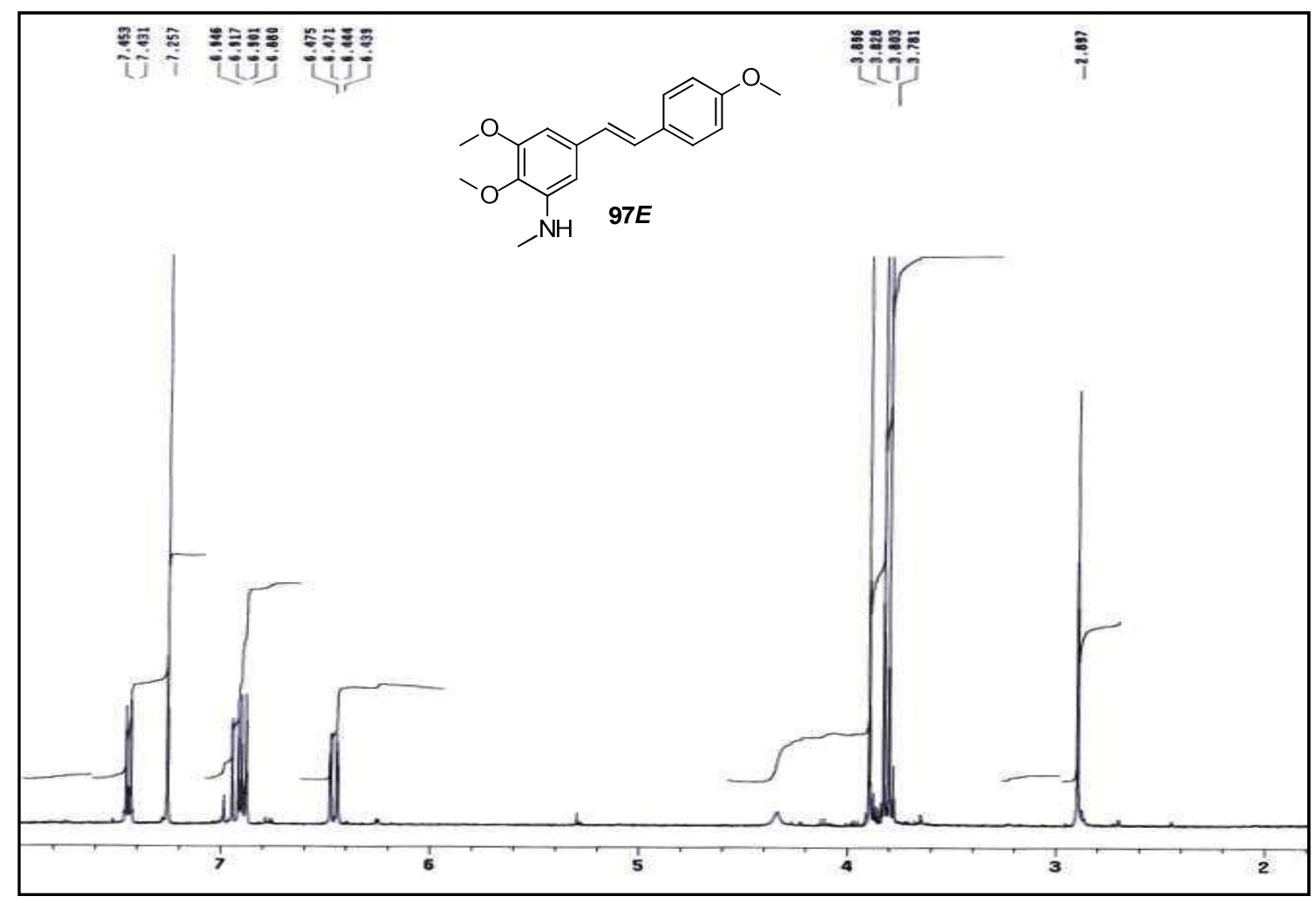

Figura LXXXVIIc: Espectro de RMN ${ }^{1} \mathrm{H}$ del compuesto $\mathbf{9 7 E}$.

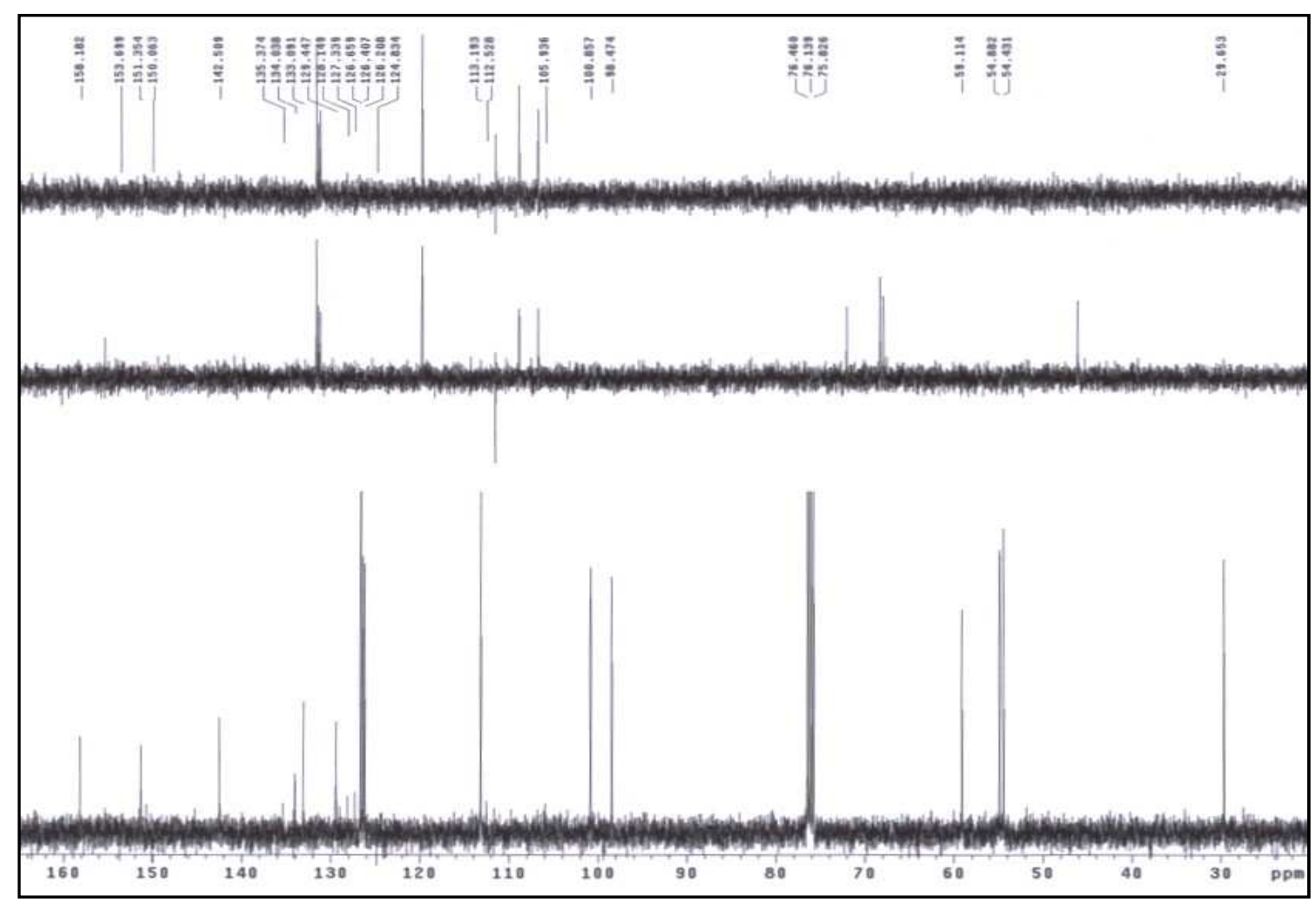

Figura LXXXVIId: Espectro de RMN ${ }^{13} \mathrm{C}$ del compuesto $\mathbf{9 7} \boldsymbol{E}$. 


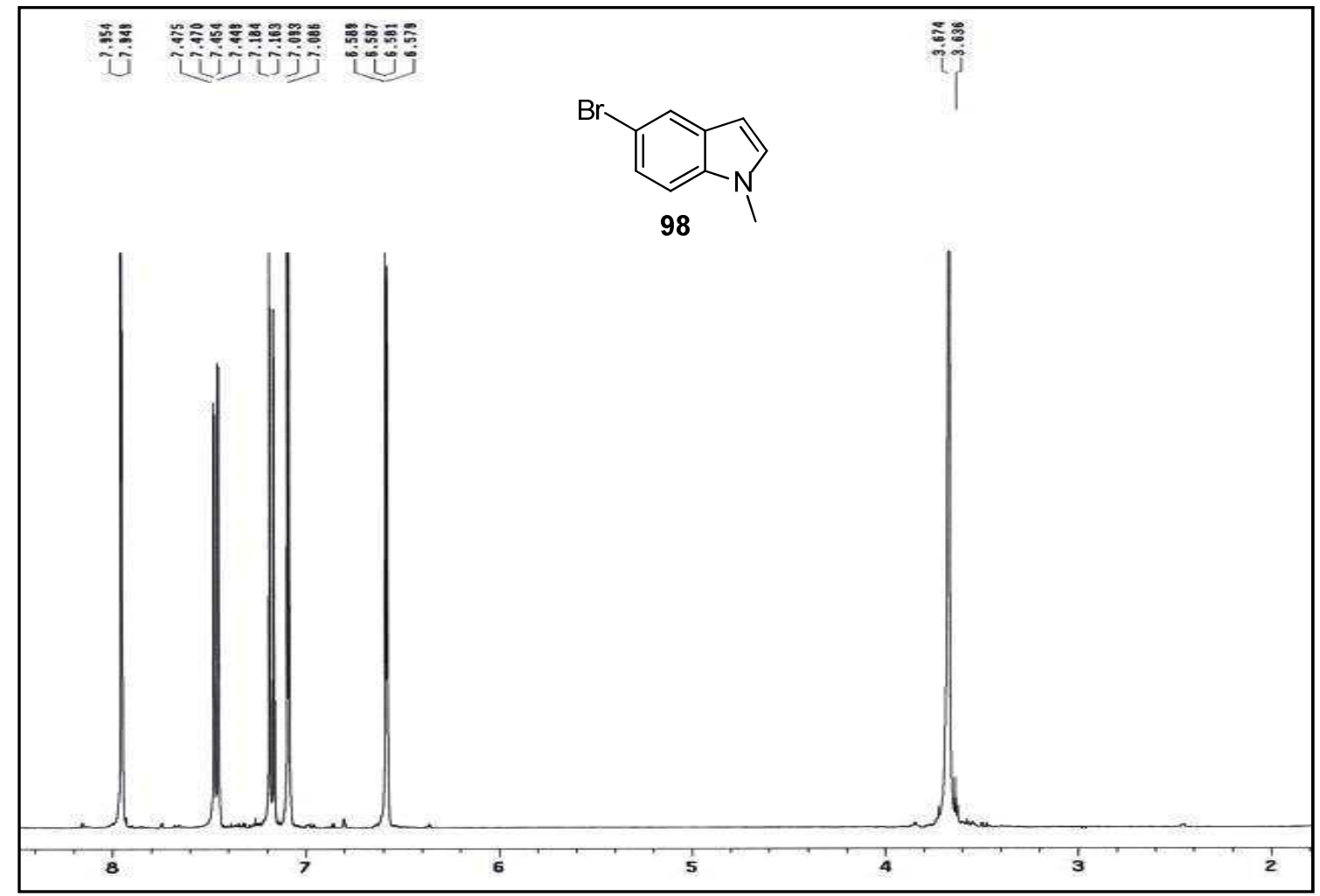

Figura LXXXVIIIa: Espectro de RMN ${ }^{1} \mathrm{H}$ del compuesto 98.

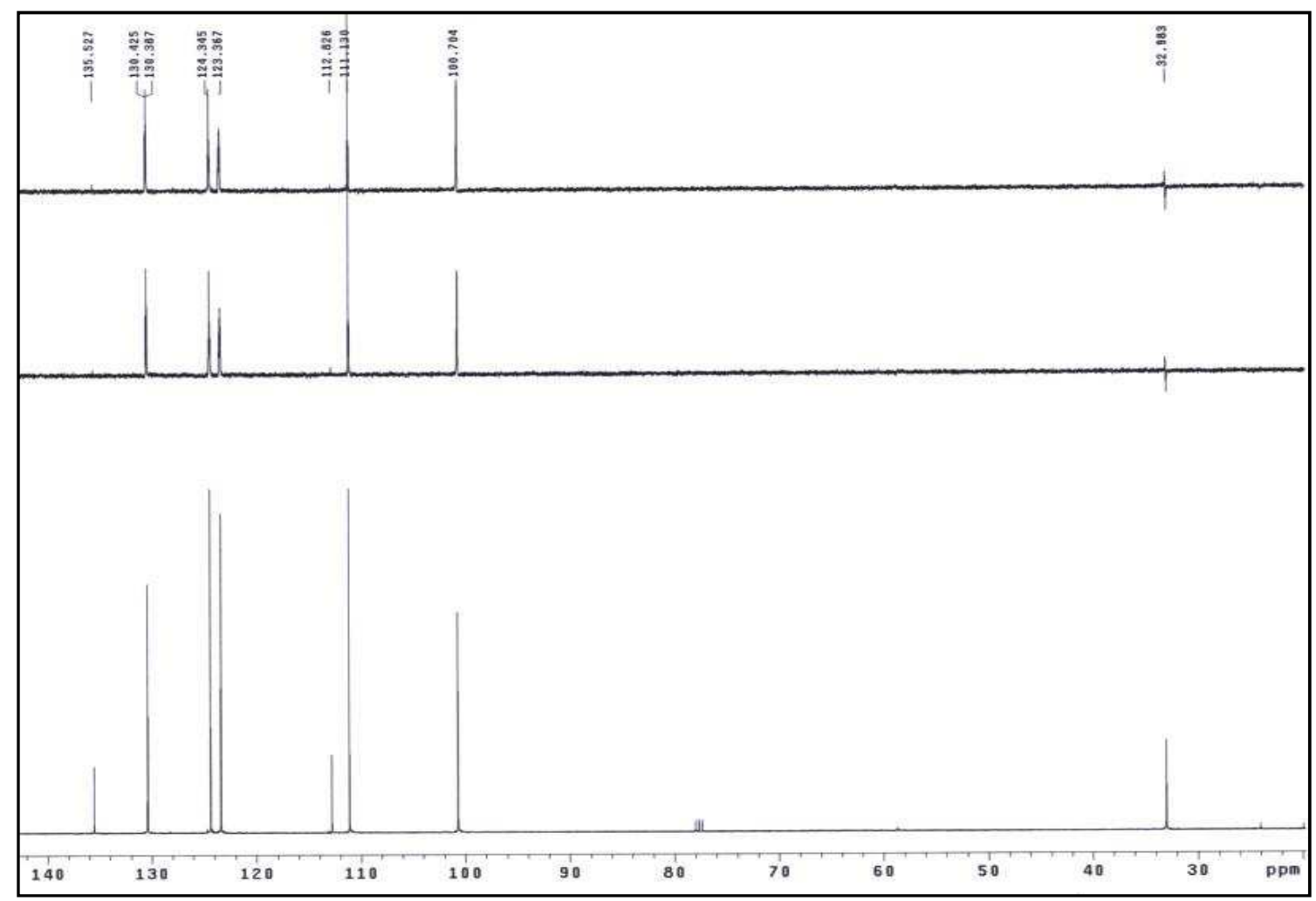

Figura LXXXVIIIb: Espectro de RMN ${ }^{13} \mathrm{C}$ del compuesto 98. 


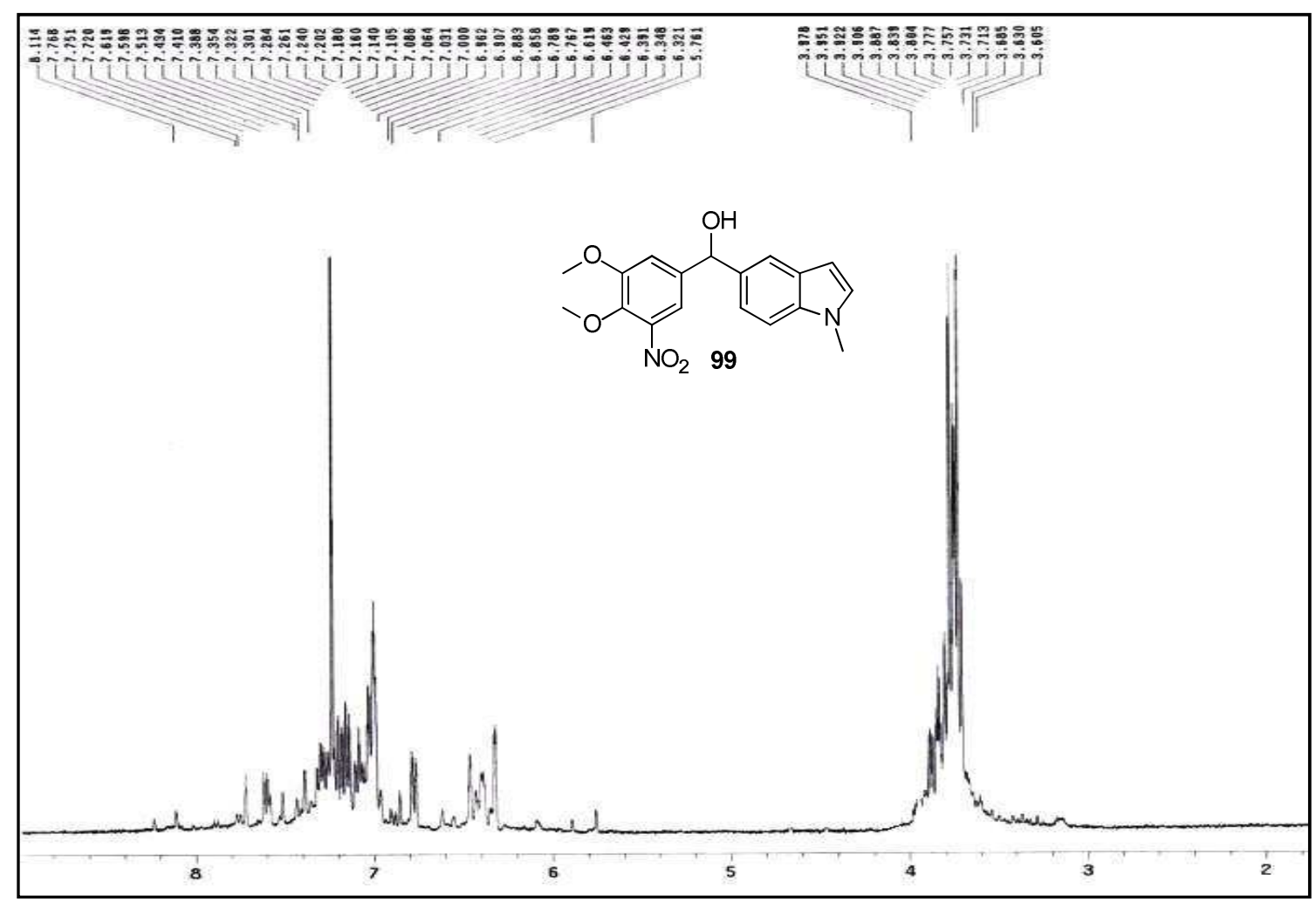

Figura LXXXIX: Espectro de RMN ${ }^{1} \mathrm{H}$ del compuesto 99. 


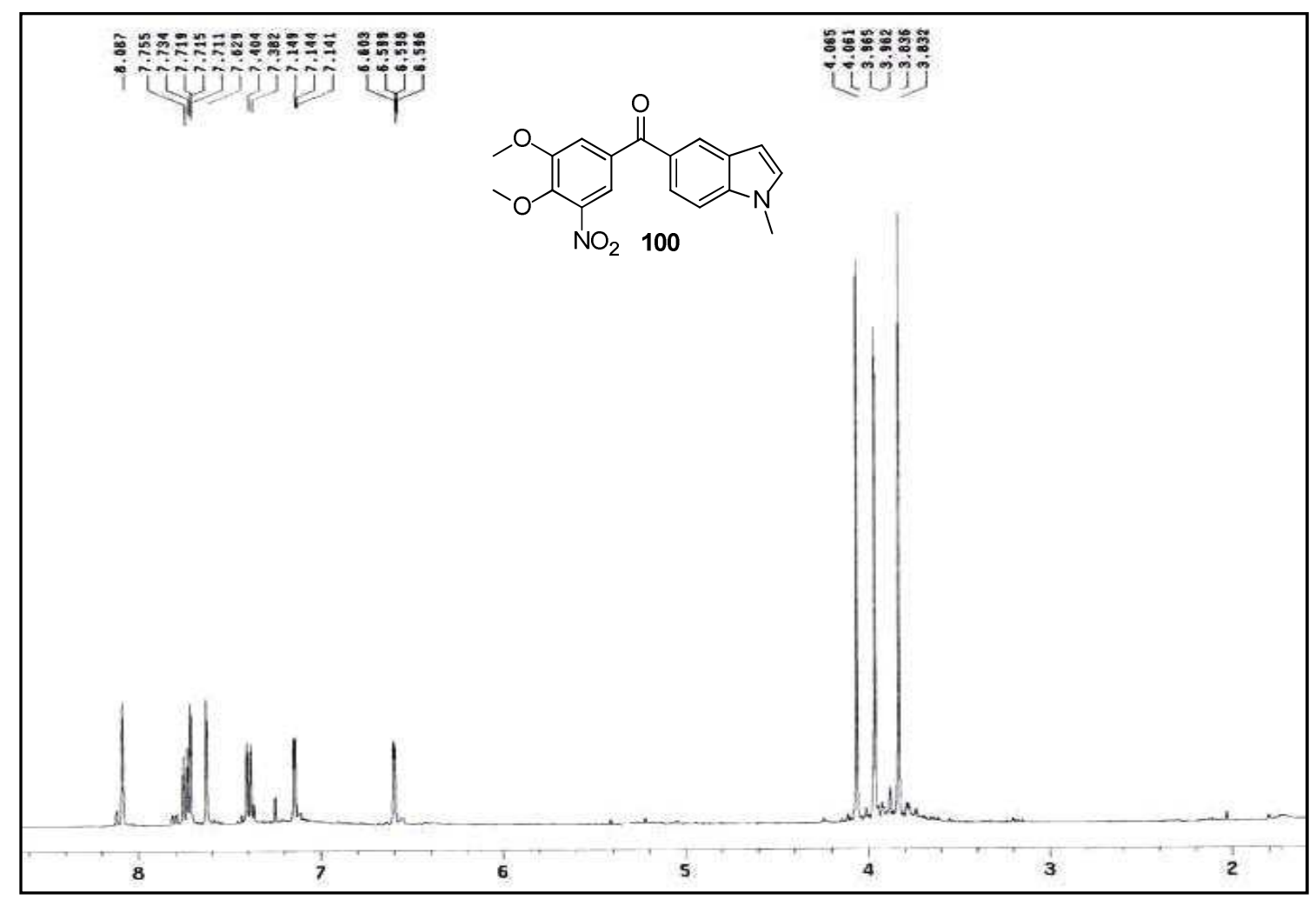

Figura XCa: Espectro de RMN ${ }^{1} \mathrm{H}$ del compuesto 100.

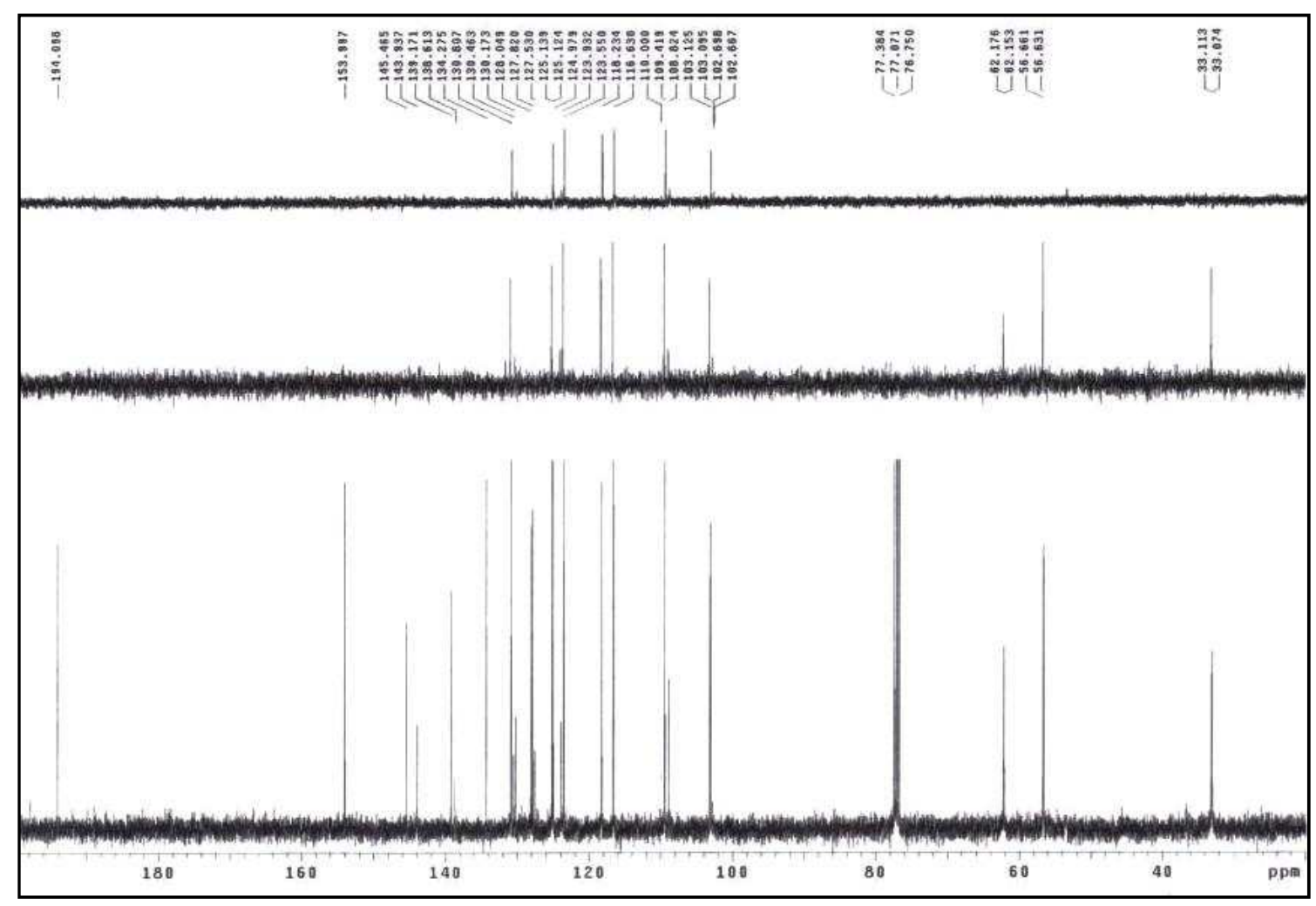

Figura XCb: Espectro de RMN ${ }^{13} \mathrm{C}$ del compuesto 100. 


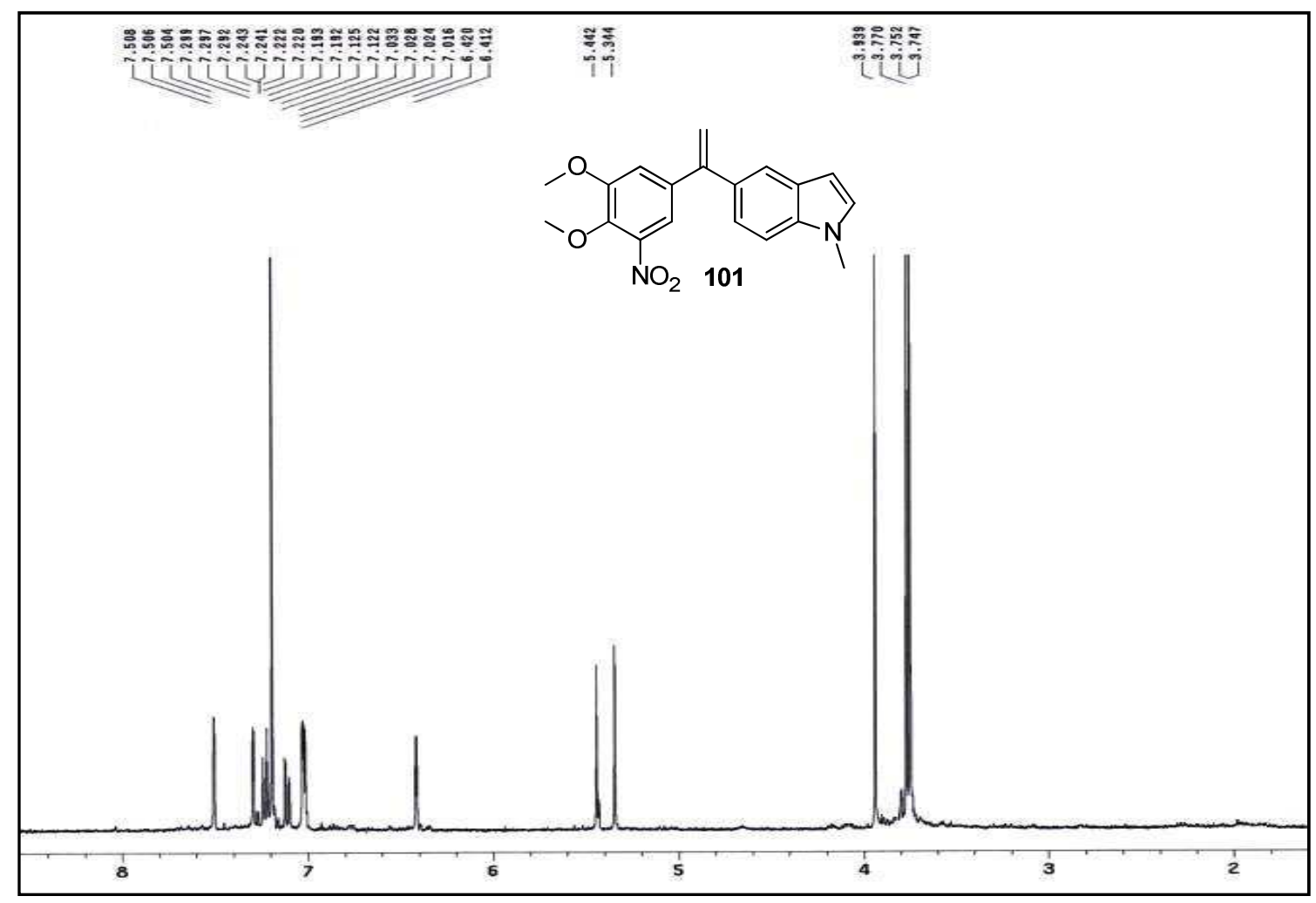

Figura XCIa: Espectro de RMN ${ }^{1} \mathrm{H}$ del compuesto 101. 


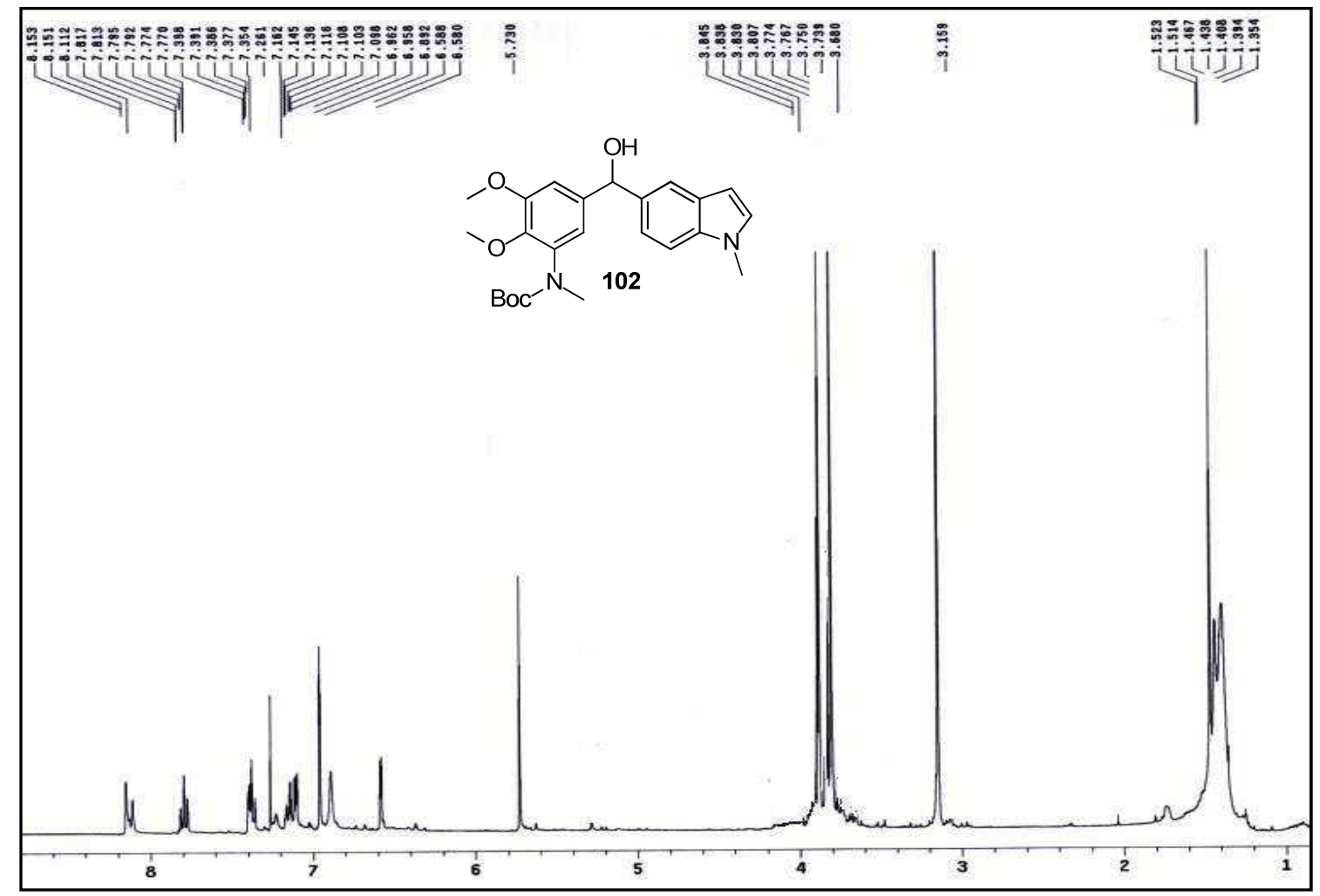

Figura XCIIa: Espectro de RMN ${ }^{1} \mathrm{H}$ del compuesto 102.

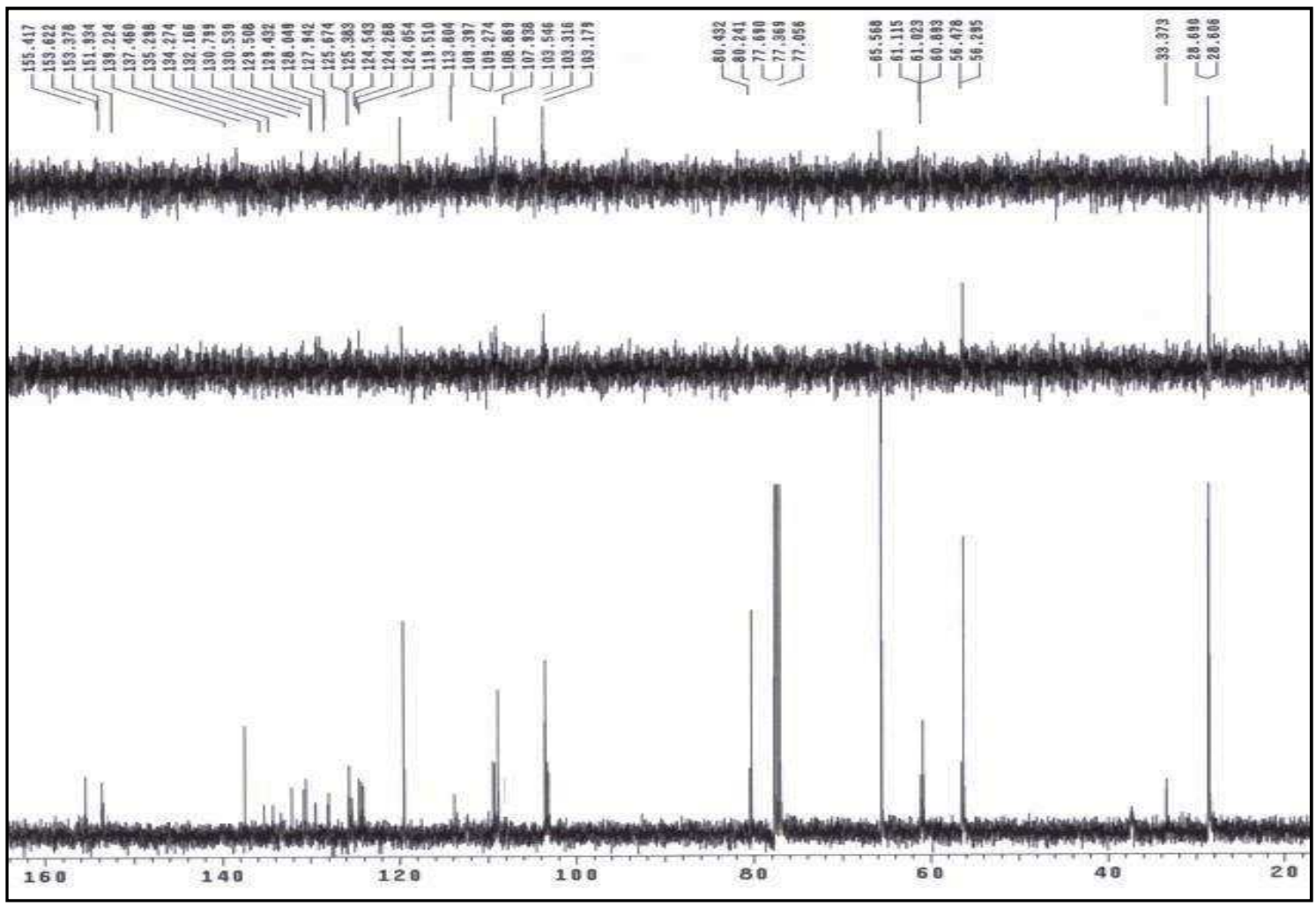

Figura XCIIb: Espectro de RMN ${ }^{13} \mathrm{C}$ del compuesto 102. 


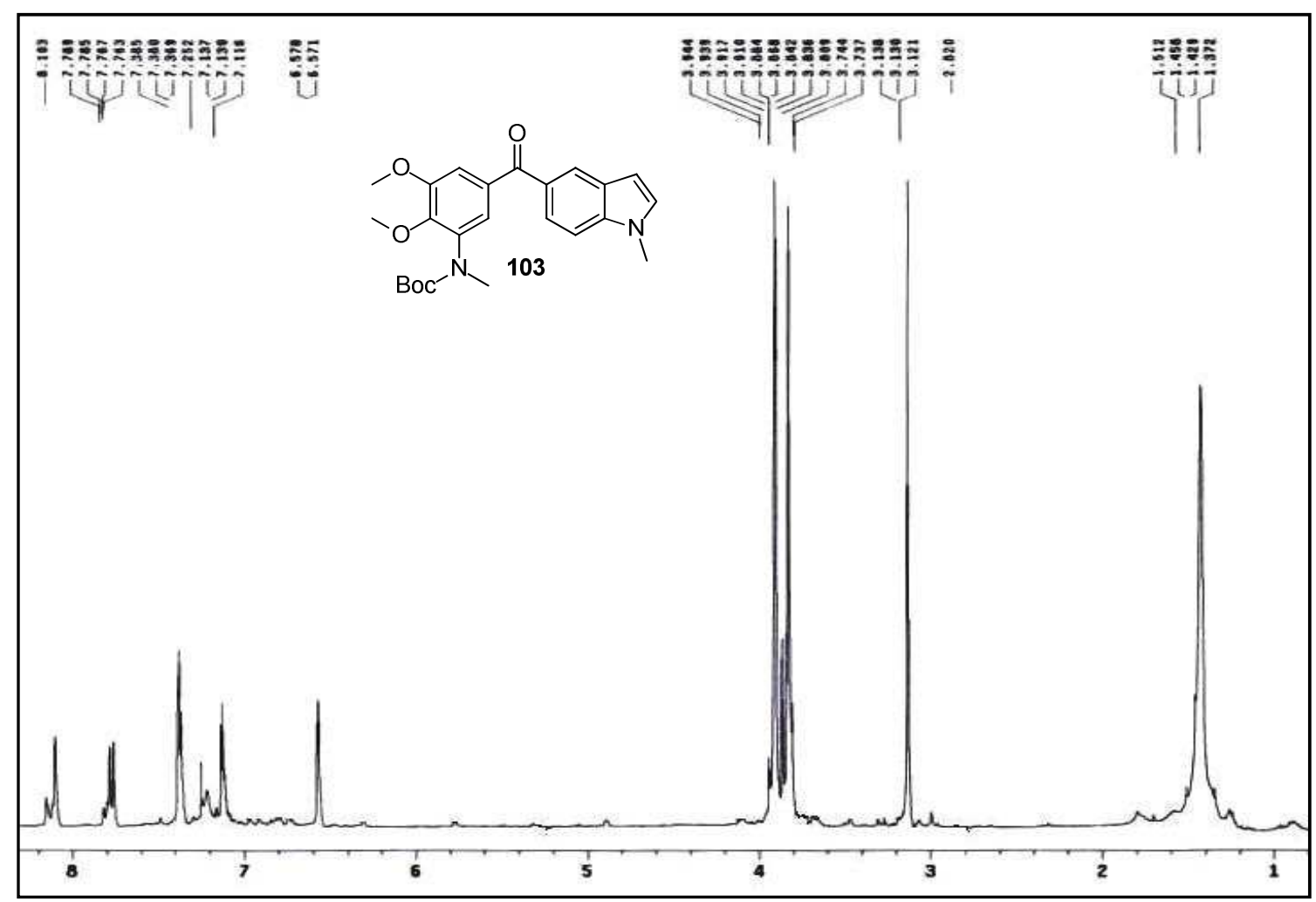

Figura XCIIIa: Espectro de RMN ${ }^{1} \mathrm{H}$ del compuesto 103.

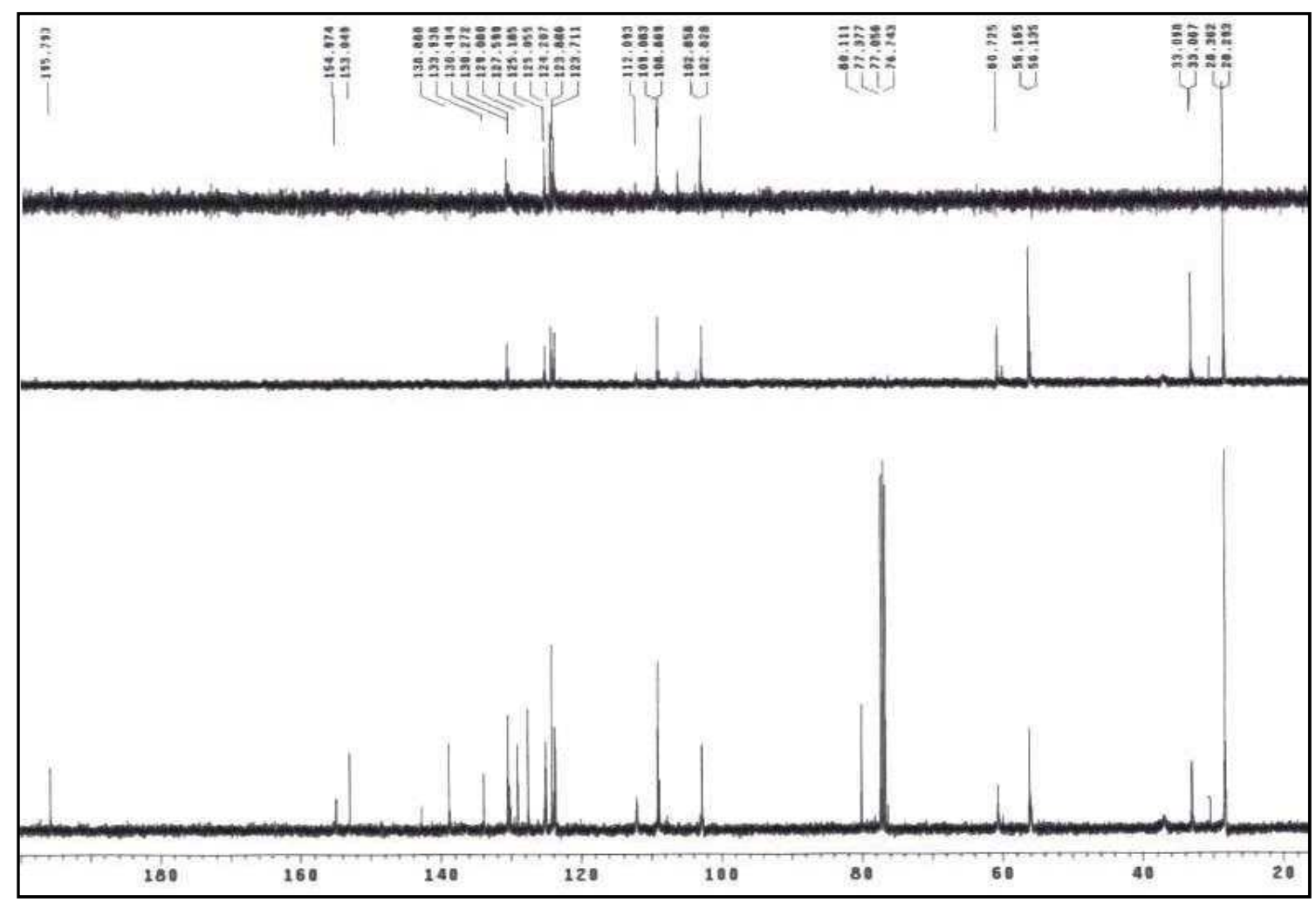

Figura XCIIIb: Espectro de RMN ${ }^{13} \mathrm{C}$ del compuesto 103. 


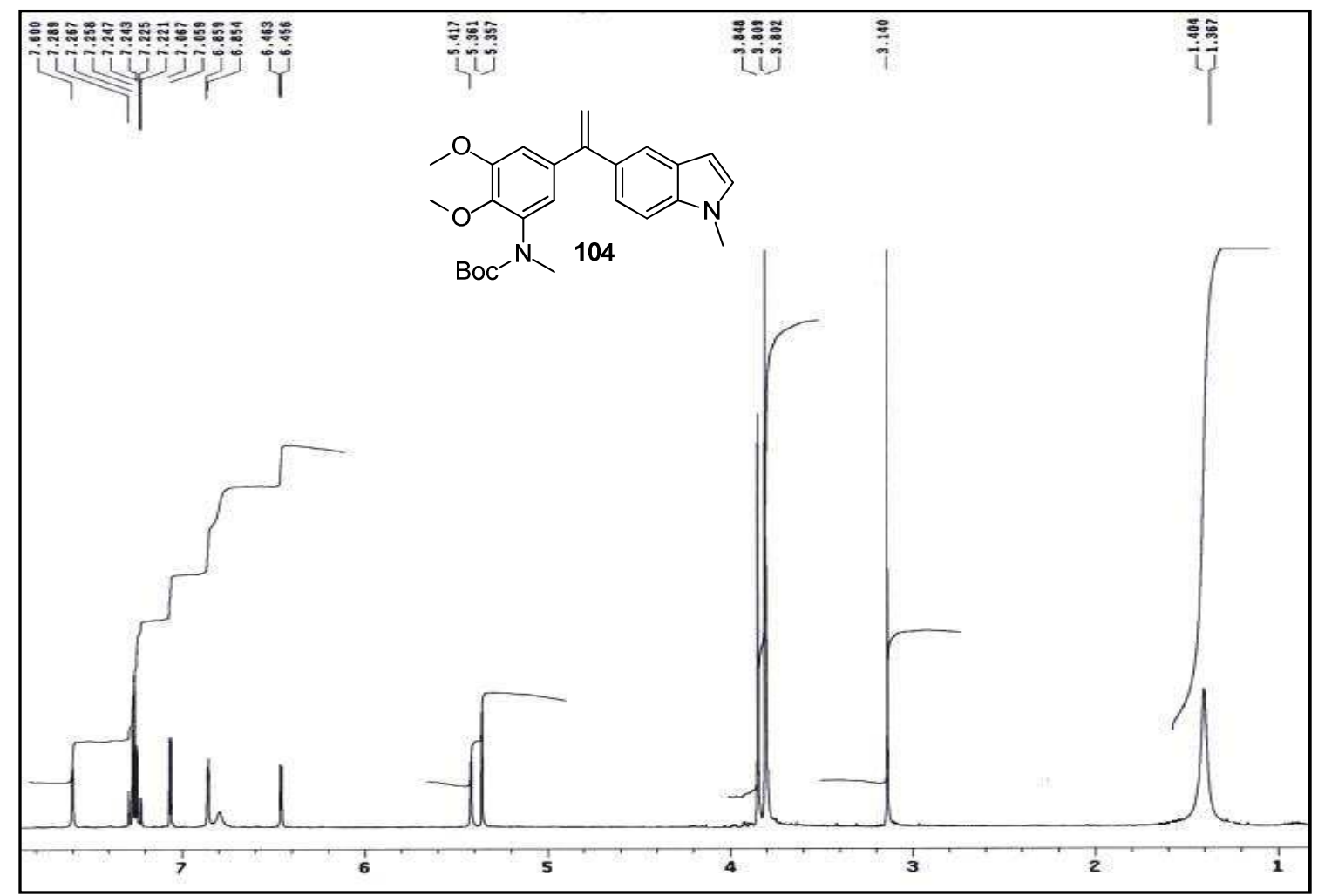

Figura XCIVa: Espectro de RMN ${ }^{1} \mathrm{H}$ del compuesto 104.

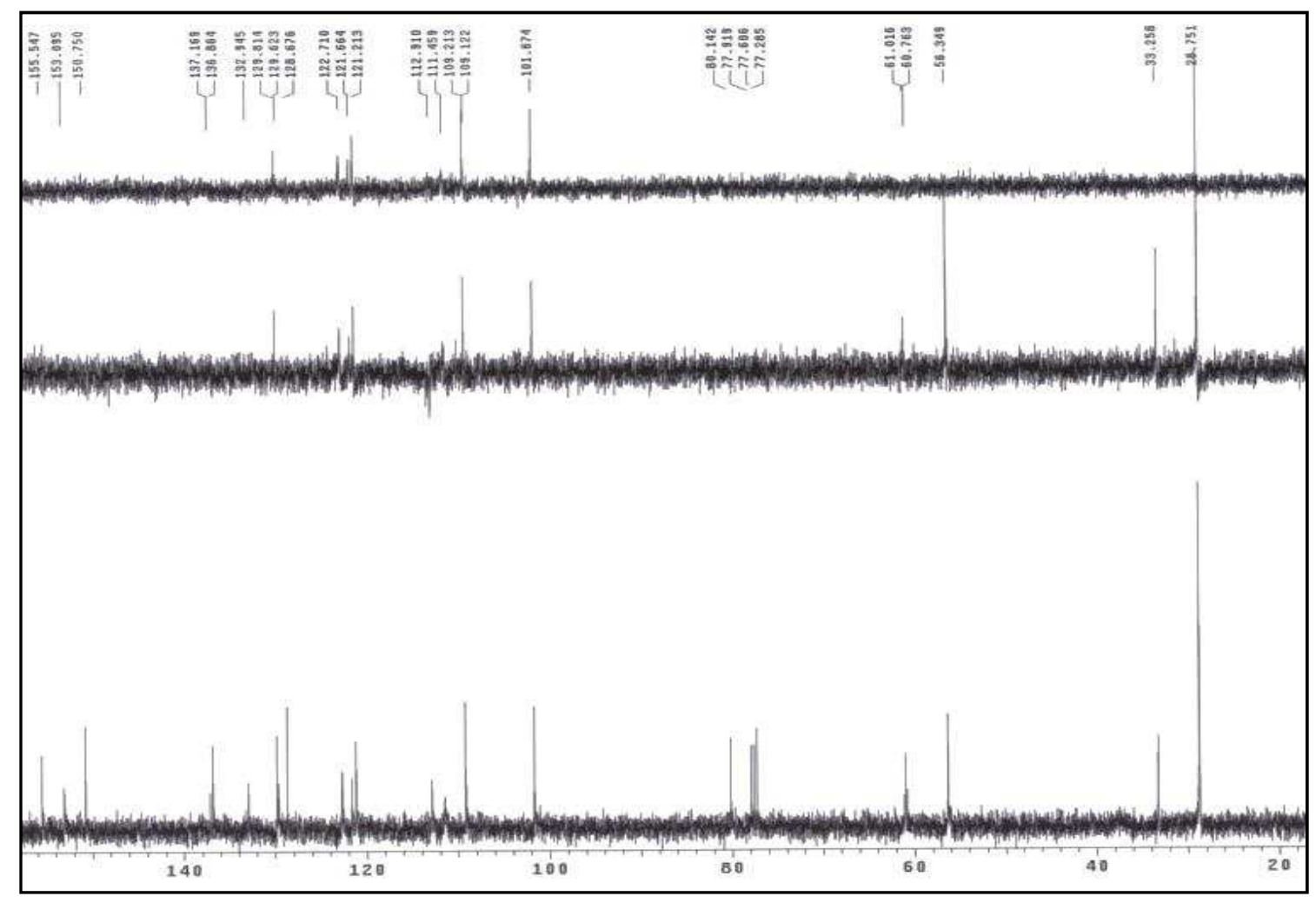

Figura XCIVb: Espectro de RMN ${ }^{13} \mathrm{C}$ del compuesto 104. 


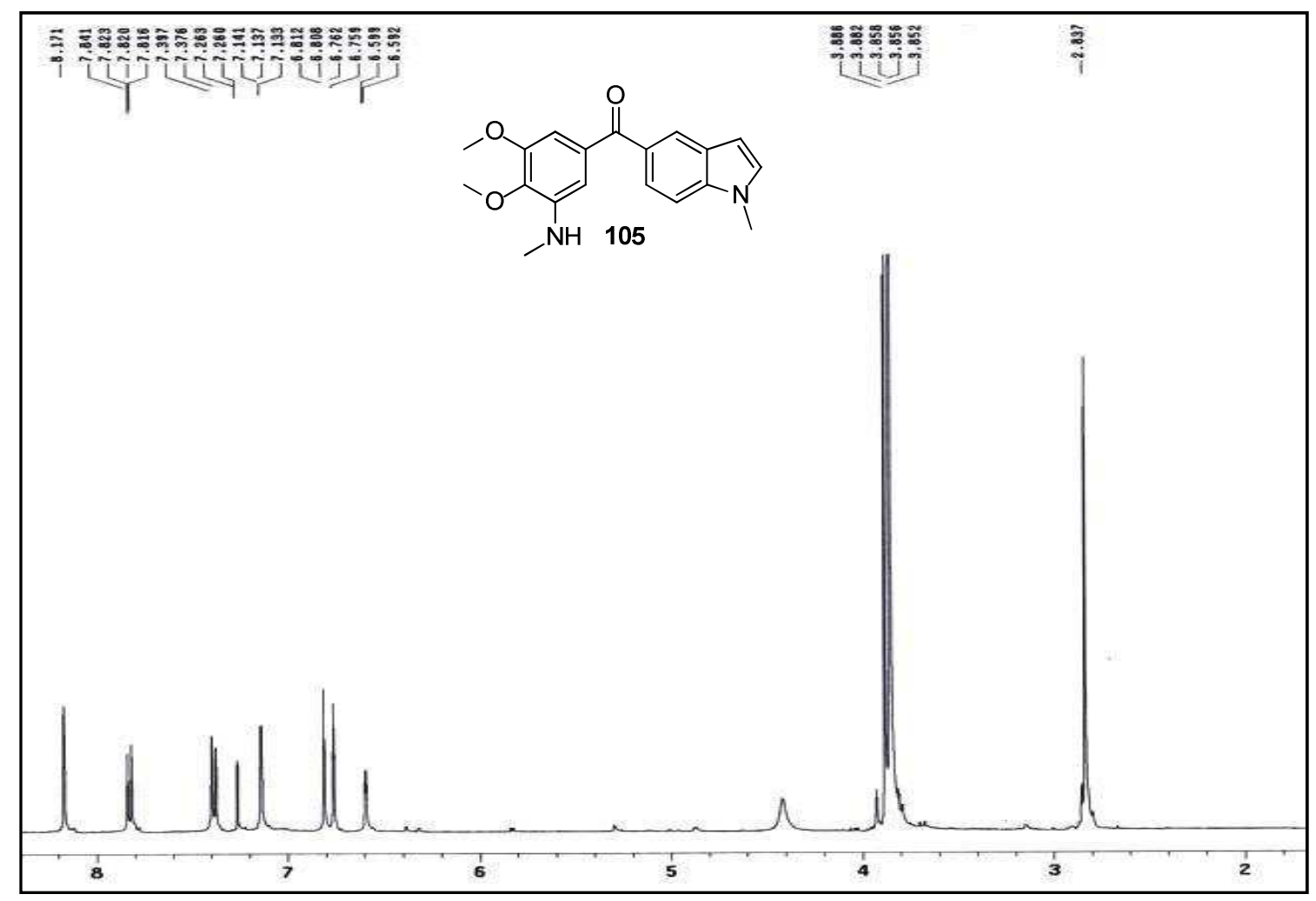

Figura XCVa: Espectro de RMN ${ }^{1} \mathrm{H}$ del compuesto 105.

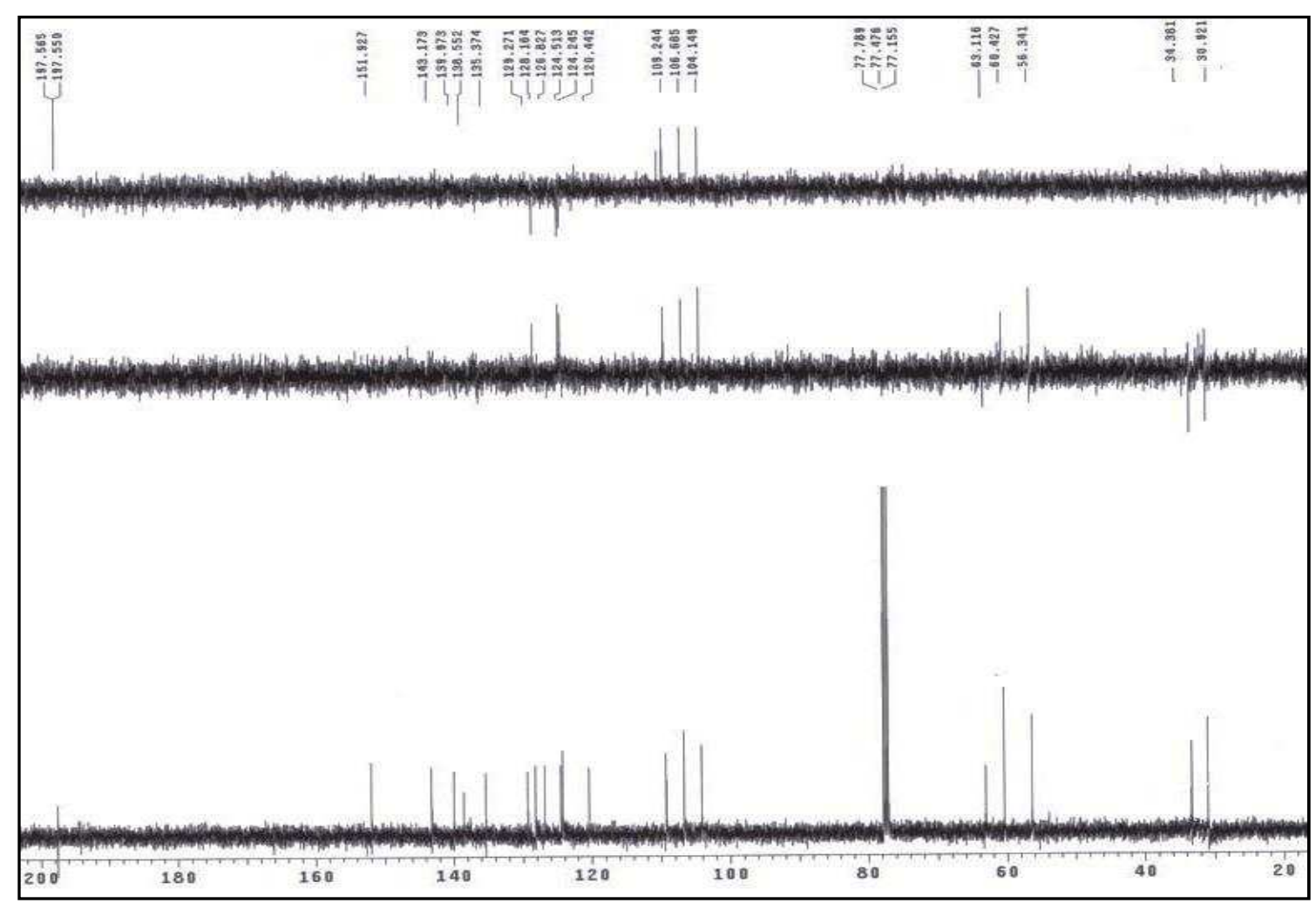

Figura XCVb: Espectro de RMN ${ }^{13} \mathrm{C}$ del compuesto 105. 


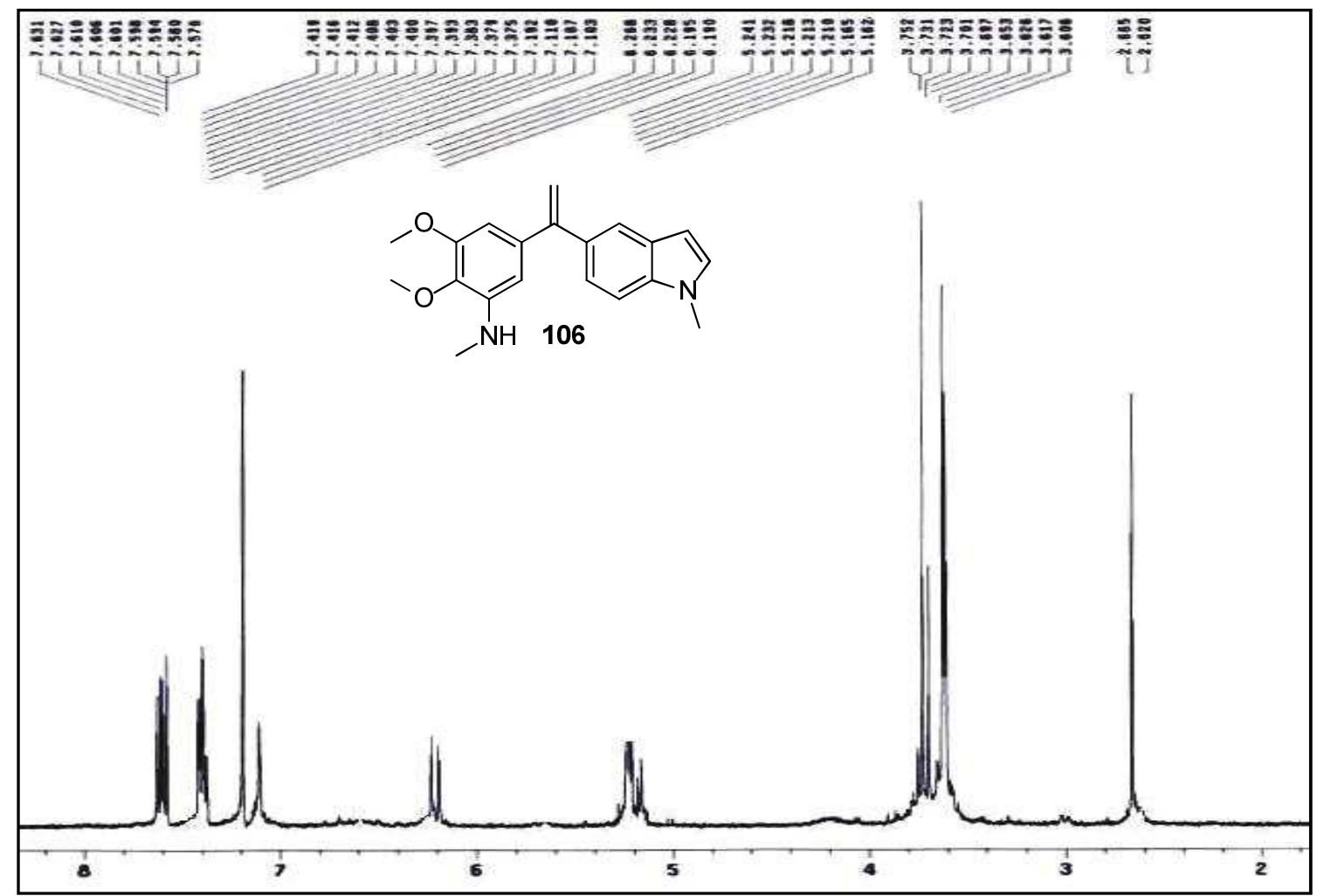

Figura XCVI: Espectro de RMN ${ }^{1} \mathrm{H}$ del compuesto 106. 


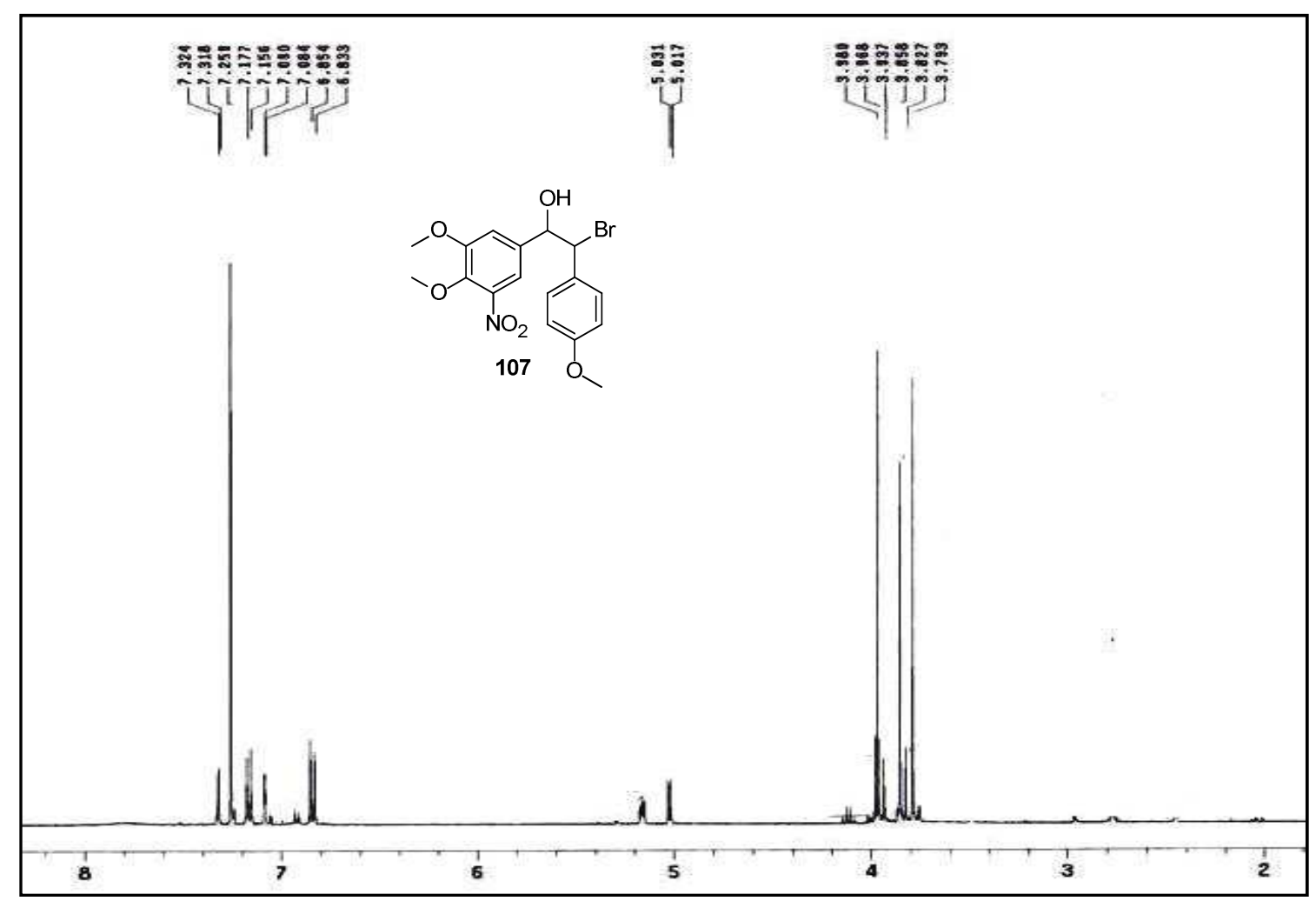

Figura XCVII: Espectro de RMN ${ }^{1} \mathrm{H}$ del compuesto 107.

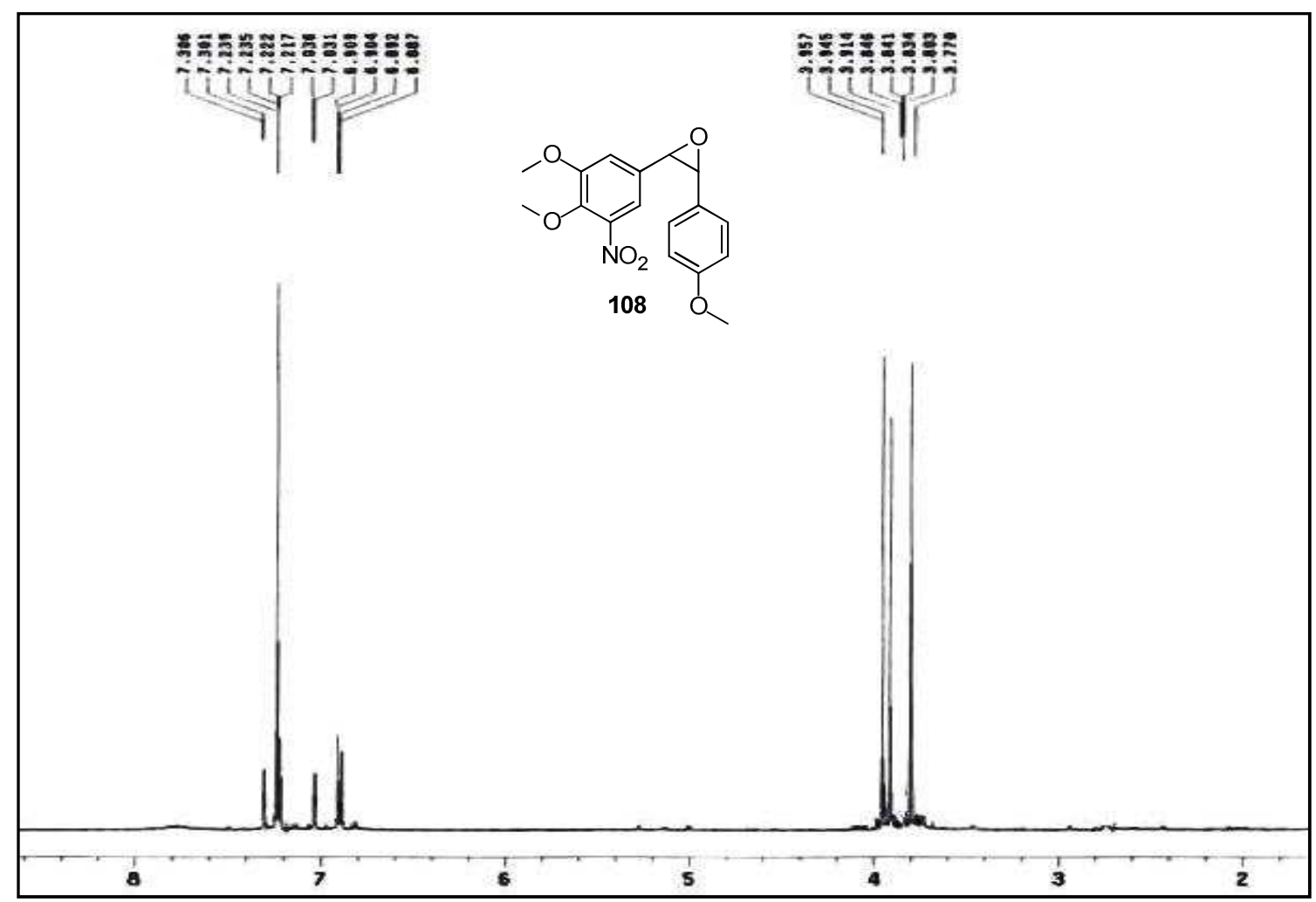

Figura XCVIII: Espectro de RMN ${ }^{1} \mathrm{H}$ del compuesto 108. 


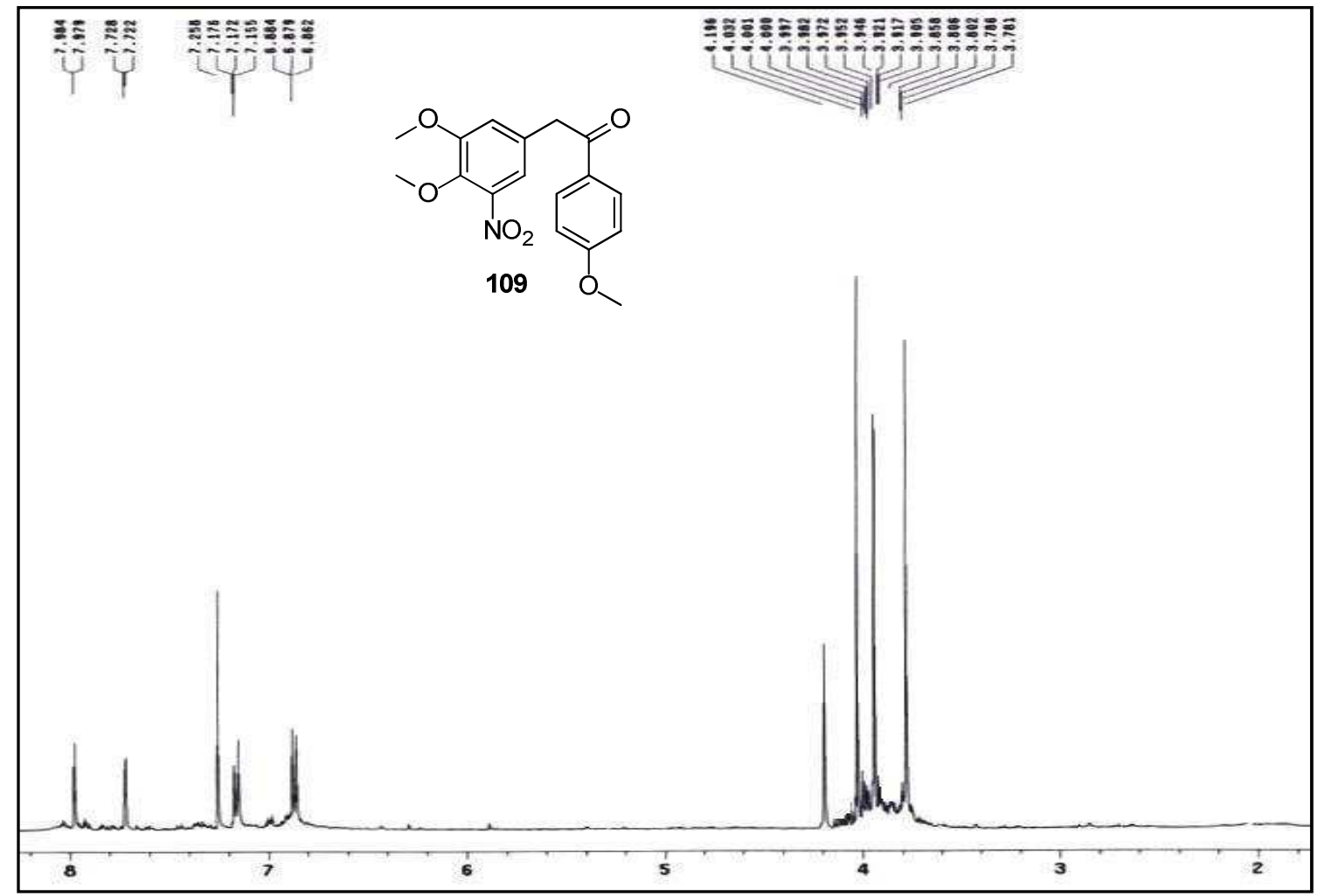

Figura XCIXa: Espectro de RMN ${ }^{1} \mathrm{H}$ del compuesto 109.

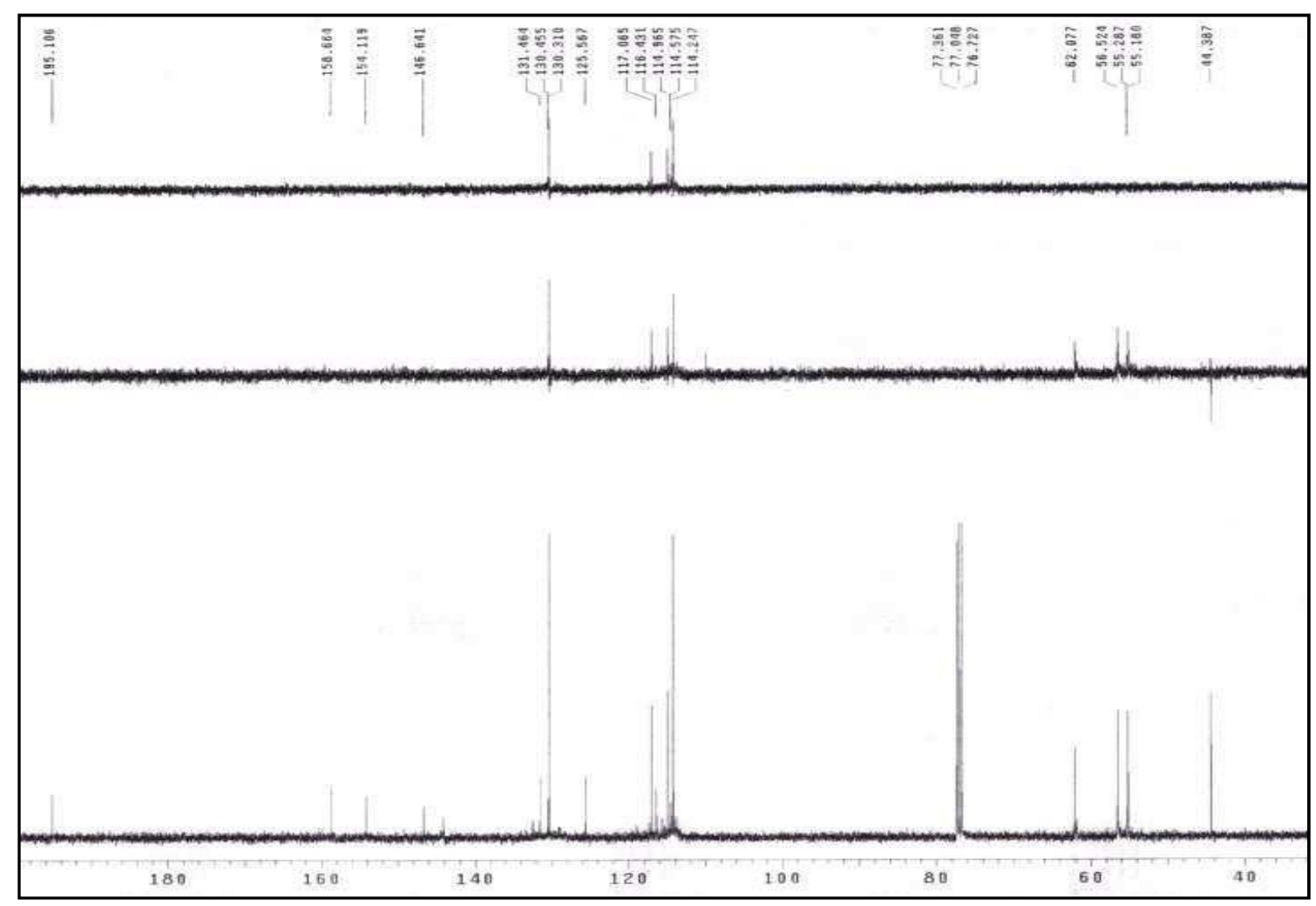

Figura XCIXb: Espectro de RMN ${ }^{13} \mathrm{C}$ del compuesto 109. 


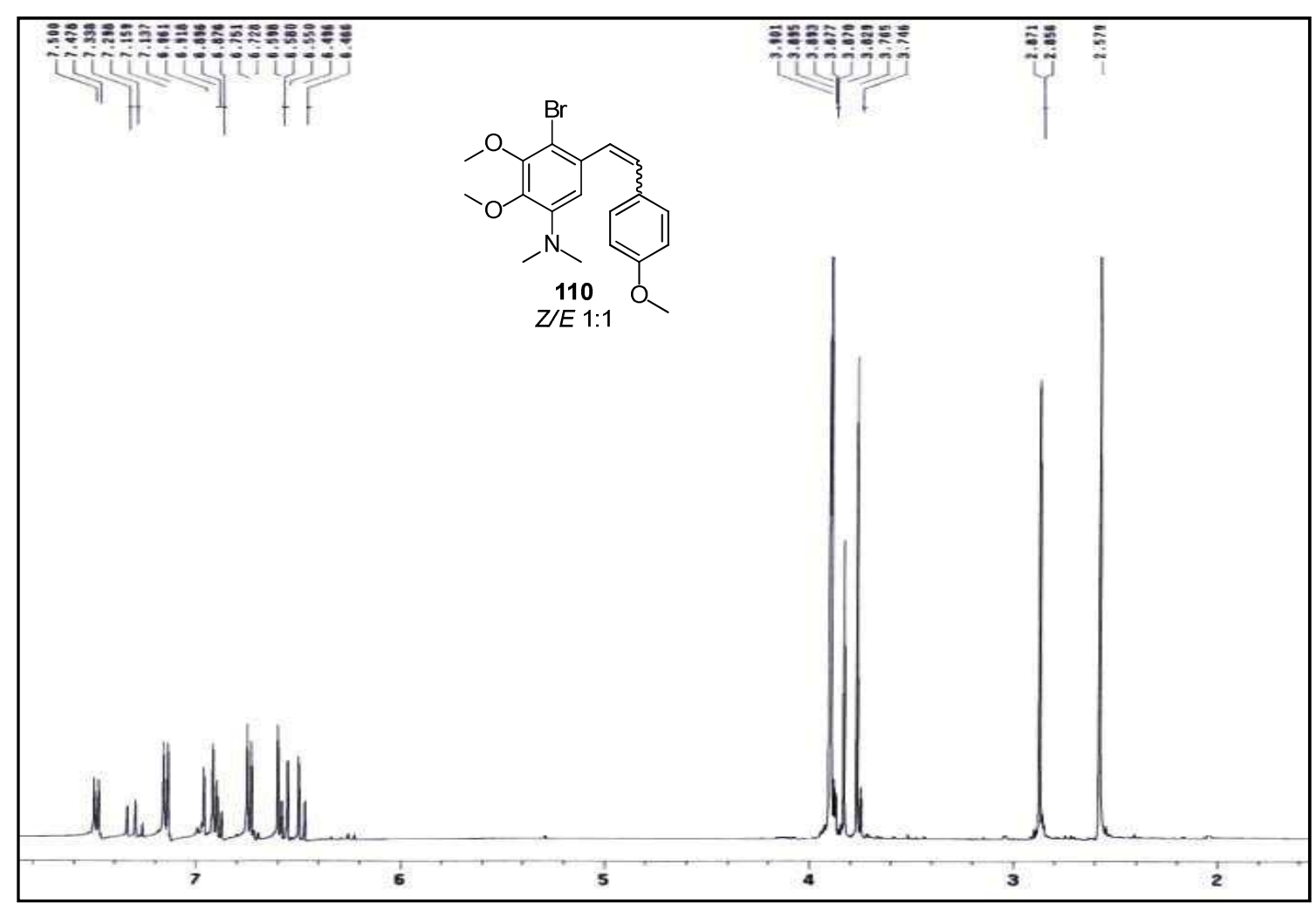

Figura Ca: Espectro de RMN ${ }^{1} \mathrm{H}$ del compuesto 110.

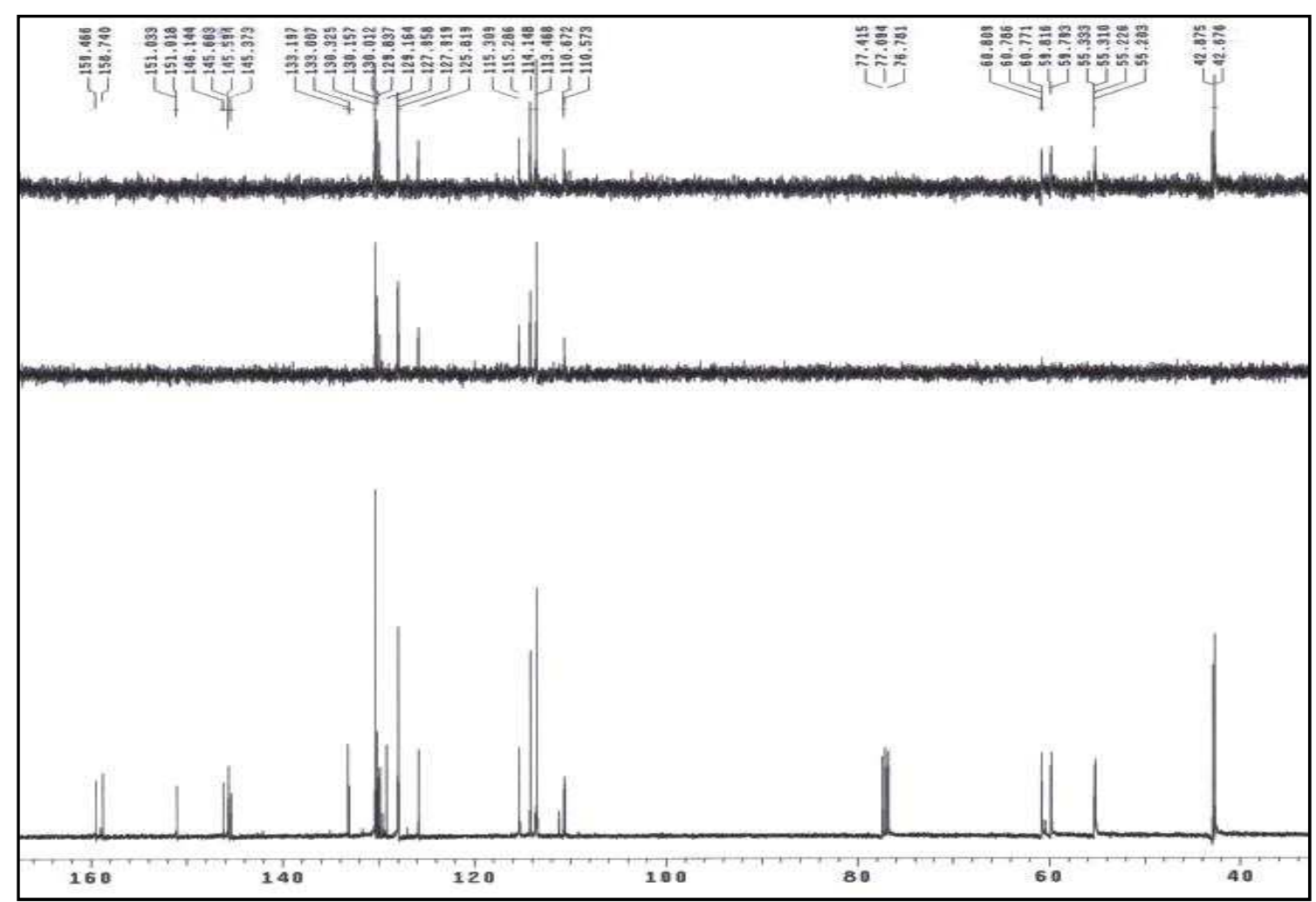

Figura $\mathrm{Cb}$ : Espectro de $\mathrm{RMN}{ }^{13} \mathrm{C}$ del compuesto 110. 


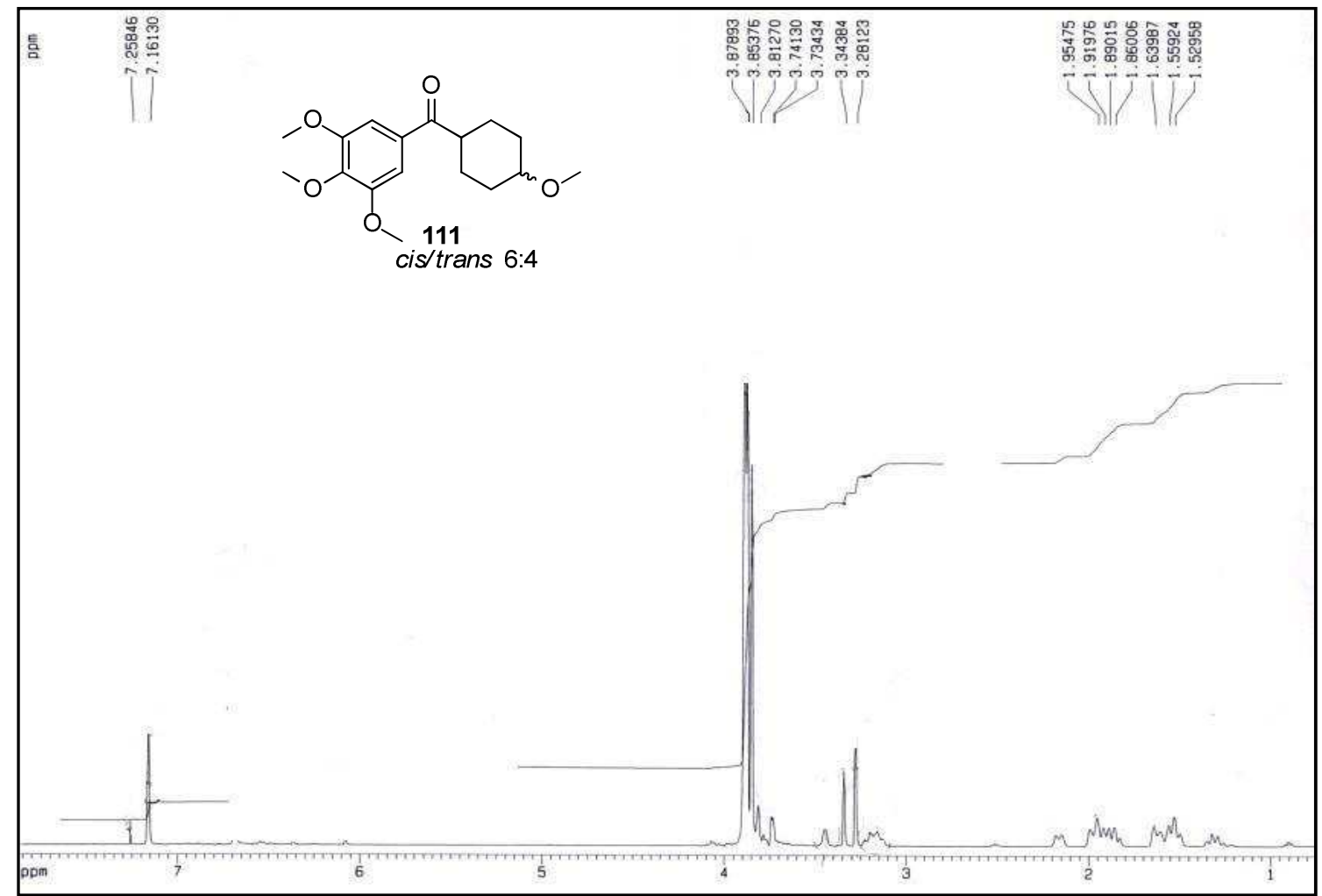

Figura Cla: Espectro de RMN ${ }^{1} \mathrm{H}$ del compuesto 111.

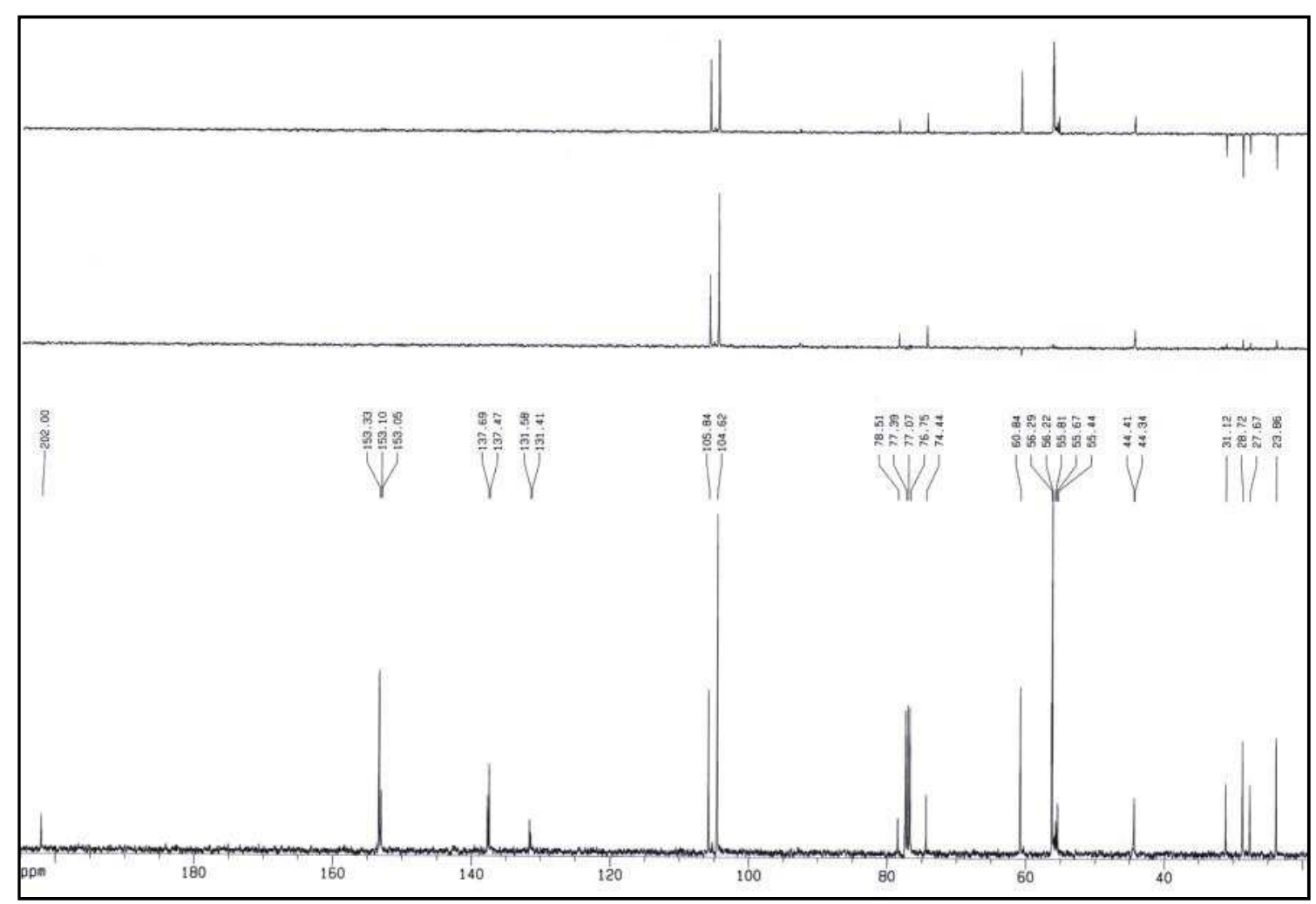

Figura CIb: Espectro de RMN ${ }^{13} \mathrm{C}$ del compuesto 111. 


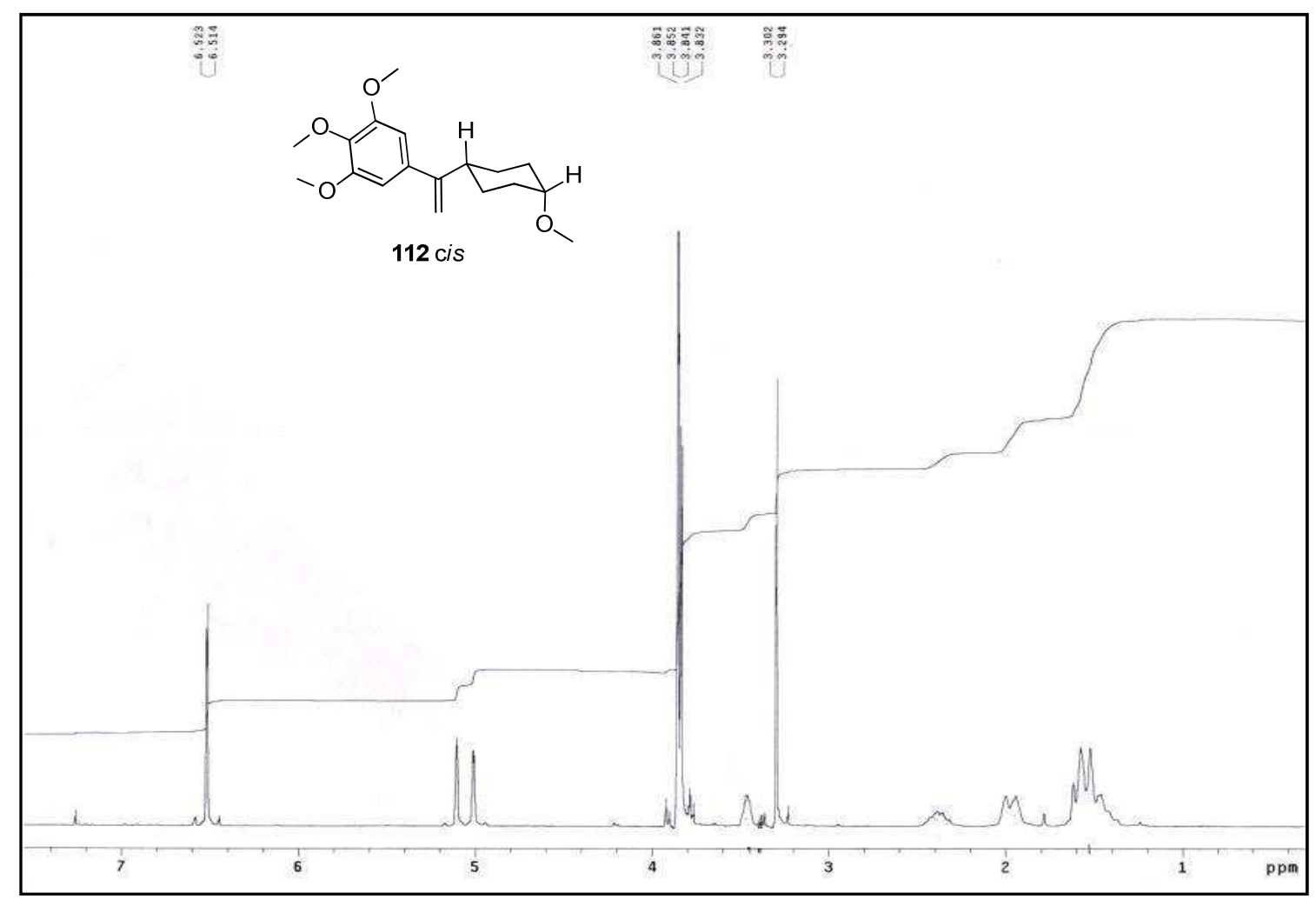

Figura CIIa: Espectro de RMN ${ }^{1} \mathrm{H}$ del compuesto 112(cis).

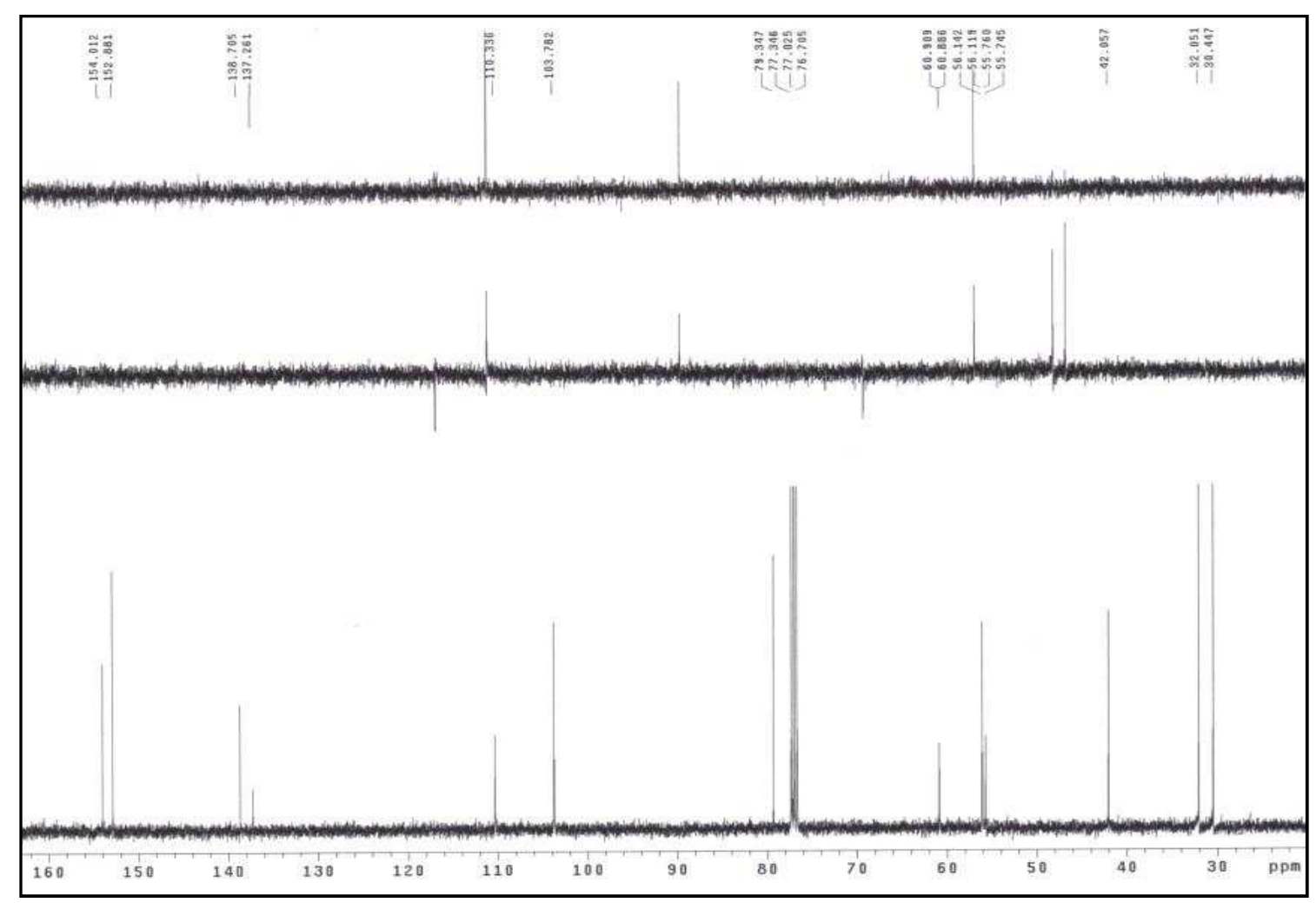

Figura CIIb: Espectro de RMN ${ }^{13} \mathrm{C}$ del compuesto 112 (cis). 


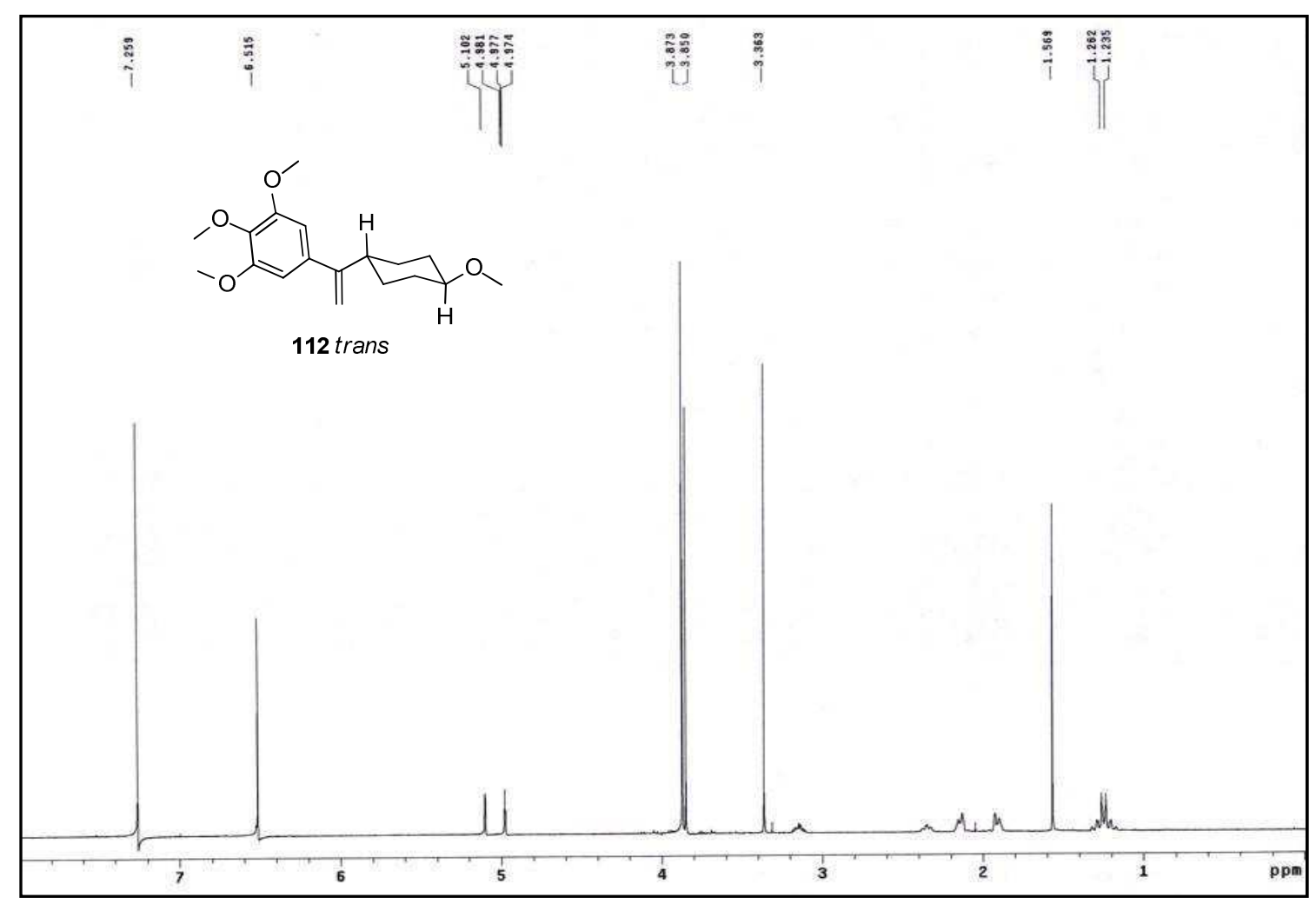

Figura CIIc: Espectro de RMN ${ }^{1} \mathrm{H}$ del compuesto 112(trans). 


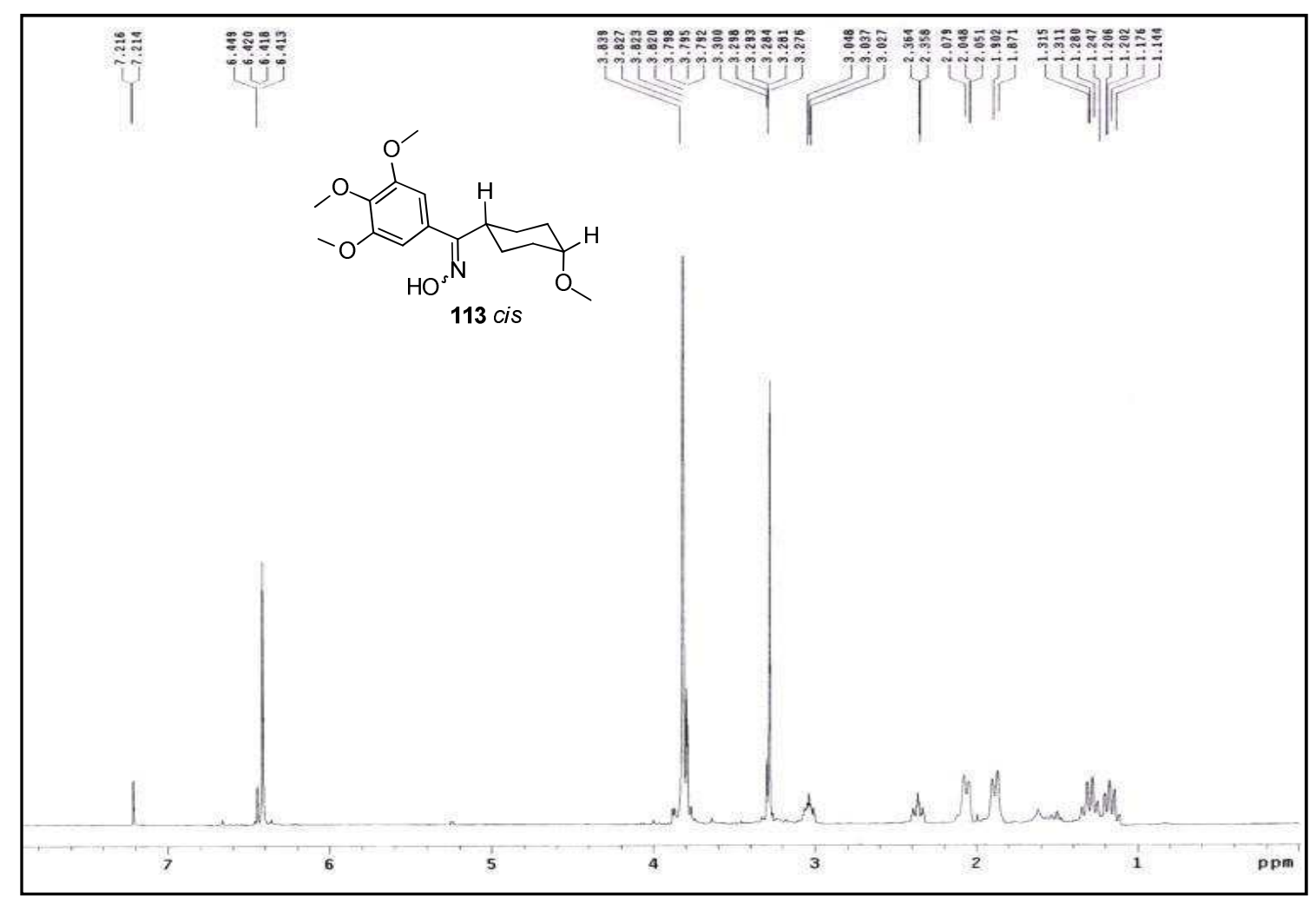

Figura CIIIa: Espectro de RMN ${ }^{1} \mathrm{H}$ del compuesto 113(cis).

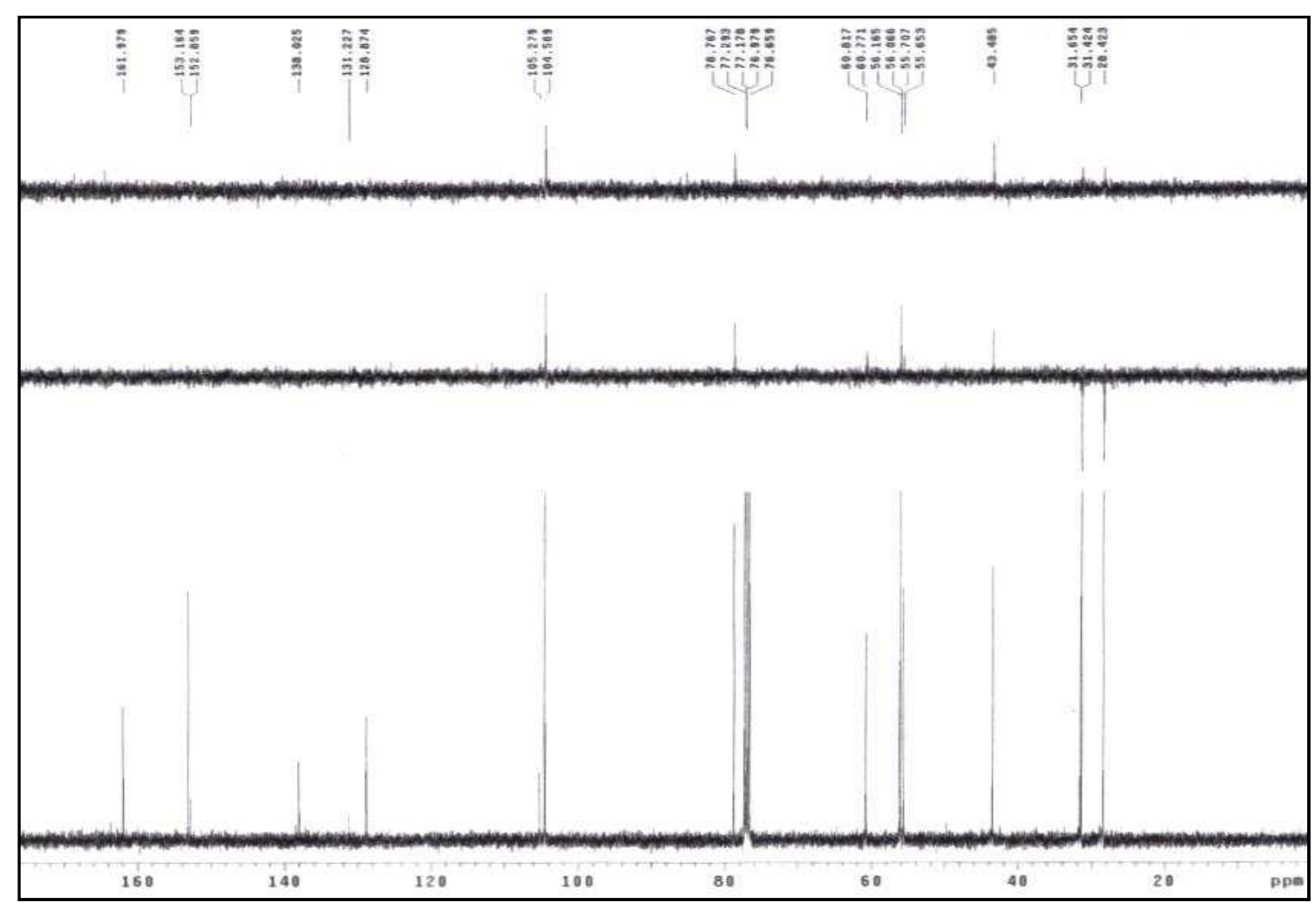

Figura CIIIb: Espectro de RMN ${ }^{13} \mathrm{C}$ del compuesto 113(cis). 


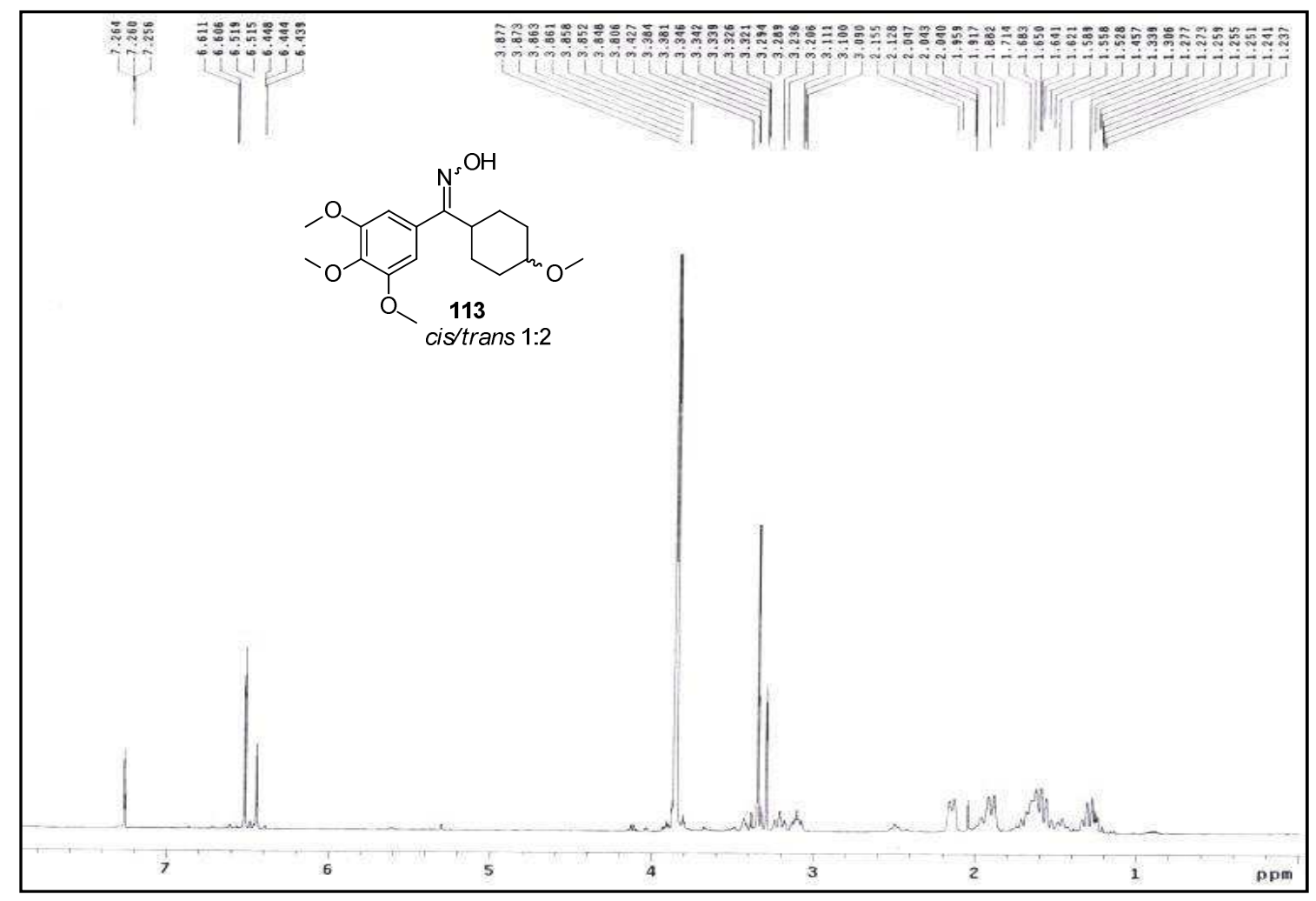

Figura CIIIc: Espectro de RMN ${ }^{1} \mathrm{H}$ del compuesto 113(cis/trans). 


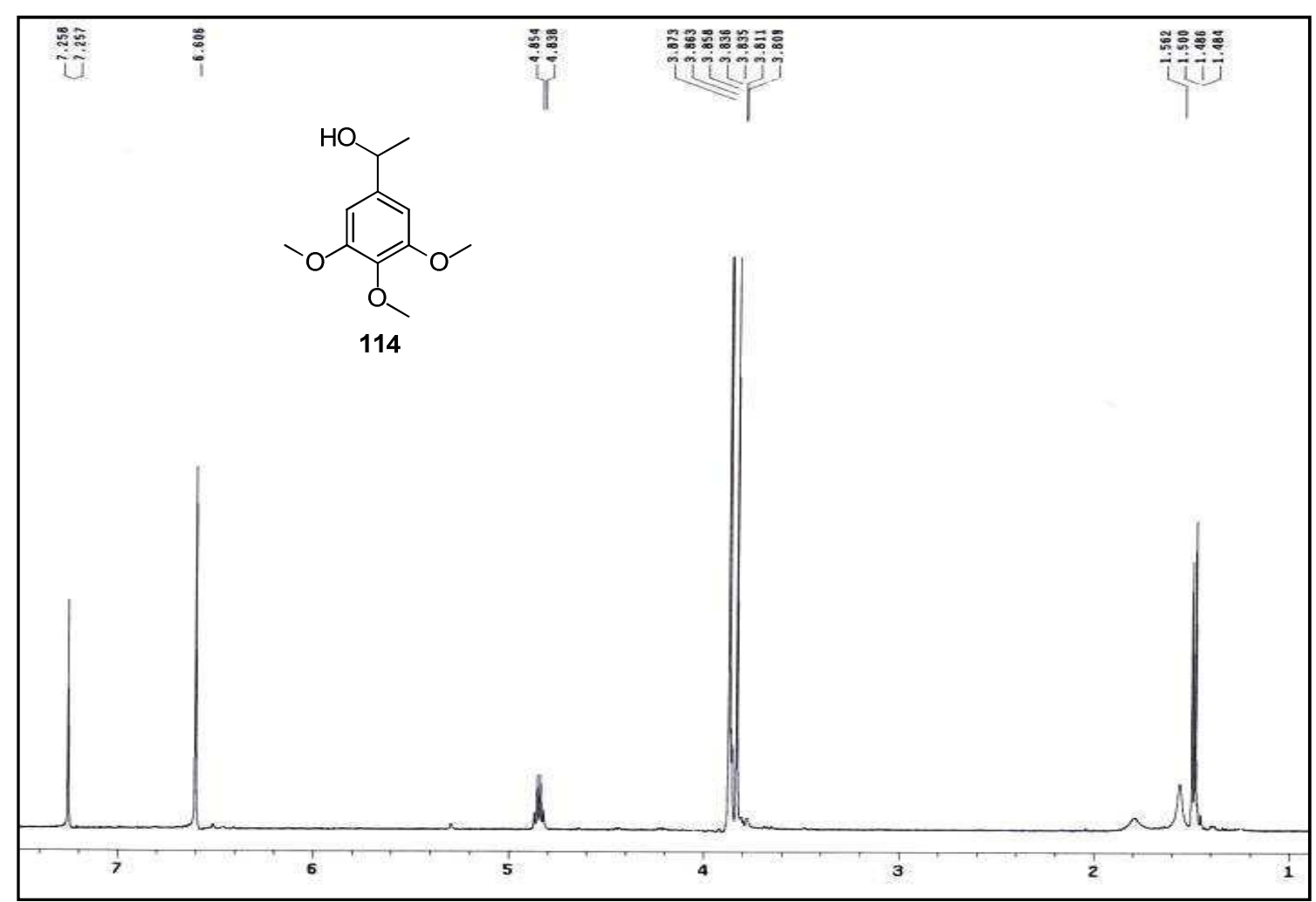

Figura CIVa: Espectro de RMN ${ }^{1} \mathrm{H}$ del compuesto 114.

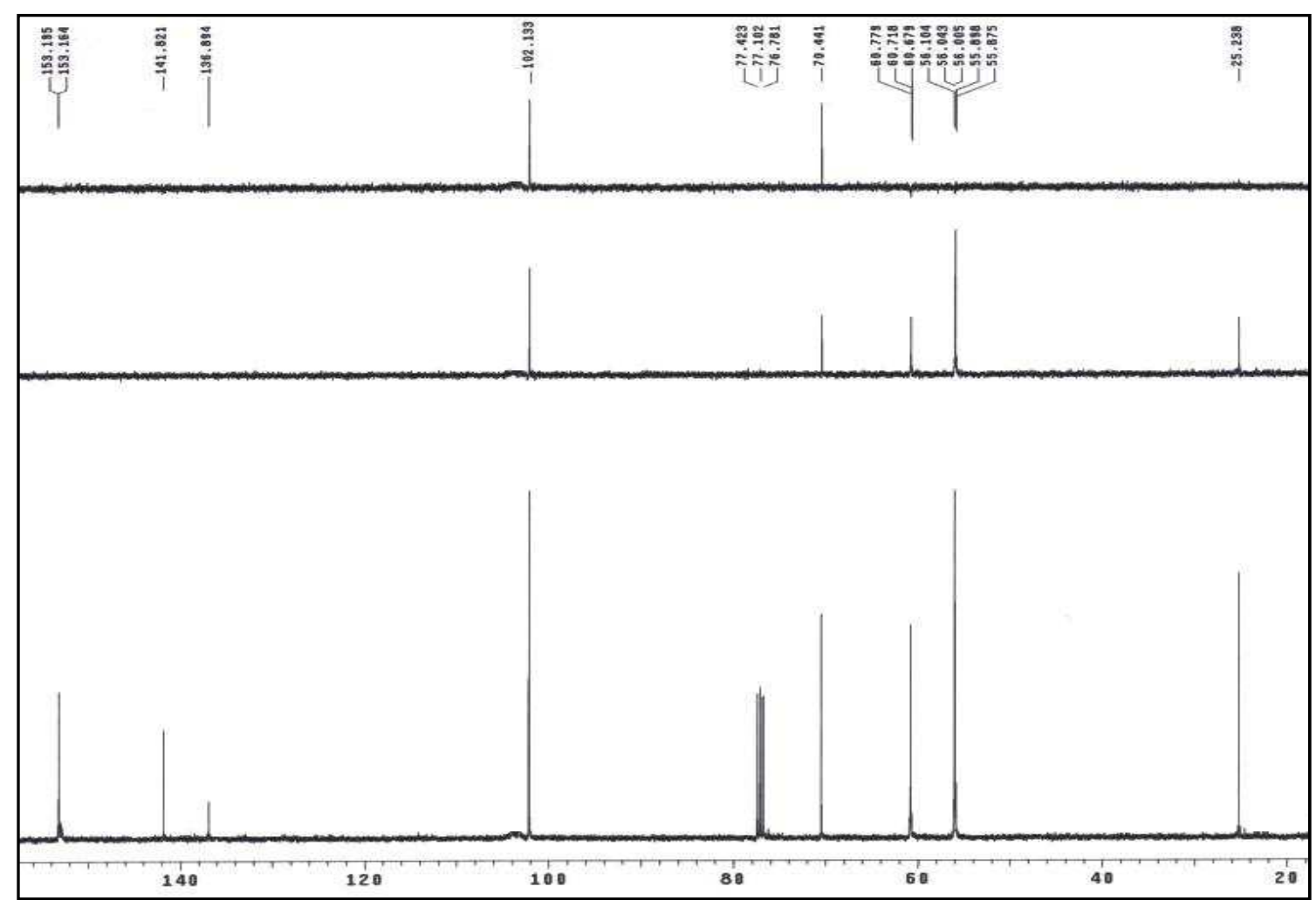

Figura CIVb: Espectro de RMN ${ }^{13} \mathrm{C}$ del compuesto 114. 


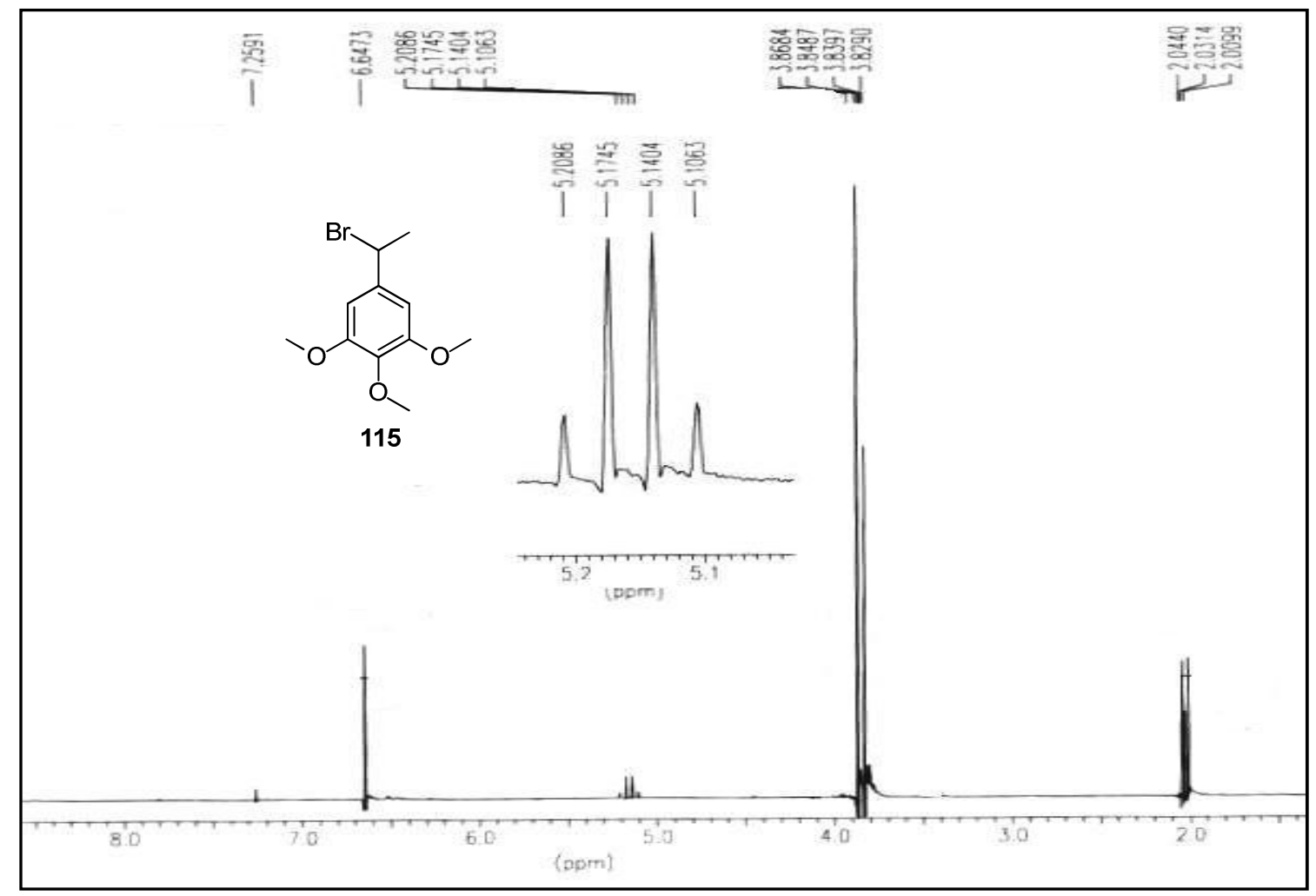

Figura CVa: Espectro de RMN ${ }^{1} \mathrm{H}$ del compuesto 115.

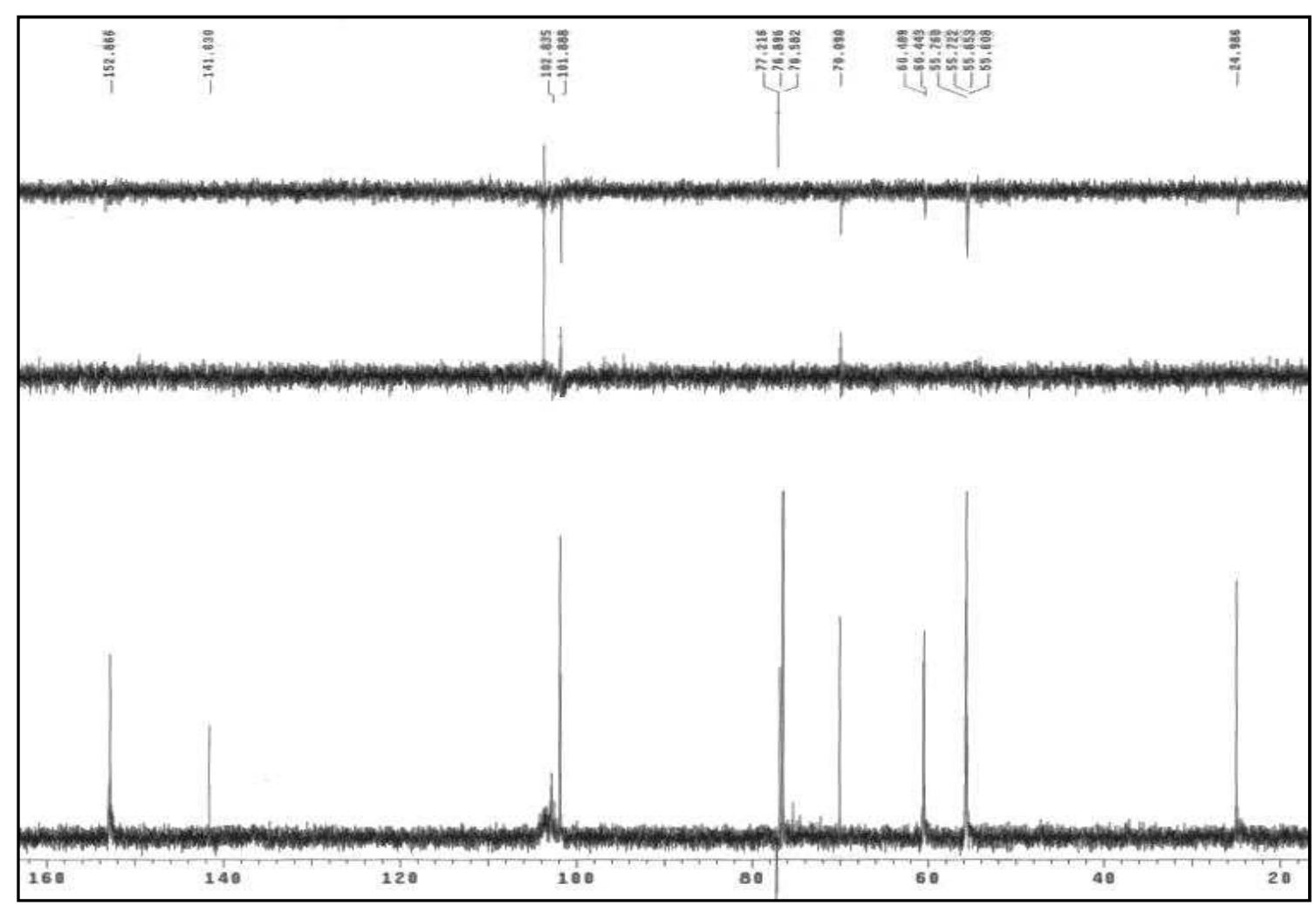

Figura CVb: Espectro de RMN ${ }^{13} \mathrm{C}$ del compuesto 115. 


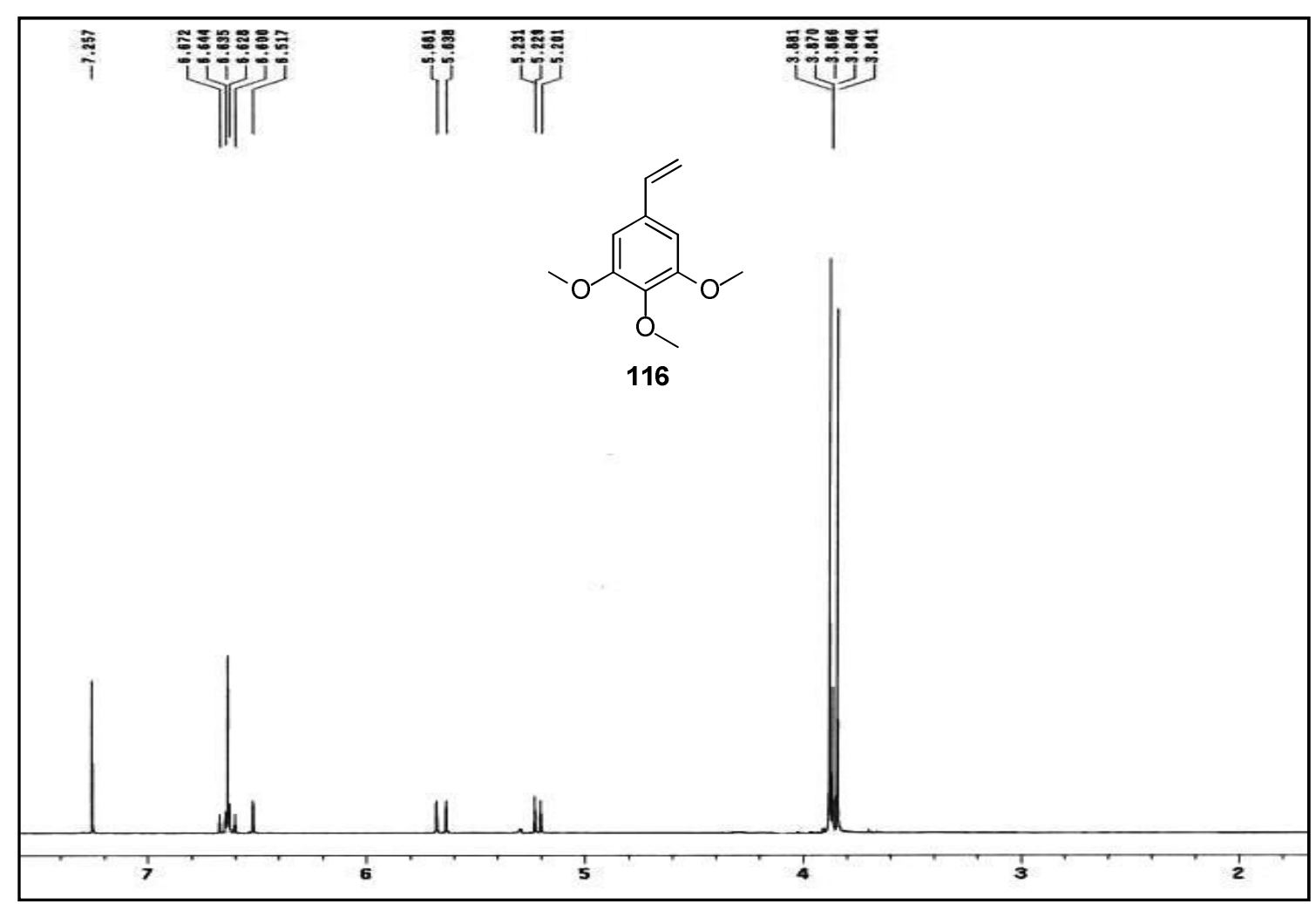

Figura CVIa: Espectro de RMN ${ }^{1} \mathrm{H}$ del compuesto 116.

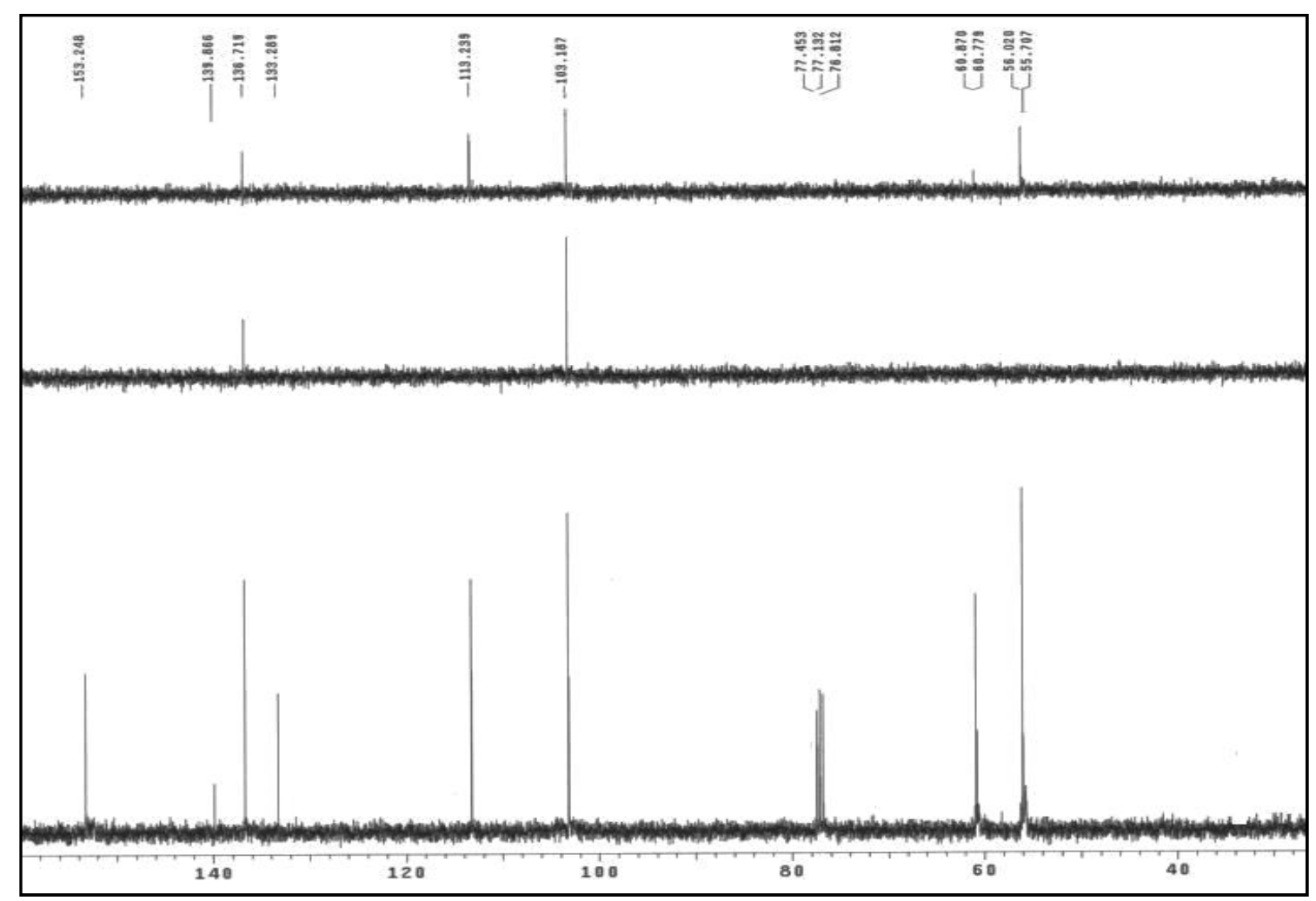

Figura CVIb: Espectro de RMN ${ }^{13} \mathrm{C}$ del compuesto 116. 


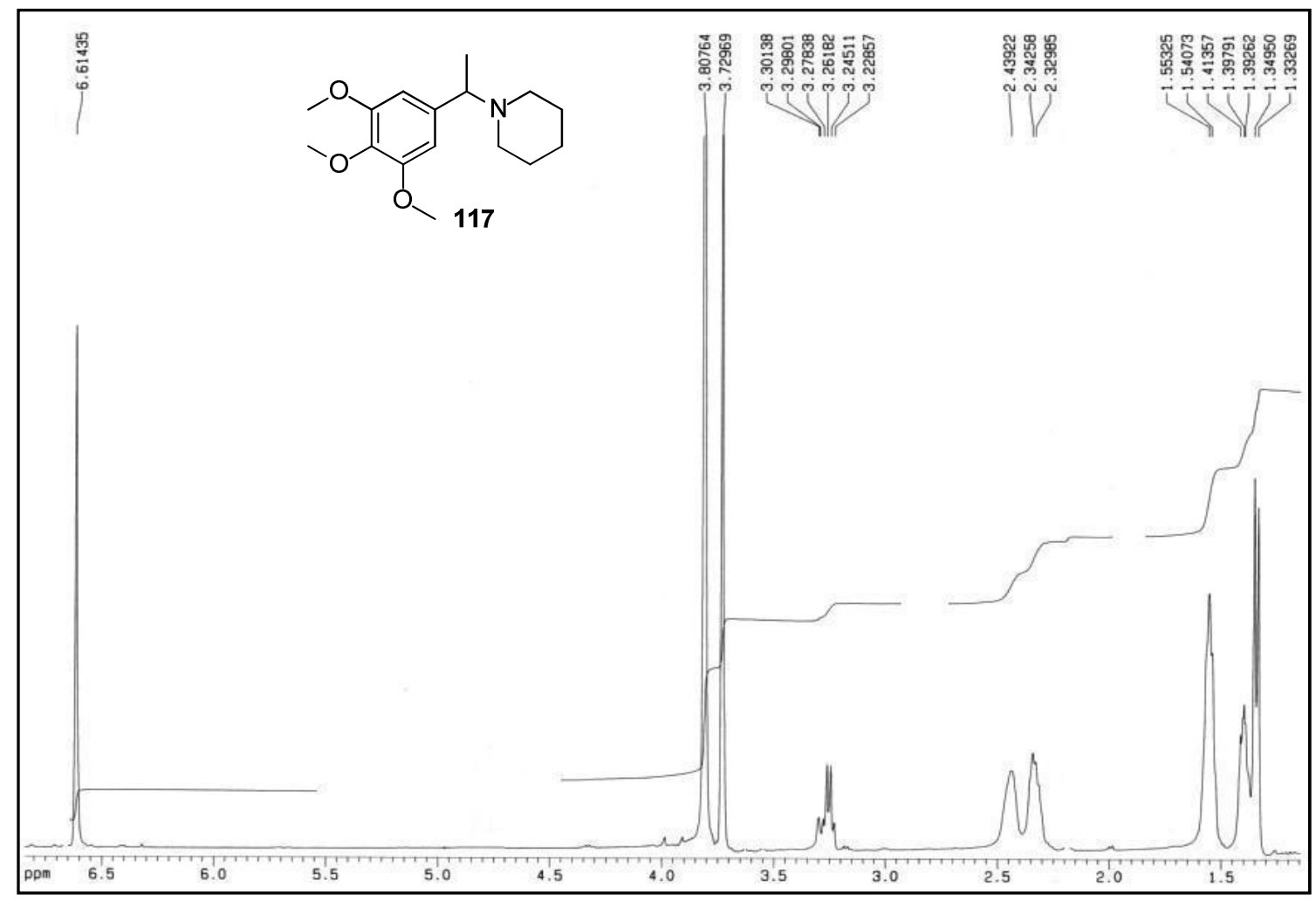

Figura CVIIa: Espectro de RMN ${ }^{1} \mathrm{H}$ del compuesto 117.

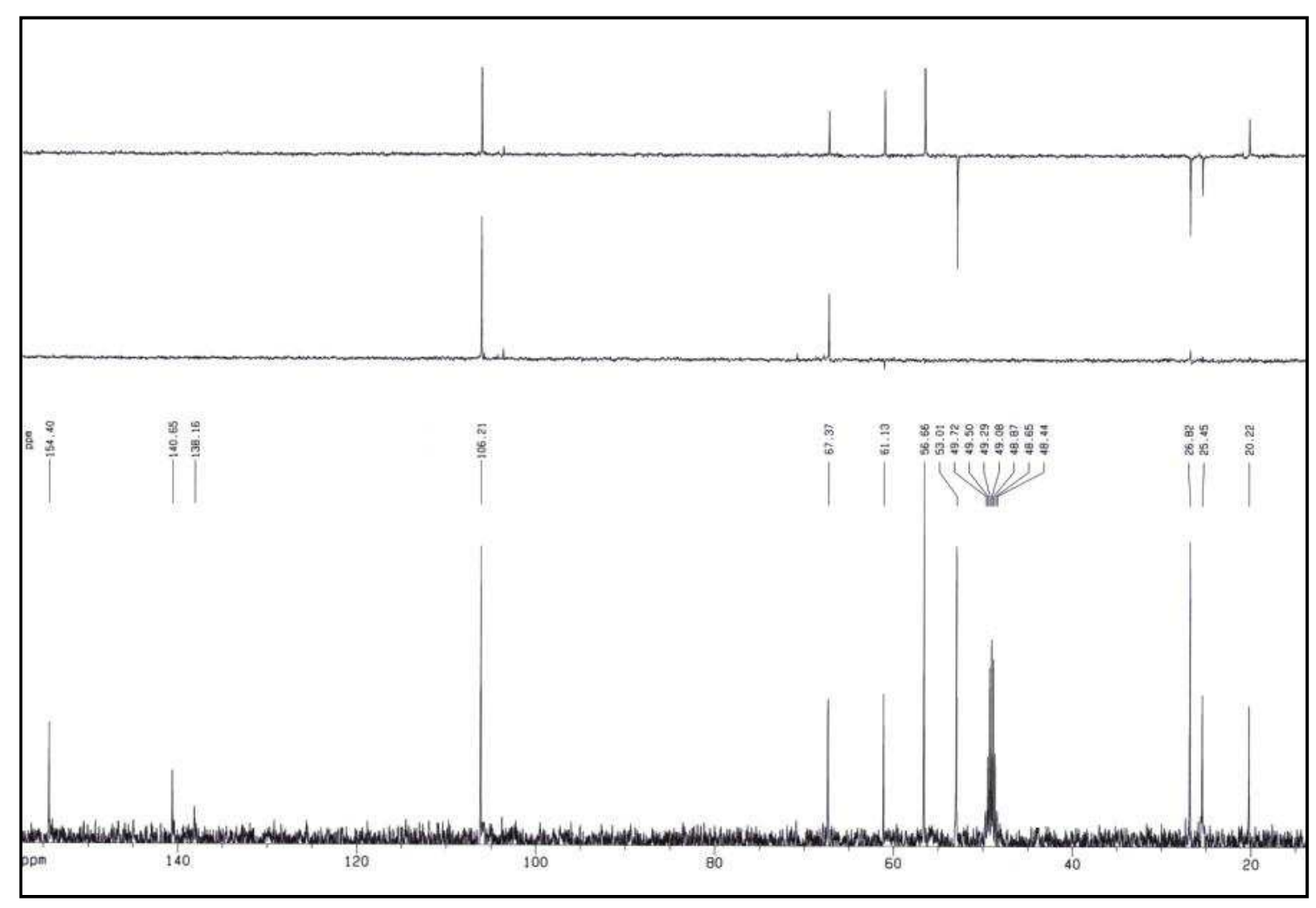

Figura CVIIb: Espectro de RMN ${ }^{13} \mathrm{C}$ del compuesto 117. 


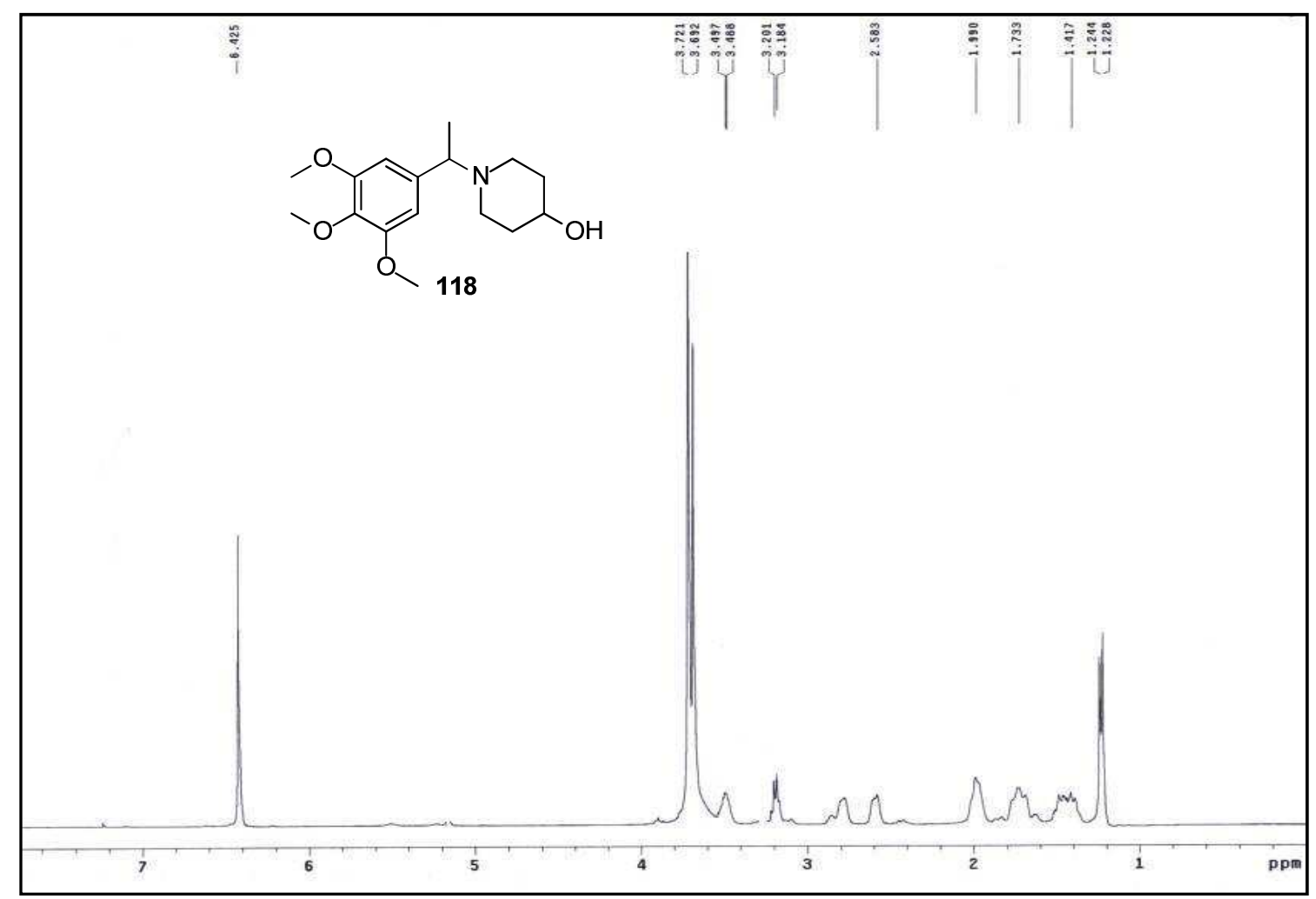

Figura CVIIIa: Espectro de RMN ${ }^{1} \mathrm{H}$ del compuesto 118.

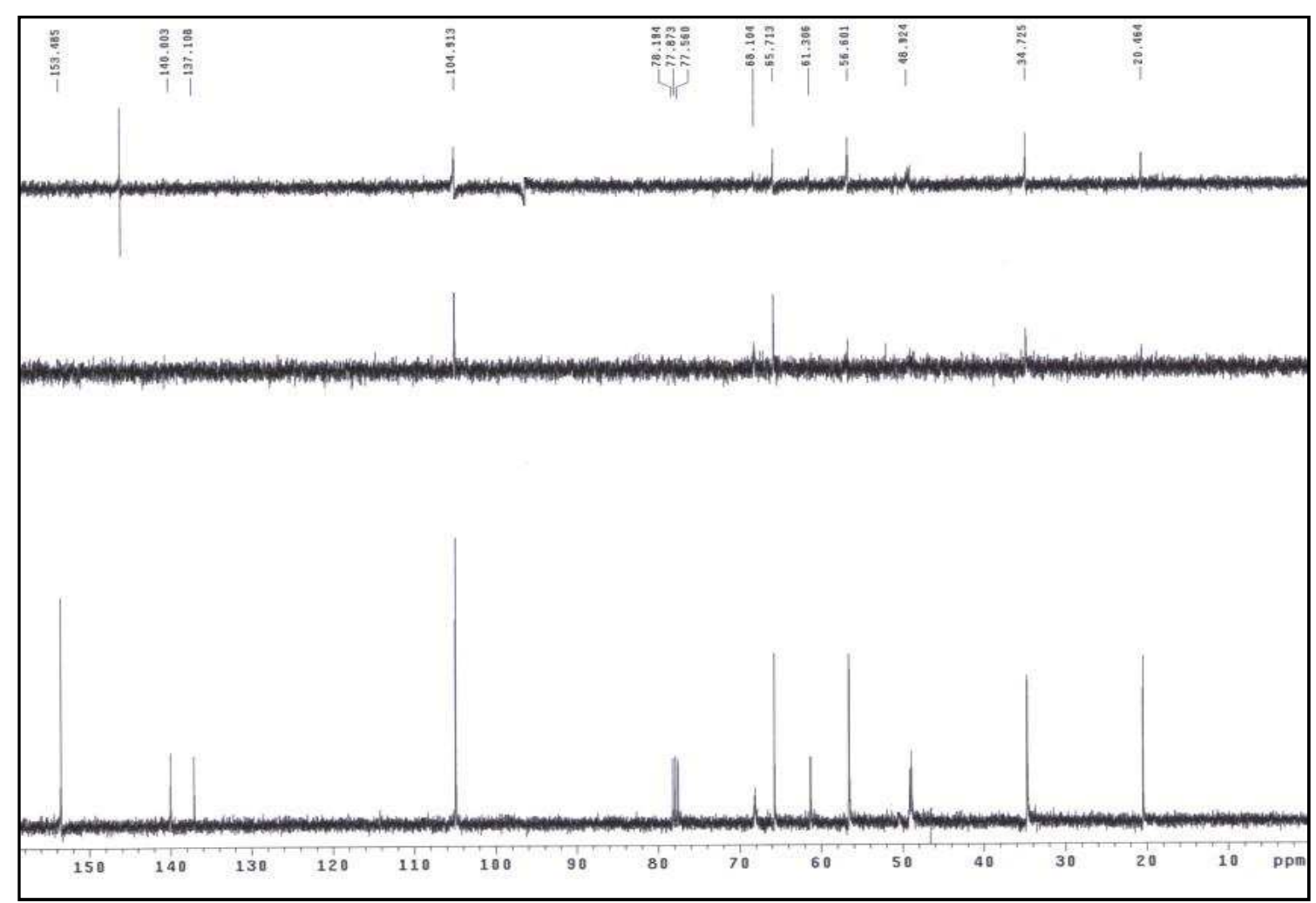

Figura CVIIIb: Espectro de RMN ${ }^{13} \mathrm{C}$ del compuesto 118. 
